\title{
Long-term follow-up of patients treated with the edgewise crowned Herbst appliance in the mixed dentition
}

Timothy G. Wigal

West Virginia University

Follow this and additional works at: https://researchrepository.wvu.edu/etd

\section{Recommended Citation}

Wigal, Timothy G., "Long-term follow-up of patients treated with the edgewise crowned Herbst appliance in the mixed dentition" (2008). Graduate Theses, Dissertations, and Problem Reports. 2650.

https://researchrepository.wvu.edu/etd/2650

This Thesis is protected by copyright and/or related rights. It has been brought to you by the The Research Repository @ WVU with permission from the rights-holder(s). You are free to use this Thesis in any way that is permitted by the copyright and related rights legislation that applies to your use. For other uses you must obtain permission from the rights-holder(s) directly, unless additional rights are indicated by a Creative Commons license in the record and/ or on the work itself. This Thesis has been accepted for inclusion in WVU Graduate Theses, Dissertations, and Problem Reports collection by an authorized administrator of The Research Repository @ WVU. For more information, please contact researchrepository@mail.wvu.edu. 


\title{
LONG-TERM FOLLOW-UP OF PATIENTS TREATED WITH THE EDGEWISE CROWNED HERBST APPLIANCE IN THE MIXED DENTITION
}

Timothy G. Wigal, D.D.S.

\author{
A THESIS \\ Submitted to: \\ The School of Dentistry \\ at West Virginia University \\ in partial fulfillment of the requirements \\ for the degree of \\ Master of Science \\ In \\ Orthodontics
}

Peter Ngan, D.M.D., Chair

Chris Martin, D.D.S., M.S.

Thomas Razmus, D.D.S., M.S.

Department of Orthodontics

Morgantown, West Virginia

2008 


\title{
ABSTRACT
}

\section{LONG-TERM FOLLOW-UP OF PATIENTS TREATED WITH THE EDGEWISE CROWNED HERBST APPLIANCE IN THE MIXED DENTITION}

\author{
Timothy G. Wigal, D.D.S.
}

Objectives: Research has indicated that the bite jumping technique employed by the crowned Herbst appliance can be effective in correcting Class II skeletal abnormalities by promoting growth of the mandible and remodeling of the glenoid fossa. This research investigated the skeletal and dental alterations of Class II patients treated at an early age with the edgewise crowned Herbst appliance and evaluated the long term stability of those effects. Methods: Cephalometric analysis was performed for a treatment group consisting of 22 radiographs taken before phase I treatment (T1), immediately after Herbst removal during phase I treatment (T2), at the completion of phase I treatment (T3), prior to beginning of phase II orthodontic treatment (T4), and immediately following phase II orthodontic treatment (T5). Measurements were compared to a matched control sample of untreated Class II patients from the BoltonBrush study. The difference in each variable between the treatment and control groups across the five time periods was analyzed for pooled subjects, and separately for male and female subjects. The differences between certain time points were analyzed to investigate treatment changes and their stability over time. For all time periods, the change in the values of the variables for pooled subjects, male subjects, and female subjects in the treatment group were compared to the change in the values of the variables for pooled subjects, male subjects, and female subjects in the control group, respectively. In total, 37 variables were evaluated for each group including sagittal variables, vertical variables, angular variables, and condyle/glenoid fossa variables. In addition, an evaluation of the overjet correction and molar relationship correction for the treatment groups and an evaluation of the net overjet correction and net molar relationship correction for the treatment vs. control groups at each time period for pooled subjects were performed. Results: Treatment of Class II patients treated with the crowned Herbst appliance in the early mixed dentition resulted in the following changes relative to normal growth: The forward movement of the maxillary base (OLp-A pt) was initially restrained after treatment (T2-T1) and gradually became more restrained in the short-term (T3-T1) and long-term (T4-T1) post-treatment periods. An even greater restraint was seen after phase II orthodontics (T5-T1). The mandibular base (OLp-Pg) was initially moved forward after treatment (T2-T1), however, a gradual relapse was seen in the short-term (T3-T1) and long-term (T4-T1) post-treatment periods. Additional 
relapse in a posterior direction was seen after phase II orthodontics (T5-T1). The maxillary molars (Ms-OLp) were initially distalized (T2-T1), relapsed slightly in the short-term post-retention period (T3-T1), and became distalized again in the long-term post-treatment period (T4-T1). The maxillary molars were mesialized during phase II orthodontic treatment (T5-T4) and most of the overall posterior molar movement was eliminated after this period (T5-T1). The mandibular molars (Mi-OLp) were initially mesialized after treatment (T2-T1), however gradual relapse occurred during the shortterm post-treatment period (T3-T1) until they returned to their pre-treatment position after the long-term post-treatment period (T4-T1). They were mesialized again after phase II orthodontic treatment (T5-T1). The maxillary incisors (Is-OLp) moved backward and retroclined after treatment (T2-T1), then relapsed slightly during the shortterm (T3-T1) and long-term (T4-T1) post-treatment period. A net posterior movement was maintained through the long-term post-treatment period (T4-T1). This posterior position of the maxillary incisor remained stable through phase II treatment (T5-T1). The mandibular incisors (Ii-OLp) moved forward and proclined after treatment (T2-T1), then relapsed to their pre-treatment position after the short-term post-treatment period (T3T1). Forward movement and proclination occurred during the long-term retention period (T4-T3), giving a net forward movement and proclination after this period (T4-T1). The mandibular incisors returned to their pre-treatment position after phase II orthodontic treatment (T5-T1). A net overjet correction of $7.0 \mathrm{~mm}$ occurred after treatment (T2-T1), then relapsed in the short-term post-treatment period (T3-T1) until a relatively stable net overjet correction between 2.5-3.0mm was maintained over the long-term (T4-T1). The overjet correction remained stable through phase II treatment (T5-T1). A molar relationship correction of $6.6 \mathrm{~mm}$ occurred after treatment (T2-T1), then relapsed in the short-term post-treatment period (T3-T1) until a relatively stable net molar correction between 2.2-3.3mm was maintained over the long-term (T4-T1). The molar correction remained stable through phase II treatment (T5-T1). Relocation of the glenoid fossa occurred in an anterior and superior direction after treatment (T2-T1) and this relative change in position was stable over the long term (T4-T1). Restriction of the downward and backward movement of the fossa was observed and might additionally contribute to Class II correction. Conclusions: The results of this study suggest that early treatment with the edgewise crowned Herbst appliance can achieve overjet correction and molar relationship correction that remains stable over the long-term. However, the skeletal and dental contributions to this overjet and molar correction shift over time with decreasing skelelal contribution and increasing dental compensation. During phase II orthodontic treatment, an increased skeletal contribution to overjet and molar relationship correction occurs. 


\section{DEDICATION}

To my beautiful wife, Julie Wigal, who is the love of my life and my best friend. The sacrifices you have made over the last seven years are unimaginable and the love and support you have given me through this process is beyond belief. Your knowledge of business is exceptional and your work ethic is second to none. I have leaned on you heavily throughout this journey and you have always delivered, without complaint. There is no one I trust more than you. Most importantly, you have been the most wonderful mother to our two daughters and I only hope they grow up to be just like you. We make a great team... we finally made it...I love you.

To my beautiful daughters, Ella Wigal and Lydia Wigal, whose smiles and personalities brightened my life and lifted me when I was down. The joy you have brought to my life keeps everything in perspective. I love you.

To my parents, Gary Wigal and Debbie Wigal, who have been with me from the start and have loved me and supported me in whatever it was I chose to do. I love you.

To my siblings, James Wigal, Paige Windland, and Dustin Wigal, who have provided a safety net of encouragement and support whenever I needed it. I wish you all the best in your lives. I love you.

To my grandparents, James Goodwin and Gloria Goodwin, who have sacrificed so much over the years to make sure I had every opportunity to succeed in life. Your constant encouragement and support gave me the confidence to excel despite the circumstances. Papaw, you are my best friend and greatest contributor to my success. Thanks for always being there, no matter what. I love you.

To my in-laws, Dave Wagner and Nancy Wagner, who have included me as one of their own. Thanks for all the support and guidance during the last seven years. We couldn't have made it without you. I love you.

To my in-laws, Jeremy Wagner and Michelle Wagner, who have offered constant support and kept me laughing through this process.

To God, who has provided me with an abundance of blessings more than I ever expected or deserved, and who continues to open doors for me. Thank you. I love you. 


\section{ACKNOWLEDGEMENTS}

I would like to take this opportunity to thank the following individuals who have contributed and assisted me throughout my specialty training.

Dr. Peter Ngan, for his lifelong commitment to education, encouragement, expertise in the clinic, and general wisdom offered on a daily basis. I consider you not only a mentor, but a true friend.

Dr. Chris Martin, for his everyday advice in the clinic, friendship, assistance with practice issues, support provided on the thesis, and full-time commitment to education.

Dr. Thomas Razmus, for his advice and encouragement throughout this thesis.

Dr. Terry Dischinger, for the use of records, for his enthusiasm for the Herbst appliance and his desire to constantly find new ways to better treat his patients.

Dr. Erdogan Gunel, for his statistical assistance and willingness to work overtime to deliver large amounts of statistics in a short period of time.

Dr. Mark Hans, Case Western Reserve University-Bolton Brush Study, for providing the records for the control group in this study.

Drs. Tim Tremont, Edward McFarland, Jeff Gilmore, Thomas Jarrett, Kerry Kirsch, Joe Bonello, John Dempsey, J.B. Wilfong, Mike Hazey, and Jennifer Hamilton, for the invaluable lessons in the classroom and the clinic. Thank you for the sacrifice of time away from your busy practices. Each of you has influenced my education in ways that will pay dividends for years to come.

Dustin Wigal, for his assistance in creating charts, graphs and tables for the thesis and his countless hours of data entry.

Pam, Charlotte, Vivian, and Karen, for their friendship and assistance in the clinic. You have all been a joy to work with.

Joyce and Carrie, for all their hard work that often goes unappreciated. You are both invaluable to this program.

Dr. Nikia Burns and Dr. Lindsay Jackfert, my co-residents, for their constant support, encouragement, and motherly guidance throughout the program. Our friendship will last forever, and I wish you both the best in your futures.

Mike, Meredith, Todd, Glenn, Spencer, and Jennifer, my fellow residents, for their friendship and guidance through the program. Thanks for everything. 
Mike, Rajia, Thuy, Mike, Dean, and Kolin, my fellow residents, for the good times, debates, friendship, and support throughout the program. Holler!

Dr. Mike Munn, for his computer expertise and willingness to help out a friend. Your computer gymnastics will never be forgotten. I appreciate all your hard work. 


\section{TABLE OF CONTENTS}

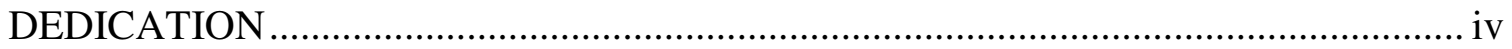

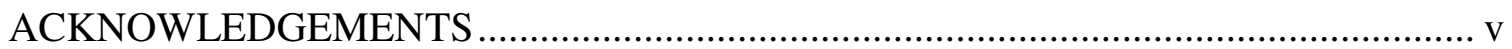

TABLE OF CONTENTS ...................................................................................... vii

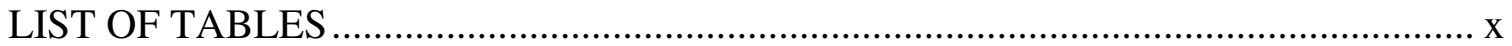

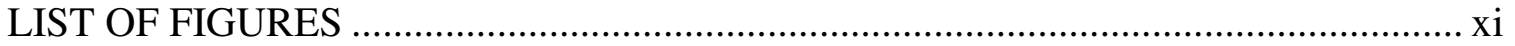

CHAPTER I: INTRODUCTION

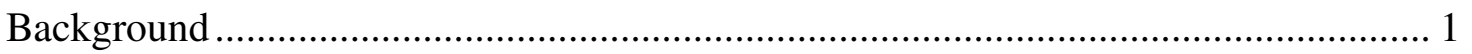

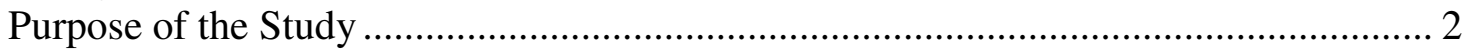

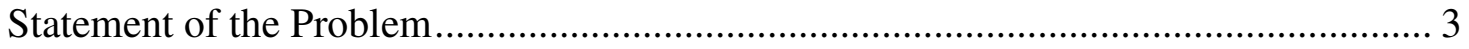

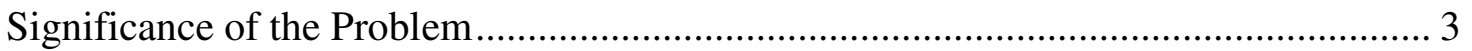

Null Hypotheses ................................................................................................. 4

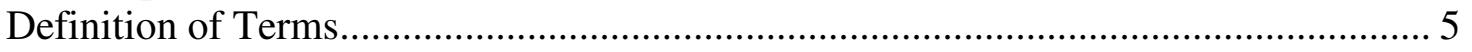

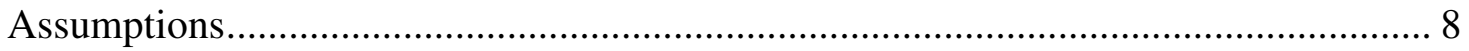

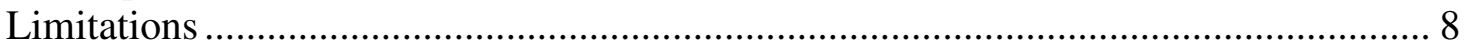

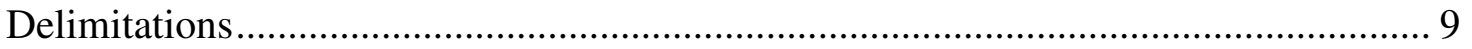

CHAPTER II: REVIEW OF THE LITERATURE ................................................... 10

History and Classification of Malocclusion............................................................ 10

Etiology of Malocclusion and the Need for Orthodontic Therapy ............................. 11

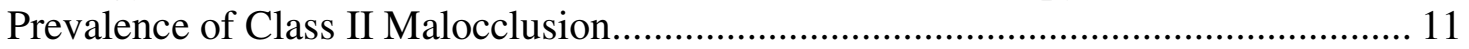

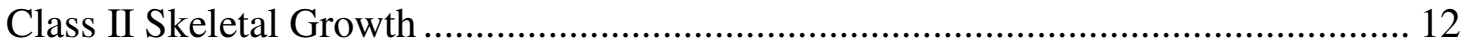

Analysis of the Dentofacial Complex ........................................................................ 14

Treatment of Class II Malocclusion............................................................................. 15

Functional Appliances Used to Treat Class II Malocclusion....................................... 17

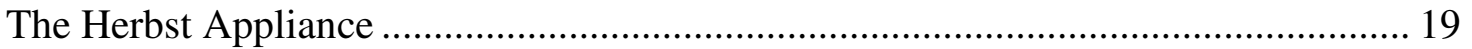

Indications for Treatment with the Herbst Appliance............................................ 21

Timing of Treatment with Functional Appliances ................................................ 21

Treatment Effects of the Herbst Appliance on the Dentofacial Complex ................... 24

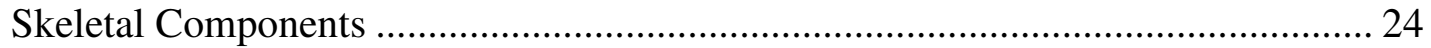

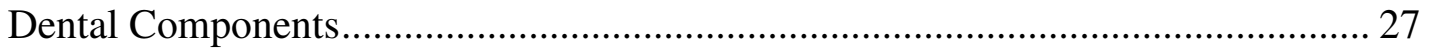

Vertical changes associated with the Herbst Appliance ........................................... 27

Post-treatment relapse following Herbst treatment.............................................. 28

The Edgewise Herbst Appliance ............................................................................... 30

The Dischinger Protocol for the Edgewise Herbst Appliance .................................... 35

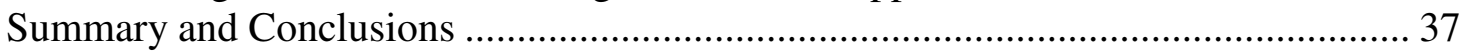

CHAPTER III: MATERIALS AND METHODS ..................................................... 40

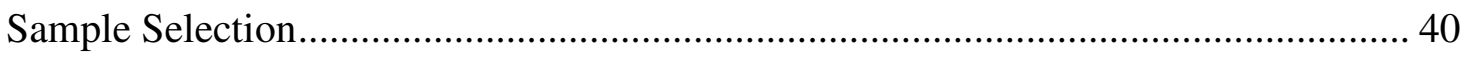

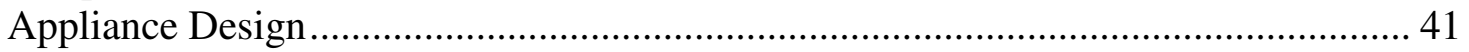

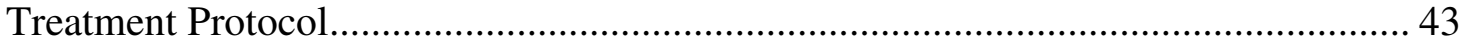

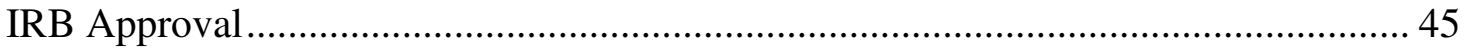

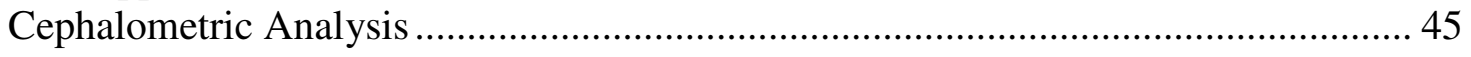

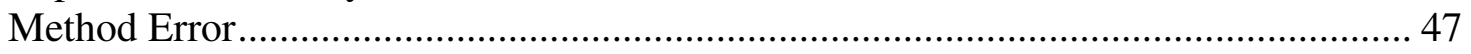

Cephalometric Landmarks and Reference Lines ............................................... 50

Evaluation of Overjet and Molar Relationship Correction ....................................... 57 


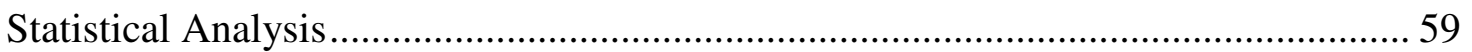

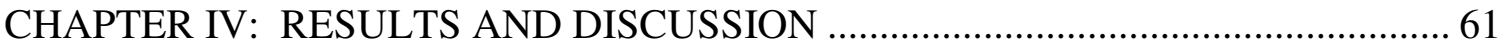

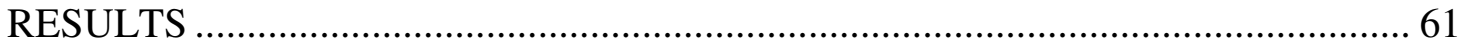

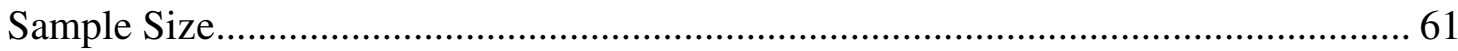

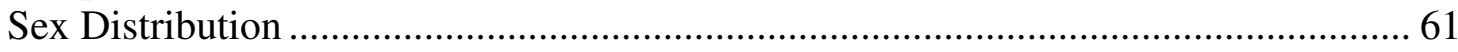

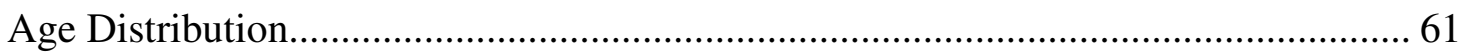

Distribution of Variable Measurements ....................................................................... 64

Pre-treatment Craniofacial Morphology of the Treatment vs. the Control Group ....... 65

Comparison of the Treatment Group and the Control Group Across the Time Periods70

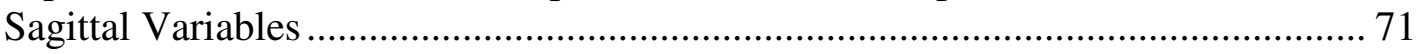

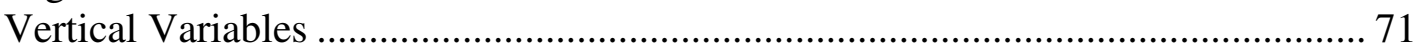

Angular Variables ......................................................................................... 71

Condyle/Glenoid Fossa Variables........................................................................ 72

Graph Analysis of Variables Across Time for the Treatment vs. Control Groups....... 74

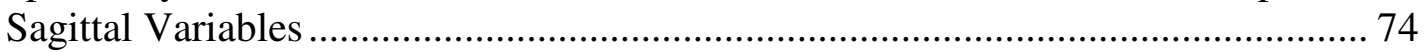

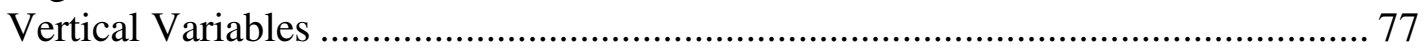

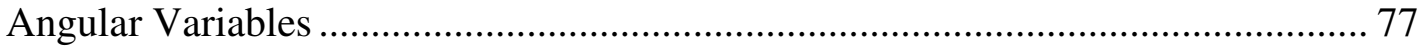

Condyle/Glenoid Fossa Variables....................................................................... 79

Comparison of the Treated Group vs. the Control Group …………………………........ 80

Comparison of T2-T1 (Treatment Effects of the Herbst Appliance)............................. 81

Overjet and Molar Relationship Correction-Treatment Group (T2-T1)...................... 87

Net Overjet and Molar Relationship Correction-Tx vs. Control Group (T2-T1) ......... 90

Comparison of T3-T1 (Phase I Treatment Effects) ...................................................... 93

Overjet and Molar Relationship Correction-Treatment Group (T3-T1)....................... 98

Net Overjet and Molar Relationship Correction-Tx vs. Control Group (T3-T1) ....... 101

Comparison of T4-T1 (Residual Phase I Treatment Effects) ..................................... 104

Overjet and Molar Relationship Correction-Treatment Group (T4-T1).................... 108

Net Overjet and Molar Relationship Correction-Tx vs. Control Group (T4-T1) ....... 111

Comparison of T5-T1 (Combined Phase I and Phase II Treatment Effects) .............. 114

Overjet and Molar Relationship Correction-Treatment Group (T5-T1).................... 120

Net Overjet and Molar Relationship Correction-Tx vs. Control Group (T5-T1) ....... 123

Comparison of T5-T4 (Phase II Treatment Effects) ……………………………....... 125

Comparison of T5-T4 (Phase II Treatment Effects) …………………........................ 126

Overjet and Molar Relationship Change-Treatment Group (T5-T4).......................... 131

Net Overjet and Molar Relationship Change-Tx vs. Control Group (T5-T4) ............ 134

Comparison of T4-T3 (Relapse after Phase I to before Phase II Treatment) ............. 137

Overjet and Molar Relationship Change-Treatment Group (T4-T3)......................... 142

Net Overjet and Molar Relationship Change-Tx vs. Control Group (T4-T3) ............ 145

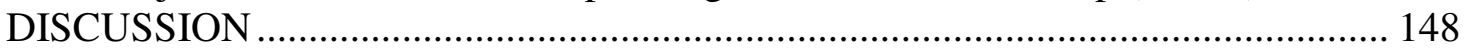

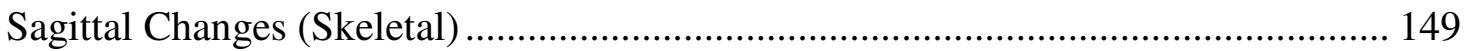

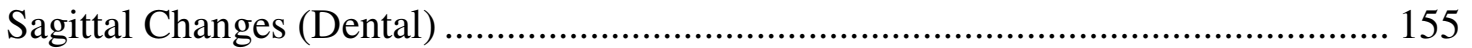

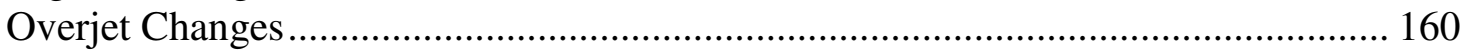

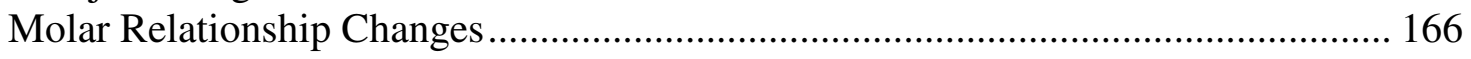

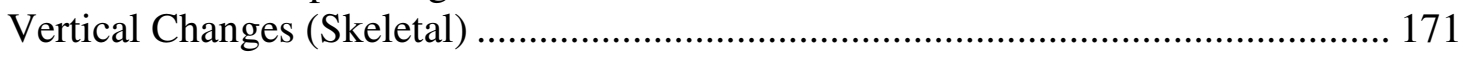

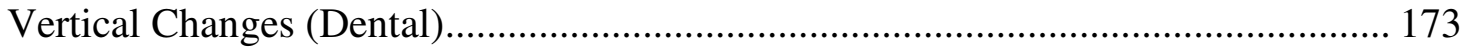

Condyle/Glenoid Fossa Changes .......................................................................... 175 
CHAPTER V: SUMMARY, CONCLUSIONS, RECOMMENDATIONS ................. 181

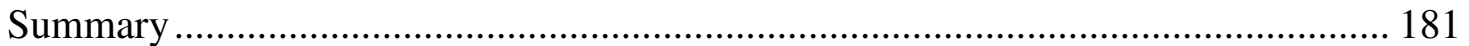

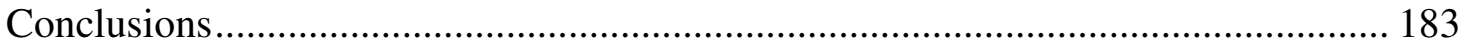

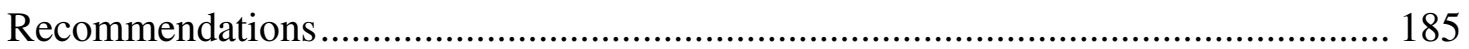

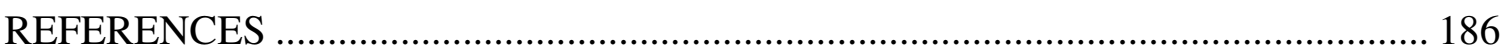

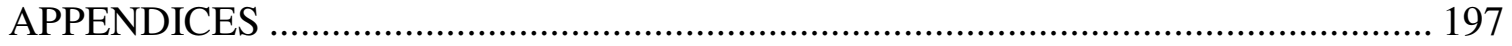

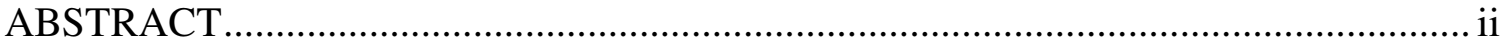

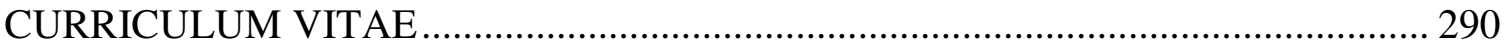




\section{LIST OF TABLES}

Table 1. Description of Timepoints used in the Study.............................................. 40

Table 2. Correlation Coefficients for all variables at T1,T2,T3,T4, and T5 .................. 49

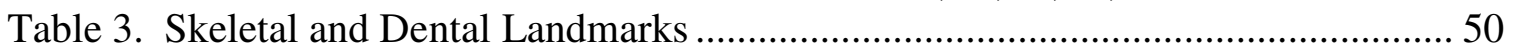

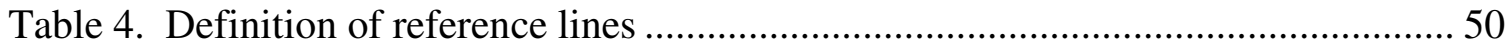

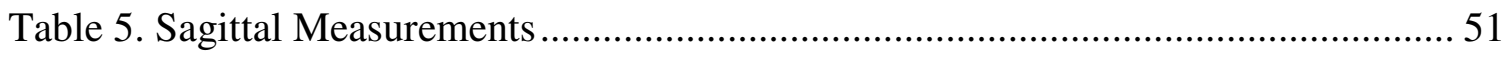

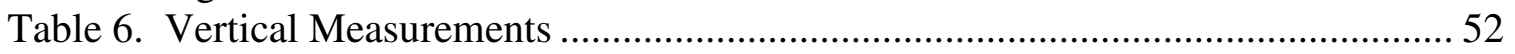

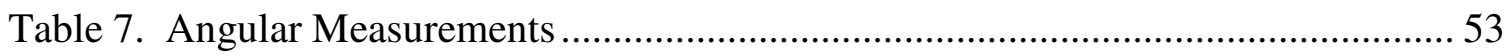

Table 8. Skeletal Landmarks of the Condyle/Glenoid Fossa Analysis.......................... 55

Table 9. Sagittal Measurements of the Condyle/Glenoid Fossa Analysis ...................... 55

Table 10. Vertical Measurements of the Condyle/Glenoid Fossa Analysis .................... 55

Table 11. Calculation of Overjet and Molar Relationship Changes ............................... 57

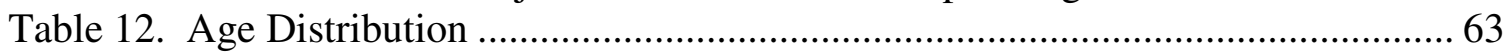

Table 13. Comparison of the pre-treatment craniofacial morphology in pooled subjects 67

Table 14. Comparison of the pre-treatment craniofacial morphology in males subjects 68

Table 15. Comparison of the pre-treatment craniofacial morphology in female subjects 69

Table 16. Comparison of the Treatment group vs the Control group across the time

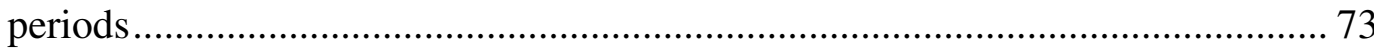

Table 17. Comparison of treated vs. control in pooled subjects at T2-T1 ..................... 84

Table 18. Comparison of treated vs. control in male subjects at T2-T1 ........................ 85

Table 19. Comparison of treated vs. control in female subjects at T2-T1 .................... 86

Table 20. Comparison of treated vs. control in pooled subjects at T3-T1 ..................... 95

Table 21. Comparison of treated vs. control in male subjects at T3-T1 ........................ 96

Table 22. Comparison of treated vs. control in female subjects at T3-T1 ..................... 97

Table 23. Comparison of treated vs. control in pooled subjects at T4-T1 .................... 105

Table 24. Comparison of treated vs. control in male subjects at T4-T1 ...................... 106

Table 25. Comparison of treated vs. control group in female subjects at T4-T1......... 107

Table 26. Comparison of treated vs. control in pooled subjects at T5-T1 ................... 117

Table 27. Comparison of treated vs. control in male subjects at T5-T1....................... 118

Table 28. Comparison of treated vs. control in female subjects at T5-T1................... 119

Table 29. Comparison of treated vs. control group in pooled subjects at T5-T4 ......... 128

Table 30. Comparison of treated vs. control in males subjects at T5-T4 ..................... 129

Table 31. Comparison of treated vs. control in female subjects at T5-T4) .................. 130

Table 32. Comparison of treated vs. control in pooled subjects at T4-T3 .................... 139

Table 33. Comparison of treated vs. control in pooled subjects at T4-T3................... 140

Table 34. Comparison of treated vs. control in female subjects at T4-T3................... 141 


\section{LIST OF FIGURES}

Figure 1. The Edgewise Crowned Herbst Appliance.................................................. 30

Figure 2. Mixed Dentition Herbst Appliance ................................................................ 31

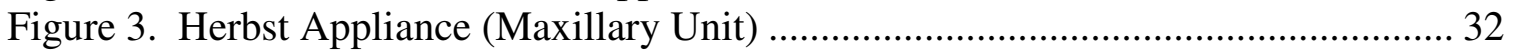

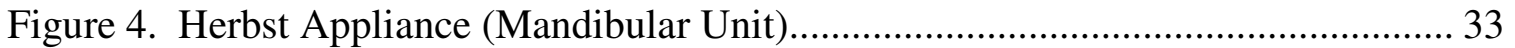

Figure 5. Corrected Tomograms taken prior to Herbst removal................................... 36

Figure 6. Corrected tomograms taken A) before, B) during, and C) after Herbst treatment

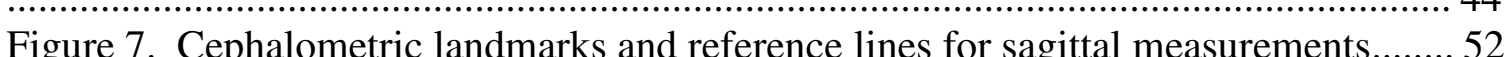

Figure 8. Cephalometric landmarks and reference lines for vertical measurements ....... 53

Figure 9. Cephalometric landmarks and reference lines for angular measurements ....... 54

Figure 10. Landmarks/reference lines for sagittal and vertical measurements of the

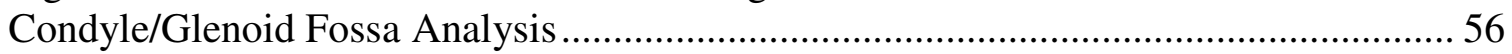

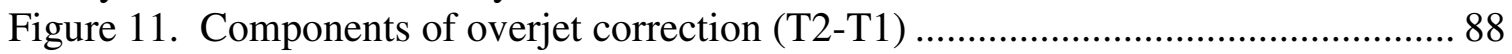

Figure 12. Components of molar relationship correction (T2-T1) ............................... 89

Figure 13. Pitchfork analysis of overjet and molar correction (T2-T1) ......................... 89

Figure 14. Components of net overjet correction (T2-T1) ...................................... 91

Figure 15. Components of net molar correction (T2-T1) ........................................... 92

Figure 16. Pitchfork analysis of net overjet and molar correction (T2-T1) ..................... 92

Figure 17. Components of overjet correction (T3-T1) ..............................................99

Figure 18. Components of molar relationship correction (T3-T1) ............................... 100

Figure 19. Pitchfork analysis of overjet and molar corrections (T3-T1) ....................... 100

Figure 20. Components of net overjet correction (T3-T1) ........................................ 102

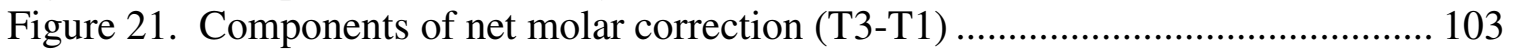

Figure 22. Pitchfork anaylsis of net overjet and molar correction (T2-T1) ................. 103

Figure 23. Components of overjet correction (T4-T1) ............................................. 109

Figure 24. Components of molar relationship correction (T4-T1) .............................. 110

Figure 25. Pitchfork analysis of overjet and molar correction (T4-T1)........................ 110

Figure 26. Components of net overjet correction (T4-T1) ........................................ 112

Figure 27. Components of net molar correction (T4-T1) .......................................... 113

Figure 28. Pitchfork analysis of net overjet and molar correction (T4-T1).................. 113

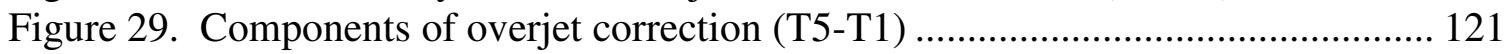

Figure 30. Components of molar relationship correction (T5-T1) ............................. 122

Figure 31. Pitchfork analysis of overjet and molar correction................................... 122

Figure 32. Components of net overjet correction (T5-T1) ......................................... 124

Figure 33. Components of net molar correction (T5-T1) ........................................ 125

Figure 34. Pitchfork analysis of net overjet and molar correction (T5-T1).................. 125

Figure 35. Components of overjet correction (T5-T4) ............................................. 132

Figure 36. Components of molar relationship correction (T5-T4) .............................. 133

Figure 37. Pitchfork analysis of overjet and molar correction (T5-T4)........................ 133

Figure 38. Components of net overjet correction (T5-T4) ....................................... 135

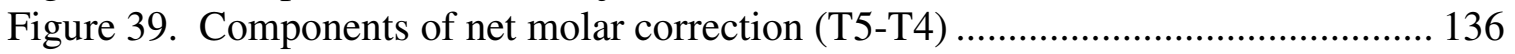

Figure 40. Pitchfork analysis of net overjet and molar correction (T5-T4).................. 136 


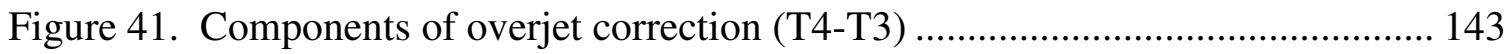

Figure 42. Components of molar relationship correction (T4-T3) .............................. 144

Figure 43. Pitchfork analysis of overjet and molar correction (T4-T3)........................ 144

Figure 44. Components of net overjet correction (T4-T3) ........................................ 146

Figure 45. Components of net molar correction (T4-T3) ........................................ 147

Figure 46. Pitchfork analysis of net overjet and molar correction (T4-T3) .................. 147

Figure 47. Skeletal contribution to net overjet correction ......................................... 164

Figure 48. Contribution of the skeletal bases and incisors to net overjet correction ..... 165

Figure 49. Skeletal contribution to net molar correction .......................................... 169

Figure 50. Contribution of skeletal bases and incisors to net molar correction............. 170 


\section{CHAPTER I: INTRODUCTION}

\section{Background}

Removable functional appliances such as the activator ${ }^{1}$, bionator $^{2}$, and Frankel appliance $^{3}$ are commonly used in the treatment of Class II malocclusion in an effort to stimulate sagittal mandibular growth in retrognathic mandibles. Unfortunately, the effectiveness of these appliances has been questioned and treatment results are inconsistent. In addition, patient compliance is often a problem with removable appliances and treatment time is usually long (2-4 years $)^{4}$. Fixed functional appliances such as the Herbst appliance offer an alternative treatment method with several advantages: the appliance is fixed to the dentition; no patient cooperation is required; treatment is continually applied ( 24 hours a day); and the treatment time is short (6-8 months $)^{4}$. Research has indicated that the bite jumping technique employed by the Herbst appliance can be effective in correcting Class II skeletal abnormalities by promoting growth of the mandible and remodeling of the glenoid fossa ${ }^{5,6,7,8}$.

Since Pancherz ${ }^{9}$ re-introduced the Herbst appliance in 1979, an increasing body of research has been published evaluating its effects on occlusion, the dentofacial complex, and the masticatory system. Pancherz et al. ${ }^{10,11,12}$ have published short-term and longterm data on the treatment effects of the banded Herbst appliance and the effects of the

acrylic splint Herbst appliance have been investigated ${ }^{13,14}$. However, after improvements in its design and increased clinical use, there seems to be an overall lack of information on the treatment changes observed with the crowned Herbst appliance and the long term stability of these effects. 
The timing of orthopedic intervention with functional appliances has also been the subject of intense controversy within the profession of orthodontics. When determining the optimal time to initiate Class II treatment, other factors must be considered such as the ability to utilize all potential growth, likelihood of incisor trauma, development of improper swallowing patterns, incomplete lip function, effects on the temporomandibular joint, and psychosocial concerns. The decision to treat either in the early, late mixed, or permanent dentition has been debated and many questions remain unresolved. Successful treatment of Class II malocclusion in the early mixed dentition have been reported ${ }^{15,16}$, however other studies report similar success during the late mixed dentition ${ }^{17,18}$ and early permanent dentition $^{19}$. Data from randomized controlled clinical trials have shown that effective skeletal changes could be achieved at either point in time and remain stable, although they suggest that treatment in the late transitional dentition is the most efficient in most cases ${ }^{20,21}$. Cozza et al. ${ }^{22}$ suggest that supplementary mandibular growth with functional appliance therapy appears to be significantly larger if the functional treatment is performed at the pubertal peak in skeletal maturation.

\section{Purpose of the Study}

This study investigated the skeletal and dental alterations of Class II patients treated in the early mixed dentition with the crowned Herbst appliance and examined the long term stability of these changes. Cephalometric analysis was performed on radiographs taken before phase I treatment (T1), immediately after Herbst removal during phase I treatment (T2), at the completion of phase I treatment (T3), prior to beginning of phase II orthodontic treatment (T4), and immediately following phase II orthodontic treatment 
(T5). Measurements were compared to a matched control sample of untreated Class II patients from the Bolton-Brush study. The results of this study provide important information on the effectiveness of early treatment with the crowned Herbst appliance and offer new information on the long term stability of these treatment effects. This information can ultimately be used by clinicians to evaluate the best time and most effective technique for treating skeletal Class II deformities.

\section{Statement of the Problem}

Are the skeletal and dental effects achieved in mixed dentition treatment with the edgewise crowned Herbst appliance stable in the long term?

\section{Significance of the Problem}

Research has indicated that the bite jumping technique employed by the Herbst appliance can be effective in correcting Class II skeletal abnormalities by promoting growth of the mandible and remodeling of the glenoid fossa. Since Pancherz re-introduced the Herbst appliance in 1979, an increasing body of research has been published evaluating its effects on occlusion, the dentofacial complex, and the masticatory system. However, after improvements in its design and increased clinical use, there seems to be an overall lack of information on the treatment effects of the edgewise crowned Herbst appliance. In addition, the long-term stability of the effects of early treatment with the Herbst appliance has been questioned. This research investigated the skeletal and dental alterations of Class II patients treated at an early age with the edgewise crowned Herbst 
appliance and evaluated the long term stability of those effects. The results provide valuable information that should help clinicians determine whether early treatment with the edgewise crowned Herbst appliance is warranted and if the results are stable over the long term.

\section{Null Hypotheses}

1) There are no significant short-term skeletal or dental changes associated with edgewise crowned Herbst treatment in the mixed dentition when compared to an untreated control group.

2) There are no significant short-term skeletal or dental changes associated with Phase I treatment (edgewise crowned Herbst treatment followed by two by four appliance treatment) when compared to an untreated control group.

3) There are no significant long-term skeletal or dental changes associated with Phase I treatment (edgewise crowned Herbst treatment followed by two by four appliance treatment) prior to Phase II treatment when compared to an untreated control group.

4) There are no significant skeletal or dental changes associated with combined Phase I treatment (edgewise crowned Herbst treatment followed by two by four appliance treatment) and Phase II treatment when compared to an untreated control group.

5) There are no significant skeletal or dental changes associated with Phase II comprehensive orthodontic treatment when compared to an untreated control group. 
6) There is no significant skeletal or dental relapse that occurred from after Phase I treatment (edgewise crowned Herbst treatment followed by two by four appliance treatment) to before Phase II comprehensive orthodontic treatment when compared to an untreated control group.

\section{Definition of Terms}

\section{Bolton-Brush Study:}

A longitudinal growth study performed at the Case Western University, which involved subjects with Class I, Class II, and Class III malocclusions who did not receive orthodontic treatment. These individuals were followed with orthodontic records for several years and their growth patterns were charted.

\section{Cephalogram:}

A term used as a synonym for a cephalometric radiograph.

\section{Cephalometric analysis:}

An analysis made on cephalometric radiographs comprised of a number of given landmarks and measurements used to describe positions and relationships of various skeletal components.

Cephalometric radiograph:

A radiograph of the head made with precise reproducible relationships between $\mathrm{x}-$ ray source, subject, and film. The generally accepted distances between x-ray source and the center of the subject are 5 feet or $150 \mathrm{~cm}$. The distance between the subject and film is usually $15 \mathrm{~cm}$, but may be standardized at a different value or varied with patient size 
and recorded for each exposure. The two standard orientations for cephalometric radiographs are lateral and postero-anterior $(\mathrm{P}-\mathrm{A})$.

\section{Cephalometric tracing:}

A tracing of selected structures from a cephalometric radiograph, made on translucent drafting paper or digitized on computer software for purposes of measurement and evaluation.

Class II malocclusion:

A type of malocclusion in which the mesiobuccal cusp of the maxillary first molar is located mesial to the buccal groove of the mandibular first molar when the teeth are in centric occlusion.

\section{Class II skeletal pattern:}

A type of skeletal malocclusion in which the mandible is in a retrusive position relative to the maxilla.

Fixed functional appliance:

An appliance that is placed in the patient's mouth to allow some type of growth guidance treatment to be carried out and which cannot be removed from the mouth by the patient.

\section{Herbst appliance:}

A type of functional appliance that protrudes the mandible into a forward position in an effort to stimulate mandibular growth and inhibit forward maxillary growth in patients with skeletal class II malocclusions. 


\section{Mixed dentition:}

A stage of dental development in which primary and permanent teeth make up the dentition.

Phase I treatment:

Limited treatment which occurs during the mixed dentition stage to correct or reduce the severity of developmental abnormalities in growing patients, with the intent of following up with phase II treatment.

\section{$\underline{\text { Phase II treatment: }}$}

Comprehensive orthodontic treatment provided when all the permanent teeth are present and following phase I treatment to achieve optimal anatomic and functional harmony of the dentition.

\section{Removable Functional Appliance:}

An appliance that is placed in the patient's mouth to allow some type of growth guidance treatment to be carried out and which can be removed from the mouth by the patient.

$\underline{\text { Retrognathic: }}$

A term used to define the position of a skeletal component that is located in a more posterior position or relation that normal. 


\section{Assumptions}

1. The lateral cephalograms are taken with teeth in centric occlusion.

2. Without treatment, growth patterns would be similar in the experimental and control groups, which are matched in age, sex, and craniofacial morphology.

\section{Limitations}

1. This is a retrospective study of a group of patients selected from the office of Dr. Terry Dischinger.

2. The experimental and control groups are selected from two different geographical sources (Lake Oswego, Oregon and Case Western Reserve University/Bolton Brush Study Center in Cleveland, Ohio, respectively).

3. Growth patterns and growth periods (peak pubertal growth period) are not available for the individuals in the study.

4. Skeletal ages of the experimental and control groups cannot be determined.

5. The experimental group was limited to patients who proceeded with Phase II orthodontic treatment after Phase I treatment with the Herbst appliance.

6. The experimental group was limited to patients who had acceptable quality radiographs available for at least four of the five time points included in the study.

7. The mechanics used in the Phase II orthodontic treatment of the experimental group were not considered in this study. 


\section{Delimitations}

1. The experimental group was composed of 22 patients ( 7 males and 15 females) treated consecutively by one clinician (Dr. Terry Dischinger).

2. Criteria of patient selection included no previous orthodontic treatment.

3. All patients in the experimental group were corrected with the crowned Herbst appliance to a position in which the maxillary cuspid was in an end-to-end relationship with the mandibular first premolar. 


\section{CHAPTER II: REVIEW OF THE LITERATURE}

\section{History and Classification of Malocclusion}

Crowding and mal-alignment of the teeth have probably been around since the beginning of man, but the prevalence has significantly increased within the last 1000 years $^{23}$. Evidence indicates that this recent increase may be the result of the transition of modern man from a primitive foraging subsistence strategy to a modern agricultural society in which foods are softer and less jaw function is necessary for survival ${ }^{24}$. The earliest orthodontic appliances have been found in Greek and Etruscan materials dating back to around $1000 \mathrm{BC}^{25}$, but it wasn't until the appearance of Norman Kingsley's Treatise on oral deformities as a branch of mechanical surgery ${ }^{26}$ after 1850 that a systematic approach to the practice of orthodontics was established in America. The publication of Edward Angle's classification of malocclusion ${ }^{27}$ in the 1890's further advanced American orthodontics and led to the first clear definition of normal occlusion. In addition, Angle described three malocclusions:

Class I-the mesiobuccal cusp of the maxillary first molar occludes with the buccal groove of the mandibular first molar, with there being a discrepancy in the line of occlusion.

Class II-the mesiobuccal cusp of the maxillary first molar is located mesial to the buccal groove of the mandibular first molar.

Class III- the mesiobuccal cusp of the maxillary first molar is located distal to the buccal groove of the mandibular first molar. 


\section{Etiology of Malocclusion and the Need for Orthodontic Therapy}

In most cases, malocclusion and dentofacial deformity is the result of moderate distortions in the normal developmental process. The primary etiologic factors associated with orthodontic problems have been cited as hereditary influences, environmental influences, and specific causes such as embryologic developmental and skeletal growth disturbances, muscle dysfunction, acromegaly and hemimandibular hypertrophy. Without proper orthodontic treatment, these dentofacial irregularities can lead to adversity for the individuals involved including: (1) psychosocial problems associated with discrimination because of facial appearance; (2) problems with the stomatognathic system including decreased jaw function, temporomandibular joint dysfunction, and problems with mastication, swallowing, and speech; and (3) increased risk of periodontal disease, tooth decay, and trauma ${ }^{28}$. The need for orthodontic therapy continues to grow and it has assumed an important role in improving self esteem and overall quality of life in our society.

\section{Prevalence of Class II Malocclusion}

Class II malocclusion is defined by the mandibular first molar being positioned in a distal relationship to the maxillary first molar with the line of occlusion not specified ${ }^{28}$. This class of malocclusion affects one third of the population in the United States and it's prevalence is greater in people of Northern European decent (30\%-40\%) than other ethnic populations. Eight to ten percent of the overall population have an overjet greater than six millimeters ${ }^{29,30,31,32}$. 


\section{Class II Skeletal Growth}

Genetics, function, deformities, size and position of bones are all factors that can lead to Class II skeletal growth ${ }^{33}$. Ultimately, Class II malocclusions are the result of either deficient mandibular growth, excessive maxillary growth, or a combination of the two. In the United States, Class II patients usually present with a convex facial profile due to a retrognathic mandible. A prognathic maxilla can be present, but this is less common. There are two divisions of Class II malocclusion. Class II division 1 malocclusion includes maxillary incisors that are in extreme labioversion, and Class II division 2 malocclusion includes relatively normal or slightly lingually tipped incisors.

Enlow divided the facial bones that contribute to a Class II skeletal pattern into segments including: (1) the anterior and posterior cranial base; (2) nasomaxillary complex; and (3) the ramus and corpus of the mandible ${ }^{33}$. The orientation of these segments to one another and their interactions during the growth process determine the final dentofacial form of an individual.

The primary growth of the cranial base occurs as a result of bone deposition on its outer cortex and endochondral growth at the spheno-occipital synchondrosis. A pressure adaptive growth mechanism provides a bi-directional growth direction causing displacement of facial bones ${ }^{33}$.

The growth of the nasomaxillary complex is the result of two mechanisms. Passive displacement, resulting from growth in the cranial base pushing the maxilla downward and forward, is an important growth mechanism during the primary dentition years, but becomes less important as the growth in the sychondrosis slows around seven years of age. Active growth of the maxillary sutures and nose is responsible for the majority of forward movement of the maxilla from ages seven to fifteen ${ }^{28}$. The normal 
growth of the maxilla is usually 1 to $2 \mathrm{~mm}$ a year ${ }^{28,34}$, and there is a linear relationship between the effective maxillary length and mandibular length. Cephalometric analysis has shown that in the majority of Class II malocclusions, the position of the maxilla was normal. In cases that were not normal, the maxilla tended to be in a retrusive position more frequently than in a protrusive position indicating that the maxilla was not the major contributing factor to a Class II malocclusion ${ }^{35}$.

Growth in the mandible is important in the establishment of a Class II malocclusion. Deposition and resorption of bone are responsible for directing growth in a posterior and superior direction. As the condyle grows directly towards its articular contact within the glenoid fossa, the entire mandible is displaced in the opposite direction to a more forward and downward position ${ }^{36}$. The growth of the mandible occurs at a relatively stable rate before puberty with an average ramus height increase of 1 to $2 \mathrm{~mm}$ per year and and an average body length increase of 2 to $3 \mathrm{~mm}$ per year ${ }^{28}$. Growth changes in the region of the glenoid fossa have a significant effect of the prominence of the chin. Any mandibular length increase to improve the prominence of the chin is usually negated by a posterior shift in the temporomandibular joint. To effectively increase the prominence of the chin, the temporomandibular joint must shift to the anterior or remain in the same antero-posterior position with an increase in mandibular length. These properties of mandibular growth allow orthodontists to alter growth patterns to provide therapy for Class II malocclusions with a retrognathic mandible. 


\section{Analysis of the Dentofacial Complex}

A Class II skeletal malocclusion can be defined as the mandible being positioned distally relative to the maxilla. This malposition of the jaws can result from a number of irregular positional relationships. Class II malocclusions are the result of either mandibular retrusion, maxillary protrusion, or a combination of both. Due to the hinging effect of the mandible, the vertical component of the dentofacial complex is also important in Class II malocclusions. A decrease in the vertical dimension of the anterior facial height causes the mandible to rotate upward and forward reducing the anteroposterior discrepancy, however an increase in vertical dimension will cause the opposite effect, making the anteroposterior relationship even worse. A Class II molar relationship usually accompanies a Class II skeletal malocclusion, however, a Class I molar relationship can be present. In addition, the incisors can be either extremely proclined, relatively normal, or even lingually inclined. Because many factors contribute to a Class II skeletal malocclusion, a thorough analysis of the dentofacial complex is important in describing the components of a particular malocclusion.

The evaluation of dentofacial form can be accomplished with cephalometric analysis. The anteroposterior position of the maxilla can be determined on a lateral cephalogram from the Sella-Nasion-Point A (SNA) angle ${ }^{37,38}$ and from Nasion perpendicular to Point $\mathrm{A}^{39}$. The position of the upper incisors relative to the maxilla can be evaluated from the distance from the facial surface of the upper incisor to a vertical line drawn perpendicular to the Frankfort horizontal plane extending through the A Point ${ }^{39}$. The relation of the lower incisors to the basal bone structures can be determined from the distance from the tip of the lower incisor to the A Point-Pogonion line ${ }^{40,41}$. 
Mandibular position relative to the cranial base can be assessed by measurements from the Pogonion to the nasion perpendicular ${ }^{39}$ and from the Sella-Nasion-Point B (SNB) $\operatorname{angle}^{37,38}$.

The vertical skeletal dimensions of a patient must also be evaluated since this dimension may either conceal or intensify the clinical parameters of the malocclusion ${ }^{41,42}$. A decrease in vertical dimension of anterior facial height causes the mandible to rotate upward and forward. Patients with an increase in lower anterior facial height exhibit a retruded mandible, a poorly defined chin with a hyperactive mentalis muscle, and a tendency towards open bite. Vertical dimensions can be measured on a lateral cephalogram from the mandibular plane angle (MP-SN, MP-FH) and lower anterior facial height (the distance from the anterior nasal spine to the menton) $)^{35}$.

The transverse relationship of the maxilla to the mandible is also important in the evaluation of dentofacial form. Tollaro et al. ${ }^{43}$ have shown that in dental arches with Class II malocclusion and seemingly normal buccal relationships, an underlying transverse discrepancy of three to five millimeters exists. Studies by Bacetti et al. ${ }^{44}$ Arya et al. ${ }^{45}$, and Bishara et al. ${ }^{46}$ indicate that maxillary transverse deficiency is associated with Class II malocclusions and tend to be self perpetuating. For this reason, Spillane ${ }^{47}$ and McNamara ${ }^{48}$ have recommended orthopedic rapid maxillary expansion during the early mixed dentition in mild to moderate Class II patients.

\section{Treatment of Class II Malocclusion}

The amount of growth remaining for an individual is an important consideration for the treatment of a Class II malocclusion. The treatment options for Class II 
malocclusions in non-growing patients are somewhat limited. Because a significant amount of growth will no longer occur in these patients, clinicians must rely on treatment options other than growth modification to correct dentoalveolar disharmony. Compromised/non-extraction, extraction/camouflage, distal movement of maxillary teeth, and surgery are the treatment options available for non-growing patients with a Class II condition. In cases where extraction and surgery are not options, a compromised/nonextraction approach is implemented in which the patient's teeth in each arch are straightened without correcting the intra-arch relationship. Because skeletal differences are not corrected between the maxilla and mandible, the patient may still have an overjet. Extractions are often indicated in patients with Class II malocclusions in order to provide space to align crowded incisors while avoiding excessive protrusion. Extractions are also recommended to camouflage a moderate skeletal discrepancy when modification by growth is not possible. In minor Class II malocclusions, the option of distalizing the maxillary molars exists. A maximum of 1-2 mm of distal movement is all that can be expected when using this approach ${ }^{16}$. In recent years, the Herbst appliance has been shown to be an effective treatment option for Class II malocclusions in non-growing adults $^{49}$. Adults have been shown to exhibit the same condylar growth and remodeling of the glenoid fossa that occurs in children and adolescents ${ }^{50}$. Orthognathic surgery is by far the most invasive and expensive treatment for non-growing patients with Class II malocclusion. The surgical movement of the maxilla and/or mandible allows the upper and lower arches to be aligned into maximum intercuspation. This treatment option is often the most effective in obtaining an ideal occlusion. 
More options for the treatment of Class II malocclusion are available when the patient is still growing. Treatment is often administered around an individual's peak pubertal growth period which occurs around age $13.9 \pm 1.0$ in males and age $11.7 \pm 1.0$ in females $^{51}$. Non-extraction/compromise, extractions, and functional appliances are among the treatment options for these individuals.

Although more options exist for the orthodontist when treating growing individuals, ideal occlusion cannot always be achieved. Many parents dislike the alternatives of surgery or extraction for their children, and choose only to have the teeth aligned. In these cases, the patient will almost certainly still have an overjet due to size discrepancies between the maxilla and mandible. In growing patients, extraction is an option only when space is needed due to severe crowding of the anterior teeth. Extractions with the intent of camouflaging skeletal disharmony are contraindicated in growing patients because of the unpredictable growth of the maxilla and mandible. When teeth are aligned and an acceptable result in unachievable, the skeletal discrepancies must be corrected. Surgery is an option, however most patients prefer an alternative method that is non-invasive and less expensive. Because of these concerns, functional appliances were introduced to correct problems of skeletal disharmony without surgery in patients with a retrognathic mandible.

\section{Functional Appliances Used to Treat Class II Malocclusion}

In 1877, Norman W. Kingsley was the first to introduce an appliance designed to stimulate sagittal mandibular growth ${ }^{52}$. The bite jumping appliance consisted of an upper plate with an inclined plane which caught the lower incisors and forced the mandible 
anteriorly. The rationale behind "bite jumping" was that forcing the mandible forward during function would stimulate condylar growth, thereby correcting the Class II malocclusion. Carl Breitner, with his experiments on rhesus monkeys, was the first to show that bite jumping led to condylar growth by means of (1) bone apposition at the distal wall of the articular fossa and resorption at the mesial wall and (2) apposition of cartilage at the posterior margin of the condylar head and resorption at the anterior $\operatorname{margin}^{53}$.

The principle of bite jumping encouraged the development of several removable functional appliances that are used today for stimulating mandibular growth in Class II patients with a deficient mandible. The activator ${ }^{1}$ was designed as a block of plastic that covered the teeth of both arches and the palate and was made to fit loose to allow advancement of the mandible several millimeters and open the bite 3-4 mm. The Bionator $^{2}$ is described as a cut-down activator with palatal coverage eliminated. The Frankel appliance ${ }^{3}$ is a tissue-borne functional appliance that consists of a small pad against the lingual mucosa beneath the lower incisors to stimulate mandibular repositioning. The Herbst appliance ${ }^{4}$ is a fixed functional appliance that forces the mandible forward by means of a pin and tube apparatus that runs between the arches.

The effect of the functional appliances have been debated with some studies showing alteration of mandibular growth ${ }^{54,55,56}$ and other studies showing no effect ${ }^{57,58}$. Evaluating the treatment results of removable functional appliances can be difficult because (1) the appliance is used only part of the day and in certain individuals the threshold for condylar growth adaptation to forward displacement may never be reached, (2) patient compliance is a problem and undetected insufficient appliance wear could 
produce erratic results, and (3) treatment time is relatively long (2-4 years) and a suitable control group is often unattainable. The fixed Herbst appliance offers several advantages in that (1) it works 24 hours a day, (2) patient cooperation is not a factor, and (3) active treatment time is relatively short (6-9 months) $)^{4}$. A review of the literature by Aelbers and Dermaut found that the Herbst appliance was the only functional appliance that could effectively alter mandibular growth to a clinically significant extent ${ }^{58}$. A randomized, controlled trial by O'Brien et al. ${ }^{59}$ concluded that the Herbst appliance had several advantages over functional appliances such as the Twin Block including better patient cooperation and decreased phase I treatment times.

\section{The Herbst Appliance}

Emil Herbst introduced a fixed bite jumping appliance called the "Scharnier" at the International Dental Congress in Berlin in 1909. The appliance was designed to alter mandibular jaw and muscle function by keeping the mandible in a continuously protruded position on both jaw closure and eccentric movements ${ }^{60}$. Its design included a bilateral telescope mechanism attached by orthodontic bands to the lower first premolars and upper first molars. In 1934, Herbst published a series of articles in which he described the appliance to be most useful in: (1) Class II malocclusions with a retrognathic mandible; (2) mandibular ramus fractures; (3) condylectomies (used as an artificial joint); and (4) TMJ problems including crepitus and bruxism ${ }^{61}$. After 1934, however, little was published about the Herbst appliance and the treatment method was more or less forgotten. 
Hans Pancherz reintroduced the Herbst appliance as an experimental tool in clinical research in 1977, and in 1979, he published a paper calling attention to the possibilities of stimulating mandibular growth with the appliance ${ }^{9}$. The popularity of the appliance increased after this time and the effects of the Herbst appliance on the occlusion, dentofacial complex, and masticatory apparatus began to be evaluated.

The Herbst appliance employs a bilateral telescope mechanism consisting of a tube, a plunger, two pivots, and two locking screws, which function to keep the mandible in a continuously anterior jumped position. The pivot for the tube is usually located on the maxillary first molar and the pivot for the plunger is usually attached to the mandibular first premolar. The length of the tube determines the amount of anterior displacement of the mandible and usually achieves an incisal end-to-end relationship. The anchorage system of the Herbst appliance has evolved since its reintroduction by Pancherz in 1979. Originally, a partial anchorage system was used in which the maxillary first premolars and first molars were banded and connected to the other side with a lingual or buccal sectional arch wire and the mandibular first premolars were banded and interconnected with a lingual sectional arch wire. Later, a total anchorage system was used in which a labial arch wire was ligated to brackets on the maxillary first premolars, canines, and incisors and a lingual sectional arch wire was extended to the first permanent molars which were also banded. Bands were eventually replaced by cobalt chromium alloy casted splints that were cemented with glass ionomer cement ensuring a precise fit on the teeth. In 1988, McNamara and Howe presented the removable acrylic splint Herbst appliance, with occlusal coverage extending posteriorly from the canines to the first molars on the maxillary arch and full occlusal coverage on 
the mandibular $\operatorname{arch}^{13}$. The crowned Herbst appliance consisting of stainless steel crowns cemented to the mandibular first premolars and maxillary first molars was introduced in the late 1980's and early 1990's to compensate for the inadequacies of the banded Herbst appliance $^{62,63,64}$. The crowned appliance offers several advantages over conventional anchorage including having no removable parts, eliminating the need for patient cooperation, having a streamlined design which facilitates hygienic procedures, and the ease of recementation in the event of a loosened crown ${ }^{63,64}$.

\section{Indications for Treatment with the Herbst Appliance}

The Herbst appliance is most useful in the treatment of growing individuals with both Class II, Division 1 and Class II, Division 2 malocclusions. The treatment method should be used cautiously in non-growing individuals as minimal changes will occur in the facial skeleton and most of the alteration will occur in the dentoalveolar area. In addition, increased chance of developing a dual bite and TMJ problems accompany treatment in non-growing individuals ${ }^{65,66}$.

The Herbst appliance has been shown to be used effectively in post-adolescent patients with minimal remaining residual growth, in mouth breathers who cannot use removable functional appliances, in uncooperative patients, and in patients who do not respond to treatment with removable functional appliances ${ }^{4}$.

\section{Timing of Treatment with Functional Appliances}

The timing of orthopedic intervention with functional appliances has been the subject of intense controversy within the profession of orthodontics. The decision to treat 
in the early mixed, late mixed, or permanent dentition has been debated and many questions remain unresolved. Two phase treatment with functional appliances became justifiable with the emergence of the functional matrix theory proposed by Moss in the $1960 \mathrm{~s}^{67}$. A shift from Brodie's genomic hypothesis that suggested craniofacial growth was established by three months old and could not be altered ${ }^{68}$, the functional matrix paradigm exposed the possibility of correcting skeletal problems in a growing child with dentofacial orthopedics. The decision of when to begin Class II orthopedic treatment is made more difficult by individual variability between patients and uncertainty about growth and treatment response.

Successful treatment of Class II malocclusions with functional appliances have been reported in both the early mixed dentition ${ }^{15,16}$ and the late mixed dentition ${ }^{17,18}$. A systematic review of mandibular changes produced by functional appliances in Class II malocclusions reported that the amount of supplementary mandibular growth appears to be significantly larger if the functional treatment is performed at the pubertal peak in skeletal maturation $^{22}$. The majority of the literature supports the idea that Class II correction can be successfully achieved in both the mixed dentition and the permanent dentition. The current debate seems to revolve around the effectiveness and the efficiency of the Class II correction. With respect to both duration and outcome, Pancherz found that late treatment of Class II Division I malocclusion (in the permanent dentition) was more efficient than earlier treatment (in the early or late mixed dentition $)^{69}$. In a review of the data from a randomized controlled clinical trial, Tulloch et al. concluded that for children with moderate to severe Class II problems, early treatment followed by later treatment does not produce major differences in jaw 
relationship or dental occlusion, compared with later one-stage treatment ${ }^{70}$. According to the same study, early treatment appeared to be less efficient, in that it did not reduce the amount of time a child was in fixed appliances in a second phase of treatment, and it did not decrease the proportion of complex treatments in phase II involving extractions or orthognathic surgery ${ }^{20}$. Other clinical studies have shown that early treatment can lead to more relapse, reduced patient motivation in the second phase of orthodontic treatment, and other potential hazards $\mathrm{s}^{71-75}$.

Despite these arguments against early treatment, many practitioners have published their opinions based on clinical experience suggesting that early treatment has many advantages. The ability to utilize all potential growth, increased probability of incisor fracture in untreated Class II patients, the development of improper swallowing patterns, incomplete lip function, temporomandibular joint dysfunction, and psychosocial considerations are all factors that support the concept of early treatment. Psychological studies have shown that younger children are good candidates for phase I orthodontics and expect orthodontics to lead to improvements in their lives ${ }^{76}$. Another study showed that early treatment with Twin-block appliances resulted in an increase in self-concept and a reduction of negative social experiences ${ }^{77}$. Surveys have shown that practice characteristics tend to affect orthodontists' decisions regarding orthodontic treatment and a wide range of acceptable treatment timing exists ${ }^{78}$. Ultimately, the decision to initiate early phase orthodontics or orthopedic treatment should include a conversation with the parents and the child and the individual circumstances for each patient should be considered. 


\section{Treatment Effects of the Herbst Appliance on the Dentofacial Complex}

The treatment effects of the Herbst appliance on the dentofacial complex are difficult to describe. The Herbst appliance directly or indirectly applies force in all three planes of space to the maxilla, the mandible, the maxillary and mandibular dental units, and the temporomandibular region. Evaluating the changes in the individual anatomic components and understanding the interaction between them becomes very complicated. In addition, treatment is usually performed on growing patients with variable growth patterns and rates. Although the Herbst appliance is considered a functional orthopedic appliance, the effects of treatment are not limited to the skeletal components. Anchorage on the dental units produces both desirable and undesirable side effects on the dentition. Changes in the angular position of the palatal plane, occlusal plane, and mandibular plane are important and should be considered. The temporomandibular joint, a ginglymodiarthrodial joint that allows both hinging and translational movement, is directly affected by treatment with the Herbst appliance and changes within the joint are very difficult to identify and quantify. When describing the treatment effects of the Herbst appliance, it is useful to divide the discussion into skeletal and dental components. The skeletal components include the maxilla, the mandible, and the temporomandibular region and the dental components include the dental units of the maxilla and mandible.

\section{Skeletal Components}

Maxilla: The Herbst appliance has a restraining effect on maxillary growth similar to a headgear ${ }^{9,10,19}$. Studies have shown that growth of the maxilla in patients treated with the Herbst is consistently less than in control groups without 
treatment $^{11,14,79,80,81,82}$. The overall size of the maxilla is reported to be unaffected by treatment $^{14,79,82}$, however there is a slight clockwise rotation of the palatal plane $e^{11,79}$.

Mandible: Many animal studies have shown that skeletal mandibular changes can be produced with functional appliances ${ }^{5,83,84}$, however the effects on humans are more controversial. A systematic review of the literature limited to randomized controlled clinical trials from 1966 to 1999 on the efficiency of functional appliances on mandibular growth by Chen et al. ${ }^{85}$ reported that there is no difference in overall mandibular change in the horizontal or vertical direction. Another systematic review by Cozza et al. ${ }^{22}$ analyzed 22 studies that met inclusion criteria in an attempt to assess the scientific evidence of functional appliances in enhancing mandibular growth in Class II subjects. Two-thirds of the samples in the 22 studies reported a clinically significant supplementary elongation in total mandibular length compared to controls (a change of greater than $2.0 \mathrm{~mm}$ in the treated groups compared to the control groups) as a result of treatment with functional appliances. However, none of the four randomized clinical trials included in the study reported a clinically significant change in mandibular length with treatment. The results were attributed to treatment timing due to the fact that three of the four randomized clinical trials described outcomes of treatment at a pre-pubertal stage of skeletal maturity.

Pancherz ${ }^{86,87}$ has reported that sagittal condylar growth is increased while vertical condylar growth is unaffected by Herbst treatment. Ruf and Pancherz ${ }^{50}$ analyzed temporomandibular joint remodeling with magnetic resonance imaging during Herbst treatment and reported signs of condylar remodeling at the posterosuperior border. Voudouris et al. ${ }^{88}$ performed radiographic investigations superimposing on metallic 
implants in nonhuman primates and showed increases in condylar length in response to treatment with functional appliances. In the same study, histological analysis using undecalcified sections and tetracycline vital staining with fluorescence microscopy also confirmed the increased condylar response. Another implant study by Araujo et al ${ }^{89}$ on twenty five patients treated with the bionator appliance showed significant changes in the direction (more posterior) but not in overall amount of condylar growth. Despite these findings, a systematic review of the literature by Popowich et al. ${ }^{90}$ evaluating the effects of Herbst treatment on temporomandibular joint morphology did not provide conclusive evidence of osseous remodeling or condyle position change.

Temporomandibular region: The response of the temporomandibular joint to mandibular forward repositioning has been very controversial in both experimental and clinical studies. Some researchers believe that the main effect of functional appliance therapy is increased condylar growth, others feel that the main effect is due to remodeling of the glenoid fossa, and others contend that little to no structural changes occur in response to treatment. Remodeling of the temporomandibular joint has been described to occur both within the glenoid fossa and the condyles of the mandible, with new bone formation on the posterior aspect of the condylar head and the roof of the fossa ${ }^{7,8,50}$. Ruf and Pancherz ${ }^{50}$ have noted glenoid fossa remodeling 6 to 12 weeks after the initiation of Herbst treatment. In a study on rats, Rabie et al. ${ }^{91}$ reported that a forward positioning of the mandible leads to increased new bone formation in the glenoid fossa of the temporal bone with the highest levels of bone deposition occurring in the posterior region of the glenoid fossa. From a study on nonhuman primates treated with the Herbst appliance, Voudouris et al. ${ }^{88}$ reported that the growth modification measured in the glenoid fossa 
was in an inferior and anterior direction. In addition, he noted that restriction of the downward and backward growth of the fossa observed in the control subjects might additionally contribute to the Class II correction.

\section{Dental Components}

Maxilla: There are significant effects on the maxillary dentition in response to treatment with the Herbst appliance ${ }^{14,92}$. The maxillary molars exhibit a "high-pull headgear effect" in which they are distalized and intruded ${ }^{9,16,80,93,95}$. The maxillary molar movements are only temporary in nature as they move downward and forward in the post-treatment phase following the normal growth pattern ${ }^{95}$.

Mandible: In general, the mandibular dentition moves in an anterior direction in response to Herbst treatment ${ }^{9,16,80,93,95}$. The mandibular molars continue to erupt in an anterior and superior direction, however their eruption can be impeded during treatment. The lower incisors are proclined and intruded during treatment, however, they recline somewhat in the post-treatment phase ${ }^{79}$.

\section{Vertical changes associated with the Herbst Appliance}

The Herbst appliance affects the vertical dimension of the dentofacial complex with a reduction in the overbite ${ }^{96}$. The reduction in the overbite is mainly the result of the intrusion of the lower incisors and the eruption of the lower molars, however, changes in the vertical mandibular incisor position can be attributed to the facial proclination of these teeth. Due to the vertical changes in the dentition, the lower facial height increases. The maxillary and mandibular jaw position is relatively unaffected, as there are no 
significant alterations in the palatal plane angle or the mandibular plane angle in the long term $^{4}$.

\section{Post-treatment relapse following Herbst treatment}

At the conclusion of treatment with the Herbst appliance, the sagittal dental arch relationships are generally overcorrected and there is often incomplete cuspal interdigitation among the teeth. Because the active treatment time is short (usually 6-8 months), the occlusion is unstable and adaptive changes will occur ${ }^{92}$. The occlusion usually settles into a Class I relationship during the first year post-treatment, and for the most part, the adjustments are of dental origin. The maxillary teeth, especially the molars move anteriorly, and the mandibular teeth move posteriorly with the incisors becoming more upright ${ }^{4}$. Accelerated maxillary growth and a reduction in mandibular growth rates occur only minimally within the first year after treatment ${ }^{92}$.

When the long-term effects of the Herbst appliance treatment were compared with a standardized control group, it was found that the Herbst appliance improves the sagittal jaw base relationship, but does not normalize it ${ }^{12,97}$. The sagittal dental arch relationship is normalized and can compensate for an unfavorable jaw base relationship. A Class I dental relationship can be maintained by a stable cuspal interdigitation of the upper and lower teeth ${ }^{4}$. When relapses in overjet and sagittal molar relationships occur in individuals who have undergone treatment with the Herbst appliance, it is a result of maxillary and mandibular dental changes ${ }^{98}$. The long-term effects of Herbst treatment on mandibular growth is difficult to evaluate. Increases in sagittal condylar growth and changes in mandibular morphology apparent during treatment could not be verified seven 
years later ${ }^{87}$. Despite these findings, it is believed that the functional stability of the occlusion prevents occlusal relapses ${ }^{4}$.

Many reports on the long-term effects of the Herbst appliance have been reported $^{12,94,95,99}$. The results indicate that the Herbst treatment had only a temporary impact on the existing skeletofacial growth pattern. After the treatment period, maxillary and mandibular growth seem to return to their pre-treatment patterns ${ }^{99}$. Voudouris et al. ${ }^{100}$ proposed a growth relativity concept to explain this phenomenon. Their nonmuscular hypothesis of condyle-fossa remodeling with Herbst treatment suggest that glenoid fossa modification is associated with decreased muscle activity of the postural masticatory muscles and is a result of the stretch forces of the retrodiskal tissues. They contend that the impact of the viscoelastic tissues may be highly significant and should be considered along with the standard skeletal, dental, neuromuscular, and age factors that influence condyle-glenoid fossa modification with orthopedic advancement. They express concerns that these biodynamic factors are also capable of reversing effects of treatment on mandibular growth direction, size, and morphology. Relapse could occur after the completion of active treatment as a result of the release of the condyle and the ensuing compression against the newly proliferated retrodiskal tissues together with reactivation of muscle activity.

Contrary to the previous mentioned studies, Croft et al. ${ }^{18}$ suggest that early treatment with the Herbst appliance, in combination with retention, results in significant long-term improvements in skeletal and dental relationships and consider it a viable treatment option. A study by Berger et al. ${ }^{101}$ compared the treatment outcome and stability of Class II patients treated with functional appliances to patients treated 
surgically with bilateral sagittal split ramus osteotomies. They reported that in the functional appliance group, the mandible continued to grow in a favorable direction even after discontinuation of the functional appliance and that both the functional appliance group and the surgical group experienced significant skeletal and soft tissue changes. This study concluded that early correction of Class II dentoskeletal malocclusions with functional appliances yielded favorable results without the possible deleterious effects of surgery.

\section{The Edgewise Herbst Appliance}

The Edgewise Herbst Appliance differs from other versions of the Herbst appliance in the fact that it is designed to incorporate edgewise brackets and mechanics into the correction of Class II malocclusions and minimize certain limitations of the original appliance ${ }^{64}$.

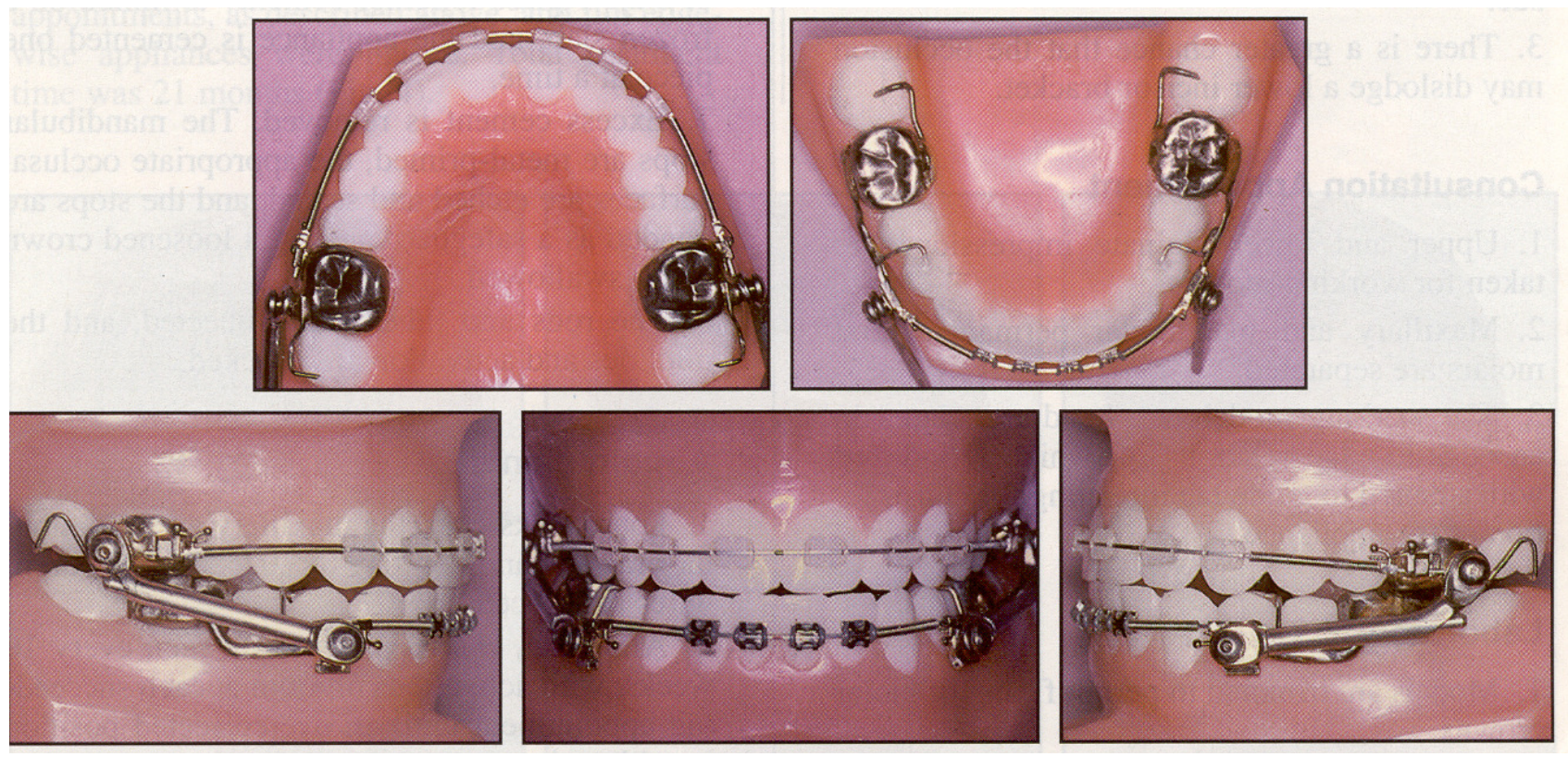

Figure 1. The Edgewise Crowned Herbst Appliance 
In most permanent dentition cases, the maxillary six anterior teeth and the four mandibular incisors are bracketed (Figure 1). The mandibular incisor brackets incorporate $\mathrm{a}-10^{\circ}$ inclination to minimize the anterior proclination that is a side effect of Herbst treatment. The maxillary bicuspids and mandibular bicuspids and canines usually are not bracketed. In the mixed dentition, brackets are usually placed on the maxillary and mandibular incisors; however, this sometimes varies depending on the individual circumstances of the case ${ }^{64}$.

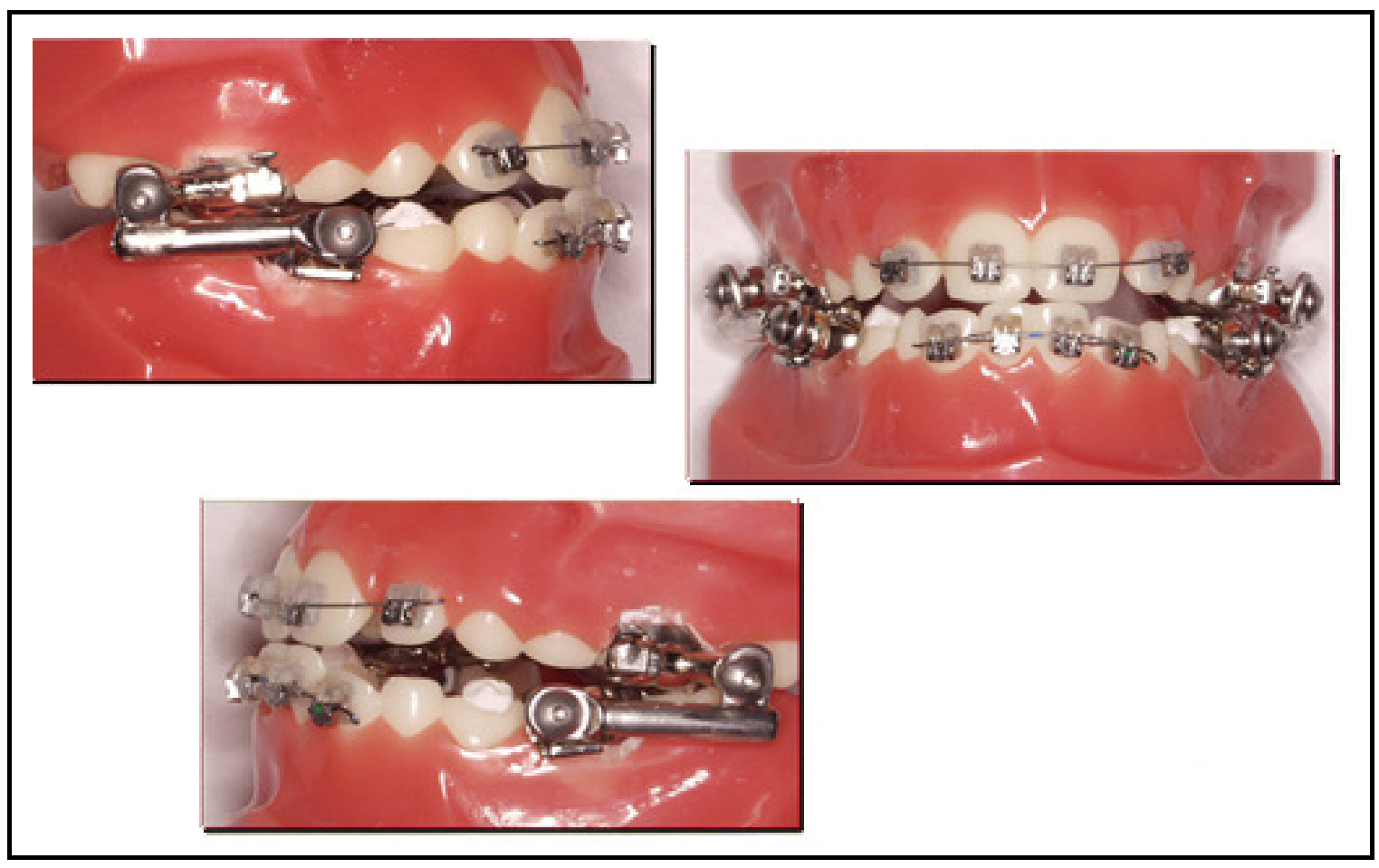

Figure 2. Mixed Dentition Herbst Appliance

Stainless steel crowns on the maxillary and mandibular permanent first molars anchor the Herbst appliance to the dentition (Figure 2). Double buccal tubes are placed on the molar crowns to permit the use of an auxiliary archwire to intrude the maxillary or mandibular incisors as necessary. The maxillary arch is tied back to hooks on the molar 
tubes to prevent space from opening in the maxillary arch because the molars tend to be driven distally during treatment. In addition, consolidating the arch distributes the load applied to the dentition to more teeth. In the mandibular arch, a $2 \mathrm{~mm}$ half-round cantilever is placed between the first molar and interproximal area between the first bicuspid and cuspid. The axle is placed at the mesial end of the cantilever, and a $.022 " X .028 "$ archwire tube is placed above and below the axle ${ }^{64}$.

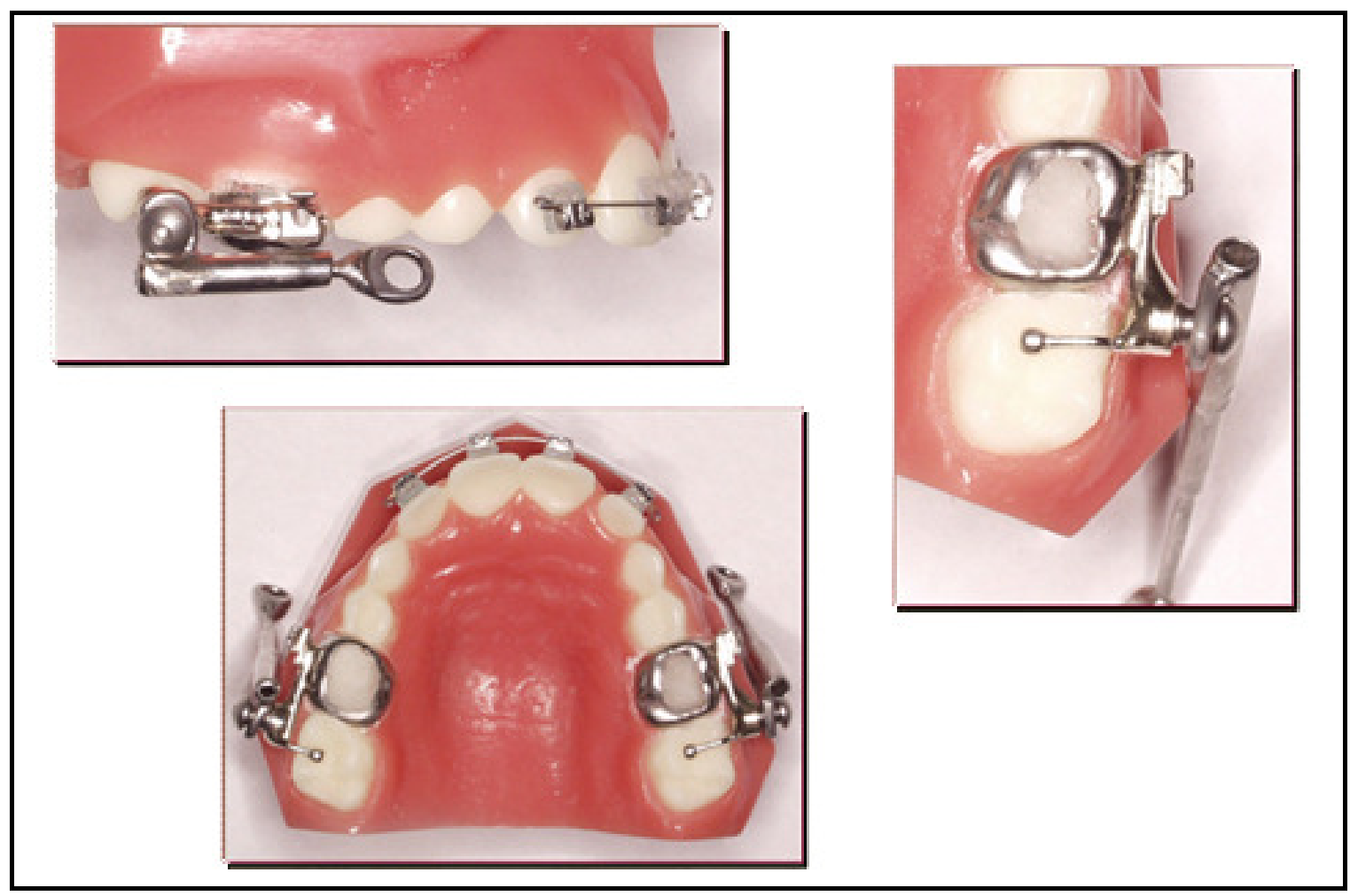

Figure 3. Herbst Appliance (Maxillary Unit)

A transpalatal arch is not included in the appliance to allow the first molars to rotate as the Class II relationship is corrected (Figure 3). A lingual arch is not included to allow easier placement of the appliance and prevent possible tipping of the lower anterior incisors (Figure 4). Both arches are free to accommodate expansion during treatment, if 
necessary. An occlusal stop off the cantilever arm or directly soldered to the stainless steel crowns extends into and rests on the distal central fossa of the first bicuspid or the mesial central fossa of the second primary molar to prevent tipping of the cantilever arm and impingement into the buccal mucosa and to minimize tipping of the mandibular first $\operatorname{molar}^{64}$.

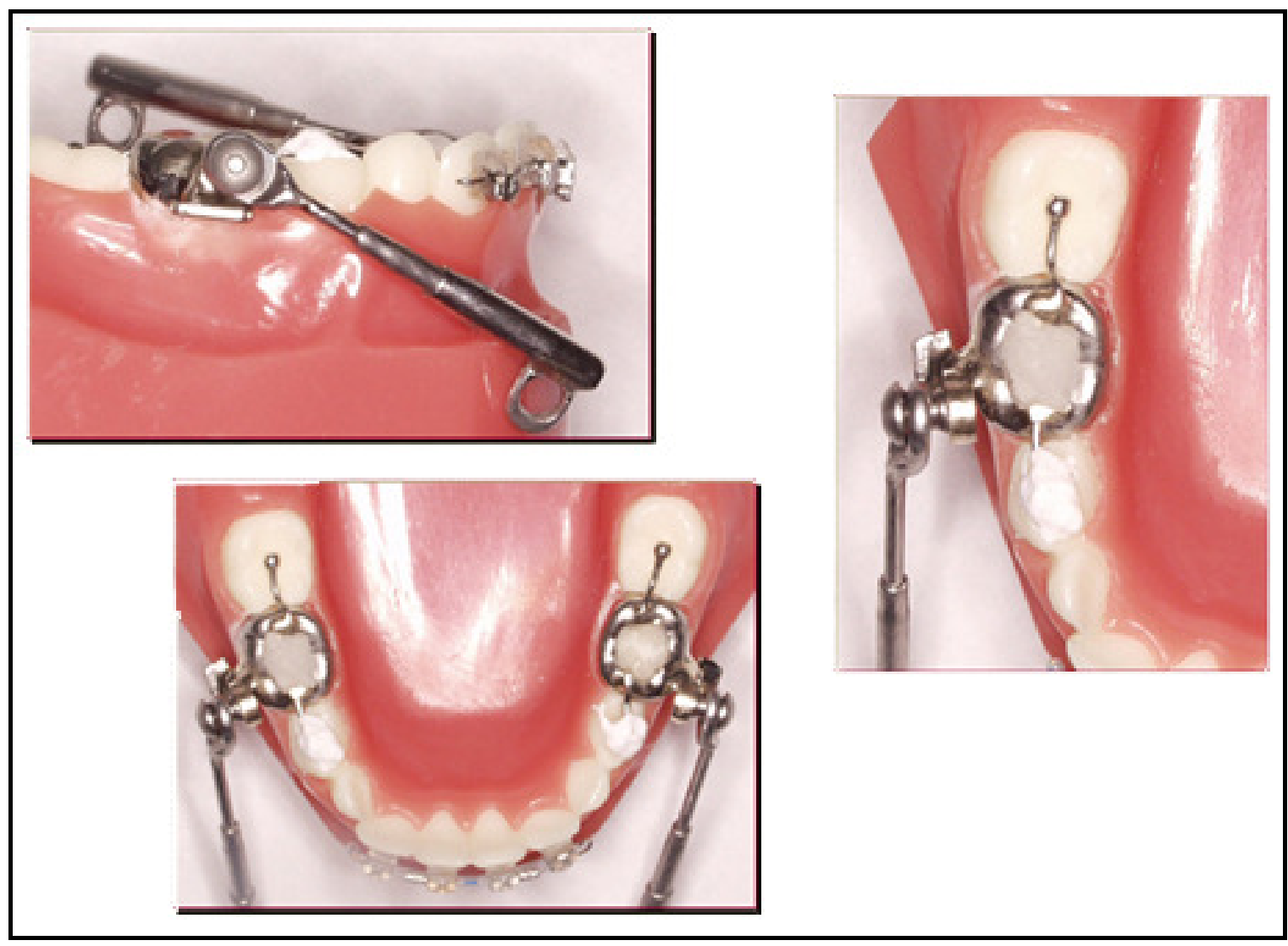

Figure 4. Herbst Appliance (Mandibular Unit) 
According to Dishinger ${ }^{64}$, the Edgewise Herbst has the following advantages over other Herbst designs and functional appliances:

1) It is a fixed functional appliance that requires no patient cooperation and has no removable parts.

2) Orthodontic tooth movements can be accomplished at the same time that orthopedic Class II correction is taking place.

3) The lower arch can expand along with the upper arch.

4) There is no lingual wire which allows easier placement of the appliance, eliminates interference with the tongue, and prevents possible tipping of the lower anterior incisors.

5) Leveling of the lower arch can be accomplished prior to Herbst removal eliminating anterior tooth contact and improving stability.

6) Appliance breakage or loosening is rare.

7) The streamlined design of the appliance allows for easy cleaning and improved oral hygiene.

8) Recementation is easy if a crown becomes loosened.

9) The appliance incorporates a built-in lip bumper effect.

10) Lower cuspids and first premolars are free to erupt.

11) The use of negative inclination brackets and the position of the archwire tube on the axle allow leveling of the lower arch with a straight wire. 


\section{The Dischinger Protocol for the Edgewise Herbst Appliance}

The Dischinger protocol ${ }^{64}$ for the clinical use of the edgewise Herbst appliance applies certain concepts and principles in an attempt to achieve maximum skeletal correction of Class II skeletal malocclusions while minimizing dentoalveolar side effects. VanLaecken et al. ${ }^{102}$ analyzed the treatment effects of the edgewise Herbst appliance on 32 patients with Class II skeletal malocclusion treated by Dr. Terry Dischinger. They found that the net effect of the edgewise Herbst treatment was primarily skeletal (85\% of the overjet correction and $96 \%$ of the molar correction). This is an increased skeletal effect compared to the $70 \%$ skeletal contribution to overjet correction reported by Hagg et al. ${ }^{103}$. These results suggest that it could be important to follow detailed procedures when treating with the Herbst appliance to achieve maximum skeletal correction with the appliance.

Dr. Dischinger developed and continues to modify his treatment protocol after 20 years of clinical practice in an attempt to achieve the greatest amount of skeletal correction possible when treating Class II malocclusions ${ }^{104}$. Initially, the Herbst appliance is activated to an edge to edge incisor relationship with the skeletal midlines in alignment. Brackets are bonded to the maxillary six anterior teeth and the mandibular incisors and high tech archwires are used to control incisor inclination and mandibular molar movement. Archwire sequence begins with a .014 Damon CuNiTi. Then a .016X.025 Damon CuNiTi with the maxillary wire tied back to the hook on the maxillary molar and the lower wire annealed and cinched to prevent anterior movement of the wire. Next, a .019X.025 lower reverse curve NiTi archwire is placed if more leveling is necessary. Finally, a .019X.025 TMA is inserted if more leveling or torque is desired ${ }^{104}$. 
To achieve maximum orthopedic effect, it is important to tie back the maxillary archwire to prevent distalization of the maxillary molars. The appliance is activated in a step-by-step fashion a distance of $4 \mathrm{~mm}$ every 12 weeks until the maxillary cuspid achieves an end-to-end relationship with the mandibular first premolar. The overcorrected position is held for a period of 12 weeks ${ }^{104}$. Several studies have reported a greater skeletal effect on the sagittal jaw relationship with an incremental step-by-step advancement of the Herbst appliance ${ }^{103,105}$. Rabie et al. ${ }^{106}$ has reported that a stepwise advancement leads to a significant increase in the number of replicating mesenchymal cells that is closely related to the increase in the level of bone formation, thus increasing the growth potential of the condyle.

A corrected tomogram is taken prior to Herbst placement and before Herbst removal to confirm condylar position (Figure 5). If the condyles are reasonably centered in the glenoid fossa, then a lateral cephalogram is taken and the patient is scheduled for Herbst removal as soon as possible. It is important to intrude the mandibular incisors so that the initial contact upon Herbst appliance removal is on the posterior teeth and not on the anterior teeth. This reduces the seating force of the condyle on the newly remodeled glenoid fossa ${ }^{104}$

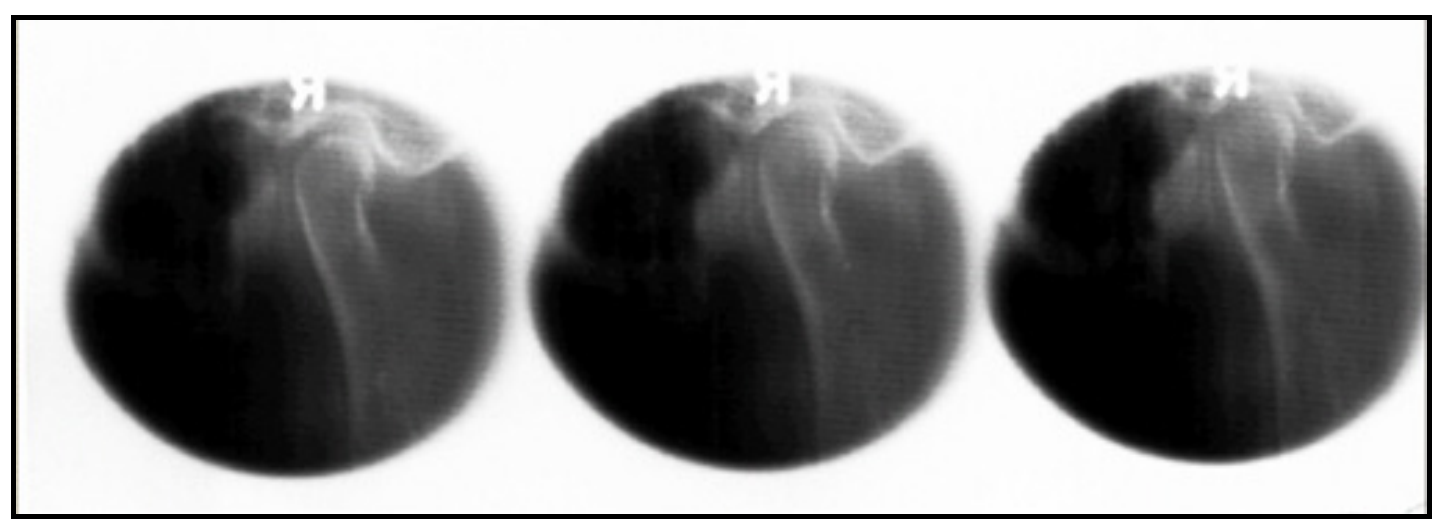

Figure 5. Corrected Tomograms taken prior to Herbst removal. 
In mixed dentition treatment after Herbst removal, the first permanent molars are banded and two by four appliance treatment continues until the anterior occlusion is correct. If more arch length is necessary, molar bands with $.022 \mathrm{X} .028$ extension tubes soldered in the archwire slots are placed and open coil springs are utilized to create more arch length. Deband occurs in two appointments. At the first appointment, upper and lower alginate impressions are taken, and sectional archwires are placed. At the second appointment, incisor brackets are removed and maxillary and mandibular lingual holding arches are placed. Patients are told that the holding arches will remain in place until all the permanent teeth have erupted. At that time they will receive comprehensive orthodontic treatment to finalize the occlusion ${ }^{104}$.

\section{Summary and Conclusions}

Removable functional appliances such as the activator ${ }^{1}$, bionator ${ }^{2}$, and Frankel appliance $^{3}$ are commonly used in the treatment of Class II malocclusion in an effort to stimulate sagittal mandibular growth in retrognathic mandibles. Unfortunately, the effectiveness of these appliances has been questioned and treatment results are inconsistent. In addition, patient compliance is often a problem with removable appliances and treatment time is usually long (2-4 years) ${ }^{4}$. Fixed functional appliances such as the Herbst appliance offer an alternative treatment method with several advantages: the appliance is fixed to the dentition; no patient cooperation is required; treatment is continually applied (24 hours a day); and the treatment time is short (6-8 months $)^{4}$. Research has indicated that the bite jumping technique employed by the 
Herbst appliance can be effective in correcting Class II skeletal abnormalities by promoting growth of the mandible and remodeling of the glenoid fossa $a^{5,6,7,8}$.

Since Pancherz ${ }^{9}$ re-introduced the Herbst appliance in 1979, an increasing body of research has been published evaluating its effects on occlusion, the dentofacial complex, and the masticatory system. However, after improvements in its design and increased clinical use, there seems to be an overall lack of information on the treatment changes observed with the edgewise crowned Herbst appliance and the long term stability of these effects.

The timing of orthopedic intervention with functional appliances has also been the subject of intense controversy within the profession of orthodontics. The decision to treat either in the early, late mixed, or permanent dentition has been debated and many questions remain unresolved. Successful treatment of Class II malocclusion in the early mixed dentition have been reported ${ }^{15}$, however other studies report similar success during the late mixed dentition ${ }^{17}$. Data from randomized controlled clinical trials have shown that effective skeletal changes could be achieved at either point in time and remain stable, although they suggest that treatment in the late transitional dentition is the most efficient in most $\operatorname{cases}^{20,21}$. When determining the optimal time to initiate Class II treatment, other factors must be considered such as the ability to utilize all potential growth, likelihood of incisor trauma, development of improper swallowing patterns, incomplete lip function, effects on the temporomandibular joint, and psychosocial concerns.

This study investigated the skeletal and dental alterations of Class II patients treated at an early age with the edgewise crowned Herbst appliance and evaluated the long term stability of those effects. The results should provide valuable information to 
help clinicians determine whether early treatment with the edgewise crowned Herbst appliance is warranted and if the results are stable over the long term. 


\section{CHAPTER III: MATERIALS AND METHODS}

\section{Sample Selection}

Experimental Group: The experimental group was obtained from a collection of 56 patients treated consecutively by Dr. Terry Dischinger at his private office in Lake Oswego, OR with the edgewise crowned Herbst appliance in the mixed dentition. The treatment records consisted of lateral cephalometric radiographs taken at five time points throughout treatment (Table 1). All patients had no history of previous orthodontic treatment. Lateral cephalograms were taken before Phase I treatment (T1), immediately following Herbst appliance removal in Phase I treatment (T2), at the completion of Phase I treatment (T3), before Phase II treatment (comprehensive orthodontic treatment) (T4), and at the completion of Phase II treatment (T5). Treatment outcome was not considered and no other inclusion criteria were used other than the availability of good quality lateral cephalograms taken at each of the five time points.

\section{Table 1. Description of Timepoints used in the Study}

\begin{tabular}{|l|l|}
\hline T1 & Before Phase I Treatment \\
\hline T2 & Immediately Following Herbst Appliance Removal in Phase I Treatment \\
\hline T3 & At the Completion of Phase I Treatment \\
\hline T3 & Before Phase II Treatment (Comprehensive Orthodontic Treatment) \\
\hline T5 & At the Completion of Phase II Treatment \\
\hline
\end{tabular}


The number of subjects included in the study from the original collection of 56 consecutively treated patients were determined based on the following inclusion criteria: no history of previous orthodontic treatment before the initial radiograph, acceptable quality radiographs for at least four of the five time points included in the study, and completion of both Phase I and Phase II orthodontic treatment. Some subjects that completed Phase I treatment did not return for Phase II treatment or were determined by Dr. Terry Dischinger not to need Phase II treatment and were eliminated from the study. Additional exclusion criteria included poor quality radiographs and missing radiographs at any of the critical timepoints (T1, T3, T4, or T5).

Control Group: Serial cephalometric radiographs of subjects with Class II malocclusion and no history of orthodontic treatment were obtained from the Case Western University Bolton-Brush Study, Cleveland, Ohio, and were used as the control group. The control subjects were matched in sex, age, and craniofacial morphology with the experimental subjects. Each control subject was matched with a treatment subject and lateral cephalometric radiographs were obtained at each time point (T1, T2, T3, T4, and T5) corresponding with those available for the treatment subjects. The Bolton-Brush cephalograms were taken at either 6 or 12 month intervals and therefore matched up effectively with the experimental cephalograms.

\section{Appliance Design}

The Herbst appliance used by Dr. Terry Dischinger employs a bilateral telescope mechanism consisting of a tube, a plunger, two pivots, and two locking screws, which function to keep the mandible in a continuously anterior jumped position (See Figures 1- 
4). The pivot for the tube is usually located on the maxillary first molar and the pivot for the plunger is usually attached to the mandibular first premolar. The length of the tube determines the amount of anterior displacement of the mandible. The appliance is designed to incorporate edgewise brackets and mechanics into the correction of Class II malocclusions.

The mandibular incisor brackets incorporate $\mathrm{a}-10^{\circ}$ inclination to minimize the anterior proclination that is a side effect of Herbst treatment. In the mixed dentition, brackets are usually placed on the maxillary and mandibular incisors; however, this sometimes varies depending on the individual circumstances of the case (See Figure 2).

Stainless steel crowns on the maxillary and mandibular permanent first molars anchor the Herbst appliance to the dentition. Double buccal tubes are placed on the molar crowns to permit the use of an auxiliary archwire to intrude the maxillary or mandibular incisors as necessary. The maxillary arch is tied back to hooks on the molar tubes to prevent space from opening in the maxillary arch because the molars tend to be driven distally during treatment. In addition, consolidating the arch distributes the load applied to the dentition to more teeth. In the mandibular arch, a $2 \mathrm{~mm}$ half-round cantilever is placed between the first molar and interproximal area between the first bicuspid and cuspid. The axle is placed at the mesial end of the cantilever, and a $.022 " X .028 "$ archwire tube is placed above and below the axle ${ }^{64}$.

A transpalatal arch is not included in the appliance to allow the first molars to rotate as the Class II relationship is corrected. A lingual arch is not included to allow easier placement of the appliance and prevent possible tipping of the lower anterior incisors. Both arches are free to accommodate expansion during treatment, if necessary. 
An occlusal stop off the cantilever arm or directly soldered to the stainless steel crowns extends into and rests on the distal central fossa of the first bicuspid or the mesial central fossa of the second primary molar to prevent tipping of the cantilever arm and impingement into the buccal mucosa and to minimize tipping of the mandibular first $\operatorname{molar}^{64}$.

\section{Treatment Protocol}

The Dischinger protocol ${ }^{104}$ was followed during the treatment of the experimental subjects included in the study. Initially, the Herbst appliance was activated to an edge to edge incisor relationship with the skeletal midlines in alignment. Brackets were bonded to the maxillary and mandibular incisors and high tech archwires were used to control incisor inclination and mandibular molar movement. Archwire sequence began with a .014 Damon CuNiTi. Then a .016X.025 Damon CuNiTi was used with the maxillary wire tied back to the hook on the maxillary molar and the lower wire annealed and cinched to prevent anterior movement of the wire. Next, a .019X.025 lower reverse curve NiTi archwire was placed when more leveling was necessary. Finally, a .019X.025 TMA was inserted if more leveling or torque was desired.

To achieve maximum orthopedic effect, Dr. Dischinger tied back the maxillary archwire to prevent distalization of the maxillary molars. The appliance was activated in a step-by-step fashion a distance of $4 \mathrm{~mm}$ every 12 weeks until the maxillary cuspid achieved an end-to-end relationship with the mandibular first premolar or primary first molar. The over-corrected position was held for a period of 12 weeks. A corrected tomogram was taken prior to Herbst placement and before Herbst removal to confirm 
condylar position. If the condyles were reasonably centered in the glenoid fossa, then a lateral cephalogram was taken and the patient was scheduled for Herbst removal as soon as possible (Figure 6).

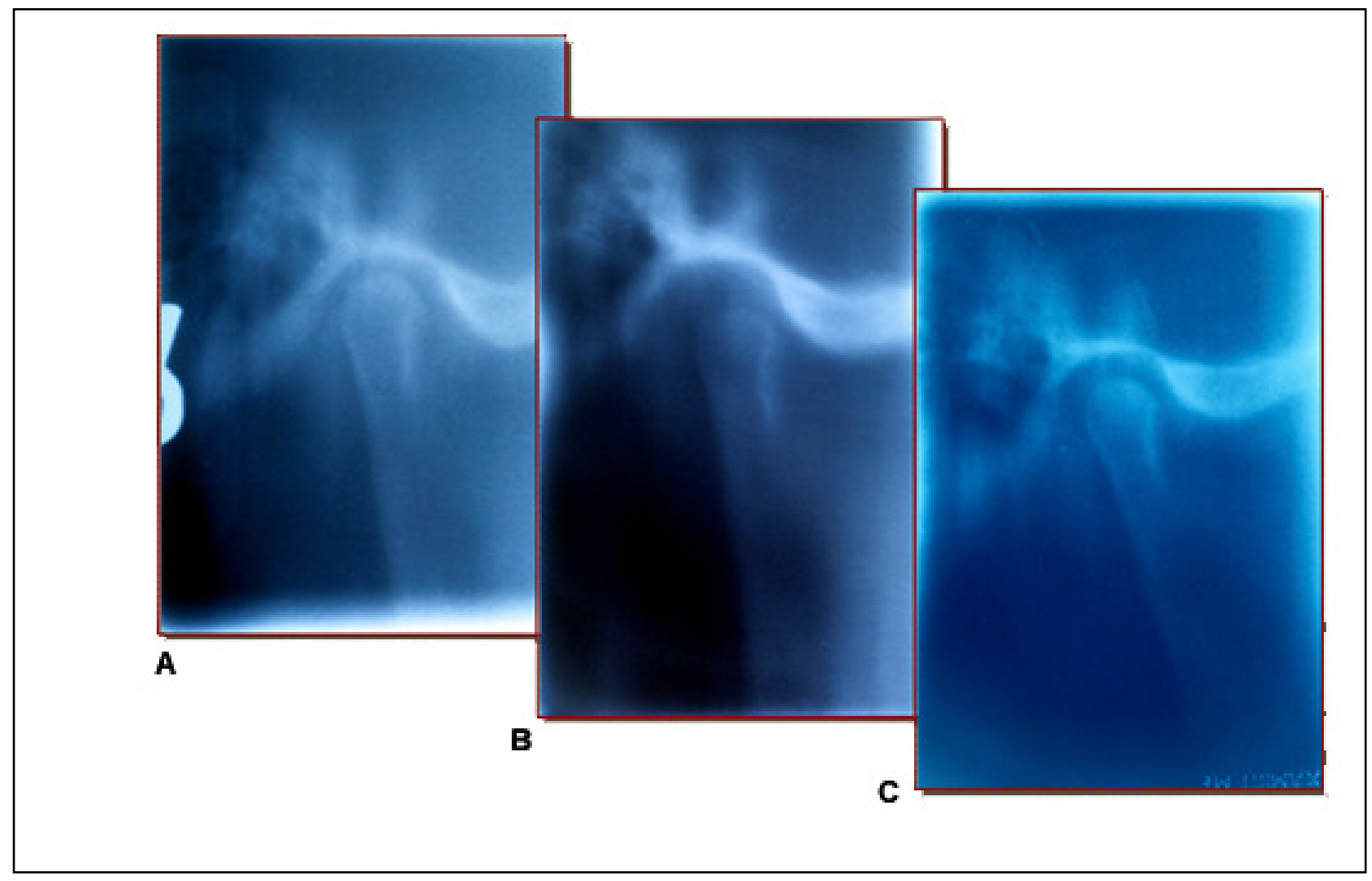

Figure 6. Corrected tomograms taken A) before, B) during, and C) after Herbst treatment

Figure 6-A shows a corrected tomogram taken before Herbst placement identifying the condyle in the center of the glenoid fossa. Figure 6-B shows a corrected tomogram taken during Herbst treatment with the condyle translated in an anterior inferior position on the articular eminence of the glenoid fossa. Figure 6-C shows a corrected tomogram taken after Herbst removal with the condyle centered in the glenoid fossa. 
In mixed dentition treatment after Herbst removal, the first permanent molars were banded and two by four appliance treatment continued until the anterior occlusion was correct. If more arch length was necessary, molar bands with .022X.028 extension tubes soldered in the archwire slots were placed and open coil springs were utilized to create more arch length. Deband occurred in two appointments. At the first appointment, upper and lower alginate impressions were taken, and sectional archwires were placed. At the second appointment, incisor brackets were removed and maxillary and mandibular lingual holding arches were placed. Patients were told that the holding arches would remain in place until all the permanent teeth had erupted. At that time the patients were re-evaluated and comprehensive orthodontic treatment to finalize the occlusion was initiated, if necessary.

\section{IRB Approval}

IRB exemption was obtained from West Virginia University prior to beginning the study (Appendix A). Approval was obtained from both Dr. Terry Dischinger and Dr. Mark Hans from Case Western University for the use of the orthodontic records and the Bolton-Brush Study lateral cephalograms, respectively (Appendix B and C).

\section{Cephalometric Analysis}

Lateral cephalograms were obtained from the office of Dr. Terry Dischinger for the experimental subjects before Phase I treatment (T1), immediately following Herbst appliance removal in Phase I treatment (T2), at the completion of Phase I treatment (T3), before Phase II treatment (Comprehensive orthodontic treatment) (T4), and at the 
completion of Phase II treatment (T5). The radiographs were scanned into digital format with an Epson Expression 1680 scanner (Epson America, Long Beach, California) and printouts of the lateral cephalometric images were made on a Lexmark C510 Printer (Lexmark International, Lexington, KY) . Each printout was superimposed on the original radiograph to ensure a 1:1 conversion with no distortion.

Digital copies of the lateral cephalograms matched closely in age, sex, and craniofacial morphology with the treatment subjects were obtained from the BoltonBrush Study at Case Western Reserve University in Cleveland, $\mathrm{OH}$ and were used as the control subjects. The images were scanned at 12 bit grayscale resolution with a spatial resolution of $0.1 \mathrm{~mm}$ per pixel and stored in uncompressed TIFF format. The images were converted to JPEG format with the IrfanView software (Version 4.0) and loaded into Adobe Photoshop 6.0 (Adobe Systems, San Jose, California) for size analysis. All original radiographs from the Bolton Study were indexed with 4 corner fiduciary points using a template according to the method described by Baumrind and Miller ${ }^{107}$. Within Adobe Photoshop, the resolutions of the images were verified (600dpi), and the images were resized to the original dimensions of the unscanned radiographs. Printouts were then made on a Lexmark C510 Printer (Lexmark International, Lexington, KY) and the fiduciary points were measured with an electronic digital caliper to ensure a 1:1 conversion with no distortion from the original radiographs.

Tracings were performed on printouts obtained from the digitized cephalograms by one operator using a \#2 HB mechanical lead pencil (Pentel $0.5 \mathrm{~mm} \mathrm{lead}$ ), an orthodontic protractor, and 0.003 inch matte cephalometric acetate tracing film ( $3 \mathrm{M}$ Unitek, Monrovia, CA). A custom cephalometric analysis was performed utilizing 
landmarks correlating with the cephalometric systems described by Bjork ${ }^{108}$, Pancherz ${ }^{96}$, and Van Laecken ${ }^{102}$. The data was normalized to account for magnification differences between the cephalometric machine used for the Bolton Brush Study (5.6\%) and the cephalometric machine used at the office of Dr. Terry Dischinger (10\%).

The measurement for each angular variable was performed with the use of a cephalometric protractor and evaluated to the nearest 0.5 degree. The measurement for each sagittal and vertical measurement was performed with an electronic digital caliper and evaluated to the nearest $0.1 \mathrm{~mm}$. The caliper was calibrated to $0.0 \mathrm{~mm}$ prior to each measurement. Because lateral cephalograms often present landmarks with right and left images, the midpoint bisecting the two images was used.

\section{Method Error}

The reliability of the cephalometric measurements was tested by investigating the error in locating, superimposing, and measuring the changes of all landmarks. Pretreatment and post-treatment lateral cephalograms of ten randomly selected patients were retraced at least two weeks after the initial tracing and analyzed to evaluate error. For all cephalometric variables, differences between the measurements recorded at the first tracing and measurements recorded at the second tracing were compared for each individual at T1, T2, T3, T4, and T5. A matched pairs t-test was performed to compare the two registrations. P-values were found to be larger than 0.05 in most measurements, indicating that there were no statistically significant differences among the duplicate registrations. Significant differences were found in the following variables at the indicated time points: T1: Mi-OLp ( $\mathrm{p}=0.0467), \operatorname{Ii-ML}(\mathrm{p}=0.0364)$, SNL-NL $(\mathrm{p}=0.0191)$; 
T2: Mic-ML ( $p=0.0324)$ Ii/ML ( $p=0.0222)$; T3: Is-OLp ( $p=0.0474)$, Ii-OLp ( $p=0.0346)$, Ms-OLp ( $p=0.0176)$, SNL-NL ( $p=0.0227)$; T4: Mi-OLp ( $p=0.0387)$, SNL-NL ( $\mathrm{p}=0.0422)$, Isa-Is/Iia-Ii ( $\mathrm{p}=0.0014)$. A correlation coefficient was established for each variable at each time point to determine the degree of reliability (Table 2).

Overall, the method of cephalometric analysis used in this study including landmark identification, superimposition of radiographs, and measurements were determined to be reliable. The correlations ranged from 0.667 to 1.0 , however, the overwhelming majority of the correlation coefficients were above 0.900 . 
Table 2. Correlation Coefficients for all variables at T1,T2,T3,T4, and T5.

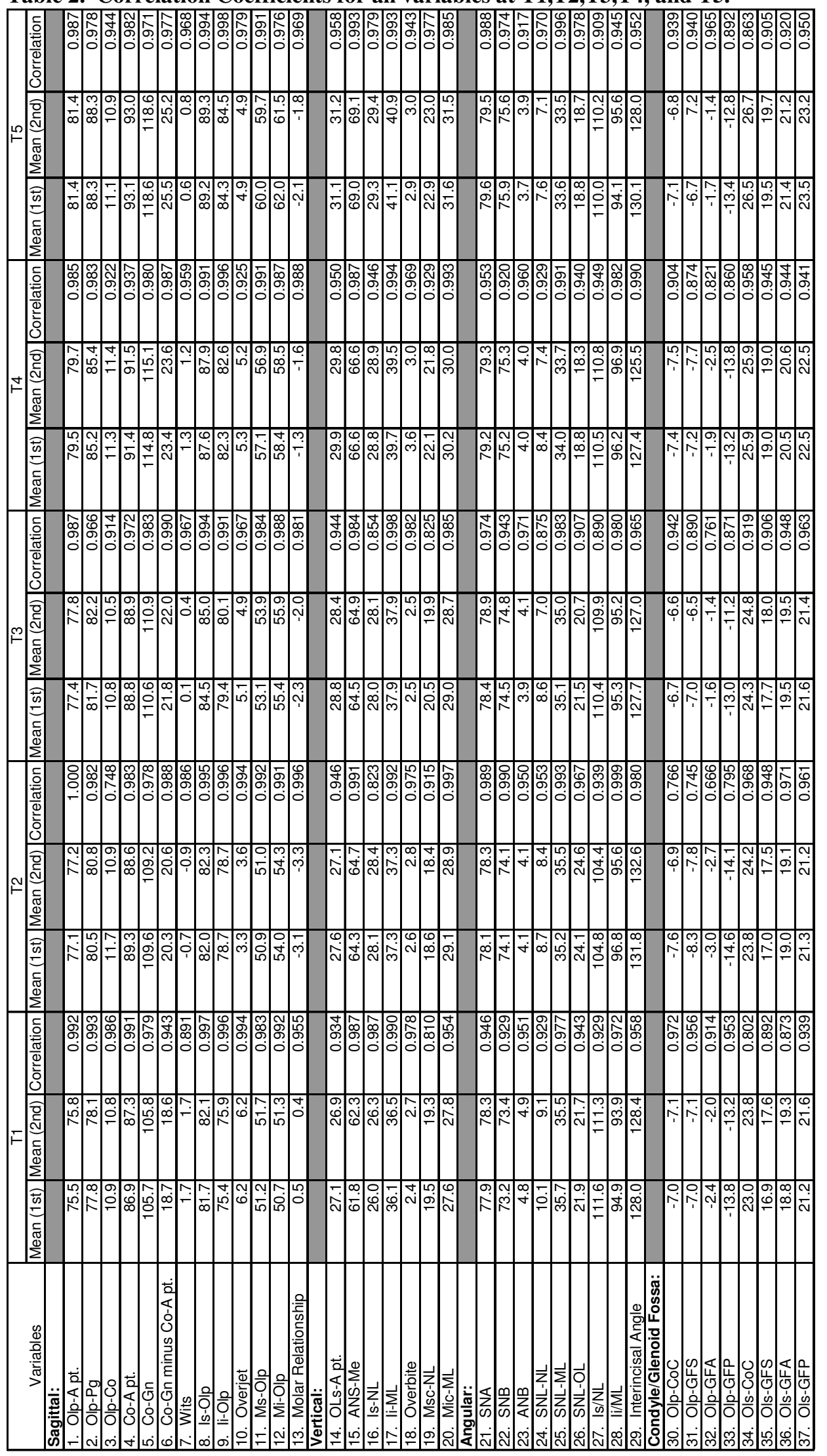




\section{Cephalometric Landmarks and Reference Lines}

The cephalometric systems described by Bjork ${ }^{108}$, Pancherz ${ }^{96}$, and Van

Laecken ${ }^{102}$ were used in this study. The landmarks are defined in Table 3. The reference

lines that were used are defined in Table 4.

Table 3. Skeletal and Dental Landmarks

\begin{tabular}{|l|l|l|}
\hline Symbol & \multicolumn{1}{|c|}{ Name } & \multicolumn{1}{c|}{ Definition } \\
\hline Ii & Incison inferious & The incisal point of the most prominent mandibular central incisor \\
\hline Is & Incison superious & The incisal point of the most prominent maxillary central incisor \\
\hline Iia & $\begin{array}{l}\text { Mandibular incisor } \\
\text { apex }\end{array}$ & The root apex of the most prominent mandibular central incisor \\
\hline Isa & Maxillary incisor apex & The root apex of the most prominent maxillary central incisor \\
\hline Mi & Molar inferious & The mesial contact point of the mandibular permanent first molar \\
\hline Mic & $\begin{array}{l}\text { Molar inferious mesial } \\
\text { cusp }\end{array}$ & The mesio-buccal cusp tip of the mandibular first molar \\
\hline Ms & Molar superious & The mesial contact point of the maxillary permanent first molar \\
\hline Msc & $\begin{array}{l}\text { Molar superious mesial } \\
\text { cusp }\end{array}$ & The mesio-buccal cusp tip of the maxillary first molar \\
\hline Co & Condylion & The most supero-posterior point on the curvature of the condylar head \\
\hline Pg & Pogonion & The most prominent point of the chin \\
\hline ANS & Anterior Nasal Spine & The apex of the spina nasalis anterior \\
\hline A pt. & Subspinale & $\begin{array}{l}\text { The deepest point in the concavity of the anterior maxilla between the } \\
\text { Ans and alveolar crest }\end{array}$ \\
\hline PNS & Posterior Nasal Spine & $\begin{array}{l}\text { The most posterior point on the contour of the palate in the } \\
\text { midsagittal plane }\end{array}$ \\
\hline Me & Menton & The deepest point of the mandibular symphysis \\
\hline Go & Gonion & The lowest point of the bony contour of the angle of the mandible \\
\hline S & Sella & The center of Sella turcica \\
\hline N & Nasion & $\begin{array}{l}\text { The most anterior point of the nasofrontal suture } \\
\text { incisor tooth and the bony chin }\end{array}$ \\
\hline B pt. & Supramentale & The center of the inferior point on the mandibular symphysis \\
\hline Gn & Gnathion &
\end{tabular}

Table 4. Definition of reference lines

\begin{tabular}{|l|l|l|}
\hline Symbol & \multicolumn{1}{|c|}{ Name } & \multicolumn{1}{c|}{ Definition } \\
\hline NSL & Sella-Nasion Line & Reference line joining Nasion and Sella \\
\hline OLp & Occlusal Line & $\begin{array}{l}\text { Reference line joining the maxillary incisal edge and the molar } \\
\text { superious mesial cusp tip }\end{array}$ \\
\hline OLs & Occlusal Line & $\begin{array}{l}\text { Reference line produced by dropping a perpendicular line from sella } \\
\text { to the occlusal plane }\end{array}$ \\
\hline NL & Maxillary Line & $\begin{array}{l}\text { Reference line parallel to OL passing through sella (perpendicular to } \\
\text { OLp passing through sella) }\end{array}$ \\
\hline ML & Mandibular Line & Reference line joining anterior nasal spine and posterior nasal spine \\
\hline
\end{tabular}


The measurements for this study were grouped into three categories: sagittal, vertical, and angular.

Sagittal Measurements: Analysis of the sagittal skeletal and dental changes were performed by forming a reference grid based on the occlusal line (OL) and occlusal line perpendicular (OLp), obtained from the T1 lateral cephalogram (Figure 7). This reference grid was used for all sagittal measurements between OLp and the cephalometric landmarks. The reference grid from T1 was transferred to T2, T3, T4, and T5 radiographs by superimposition on the anterior cranial base. Measurements were taken from OLp to designated landmarks as well as four other measurements: Condylion-A pt (Co-Apt); Condylion-Gnathion (Co-Gn); Condylion-Gnathion minus Condylion-A pt. (Co-Gn minus Co-Apt); and Wits analysis. In total, there were thirteen sagittal measurements recorded for each cephalogram (Table 4).

Table 5. Sagittal Measurements

\begin{tabular}{|l|l|}
\hline \multicolumn{1}{|c|}{ Variables } & \multicolumn{1}{c|}{ Definition } \\
\hline Skeletal measuring points: & \\
\hline OLp-A pt. & Position of maxillary base \\
\hline OLp-Pg & Position of mandibular base \\
\hline OLp-Co & Position of Condyle \\
\hline Co-A pt. & Effective midface length \\
\hline Co-Gn & Effective mandibular length \\
\hline Co-Gn minus Co-A pt. & Maxillomandibular length differential \\
\hline Wits analysis & Position of the maxillary base relative to the mandibular base \\
\hline Dental measuring points: & \\
\hline Is-OLp & Position of maxillary central incisor \\
\hline Ii-OLp & Position of mandibular incisor \\
\hline Is-OLp minus Ii-OLp & Overjet \\
\hline Ms-OLp & Position of maxillary first permanent molar \\
\hline Mi-OLp & Position of mandibular first molar \\
\hline Ms-OLp minus Mi-OLp & Molar Relationship \\
\hline
\end{tabular}




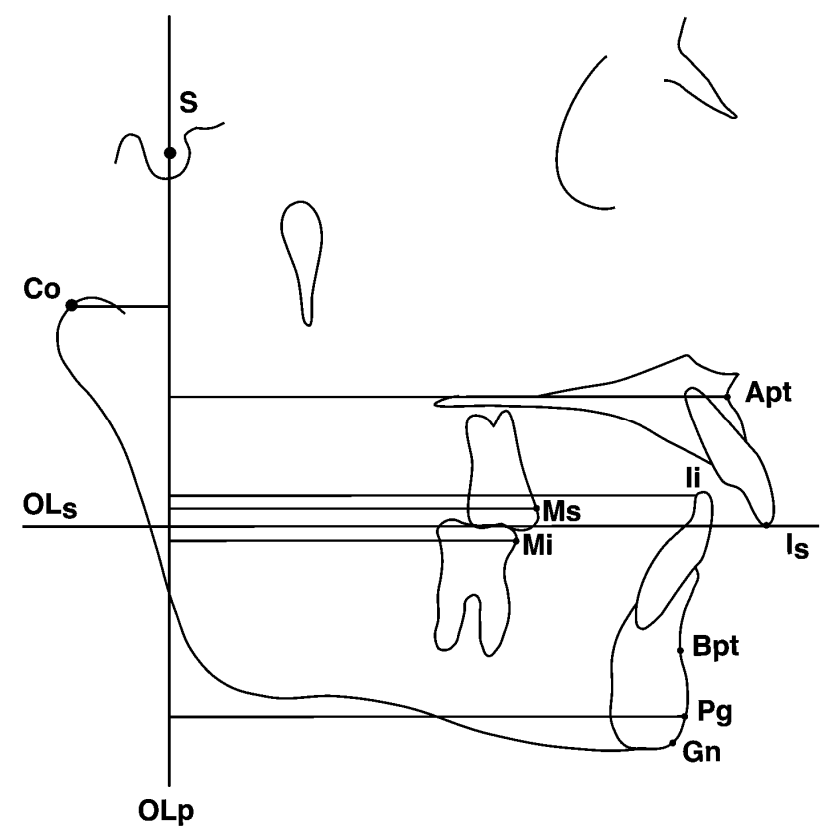

Figure 7. Cephalometric landmarks and reference lines for sagittal measurements

Vertical Measurements: The reference lines that were used for vertical measurements included OLs, NL, and ML, and OL (Figure 8). OLs was obtained from the $\mathrm{T} 1$ radiograph and transferred by superimposition on the anterior cranial base to the T2, T3, T4, and T5 radiographs. A measurement from ANS to Me (ANS-Me) was also included. The seven variables are listed in Table 5.

Table 6. Vertical Measurements

\begin{tabular}{|l|l|}
\hline \multicolumn{1}{|c|}{ Variables } & \multicolumn{1}{c|}{ Definition } \\
\hline Skeletal measuring points: & Maxillary vertical position \\
\hline OLs-A pt. & Lower facial height \\
\hline ANS-Me & \\
\hline Dental measuring points: & Position of maxillary central incisor \\
\hline Is-NL & Position of mandibular central incisor \\
\hline Ii-ML & Overbite \\
\hline Distance from Ii perpendicular To OL & Position of maxillary permanent first molar \\
\hline Msc-NL & Position of mandibular permanent first molar \\
\hline Mic-ML &
\end{tabular}




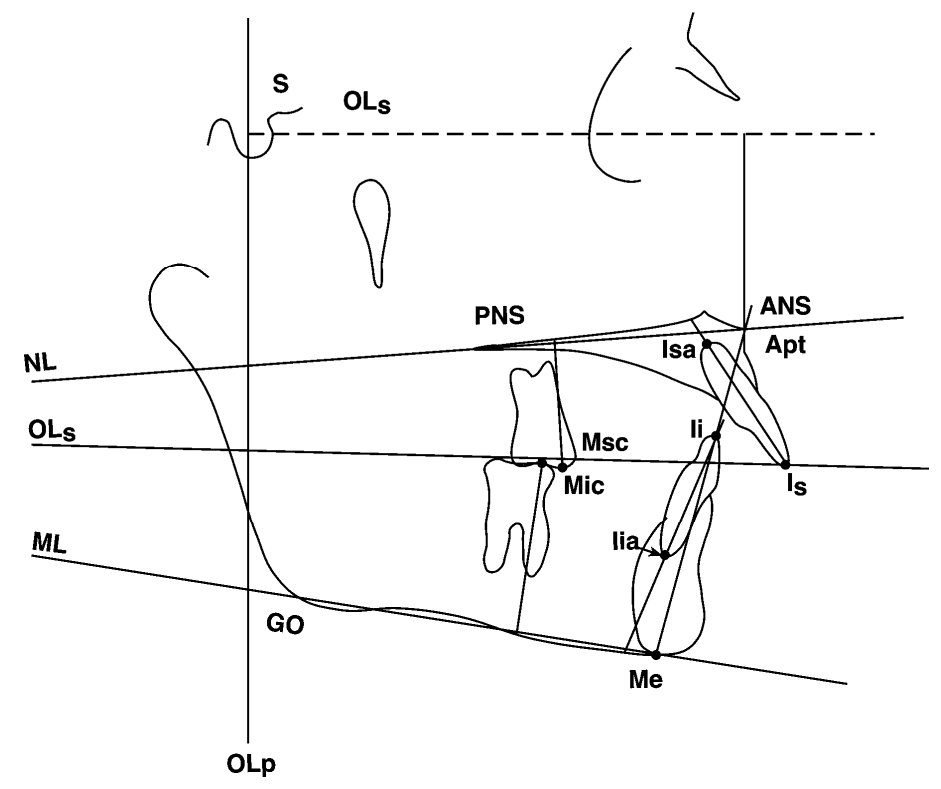

Figure 8. Cephalometric landmarks and reference lines for vertical measurements

Angular Measurements: Angular measurements were used to identify changes in the dentofacial complex (Table 7). Cephalometric landmarks and reference lines for angular measurements are illustrated in Figure 9.

Table 7. Angular Measurements

\begin{tabular}{|l|l|}
\hline \multicolumn{1}{|c|}{ Variables } & \\
\hline Skeletal measuring points: & \\
\hline SNA & Maxillary base relative to SNL \\
\hline SNB & Mandibular base relative to SNL \\
\hline ANB & SNA minus SNB \\
\hline SNL-NL & Palatal plane angle \\
\hline SNL-ML & Mandibular plane angle \\
\hline SNL-OLf & Occlusal plane angle (Functional occlusal plane) \\
\hline Dental measuring points: & \\
\hline Is/NL & Maxillary central incisor angle \\
\hline Ii/ML & Mandibular central incisor angle \\
\hline Isa-Is/lia-Ii & Interincisal angle \\
\hline
\end{tabular}




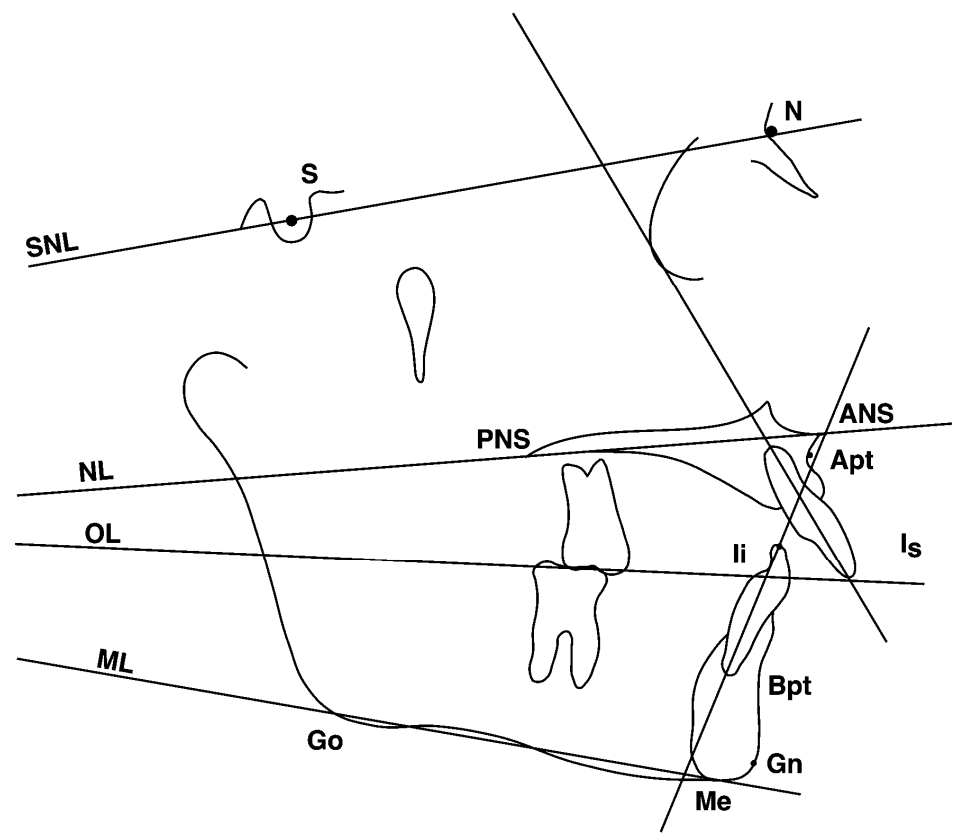

Figure 9. Cephalometric landmarks and reference lines for angular measurements

Condyle/Glenoid Fossa Measurements: In addition to the preceding cephalometric evaluations, an additional analysis of the condyle and glenoid fossa was performed for each of the subjects. The reference lines used for this analysis included OLp and OLs, the same lines that were used in the previous analyses (Figure 10). A reference grid was formed from the OLp and OLs reference lines from the T1 radiograph and transferred to the $\mathrm{T} 2, \mathrm{~T} 3, \mathrm{~T} 4$, and $\mathrm{T} 5$ radiographs through superimposition on the anterior cranial base. The additional skeletal landmarks used in this analysis are defined in Table 8. The sagittal and vertical measurements used in this analysis are described in Table 9 and Table 10, respectively. 
Table 8. Skeletal Landmarks of the Condyle/Glenoid Fossa Analysis

\begin{tabular}{|l|l|l|}
\hline Symbol & \multicolumn{1}{|c|}{ Name } & \multicolumn{1}{c|}{ Definition } \\
\hline CoC & Center of Condyle & A point located at the center of the condylar head \\
\hline GFS & $\begin{array}{l}\text { Glenoid Fossa } \\
\text { Superior }\end{array}$ & The most superior point of the Glenoid Fossa \\
\hline GFA & $\begin{array}{l}\text { Glenoid Fossa } \\
\text { Anterior }\end{array}$ & $\begin{array}{l}\text { The midpoint of the anterior aspect of the Glenoid Fossa between GFS and } \\
\text { ATI }\end{array}$ \\
\hline GFP & $\begin{array}{l}\text { Glenoid Fossa } \\
\text { Posterior }\end{array}$ & $\begin{array}{l}\text { A point through which a line perpendicular to OLp passing through ATI } \\
\text { intersects with the posterior aspect of the Glenoid Fossa }\end{array}$ \\
\hline ATI & $\begin{array}{l}\text { Articular Tubercle } \\
\text { Inferior }\end{array}$ & The most inferior point of the articular tubercle \\
\hline
\end{tabular}

Table 9. Sagittal Measurements of the Condyle/Glenoid Fossa Analysis

\begin{tabular}{|l|l|}
\hline Variables & \multicolumn{1}{|c|}{ Definition } \\
\hline OLp-CoC & Sagittal position of the center of the mandibular condylar head \\
\hline OLp-GFS & Sagittal position of the most superior aspect of the glenoid fossa \\
\hline OLP-GFA & Sagittal position of the most anterior aspect of the glenoid fossa \\
\hline OLp-GFP & Sagittal position of the most posterior aspect of the glenoid fossa \\
\hline
\end{tabular}

Table 10. Vertical Measurements of the Condyle/Glenoid Fossa Analysis

\begin{tabular}{|l|l|}
\hline Variables & \multicolumn{1}{|c|}{ Definition } \\
\hline OLs-CoC & Vertical position of the center of the mandibular condylar head \\
\hline OLs-GFS & Vertical position of the most superior aspect of the glenoid fossa \\
\hline OLs-GFA & Vertical position of the most anterior aspect of the glenoid fossa \\
\hline OLs-GFP & Vertical position of the most posterior aspect of the glenoid fossa \\
\hline
\end{tabular}




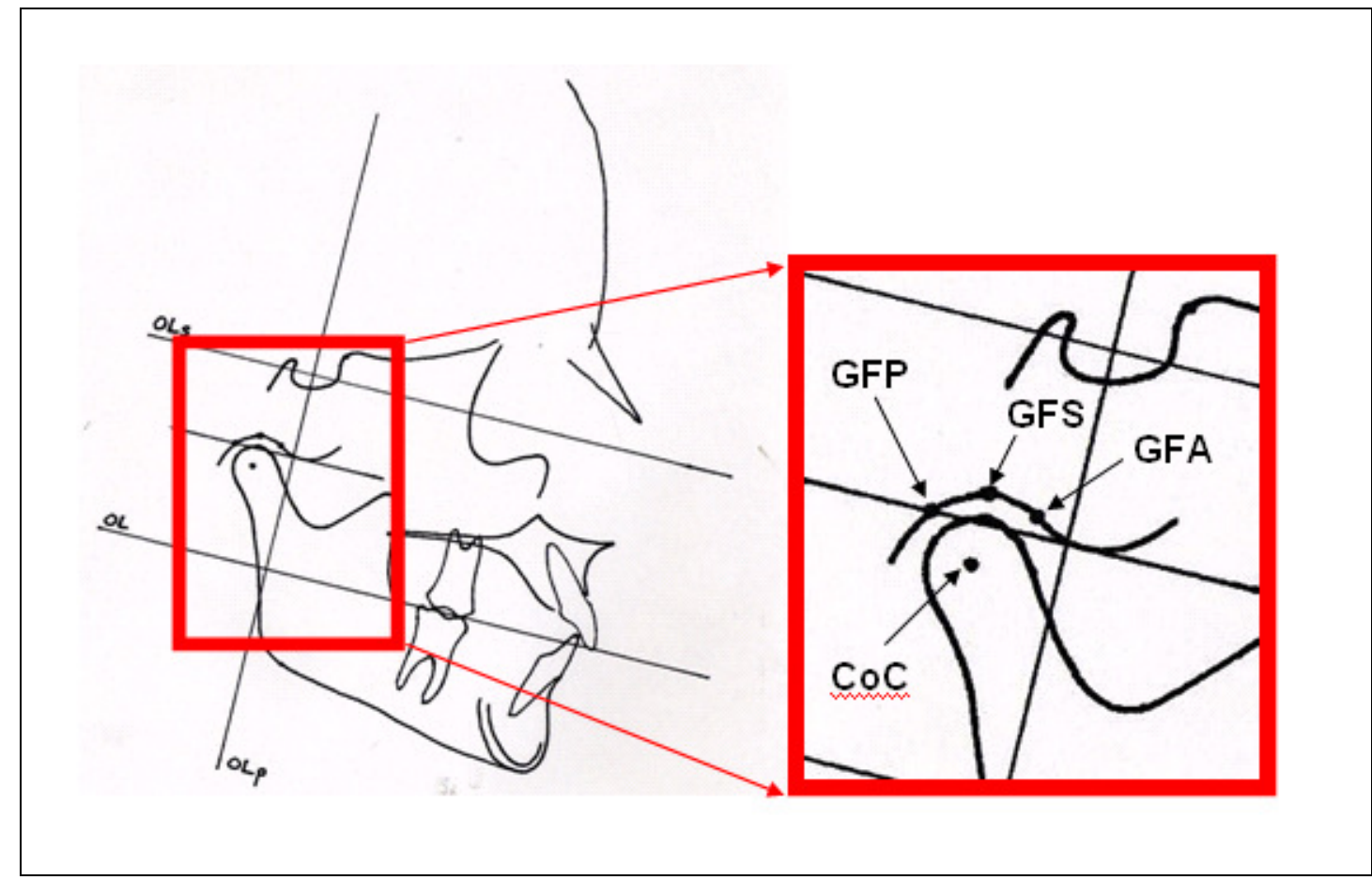

Figure 10. Landmarks/reference lines for sagittal and vertical measurements of the Condyle/Glenoid Fossa Analysis 


\section{Evaluation of Overjet and Molar Relationship Correction}

To determine the amount of skeletal and dental contribution to the overjet and molar relationship correction, the amount of dental change in the maxilla and mandible were calculated. The method of calculation is shown below (Table 11).

Table 11. Calculation of Overjet and Molar Relationship Changes

\begin{tabular}{|c|c|}
\hline \multicolumn{1}{|c|}{ Overjet } & Molar Relationship \\
\hline Skeletal contributions: & Skeletal contributions: \\
1. OLp-Apt & 1. OLp-Apt \\
2. OLP-Pg & 2. OLP-Pg \\
Dental contributions: & Dental contributions: \\
3. Is-OLp minus OLp-Apt & 3. Ms-OLp minus OLp-Apt \\
4. Ii-OLp minus OLp-Pg & 4. Mi-OLp minus OLp-Pg \\
Overjet correction: & Molar relationship correction: \\
Sum of $1,2,3$, and 4 & Sum of $1,2,3$, and 4 \\
& \\
\hline
\end{tabular}

When adding figures from the above table, the following formula was used for overjet correction:

Overjet Correction = Maxilla + Mx incisor - Mandible - Md incisor

Maxilla $=$ OLp-A pt.
Mx incisor $=$ Is-OLp minus OLp-A pt.
Mandible $=$ OLp-Pg
Mandibular incisor $=$ Ii-OLp minus OLP-Pg


When adding figures from the above table, the following formula was used for molar relationship correction or increase;

\section{Molar Relationship Correction = Maxilla + Mx Molar - Mandible - Md Molar}

$$
\begin{aligned}
& \text { Maxilla = OLp-A pt. } \\
& \text { Maxillar molar = Ms-OLp minus OLp-A pt. } \\
& \text { Mandible = OLp-Pg } \\
& \text { Mandibular molar = Mi-OLp minus OLp-Pg }
\end{aligned}
$$

Net Overjet/Molar Relationship Changes: When determining the net treatment effect of overjet and molar relationship correction, the control group figures were subtracted from the treated group. Calculations were made for the treatment group minus the control group at various time periods and the same formulas were used to calculate net overjet and net molar relationship correction or change:

\section{Net Overjet Correction $=$ Maxilla + Mx incisor - Mandible - Md incisor}

\footnotetext{
Maxilla $=$ OLp-A pt. (treated) minus OLp-A pt. (control)

Mx incisor $=($ Is-OLp minus OLp-A pt.(treated $))$ minus (Is-OLp minus OLp-A pt. $($ control $))$

Mandible $=$ OLp-Pg (treated) minus OLp-Pg (control)

Mandibular incisor $=(\mathrm{Ii}-\mathrm{OLp}$ minus OLp-Pg(treated $))$ minus $(\mathrm{Ii}-\mathrm{OLp}$ minus OLp-Pg(control) $)$
} 
When comparing the treated and control subjects for net molar relationship correction the following formula was used:

Net Molar Relationship Correction = Maxilla + Mx molar - Mandible - Md molar

Maxilla $=$ OLp-A pt. (treated) minus OLp-A pt. (control)

Mx molar $=($ Ms-OLp minus OLp-A pt.(treated) $)$ minus (Ms-OLp minus OLp-A pt. $($ control $))$

Mandible $=$ OLp-Pg (treated) minus OLp-Pg (control)

Mandibular incisor $=($ Mi-OLp minus OLp-Pg(treated $))$ minus $($ Mi-OLp minus OLP-Pg(control) $)$

\section{Statistical Analysis}

A matched pairs t-test was used to compare the starting forms between the treatment and control subjects at T1. The difference between the treatment and control subjects for each variable across the five time periods (T1 through T5) was analyzed for pooled subjects (males and females combined), male subjects, and female subjects. A repeated measures analysis of variance (ANOVA) was performed to determine if the differences between the treatment and control subjects were the same across the five time periods. A matched pairs t-test was performed for each variable to identify treatment effects of the Herbst appliance (Tx (T2-T1)) minus (Control (t2-t1)), Phase I treatment effects (Tx (T3-T1)) minus (Control (t3-t1)), residual Phase I treatment effects (Tx (T4T1)) minus (Control (t4-t1)), and combined Phase I and Phase II treatment effects (Tx (T5-T1)) minus (Control (t5-t1)). In addition, Phase II treatment effects were evaluated (Tx (T5-T4)) minus (Control (t5-t4)) as well as the relapse that occurred from after Phase I treatment to before Phase II treatment (Tx (T4-T3)) minus (Control (t4-t3)) 
with a matched pairs t-test. A level of significance of $\mathrm{p}<0.05$ (95\% confidence interval) was used in this study.

Reliability was tested with a matched pairs t-test to evaluate the correlation between measurements made at the intitial tracing and measurements made on the same tracing at a later time. Correlation coefficients were reported to determine how strongly the first measurements were associated with the second measurements for each variable at every time period in ten individuals. 


\section{CHAPTER IV: RESULTS AND DISCUSSION}

\section{RESULTS}

\section{Sample Size}

The control and treatment groups at T1, T3, T4, and T5 each consisted of 22 subjects (7 males and 15 females). Some of the radiographs were not available at T2 immediately after the Herbst appliance was removed and the control and treatment groups at T2 each consisted of 13 subjects ( 7 males and 6 females).

\section{Sex Distribution}

The sex of the treated and control groups were matched exactly. The control and treatment groups at T1, T3, T4, and T5 each consisted of 7 males and 15 females. The control and treatment groups at T2 each consisted of 7 males and 6 females.

\section{Age Distribution}

The age of the treatment and control groups were matched very closely (Table 12). The mean age of the treatment group at $\mathrm{T} 1$ for pooled subjects was 8.4 years. The mean age of the control group at $\mathrm{T} 1$ for pooled subjects was 8.4 years. The mean age of the treatment group at $\mathrm{T} 1$ for male subjects was 8.7 years. The mean age of the control group at $\mathrm{T} 1$ for male subjects was 8.7 years. The mean age of the treatment group at $\mathrm{T} 1$ for female subjects was 8.3 years. The mean age of the control group at $\mathrm{T} 1$ for female subjects was 8.3 years. Age distributions for both the treatment and control groups for pooled subjects, male subjects, and female subjects at each Time period (T1, T2, T3, T4, 
and T5) are reported in Table 12. No significant differences were found between the treatment and control groups for any of the Time periods (T1, T2, T3, T4 or T5). 
Table 12. Age Distribution

\begin{tabular}{|c|c|c|c|c|c|c|c|}
\hline & & MEAN & S.D. & MAX & MIN & DIFF & SIG \\
\hline \multicolumn{8}{|c|}{ POOLED } \\
\hline \multirow[b]{2}{*}{ T1 } & Control & 8.4 & 1.1 & 10.7 & 6.3 & \multirow[b]{2}{*}{0.0} & \multirow[b]{2}{*}{ NS } \\
\hline & Treatment & 8.4 & 1.0 & 11.0 & 6.5 & & \\
\hline \multirow[b]{2}{*}{$\mathrm{T} 2$} & Control & 9.4 & 0.8 & 11.6 & 8.1 & \multirow[b]{2}{*}{0.1} & \multirow[b]{2}{*}{ NS } \\
\hline & Treatment & 9.3 & 0.9 & 11.5 & 7.9 & & \\
\hline \multirow[b]{2}{*}{ T3 } & Control & 10.4 & 1.1 & 13.1 & 8.1 & \multirow[b]{2}{*}{0.2} & \multirow[b]{2}{*}{ NS } \\
\hline & Treatment & 10.2 & 1.0 & 12.8 & 8.4 & & \\
\hline \multirow[b]{2}{*}{$\mathrm{T} 4$} & Control & 13.0 & 1.4 & 16.0 & 10.9 & \multirow[b]{2}{*}{0.1} & \multirow[b]{2}{*}{ NS } \\
\hline & Treatment & 12.9 & 1.4 & 15.7 & 11.1 & & \\
\hline \multirow[b]{2}{*}{ T5 } & Control & 14.7 & 1.5 & 18.7 & 13.0 & \multirow[b]{2}{*}{0.1} & \multirow[b]{2}{*}{ NS } \\
\hline & Treatment & 14.6 & 1.4 & 17.9 & 12.8 & & \\
\hline \multicolumn{8}{|c|}{ MALES } \\
\hline \multirow[b]{2}{*}{ T1 } & Control & 8.7 & 1.1 & 10.7 & 7.0 & \multirow[b]{2}{*}{0.0} & \multirow[b]{2}{*}{ NS } \\
\hline & Treatment & 8.7 & 1.3 & 11.0 & 7.0 & & \\
\hline \multirow[b]{2}{*}{ T2 } & Control & 9.6 & 1.1 & 11.6 & 8.1 & \multirow[b]{2}{*}{0.0} & \multirow[b]{2}{*}{ NS } \\
\hline & Treatment & 9.6 & 1.2 & 11.5 & 7.9 & & \\
\hline \multirow[b]{2}{*}{ T3 } & Control & 10.5 & 1.4 & 13.1 & 8.5 & \multirow[b]{2}{*}{0.2} & \multirow[b]{2}{*}{ NS } \\
\hline & Treatment & 10.3 & 1.4 & 12.8 & 8.4 & & \\
\hline \multirow[b]{2}{*}{ T4 } & Control & 13.4 & 1.3 & 15.0 & 10.9 & \multirow[b]{2}{*}{0.1} & \\
\hline & Treatment & 13.3 & 1.3 & 14.7 & 11.2 & & NS \\
\hline & Control & 15.2 & 1.9 & 18.7 & 13.0 & & \\
\hline T5 & Treatment & 15.2 & 1.5 & 17.9 & 13.2 & 0.0 & NS \\
\hline FEMAL & & & & & & & \\
\hline & Control & 8.3 & 1.1 & 10.0 & 6.3 & & \\
\hline $\mathrm{T} 1$ & Treatment & 8.3 & 0.9 & 9.9 & 6.5 & 0.0 & NS \\
\hline & Control & 9.2 & 0.3 & 9.8 & 9.0 & & \\
\hline $\mathrm{T} 2$ & Treatment & 9.1 & 0.4 & 9.6 & 8.6 & 0.1 & NS \\
\hline & Control & 10.3 & 1.0 & 12.0 & 8.1 & & \\
\hline T3 & Treatment & 10.1 & 0.9 & 11.8 & 8.9 & 0.2 & NS \\
\hline & Control & 12.9 & 1.5 & 16.0 & 10.9 & & \\
\hline $\mathrm{T} 4$ & Treatment & 12.7 & 1.4 & 15.7 & 11.1 & 0.2 & NS \\
\hline & Control & 14.4 & 1.3 & 17.0 & 13.0 & & \\
\hline T5 & Treatment & 14.3 & 1.3 & 16.8 & 12.8 & 0.1 & NS \\
\hline
\end{tabular}




\section{Distribution of Variable Measurements}

The measurements for each of the 37 variables in both the treatment and control groups were analyzed. The mean, standard deviation, maximum, and minimum for each variable measurement were recorded for pooled subjects, male subjects, and female subjects at each Time period (T1, T2, T3, T4, and T5). In the treatment and control groups at T1, T3, T4, and T5, 22 measurements were made for each variable for pooled subjects, 7 measurements were made for each variable for male subjects, and 15 measurements were made for each variable for female subjects. In the treatment and control groups at T2, 13 measurements were made for each variable for pooled subjects, 7 measurements were made for each variable for male subjects, and 6 measurements were made for each variable for female subjects. Distributions of the variable measurements in both treatment and control groups for pooled subjects, male subjects, and female subjects at each Time period (T1, T2, T3, T4, and T5) are reported in Appendices D-AA. 


\section{Pre-treatment Craniofacial Morphology of the Treatment vs. the Control Group}

The pre-treatment craniofacial morphology of the treatment group and the control group were compared to determine if there were statistically significant differences in any of the 37 variables used in this study. Differences were analyzed at T1 for pooled subjects, male subjects, and female subjects.

For pooled subjects, only 4 of the 37 variables were significantly different between the treatment group and control group at T1 (Table 13). OLp-A pt., Is-OLp, and ANB were significantly greater in the treatment group than in the control group. OLs-A pt. was significantly less in the treatment group than in the control group. All other variables showed no significant differences at $\mathrm{T} 1$ between the treatment and control groups.

For males, only 3 of the 37 variables were significantly different between the treatment group and control group at T1 (Table 14). Overjet and molar relationship were significantly greater in the treatment group than in the control group. ANS-Me was significantly less in the treatment group than in the control group. All other variables showed no significant differences at T1 between the treatment and control groups.

For females, 9 of the 37 variables were significantly different between the treatment group and control group at T1 (Table 15). OL-A pt., Is-OLp, Ii-OLp, Ms-OLp, Mi-OLp, ANB, and OLp-CoC were significantly greater in the treatment group than in the control group. OLp-Co and OLs-A pt. were significantly less in the treatment group than in the control group. All other variables showed no significant differences at T1 between the treatment and control groups. 
The data suggest that the pre-treatment craniofacial morphology of the treatment group and the control group were similar. For pooled subjects, the maxilla and maxillary incisors were slightly more anterior in the treatment group than in the control group. In addition, the ANB angle was $1.8^{\circ}$ greater in the treatment group than in the control group. 
Table 13. Comparison of the pre-treatment craniofacial morphology in pooled subjects

\begin{tabular}{|c|c|c|c|c|c|c|c|}
\hline \multicolumn{8}{|c|}{ POOLED (MALES AND FEMALES) } \\
\hline \multirow[b]{2}{*}{ Variable } & \multicolumn{2}{|c|}{ Control } & \multicolumn{2}{|c|}{ Treated } & \multirow[b]{2}{*}{$p$ value } & \multirow[b]{2}{*}{ Diff. } & \multirow[b]{2}{*}{ Sig } \\
\hline & Mean & S.D. & Mean & S.D. & & & \\
\hline \multicolumn{8}{|l|}{ Sagittal: } \\
\hline 1. Olp-A pt. & 68.3 & 4.2 & 70.6 & 3.3 & 0.0479 & 2.3 & * \\
\hline 2. Olp-Pg & 71.0 & 5.5 & 71.9 & 4.5 & 0.5437 & 0.9 & NS \\
\hline 3. Olp-Co & 9.6 & 2.1 & 8.2 & 2.9 & 0.0738 & 1.4 & NS \\
\hline 4. Co-A pt. & 78.3 & 4.3 & 79.7 & 4.9 & 0.3255 & 1.4 & NS \\
\hline 5. Co-Gn & 95.5 & 5.0 & 95.1 & 4.9 & 0.8154 & 0.4 & NS \\
\hline 6. Co-Gn minus Co-A pt. & 17.1 & 2.9 & 15.8 & 3.8 & 0.2072 & 1.3 & NS \\
\hline 7. Wits & 1.1 & 1.6 & 1.1 & 1.9 & 0.983 & 0.0 & NS \\
\hline 8. Is-Olp & 73.5 & 5.6 & 76.6 & 4.3 & 0.0403 & 3.1 & * \\
\hline 9. li-Olp & 68.8 & 4.4 & 71.0 & 3.5 & 0.0782 & 2.2 & NS \\
\hline 10. Overjet & 4.7 & 2.1 & 5.6 & 2.6 & 0.1694 & 0.9 & NS \\
\hline 11. Ms-Olp & 46.0 & 3.7 & 47.9 & 2.7 & 0.0524 & 1.9 & NS \\
\hline 12. Mi-Olp & 45.7 & 4.3 & 47.1 & 2.9 & 0.1894 & 1.4 & NS \\
\hline 13. Molar Relationship & 0.3 & 0.9 & 0.8 & 2.0 & 0.3244 & 0.5 & NS \\
\hline \multicolumn{8}{|l|}{ Vertical: } \\
\hline 14. OLs-A pt. & 25.2 & 2.2 & 22.8 & 4.1 & 0.0215 & 2.4 & * \\
\hline 15. ANS-Me & 57.0 & 4.6 & 56.9 & 3.2 & 0.9324 & 0.1 & NS \\
\hline 16. Is-NL & 23.7 & 4.1 & 23.6 & 2.8 & 0.9635 & 0.1 & NS \\
\hline 17. Ii-ML & 34.1 & 3.2 & 33.2 & 2.4 & 0.3418 & 0.9 & NS \\
\hline 18. Overbite & 1.6 & 3.0 & 1.4 & 3.4 & 0.8021 & 0.2 & NS \\
\hline 19. Msc-NL & 16.7 & 3.0 & 17.0 & 1.9 & 0.7502 & 0.3 & NS \\
\hline 20. Mic-ML & 25.7 & 1.9 & 25.6 & 2.1 & 0.8807 & 0.1 & NS \\
\hline \multicolumn{8}{|l|}{ Angular: } \\
\hline 21. SNA & 79.9 & 3.2 & 81.4 & 3.9 & 0.1633 & 1.5 & NS \\
\hline 22. SNB & 75.3 & 3.0 & 75.0 & 3.6 & 0.8058 & 0.3 & NS \\
\hline 23. ANB & 4.6 & 1.3 & 6.4 & 2.1 & 0.0018 & 1.8 & * \\
\hline 24. SNL-NL & 7.5 & 3.2 & 8.3 & 3.6 & 0.459 & 0.8 & NS \\
\hline 25. SNL-ML & 34.1 & 4.6 & 34.4 & 7.9 & 0.8803 & 0.3 & NS \\
\hline 26. SNL-OL & 20.3 & 3.5 & 22.3 & 4.2 & 0.1057 & 2.0 & NS \\
\hline 27. Is/NL & 111.0 & 5.9 & 109.6 & 6.0 & 0.4226 & 1.4 & NS \\
\hline 28. $\mathrm{li} / \mathrm{ML}$ & 94.6 & 5.7 & 96.0 & 9.3 & 0.5413 & 1.4 & NS \\
\hline 29. Interincisal Angle & 127.6 & 7.9 & 126.7 & 10.3 & 0.7386 & 0.9 & NS \\
\hline \multicolumn{8}{|l|}{ Condyle/Glenoid Fossa: } \\
\hline 30. Olp-CoC & -5.9 & 2.0 & -5.1 & 2.8 & 0.2822 & 0.8 & NS \\
\hline 31. Olp-GFS & -6.1 & 2.4 & -5.9 & 2.9 & 0.7938 & 0.2 & NS \\
\hline 32. Olp-GFA & -1.8 & 2.1 & -1.4 & 2.5 & 0.573 & 0.4 & NS \\
\hline 33. Olp-GFP & -11.7 & 2.2 & -11.8 & 3.4 & 0.9092 & 0.1 & NS \\
\hline 34. Ols-CoC & 21.7 & 2.3 & 20.9 & 2.6 & 0.2862 & 0.8 & NS \\
\hline 35. Ols-GFS & 15.8 & 2.4 & 14.8 & 2.8 & 0.1998 & 1.0 & NS \\
\hline 36. Ols-GFA & 17.3 & 2.3 & 16.6 & 2.6 & 0.3536 & 0.7 & NS \\
\hline 37. Ols-GFP & 19.2 & 2.2 & 19.0 & 2.5 & 0.8521 & 0.2 & NS \\
\hline
\end{tabular}


Table 14. Comparison of the pre-treatment craniofacial morphology in males subjects

\begin{tabular}{|c|c|c|c|c|c|c|c|}
\hline \multicolumn{8}{|c|}{ MALES } \\
\hline \multirow[b]{2}{*}{ Variable } & \multicolumn{2}{|c|}{ Control } & \multicolumn{2}{|c|}{ Treated } & \multirow[b]{2}{*}{$p$ value } & \multirow[b]{2}{*}{ Diff } & \multirow[b]{2}{*}{ Sig } \\
\hline & Mean & S.D. & Mean & S.D. & & & \\
\hline \multicolumn{8}{|l|}{ Sagittal: } \\
\hline 1. Olp-A pt. & 72.5 & 4.4 & 71.4 & 3.3 & 0.5976 & 1.1 & NS \\
\hline 2. Olp-Pg & 75.0 & 6.9 & 72.5 & 5.5 & 0.4822 & 2.5 & NS \\
\hline 3. Olp-Co & 9.2 & 2.5 & 9.2 & 4.3 & 0.9822 & 0 & NS \\
\hline 4. Co-A pt. & 82.0 & 3.2 & 82.4 & 4.0 & 0.8793 & 0.4 & NS \\
\hline 5. Co-Gn & 99.1 & 3.5 & 97.3 & 4.6 & 0.4244 & 1.8 & NS \\
\hline 6. Co-Gn minus Co-A pt. & 17.0 & 3.4 & 16.2 & 2.9 & 0.6313 & 0.8 & NS \\
\hline 7. Wits & 2.2 & 1.5 & 1.9 & 2.1 & 0.7745 & 0.3 & NS \\
\hline 8. Is-Olp & 78.1 & 6.4 & 78.4 & 4.6 & 0.9224 & 0.3 & NS \\
\hline 9. li-Olp & 72.7 & 4.5 & 70.7 & 5.0 & 0.4367 & 2 & NS \\
\hline 10. Overjet & 5.4 & 2.5 & 7.7 & 1.2 & 0.0462 & 2.3 & * \\
\hline 11. Ms-Olp & 48.5 & 4.1 & 48.6 & 3.8 & 0.9757 & 0.1 & NS \\
\hline 12. Mi-Olp & 48.5 & 5.0 & 46.4 & 3.4 & 0.3764 & 2.1 & NS \\
\hline 13. Molar Relationship & 0.1 & 1.2 & 2.2 & 1.3 & 0.0065 & 2.1 & * \\
\hline \multicolumn{8}{|l|}{ Vertical: } \\
\hline 14. OLs-A pt. & 25.0 & 2.3 & 24.5 & 3.2 & 0.6971 & 0.5 & NS \\
\hline 15. ANS-Me & 60.9 & 3.7 & 57.0 & 2.3 & 0.0361 & 3.9 & * \\
\hline 16. Is-NL & 25.5 & 3.8 & 24.7 & 2.1 & 0.6326 & 0.8 & NS \\
\hline 17. Ii-ML & 36.5 & 2.8 & 34.7 & 1.1 & 0.143 & 1.8 & NS \\
\hline 18. Overbite & 1.8 & 2.8 & 3.3 & 1.4 & 0.2465 & 1.5 & NS \\
\hline 19. Msc-NL & 17.4 & 3.2 & 17.3 & 2.3 & 0.9725 & 0.1 & NS \\
\hline 20. Mic-ML & 27.2 & 2.0 & 25.1 & 2.4 & 0.1012 & 2.1 & NS \\
\hline \multicolumn{8}{|l|}{ Angular: } \\
\hline 21. SNA & 79.7 & 1.8 & 80.6 & 3.9 & 0.5772 & 0.9 & NS \\
\hline 22. SNB & 74.4 & 1.8 & 74.9 & 3.6 & 0.7481 & 0.5 & NS \\
\hline 23. ANB & 5.4 & 0.4 & 5.8 & 2.2 & 0.6229 & 0.4 & NS \\
\hline 24. SNL-NL & 7.9 & 2.6 & 7.6 & 3.7 & 0.8394 & 0.3 & NS \\
\hline 25. SNL-ML & 35.9 & 3.4 & 33.2 & 6.1 & 0.3366 & 2.7 & NS \\
\hline 26. SNL-OL & 20.4 & 3.3 & 20.6 & 3.7 & 0.9112 & 0.2 & NS \\
\hline 27. Is/NL & 108.7 & 3.6 & 112.3 & 7.4 & 0.2716 & 3.6 & NS \\
\hline 28. $\mathrm{li} / \mathrm{ML}$ & 93.2 & 4.6 & 94.3 & 10.6 & 0.8102 & 1.1 & NS \\
\hline 29. Interincisal Angle & 130.1 & 5.5 & 127.3 & 12.7 & 0.5947 & 2.8 & NS \\
\hline \multicolumn{8}{|l|}{ Condyle/Glenoid Fossa: } \\
\hline 30. Olp-CoC & -5.3 & 2.4 & -6.1 & 4.1 & 0.6427 & 0.8 & NS \\
\hline 31. Olp-GFS & -5.7 & 2.2 & -6.9 & 3.9 & 0.5115 & 1.2 & NS \\
\hline 32. Olp-GFA & -1.3 & 2.4 & -2.0 & 3.3 & 0.6349 & 0.7 & NS \\
\hline 33. Olp-GFP & -11.2 & 2.3 & -12.9 & 4.9 & 0.4241 & 1.7 & NS \\
\hline 34. Ols-CoC & 22.2 & 3.2 & 21.3 & 3.3 & 0.6254 & 0.9 & NS \\
\hline 35. Ols-GFS & 16.0 & 3.4 & 15.8 & 3.3 & 0.8817 & 0.2 & NS \\
\hline 36. Ols-GFA & 17.5 & 3.4 & 17.9 & 2.7 & 0.8014 & 0.4 & NS \\
\hline 37. Ols-GFP & 19.3 & 3.4 & 20.6 & 2.2 & 0.4028 & 1.3 & NS \\
\hline
\end{tabular}


Table 15. Comparison of the pre-treatment craniofacial morphology in female subjects

\begin{tabular}{|c|c|c|c|c|c|c|c|}
\hline \multicolumn{8}{|c|}{ FEMALES } \\
\hline \multirow[b]{2}{*}{ Variable } & \multicolumn{2}{|c|}{ Control } & \multicolumn{2}{|c|}{ Treated } & \multirow[b]{2}{*}{$p$ value } & \multirow[b]{2}{*}{ Diff } & \multirow[b]{2}{*}{ Sig } \\
\hline & Mean & S.D. & Mean & S.D. & & & \\
\hline \multicolumn{8}{|l|}{ Sagittal: } \\
\hline 1. Olp-A pt. & 66.4 & 2.3 & 70.3 & 3.3 & 0.0008 & 3.9 & * \\
\hline 2. Olp-Pg & 69.1 & 3.7 & 71.6 & 4.1 & 0.0914 & 2.5 & NS \\
\hline 3. Olp-Co & 9.8 & 2.0 & 7.8 & 2.0 & 0.009 & 2 & * \\
\hline 4. Co-A pt. & 76.6 & 3.5 & 78.5 & 4.9 & 0.2392 & 1.9 & NS \\
\hline 5. Co-Gn & 93.8 & 4.8 & 94.1 & 4.9 & 0.8519 & 0.3 & NS \\
\hline 6. Co-Gn minus Co-A pt. & 17.2 & 2.8 & 15.6 & 4.3 & 0.2527 & 1.6 & NS \\
\hline 7. Wits & 0.6 & 1.4 & 0.7 & 1.8 & 0.8446 & 0.1 & NS \\
\hline 8. Is-Olp & 71.3 & 3.7 & 75.8 & 4.1 & 0.0035 & 4.5 & * \\
\hline 9. li-Olp & 67.0 & 3.1 & 71.1 & 2.8 & 0.0006 & 4.1 & * \\
\hline 10. Overjet & 4.3 & 1.8 & 4.7 & 2.6 & 0.6545 & 0.4 & NS \\
\hline 11. Ms-Olp & 44.9 & 2.9 & 47.7 & 2.0 & 0.0047 & 2.8 & * \\
\hline 12. Mi-Olp & 44.4 & 3.3 & 47.5 & 2.7 & 0.0082 & 3.1 & * \\
\hline 13. Molar Relationship & 0.5 & 0.7 & 0.1 & 1.9 & 0.5213 & 0.4 & NS \\
\hline \multicolumn{8}{|l|}{ Vertical: } \\
\hline 14. OLs-A pt. & 25.2 & 2.2 & 22.1 & 4.3 & 0.017 & 3.1 & * \\
\hline 15. ANS-Me & 55.1 & 3.9 & 56.8 & 3.7 & 0.2407 & 1.7 & NS \\
\hline 16. Is-NL & 22.9 & 4.2 & 23.2 & 3.0 & 0.8208 & 0.3 & NS \\
\hline 17. Ii-ML & 32.9 & 2.8 & 32.6 & 2.5 & 0.711 & 0.3 & NS \\
\hline 18. Overbite & 1.5 & 3.2 & 0.5 & 3.7 & 0.4157 & 1 & NS \\
\hline 19. Msc-NL & 16.4 & 2.9 & 16.8 & 1.8 & 0.6721 & 0.4 & NS \\
\hline 20. Mic-ML & 25.0 & 1.5 & 25.8 & 2.0 & 0.2038 & 0.8 & NS \\
\hline \multicolumn{8}{|l|}{ Angular: } \\
\hline 21. SNA & 79.9 & 3.8 & 81.7 & 3.9 & 0.2114 & 1.8 & NS \\
\hline 22. SNB & 75.7 & 3.4 & 75.1 & 3.8 & 0.6531 & 0.6 & NS \\
\hline 23. ANB & 4.3 & 1.4 & 6.7 & 2.1 & 0.0011 & 2.4 & * \\
\hline 24. SNL-NL & 7.3 & 3.5 & 8.6 & 3.7 & 0.3306 & 1.3 & NS \\
\hline 25. SNL-ML & 33.2 & 4.9 & 34.9 & 8.8 & 0.5263 & 1.7 & NS \\
\hline 26. SNL-OL & 20.3 & 3.7 & 23.0 & 4.3 & 0.0733 & 2.7 & NS \\
\hline 27. Is/NL & 112.1 & 6.5 & 108.3 & 5.1 & 0.0858 & 3.8 & NS \\
\hline 28. $\mathrm{li} / \mathrm{ML}$ & 95.2 & 6.1 & 96.8 & 9.0 & 0.5724 & 1.6 & NS \\
\hline 29. Interincisal Angle & 126.4 & 8.8 & 126.4 & 9.5 & 0.9921 & 0 & NS \\
\hline \multicolumn{8}{|l|}{ Condyle/Glenoid Fossa: } \\
\hline 30. Olp-CoC & -6.2 & 1.9 & -4.6 & 2.0 & 0.0322 & 1.6 & * \\
\hline 31. Olp-GFS & -6.3 & 2.5 & -5.4 & 2.3 & 0.3495 & 0.9 & NS \\
\hline 32. Olp-GFA & -2.1 & 2.1 & -1.2 & 2.1 & 0.2315 & 0.9 & NS \\
\hline 33. Olp-GFP & -11.9 & 2.2 & -11.3 & 2.5 & 0.4641 & 0.6 & NS \\
\hline 34. Ols-CoC & 21.5 & 1.8 & 20.7 & 2.4 & 0.3255 & 0.8 & NS \\
\hline 35. Ols-GFS & 15.7 & 2.0 & 14.4 & 2.5 & 0.107 & 1.3 & NS \\
\hline 36. Ols-GFA & 17.2 & 1.7 & 16.0 & 2.4 & 0.1231 & 1.2 & NS \\
\hline 37. Ols-GFP & 19.1 & 1.5 & 18.3 & 2.3 & 0.2605 & 0.8 & NS \\
\hline
\end{tabular}




\section{Comparison of the Treatment Group and the Control Group Across the Time Periods}

The difference in each variable between the treatment and control groups across the five time periods (T1 through T5) was analyzed for pooled subjects, and separately for male and female subjects. A repeated measures ANOVA was performed to determine if the differences between the treatment and control groups were the same across the five time periods. Graphs plotting the values of the 37 variables across time for the treatment and control groups for pooled subjects, male subjects, and female subjects are provided in Appendix $\mathrm{AB}$. If there were no differences between the variables in the treatment and control groups across the five time periods at a $\mathrm{p}<.05$ confidence level, plots of the variables across time for the treatment and control groups would be close to parallel and the effects of treatment on the variable were considered insignificant. If there were significant differences between the variables in the treatment group and the control group across the five time periods, plots of the variables across time for the treatment and control groups would deviate from parallel, and the effects of the treatment on the variable were considered significant.

Statistical analysis comparing the differences between the treatment and control groups across the time periods for all 37 variables for pooled subjects, male subjects, and female subjects is reported in Table 16. For pooled subjects, significant differences were found between the treatment and control groups across the five time periods for sagittal, angular, vertical, and condyle/glenoid fossa variables. For male subjects, significant differences were found between the treatment and control groups across the five time 
periods for sagittal, angular, and vertical variables. For female subjects, significant differences were found between the treatment and control groups across the five time periods for sagittal, angular, vertical, and condyle/glenoid fossa variables.

\section{Sagittal Variables}

For pooled subjects, significant differences between the treatment and control groups across the time periods were found for all sagittal variables $(\mathrm{p}<.05)$ except for the variable OLp-Co $(p=0.0898)$. For male subjects, significant differences were found between the treatment and control groups for the variables Wits $(p=0.0001)$, Is-OLp $(p=$ 0.0034), Ii-OLP $(\mathrm{p}=0.0491)$, Overjet $(\mathrm{p}=0.0001)$, and molar relationship $(\mathrm{p}=0.0001)$. For female subjects, significant differences were found between the treatment and control groups for all sagittal variables except for the variable Co-Gn minus Co-A pt. $(\mathrm{p}=$ 0.4056).

\section{Vertical Variables}

For pooled subjects, significant differences between the treatment and control groups across the time periods $(\mathrm{p}<.05)$ were found for the vertical variables ANS-Me ( $\mathrm{p}$ $=0.0431)$ and Msc-NL $(p=0.0061)$. For male subjects, significant differences were found between the treatment and control groups for the vertical variables Ii-ML ( $\mathrm{p}=$ $0.0246)$ and Overbite $(p=0.0126)$. For female subjects, significant differences were found between the treatment and control groups for the vertical variable Msc-NL ( $\mathrm{p}=$ $0.0387)$.

\section{Angular Variables}

For pooled subjects, significant differences between the treatment and control groups across the time periods were found for all angular variables $(\mathrm{p}<.05)$ except for 
the variables SNL-NL ( $p=0.4629)$, SNL-ML $(p=0.6299)$, and Interincisal angle $(p=$ 0.4484). For male subjects, significant differences were found between the treatment and control groups for the variables ANB ( $\mathrm{p}=0.0111)$, SNL-OL $(\mathrm{p}=0.0054)$, and Is/NL $(\mathrm{p}=$ 0.0012). For female subjects, significant differences were found between the treatment and control groups for the angular variables SNA $(p=0.0024), \operatorname{SNB}(p=0.0323)$, ANB $(\mathrm{p}=0.0061)$, and $\mathrm{Ii} / \mathrm{ML}(\mathrm{p}=0.0130)$

\section{Condyle/Glenoid Fossa Variables}

For pooled subjects, significant differences between the treatment and control groups across the time periods were found $(\mathrm{p}<.05)$ for the condyle/glenoid fossa variable OLp-CoC $(\mathrm{p}=0.0264)$. For male subjects, no significant differences were found between the treatment and control groups for any of the condyle/glenoid fossa variables.

For female subjects, significant differences were found between the treatment and control groups for the condyle/glenoid fossa variables OLp-CoC $(p=0.0108)$, OLp-GFA ( $p=$ 0.0462), OLp-GFP ( $\mathrm{p}=0.0451)$. 
Table 16. Comparison of the Treatment group vs the Control group across the time periods

\begin{tabular}{|c|c|c|c|c|c|c|}
\hline \multirow{2}{*}{ Variables } & \multicolumn{2}{|c|}{ Pooled Subjects } & \multicolumn{2}{|c|}{ Male Subjects } & \multicolumn{2}{|c|}{ Female Subjects } \\
\hline & $\begin{array}{c}\mathrm{p} \\
\text { value }\end{array}$ & Significant & $\begin{array}{c}p \\
\text { value }\end{array}$ & Significant & $\begin{array}{c}\mathrm{p} \\
\text { value }\end{array}$ & Significant \\
\hline \multicolumn{7}{|l|}{ Sagittal: } \\
\hline 1. Olp-A pt. & 0.0002 & * & 0.2888 & NS & 0.0001 & * \\
\hline 2. Olp-Pg & 0.0211 & * & 0.4693 & NS & 0.0003 & * \\
\hline 3. Olp-Co & 0.0898 & NS & 0.6754 & NS & 0.0123 & * \\
\hline 4. Co-A pt. & 0.0009 & * & 0.5267 & NS & 0.0002 & * \\
\hline 5. Co-Gn & 0.0154 & * & 0.7683 & NS & 0.0013 & * \\
\hline 6. Co-Gn minus Co-A pt. & 0.0235 & * & 0.1226 & NS & 0.4056 & NS \\
\hline 7. Wits & 0.0001 & * & 0.0001 & * & 0.0251 & * \\
\hline 8. Is-Olp & 0.0001 & * & 0.0034 & * & 0.0079 & * \\
\hline 9. li-Olp & 0.0005 & * & 0.0491 & * & 0.0041 & * \\
\hline 10. Overjet & 0.0001 & * & 0.0001 & * & 0.0002 & * \\
\hline 11. Ms-Olp & 0.0001 & * & 0.1642 & NS & 0.0001 & * \\
\hline 12. Mi-Olp & 0.0002 & * & 0.1355 & NS & 0.0002 & * \\
\hline 13. Molar Relationship & 0.0001 & * & 0.0001 & * & 0.0001 & * \\
\hline \multicolumn{7}{|l|}{ Vertical: } \\
\hline 14. OLs-A pt. & 0.7155 & NS & 0.4930 & NS & 0.7704 & NS \\
\hline 15. ANS-Me & 0.0431 & * & 0.1691 & NS & 0.2974 & NS \\
\hline 16. Is-NL & 0.5956 & NS & 0.2595 & NS & 0.8916 & NS \\
\hline 17. Ii-ML & 0.2252 & NS & 0.0246 & * & 0.8711 & NS \\
\hline 18. Overbite & 0.0600 & NS & 0.0126 & * & 0.5826 & NS \\
\hline 19. Msc-NL & 0.0061 & * & 0.2760 & NS & 0.0387 & $*$ \\
\hline 20. Mic-ML & 0.7173 & NS & 0.5470 & NS & 0.7433 & NS \\
\hline \multicolumn{7}{|l|}{ Angular: } \\
\hline 21. SNA & 0.0027 & * & 0.0775 & NS & 0.0024 & * \\
\hline 22. SNB & 0.0329 & * & 0.2159 & NS & 0.0323 & * \\
\hline 23. ANB & 0.0001 & * & 0.0111 & * & 0.0061 & * \\
\hline 24. SNL-NL & 0.4629 & NS & 0.1407 & NS & 0.4422 & NS \\
\hline 25. SNL-ML & 0.6299 & NS & 0.1267 & NS & 0.7682 & NS \\
\hline 26. SNL-OL & 0.0031 & * & 0.0054 & * & 0.0895 & NS \\
\hline 27. Is/NL & 0.0033 & * & 0.0012 & * & 0.2680 & NS \\
\hline 28. $\mathrm{li} / \mathrm{ML}$ & 0.0011 & * & 0.0840 & NS & 0.0130 & * \\
\hline 29. Interincisal Angle & 0.4484 & NS & 0.0966 & NS & 0.7365 & NS \\
\hline \multicolumn{7}{|l|}{$\begin{array}{l}\text { Condyle/Glenoid } \\
\text { Fossa: }\end{array}$} \\
\hline 30. Olp-CoC & 0.0264 & * & 0.5061 & NS & 0.0108 & * \\
\hline 31. Olp-GFS & 0.1113 & NS & 0.7518 & NS & 0.0696 & NS \\
\hline 32. Olp-GFA & 0.1677 & NS & 0.7404 & NS & 0.0462 & * \\
\hline 33. Olp-GFP & 0.1221 & NS & 0.8220 & NS & 0.0451 & * \\
\hline 34. Ols-CoC & 0.2181 & NS & 0.2043 & NS & 0.6226 & NS \\
\hline 35. Ols-GFS & 0.6034 & NS & 0.6719 & NS & 0.8038 & NS \\
\hline 36. Ols-GFA & 0.6553 & NS & 0.5985 & NS & 0.8383 & NS \\
\hline 37. Ols-GFP & 0.2059 & NS & 0.4149 & NS & 0.3598 & NS \\
\hline
\end{tabular}




\section{Graph Analysis of Variables Across Time for the Treatment vs. Control Groups}

A visual inspection of the graphs plotting the values of the 37 variables across time for the treatment and control groups can indicate the time points at which differences between the treatment and control groups became apparent. An abrupt change in the value of the reported variable can suggest an important effect of treatment and the distance between the treatment and control variables over time indicate whether any change was temporary in nature or stable over the long term. A description of the graphs of the treatment and control group for the pooled subjects variables that were determined to be significantly different across the five time periods follow. Graphs plotting the values of the 37 variables across time of the treatment and control groups for pooled subjects, male subjects, and female subjects are shown in Appendix AB.

\section{Sagittal Variables}

OLP-A pt. Initially, the value of OLp-A pt. was greater in the treatment group than in the control group. Although this difference became smaller at T2 indicating a possible restriction of maxillary growth with treatment, the treatment group value remained greater than the control group value throughout the time periods until T5 when the control group value of OLp-A pt. became greater than the treatment group value.

OLp-Pg Initially, the value of OLp-Pg was greater in the treatment group than in the control group. This difference became larger at T2 indicating an initial enhanced forward positioning of the lower jaw, and then progressively declined. The control group value became greater than the treatment group value at T5 indicating the loss of any initial enhanced forward positioning of the lower jaw after treatment at T2. 
Co-A pt. Initially, the value of Co-A pt. was greater in the treatment group than in the control group. At T2, the treatment group value dropped below the value of the control group indicating a restriction of maxillary growth during treatment. The treatment group value remained lower than the control group value through T5 indicating a possible sustained treatment effect.

Co-Gn The values of Co-Gn for the treatment group and the control group were very similar through T3. At T4 the control group value became greater than the treatment group and remained this way through $\mathrm{T} 5$.

Co-Gn minus Co-A pt. Initially, the value of Co-Gn minus Co-A pt. was lower in the treatment group than in the control group. At T2, the value of the treatment group became greater than the value of the control group indicating an initial reduction in jaw discrepancy with treatment. However, the values of the treatment group and control group became similar at $\mathrm{T} 3$, returned to treatment value lower than control value at $\mathrm{T} 4$, and finished with similar values at T5.

Wits Analysis Initially, the values of the Wits analysis were very similar for the treatment and control groups. An abrupt decline to negative values occurred in the treatment group at $\mathrm{T} 2$, however a gradual reduction in the difference in values occurred until they became very similar again at T4. At T5, the Wits analysis values for the treatment group once again dropped below the control group values.

Is-OLp Initially, the value of Is-OLp in the treatment group was greater than the value in the control group. The value of the treatment group dropped to become very similar to the control group value at $\mathrm{T} 2$, indicating retroclination of the maxillary incisor 
during treatment. The values of the treatment and control groups remained similar through T5.

Ii-OLp Initially, the value of Ii-OLp of the treatment group was greater than the value of the control group. At T2, this difference became even larger indicating proclination of the mandibular incisors during treatment. The difference between the treatment and control group values gradually became smaller through T5 where they ended up very similar.

Overjet Initially, the value of Overjet for the treatment group was slightly greater than the value for the control group. At T2, an abrupt decline in the treatment group brought the value well below the control group, indicating a major reduction in overjet with treatment. Although this difference gradually became smaller until T4, the value of the treatment group remained well below the value of the control group. At T5, the difference became larger as the treatment group value was decreased again.

Ms-OLp Initially, the value of Ms-OLp was greater in the treatment group than in the control group. At T2, the treatment group value dropped below the control group value indicating a posterior movement of the maxillary molar with treatment. The values of the treatment group and control group became very similar at $\mathrm{T} 3$, however the treatment group value remained slightly below the control group value through T5.

Mi-OLp Initially, the value of Mi-OLp was greater in the treatment group than in the control group. At T2, the difference became even larger as the treatment group value increased more than the control value, indicating a mesial movement of the mandibular first molar during treatment. The difference in values gradually decreased to very similar 
levels at T5, although the treatment group value remained slightly larger than the control group value.

Molar relationship Initially, the value of Molar relationship for the treatment group was slightly greater than the value for the control group. At T2, an abrupt decline in the treatment group brought the value well below the control group, indicating overcorrection of molar relationship with treatment. Although this difference gradually became smaller through $\mathrm{T} 5$, the value of the treatment group remained well below the value of the control group indicating a sustained molar relationship correction over the long term.

\section{Vertical Variables}

ANS-Me The values of ANS-Me for the treatment group and the control group were very similar through T3. At T4 the control group value became greater than the treatment group and remained this way through $\mathrm{T} 5$.

Msc-NL Initially, the values of Msc-NL for the treatment group and the control group were very similar. At $\mathrm{T} 2$, the value for the treatment group became smaller than the control group indicating intrusion of the maxillary molar during treatment. The values of the treatment group rebounded slightly, but remained lower than the control group through T5.

\section{Angular Variables}

SNA Initially, the value of SNA in the treatment group was larger than in the control group. At T2, the difference was smaller although the value in the treatment group remained larger than in the control group. The treatment group values remained 
slightly larger than the control group values through T4, however at T5 the treatment group value became less than the control group value.

$\underline{\text { SNB }}$ Initially, the values of SNB in the treatment group and the control group were very similar. At T2, the treatment group value became slightly larger than the control group value, however this difference gradually became smaller through T4. At T5, the treatment group value dropped below the control group value.

ANB Initially, the value of ANB in the treatment group was greater than the value in the control group. At T2, the value in the treatment group was reduced to a value very similar to the control group value. The treatment value gradually became slightly larger than the control value through T4. At T5, the treatment value was once again reduced to a very similar level as the control value.

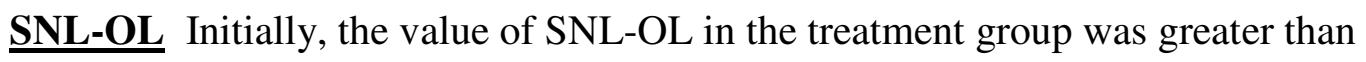
the value of the control group. At T2, the treatment group value increased and the difference between the values became larger. This difference gradually became smaller through T4 until the treatment group value was only slightly greater than the control group value. At T5, the treatment group value once again became greater than the control group value.

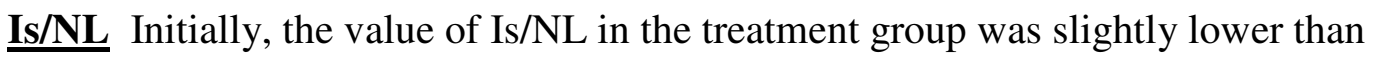
the value of the control group. At T2, the treatment group value decreased and the difference between the values became larger. This difference gradually became smaller through T4 until the treatment group value was very similar to the control group value. The values remained similar through T5. 
Ii/ML Initially, the values of Ii/ML in the treatment group and the control group were very similar. At $\mathrm{T} 2$, the value of the treatment group became larger than the value of the control group. At T3, the value of the treatment group decreased to a level only slightly higher than the value of the control group. At T4, the treatment group value increased again and remained at this level through T5.

\section{Condyle/Glenoid Fossa Variables}

OLp-CoC Initially, the value of OLp-CoC in the treatment group was slightly

larger than the value in the control group. At T2, the treatment group value increased and the difference between the values became larger. This difference remained fairly consistent through T5. 


\section{Comparison of the Treated Group vs. the Control Group}

Treatment effects of the edgewise crowned Herbst appliance in the mixed dentition and the long term stability of these effects in the treatment group were compared with an untreated control sample. The differences between certain time points were analyzed to investigate: T2-T1: treatment effects of the Herbst appliance (Tx (T2T1)) minus (Control (t2-t1)), T3-T1: Phase I treatment effects (Tx (T3-T1)) minus (Control (t3-t1)), T4-T1: residual Phase I treatment effects (Tx (T4-T1)) minus (Control (t4-t1)), and T5-T1 combined Phase I and Phase II treatment effects (Tx (T5-T1)) minus (Control (t5-t1)). In addition, T5-T4: phase II treatment effects (Tx (T5-T4)) minus (Control (t5-t4)) were evaluated as well as T4-T3: the relapse that occurred from after Phase I treatment to before Phase II treatment (Tx (T4-T3)) minus (Control (t4-t3)).

For all time periods, the change in the values of the variables for pooled subjects, male subjects, and female subjects in the treatment group were compared to the change in the values of the variables for pooled subjects, male subjects, and female subjects in the control group, respectively. In total, 37 variables were evaluated for each group including sagittal variables, vertical variables, angular variables, and condyle/glenoid fossa variables. In addition, an evaluation of the overjet correction and molar relationship correction for the treatment groups and an evaluation of the net overjet correction and net molar relationship correction for the treatment vs. control groups at each time period for pooled subjects were performed. 


\section{Comparison of T2-T1 (Treatment Effects of the Herbst Appliance)}

Of the 37 variables investigated, 19 showed statistically significant differences between the treatment group and control group in pooled subjects in the time period T2T1 (Table 17). The majority of the sagittal and angular variables showed significant differences, however, only two of the vertical variables showed significant differences. Only two of the condyle/glenoid fossa variables showed significant differences. Significance differences in variables are apparent for male subjects only and female subjects only and are reported in Tables 18 and 19, respectively. Only data from pooled subjects is reported here.

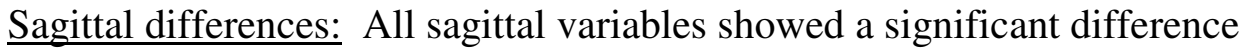
between the treatment and control groups except for OLp-A pt., OLp-Pg, and Co-Gn. The position of the maxillary base (OLp-A pt.) in the treatment group moved forward 1.0 $\mathrm{mm}$ from its original position and although it was not significant, the maxillary base was restricted $0.4 \mathrm{~mm}$ in the treatment group relative to the control group. The position of the mandibular base (OLp-Pg) moved forward $2.8 \mathrm{~mm}$ from its original position and although it was not significant, the mandibular base in the treatment group moved forward $2.0 \mathrm{~mm}$ relative to the control group. The position of the condyle (OLp-Co) moved anteriorly $1.5 \mathrm{~mm}$ in the treatment group relative to the control group. Effective maxillary length (Co-A pt.) and mandibular length (Co-Gn) showed a $-2.6 \mathrm{~mm}$ and a 0.7 $\mathrm{mm}$ difference from the control group, respectively. The difference in effective mandibular length was not significant. The difference between the effective maxillary and mandibular length (Co-Gn minus Co-A pt.) between the treatment and control groups was significant with a $2.6 \mathrm{~mm}$ difference. The position of the maxilla relative to the 
mandible along the functional occlusal plane (Wits) showed a difference of $-3.7 \mathrm{~mm}$ for the treatment group. The position of the maxillary incisor (Is-OLp) in the treatment group moved backwards $1.6 \mathrm{~mm}$ while the control group moved forwards $2.5 \mathrm{~mm}$, a net difference of $4.1 \mathrm{~mm}$ in a posterior direction. The mandibular incisors (Ii-OLp) moved forward $4.8 \mathrm{~mm}$ in the treatment group and only $1.9 \mathrm{~mm}$ in the control group, a net difference of $2.9 \mathrm{~mm}$ in an anterior direction. The maxillary molars (Ms-OLp) moved posteriorly $1.9 \mathrm{~mm}$ in the treatment group and $1.6 \mathrm{~mm}$ anteriorly in the control group, a net difference of $-3.5 \mathrm{~mm}$ in the treatment group. The mandibular molars (Mi-OLp) moved forward $4.8 \mathrm{~mm}$ in the treatment group and $1.7 \mathrm{~mm}$ forward in the control group, a net difference of $3.1 \mathrm{~mm}$ in an anterior direction.

Vertical differences: All vertical variables showed no significant difference between the treatment and control groups at T2-T1 except for Ii-ML and Msc-NL. The lower incisor (Ii-ML) was intruded significantly showing $0.8 \mathrm{~mm}$ of downward movement in the treatment group compared to $1.0 \mathrm{~mm}$ of upward movement in the control group, a net intrusion of $1.8 \mathrm{~mm}$. The maxillary molar was also intruded significantly showing $1.3 \mathrm{~mm}$ of upward movement in the treatment group compared to $1.3 \mathrm{~mm}$ of downward movement in the control group, a net intrusion of $2.6 \mathrm{~mm}$.

Angular differences: Significant differences in the angular variables between the control and treatment groups were found in ANB, SNL-NL, SNL-OL, Is/NL, and Ii/ML. A net decrease in ANB of $2.0^{\circ}$ was found in the treatment group relative to the control groups. A net increase of $1.7^{\circ}$ and $2.8^{\circ}$ in the treatment group was found in the palatal plane angle (SNL-NL) and the functional occlusal plane angle (SNL-OL), respectively. The maxillary incisor proclination (Is/NL) had a net decrease of $7.0^{\circ}$ in the treatment 
group compared to the control group, however the mandibular incisor angle (Ii/ML) experienced a net increase of $7.6^{\circ}$ in the treatment group.

Condyle/Glenoid Fossa differences: Only two condyle/glenoid fossa variables showed significant differences between the treatment and control groups; OLp-CoC and OLp-GFA. Although not all significant, every sagittal condyle/glenoid fossa variable (OLp-CoC, OLp-GFS, OLp-GFA, and OLp-GFP) showed a forward movement in the treatment group and a backward movement in the control group. Net anterior movements of $1.7 \mathrm{~mm}, 1.0 \mathrm{~mm}, 2.1 \mathrm{~mm}$, and $1.6 \mathrm{~mm}$ were found in the treatment group relative to the control group for the condylar position (OLp-CoC), the superior aspect of the glenoid fossa (OLp-GFS), the anterior aspect of the glenoid fossa (OLp-GFA), and the posterior aspect of the glenoid fossa (OLp-GFP). No significant differences were found in the vertical condyle/glenoid fossa variables between the treatment and control groups. 
Table 17. Comparison of treated vs. control in pooled subjects at T2-T1

\begin{tabular}{|c|c|c|c|c|c|c|c|}
\hline \multicolumn{8}{|c|}{ POOLED (MALES AND FEMALES) } \\
\hline \multirow[b]{2}{*}{ Variable } & \multicolumn{2}{|c|}{$\begin{array}{c}\text { Control } \\
(\mathrm{t} 2-\mathrm{t} 1)\end{array}$} & \multicolumn{2}{|c|}{$\begin{array}{l}\text { Treated } \\
\text { (T2-T1) }\end{array}$} & \multirow[b]{2}{*}{ Diff. } & \multirow[b]{2}{*}{$p$ value } & \multirow[b]{2}{*}{$\mathrm{Sig}$} \\
\hline & Mean & S.D. & Mean & S.D. & & & \\
\hline Age & 13.5 & 6.9 & 12.2 & 6.8 & -1.3 & 0.6304 & NS \\
\hline \multicolumn{8}{|l|}{ Sagittal: } \\
\hline 1. Olp-A pt. & 1.4 & 0.6 & 1.0 & 1.9 & -0.5 & 0.4206 & NS \\
\hline 2. Olp-Pg & 0.8 & 2.8 & 2.8 & 3.5 & 2.0 & 0.1221 & NS \\
\hline 3. Olp-Co & 0.7 & 1.6 & -0.8 & 1.9 & -1.5 & 0.0396 & * \\
\hline 4. Co-A pt. & 2.1 & 1.7 & -0.5 & 3.4 & -2.6 & 0.0205 & * \\
\hline 5. Co-Gn & 2.7 & 2.5 & 3.4 & 2.3 & 0.7 & 0.4778 & NS \\
\hline 6. Co-Gn minus Co-A pt. & 0.6 & 2.1 & 3.2 & 2.9 & 2.6 & 0.0159 & $*$ \\
\hline 7. Wits & -0.7 & 1.6 & -4.4 & 3.0 & -3.7 & 0.0009 & * \\
\hline 8. Is-Olp & 2.5 & 1.9 & -1.6 & 4.5 & -4.0 & 0.0065 & * \\
\hline 9. li-Olp & 1.9 & 1.5 & 4.8 & 3.0 & 3.0 & 0.0041 & * \\
\hline 10. Overjet & 0.6 & 1.6 & -6.4 & 3.9 & -6.9 & 0.0001 & * \\
\hline 11. Ms-Olp & 1.6 & 1.3 & -1.9 & 2.2 & -3.4 & 0.0001 & * \\
\hline 12. Mi-Olp & 1.7 & 1.4 & 4.8 & 1.9 & 3.1 & 0.0001 & * \\
\hline 13. Molar Relationship & -0.2 & 0.9 & -6.6 & 2.8 & -6.4 & 0.0001 & * \\
\hline \multicolumn{8}{|l|}{ Vertical: } \\
\hline 14. OLs-A pt. & 1.4 & 1.2 & 2.0 & 1.6 & 0.6 & 0.3174 & NS \\
\hline 15. ANS-Me & 1.7 & 1.4 & 1.3 & 1.7 & -0.4 & 0.5006 & NS \\
\hline 16. Is-NL & 1.8 & 3.1 & 0.9 & 3.0 & -0.9 & 0.4766 & NS \\
\hline 17. Ii-ML & 1.0 & 0.8 & -0.8 & 2.5 & -1.8 & 0.0175 & ${ }^{*}$ \\
\hline 18. Overbite & 1.3 & 2.9 & -1.1 & 3.6 & -2.4 & 0.0821 & NS \\
\hline 19. Msc-NL & 1.3 & 2.0 & -1.3 & 1.2 & -2.7 & 0.0005 & * \\
\hline 20. Mic-ML & 0.6 & 1.0 & 1.2 & 1.3 & 0.7 & 0.1517 & NS \\
\hline \multicolumn{8}{|l|}{ Angular: } \\
\hline 21. SNA & 0.6 & 1.4 & -0.3 & 2.4 & -1.0 & 0.2269 & NS \\
\hline 22. SNB & 0.6 & 1.6 & 1.6 & 2.1 & 1.0 & 0.1745 & NS \\
\hline 23. ANB & 0.0 & 1.2 & -2.0 & 2.4 & -2.0 & 0.0141 & * \\
\hline 24. SNL-NL & -0.7 & 2.0 & 1.0 & 1.8 & 1.7 & 0.0283 & * \\
\hline 25. SNL-ML & -0.1 & 1.8 & 0.1 & 1.6 & 0.2 & 0.7347 & NS \\
\hline 26. SNL-OL & 0.6 & 2.1 & 3.4 & 3.8 & 2.8 & 0.0306 & * \\
\hline 27. Is/NL & -0.3 & 3.4 & -7.3 & 7.3 & -7.0 & 0.0043 & * \\
\hline 28. Ii/ML & -0.5 & 2.8 & 7.1 & 6.9 & 7.6 & 0.0012 & * \\
\hline 29. Interincisal Angle & -0.8 & 6.0 & 1.4 & 9.4 & 2.2 & 0.4922 & NS \\
\hline \multicolumn{8}{|l|}{ Condyle/Glenoid Fossa: } \\
\hline 30. Olp-CoC & -0.5 & 1.6 & 1.2 & 1.7 & 1.6 & 0.0206 & * \\
\hline 31. Olp-GFS & -0.1 & 1.7 & 0.9 & 1.8 & 1.0 & 0.1583 & NS \\
\hline 32. OIp-GFA & -0.5 & 1.7 & 1.6 & 1.8 & 2.1 & 0.0118 & * \\
\hline 33. Olp-GFP & -0.3 & 2.0 & 1.3 & 2.5 & 1.6 & 0.0841 & NS \\
\hline 34. Ols-CoC & 1.1 & 1.3 & 0.5 & 1.6 & -0.6 & 0.2832 & NS \\
\hline 35. Ols-GFS & 0.5 & 1.2 & 0.5 & 1.5 & 0.0 & 0.9293 & NS \\
\hline 36. Ols-GFA & 0.5 & 1.0 & 0.2 & 1.3 & -0.2 & 0.5962 & NS \\
\hline 37. Ols-GFP & 0.2 & 1.2 & 0.0 & 1.7 & -0.1 & 0.8123 & NS \\
\hline
\end{tabular}


Table 18. Comparison of treated vs. control in male subjects at T2-T1.

\begin{tabular}{|c|c|c|c|c|c|c|c|}
\hline \multicolumn{8}{|c|}{ MALE SUBJECTS } \\
\hline \multirow[b]{2}{*}{ Variable } & \multicolumn{2}{|c|}{$\begin{array}{c}\text { Control } \\
\text { (t2-t1) }\end{array}$} & \multicolumn{2}{|c|}{$\begin{array}{l}\text { Treated } \\
\text { (T2-T1) }\end{array}$} & \multirow[b]{2}{*}{ Diff } & \multirow[b]{2}{*}{$p$ value } & \multirow[b]{2}{*}{ Sig } \\
\hline & Mean & S.D. & Mean & S.D. & & & \\
\hline Age & 11.0 & 2.0 & 10.1 & 3.4 & -0.9 & 0.5000 & NS \\
\hline \multicolumn{8}{|l|}{ Sagittal: } \\
\hline 1. Olp-A pt. & 1.2 & 0.7 & 0.4 & 1.0 & -0.8 & 0.1274 & NS \\
\hline 2. Olp-Pg & -0.4 & 3.1 & 2.8 & 4.0 & 3.2 & 0.1186 & NS \\
\hline 3. Olp-Co & 0.1 & 1.5 & -0.6 & 2.2 & -0.7 & 0.4585 & NS \\
\hline 4. Co-A pt. & 1.3 & 1.4 & -1.5 & 3.9 & -2.8 & 0.1008 & NS \\
\hline 5. Co-Gn & 1.4 & 2.0 & 3.6 & 2.2 & 2.2 & 0.0841 & NS \\
\hline 6. Co-Gn minus Co-A pt. & 0.1 & 2.4 & 3.8 & 2.7 & 3.7 & 0.0213 & * \\
\hline 7. Wits & -0.3 & 1.9 & -5.4 & 2.9 & -5.1 & 0.0042 & * \\
\hline 8. Is-Olp & 2.2 & 0.9 & -3.0 & 2.8 & -5.2 & 0.0006 & * \\
\hline 9. li-Olp & 1.3 & 1.3 & 5.0 & 1.8 & 3.7 & 0.0012 & * \\
\hline 10. Overjet & 0.8 & 1.3 & -8.1 & 3.2 & -8.9 & 0.0001 & * \\
\hline 11. Ms-Olp & 0.9 & 0.9 & -2.4 & 1.4 & -3.3 & 0.0003 & * \\
\hline 12. Mi-Olp & 1.1 & 1.2 & 5.1 & 1.7 & 4.0 & 0.0004 & * \\
\hline 13. Molar Relationship & -0.3 & 1.1 & -7.5 & 2.1 & -7.2 & 0.0001 & * \\
\hline \multicolumn{8}{|l|}{ Vertical: } \\
\hline 14. OLs-A pt. & 0.9 & 0.6 & 2.2 & 1.1 & 1.3 & 0.0316 & * \\
\hline 15. ANS-Me & 1.9 & 1.7 & 2.0 & 1.8 & 0.1 & 0.9706 & NS \\
\hline 16. Is-NL & 1.4 & 2.9 & 1.0 & 2.2 & -0.4 & 0.8006 & NS \\
\hline 17. Ii-ML & 0.8 & 0.6 & -1.8 & 2.1 & -2.6 & 0.0088 & * \\
\hline 18. Overbite & 0.7 & 2.4 & -2.6 & 1.6 & -3.3 & 0.0115 & * \\
\hline 19. Msc-NL & 0.8 & 1.7 & -1.3 & 1.2 & -2.1 & 0.0171 & * \\
\hline 20. Mic-ML & 0.5 & 0.9 & 1.5 & 1.3 & 1.0 & 0.1294 & NS \\
\hline \multicolumn{8}{|l|}{ Angular: } \\
\hline 21. SNA & 0.0 & 0.7 & -1.4 & 1.4 & -1.4 & 0.0336 & * \\
\hline 22. SNB & 0.0 & 0.9 & 1.2 & 1.8 & 1.2 & 0.1244 & NS \\
\hline 23. ANB & 0.0 & 1.2 & -2.7 & 2.2 & -2.7 & 0.0132 & * \\
\hline 24. SNL-NL & -0.9 & 1.9 & 1.0 & 2.0 & 1.9 & 0.0939 & NS \\
\hline 25. SNL-ML & 0.5 & 1.6 & 0.2 & 1.7 & -0.3 & 0.8169 & NS \\
\hline 26. SNL-OL & 0.5 & 2.3 & 4.4 & 3.6 & 3.9 & 0.0340 & * \\
\hline 27. Is/NL & 0.5 & 3.6 & -10.5 & 7.5 & $1 \overline{11.0}$ & 0.0045 & * \\
\hline 28. li/ML & -0.3 & 2.1 & 7.3 & 7.9 & 7.6 & 0.0300 & * \\
\hline 29. Interincisal Angle & -1.7 & 5.4 & 4.0 & 9.4 & 5.7 & 0.1856 & NS \\
\hline \multicolumn{8}{|l|}{ Condyle/Glenoid Fossa: } \\
\hline 30. Olp-CoC & 0.0 & 1.5 & 1.1 & 2.0 & 1.1 & 0.2742 & NS \\
\hline 31. Olp-GFS & 0.5 & 1.6 & 0.7 & 1.8 & 0.2 & 0.7930 & NS \\
\hline 32. Olp-GFA & 0.1 & 1.4 & 0.8 & 1.1 & 0.7 & 0.3964 & NS \\
\hline 33. Olp-GFP & 0.2 & 1.8 & 1.5 & 2.6 & 1.3 & 0.3186 & NS \\
\hline 34. Ols-CoC & 0.8 & 1.0 & 0.9 & 1.3 & 0.1 & 0.9402 & NS \\
\hline 35. Ols-GFS & 0.4 & 1.4 & 0.5 & 1.4 & 0.1 & 0.9975 & NS \\
\hline 36. Ols-GFA & 0.5 & 1.1 & -0.1 & 1.0 & -0.6 & 0.2870 & NS \\
\hline 37. Ols-GFP & 0.3 & 1.1 & -0.7 & 1.1 & -1.0 & 0.1023 & NS \\
\hline
\end{tabular}


Table 19. Comparison of treated vs. control in female subjects at T2-T1.

\begin{tabular}{|c|c|c|c|c|c|c|c|}
\hline \multicolumn{8}{|c|}{ FEMALE SUBJECTS } \\
\hline \multirow[b]{2}{*}{ Variable } & \multicolumn{2}{|c|}{$\begin{array}{l}\text { Control } \\
\text { (t2-t1) }\end{array}$} & \multicolumn{2}{|c|}{$\begin{array}{c}\text { Treated } \\
\text { (T2-T1) }\end{array}$} & \multirow[b]{2}{*}{ Diff. } & \multirow[b]{2}{*}{$p$ value } & \multirow[b]{2}{*}{ Sig } \\
\hline & Mean & S.D. & Mean & S.D. & & & \\
\hline Age & 16.3 & 9.5 & 14.5 & 9.2 & -1.8 & 0.7413 & NS \\
\hline \multicolumn{8}{|l|}{ Sagittal: } \\
\hline 1. Olp-A pt. & 1.6 & 0.4 & 1.5 & 2.5 & -0.1 & 0.9555 & NS \\
\hline 2. Olp-Pg & 2.3 & 1.4 & 2.8 & 3.0 & 0.5 & 0.7242 & NS \\
\hline 3. Olp-Co & 1.2 & 1.6 & -1.0 & 1.6 & -2.2 & 0.0314 & * \\
\hline 4. Co-A pt. & 3.0 & 1.5 & 0.6 & 2.3 & -2.4 & 0.0708 & NS \\
\hline 5. Co-Gn & 4.1 & 2.4 & 3.1 & 2.4 & -1.0 & 0.4847 & NS \\
\hline 6. Co-Gn minus Co-A pt. & 1.1 & 1.7 & 2.4 & 3.1 & 1.3 & 0.3941 & NS \\
\hline 7. Wits & -1.0 & 1.1 & -3.1 & 2.6 & -2.1 & 0.1091 & NS \\
\hline 8. Is-Olp & 2.7 & 2.6 & 0.1 & 5.7 & -2.6 & 0.3401 & NS \\
\hline 9. li-Olp & 2.4 & 1.5 & 4.5 & 4.2 & 2.1 & 0.2666 & NS \\
\hline 10. Overjet & 0.2 & 1.8 & -3.2 & 3.3 & -3.4 & 0.0575 & NS \\
\hline 11. Ms-Olp & 2.3 & 1.3 & -1.2 & 2.9 & -3.5 & 0.0230 & * \\
\hline 12. Mi-Olp & 2.3 & 1.3 & 4.3 & 2.1 & 2.0 & 0.0809 & NS \\
\hline 13. Molar Relationship & 0.0 & 0.5 & -5.6 & 3.3 & -5.6 & 0.0025 & * \\
\hline \multicolumn{8}{|l|}{ Vertical: } \\
\hline 14. OLs-A pt. & 1.8 & 1.5 & 1.6 & 2.0 & -0.2 & 0.8362 & NS \\
\hline 15. ANS-Me & 1.3 & 0.9 & 0.3 & 0.9 & -1.0 & 0.1241 & NS \\
\hline 16. Is-NL & 2.1 & 3.4 & 0.7 & 3.8 & -1.4 & 0.5135 & NS \\
\hline 17. Ii-ML & 1.2 & 0.9 & 0.3 & 2.3 & -0.9 & 0.4368 & NS \\
\hline 18. Overbite & 2.0 & 3.3 & 1.5 & 4.9 & -0.5 & 0.8634 & NS \\
\hline 19. Msc-NL & 1.8 & 2.3 & -1.3 & 1.3 & -3.1 & 0.0176 & -1 \\
\hline 20. Mic-ML & 0.6 & 1.1 & 0.8 & 1.1 & 0.2 & 0.7321 & NS \\
\hline \multicolumn{8}{|l|}{ Angular: } \\
\hline 21. SNA & 1.2 & 1.6 & 0.9 & 2.8 & -0.3 & 0.8107 & NS \\
\hline 22. SNB & 1.3 & 1.8 & 2.0 & 2.4 & 0.7 & 0.6053 & NS \\
\hline 23. ANB & 0.0 & 1.2 & -1.0 & 2.4 & -1.0 & 0.3976 & NS \\
\hline 24. SNL-NL & -0.5 & 2.3 & 1.0 & 1.5 & 1.5 & 0.2122 & NS \\
\hline 25. SNL-ML & -0.8 & 1.9 & 0.0 & 1.5 & 0.8 & 0.4708 & NS \\
\hline 26. SNL-OL & 0.7 & 2.0 & 2.1 & 3.8 & 1.4 & 0.4484 & NS \\
\hline 27. Is/NL & -1.3 & 3.0 & -3.6 & 5.2 & -2.3 & 0.3747 & NS \\
\hline 28. $\mathrm{l} / \mathrm{ML}$ & -0.5 & 3.6 & 6.8 & 6.0 & 7.3 & 0.0287 & 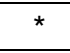 \\
\hline 29. Interincisal Angle & 0.3 & 7.0 & -1.7 & 8.9 & -2.0 & 0.6644 & NS \\
\hline \multicolumn{8}{|l|}{ Condyle/Glenoid Fossa: } \\
\hline 30. Olp-CoC & -1.0 & 1.6 & 1.2 & 1.4 & 2.2 & 0.0330 & * \\
\hline 31. Olp-GFS & -0.7 & 1.7 & 1.1 & 1.8 & 1.8 & 0.1022 & NS \\
\hline 32. Olp-GFA & -1.0 & 1.8 & 2.6 & 2.0 & 3.6 & 0.0156 & \\
\hline 33. Olp-GFP & -0.9 & 2.0 & 0.9 & 2.4 & 1.8 & 0.1670 & NS \\
\hline 34. Ols-CoC & 1.3 & 1.6 & 0.0 & 1.7 & -1.3 & 0.1819 & NS \\
\hline 35. Ols-GFS & 0.5 & 0.9 & 0.5 & 1.5 & 0.0 & 0.8981 & NS \\
\hline 36. Ols-GFA & 0.3 & 0.9 & 0.5 & 1.4 & 0.2 & 0.7481 & NS \\
\hline 37. Ols-GFP & 0.0 & 1.4 & 0.9 & 1.8 & 0.9 & 0.3500 & NS \\
\hline
\end{tabular}




\section{Overjet and Molar Relationship Correction-Treatment Group (T2- T1)}

The amount of skeletal and dental contribution to the overjet and molar relationship correction in the treatment group at T2-T1 was calculated using the formulas in Table 11. The amount of overjet correction in the treatment group was $6.4 \mathrm{~mm} .1 .8$ $\mathrm{mm}(28.1 \%)$ of the correction was due to skeletal correction. $4.6 \mathrm{~mm}(71.9 \%)$ of the correction was due to dental correction. The amount of molar relationship correction was $6.7 \mathrm{~mm} .1 .8 \mathrm{~mm}(26.9 \%)$ of the correction was skeletal in nature and $4.9 \mathrm{~mm}(73.1 \%)$ of the correction was dental in nature. Calculations are shown for the overjet and molar relationship correction on the following pages. In addition, diagrams are provided to illustrate the anterior or posterior movement of the maxillary base, mandibular base, maxillary incisors, mandibular incisors, maxillary molars, and mandibular molars

(Figures 11 and 12). A pitchfork analysis describing the skeletal and dental contributions to overjet and molar relationship correction is shown in Figure 13. 


\begin{tabular}{|cccc|}
\hline Overjet Correction: & & Molar relationship: & \\
\hline Skeletal Contribution: & 1.0 & Skeletal Contribution: & \\
1) Maxilla & 2.8 & 1) Maxilla & 1.0 \\
2) Mandible & & 2) Mandible & 2.8 \\
Dental Contribution: & -2.6 & Dental Contribution: & \\
3) Mx incisor & 2.0 & 3) Mx molar & -2.9 \\
4) Md incisor & & 4) Md molar & 2.0 \\
\hline
\end{tabular}

Overjet Correction $=$ Maxilla + Mx incisor - Mandible - Md incisor

Overjet Correction $=1.0+(-2.6)-2.8-2.0=-6.4 \mathrm{~mm}$
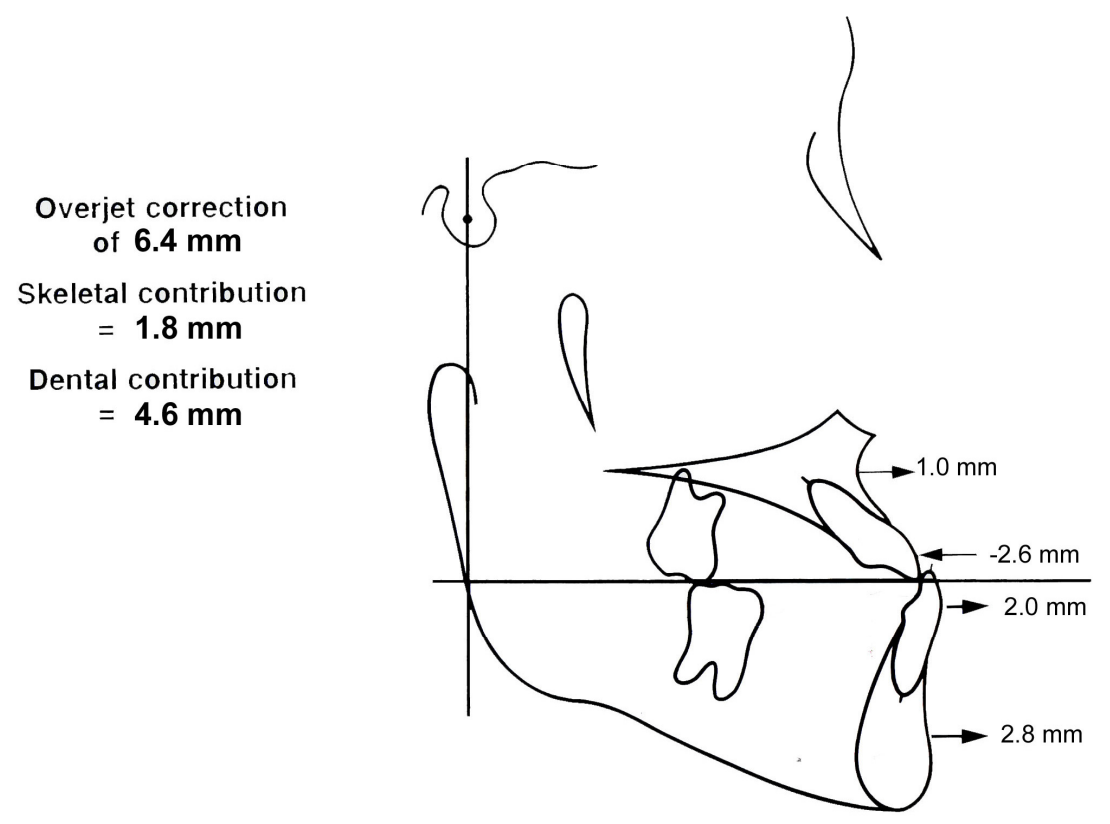

Figure 11. Components of overjet correction (T2-T1) 
Molar Relationship Correction = Maxilla + Mx molar - Mandible - Md molar

Molar Relationship Correction $=1.0+(-2.9)-2.8-2.0=-6.7 \mathrm{~mm}$
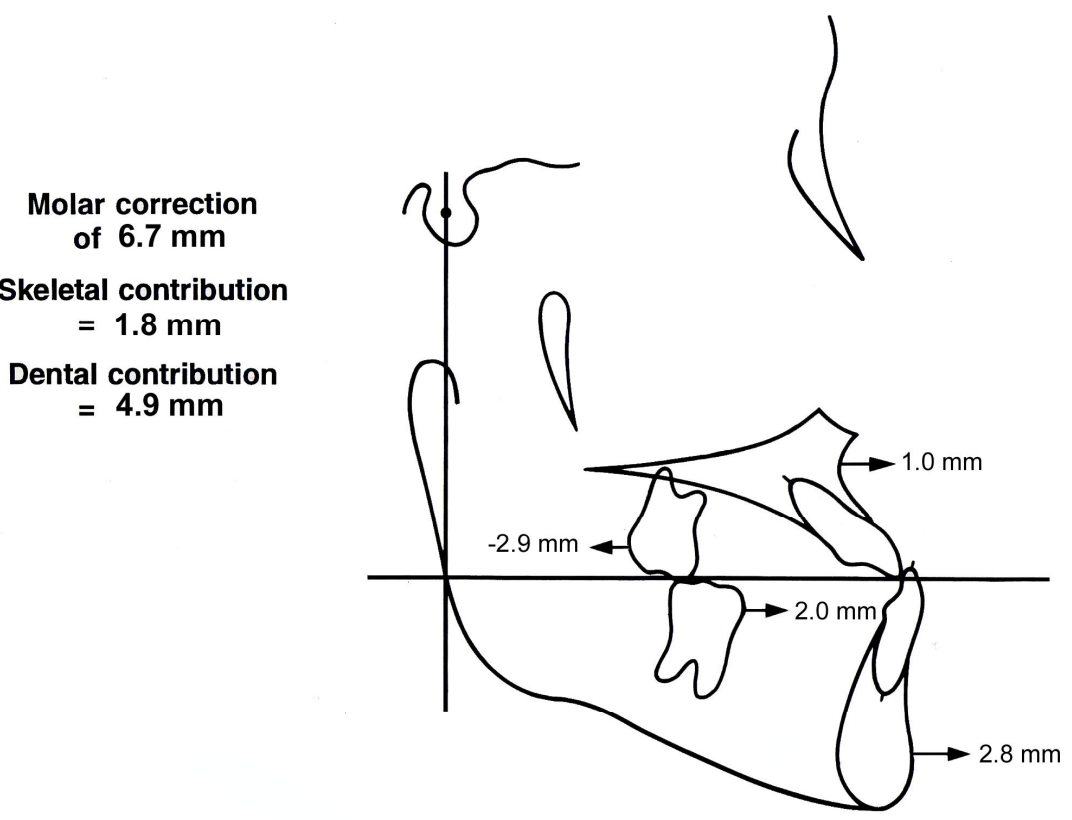

Figure 12. Components of molar relationship correction (T2-T1)

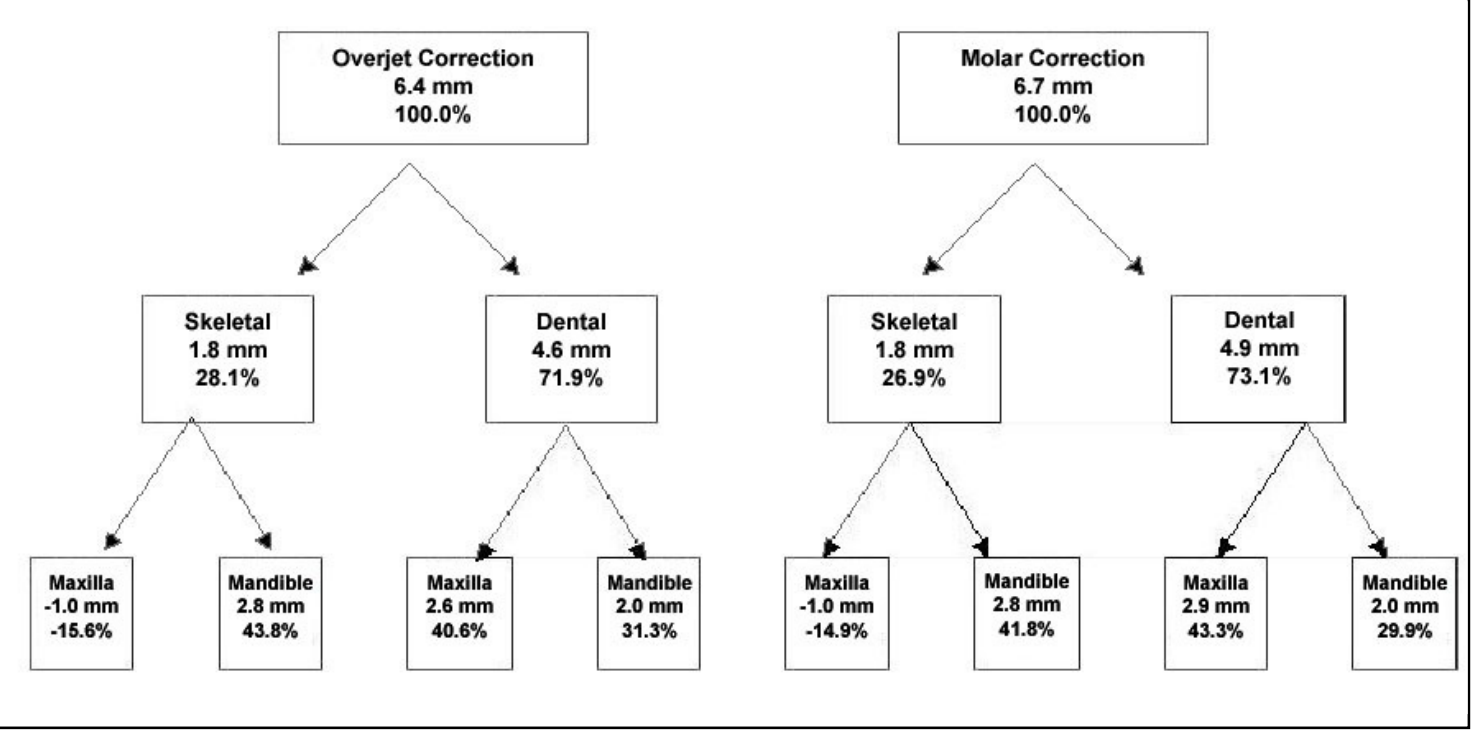

Figure 13. Pitchfork analysis of overjet and molar correction (T2-T1) 


\section{Net Overjet and Molar Relationship Correction-Tx vs. Control Group (T2-T1)}

The amount of skeletal and dental contribution to the net overjet and net molar relationship correction in the treatment group vs. the control group at T2-T1 was calculated using the formulas in Table 11. The amount of net overjet correction in the treatment group relative to the control group was $7.0 \mathrm{~mm} .2 .4 \mathrm{~mm}(34.3 \%)$ of the correction was due to skeletal movement. $4.6 \mathrm{~mm}(65.7 \%)$ of the correction was due to dental movement. The amount of net molar relationship correction was $6.6 \mathrm{~mm} .2 .4 \mathrm{~mm}$ $(36.4 \%)$ of the correction was skeletal in nature and $4.2 \mathrm{~mm}(63.6 \%)$ of the correction was dental in nature. Calculations are shown for the net overjet and net molar relationship correction on the following pages. In addition, diagrams are provided to illustrate the net anterior or posterior movement of the maxillary base, mandibular base, maxillary incisors, mandibular incisors, maxillary molars, and mandibular molars (Figures 14 and 15). A pitchfork analysis describing the net skeletal and dental contributions to overjet and molar relationship correction is shown in Figure 16. 


\begin{tabular}{|cccc|}
\hline Net Overjet Correction: & & Net Molar relationship: & \\
\hline Skeletal Contribution: & & Skeletal Contribution: & \\
1) Maxilla & -0.4 & 1) Maxilla & -0.4 \\
2) Mandible & 2.0 & 2) Mandible & 2.0 \\
Dental Contribution: & & Dental Contribution: & \\
3) Mx incisor & -3.7 & 3) Mx molar & -3.1 \\
4) Md incisor & 0.9 & 4) Md molar & 1.1 \\
\end{tabular}

Net Overjet Correction $=$ Maxilla + Mx incisor - Mandible - Md incisor

Net Overjet Correction $=(-0.4)+(-3.7)-2.0-0.9=-7.0 \mathrm{~mm}$
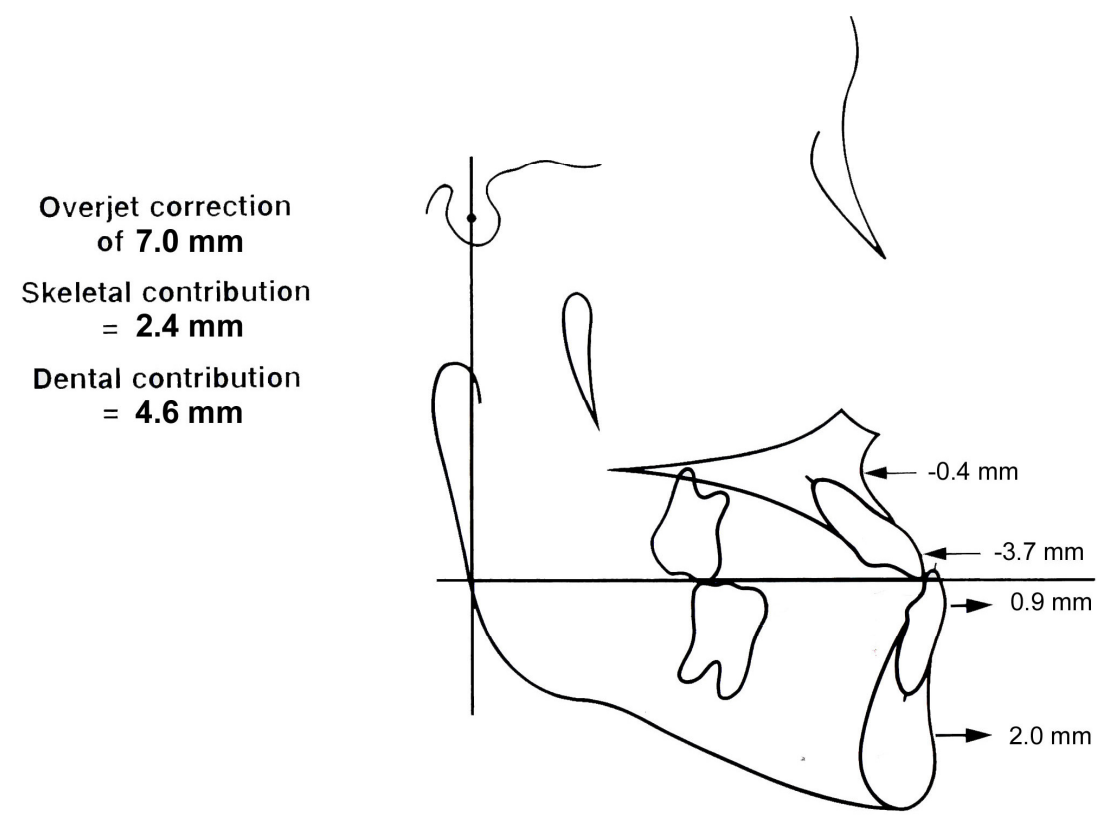

Figure 14. Components of net overjet correction (T2-T1) 
Net Molar Relationship Correction $=$ Maxilla + Mx molar - Mandible - Md molar

Net Molar Relationship Correction $=(-0.4)+(-3.1)-2.0-1.1=-6.6 \mathrm{~mm}$
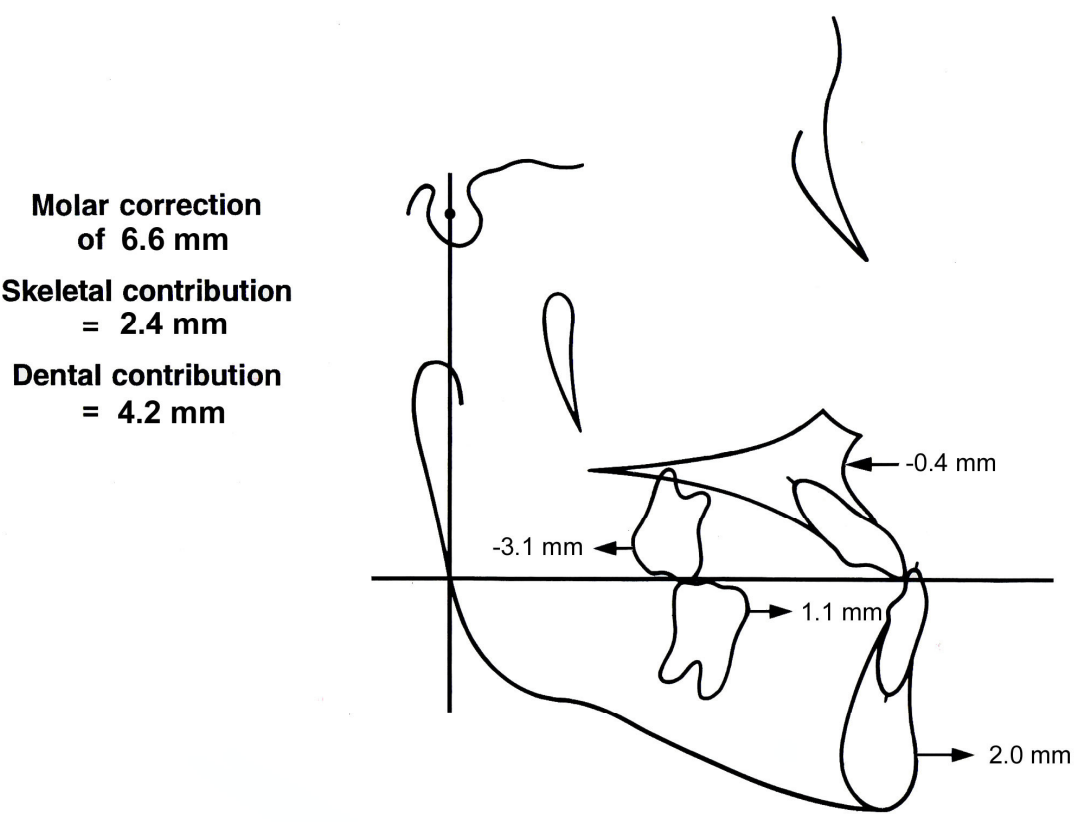

Figure 15. Components of net molar correction (T2-T1)

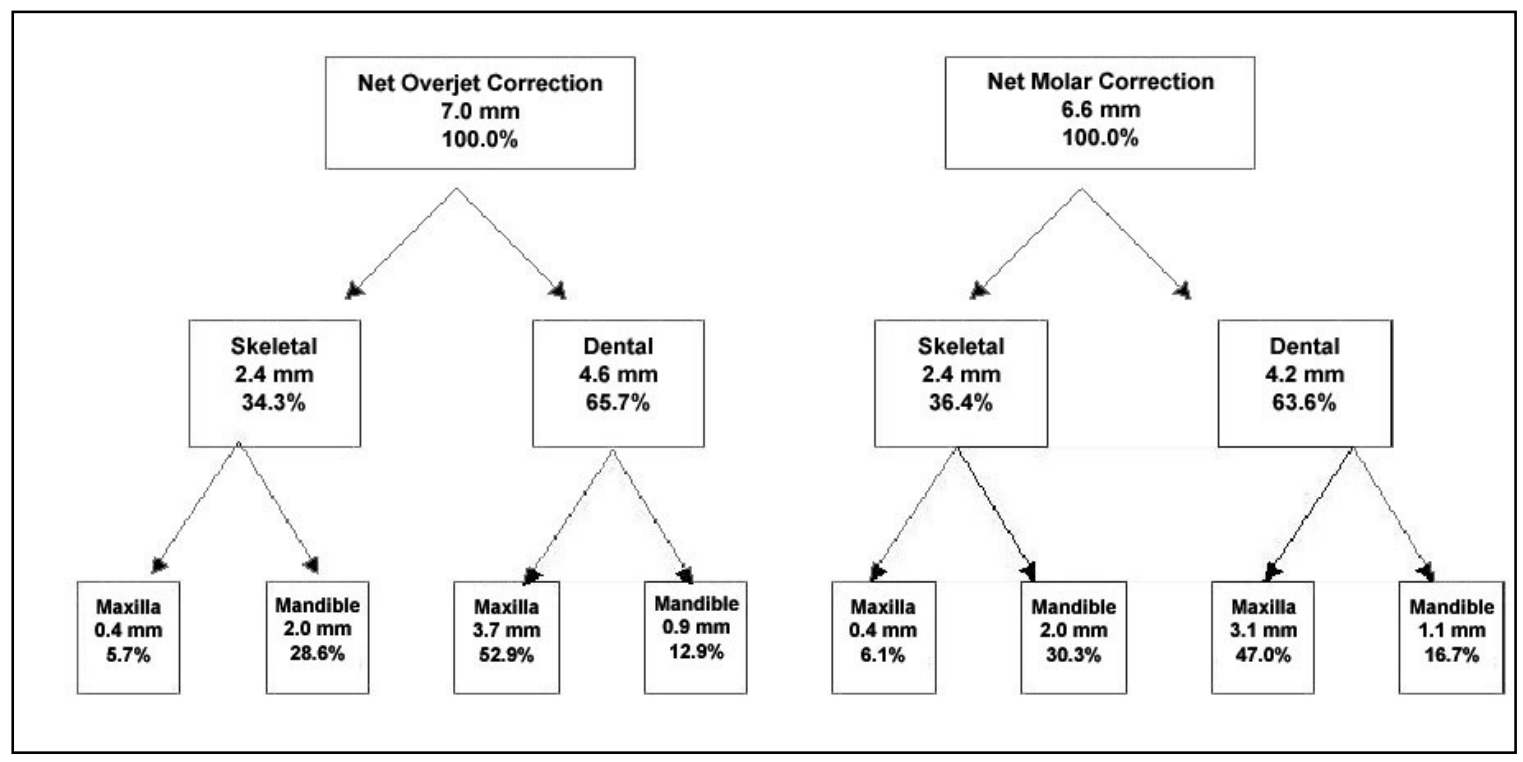

Figure 16. Pitchfork analysis of net overjet and molar correction (T2-T1) 


\section{Comparison of T3-T1 (Phase I Treatment Effects)}

Of the 37 variables investigated, 9 showed statistically significant differences between the treatment group and control group in pooled subjects in the time period T3T1 (Table 20). Six of the sagittal variables showed significant differences, however, only one of each of the vertical, angular, and condyle/fossa variables significant differences between the treatment and control groups. Significance differences in variables are apparent for male subjects only and female subjects only and are reported in Tables 21 and 22 , respectively. Only data from pooled subjects is reported here.

Sagittal differences: The six sagittal variables that showed a significant difference between the treatment and control groups at T3-T1 were Co-A pt., Wits analysis, Is-OLp, Overjet, Ms-OLp, and molar relationship. Effective maxillary length (Co-A pt.) showed a $-2.0 \mathrm{~mm}$ difference from the control group. The position of the maxilla relative to the mandible along the functional occlusal plane (Wits) showed a difference of $-1.7 \mathrm{~mm}$ for the treatment group. The position of the maxillary incisor (IsOLp) in the treatment group moved forward $1.0 \mathrm{~mm}$ while the control group moved forwards $3.7 \mathrm{~mm}$, a net difference of $2.7 \mathrm{~mm}$ in a posterior direction. The maxillary molars (Ms-OLp) moved forward $0.9 \mathrm{~mm}$ in the treatment group and $3.1 \mathrm{~mm}$ anteriorly in the control group, a net difference of $-2.2 \mathrm{~mm}$ in the treatment group. Overjet and molar relationship correction will be discussed later.

Vertical differences: All vertical variables showed no significant difference between the treatment and control groups at T3-T1 except Msc-NL. The maxillary molar (Msc-NL) erupted $0.6 \mathrm{~mm}$ in the treatment group and $1.7 \mathrm{~mm}$ in the control group, a net difference of $-1.1 \mathrm{~mm}$. 
Angular differences: All angular variables showed no significant difference between the treatment and control groups at T3-T1 except ANB. ANB decreased $1.7^{\circ}$ in the treatment group and only $0.3^{\circ}$ in the control group, giving a net decrease of $1.4^{\circ}$.

Condyle/Glenoid Fossa differences: Only one condyle/glenoid fossa variable, OLp-CoC, showed a significant difference between the treatment and control groups at T3-T1. Although not all significant, once again every sagittal condyle/glenoid fossa variable (OLp-CoC, OLp-GFS, OLp-GFA, and OLp-GFP) showed a forward movement in the treatment group and a backward or only slightly forward movement in the control group. Net anterior movements of $1.2 \mathrm{~mm}, 1.0 \mathrm{~mm}, 0.9 \mathrm{~mm}$, and $1.3 \mathrm{~mm}$ were found in the treatment group relative to the control group for the condylar position (OLp-CoC), the superior aspect of the glenoid fossa (OLp-GFS), the anterior aspect of the glenoid fossa (OLp-GFA), and the posterior aspect of the glenoid fossa (OLp-GFP). No significant differences were found in the vertical condyle/glenoid fossa variables between the treatment and control groups. 
Table 20. Comparison of treated vs. control in pooled subjects at T3-T1

\begin{tabular}{|c|c|c|c|c|c|c|c|}
\hline \multicolumn{8}{|c|}{ POOLED (MALES AND FEMALES) } \\
\hline \multirow[b]{2}{*}{ Variable } & \multicolumn{2}{|c|}{$\begin{array}{c}\text { Control } \\
\text { (t3-t1) }\end{array}$} & \multicolumn{2}{|c|}{$\begin{array}{l}\text { Treated } \\
\text { (T3-T1) }\end{array}$} & \multirow[b]{2}{*}{ Diff } & \multirow[b]{2}{*}{$p$ value } & \multirow[b]{2}{*}{ Sig } \\
\hline & Mean & S.D. & Mean & S.D. & & & \\
\hline Age & 23.1 & 7.0 & 21.3 & 7.1 & -1.8 & 0.4137 & NS \\
\hline \multicolumn{8}{|l|}{ Sagittal: } \\
\hline 1. Olp-A pt. & 1.9 & 0.9 & 1.2 & 1.8 & -0.7 & 0.0932 & NS \\
\hline 2. Olp-Pg & 2.8 & 2.7 & 3.4 & 2.4 & 0.6 & 0.5019 & NS \\
\hline 3. Olp-Co & 0.3 & 2.1 & -0.5 & 1.8 & -0.8 & 0.1299 & NS \\
\hline 4. Co-A pt. & 2.3 & 2.5 & 0.3 & 2.9 & -2.0 & 0.0207 & * \\
\hline 5. Co-Gn & 4.2 & 2.8 & 4.1 & 2.5 & -0.1 & 0.8907 & NS \\
\hline 6. Co-Gn minus Co-A pt. & 1.8 & 1.9 & 3.3 & 3.2 & 1.5 & 0.0739 & NS \\
\hline 7. Wits & -0.5 & 1.1 & -2.2 & 2.5 & -1.7 & 0.0049 & * \\
\hline 8. Is-Olp & 3.7 & 1.7 & 1.0 & 3.3 & -2.7 & 0.0018 & * \\
\hline 9. li-Olp & 3.1 & 1.7 & 3.5 & 2.6 & 0.4 & 0.5232 & NS \\
\hline 10. Overjet & 0.6 & 1.5 & -2.5 & 2.7 & -3.1 & 0.0001 & * \\
\hline 11. Ms-Olp & 3.1 & 1.6 & 0.9 & 1.9 & -2.2 & 0.0003 & * \\
\hline 12. Mi-Olp & 3.3 & 1.8 & 4.4 & 2.0 & 1.1 & 0.0582 & NS \\
\hline 13. Molar Relationship & -0.1 & 1.0 & -3.4 & 2.3 & -3.3 & 0.0001 & * \\
\hline \multicolumn{8}{|l|}{ Vertical: } \\
\hline 14. OLs-A pt. & 1.6 & 1.2 & 2.3 & 1.4 & 0.7 & 0.1158 & NS \\
\hline 15. ANS-Me & 1.9 & 1.1 & 2.1 & 1.4 & 0.2 & 0.7051 & NS \\
\hline 16. Is-NL & 2.2 & 2.3 & 1.8 & 2.8 & -0.4 & 0.5621 & $\mathrm{NS}$ \\
\hline 17. Ii-ML & 1.3 & 1.0 & 0.7 & 2.2 & -0.6 & 0.2741 & NS \\
\hline 18. Overbite & 1.4 & 2.5 & -0.1 & 3.3 & -1.5 & 0.0811 & NS \\
\hline 19. Msc-NL & 1.7 & 1.8 & 0.6 & 1.2 & -1.1 & 0.0175 & * \\
\hline 20. Mic-ML & 1.3 & 1.4 & 1.3 & 1.3 & 0.0 & 0.9558 & NS \\
\hline \multicolumn{8}{|l|}{ Angular: } \\
\hline 21. SNA & 0.2 & 1.2 & -0.3 & 2.5 & -0.5 & 0.3549 & NS \\
\hline 22. SNB & 0.5 & 1.1 & 1.4 & 1.8 & 0.9 & 0.0608 & NS \\
\hline 23. ANB & -0.3 & 0.8 & -1.7 & 2.3 & -1.4 & 0.0079 & * \\
\hline 24. SNL-NL & -1.0 & 2.0 & -0.6 & 1.9 & 0.4 & 0.4982 & NS \\
\hline 25. SNL-ML & -0.6 & 1.4 & -0.1 & 1.9 & 0.5 & 0.3355 & NS \\
\hline 26. SNL-OL & -0.4 & 2.1 & 0.2 & 2.4 & 0.6 & 0.3603 & NS \\
\hline 27. Is/NL & -0.8 & 4.9 & -2.1 & 4.7 & -1.3 & 0.4035 & NS \\
\hline 28. Ii/ML & 0.5 & 2.6 & 1.3 & 7.4 & 0.8 & 0.6296 & NS \\
\hline 29. Interincisal Angle & -0.1 & 6.1 & 1.7 & 11.1 & 1.8 & 0.479 & NS \\
\hline \multicolumn{8}{|l|}{ Condyle/Glenoid Fossa: } \\
\hline 30. Olp-CoC & -0.2 & 1.9 & 1.0 & 1.8 & 1.2 & 0.0227 & * \\
\hline 31. Olp-GFS & -0.1 & 2.5 & 0.9 & 2.0 & 1.0 & 0.0966 & NS \\
\hline 32. Olp-GFA & 0.2 & 1.9 & 1.1 & 1.8 & 0.9 & 0.1134 & NS \\
\hline 33. Olp-GFP & 0.0 & 2.5 & 1.3 & 2.6 & 1.3 & 0.1006 & NS \\
\hline 34. Ols-CoC & 1.4 & 1.7 & 1.4 & 1.6 & 0.0 & 0.9719 & NS \\
\hline 35. Ols-GFS & 1.0 & 1.6 & 1.0 & 1.8 & 0.0 & 0.9435 & NS \\
\hline 36. Ols-GFA & 1.0 & 1.4 & 0.7 & 1.5 & -0.3 & 0.5025 & NS \\
\hline 37. Ols-GFP & 0.7 & 1.5 & 0.3 & 1.3 & -0.4 & 0.4171 & NS \\
\hline
\end{tabular}


Table 21. Comparison of treated vs. control in male subjects at T3-T1

\begin{tabular}{|c|c|c|c|c|c|c|c|}
\hline \multirow[b]{3}{*}{ Variable } & \multicolumn{7}{|c|}{ SUBJECTS } \\
\hline & \multicolumn{2}{|c|}{$\begin{array}{c}\text { Control } \\
\text { (t3-t1) }\end{array}$} & \multicolumn{2}{|c|}{$\begin{array}{l}\text { Treated } \\
\text { (T3-T1) }\end{array}$} & \multirow[b]{2}{*}{ Diff } & \multirow[b]{2}{*}{$p$ value } & \multirow[b]{2}{*}{ Sig } \\
\hline & Mean & S.D. & Mean & S.D. & & & \\
\hline Age & 22.4 & 3.8 & 19.7 & 2.4 & -2.7 & 0.1418 & NS \\
\hline \multicolumn{8}{|l|}{ Sagittal: } \\
\hline 1. Olp-A pt. & 1.7 & 0.5 & 1.5 & 1.9 & -0.2 & 0.7745 & NS \\
\hline 2. Olp-Pg & 1.3 & 4.1 & 3.3 & 3.0 & 2.0 & 0.3478 & NS \\
\hline 3. Olp-Co & 0.4 & 2.3 & -0.1 & 1.8 & -0.5 & 0.5958 & NS \\
\hline 4. Co-A pt. & 2.1 & 2.5 & 0.2 & 4.0 & -1.9 & 0.3108 & NS \\
\hline 5. Co-Gn & 4.2 & 2.3 & 5.2 & 2.4 & 1.0 & 0.4326 & NS \\
\hline 6. Co-Gn minus Co-A pt. & 2.0 & 2.7 & 3.6 & 3.2 & 1.6 & 0.3288 & NS \\
\hline 7. Wits & -0.2 & 1.4 & -2.7 & 2.7 & -2.5 & 0.0551 & NS \\
\hline 8. Is-Olp & 3.8 & 1.6 & -0.7 & 2.3 & -4.5 & 0.0013 & 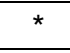 \\
\hline 9. li-Olp & 2.9 & 2.2 & 3.8 & 2.2 & 0.9 & 0.4787 & NS \\
\hline 10. Overjet & 0.9 & 1.4 & -4.5 & 1.7 & -5.4 & 0.0001 & 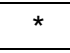 \\
\hline 11. Ms-Olp & 2.7 & 2.0 & 0.2 & 1.8 & -2.5 & 0.0326 & * \\
\hline 12. Mi-Olp & 2.8 & 2.6 & 4.7 & 2.2 & 1.9 & 0.1773 & NS \\
\hline 13. Molar Relationship & -0.1 & 1.7 & -4.5 & 2.1 & -4.4 & 0.0013 & * \\
\hline \multicolumn{8}{|l|}{ Vertical: } \\
\hline 14. OLs-A pt. & 1.4 & 0.8 & 2.9 & 0.7 & 1.5 & 0.0047 & * \\
\hline 15. ANS-Me & 2.4 & 1.6 & 2.6 & 0.9 & 0.2 & 0.8173 & NS \\
\hline 16. Is-NL & 2.1 & 2.3 & 0.7 & 2.3 & -1.4 & 0.2937 & NS \\
\hline 17. Ii-ML & 1.8 & 1.1 & -0.3 & 1.8 & -2.1 & 0.0256 & * \\
\hline 18. Overbite & 1.0 & 1.7 & -2.0 & 1.9 & -3.0 & 0.0087 & * \\
\hline 19. Msc-NL & 1.4 & 2.2 & 0.7 & 0.9 & -0.7 & 0.4904 & NS \\
\hline 20. Mic-ML & 1.5 & 0.8 & 2.1 & 0.9 & 0.6 & 0.2505 & NS \\
\hline \multicolumn{8}{|l|}{ Angular: } \\
\hline 21. SNA & -0.3 & 0.9 & -0.5 & 2.1 & -0.2 & 0.8762 & NS \\
\hline 22. SNB & 0.0 & 0.9 & 1.2 & 1.7 & 1.2 & 0.1089 & NS \\
\hline 23. ANB & -0.2 & 1.0 & -1.7 & 2.7 & -1.5 & 0.2207 & NS \\
\hline 24. SNL-NL & -1.7 & 2.1 & 0.5 & 1.1 & 2.2 & 0.0304 & \\
\hline 25. SNL-ML & -0.2 & 1.1 & 0.0 & 1.2 & 0.2 & 0.5917 & NS \\
\hline 26. SNL-OL & -0.2 & 1.7 & 1.2 & 2.6 & 1.4 & 0.2310 & NS \\
\hline 27. Is/NL & 1.1 & 4.5 & -4.9 & 2.2 & -6.0 & 0.0081 & \\
\hline 28. $\mathrm{li} / \mathrm{ML}$ & 1.0 & 2.6 & 2.2 & 10.4 & 1.2 & 0.7698 & NS \\
\hline 29. Interincisal Angle & -4.0 & 4.8 & 3.5 & 10.7 & 7.5 & 0.1136 & NS \\
\hline \multicolumn{8}{|l|}{ Condyle/Glenoid Fossa: } \\
\hline 30. Olp-CoC & -0.4 & 1.9 & 0.6 & 1.9 & 1.0 & 0.2935 & NS \\
\hline 31. Olp-GFS & 0.1 & 2.5 & 0.7 & 1.6 & 0.6 & 0.5932 & NS \\
\hline 32. Olp-GFA & 0.2 & 1.9 & 0.8 & 1.8 & 0.6 & 0.5992 & NS \\
\hline 33. Olp-GFP & 0.4 & 2.8 & 0.8 & 2.5 & 0.4 & 0.8194 & NS \\
\hline 34. Ols-CoC & 1.1 & 1.4 & 0.8 & 1.4 & -0.3 & 0.7053 & NS \\
\hline 35. Ols-GFS & 0.9 & 1.6 & 0.0 & 1.8 & -0.9 & 0.3843 & NS \\
\hline 36. Ols-GFA & 0.8 & 1.5 & 0.0 & 1.3 & -0.8 & 0.2660 & NS \\
\hline 37. Ols-GFP & 0.2 & 1.8 & -0.4 & 1.0 & -0.6 & 0.3743 & NS \\
\hline
\end{tabular}


Table 22. Comparison of treated vs. control in female subjects at T3-T1

\begin{tabular}{|c|c|c|c|c|c|c|c|}
\hline \multicolumn{8}{|c|}{ FEMALE SUBJECTS } \\
\hline \multirow[b]{2}{*}{ Variable } & \multicolumn{2}{|c|}{$\begin{array}{c}\text { Control } \\
(\mathrm{t} 3-\mathrm{t} 1)\end{array}$} & \multicolumn{2}{|c|}{$\begin{array}{l}\text { Treated } \\
\text { (T3-T1) }\end{array}$} & \multirow[b]{2}{*}{ Diff } & \multirow[b]{2}{*}{$p$ value } & \multirow[b]{2}{*}{ Sig } \\
\hline & Mean & S.D. & Mean & S.D. & & & \\
\hline Age & 23.4 & 8.2 & 22.1 & 8.5 & -1.3 & 0.6668 & NS \\
\hline \multicolumn{8}{|l|}{ Sagittal: } \\
\hline 1. Olp-A pt. & 2.1 & 1.0 & 1.0 & 1.9 & -1.1 & 0.0803 & NS \\
\hline 2. Olp-Pg & 3.5 & 1.6 & 3.4 & 2.2 & -0.1 & 0.8811 & NS \\
\hline 3. Olp-Co & 0.3 & 2.0 & -0.6 & 1.9 & -0.9 & 0.1534 & NS \\
\hline 4. Co-A pt. & 2.4 & 2.6 & 0.4 & 2.5 & -2.0 & 0.0375 & * \\
\hline 5. Co-Gn & 4.2 & 3.0 & 3.5 & 2.4 & -0.7 & 0.5310 & NS \\
\hline 6. Co-Gn minus Co-A pt. & 1.7 & 1.5 & 3.1 & 3.3 & 1.4 & 0.1513 & NS \\
\hline 7. Wits & -0.6 & 1.0 & -2.0 & 2.4 & -1.4 & 0.0511 & NS \\
\hline 8. Is-Olp & 3.6 & 1.7 & 1.8 & 3.5 & -1.8 & 0.0848 & NS \\
\hline 9. li-Olp & 3.2 & 1.5 & 3.4 & 2.9 & 0.2 & 0.7904 & NS \\
\hline 10. Overjet & 0.4 & 1.6 & -1.6 & 2.6 & -2.0 & 0.0160 & * \\
\hline 11. Ms-Olp & 3.3 & 1.5 & 1.3 & 2.0 & -2.0 & 0.0039 & * \\
\hline 12. Mi-Olp & 3.5 & 1.5 & 4.3 & 1.9 & 0.8 & 0.2161 & NS \\
\hline 13. Molar Relationship & -0.1 & 0.7 & -2.9 & 2.2 & -2.8 & 0.0001 & * \\
\hline \multicolumn{8}{|l|}{ Vertical: } \\
\hline 14. OLs-A pt. & 1.7 & 1.4 & 2.0 & 1.5 & 0.3 & 0.6332 & NS \\
\hline 15. ANS-Me & 1.7 & 0.3 & 1.9 & 0.3 & 0.2 & 0.7627 & NS \\
\hline 16. Is-NL & 2.3 & 2.4 & 2.3 & 3.0 & 0.0 & 0.9703 & NS \\
\hline 17. Ii-ML & 1.1 & 0.8 & 1.2 & 2.3 & 0.1 & 0.8463 & NS \\
\hline 18. Overbite & 1.6 & 2.8 & 0.7 & 3.4 & -0.9 & 0.4504 & NS \\
\hline 19. Msc-NL & 1.9 & 1.6 & 0.5 & 1.3 & -1.4 & 0.0184 & * \\
\hline 20. Mic-ML & 1.1 & 1.7 & 0.9 & 1.3 & -0.2 & 0.6812 & NS \\
\hline \multicolumn{8}{|l|}{ Angular: } \\
\hline 21. SNA & 0.4 & 1.2 & -0.3 & 2.8 & -0.7 & 0.3438 & NS \\
\hline 22. SNB & 0.8 & 1.1 & 1.5 & 2.0 & 0.7 & 0.2319 & NS \\
\hline 23. ANB & -0.3 & 0.8 & -1.8 & 2.2 & -1.5 & 0.0204 & * \\
\hline 24. SNL-NL & -0.7 & 1.9 & -1.2 & 2.0 & -0.5 & 0.5241 & NS \\
\hline 25. SNL-ML & -0.8 & 1.5 & -0.2 & 2.2 & 0.6 & 0.4238 & NS \\
\hline 26. SNL-OL & -0.5 & 2.3 & -0.2 & 2.2 & 0.3 & 0.7827 & NS \\
\hline 27. Is/NL & -1.8 & 4.9 & -0.8 & 5.0 & 1.0 & 0.5756 & NS \\
\hline 28. li/ML & 0.3 & 2.6 & 0.9 & 6.0 & 0.6 & 0.7124 & NS \\
\hline 29. Interincisal Angle & 1.6 & 5.9 & 0.9 & 11.5 & -0.7 & 0.8363 & NS \\
\hline \multicolumn{8}{|l|}{ Condyle/Glenoid Fossa: } \\
\hline 30. Olp-CoC & -0.2 & 2.0 & 1.2 & 1.8 & 1.4 & 0.0483 & * \\
\hline 31. Olp-GFS & -0.3 & 2.5 & 1.1 & 2.2 & 1.4 & 0.1171 & NS \\
\hline 32. Olp-GFA & 0.2 & 2.0 & 1.3 & 1.8 & 1.1 & 0.1340 & NS \\
\hline 33. OIp-GFP & -0.1 & 2.5 & 1.6 & 2.7 & 1.7 & 0.0736 & NS \\
\hline 34. Ols-CoC & 1.5 & 1.8 & 1.7 & 1.6 & 0.2 & 0.8646 & NS \\
\hline 35. Ols-GFS & 1.1 & 1.7 & 1.4 & 1.7 & 0.3 & 0.5918 & NS \\
\hline 36. Ols-GFA & 1.1 & 1.4 & 1.1 & 1.4 & 0.0 & 0.9732 & NS \\
\hline 37. Ols-GFP & 0.9 & 1.4 & 0.7 & 1.2 & -0.2 & 0.7327 & NS \\
\hline
\end{tabular}




\section{Overjet and Molar Relationship Correction-Treatment Group (T3-}

T1)

The amount of skeletal and dental contribution to the overjet and molar relationship correction in the treatment group at T3-T1 was calculated using the formula in Table 11. The amount of overjet correction in the treatment group was $2.5 \mathrm{~mm} .2 .2$ $\mathrm{mm}(88.0 \%)$ of the correction was due to skeletal change. $0.3 \mathrm{~mm}(12.0 \%)$ of the correction was due to dental change. The amount of molar relationship correction was $3.5 \mathrm{~mm} .2 .2 \mathrm{~mm}(62.9 \%)$ of the correction was skeletal in nature and $1.3 \mathrm{~mm}(37.1 \%)$ of the correction was dental in nature. Calculations are shown for the overjet and molar relationship correction on the following pages. In addition, diagrams are provided to illustrate the anterior or posterior movement of the maxillary base, mandibular base, maxillary incisors, mandibular incisors, maxillary molars, and mandibular molars (Figures 17 and 18). A pitchfork analysis describing the skeletal and dental contributions to overjet and molar relationship correction is shown in Figure 19. 


\begin{tabular}{|cccc|}
\hline Overjet Correction: & & Molar relationship: & \\
\hline Skeletal Contribution: & 1.2 & Skeletal Contribution: & 1.2 \\
1) Maxilla & 3.4 & 1) Maxilla & 3.4 \\
2) Mandible & & 2) Mandible & \\
Dental Contribution: & -0.2 & Dental Contribution: & -0.3 \\
3) Mx incisor & 0.1 & 3) Mx molar & 1.0 \\
4) Md incisor & & 4) Md molar & \\
\hline
\end{tabular}

Overjet Correction $=$ Maxilla + Mx incisor - Mandible - Md incisor

Overjet Correction $=1.2+(-0.2)-3.4-0.1=-2.5 \mathrm{~mm}$

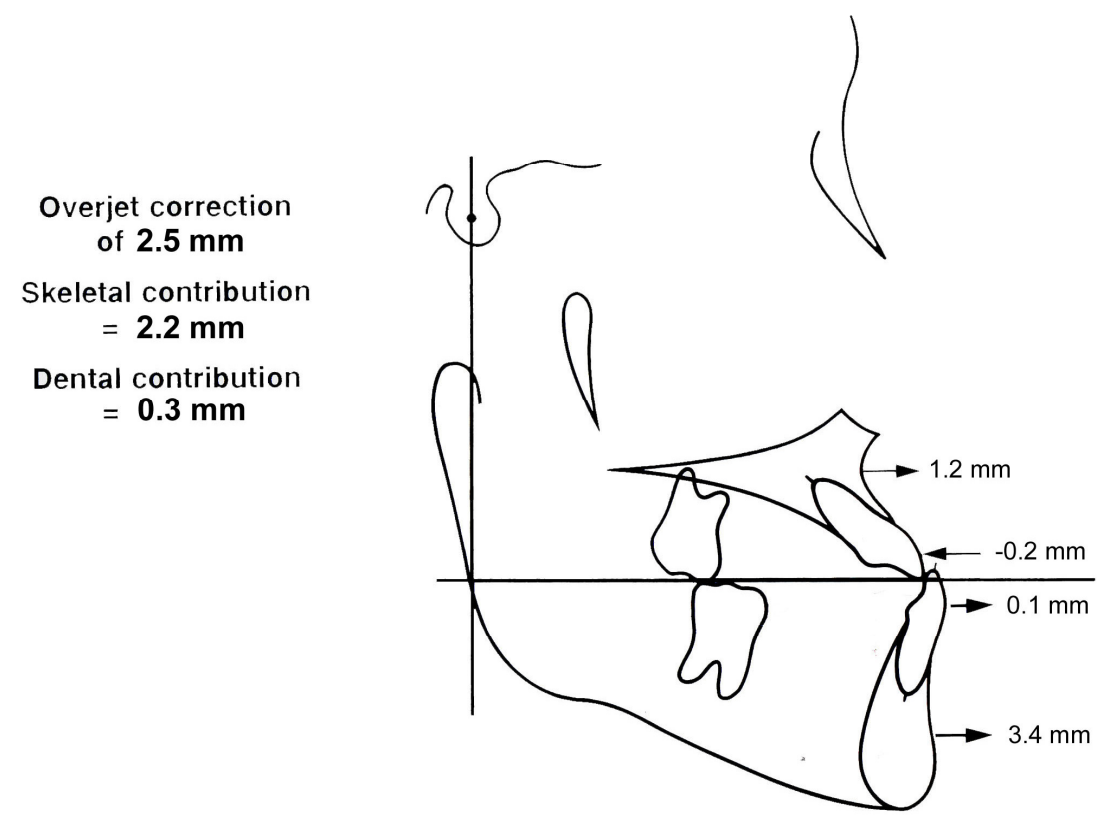

Figure 17. Components of overjet correction (T3-T1) 
Molar Relationship Correction $=$ Maxilla + Mx molar - Mandible - Md molar

Molar Relationship Correction $=1.2+(-0.3)-3.4-1.0=-3.5 \mathrm{~mm}$

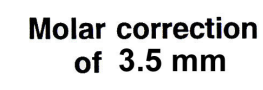

Skeletal contribution

$=2.2 \mathrm{~mm}$

Dental contribution

$=1.3 \mathrm{~mm}$

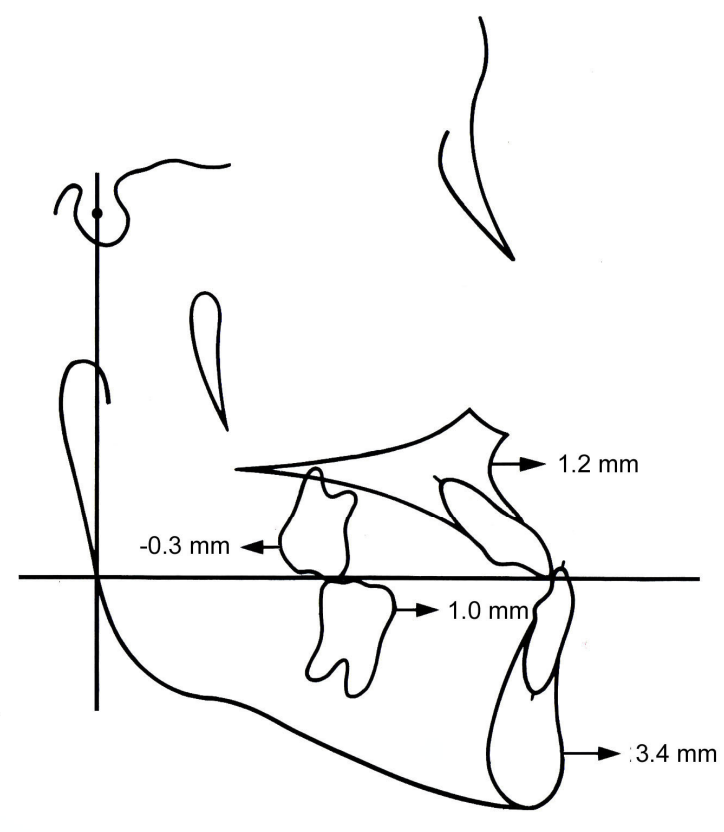

Figure 18. Components of molar relationship correction (T3-T1)

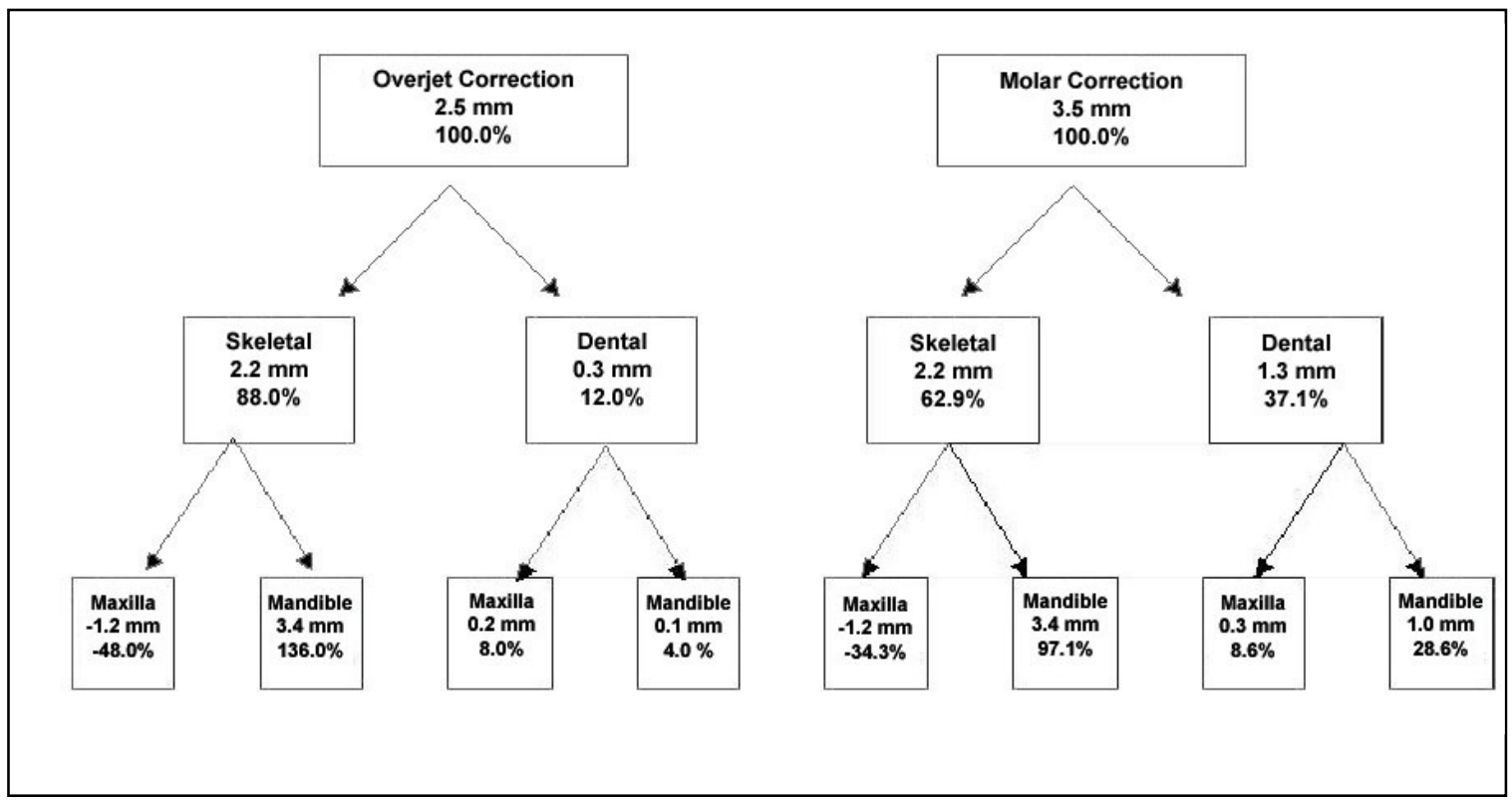

Figure 19. Pitchfork analysis of overjet and molar corrections (T3-T1) 


\section{Net Overjet and Molar Relationship Correction-Tx vs. Control Group (T3-T1)}

The amount of skeletal and dental contribution to the net overjet and net molar relationship correction in the treatment group vs. the control group at T3-T1 was calculated using the formulas in Table 11. The amount of net overjet correction in the treatment group relative to the control group was $3.1 \mathrm{~mm} .1 .3 \mathrm{~mm}(41.9 \%)$ of the correction was due to skeletal movement. $1.8 \mathrm{~mm}(58.1 \%)$ of the correction was due to dental movement. The amount of net molar relationship correction was $3.3 \mathrm{~mm} .1 .3 \mathrm{~mm}$ $(39.4 \%)$ of the correction was skeletal in nature and $2.0 \mathrm{~mm}(60.6 \%)$ of the correction was dental in nature. Calculations are shown for the net overjet and net molar relationship correction on the following pages. In addition, diagrams are provided to illustrate the net anterior or posterior movement of the maxillary base, mandibular base, maxillary incisors, mandibular incisors, maxillary molars, and mandibular molars (Figures 20 and 21). A pitchfork analysis describing the net skeletal and dental contributions to overjet and molar relationship correction is shown in Figure 22. 


\begin{tabular}{|cccc|}
\hline Net Overjet Correction: & & Net Molar relationship: & \\
\hline Skeletal Contribution: & -0.7 & Skeletal Contribution: & -0.7 \\
1) Maxilla & 0.6 & 1) Maxilla & 0.6 \\
2) Mandible & & 2) Mandible & \\
Dental Contribution: & -2.0 & Dental Contribution: & -1.5 \\
3) Mx incisor & -0.2 & 3) Mx molar & 0.5 \\
4) Md incisor & & 4) Md molar & \\
\hline
\end{tabular}

Net Overjet Correction $=$ Maxilla + Mx incisor - Mandible - Md incisor

Net Overjet Correction $=(-0.7)+(-2.0)-0.6-(-0.2)=-3.1 \mathrm{~mm}$

\section{Overjet correction \\ of $3.1 \mathrm{~mm}$}

Skeletal contribution

$=1.3 \mathrm{~mm}$

Dental contribution

$=1.8 \mathrm{~mm}$

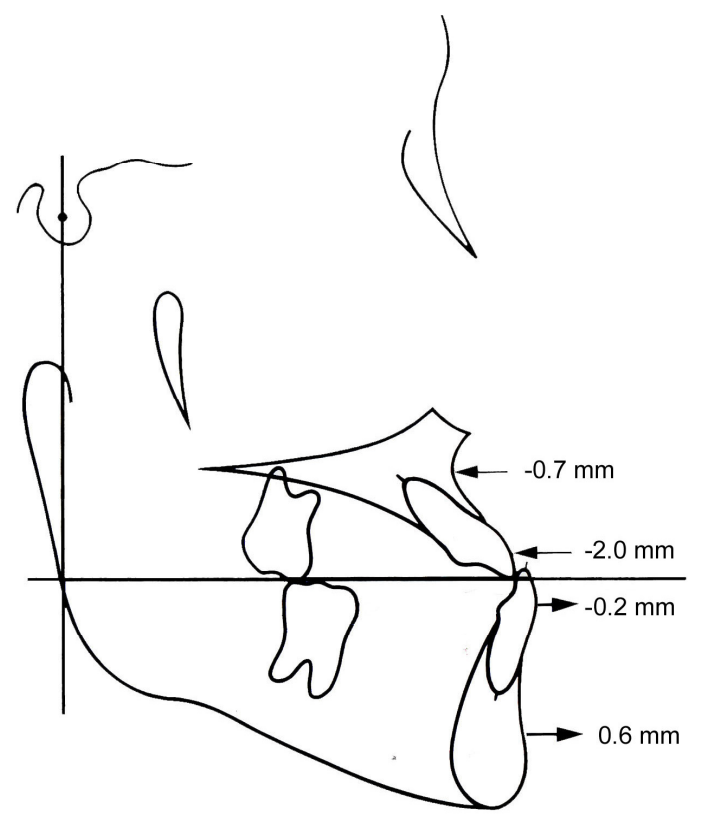

Figure 20. Components of net overjet correction (T3-T1) 
Net Molar Relationship Correction $=$ Maxilla + Mx molar - Mandible - Md molar

Net Molar Relationship Correction $=(-0.7)+(-1.5)-0.6-0.5=-3.3 \mathrm{~mm}$
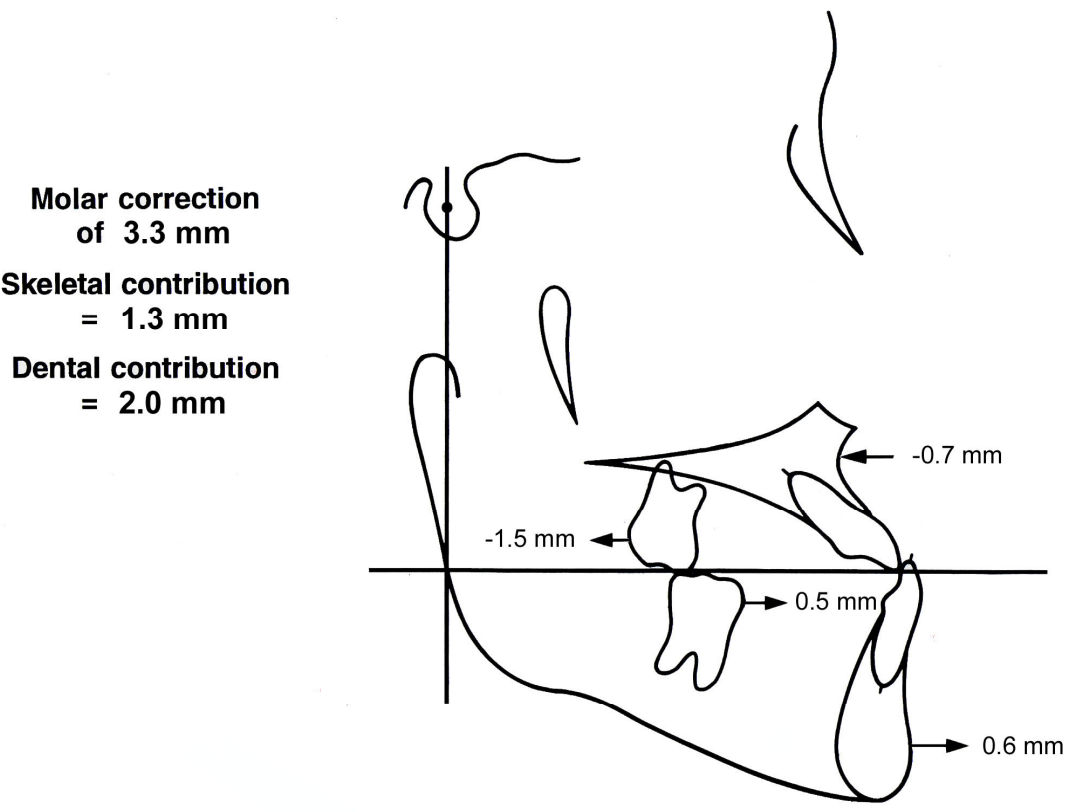

Figure 21. Components of net molar correction (T3-T1)

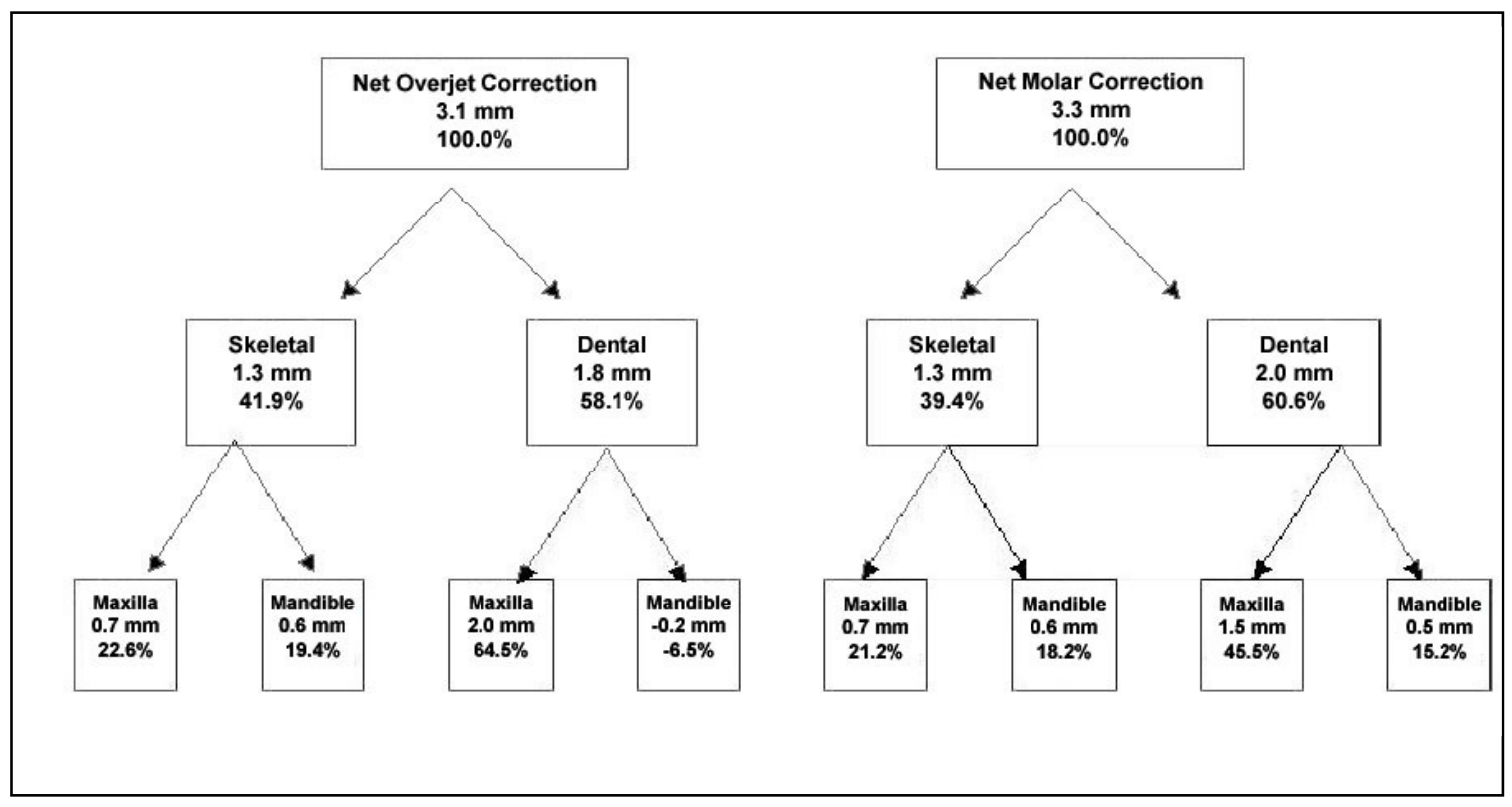

Figure 22. Pitchfork anaylsis of net overjet and molar correction (T2-T1) 


\section{Comparison of T4-T1 (Residual Phase I Treatment Effects)}

Of the 37 variables investigated, 13 showed statistically significant differences

between the treatment group and control group in pooled subjects in the time period T4T1 (Table 23). Seven of the sagittal variables showed significant differences, however, only one of each of the vertical and angular variables had significant differerences between the treatment and control groups. Four condyle/fossa variables showed significant differences between the treatment and control groups. Significance differences in variables are apparent for male subjects only and female subjects only and are reported in Tables 24 and 25, respectively. Only data from pooled subjects is reported here.

Sagittal differences: The seven sagittal variables that showed a significant difference between the treatment and control groups at T4-T1 were OLp-Co, Co-A pt., Co-Gn, Is-OLp, Overjet, Ms-OLp, and molar relationship. The position of the condyle (OLp-Co) moved anteriorly $1.6 \mathrm{~mm}$ in the treatment group relative to the control group. Effective maxillary length (Co-A pt.) and mandibular length (Co-Gn) showed a $-3.0 \mathrm{~mm}$ and a $-2.6 \mathrm{~mm}$ difference from the control group, respectively. The position of the maxillary incisor (Is-OLp) in the treatment group moved forwards $5.1 \mathrm{~mm}$ while the control group moved forwards $7.2 \mathrm{~mm}$, a net difference of $2.1 \mathrm{~mm}$ in a posterior direction. The maxillary molars (Ms-OLp) moved forward $4.4 \mathrm{~mm}$ in the treatment group and $7.4 \mathrm{~mm}$ anteriorly in the control group, a net difference of $-3.0 \mathrm{~mm}$ in the treatment group. Overjet and molar relationship correction will be discussed in a later section. 
Table 23. Comparison of treated vs. control in pooled subjects at T4-T1

\begin{tabular}{|c|c|c|c|c|c|c|c|}
\hline \multicolumn{8}{|c|}{ POOLED (MALES AND FEMALES) } \\
\hline \multirow[b]{2}{*}{ Variable } & \multicolumn{2}{|c|}{$\begin{array}{c}\text { Control } \\
(\mathrm{t} 4-\mathrm{t} 1)\end{array}$} & \multicolumn{2}{|c|}{$\begin{array}{l}\text { Treated } \\
\text { (T4-T1) }\end{array}$} & \multirow[b]{2}{*}{ Diff } & \multirow[b]{2}{*}{$p$ value } & \multirow[b]{2}{*}{ Sig } \\
\hline & Mean & S.D. & Mean & S.D. & & & \\
\hline Age & 55.4 & 15.1 & 53.7 & 15.2 & -1.6 & 0.7219 & NS \\
\hline \multicolumn{8}{|l|}{ Sagittal: } \\
\hline 1. Olp-A pt. & 4.5 & 1.7 & 3.6 & 2.7 & -0.9 & 0.1916 & NS \\
\hline 2. Olp-Pg & 6.9 & 2.8 & 6.4 & 3.5 & -0.5 & 0.5671 & NS \\
\hline 3. Olp-Co & 1.7 & 2.4 & 0.1 & 2.5 & -1.6 & 0.0372 & * \\
\hline 4. Co-A pt. & 6.4 & 3.0 & 3.4 & 4.4 & -3.0 & 0.0125 & * \\
\hline 5. Co-Gn & 10.6 & 3.1 & 8.0 & 4.4 & -2.5 & 0.0327 & * \\
\hline 6. Co-Gn minus Co-A pt. & 4.2 & 2.4 & 4.3 & 3.5 & 0.0 & 0.9827 & NS \\
\hline 7. Wits & -0.8 & 1.3 & -0.8 & 2.0 & 0.0 & 0.9598 & NS \\
\hline 8. Is-Olp & 7.2 & 2.3 & 5.1 & 3.8 & -2.1 & 0.0332 & * \\
\hline 9. li-Olp & 6.5 & 2.0 & 6.9 & 3.7 & 0.4 & 0.6815 & NS \\
\hline 10. Overjet & 0.6 & 1.7 & -1.8 & 2.2 & -2.4 & 0.0002 & * \\
\hline 11. Ms-Olp & 7.4 & 2.5 & 4.4 & 2.7 & -3.0 & 0.0004 & * \\
\hline 12. Mi-Olp & 7.7 & 2.8 & 7.1 & 3.0 & -0.6 & 0.5011 & NS \\
\hline 13. Molar Relationship & -0.4 & 1.1 & -2.7 & 1.8 & -2.3 & 0.0001 & * \\
\hline \multicolumn{8}{|l|}{ Vertical: } \\
\hline 14. OLs-A pt. & 3.4 & 1.7 & 4.1 & 1.5 & 0.7 & 0.1590 & NS \\
\hline 15. ANS-Me & 5.3 & 2.3 & 3.6 & 3.2 & -1.7 & 0.0505 & NS \\
\hline 16. Is-NL & 3.5 & 2.7 & 2.6 & 3.0 & -0.9 & 0.2604 & NS \\
\hline 17. li-ML & 3.3 & 1.8 & 2.6 & 2.0 & -0.7 & 0.2338 & NS \\
\hline 18. Overbite & 1.5 & 2.9 & 0.6 & 3.2 & -0.9 & 0.3300 & NS \\
\hline 19. Msc-NL & 3.7 & 2.2 & 2.3 & 2.0 & -1.4 & 0.0264 & ${ }^{*}$ \\
\hline 20. Mic-ML & 2.6 & 1.5 & 2.2 & 1.7 & -0.4 & 0.3738 & NS \\
\hline \multicolumn{8}{|l|}{ Angular: } \\
\hline 21. SNA & 0.8 & 1.8 & 0.1 & 3.3 & -0.7 & 0.3883 & NS \\
\hline 22. SNB & 1.4 & 1.5 & 1.7 & 2.6 & 0.3 & 0.5800 & NS \\
\hline 23. ANB & -0.5 & 1.0 & -1.6 & 1.6 & -1.1 & 0.0131 & ${ }^{*}$ \\
\hline 24. SNL-NL & -1.5 & 2.0 & -0.7 & 3.0 & 0.8 & 0.3251 & NS \\
\hline 25. SNL-ML & -1.3 & 2.2 & -1.6 & 2.8 & -0.3 & 0.6326 & NS \\
\hline 26. SNL-OL & -1.4 & 2.2 & -2.5 & 3.3 & -1.1 & 0.2087 & NS \\
\hline 27. Is/NL & -1.1 & 5.6 & 0.6 & 6.1 & 1.7 & 0.6416 & NS \\
\hline 28. li/ML & 1.0 & 3.8 & 4.3 & 7.0 & 3.3 & 0.0596 & NS \\
\hline 29. Interincisal Angle & -0.1 & 6.9 & -2.6 & 11.8 & -2.5 & 0.3908 & NS \\
\hline \multicolumn{8}{|l|}{ Condyle/Glenoid Fossa: } \\
\hline 30. Olp-CoC & -1.5 & 2.3 & 0.3 & 2.1 & 1.8 & 0.0099 & * \\
\hline 31. Olp-GFS & -1.2 & 2.7 & 0.6 & 2.4 & 1.8 & 0.0265 & * \\
\hline 32. Olp-GFA & -0.6 & 2.1 & 0.7 & 2.1 & 1.3 & 0.0471 & * \\
\hline 33. Olp-GFP & -1.2 & 2.6 & 0.7 & 3.4 & 1.9 & 0.0389 & ${ }^{*}$ \\
\hline 34. Ols-CoC & 3.1 & 2.3 & 2.8 & 2.7 & -0.3 & 0.6539 & NS \\
\hline 35. Ols-GFS & 2.4 & 2.1 & 2.2 & 2.4 & -0.2 & 0.8167 & NS \\
\hline 36. Ols-GFA & 2.3 & 1.9 & 2.0 & 2.0 & -0.3 & 0.6848 & NS \\
\hline 37. Ols-GFP & 2.2 & 1.7 & 1.7 & 1.5 & -0.5 & 0.2601 & NS \\
\hline
\end{tabular}


Table 24. Comparison of treated vs. control in male subjects at T4-T1.

\begin{tabular}{|c|c|c|c|c|c|c|c|}
\hline \multirow[b]{3}{*}{ Variable } & \multicolumn{7}{|c|}{ MALE SUBJECTS } \\
\hline & \multicolumn{2}{|c|}{$\begin{array}{c}\text { Control } \\
\text { (t4-t1) }\end{array}$} & \multicolumn{2}{|c|}{$\begin{array}{l}\text { Treated } \\
\text { (T4-T1) }\end{array}$} & \multirow[b]{2}{*}{ Diff } & \multirow[b]{2}{*}{$p$ value } & \multirow[b]{2}{*}{ Sig } \\
\hline & Mean & S.D. & Mean & S.D. & & & \\
\hline Age & 57.1 & 17.3 & 55.1 & 16.9 & -2.0 & 0.8304 & NS \\
\hline \multicolumn{8}{|l|}{ Sagittal: } \\
\hline 1. Olp-A pt. & 5.1 & 2.3 & 5.2 & 2.9 & 0.1 & 0.9682 & NS \\
\hline 2. Olp-Pg & 6.1 & 4.3 & 8.2 & 2.3 & 2.1 & 0.2739 & NS \\
\hline 3. Olp-Co & 0.7 & 2.1 & 1.1 & 2.7 & 0.4 & 0.7552 & NS \\
\hline 4. Co-A pt. & 5.9 & 3.3 & 5.0 & 6.5 & -0.9 & 0.7520 & NS \\
\hline 5. Co-Gn & 10.6 & 3.6 & 10.8 & 5.0 & 0.2 & 0.9194 & NS \\
\hline 6. Co-Gn minus Co-A pt. & 4.7 & 3.1 & 4.5 & 3.1 & -0.2 & 0.9283 & NS \\
\hline 7. Wits & -0.6 & 2.0 & -1.0 & 1.4 & -0.4 & 0.7368 & NS \\
\hline 8. Is-Olp & 7.9 & 3.4 & 5.7 & 2.9 & -2.2 & 0.1963 & NS \\
\hline 9. li-Olp & 7.3 & 2.8 & 9.3 & 2.9 & 2.0 & 0.2136 & NS \\
\hline 10. Overjet & 0.6 & 2.5 & -3.6 & 0.7 & -4.2 & 0.0009 & * \\
\hline 11. Ms-Olp & 7.9 & 3.0 & 5.1 & 2.6 & -2.7 & 0.0840 & NS \\
\hline 12. Mi-Olp & 8.1 & 3.7 & 8.4 & 3.0 & 0.3 & 0.8644 & NS \\
\hline 13. Molar Relationship & -0.1 & 1.7 & -3.3 & 1.6 & -3.2 & 0.0036 & * \\
\hline \multicolumn{8}{|l|}{ Vertical: } \\
\hline 14. OLs-A pt. & 3.7 & 1.7 & 4.2 & 1.7 & 0.5 & 0.5591 & NS \\
\hline 15. ANS-Me & 6.8 & 2.0 & 3.8 & 3.8 & -3.0 & 0.0917 & NS \\
\hline 16. Is-NL & 3.7 & 2.7 & 1.2 & 2.7 & -2.5 & 0.1035 & NS \\
\hline 17. Ii-ML & 4.1 & 2.4 & 1.8 & 0.9 & -2.3 & 0.0373 & * \\
\hline 18. Overbite & 1.0 & 2.7 & -1.4 & 2.4 & -2.4 & 0.0939 & NS \\
\hline 19. Msc-NL & 3.9 & 3.1 & 2.6 & 2.6 & -1.3 & 0.4033 & NS \\
\hline 20. Mic-ML & 3.4 & 1.4 & 3.9 & 1.8 & 0.5 & 0.8472 & NS \\
\hline \multicolumn{8}{|l|}{ Angular: } \\
\hline 21. SNA & 0.8 & 1.5 & 1.7 & 2.6 & 0.9 & 0.4344 & NS \\
\hline 22. SNB & 1.1 & 1.5 & 2.9 & 1.7 & 1.8 & 0.0618 & NS \\
\hline 23. ANB & -0.3 & 1.5 & -1.1 & 1.6 & -0.8 & 0.3169 & NS \\
\hline 24. SNL-NL & -2.0 & 2.0 & 0.4 & 2.1 & 2.4 & 0.0494 & * \\
\hline 25. SNL-ML & -0.8 & 2.8 & -2.9 & 2.0 & -2.1 & 0.1232 & NS \\
\hline 26. SNL-OL & -0.9 & 2.2 & -2.7 & 1.7 & -1.8 & 0.0956 & NS \\
\hline 27. Is/NL & 0.3 & 5.3 & 1.0 & 4.8 & 0.7 & 0.7958 & NS \\
\hline 28. $\mathrm{li} / \mathrm{ML}$ & 0.6 & 5.1 & 7.6 & 8.6 & 7.0 & 0.0848 & NS \\
\hline 29. Interincisal Angle & -2.4 & 6.8 & -5.1 & 9.6 & -2.7 & 0.5433 & NS \\
\hline \multicolumn{8}{|l|}{ Condyle/Glenoid Fossa: } \\
\hline 30. Olp-CoC & -0.5 & 1.9 & -0.3 & 2.2 & 0.2 & 0.8298 & NS \\
\hline 31. Olp-GFS & 0.0 & 2.2 & 0.6 & 1.7 & 0.6 & 0.6003 & NS \\
\hline 32. Olp-GFA & 0.1 & 1.9 & 0.4 & 2.7 & 0.3 & 0.8331 & NS \\
\hline 33. Olp-GFP & 0.1 & 2.5 & 0.2 & 2.3 & 0.1 & 0.9010 & NS \\
\hline 34. Ols-CoC & 3.3 & 2.7 & 2.2 & 3.9 & -1.1 & 0.5553 & NS \\
\hline 35. Ols-GFS & 2.5 & 3.1 & 1.5 & 2.9 & -1.0 & 0.5406 & NS \\
\hline 36. Ols-GFA & 2.5 & 2.7 & 1.1 & 2.4 & -1.4 & 0.3163 & NS \\
\hline 37. Ols-GFP & 2.3 & 2.2 & 0.7 & 1.6 & -1.6 & 0.1468 & NS \\
\hline
\end{tabular}


Table 25. Comparison of treated vs. control group in female subjects at T4-T1.

\begin{tabular}{|c|c|c|c|c|c|c|c|}
\hline \multicolumn{8}{|c|}{ MALE SUBJECTS } \\
\hline \multirow[b]{2}{*}{ Variable } & \multicolumn{2}{|c|}{$\begin{array}{c}\text { Control } \\
\text { (t4-t1) }\end{array}$} & \multicolumn{2}{|c|}{$\begin{array}{l}\text { Treated } \\
\text { (T4-T1) }\end{array}$} & \multirow[b]{2}{*}{ Diff } & \multirow[b]{2}{*}{$\mathrm{p}$ value } & \multirow[b]{2}{*}{$\mathrm{Sic}$} \\
\hline & Mean & S.D. & Mean & S.D. & & & \\
\hline Age & 57.1 & 17.3 & 55.1 & 16.9 & -2.0 & 0.8304 & NS \\
\hline \multicolumn{8}{|l|}{ Sagittal: } \\
\hline 1. Olp-A pt. & 5.1 & 2.3 & 5.2 & 2.9 & 0.1 & 0.9682 & NS \\
\hline 2. Olp-Pg & 6.1 & 4.3 & 8.2 & 2.3 & 2.1 & 0.2739 & NS \\
\hline 3. Olp-Co & 0.7 & 2.1 & 1.1 & 2.7 & 0.4 & 0.7552 & NS \\
\hline 4. Co-A pt. & 5.9 & 3.3 & 5.0 & 6.5 & -0.9 & 0.7520 & NS \\
\hline 5. Co-Gn & 10.6 & 3.6 & 10.8 & 5.0 & 0.2 & 0.9194 & NS \\
\hline 6. Co-Gn minus Co-A pt. & 4.7 & 3.1 & 4.5 & 3.1 & -0.2 & 0.9283 & NS \\
\hline 7. Wits & -0.6 & 2.0 & -1.0 & 1.4 & -0.4 & 0.7368 & NS \\
\hline 8. Is-Olp & 7.9 & 3.4 & 5.7 & 2.9 & -2.2 & 0.1963 & NS \\
\hline 9. li-Olp & 7.3 & 2.8 & 9.3 & 2.9 & 2.0 & 0.2136 & NS \\
\hline 10. Overjet & 0.6 & 2.5 & -3.6 & 0.7 & -4.2 & 0.0009 & * \\
\hline 11. Ms-Olp & 7.9 & 3.0 & 5.1 & 2.6 & -2.7 & 0.0840 & NS \\
\hline 12. Mi-Olp & 8.1 & 3.7 & 8.4 & 3.0 & 0.3 & 0.8644 & NS \\
\hline 13. Molar Relationship & -0.1 & 1.7 & -3.3 & 1.6 & -3.2 & 0.0036 & * \\
\hline \multicolumn{8}{|l|}{ Vertical: } \\
\hline 14. OLs-A pt. & 3.7 & 1.7 & 4.2 & 1.7 & 0.5 & 0.5591 & NS \\
\hline 15. ANS-Me & 6.8 & 2.0 & 3.8 & 3.8 & -3.0 & 0.0917 & NS \\
\hline 16. Is-NL & 3.7 & 2.7 & 1.2 & 2.7 & -2.5 & 0.1035 & NS \\
\hline 17. Ii-ML & 4.1 & 2.4 & 1.8 & 0.9 & -2.3 & 0.0373 & * \\
\hline 18. Overbite & 1.0 & 2.7 & -1.4 & 2.4 & -2.4 & 0.0939 & NS \\
\hline 19. Msc-NL & 3.9 & 3.1 & 2.6 & 2.6 & -1.3 & 0.4033 & NS \\
\hline 20. Mic-ML & 3.4 & 1.4 & 3.9 & 1.8 & 0.5 & 0.8472 & NS \\
\hline \multicolumn{8}{|l|}{ Angular: } \\
\hline 21. SNA & 0.8 & 1.5 & 1.7 & 2.6 & 0.9 & 0.4344 & NS \\
\hline 22. SNB & 1.1 & 1.5 & 2.9 & 1.7 & 1.8 & 0.0618 & NS \\
\hline 23. ANB & -0.3 & 1.5 & -1.1 & 1.6 & -0.8 & 0.3169 & NS \\
\hline 24. SNL-NL & -2.0 & 2.0 & 0.4 & 2.1 & 2.4 & 0.0494 & * \\
\hline 25. SNL-ML & -0.8 & 2.8 & -2.9 & 2.0 & -2.1 & 0.1232 & NS \\
\hline 26. SNL-OL & -0.9 & 2.2 & -2.7 & 1.7 & -1.8 & 0.0956 & NS \\
\hline 27. Is/NL & 0.3 & 5.3 & 1.0 & 4.8 & 0.7 & 0.7958 & NS \\
\hline 28. li/ML & 0.6 & 5.1 & 7.6 & 8.6 & 7.0 & 0.0848 & NS \\
\hline 29. Interincisal Angle & -2.4 & 6.8 & -5.1 & 9.6 & -2.7 & 0.5433 & NS \\
\hline \multicolumn{8}{|l|}{ Condyle/Glenoid Fossa: } \\
\hline 30. Olp-CoC & -0.5 & 1.9 & -0.3 & 2.2 & 0.2 & 0.8298 & NS \\
\hline 31. Olp-GFS & 0.0 & 2.2 & 0.6 & 1.7 & 0.6 & 0.6003 & NS \\
\hline 32. Olp-GFA & 0.1 & 1.9 & 0.4 & 2.7 & 0.3 & 0.8331 & NS \\
\hline 33. Olp-GFP & 0.1 & 2.5 & 0.2 & 2.3 & 0.1 & 0.9010 & NS \\
\hline 34. Ols-CoC & 3.3 & 2.7 & 2.2 & 3.9 & -1.1 & 0.5553 & NS \\
\hline 35. Ols-GFS & 2.5 & 3.1 & 1.5 & 2.9 & -1.0 & 0.5406 & NS \\
\hline 36. Ols-GFA & 2.5 & 2.7 & 1.1 & 2.4 & -1.4 & 0.3163 & NS \\
\hline 37. Ols-GFP & 2.3 & 2.2 & 0.7 & 1.6 & -1.6 & 0.1468 & NS \\
\hline
\end{tabular}




\section{Overjet and Molar Relationship Correction-Treatment Group (T4-}

T1)

The amount of skeletal and dental contribution to the overjet and molar relationship correction in the treatment group at T4-T1 was calculated using the formulas in Table 11. The amount of overjet correction in the treatment group was $1.8 \mathrm{~mm} .2 .8$ $\mathrm{mm}(155.6 \%)$ of the correction was due to skeletal change. $-1.0 \mathrm{~mm}(-55.6 \%)$ of the correction was due to dental change. The amount of molar relationship correction was $2.7 \mathrm{~mm} .2 .8 \mathrm{~mm}(103.7 \%)$ of the correction was skeletal in nature and $-0.1 \mathrm{~mm}(-3.7 \%)$ of the correction was dental in nature. Calculations are shown for the overjet and molar relationship correction on the following pages. In addition, diagrams are provided to illustrate the anterior or posterior movement of the maxillary base, mandibular base, maxillary incisors, mandibular incisors, maxillary molars, and mandibular molars (Figure 23 and 24). A pitchfork analysis describing the skeletal and dental contributions to overjet and molar relationship correction is shown in Figure 25. 


\begin{tabular}{|cccc|}
\hline Overiet Correction: & & Molar relationship: & \\
\hline $\begin{array}{c}\text { Skeletal Contribution: } \\
\text { 1) Maxilla }\end{array}$ & 3.6 & 1) Maxilla & 3.6 \\
2) Mandible & 6.4 & 2) Mandible & 6.4 \\
Dental Contribution: & & Dental Contribution: & \\
3) Mx incisor & 1.5 & 3) Mx molar & 0.8 \\
4) Md incisor & 0.5 & 4) Md molar & 0.7 \\
\hline
\end{tabular}

Overjet Correction $=$ Maxilla + Mx incisor - Mandible - Md incisor

Overjet Correction $=3.6+1.5-6.4-0.5=-1.8 \mathrm{~mm}$

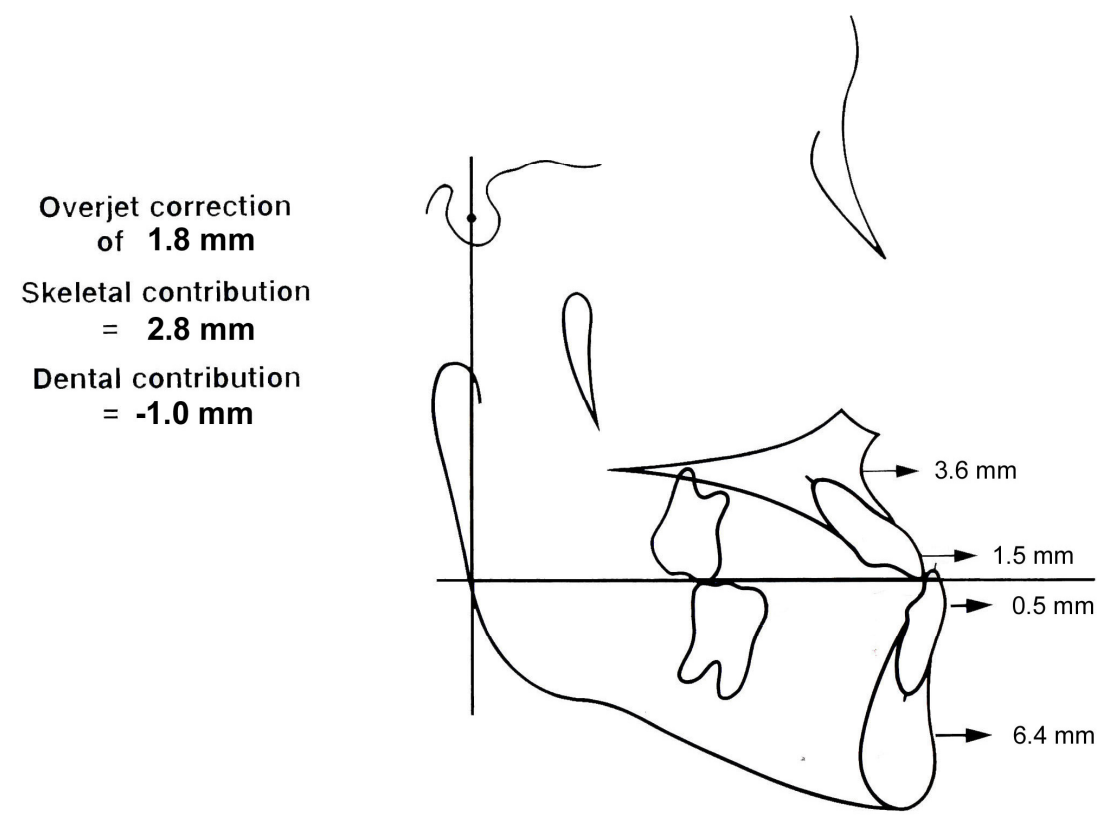

Figure 23. Components of overjet correction (T4-T1) 
Molar Relationship Correction $=$ Maxilla + Mx molar - Mandible - Md molar

Molar Relationship Correction $=3.6+0.8-6.4-0.7=-2.7 \mathrm{~mm}$

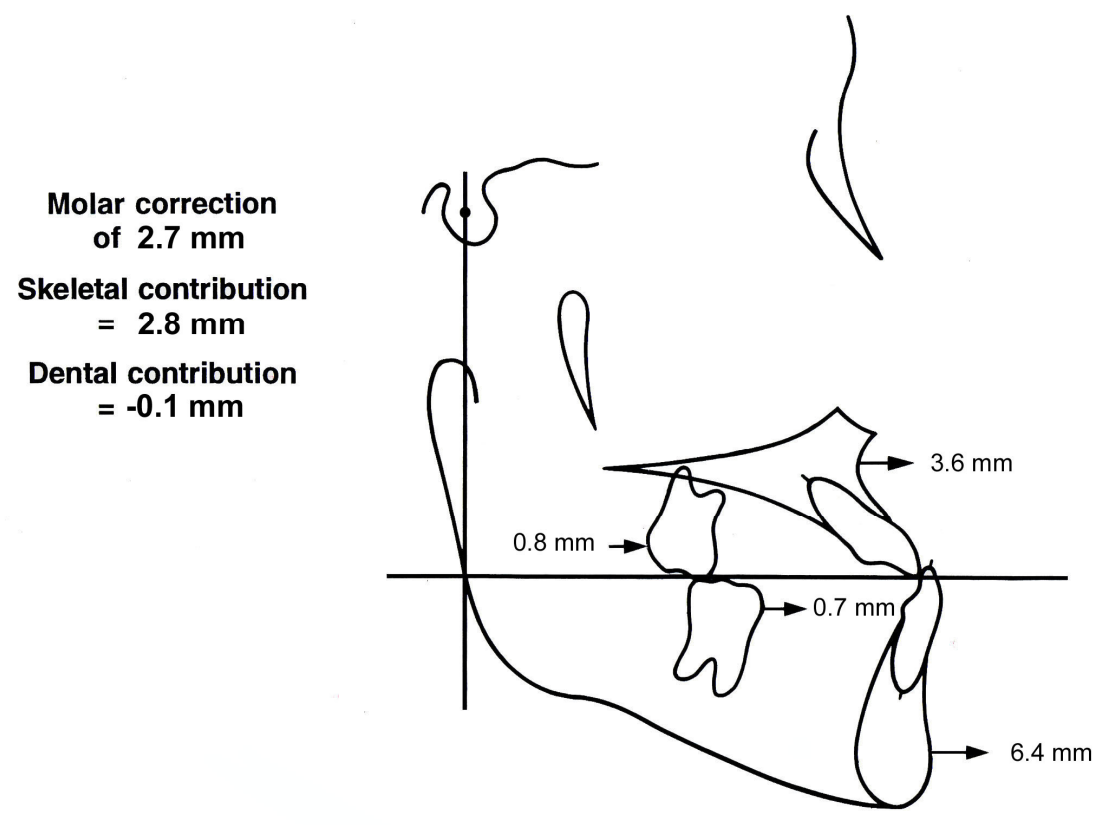

Figure 24. Components of molar relationship correction (T4-T1)

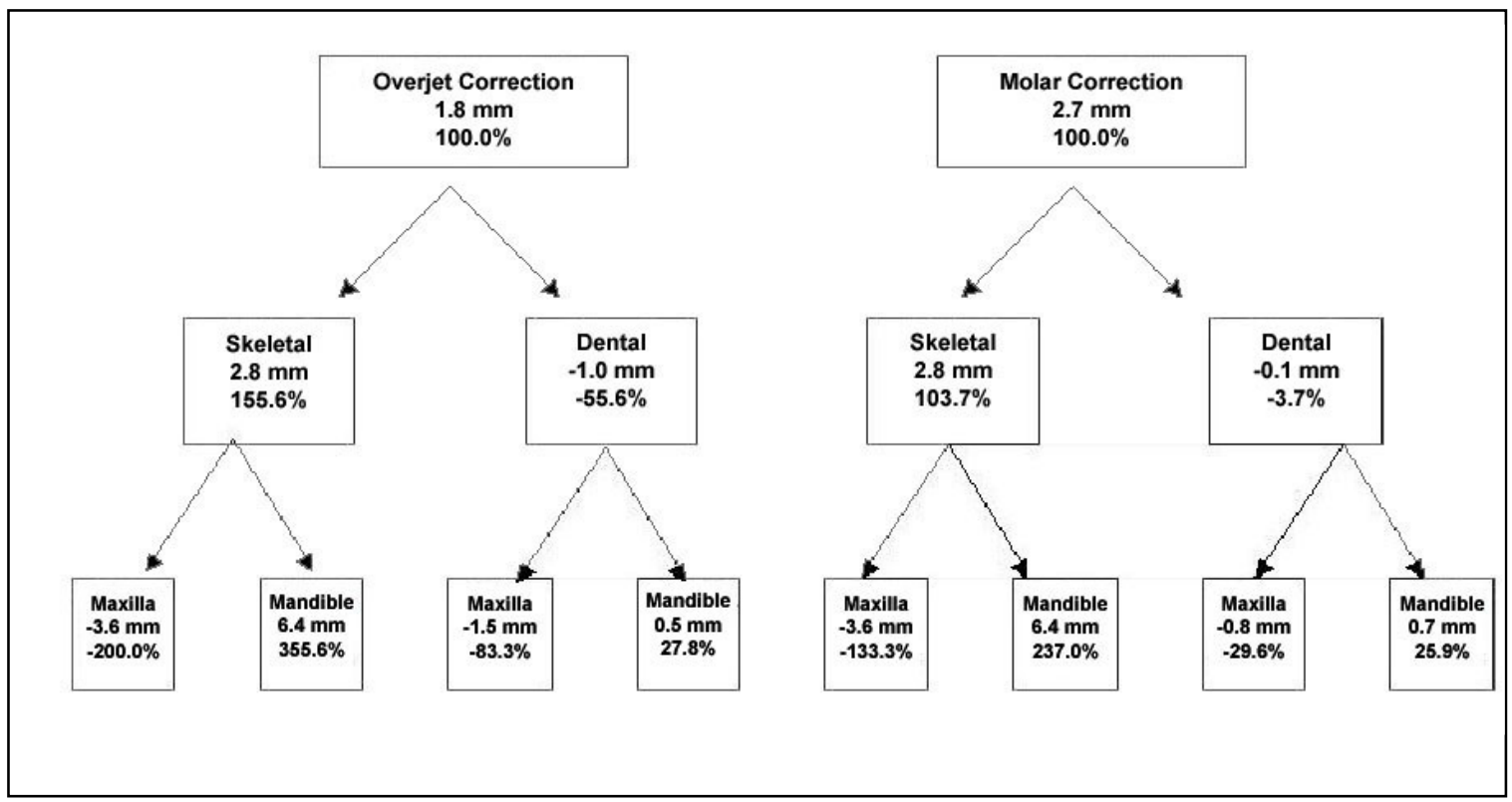

Figure 25. Pitchfork analysis of overjet and molar correction (T4-T1) 


\section{Net Overjet and Molar Relationship Correction-Tx vs. Control Group (T4-T1)}

The amount of skeletal and dental contribution to the net overjet and net molar relationship correction in the treatment group vs. the control group at T4-T1 was calculated using the formulas in Table 11. The amount of net overjet correction in the treatment group relative to the control group was $2.5 \mathrm{~mm} .0 .4 \mathrm{~mm}(16.0 \%)$ of the correction was due to skeletal movement. $2.1 \mathrm{~mm}(84.0 \%)$ of the correction was due to dental movement. The amount of net molar relationship correction was $2.4 \mathrm{~mm}$. $0.4 \mathrm{~mm}$ $(16.7 \%)$ of the correction was skeletal in nature and $2.0 \mathrm{~mm}(83.3 \%)$ of the correction was dental in nature. Calculations are shown for the net overjet and net molar relationship correction on the following pages. In addition, diagrams are provided to illustrate the net anterior or posterior movement of the maxillary base, mandibular base, maxillary incisors, mandibular incisors, maxillary molars, and mandibular molars (Figures 26 and 27). A pitchfork analysis describing the net skeletal and dental contributions to overjet and molar relationship correction is shown in Figure 28. 


\begin{tabular}{|cccc|}
\hline Net Overjet Correction: & & Net Molar relationship: & \\
\hline Skeletal Contribution: & -0.9 & Skeletal Contribution: & -0.9 \\
1) Maxilla & -0.5 & 1) Maxilla & -0.5 \\
2) Mandible & & 2) Mandible & \\
Dental Contribution: & -1.2 & Dental Contribution: & -2.1 \\
3) Mx incisor & 0.9 & 3) Mx molar & -0.1 \\
4) Md incisor & & 4) Md molar & \\
\hline
\end{tabular}

Net Overjet Correction $=$ Maxilla + Mx incisor - Mandible - Md incisor

Net Overjet Correction $=(-0.9)+(-1.2)-(-0.5)-0.9=-2.5 \mathrm{~mm}$
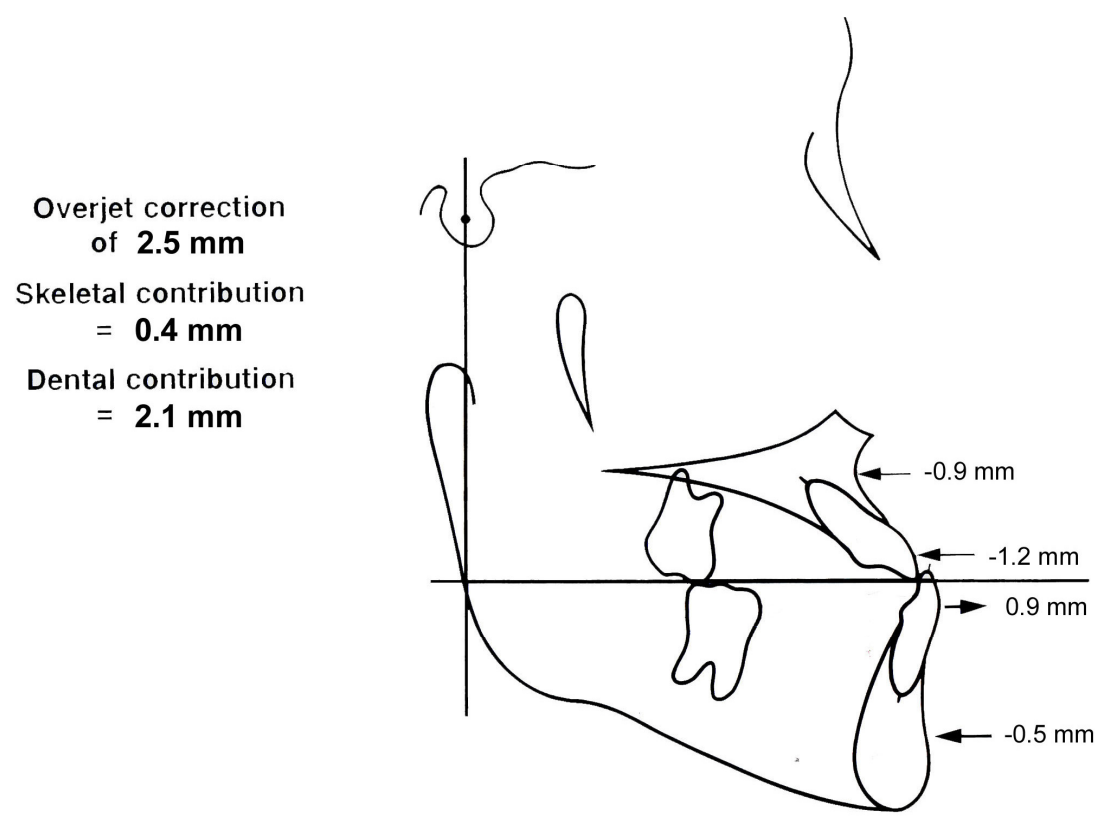

Figure 26. Components of net overjet correction (T4-T1) 
Net Molar Relationship Correction $=$ Maxilla + Mx molar - Mandible - Md molar

Net Molar Relationship Correction $=(-0.9)+(-2.1)-(-0.5)-(-0.1)=-2.4 \mathrm{~mm}$
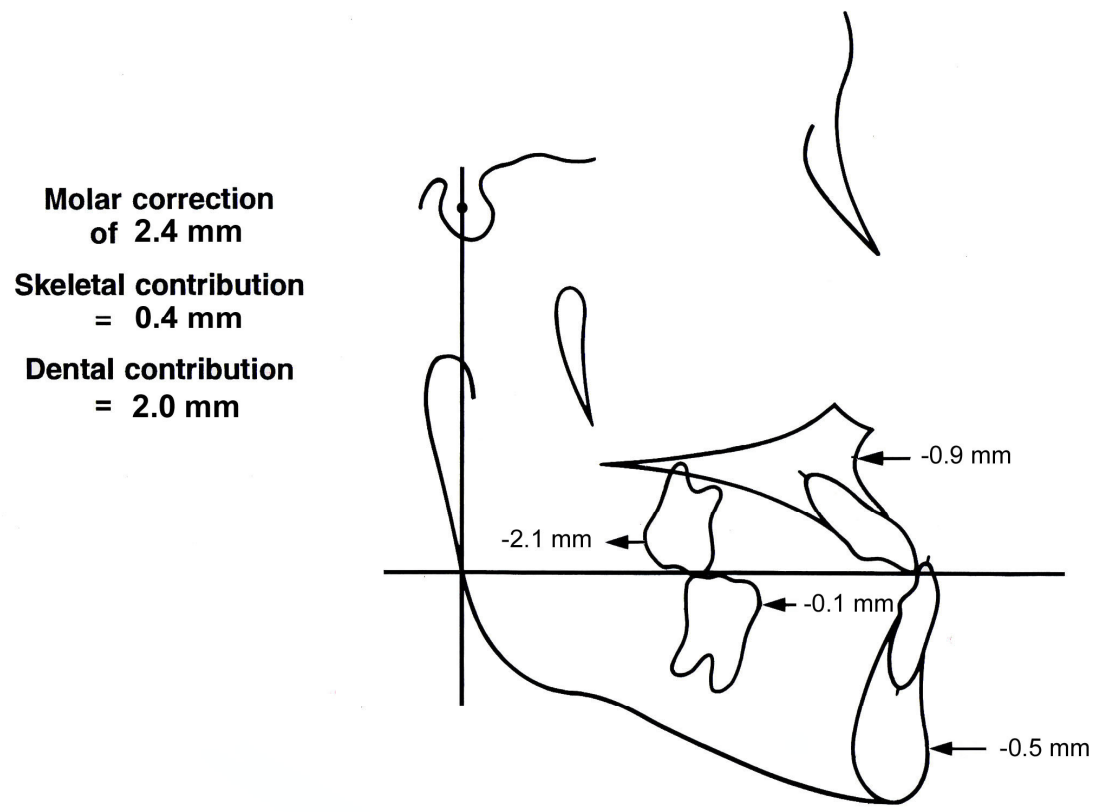

Figure 27. Components of net molar correction (T4-T1)

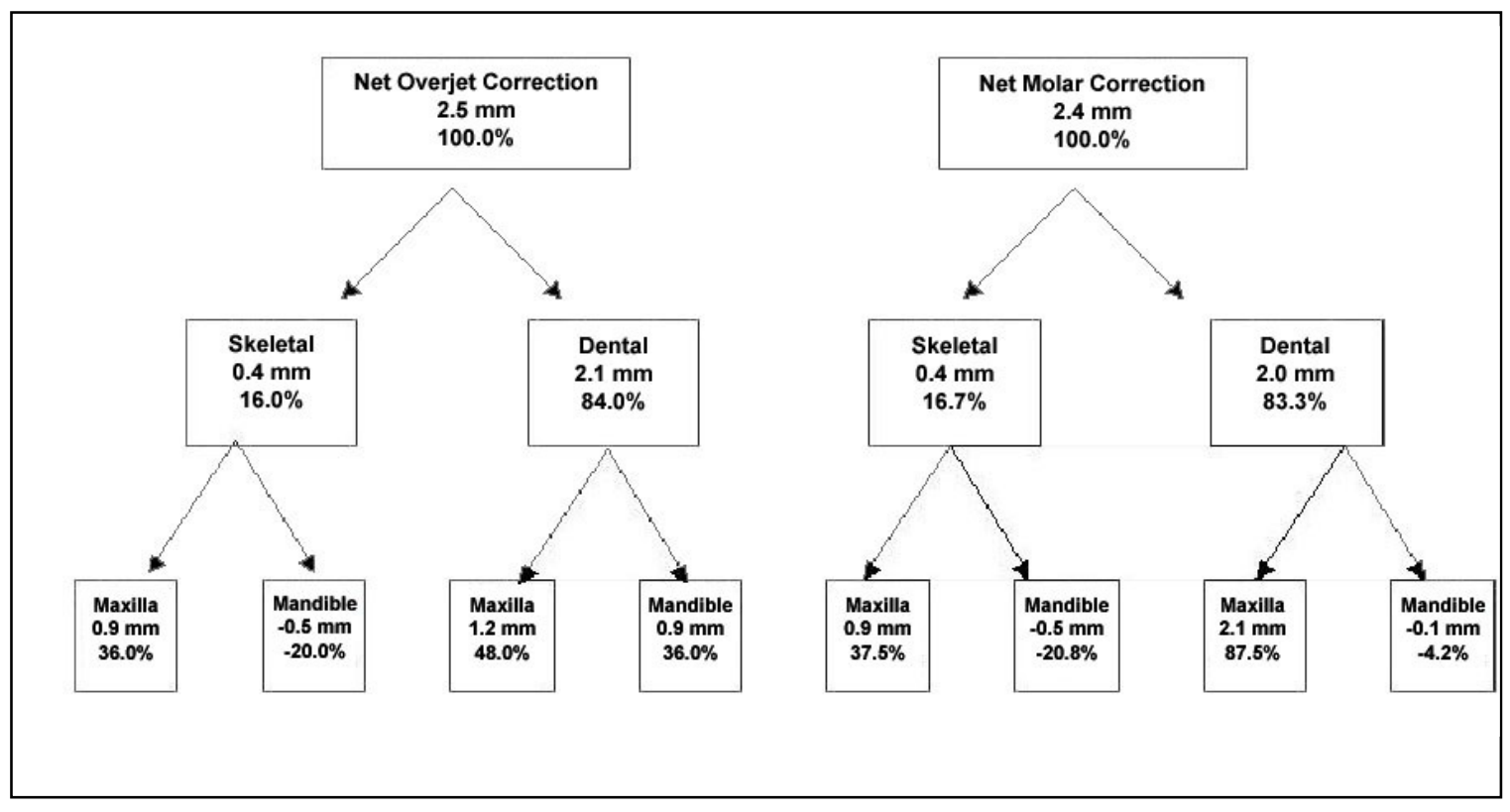

Figure 28. Pitchfork analysis of net overjet and molar correction (T4-T1) 


\section{Comparison of T5-T1 (Combined Phase I and Phase II Treatment Effects)}

Of the 37 variables investigated, 10 showed statistically significant differences between the treatment group and control group in pooled subjects in the time period T5T1 (Table 26). Seven of the sagittal variables showed significant differences, however, only two of the angular variables, one of the condyle/glenoid fossa variables, and none of the vertical variables showed significant differences between the treatment and control groups. Significance differences in variables are apparent for male subjects only and female subjects only and are reported in Tables 27 and 28, respectively. Only data from pooled subjects is reported here.

Sagittal differences: The seven sagittal variables that showed a significant difference between the treatment and control groups at T5-T1 were OLp-A pt., Co-A pt., Wits analysis, Is-OLp, Overjet, Ms-OLp, and molar relationship. The position of the maxillary base (OLp-A pt.) moved forward $4.3 \mathrm{~mm}$ from its original position in the treatment group and in the control group it moved forward $7.1 \mathrm{~mm}$. The maxillary base showed an overall net restriction of $2.8 \mathrm{~mm}$ in the treatment group relative to the control group at T5-T1. Effective maxillary length (Co-A pt.) showed a $-3.8 \mathrm{~mm}$ difference from the control group. The position of the maxilla relative to the mandible along the functional occlusal plane (Wits) showed a difference of $-1.6 \mathrm{~mm}$ for the treatment group. The position of the maxillary incisor (Is-OLp) in the treatment group moved forward 5.1 $\mathrm{mm}$ while the control group moved forwards $9.3 \mathrm{~mm}$, a net difference of $4.2 \mathrm{~mm}$ in a posterior direction. The maxillary molars (Ms-OLp) moved forward $6.6 \mathrm{~mm}$ in the treatment group and $9.6 \mathrm{~mm}$ anteriorly in the control group, a net difference of $-3.0 \mathrm{~mm}$ 
in the treatment group relative to the control group. Overjet and molar relationship correction will be discussed in a later section.

Vertical differences: All vertical variables showed no significant difference between the treatment and control groups at T5-T1.

Angular differences: All angular variables showed no significant difference between the treatment and control groups at T5-T1 except SNA and ANB. A net decrease in SNA of $2.6^{\circ}$ was found in the treatment group relative to the control group. ANB decreased $2.2^{\circ}$ in the treatment group and only $0.1^{\circ}$ in the control group, giving a net decrease of $2.1^{\circ}$.

Condyle/Glenoid Fossa differences: Only one condyle/glenoid fossa variable, OLs-GFP, showed a significant difference between the treatment and control groups. Although not significant, every sagittal glenoid fossa variable (OLp-GFS, OLp-GFA, and OLp-GFP) showed a forward movement in the treatment group and a backward movement in the control group. The sagittal condyle variable OLp-CoC showed only a slight backward movement of $0.3 \mathrm{~mm}$ in the treatment group compared to a greater backward movement of $1.1 \mathrm{~mm}$ in the control group. Net anterior movements of $0.8 \mathrm{~mm}$, $0.9 \mathrm{~mm}, 0.6 \mathrm{~mm}$, and $1.7 \mathrm{~mm}$ were found in the treatment group relative to the control group for the condylar position (OLp-CoC), the superior aspect of the glenoid fossa (OLp-GFS), the anterior aspect of the glenoid fossa (OLp-GFA), and the posterior aspect of the glenoid fossa (OLp-GFP), respectively. The posterior aspect of the glenoid fossa (OLs-GFP) showed a significant upward movement in the treatment group relative to the control group. Although not significant, all other vertical condyle/glenoid fossa variables (OLs-CoC, OLs-GFS, and OLs-GFA) showed an overall upward net relative movement 
of the treatment group compared to the control group. Net superior movements of 1.3 $\mathrm{mm}, 0.7 \mathrm{~mm}, 0.7 \mathrm{~mm}$, and $1.1 \mathrm{~mm}$ were found in the treatment group relative to the control group for the condylar position (OLs-CoC), the superior aspect of the glenoid fossa (OLs-GFS), the anterior aspect of the glenoid fossa (OLs-GFA), and the posterior aspect of the glenoid fossa (OLs-GFP), respectively. 
Table 26. Comparison of treated vs. control in pooled subjects at T5-T1.

\begin{tabular}{|c|c|c|c|c|c|c|c|}
\hline \multicolumn{8}{|c|}{ POOLED (MALES AND FEMALES) } \\
\hline \multirow[b]{2}{*}{ Variable } & \multicolumn{2}{|c|}{$\begin{array}{c}\text { Control } \\
\text { (t5-t1) }\end{array}$} & \multicolumn{2}{|c|}{$\begin{array}{l}\text { Treated } \\
\text { (T5-T1) }\end{array}$} & \multirow[b]{2}{*}{ Diff } & \multirow[b]{2}{*}{$p$ value } & \multirow[b]{2}{*}{ Sig } \\
\hline & Mean & S.D. & Mean & S.D. & & & \\
\hline Age & 75.1 & 15.3 & 73.8 & 15.5 & -1.3 & 0.7628 & NS \\
\hline \multicolumn{8}{|l|}{ Sagittal: } \\
\hline 1. Olp-A pt. & 7.1 & 2.3 & 4.3 & 2.5 & -2.8 & 0.0005 & * \\
\hline 2. Olp-Pg & 9.5 & 2.8 & 7.9 & 3.8 & -1.6 & 0.1248 & NS \\
\hline 3. Olp-Co & 1.4 & 2.3 & 0.8 & 2.5 & -0.6 & 0.3788 & NS \\
\hline 4. Co-A pt. & 8.6 & 3.1 & 4.8 & 3.7 & -3.8 & 0.0006 & * \\
\hline 5. Co-Gn & 13.5 & 3.3 & 11.6 & 4.3 & -1.9 & 0.0967 & NS \\
\hline 6. Co-Gn minus Co-A pt. & 5.0 & 2.6 & 6.4 & 3.5 & 1.4 & 0.1261 & NS \\
\hline 7. Wits & 0.0 & 1.7 & -1.6 & 2.0 & -1.6 & 0.0091 & * \\
\hline 8. Is-Olp & 9.3 & 2.7 & 5.1 & 4.5 & -4.2 & 0.0004 & * \\
\hline 9. li-Olp & 8.7 & 2.2 & 7.3 & 3.9 & -1.4 & 0.1735 & NS \\
\hline 10. Overjet & 0.7 & 1.6 & -2.3 & 2.8 & -3.0 & 0.0001 & * \\
\hline 11. Ms-Olp & 9.6 & 2.9 & 6.6 & 2.7 & -3.0 & 0.0008 & * \\
\hline 12. $\mathrm{Mi}-\mathrm{Olp}$ & 10.3 & 3.1 & 9.5 & 2.8 & -0.8 & 0.3965 & NS \\
\hline 13. Molar Relationship & -0.7 & 1.1 & -2.9 & 2.0 & -2.2 & 0.0001 & * \\
\hline \multicolumn{8}{|l|}{ Vertical: } \\
\hline 14. OLs-A pt. & 4.8 & 2.2 & 5.2 & 2.5 & 0.4 & 0.6137 & NS \\
\hline 15. ANS-Me & 6.8 & 2.4 & 5.8 & 3.0 & -1.0 & 0.2234 & NS \\
\hline 16. Is-NL & 3.9 & 3.0 & 3.0 & 3.4 & -0.9 & 0.3716 & NS \\
\hline 17. li-ML & 4.5 & 1.9 & 3.6 & 2.3 & -0.9 & 0.1547 & NS \\
\hline 18. Overbite & 1.7 & 3.2 & 0.3 & 3.2 & -1.4 & 0.1695 & NS \\
\hline 19. Msc-NL & 4.7 & 2.0 & 3.6 & 2.3 & -1.1 & 0.0834 & NS \\
\hline 20. Mic-ML & 3.9 & 2.2 & 4.1 & 1.6 & 0.2 & 0.7349 & NS \\
\hline \multicolumn{8}{|l|}{ Angular: } \\
\hline 21. SNA & 1.8 & 2.3 & -0.8 & 2.9 & -2.6 & 0.0016 & * \\
\hline 22. SNB & 1.9 & 2.0 & 1.4 & 2.4 & -0.5 & 0.3924 & NS \\
\hline 23. ANB & -0.1 & 1.3 & -2.2 & 1.6 & -2.1 & 0.0001 & * \\
\hline 24. SNL-NL & -0.9 & 2.7 & 0.3 & 3.3 & 1.2 & 0.1957 & NS \\
\hline 25. SNL-ML & -1.3 & 2.3 & -1.1 & 2.6 & 0.2 & 0.7839 & NS \\
\hline 26. SNL-OL & -2.4 & 3.2 & -0.9 & 3.2 & 1.5 & 0.1317 & NS \\
\hline 27. Is/NL & -1.0 & 5.6 & 0.5 & 6.4 & 1.5 & 0.4359 & NS \\
\hline 28. $\mathrm{li} / \mathrm{ML}$ & 0.0 & 4.9 & 3.0 & 7.7 & 3.0 & 0.1102 & NS \\
\hline 29. Interincisal Angle & 1.6 & 7.4 & -0.3 & 13.4 & -1.9 & 0.5704 & NS \\
\hline \multicolumn{8}{|l|}{ Condyle/Glenoid Fossa: } \\
\hline 30. Olp-CoC & -1.1 & 2.1 & -0.3 & 2.3 & 0.8 & 0.2388 & NS \\
\hline 31. Olp-GFS & -0.9 & 2.9 & 0.0 & 2.6 & 0.9 & 0.2897 & NS \\
\hline 32. Olp-GFA & -0.1 & 2.5 & 0.5 & 2.5 & 0.6 & 0.4171 & NS \\
\hline 33. Olp-GFP & -1.2 & 2.6 & 0.5 & 3.5 & 1.7 & 0.0705 & NS \\
\hline 34. Ols-CoC & 3.7 & 1.9 & 2.4 & 2.8 & -1.3 & 0.0601 & NS \\
\hline 35. Ols-GFS & 3.0 & 1.9 & 2.3 & 1.9 & -0.7 & 0.1921 & NS \\
\hline 36. Ols-GFA & 3.0 & 1.6 & 2.3 & 1.6 & -0.7 & 0.1339 & NS \\
\hline 37. Ols-GFP & 3.0 & 1.5 & 1.9 & 1.7 & -1.1 & 0.0226 & * \\
\hline
\end{tabular}


Table 27. Comparison of treated vs. control in male subjects at T5-T1.

\begin{tabular}{|c|c|c|c|c|c|c|c|}
\hline \multicolumn{8}{|c|}{ MALE SUBJECTS } \\
\hline \multirow[b]{2}{*}{ Variable } & \multicolumn{2}{|c|}{$\begin{array}{c}\text { Control } \\
\text { (t5-t1) }\end{array}$} & \multicolumn{2}{|c|}{$\begin{array}{l}\text { Treated } \\
\text { (T5-T1) }\end{array}$} & \multirow[b]{2}{*}{ Diff } & \multirow[b]{2}{*}{$p$ value } & \multirow[b]{2}{*}{ Sig } \\
\hline & Mean & S.D. & Mean & S.D. & & & \\
\hline Age & 78.9 & 19.6 & 77.7 & 18.7 & -1.2 & 0.9130 & NS \\
\hline \multicolumn{8}{|l|}{ Sagittal: } \\
\hline 1. Olp-A pt. & 8.1 & 2.4 & 6.2 & 2.2 & -1.9 & 0.1389 & NS \\
\hline 2. Olp-Pg & 9.2 & 4.3 & 10.9 & 2.7 & 1.7 & 0.3978 & NS \\
\hline 3. Olp-Co & 0.6 & 3.2 & 1.4 & 3.3 & 0.8 & 0.6647 & NS \\
\hline 4. Co-A pt. & 8.8 & 3.9 & 6.4 & 4.4 & -2.4 & 0.3014 & NS \\
\hline 5. Co-Gn & 14.1 & 3.0 & 15.4 & 4.5 & 1.3 & 0.6016 & NS \\
\hline 6. Co-Gn minus Co-A pt. & 5.4 & 2.8 & 7.7 & 1.8 & 2.3 & 0.0900 & NS \\
\hline 7. Wits & 0.1 & 2.2 & -2.2 & 2.1 & -2.3 & 0.0733 & NS \\
\hline 8. Is-Olp & 10.9 & 3.7 & 5.8 & 3.7 & -5.1 & 0.0232 & * \\
\hline 9. li-Olp & 10.1 & 3.0 & 9.8 & 2.6 & -0.3 & 0.8901 & NS \\
\hline 10. Overjet & 0.8 & 2.1 & -4.1 & 1.3 & -4.9 & 0.0003 & * \\
\hline 11. Ms-Olp & 10.3 & 3.8 & 8.2 & 1.7 & -2.1 & 0.2164 & NS \\
\hline 12. Mi-Olp & 10.5 & 4.2 & 11.9 & 2.8 & 1.4 & 0.4903 & NS \\
\hline 13. Molar Relationship & -0.2 & 1.2 & -3.7 & 1.5 & -3.5 & 0.0004 & * \\
\hline \multicolumn{8}{|l|}{ Vertical: } \\
\hline 14. OLs-A pt. & 5.1 & 1.6 & 5.7 & 2.9 & 0.6 & 0.6231 & NS \\
\hline 15. ANS-Me & 8.1 & 2.3 & 7.2 & 3.8 & -0.9 & 0.6006 & NS \\
\hline 16. Is-NL & 4.0 & 3.2 & 2.8 & 3.3 & -1.2 & 0.5126 & NS \\
\hline 17. li-ML & 5.8 & 2.1 & 2.9 & 1.7 & -2.9 & 0.0125 & * \\
\hline 18. Overbite & 1.6 & 3.1 & -1.5 & 1.7 & -3.1 & 0.0382 & * \\
\hline 19. Msc-NL & 4.4 & 2.7 & 4.0 & 2.8 & -0.4 & 0.7692 & NS \\
\hline 20. Mic-ML & 4.9 & 1.1 & 5.2 & 1.2 & 0.3 & 0.6434 & NS \\
\hline \multicolumn{8}{|l|}{ Angular: } \\
\hline 21. SNA & 1.6 & 1.6 & 0.1 & 2.4 & -1.5 & 0.1717 & NS \\
\hline 22. SNB & 1.4 & 1.8 & 2.1 & 2.2 & 0.7 & 0.5253 & NS \\
\hline 23. ANB & 0.2 & 1.2 & -2.1 & 1.6 & -2.3 & 0.0096 & $*$ \\
\hline 24. SNL-NL & -1.3 & 2.5 & -0.1 & 2.0 & 1.2 & 0.3341 & NS \\
\hline 25. SNL-ML & -0.7 & 2.7 & -2.1 & 2.2 & -1.4 & 0.3192 & NS \\
\hline 26. SNL-OL & -1.3 & 3.9 & -1.1 & 3.1 & 0.2 & 0.9115 & NS \\
\hline 27. Is/NL & 0.4 & 6.2 & -2.9 & 7.2 & -3.3 & 0.3894 & NS \\
\hline 28. $\mathrm{li} / \mathrm{ML}$ & 0.6 & 4.9 & 4.9 & 7.4 & 4.3 & 0.2306 & NS \\
\hline 29. Interincisal Angle & -1.6 & 7.5 & 0.5 & 11.3 & 2.1 & 0.6931 & NS \\
\hline \multicolumn{8}{|l|}{ Condyle/Glenoid Fossa: } \\
\hline 30. Olp-CoC & -0.4 & 2.7 & -1.0 & 2.9 & -0.6 & 0.7049 & NS \\
\hline 31. Olp-GFS & 0.2 & 2.8 & -0.6 & 3.1 & -0.8 & 0.6312 & NS \\
\hline 32. OIp-GFA & 0.7 & 2.5 & -0.2 & 3.4 & -0.9 & 0.6037 & NS \\
\hline 33. Olp-GFP & -0.3 & 3.5 & -0.6 & 3.3 & -0.3 & 0.8463 & NS \\
\hline 34. Ols-CoC & 4.6 & 1.3 & 1.6 & 4.4 & -3.0 & 0.1182 & NS \\
\hline 35. Ols-GFS & 3.9 & 1.6 & 2.3 & 2.9 & -1.6 & 0.2267 & NS \\
\hline 36. Ols-GFA & 3.9 & 1.6 & 2.2 & 2.5 & -1.7 & 0.1589 & NS \\
\hline 37. Ols-GFP & 3.9 & 1.6 & 1.8 & 2.8 & -2.1 & 0.1064 & NS \\
\hline
\end{tabular}


Table 28. Comparison of treated vs. control in female subjects at T5-T1.

\begin{tabular}{|c|c|c|c|c|c|c|c|}
\hline \multicolumn{8}{|c|}{ FEMALE SUBJECTS } \\
\hline \multirow[b]{2}{*}{ Variable } & \multicolumn{2}{|c|}{$\begin{array}{c}\text { Control } \\
\text { (t5-t1) }\end{array}$} & \multicolumn{2}{|c|}{$\begin{array}{l}\text { Treated } \\
\text { (T5-T1) }\end{array}$} & \multirow[b]{2}{*}{ Diff } & \multirow[b]{2}{*}{ p value } & \multirow[b]{2}{*}{ Sig } \\
\hline & Mean & S.D. & Mean & S.D. & & & \\
\hline Age & 73.5 & 13.2 & 71.9 & 14.1 & -1.6 & 0.7611 & NS \\
\hline \multicolumn{8}{|l|}{ Sagittal: } \\
\hline 1. Olp-A pt. & 6.6 & 2.1 & 3.5 & 2.3 & -3.1 & 0.0005 & * \\
\hline 2. Olp-Pg & 9.7 & 1.9 & 6.6 & 3.5 & -3.1 & 0.0054 & * \\
\hline 3. Olp-Co & 1.8 & 1.8 & 0.5 & 2.1 & -1.3 & 0.0773 & NS \\
\hline 4. Co-A pt. & 8.5 & 2.9 & 4.0 & 3.2 & -4.5 & 0.0004 & * \\
\hline 5. Co-Gn & 13.3 & 3.0 & 9.8 & 2.3 & -3.5 & 0.0034 & * \\
\hline 6. Co-Gn minus Co-A pt. & 4.8 & 2.5 & 5.8 & 4.0 & 1.0 & 0.4038 & NS \\
\hline 7. Wits & -0.1 & 1.6 & -1.3 & 1.9 & -1.2 & 0.0716 & NS \\
\hline 8. Is-Olp & 8.6 & 1.7 & 4.7 & 4.9 & -3.9 & 0.0074 & * \\
\hline 9. li-Olp & 8.0 & 1.5 & 6.2 & 3.9 & -1.8 & 0.0995 & NS \\
\hline 10. Overjet & 0.6 & 1.4 & -1.4 & 2.9 & -2.0 & 0.0255 & * \\
\hline 11. Ms-Olp & 9.3 & 2.4 & 5.8 & 2.8 & -3.5 & 0.0009 & * \\
\hline 12. Mi-Olp & 10.2 & 2.7 & 8.4 & 2.0 & -1.8 & 0.0513 & NS \\
\hline 13. Molar Relationship & -0.8 & 1.0 & -2.3 & 2.1 & -1.5 & 0.0075 & * \\
\hline \multicolumn{8}{|l|}{ Vertical: } \\
\hline 14. OLs-A pt. & 4.7 & 2.5 & 5.0 & 2.4 & 0.3 & 0.7889 & NS \\
\hline 15. ANS-Me & 6.2 & 2.3 & 5.1 & 2.4 & -1.1 & 0.2257 & NS \\
\hline 16. Is-NL & 3.8 & 3.0 & 3.1 & 3.6 & -0.7 & 0.5464 & NS \\
\hline 17. Ii-ML & 3.9 & 1.5 & 4.0 & 2.5 & 0.1 & 0.9520 & NS \\
\hline 18. Overbite & 1.7 & 3.3 & 1.2 & 3.4 & -0.5 & 0.6707 & NS \\
\hline 19. Msc-NL & 4.9 & 1.8 & 3.4 & 2.1 & -1.5 & 0.0433 & * \\
\hline 20. Mic-ML & 3.5 & 2.4 & 3.6 & 1.6 & 0.1 & 0.8386 & NS \\
\hline \multicolumn{8}{|l|}{ Angular: } \\
\hline 21. SNA & 1.9 & 2.6 & -1.3 & 3.1 & -3.2 & 0.0053 & * \\
\hline 22. SNB & 2.2 & 2.1 & 1.0 & 2.4 & -1.2 & 0.1653 & NS \\
\hline 23. ANB & -0.3 & 1.4 & -2.3 & 1.7 & -2.0 & 0.0016 & * \\
\hline 24. SNL-NL & -0.7 & 2.9 & 0.5 & 3.8 & 1.2 & 0.3416 & NS \\
\hline 25. SNL-ML & -1.6 & 2.2 & -0.7 & 2.7 & 0.9 & 0.3070 & NS \\
\hline 26. SNL-OL & -2.9 & 2.8 & -0.8 & 3.3 & 2.1 & 0.0762 & NS \\
\hline 27. Is/NL & -1.6 & 5.4 & 2.0 & 5.7 & 3.6 & 0.0853 & NS \\
\hline 28. li/ML & -0.3 & 4.0 & 2.2 & 7.9 & 2.5 & 0.2845 & NS \\
\hline 29. Interincisal Angle & 3.0 & 7.1 & -0.7 & 14.6 & -3.7 & 0.3853 & NS \\
\hline \multicolumn{8}{|l|}{ Condyle/Glenoid Fossa: } \\
\hline 30. Olp-CoC & -1.4 & 1.7 & 0.0 & 2.0 & 1.4 & 0.0442 & * \\
\hline 31. Olp-GFS & -1.4 & 2.9 & 0.2 & 2.5 & 1.6 & 0.1018 & NS \\
\hline 32. Olp-GFA & -0.5 & 2.5 & 0.8 & 2.1 & 1.3 & 0.1317 & NS \\
\hline 33. Olp-GFP & -1.7 & 2.1 & 1.0 & 3.6 & 2.7 & 0.0175 & * \\
\hline 34. Ols-CoC & 3.4 & 2.0 & 2.7 & 1.6 & -0.7 & 0.3416 & NS \\
\hline 35. Ols-GFS & 2.6 & 1.9 & 2.3 & 1.4 & -0.3 & 0.5488 & NS \\
\hline 36. Ols-GFA & 2.6 & 1.5 & 2.3 & 1.1 & -0.3 & 0.5311 & NS \\
\hline 37. Ols-GFP & 2.6 & 1.3 & 1.9 & 1.1 & -0.7 & 0.1179 & NS \\
\hline
\end{tabular}




\section{Overjet and Molar Relationship Correction-Treatment Group (T5-}

T1)

The amount of skeletal and dental contribution to the overjet and molar relationship correction in the treatment group at T5-T1 was calculated using the formulas in Table 11. The amount of overjet correction in the treatment group was $2.2 \mathrm{~mm}$. 3.6 $\mathrm{mm}(163.6 \%)$ of the correction was due to skeletal change. $-1.4 \mathrm{~mm}(-63.6 \%)$ of the correction was due to dental change. The amount of molar relationship correction was $2.9 \mathrm{~mm} .3 .6 \mathrm{~mm}(124.1 \%)$ of the correction was skeletal in nature and $-0.7 \mathrm{~mm}(-24.1 \%)$ of the correction was dental in nature. Calculations are shown for the overjet and molar relationship correction on the following pages. In addition, diagrams are provided to illustrate the anterior or posterior movement of the maxillary base, mandibular base, maxillary incisors, mandibular incisors, maxillary molars, and mandibular molars (Figures 29 and 30). A pitchfork analysis describing the skeletal and dental contributions to overjet and molar relationship correction is shown in Figure 31. 


\begin{tabular}{|cccc|}
\hline Overjet Correction: & & Molar relationship: & \\
\hline Skeletal Contribution: & 4.3 & Skeletal Contribution: & 4.3 \\
1) Maxilla & 7.9 & 1) Maxilla & 7.9 \\
2) Mandible & & 2) Mandible & \\
Dental Contribution: & 0.8 & Dental Contribution: & 2.3 \\
3) Mx incisor & -0.6 & 3) Mx molar & 1.6 \\
4) Md incisor & & & \\
\hline
\end{tabular}

Overjet Correction $=$ Maxilla + Mx incisor - Mandible - Md incisor

Overjet Correction $=4.3+0.8-7.9-(-0.6)=-2.2 \mathrm{~mm}$

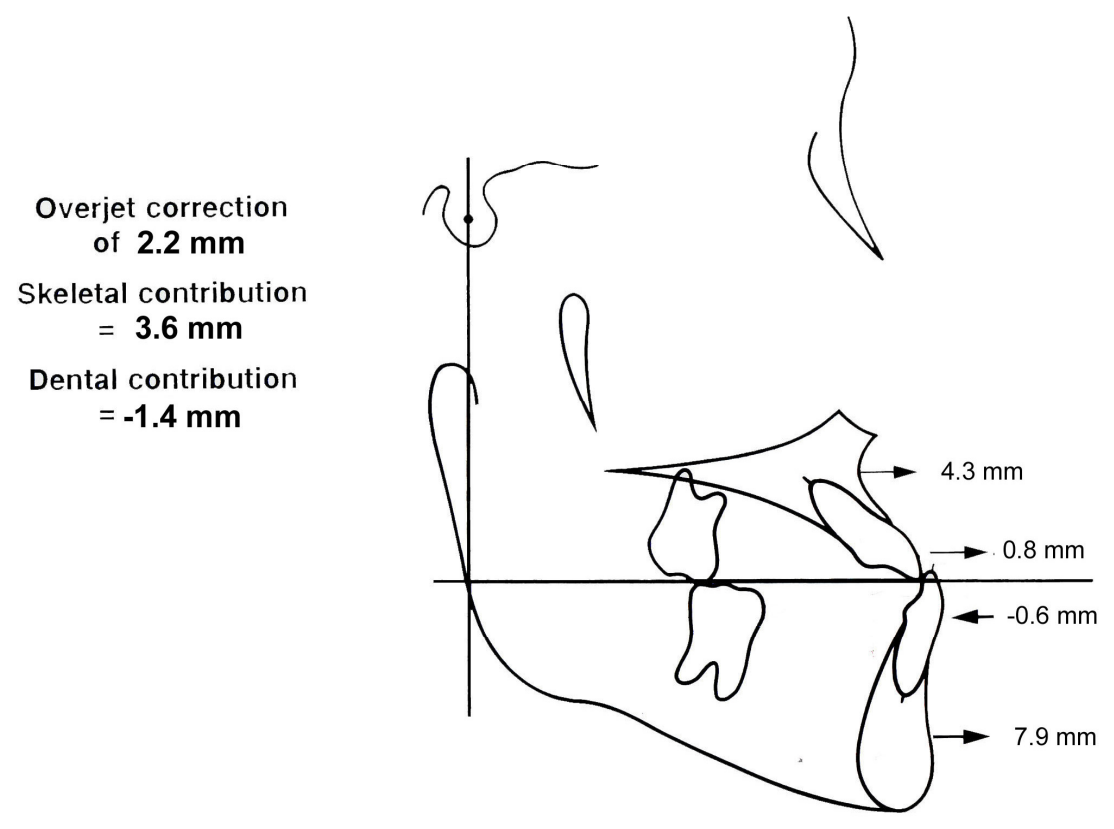

Figure 29. Components of overjet correction (T5-T1) 
Molar Relationship Correction $=$ Maxilla + Mx molar - Mandible - Md molar

Molar Relationship Correction $=4.3+2.3-7.9-1.6=-2.9 \mathrm{~mm}$

Molar correction

of $2.9 \mathrm{~mm}$

Skeletal contribution

$=3.6 \mathrm{~mm}$

Dental contribution

$=-0.7 \mathrm{~mm}$

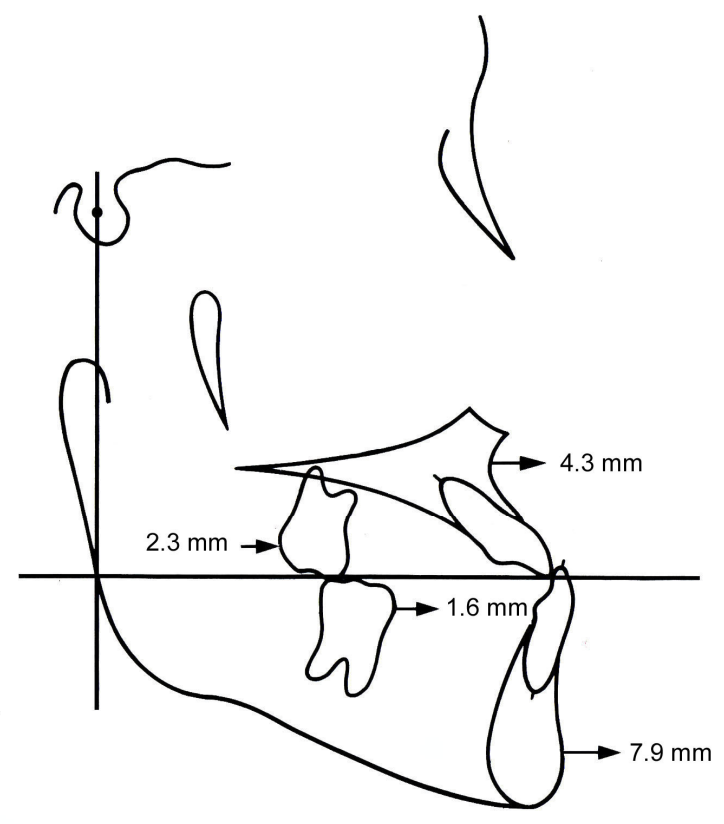

Figure 30. Components of molar relationship correction (T5-T1)

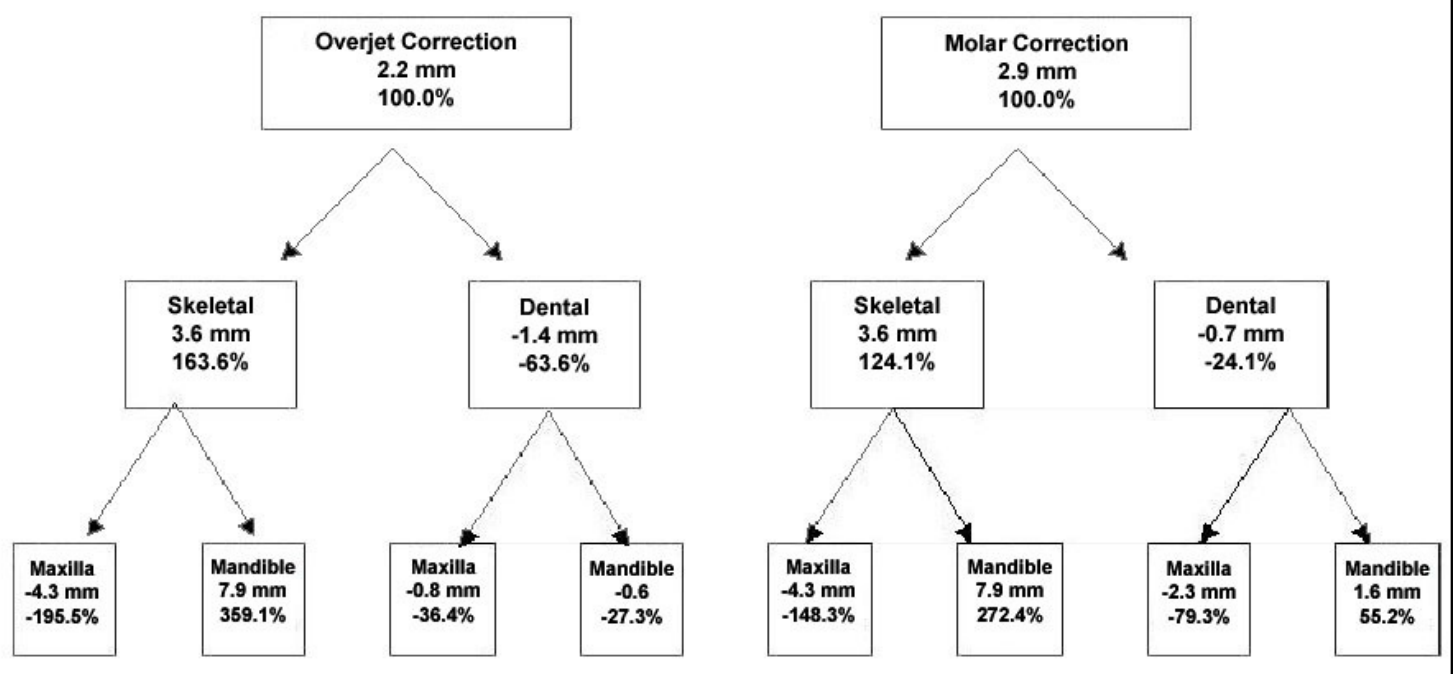

Figure 31. Pitchfork analysis of overjet and molar correction 


\section{Net Overjet and Molar Relationship Correction-Tx vs. Control Group (T5-T1)}

The amount of skeletal and dental contribution to the net overjet and net molar relationship correction in the treatment group vs. the control group at T5-T1 was calculated using the formulas in Table 11. The amount of net overjet correction in the treatment group relative to the control group was $2.8 \mathrm{~mm} .1 .2 \mathrm{~mm}(42.9 \%)$ of the correction was due to skeletal movement. $1.6 \mathrm{~mm}(57.1 \%)$ of the correction was due to dental movement. The amount of net molar relationship correction was $2.2 \mathrm{~mm} .1 .2 \mathrm{~mm}$ $(54.5 \%)$ of the correction was skeletal in nature and $1.0 \mathrm{~mm}(45.5 \%)$ of the correction was dental in nature. Calculations are shown for the net overjet and net molar relationship correction on the following pages. In addition, diagrams are provided to illustrate the net anterior or posterior movement of the maxillary base, mandibular base, maxillary incisors, mandibular incisors, maxillary molars, and mandibular molars (Figures 32 and 33). A pitchfork analysis describing the net skeletal and dental contributions to overjet and molar relationship correction is shown in Figure 34. 


\begin{tabular}{|cccc|}
\hline Net Overjet Correction: & & Net Molar relationship: & \\
\hline Skeletal Contribution: & -2.8 & Skeletal Contribution: & -2.8 \\
1) Maxilla & -1.6 & 1) Maxilla & -1.6 \\
2) Mandible & & 2) Mandible & \\
Dental Contribution: & -1.4 & Dental Contribution: & -0.2 \\
3) Mx incisor & 0.2 & 3) Mx molar & 0.8 \\
4) Md incisor & & 4) Md molar & \\
\hline
\end{tabular}

Net Overjet Correction $=$ Maxilla + Mx incisor - Mandible - Md incisor

Net Overjet Correction $=(-2.8)+(-1.4)-(-1.6)-0.2=-2.8 \mathrm{~mm}$
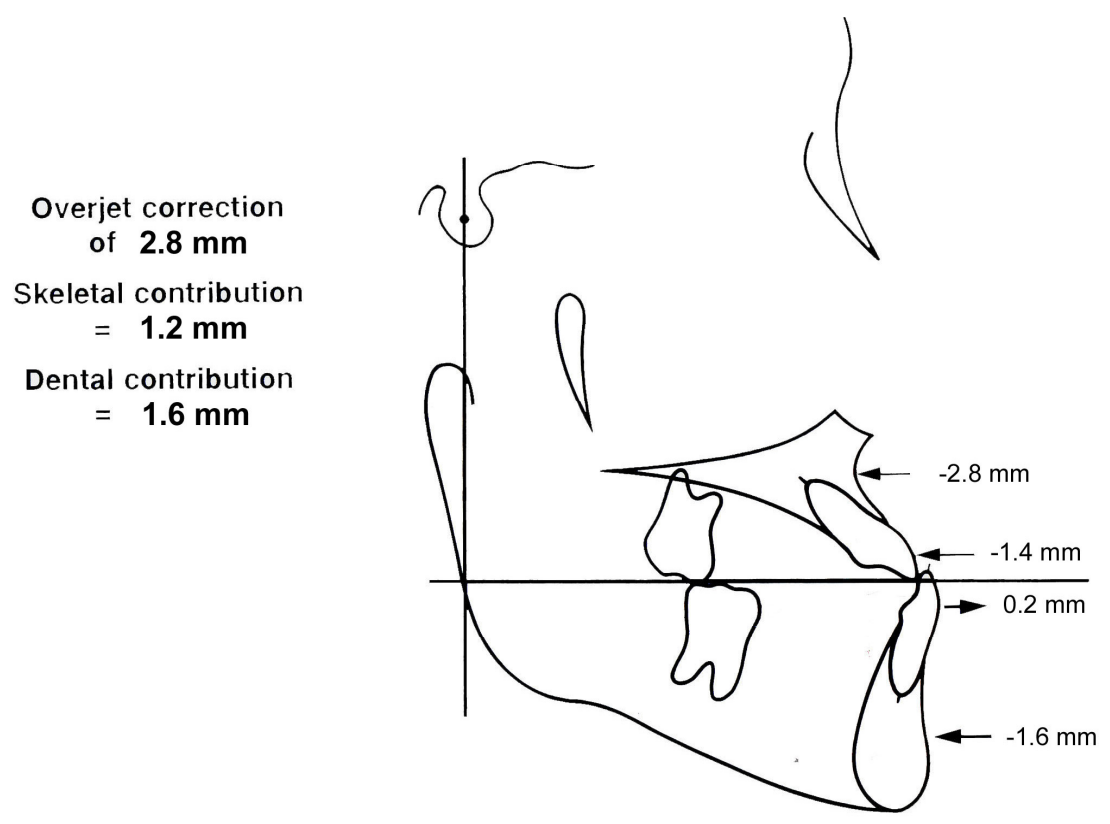

Figure 32. Components of net overjet correction (T5-T1) 
Net Molar Relationship Correction $=$ Maxilla + Mx molar - Mandible - Md molar

Net Molar Relationship Correction $=(-2.8)+(-0.2)-(-1.6)-0.8=-2.2 \mathrm{~mm}$
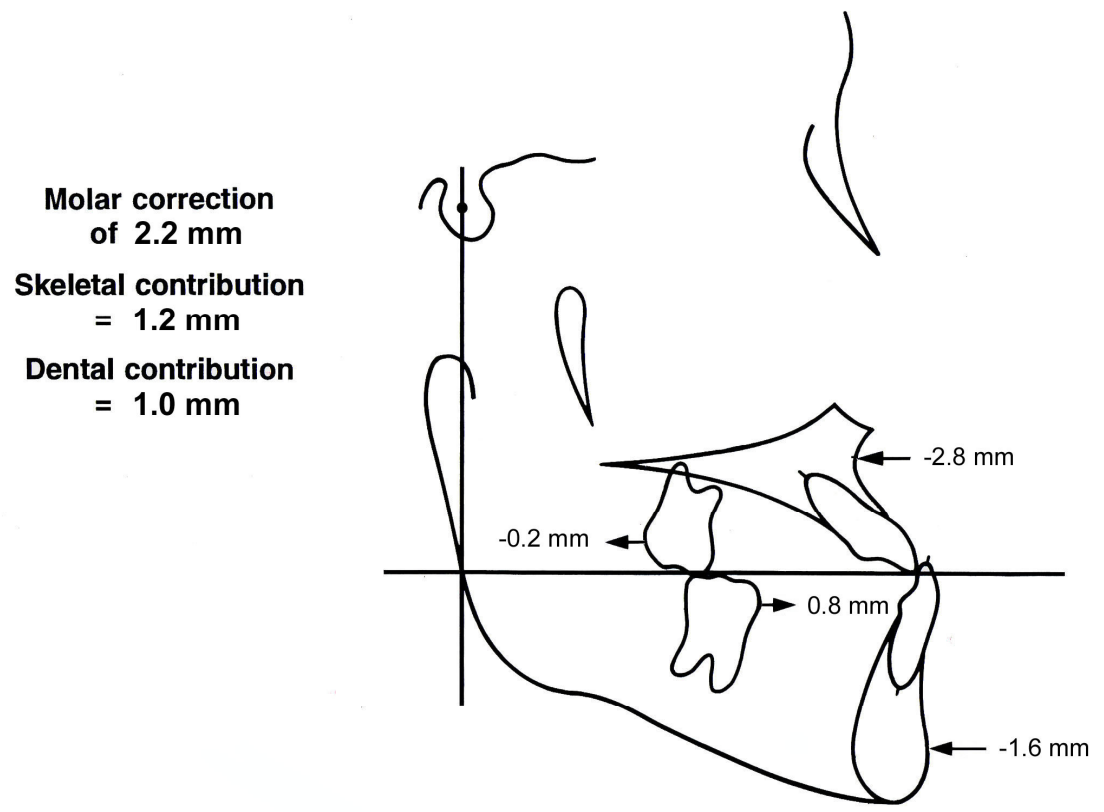

Figure 33. Components of net molar correction (T5-T1)

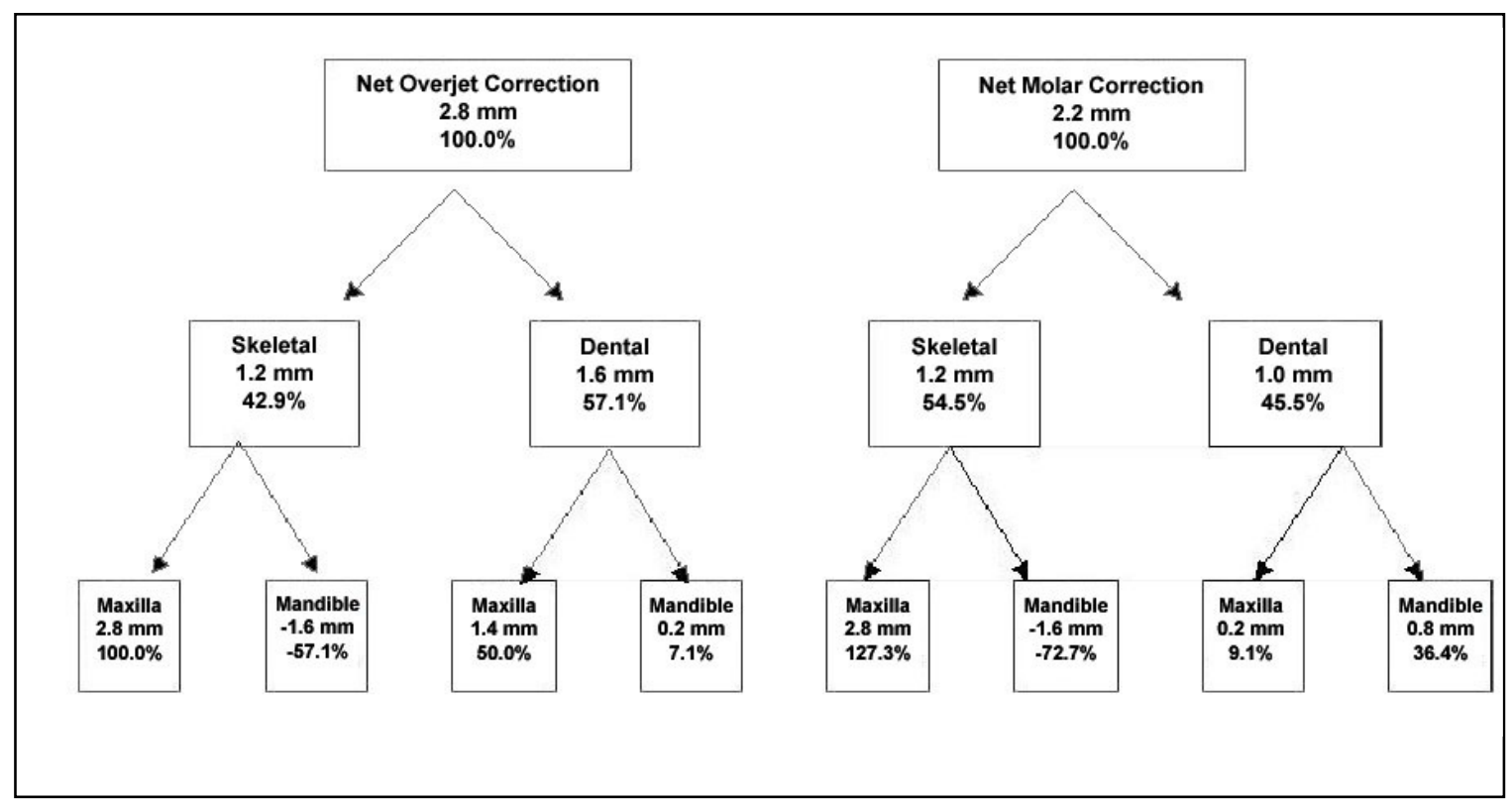

Figure 34. Pitchfork analysis of net overjet and molar correction (T5-T1) 


\section{Comparison of T5-T4 (Phase II Treatment Effects)}

Of the 37 variables investigated, 10 showed statistically significant differences between the treatment group and control group in pooled subjects in the time period T5T4 (Table 29). Five of the sagittal variables, four of the angular variables, one of the condyle/glenoid fossa variables, and none of the vertical variables showed significant differences between the treatment and control groups. Significance differences in variables are apparent for male subjects only and female subjects only and are reported in Tables 30 and 31, respectively. Only data from pooled subjects is reported here.

Sagittal differences: The five sagittal variables that showed a significant difference between the treatment and control groups at T5-T4 were OLp-A pt., Co-Gn minus Co-A pt., Wits analysis, Is-OLp, and Ii-OLp. The position of the maxillary base (OLp-A pt.) moved forward $0.7 \mathrm{~mm}$ from $\mathrm{T} 4$ to $\mathrm{T} 5 \mathrm{in}$ the treatment group and in the control group it moved forward $2.5 \mathrm{~mm}$ during the same time period. The maxillary base showed an overall net backward movement of $1.8 \mathrm{~mm}$ in the treatment group relative to the control group from T4 to T5. The difference between the effective maxillary and mandibular length (Co-Gn minus Co-A pt.) between the treatment and control groups from $\mathrm{T} 4$ to $\mathrm{T} 5$ was significant with a $1.5 \mathrm{~mm}$ difference. The position of the maxilla relative to the mandible along the functional occlusal plane (Wits) showed a net difference of $-1.5 \mathrm{~mm}$ for the treatment group relative to the control group. The position of the maxillary incisor (Is-OLp) and the mandibular incisors (Ii-OLp) in the treatment group experienced a net backwards movement of $2.2 \mathrm{~mm}$ and $1.7 \mathrm{~mm}$, respectively from T4 to T5.

Vertical differences: All vertical variables showed no significant difference between the treatment and control groups at T5-T4. 
Angular differences: Significant differences in the angular variables between the control and treatment groups were found in SNA, SNB, ANB, and SNL-OL. A net decrease of $2.0^{\circ}, 1.0^{\circ}$, and $1.0^{\circ}$ was found in SNA, SNB, and ANB, respectively, when the treatment group when compared to the control group at T5-T4. A net increase of $2.6^{\circ}$ was seen in the treatment group when compared to the control group at this same time period.

Condyle/Glenoid Fossa differences: Only one condyle/glenoid fossa variable, OLs-CoC, showed a significant difference between the treatment and control groups. Although not significant, every sagittal condyle/glenoid fossa variable (OLp-CoC, OLpGFS, OLp-GFA, and OLp-GFP) showed a backward movement in the treatment group and a forward movement in the control group from T4 to T5. This suggests possible relapse in the anteriorly relocated condyle and glenoid fossa in the treatment group. Net posterior movements of $1.0 \mathrm{~mm}, 0.9 \mathrm{~mm}, 0.7 \mathrm{~mm}$, and $0.2 \mathrm{~mm}$ were found in the treatment group relative to the control group for the condylar position (OLp-CoC), the superior aspect of the glenoid fossa (OLp-GFS), the anterior aspect of the glenoid fossa (OLp-GFA), and the posterior aspect of the glenoid fossa (OLp-GFP). Although only OLs-CoC was significant, all vertical condyle/glenoid fossa variables (OLs-CoC, OLsGFS, and OLs-GFA) showed an overall upward net relative movement of the treatment group compared to the control group from T4 to T5. Net upward movements of $1.0 \mathrm{~mm}$, $0.6 \mathrm{~mm}, 0.6 \mathrm{~mm}$, and $0.6 \mathrm{~mm}$ were found in the treatment group relative to the control group for the condylar position (OLs-CoC), the superior aspect of the glenoid fossa (OLsGFS), the anterior aspect of the glenoid fossa (OLs-GFA), and the posterior aspect of the glenoid fossa (OLs-GFP), respectively. 
Table 29. Comparison of treated vs. control group in pooled subjects at T5-T4

\begin{tabular}{|c|c|c|c|c|c|c|c|}
\hline \multicolumn{8}{|c|}{ POOLED (MALES AND FEMALES) } \\
\hline \multirow[b]{2}{*}{ Variable } & \multicolumn{2}{|c|}{$\begin{array}{c}\text { Control } \\
(\mathrm{t} 5-\mathrm{t} 4)\end{array}$} & \multicolumn{2}{|c|}{$\begin{array}{l}\text { Treated } \\
\text { (T5-T4) }\end{array}$} & \multirow[b]{2}{*}{ Diff } & \multirow[b]{2}{*}{$p$ value } & \multirow[b]{2}{*}{ Sig } \\
\hline & Mean & S.D. & Mean & S.D. & & & \\
\hline Age & 19.8 & 8.1 & 20.0 & 6.6 & 0.2 & 0.9192 & NS \\
\hline \multicolumn{8}{|l|}{ Sagittal: } \\
\hline 1. Olp-A pt. & 2.5 & 1.5 & 0.7 & 1.5 & -1.8 & 0.0002 & * \\
\hline 2. Olp-Pg & 2.6 & 2.4 & 1.5 & 1.7 & -1.1 & 0.1134 & NS \\
\hline 3. Olp-Co & -0.3 & 2.0 & 0.6 & 1.4 & 0.9 & 0.0755 & NS \\
\hline 4. Co-A pt. & 2.2 & 2.1 & 1.4 & 2.1 & -0.8 & 0.1952 & NS \\
\hline 5. Co-Gn & 2.9 & 2.5 & 3.5 & 2.5 & 0.6 & 0.4366 & NS \\
\hline 6. Co-Gn minus Co-A pt. & 0.7 & 1.8 & 2.2 & 2.3 & 1.5 & 0.0260 & * \\
\hline 7. Wits & 0.7 & 1.4 & -0.8 & 1.6 & -1.5 & 0.0022 & * \\
\hline 8. Is-Olp & 2.2 & 1.5 & 0.0 & 1.9 & -2.2 & 0.0002 & * \\
\hline 9. li-Olp & 2.1 & 1.7 & 0.4 & 1.6 & -1.7 & 0.0014 & * \\
\hline 10. Overjet & 0.0 & 0.7 & -0.4 & 1.5 & -0.4 & 0.1899 & NS \\
\hline 11. Ms-Olp & 2.3 & 1.5 & 2.2 & 1.8 & -0.1 & 0.9175 & NS \\
\hline 12. Mi-Olp & 2.6 & 2.2 & 2.4 & 1.8 & -0.2 & 0.7785 & NS \\
\hline 13. Molar Relationship & -0.3 & 0.9 & -0.1 & 1.0 & 0.2 & 0.6962 & NS \\
\hline \multicolumn{8}{|l|}{ Vertical: } \\
\hline 14. OLs-A pt. & 1.5 & 1.6 & 1.1 & 2.0 & -0.4 & 0.5352 & NS \\
\hline 15. ANS-Me & 1.5 & 1.3 & 2.2 & 2.2 & 0.7 & 0.2114 & NS \\
\hline 16. Is-NL & 0.3 & 1.2 & 0.4 & 1.7 & 0.1 & 0.8341 & NS \\
\hline 17. li-ML & 1.2 & 1.1 & 1.0 & 1.4 & -0.2 & 0.5409 & NS \\
\hline 18. Overbite & 0.1 & 0.9 & -0.3 & 1.4 & -0.4 & 0.2443 & NS \\
\hline 19. Msc-NL & 1.0 & 1.0 & 1.3 & 1.4 & 0.3 & 0.4221 & NS \\
\hline 20. Mic-ML & 1.3 & 1.7 & 1.9 & 1.8 & 0.6 & 0.2327 & NS \\
\hline \multicolumn{8}{|l|}{ Angular: } \\
\hline 21. SNA & 1.0 & 1.3 & -1.0 & 2.2 & -2.0 & 0.0008 & * \\
\hline 22. SNB & 0.6 & 1.4 & -0.4 & 1.3 & -1.0 & 0.0278 & * \\
\hline 23. ANB & 0.4 & 1.0 & -0.6 & 1.2 & -1.0 & 0.0033 & * \\
\hline 24. SNL-NL & 0.6 & 1.8 & 1.0 & 2.3 & 0.4 & 0.4917 & NS \\
\hline 25. SNL-ML & -0.1 & 1.2 & 0.5 & 2.1 & 0.6 & 0.2802 & NS \\
\hline 26. SNL-OL & -1.0 & 2.0 & 1.6 & 2.8 & 2.6 & 0.0013 & * \\
\hline 27. Is/NL & 0.1 & 3.1 & -0.2 & 6.3 & -0.3 & 0.8566 & NS \\
\hline 28. $\mathrm{li} / \mathrm{ML}$ & -1.0 & 2.4 & -1.2 & 5.3 & -0.2 & 0.8400 & NS \\
\hline 29. Interincisal Angle & 1.7 & 3.3 & 2.3 & 9.4 & 0.6 & 0.7573 & NS \\
\hline \multicolumn{8}{|l|}{ Condyle/Glenoid Fossa: } \\
\hline 30. Olp-CoC & 0.4 & 2.1 & -0.6 & 1.4 & -1.0 & 0.0665 & NS \\
\hline 31. Olp-GFS & 0.3 & 2.2 & -0.6 & 1.7 & -0.9 & 0.1426 & NS \\
\hline 32. Olp-GFA & 0.5 & 2.1 & -0.2 & 1.6 & -0.7 & 0.2379 & NS \\
\hline 33. Olp-GFP & 0.0 & 2.4 & -0.2 & 3.0 & -0.2 & 0.8158 & NS \\
\hline 34. Ols-CoC & 0.6 & 1.5 & -0.4 & 1.9 & -1.0 & 0.0484 & * \\
\hline 35. Ols-GFS & 0.6 & 1.6 & 0.0 & 1.7 & -0.6 & 0.2376 & NS \\
\hline 36. Ols-GFA & 0.8 & 1.5 & 0.2 & 1.7 & -0.6 & 0.3021 & NS \\
\hline 37. Ols-GFP & 0.8 & 1.6 & 0.2 & 2.0 & -0.6 & 0.2796 & NS \\
\hline
\end{tabular}


Table 30. Comparison of treated vs. control in males subjects at T5-T4

\begin{tabular}{|c|c|c|c|c|c|c|c|}
\hline \multicolumn{8}{|c|}{ MALE SUBJECTS } \\
\hline \multirow[b]{2}{*}{ Variable } & \multicolumn{2}{|c|}{$\begin{array}{c}\text { Control } \\
(\mathrm{t} 5-\mathrm{t} 4)\end{array}$} & \multicolumn{2}{|c|}{$\begin{array}{l}\text { Treated } \\
\text { (T5-T4) }\end{array}$} & \multirow[b]{2}{*}{ Diff } & \multirow[b]{2}{*}{$p$ value } & \multirow[b]{2}{*}{ Sig } \\
\hline & Mean & S.D. & Mean & S.D. & & & \\
\hline Age & 21.7 & 12.3 & 22.6 & 8.4 & 0.9 & 0.8814 & NS \\
\hline \multicolumn{8}{|l|}{ Sagittal: } \\
\hline 1. Olp-A pt. & 3.0 & 1.5 & 1.0 & 1.9 & -2.0 & 0.0503 & NS \\
\hline 2. Olp-Pg & 3.1 & 3.6 & 2.7 & 1.5 & -0.4 & 0.7843 & NS \\
\hline 3. Olp-Co & 0.0 & 1.9 & 0.3 & 1.8 & 0.3 & 0.7295 & NS \\
\hline 4. Co-A pt. & 2.9 & 1.7 & 1.4 & 2.5 & -1.5 & 0.2180 & NS \\
\hline 5. Co-Gn & 3.6 & 2.6 & 4.6 & 1.7 & 1.0 & 0.4192 & NS \\
\hline 6. Co-Gn minus Co-A pt. & 0.7 & 2.0 & 3.2 & 2.9 & 2.5 & 0.0830 & NS \\
\hline 7. Wits & 0.7 & 1.2 & -1.2 & 1.9 & -1.9 & 0.0456 & * \\
\hline 8. Is-Olp & 2.9 & 1.8 & 0.1 & 2.1 & -2.8 & 0.0194 & * \\
\hline 9. li-Olp & 2.8 & 2.3 & 0.6 & 2.0 & -2.2 & 0.0859 & NS \\
\hline 10. Overjet & 0.2 & 0.7 & -0.5 & 1.4 & -0.7 & 0.3142 & NS \\
\hline 11. Ms-Olp & 2.3 & 2.1 & 3.1 & 1.5 & 0.8 & 0.4510 & NS \\
\hline 12. Mi-Olp & 2.4 & 2.9 & 3.4 & 1.1 & 1.0 & 0.3899 & NS \\
\hline 13. Molar Relationship & -0.1 & 1.2 & -0.4 & 1.0 & -0.3 & 0.6502 & NS \\
\hline \multicolumn{8}{|l|}{ Vertical: } \\
\hline 14. OLs-A pt. & 1.4 & 1.2 & 1.5 & 2.0 & 0.1 & 0.9329 & NS \\
\hline 15. ANS-Me & 1.3 & 1.0 & 3.3 & 1.9 & 2.0 & 0.0262 & * \\
\hline 16. Is-NL & 0.3 & 1.4 & 1.7 & 1.7 & 1.4 & 0.1228 & NS \\
\hline 17. Ii-ML & 1.8 & 1.2 & 1.1 & 1.1 & -0.7 & 0.3018 & NS \\
\hline 18. Overbite & 0.6 & 0.9 & -0.1 & 1.7 & -0.7 & 0.4060 & NS \\
\hline 19. Msc-NL & 0.5 & 0.9 & 1.4 & 1.2 & 0.9 & 0.1625 & NS \\
\hline 20. Mic-ML & 1.5 & 0.9 & 2.0 & 1.7 & 0.5 & 0.5478 & NS \\
\hline \multicolumn{8}{|l|}{ Angular: } \\
\hline 21. SNA & 0.9 & 1.6 & -1.6 & 2.0 & -2.5 & 0.0238 & * \\
\hline 22. SNB & 0.4 & 1.9 & -0.7 & 1.1 & -1.1 & 0.2162 & NS \\
\hline 23. ANB & 0.5 & 0.8 & -0.9 & 1.5 & -1.4 & 0.0455 & $*$ \\
\hline 24. SNL-NL & 0.7 & 1.3 & -0.4 & 1.2 & -1.1 & 0.1205 & NS \\
\hline 25. SNL-ML & 0.1 & 1.5 & 0.9 & 2.0 & 0.8 & 0.4223 & NS \\
\hline 26. SNL-OL & -0.4 & 2.5 & 1.6 & 2.2 & 2.0 & 0.1207 & NS \\
\hline 27. Is/NL & 0.1 & 2.5 & -3.9 & 5.7 & -4.0 & 0.1230 & NS \\
\hline 28. $\mathrm{li} / \mathrm{ML}$ & 0.1 & 2.6 & -2.8 & 4.4 & -2.9 & 0.1648 & NS \\
\hline 29. Interincisal Angle & 0.8 & 2.1 & 5.6 & 7.6 & 4.8 & 0.1299 & NS \\
\hline \multicolumn{8}{|l|}{ Condyle/Glenoid Fossa: } \\
\hline 30. Olp-CoC & 0.1 & 2.0 & -0.7 & 1.8 & -0.8 & 0.4391 & NS \\
\hline 31. Olp-GFS & 0.2 & 2.0 & -1.1 & 2.0 & -1.3 & 0.2318 & NS \\
\hline 32. Olp-GFA & 0.6 & 1.2 & -0.6 & 1.8 & -1.2 & 0.2035 & NS \\
\hline 33. Olp-GFP & -0.3 & 2.8 & -0.9 & 2.0 & -0.6 & 0.6958 & NS \\
\hline 34. Ols-CoC & 1.2 & 1.5 & -0.6 & 2.1 & -1.8 & 0.0836 & NS \\
\hline 35. Ols-GFS & 1.3 & 1.5 & 0.7 & 1.9 & -0.6 & 0.5503 & NS \\
\hline 36. Ols-GFA & 1.4 & 1.2 & 1.1 & 2.0 & -0.3 & 0.7781 & NS \\
\hline 37. Ols-GFP & 1.6 & 1.2 & 1.1 & 2.7 & -0.5 & 0.6419 & NS \\
\hline
\end{tabular}


Table 31. Comparison of treated vs. control in female subjects at T5-T4)

\begin{tabular}{|c|c|c|c|c|c|c|c|}
\hline \multicolumn{8}{|c|}{ FEMALE SUBJECTS } \\
\hline \multirow[b]{2}{*}{ Variable } & \multicolumn{2}{|c|}{$\begin{array}{c}\text { Control } \\
\text { (t5-t4) }\end{array}$} & \multicolumn{2}{|c|}{$\begin{array}{l}\text { Treated } \\
\text { (T5-T4) }\end{array}$} & \multirow[b]{2}{*}{ Diff } & \multirow[b]{2}{*}{$p$ value } & \multirow[b]{2}{*}{ Sig } \\
\hline & Mean & S.D. & Mean & S.D. & & & \\
\hline Age & 18.9 & 5.6 & 18.9 & 5.5 & 0.0 & 0.9739 & NS \\
\hline \multicolumn{8}{|l|}{ Sagittal: } \\
\hline 1. Olp-A pt. & 2.3 & 1.4 & 0.6 & 1.4 & -1.7 & 0.0018 & * \\
\hline 2. Olp-Pg & 2.3 & 1.7 & 1.0 & 1.6 & -1.3 & 0.0387 & * \\
\hline 3. Olp-Co & -0.5 & 2.1 & 0.8 & 1.2 & 1.3 & 0.0609 & NS \\
\hline 4. Co-A pt. & 1.9 & 2.2 & 1.4 & 1.9 & -0.5 & 0.5068 & NS \\
\hline 5. Co-Gn & 2.7 & 2.5 & 3.1 & 2.8 & 0.4 & 0.6676 & NS \\
\hline 6. Co-Gn minus Co-A pt. & 0.8 & 1.8 & 1.7 & 1.8 & 0.9 & 0.1734 & NS \\
\hline 7. Wits & 0.8 & 1.5 & -0.5 & 1.5 & -1.3 & 0.0255 & * \\
\hline 8. Is-Olp & 1.8 & 1.3 & -0.1 & 1.9 & -1.9 & 0.0040 & * \\
\hline 9. Ii-Olp & 1.8 & 1.3 & 0.3 & 1.4 & -1.5 & 0.0061 & * \\
\hline 10. Overjet & 0.0 & 0.7 & -0.4 & 1.6 & -0.4 & 0.3862 & NS \\
\hline 11. Ms-Olp & 2.2 & 1.3 & 1.8 & 1.8 & -0.4 & 0.4503 & NS \\
\hline 12. Mi-Olp & 2.6 & 1.8 & 1.9 & 1.8 & -0.7 & 0.2831 & NS \\
\hline 13. Molar Relationship & -0.4 & 0.8 & -0.1 & 1.1 & 0.3 & 0.3879 & NS \\
\hline \multicolumn{8}{|l|}{ Vertical: } \\
\hline 14. OLs-A pt. & 1.5 & 1.8 & 0.9 & 2.1 & -0.6 & 0.4527 & NS \\
\hline 15. ANS-Me & 1.6 & 1.4 & 1.6 & 2.1 & 0.0 & 0.9652 & NS \\
\hline 16. Is-NL & 0.4 & 1.2 & -0.1 & 1.4 & -0.5 & 0.3114 & NS \\
\hline 17. Ii-ML & 1.0 & 1.0 & 1.0 & 1.5 & 0.0 & 0.9618 & NS \\
\hline 18. Overbite & -0.1 & 0.9 & -0.4 & 1.3 & -0.3 & 0.4243 & NS \\
\hline 19. Msc-NL & 1.2 & 1.0 & 1.3 & 1.6 & 0.1 & 0.9450 & NS \\
\hline 20. Mic-ML & 1.2 & 1.9 & 1.9 & 1.9 & 0.7 & 0.3150 & NS \\
\hline \multicolumn{8}{|l|}{ Angular: } \\
\hline 21. SNA & 1.0 & 1.2 & -0.7 & 2.2 & -1.7 & 0.0149 & * \\
\hline 22. SNB & 0.7 & 1.1 & -0.2 & 1.4 & -0.9 & 0.0783 & NS \\
\hline 23. ANB & 0.4 & 1.1 & -0.5 & 1.0 & -0.9 & 0.0401 & * \\
\hline 24. SNL-NL & 0.5 & 2.0 & 1.7 & 2.4 & 1.2 & 0.1606 & NS \\
\hline 25. SNL-ML & -0.1 & 1.1 & 0.3 & 2.2 & 0.4 & 0.4708 & NS \\
\hline 26. SNL-OL & -1.2 & 1.8 & 1.5 & 3.1 & 2.7 & 0.0062 & * \\
\hline 27. Is/NL & 0.1 & 3.4 & 1.6 & 6.0 & 1.5 & 0.4267 & NS \\
\hline 28. $\mathrm{li} / \mathrm{ML}$ & -1.5 & 2.2 & -0.5 & 5.6 & 1.0 & 0.5390 & NS \\
\hline 29. Interincisal Angle & 2.1 & 3.7 & 0.8 & 9.9 & -1.3 & 0.6391 & NS \\
\hline \multicolumn{8}{|l|}{ Condyle/Glenoid Fossa: } \\
\hline 30. Olp-CoC & 0.5 & 2.2 & -0.6 & 1.2 & -1.1 & 0.1004 & NS \\
\hline 31. Olp-GFS & 0.3 & 2.3 & -0.4 & 1.6 & -0.7 & 0.3607 & NS \\
\hline 32. Olp-GFA & 0.5 & 2.4 & 0.0 & 1.6 & -0.5 & 0.5331 & NS \\
\hline 33. Olp-GFP & 0.2 & 2.3 & 0.2 & 3.4 & 0.0 & 0.9711 & NS \\
\hline 34. Ols-CoC & 0.4 & 1.5 & -0.3 & 1.8 & -0.7 & 0.2820 & NS \\
\hline 35. Ols-GFS & 0.3 & 1.6 & -0.3 & 1.6 & -0.6 & 0.2974 & NS \\
\hline 36. Ols-GFA & 0.5 & 1.6 & -0.2 & 1.5 & -0.7 & 0.2683 & NS \\
\hline 37. Ols-GFP & 0.4 & 1.7 & -0.3 & 1.5 & -0.7 & 0.2892 & NS \\
\hline
\end{tabular}




\section{Overjet and Molar Relationship Change-Treatment Group (T5-T4)}

The amount of skeletal and dental contribution to the overjet and molar relationship change in the treatment group at T5-T4 was calculated using the formulas in Table 11. The amount of overjet change in the treatment group was $0.4 \mathrm{~mm} .0 .8 \mathrm{~mm}$ (200.0\%) of the correction was due to skeletal change. $-0.4 \mathrm{~mm}(-100.0 \%)$ of the correction was due to dental change. The amount of molar relationship change was 0.2 mm. $0.8 \mathrm{~mm}(400.0 \%)$ of the correction was skeletal in nature and $-0.6 \mathrm{~mm}(-300.0 \%)$ of the correction was dental in nature. Calculations are shown for the overjet and molar relationship change on the following pages. In addition, diagrams are provided to illustrate the anterior or posterior movement of the maxillary base, mandibular base, maxillary incisors, mandibular incisors, maxillary molars, and mandibular molars (Figures 35 and 36). A pitchfork analysis describing the skeletal and dental contributions to overjet and molar relationship change is shown in Figure 37. 


\begin{tabular}{|cccc|}
\hline Overiet Change: & \multicolumn{3}{c|}{ Molar relationship change: } \\
\hline Skeletal Contribution: & 0.7 & Skeletal Contribution: & 0.7 \\
1) Maxilla & 1.5 & 1) Maxilla & 1.5 \\
2) Mandible & & 2) Mandible & \\
Dental Contribution: & -0.7 & Dental Contribution: & 1.5 \\
3) Mx incisor & -1.1 & 3) Mx molar & 0.9 \\
4) Md incisor & & 4) Md molar & \\
\hline
\end{tabular}

\section{Overjet Change $=$ Maxilla + Mx incisor - Mandible - Md incisor}

\section{Overjet Change $=0.7+(-0.7)-1.5-(-1.1)=-0.4 \mathrm{~mm}$}
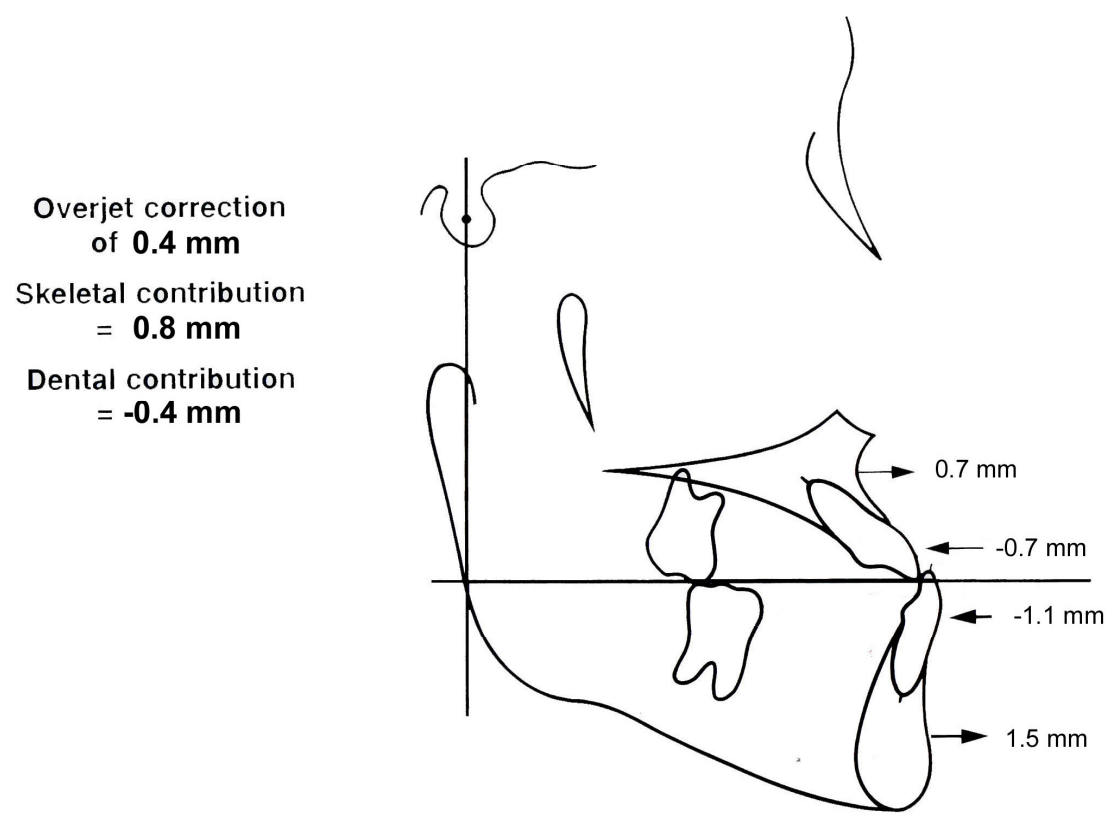

Figure 35. Components of overjet correction (T5-T4) 
Molar Relationship Change = Maxilla + Mx molar - Mandible - Md molar

Molar Relationship Change $=0.7+1.5-1.5-0.9=-0.2 \mathrm{~mm}$

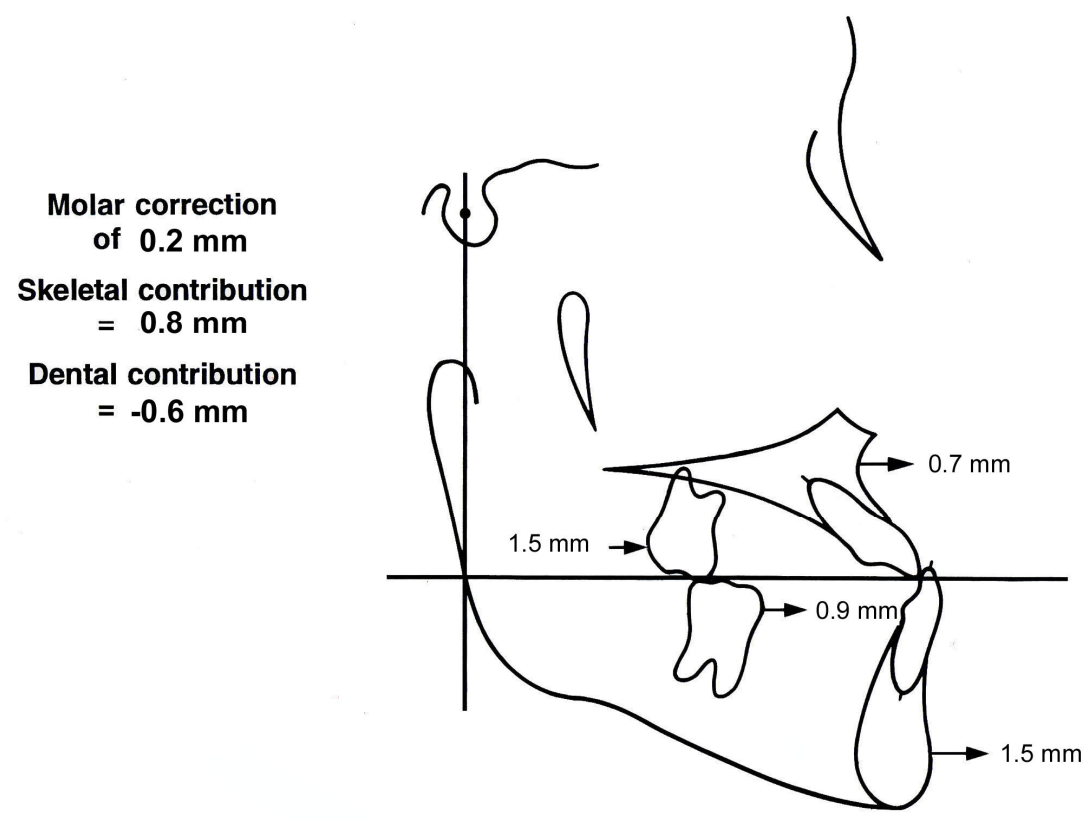

Figure 36. Components of molar relationship correction (T5-T4)

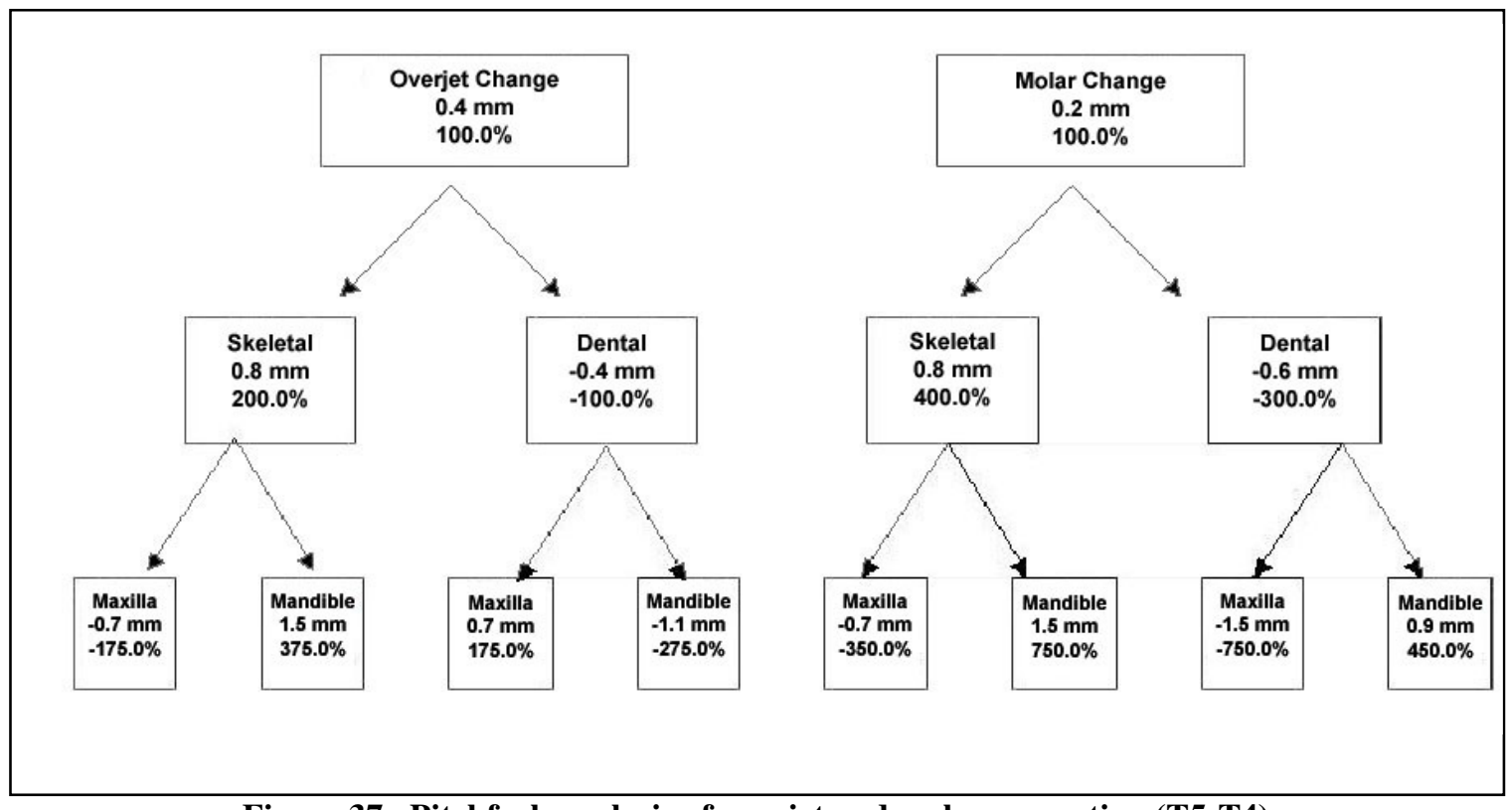

Figure 37. Pitchfork analysis of overjet and molar correction (T5-T4) 


\section{Net Overjet and Molar Relationship Change-Tx vs. Control Group (T5-T4)}

The amount of skeletal and dental contribution to the net overjet and net molar relationship change in the treatment group vs. the control group at T5-T4 was calculated using the formulas in Table 11. The amount of net overjet change in the treatment group relative to the control group was $0.5 \mathrm{~mm}$. $0.7 \mathrm{~mm}(140.0 \%)$ of the correction was due to skeletal movement. $-0.2 \mathrm{~mm}(-40.0 \%)$ of the correction was due to dental movement. The amount of net molar relationship change was $-0.1 \mathrm{~mm} .0 .7 \mathrm{~mm}(-700.0 \%)$ of the correction was skeletal in nature and $-0.8 \mathrm{~mm}(800.0 \%)$ of the correction was dental in nature. Calculations are shown for the net overjet and net molar relationship change on the following pages. In addition, diagrams are provided to illustrate the net anterior or posterior movement of the maxillary base, mandibular base, maxillary incisors, mandibular incisors, maxillary molars, and mandibular molars (Figures 38 and 39). A pitchfork analysis describing the net skeletal and dental contributions to overjet and molar relationship change is shown in Figure 40. 


\begin{tabular}{|cccc|}
\hline Net Overiet Change: & & Net Molar change: & \\
\hline Skeletal Contribution: & -1.8 & Skeletal Contribution: & -1.8 \\
1) Maxilla & -1.1 & 1) Maxilla & -1.1 \\
2) Mandible & & 2) Mandible & \\
Dental Contribution: & -0.4 & 3) Mx molar & 1.7 \\
3) Mx incisor & -0.6 & 4) Md molar & 0.9 \\
4) Md incisor & & & \\
\hline
\end{tabular}

Net Overjet Change $=$ Maxilla + Mx incisor - Mandible - Md incisor

Net Overjet Change $=(-1.8)+(-0.4)-(-1.1)-(-0.6)=-0.5 \mathrm{~mm}$
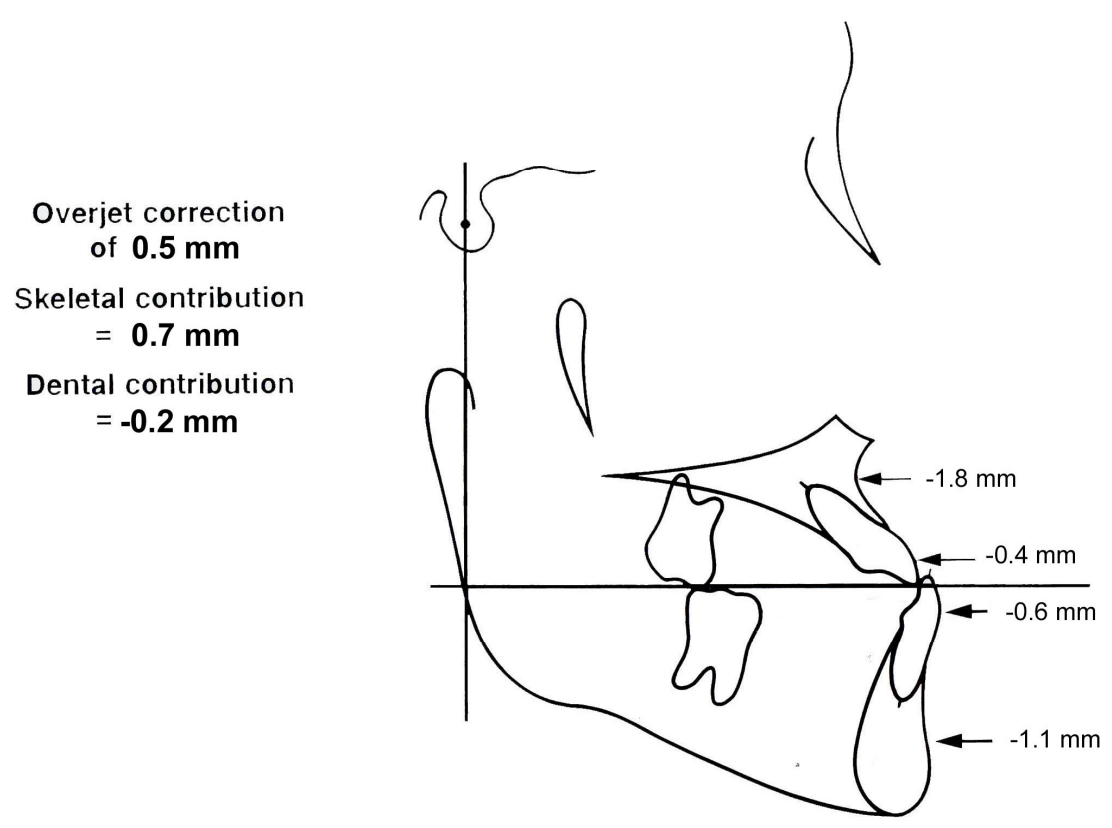

Figure 38. Components of net overjet correction (T5-T4) 
Net Molar Relationship Change $=$ Maxilla + Mx molar - Mandible - Md molar

Net Molar Relationship Change $=(-1.8)+1.7-(-1.1)-0.9=0.1 \mathrm{~mm}$

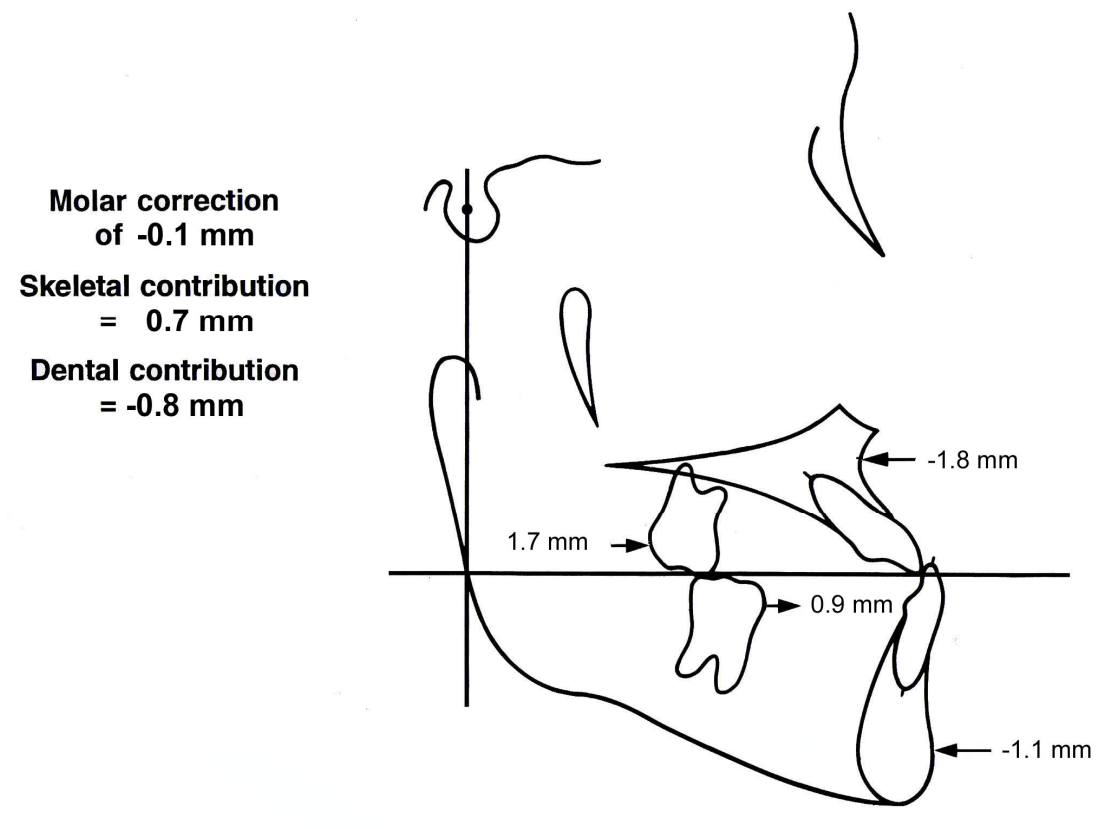

Figure 39. Components of net molar correction (T5-T4)

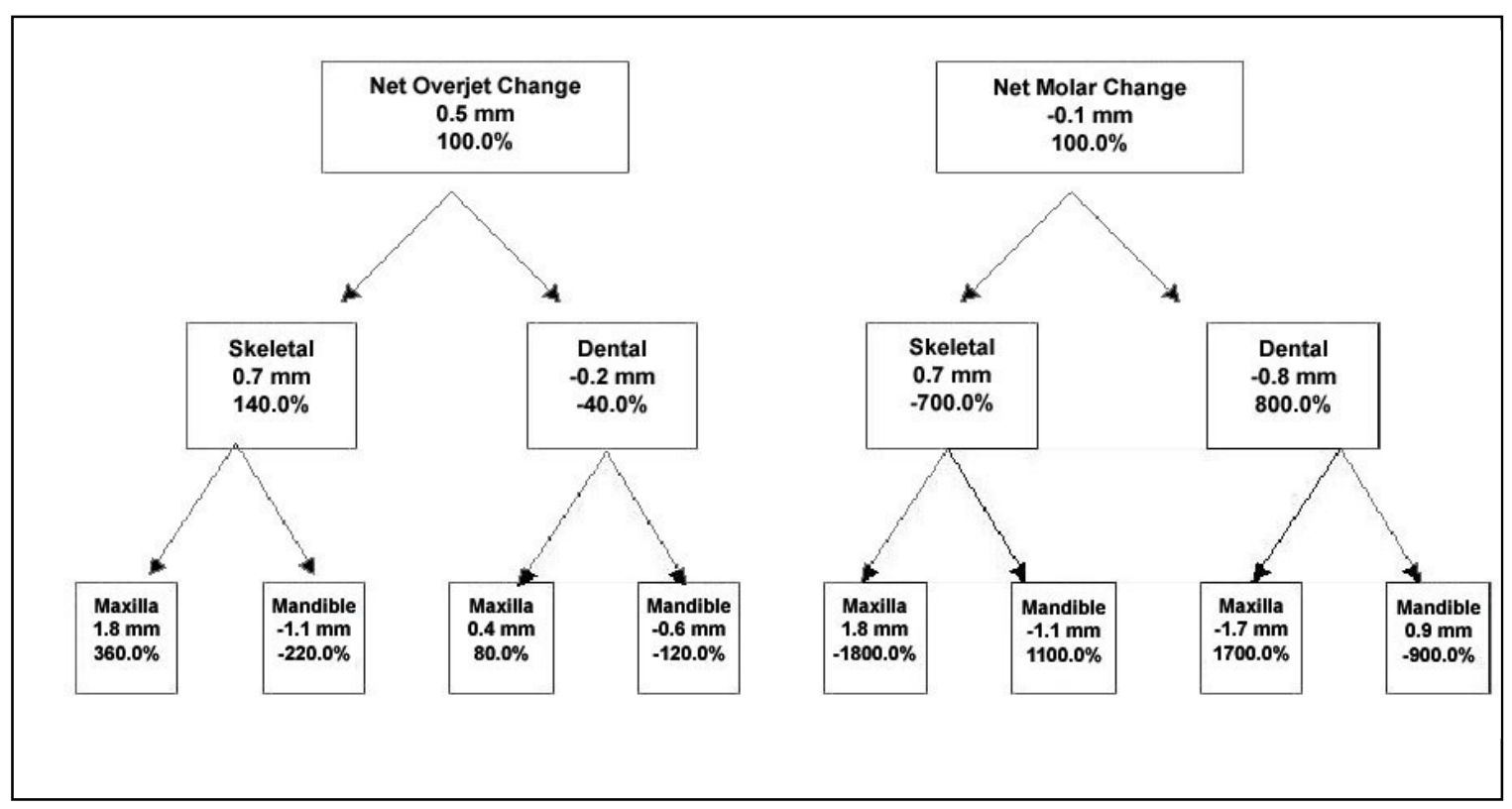

Figure 40. Pitchfork analysis of net overjet and molar correction (T5-T4) 


\section{Comparison of T4-T3 (Relapse after Phase I to before Phase II Treatment)}

Of the 37 variables investigated, 7 showed statistically significant differences between the treatment group and control group in pooled subjects in the time period T4T3 (Table 32). Four of the sagittal variables, one of the vertical variables, two of the angular variables, and none of the condyle/glenoid fossa variables showed significant differences between the treatment and control groups during this time period. Significance differences in variables are apparent for male subjects only and female subjects only and are reported in Tables 33 and 34, respectively. Only data from pooled subjects is reported here.

Sagittal differences: The four sagittal variables that showed a significant difference between the treatment and control groups at T4-T3 were Co-Gn, Wits analysis, Mi-OLp, and molar relationship. . Effective mandibular length (Co-Gn) showed a -2.5 $\mathrm{mm}$ difference in the treatment group relative to the the control group, indicating a possible "catch-up" period of mandibular growth in the control group. The position of the maxilla relative to the mandible along the functional occlusal plane (Wits) showed a net difference of $1.7 \mathrm{~mm}$ in the treatment group compared to the control group, suggesting a period of relapse in maxillary-mandibular relationship during this time period. The mandibular molars (Mi-OLp) moved forward a distance of $2.6 \mathrm{~mm}$ in the treatment group and $4.4 \mathrm{~mm}$ forward in the control group during this time period, suggesting a net relapse of $1.8 \mathrm{~mm}$ in a posterior direction in the treatment group compared to the control. Molar relationship will be addressed in a later section.

Vertical differences: All vertical variables showed no significant difference between the treatment and control groups at T4-T3 except for ANS-Me. The lower face 
height (ANS-Me) decreased a net distance of $1.8 \mathrm{~mm}$ in the treatment group relative to the control group during this time period.

Angular differences: All angular variables showed no significant difference between the treatment and control groups at T4-T3 except for SNL-OL and Interincisal angle. A net decrease of $3.7^{\circ}$ in the treatment group was found in the functional occlusal plane angle (SNL-OL), suggesting a return to the pre-treatment level. The interincisal angle decreased $4.4^{\circ}$ in the treatment group relative to the control group during this time period, suggesting flaring of the maxillary and mandibular incisors. Although not significant, the maxillary incisor angle (Is/NL) and the mandibular incisor angle (Ii/ML) showed a net increase of $2.9^{\circ}$ and $2.5^{\circ}$, respectively, in the treatment group compared to the control group.

Condyle/Glenoid Fossa differences: None of the condyle/glenoid fossa variables showed significant differences between the treatment and control groups at T4-T3. Every sagittal condyle/glenoid fossa variable (OLp-CoC, OLp-GFS, OLp-GFA, and OLp-GFP) in the treatment group moved backward, although the distance was less than the backward movement of the sagittal condyle/glenoid fossa variables in the control group. No significant differences or trends were found in the vertical condyle/glenoid fossa variables between the treatment and control groups. 
Table 32. Comparison of treated vs. control in pooled subjects at T4-T3

\begin{tabular}{|c|c|c|c|c|c|c|c|}
\hline \multicolumn{8}{|c|}{ POOLED (MALES AND FEMALES) } \\
\hline \multirow[b]{2}{*}{ Variable } & \multicolumn{2}{|c|}{$\begin{array}{c}\text { Control } \\
(\mathrm{t} 5-\mathrm{t} 4)\end{array}$} & \multicolumn{2}{|c|}{$\begin{array}{l}\text { Treated } \\
\text { (T5-T4) }\end{array}$} & \multirow[b]{2}{*}{ Diff } & \multirow[b]{2}{*}{$p$ value } & \multirow[b]{2}{*}{ Sig } \\
\hline & Mean & S.D. & Mean & S.D. & & & \\
\hline Age & 19.8 & 8.1 & 20.0 & 6.6 & 0.2 & 0.9192 & NS \\
\hline \multicolumn{8}{|l|}{ Sagittal: } \\
\hline 1. Olp-A pt. & 2.5 & 1.5 & 0.7 & 1.5 & -1.8 & 0.0002 & * \\
\hline 2. Olp-Pg & 2.6 & 2.4 & 1.5 & 1.7 & -1.1 & 0.1134 & NS \\
\hline 3. Olp-Co & -0.3 & 2.0 & 0.6 & 1.4 & 0.9 & 0.0755 & NS \\
\hline 4. Co-A pt. & 2.2 & 2.1 & 1.4 & 2.1 & -0.8 & 0.1952 & NS \\
\hline 5. Co-Gn & 2.9 & 2.5 & 3.5 & 2.5 & 0.6 & 0.4366 & NS \\
\hline 6. Co-Gn minus Co-A pt. & 0.7 & 1.8 & 2.2 & 2.3 & 1.5 & 0.0260 & * \\
\hline 7. Wits & 0.7 & 1.4 & -0.8 & 1.6 & -1.5 & 0.0022 & * \\
\hline 8. Is-Olp & 2.2 & 1.5 & 0.0 & 1.9 & -2.2 & 0.0002 & * \\
\hline 9. li-Olp & 2.1 & 1.7 & 0.4 & 1.6 & -1.7 & 0.0014 & * \\
\hline 10. Overjet & 0.0 & 0.7 & -0.4 & 1.5 & -0.4 & 0.1899 & NS \\
\hline 11. Ms-Olp & 2.3 & 1.5 & 2.2 & 1.8 & -0.1 & 0.9175 & NS \\
\hline 12. Mi-Olp & 2.6 & 2.2 & 2.4 & 1.8 & -0.2 & 0.7785 & NS \\
\hline 13. Molar Relationship & -0.3 & 0.9 & -0.1 & 1.0 & 0.2 & 0.6962 & NS \\
\hline \multicolumn{8}{|l|}{ Vertical: } \\
\hline 14. OLs-A pt. & 1.5 & 1.6 & 1.1 & 2.0 & -0.4 & 0.5352 & NS \\
\hline 15. ANS-Me & 1.5 & 1.3 & 2.2 & 2.2 & 0.7 & 0.2114 & NS \\
\hline 16. Is-NL & 0.3 & 1.2 & 0.4 & 1.7 & 0.1 & 0.8341 & NS \\
\hline 17. Ii-ML & 1.2 & 1.1 & 1.0 & 1.4 & -0.2 & 0.5409 & NS \\
\hline 18. Overbite & 0.1 & 0.9 & -0.3 & 1.4 & -0.4 & 0.2443 & NS \\
\hline 19. Msc-NL & 1.0 & 1.0 & 1.3 & 1.4 & 0.3 & 0.4221 & NS \\
\hline 20. Mic-ML & 1.3 & 1.7 & 1.9 & 1.8 & 0.6 & 0.2327 & NS \\
\hline \multicolumn{8}{|l|}{ Angular: } \\
\hline 21. SNA & 1.0 & 1.3 & -1.0 & 2.2 & -2.0 & 0.0008 & * \\
\hline 22. SNB & 0.6 & 1.4 & -0.4 & 1.3 & -1.0 & 0.0278 & * \\
\hline 23. ANB & 0.4 & 1.0 & -0.6 & 1.2 & -1.0 & 0.0033 & $*$ \\
\hline 24. SNL-NL & 0.6 & 1.8 & 1.0 & 2.3 & 0.4 & 0.4917 & NS \\
\hline 25. SNL-ML & -0.1 & 1.2 & 0.5 & 2.1 & 0.6 & 0.2802 & NS \\
\hline 26. SNL-OL & -1.0 & 2.0 & 1.6 & 2.8 & 2.6 & 0.0013 & * \\
\hline 27. Is/NL & 0.1 & 3.1 & -0.2 & 6.3 & -0.3 & 0.8566 & NS \\
\hline 28. $\mathrm{li} / \mathrm{ML}$ & -1.0 & 2.4 & -1.2 & 5.3 & -0.2 & 0.8400 & NS \\
\hline 29. Interincisal Angle & 1.7 & 3.3 & 2.3 & 9.4 & 0.6 & 0.7573 & NS \\
\hline \multicolumn{8}{|l|}{ Condyle/Glenoid Fossa: } \\
\hline 30. Olp-CoC & 0.4 & 2.1 & -0.6 & 1.4 & -1.0 & 0.0665 & NS \\
\hline 31. Olp-GFS & 0.3 & 2.2 & -0.6 & 1.7 & -0.9 & 0.1426 & NS \\
\hline 32. OIp-GFA & 0.5 & 2.1 & -0.2 & 1.6 & -0.7 & 0.2379 & NS \\
\hline 33. Olp-GFP & 0.0 & 2.4 & -0.2 & 3.0 & -0.2 & 0.8158 & NS \\
\hline 34. Ols-CoC & 0.6 & 1.5 & -0.4 & 1.9 & -1.0 & 0.0484 & * \\
\hline 35. Ols-GFS & 0.6 & 1.6 & 0.0 & 1.7 & -0.6 & 0.2376 & NS \\
\hline 36. Ols-GFA & 0.8 & 1.5 & 0.2 & 1.7 & -0.6 & 0.3021 & NS \\
\hline 37. Ols-GFP & 0.8 & 1.6 & 0.2 & 2.0 & -0.6 & 0.2796 & NS \\
\hline
\end{tabular}


Table 33. Comparison of treated vs. control in pooled subjects at T4-T3.

\begin{tabular}{|c|c|c|c|c|c|c|c|}
\hline \multicolumn{8}{|c|}{ MALE SUBJECTS } \\
\hline \multirow[b]{2}{*}{ Variable } & \multicolumn{2}{|c|}{$\begin{array}{c}\text { Control } \\
(\mathrm{t} 5-\mathrm{t} 4)\end{array}$} & \multicolumn{2}{|c|}{$\begin{array}{l}\text { Treated } \\
\text { (T5-T4) }\end{array}$} & \multirow[b]{2}{*}{ Diff } & \multirow[b]{2}{*}{$p$ value } & \multirow[b]{2}{*}{ Sig } \\
\hline & Mean & S.D. & Mean & S.D. & & & \\
\hline Age & 21.7 & 12.3 & 22.6 & 8.4 & 0.9 & 0.8814 & NS \\
\hline \multicolumn{8}{|l|}{ Sagittal: } \\
\hline 1. Olp-A pt. & 3.0 & 1.5 & 1.0 & 1.9 & -2.0 & 0.0503 & NS \\
\hline 2. Olp-Pg & 3.1 & 3.6 & 2.7 & 1.5 & -0.4 & 0.7843 & NS \\
\hline 3. Olp-Co & 0.0 & 1.9 & 0.3 & 1.8 & 0.3 & 0.7295 & NS \\
\hline 4. Co-A pt. & 2.9 & 1.7 & 1.4 & 2.5 & -1.5 & 0.2180 & NS \\
\hline 5. Co-Gn & 3.6 & 2.6 & 4.6 & 1.7 & 1.0 & 0.4192 & NS \\
\hline 6. Co-Gn minus Co-A pt. & 0.7 & 2.0 & 3.2 & 2.9 & 2.5 & 0.0830 & NS \\
\hline 7. Wits & 0.7 & 1.2 & -1.2 & 1.9 & -1.9 & 0.0456 & * \\
\hline 8. Is-Olp & 2.9 & 1.8 & 0.1 & 2.1 & -2.8 & 0.0194 & * \\
\hline 9. li-Olp & 2.8 & 2.3 & 0.6 & 2.0 & -2.2 & 0.0859 & NS \\
\hline 10. Overjet & 0.2 & 0.7 & -0.5 & 1.4 & -0.7 & 0.3142 & NS \\
\hline 11. Ms-Olp & 2.3 & 2.1 & 3.1 & 1.5 & 0.8 & 0.4510 & NS \\
\hline 12. Mi-Olp & 2.4 & 2.9 & 3.4 & 1.1 & 1.0 & 0.3899 & NS \\
\hline 13. Molar Relationship & -0.1 & 1.2 & -0.4 & 1.0 & -0.3 & 0.6502 & NS \\
\hline \multicolumn{8}{|l|}{ Vertical: } \\
\hline 14. OLs-A pt. & 1.4 & 1.2 & 1.5 & 2.0 & 0.1 & 0.9329 & NS \\
\hline 15. ANS-Me & 1.3 & 1.0 & 3.3 & 1.9 & 2.0 & 0.0262 & * \\
\hline 16. Is-NL & 0.3 & 1.4 & 1.7 & 1.7 & 1.4 & 0.1228 & NS \\
\hline 17. Ii-ML & 1.8 & 1.2 & 1.1 & 1.1 & -0.7 & 0.3018 & NS \\
\hline 18. Overbite & 0.6 & 0.9 & -0.1 & 1.7 & -0.7 & 0.4060 & NS \\
\hline 19. Msc-NL & 0.5 & 0.9 & 1.4 & 1.2 & 0.9 & 0.1625 & NS \\
\hline 20. Mic-ML & 1.5 & 0.9 & 2.0 & 1.7 & 0.5 & 0.5478 & NS \\
\hline \multicolumn{8}{|l|}{ Angular: } \\
\hline 21. SNA & 0.9 & 1.6 & -1.6 & 2.0 & -2.5 & 0.0238 & * \\
\hline 22. SNB & 0.4 & 1.9 & -0.7 & 1.1 & -1.1 & 0.2162 & NS \\
\hline 23. ANB & 0.5 & 0.8 & -0.9 & 1.5 & -1.4 & 0.0455 & * \\
\hline 24. SNL-NL & 0.7 & 1.3 & -0.4 & 1.2 & -1.1 & 0.1205 & NS \\
\hline 25. SNL-ML & 0.1 & 1.5 & 0.9 & 2.0 & 0.8 & 0.4223 & NS \\
\hline 26. SNL-OL & -0.4 & 2.5 & 1.6 & 2.2 & 2.0 & 0.1207 & NS \\
\hline 27. Is/NL & 0.1 & 2.5 & -3.9 & 5.7 & -4.0 & 0.1230 & NS \\
\hline 28. $\mathrm{li} / \mathrm{ML}$ & 0.1 & 2.6 & -2.8 & 4.4 & -2.9 & 0.1648 & NS \\
\hline 29. Interincisal Angle & 0.8 & 2.1 & 5.6 & 7.6 & 4.8 & 0.1299 & NS \\
\hline \multicolumn{8}{|l|}{ Condyle/Glenoid Fossa: } \\
\hline 30. Olp-CoC & 0.1 & 2.0 & -0.7 & 1.8 & -0.8 & 0.4391 & NS \\
\hline 31. Olp-GFS & 0.2 & 2.0 & -1.1 & 2.0 & -1.3 & 0.2318 & NS \\
\hline 32. Olp-GFA & 0.6 & 1.2 & -0.6 & 1.8 & -1.2 & 0.2035 & NS \\
\hline 33. Olp-GFP & -0.3 & 2.8 & -0.9 & 2.0 & -0.6 & 0.6958 & NS \\
\hline 34. Ols-CoC & 1.2 & 1.5 & -0.6 & 2.1 & -1.8 & 0.0836 & NS \\
\hline 35. Ols-GFS & 1.3 & 1.5 & 0.7 & 1.9 & -0.6 & 0.5503 & NS \\
\hline 36. Ols-GFA & 1.4 & 1.2 & 1.1 & 2.0 & -0.3 & 0.7781 & NS \\
\hline 37. Ols-GFP & 1.6 & 1.2 & 1.1 & 2.7 & -0.5 & 0.6419 & NS \\
\hline
\end{tabular}


Table 34. Comparison of treated vs. control in female subjects at T4-T3.

\begin{tabular}{|c|c|c|c|c|c|c|c|}
\hline \multicolumn{8}{|c|}{ FEMALE SUBJECTS } \\
\hline \multirow[b]{2}{*}{ Variable } & \multicolumn{2}{|c|}{$\begin{array}{c}\text { Control } \\
(\mathrm{t} 5-\mathrm{t} 4)\end{array}$} & \multicolumn{2}{|c|}{$\begin{array}{l}\text { Treated } \\
\text { (T5-T4) }\end{array}$} & \multirow[b]{2}{*}{ Diff } & \multirow[b]{2}{*}{$p$ value } & \multirow[b]{2}{*}{ Sig } \\
\hline & Mean & S.D. & Mean & S.D. & & & \\
\hline Age & 18.9 & 5.6 & 18.9 & 5.5 & 0.0 & 0.9739 & NS \\
\hline \multicolumn{8}{|l|}{ Sagittal: } \\
\hline 1. Olp-A pt. & 2.3 & 1.4 & 0.6 & 1.4 & -1.7 & 0.0018 & * \\
\hline 2. Olp-Pg & 2.3 & 1.7 & 1.0 & 1.6 & -1.3 & 0.0387 & * \\
\hline 3. Olp-Co & -0.5 & 2.1 & 0.8 & 1.2 & 1.3 & 0.0609 & NS \\
\hline 4. Co-A pt. & 1.9 & 2.2 & 1.4 & 1.9 & -0.5 & 0.5068 & NS \\
\hline 5. Co-Gn & 2.7 & 2.5 & 3.1 & 2.8 & 0.4 & 0.6676 & NS \\
\hline 6. Co-Gn minus Co-A pt. & 0.8 & 1.8 & 1.7 & 1.8 & 0.9 & 0.1734 & NS \\
\hline 7. Wits & 0.8 & 1.5 & -0.5 & 1.5 & -1.3 & 0.0255 & * \\
\hline 8. Is-Olp & 1.8 & 1.3 & -0.1 & 1.9 & -1.9 & 0.0040 & * \\
\hline 9. li-Olp & 1.8 & 1.3 & 0.3 & 1.4 & -1.5 & 0.0061 & * \\
\hline 10. Overjet & 0.0 & 0.7 & -0.4 & 1.6 & -0.4 & 0.3862 & NS \\
\hline 11. Ms-Olp & 2.2 & 1.3 & 1.8 & 1.8 & -0.4 & 0.4503 & NS \\
\hline 12. Mi-Olp & 2.6 & 1.8 & 1.9 & 1.8 & -0.7 & 0.2831 & NS \\
\hline 13. Molar Relationship & -0.4 & 0.8 & -0.1 & 1.1 & 0.3 & 0.3879 & NS \\
\hline \multicolumn{8}{|l|}{ Vertical: } \\
\hline 14. OLs-A pt. & 1.5 & 1.8 & 0.9 & 2.1 & -0.6 & 0.4527 & NS \\
\hline 15. ANS-Me & 1.6 & 1.4 & 1.6 & 2.1 & 0.0 & 0.9652 & NS \\
\hline 16. Is-NL & 0.4 & 1.2 & -0.1 & 1.4 & -0.5 & 0.3114 & NS \\
\hline 17. Ii-ML & 1.0 & 1.0 & 1.0 & 1.5 & 0.0 & 0.9618 & NS \\
\hline 18. Overbite & -0.1 & 0.9 & -0.4 & 1.3 & -0.3 & 0.4243 & NS \\
\hline 19. Msc-NL & 1.2 & 1.0 & 1.3 & 1.6 & 0.1 & 0.9450 & NS \\
\hline 20. Mic-ML & 1.2 & 1.9 & 1.9 & 1.9 & 0.7 & 0.3150 & NS \\
\hline \multicolumn{8}{|l|}{ Angular: } \\
\hline 21. SNA & 1.0 & 1.2 & -0.7 & 2.2 & -1.7 & 0.0149 & * \\
\hline 22. SNB & 0.7 & 1.1 & -0.2 & 1.4 & -0.9 & 0.0783 & NS \\
\hline 23. ANB & 0.4 & 1.1 & -0.5 & 1.0 & -0.9 & 0.0401 & * \\
\hline 24. SNL-NL & 0.5 & 2.0 & 1.7 & 2.4 & 1.2 & 0.1606 & NS \\
\hline 25. SNL-ML & -0.1 & 1.1 & 0.3 & 2.2 & 0.4 & 0.4708 & NS \\
\hline 26. SNL-OL & -1.2 & 1.8 & 1.5 & 3.1 & 2.7 & 0.0062 & ${ }^{*}$ \\
\hline 27. Is/NL & 0.1 & 3.4 & 1.6 & 6.0 & 1.5 & 0.4267 & NS \\
\hline 28. $\mathrm{li} / \mathrm{ML}$ & -1.5 & 2.2 & -0.5 & 5.6 & 1.0 & 0.5390 & NS \\
\hline 29. Interincisal Angle & 2.1 & 3.7 & 0.8 & 9.9 & -1.3 & 0.6391 & NS \\
\hline \multicolumn{8}{|l|}{ Condyle/Glenoid Fossa: } \\
\hline 30. Olp-CoC & 0.5 & 2.2 & -0.6 & 1.2 & -1.1 & 0.1004 & NS \\
\hline 31. Olp-GFS & 0.3 & 2.3 & -0.4 & 1.6 & -0.7 & 0.3607 & NS \\
\hline 32. Olp-GFA & 0.5 & 2.4 & 0.0 & 1.6 & -0.5 & 0.5331 & NS \\
\hline 33. Olp-GFP & 0.2 & 2.3 & 0.2 & 3.4 & 0.0 & 0.9711 & NS \\
\hline 34. Ols-CoC & 0.4 & 1.5 & -0.3 & 1.8 & -0.7 & 0.2820 & NS \\
\hline 35. Ols-GFS & 0.3 & 1.6 & -0.3 & 1.6 & -0.6 & 0.2974 & NS \\
\hline 36. Ols-GFA & 0.5 & 1.6 & -0.2 & 1.5 & -0.7 & 0.2683 & NS \\
\hline 37. Ols-GFP & 0.4 & 1.7 & -0.3 & 1.5 & -0.7 & 0.2892 & NS \\
\hline
\end{tabular}




\section{Overjet and Molar Relationship Change-Treatment Group (T4-T3)}

The amount of skeletal and dental contribution to the overjet and molar relationship change in the treatment group at T4-T3 was calculated using the formulas in Table 11. The amount of overjet change in the treatment group was $-0.8 \mathrm{~mm} .0 .6 \mathrm{~mm}(-$ $75.0 \%)$ of the correction was due to skeletal change. $-1.4 \mathrm{~mm}(175.0 \%)$ of the correction was due to dental change. The amount of molar relationship change was $-0.8 \mathrm{~mm} .0 .6$ $\mathrm{mm}(-75.0 \%)$ of the correction was skeletal in nature and $-1.4 \mathrm{~mm}(175.0 \%)$ of the correction was dental in nature. Calculations are shown for the overjet and molar relationship change on the following pages. In addition, diagrams are provided to illustrate the anterior or posterior movement of the maxillary base, mandibular base, maxillary incisors, mandibular incisors, maxillary molars, and mandibular molars (Figures 41 and 42). A pitchfork analysis describing the skeletal and dental contributions to overjet and molar relationship change is shown in Figure 43. 


\begin{tabular}{|cccc|}
\hline Overiet Change: & \multicolumn{3}{c|}{ Molar relationship change: } \\
\hline Skeletal Contribution: & 2.4 & Skeletal Contribution: & \\
1) Maxilla & 3.0 & 1) Maxilla & 2.4 \\
2) Mandible & & 2) Mandible & 3.0 \\
Dental Contribution: & 1.7 & Dental Contribution: & \\
3) Mx incisor & 0.3 & 3) Mx molar & 1.0 \\
4) Md incisor & & 4) Md molar & -0.4 \\
\hline
\end{tabular}

\section{Overjet Change $=$ Maxilla + Mx incisor - Mandible - Md incisor}

\section{Overjet Change $=2.4+1.7-3.0-0.3=0.8 \mathrm{~mm}$}
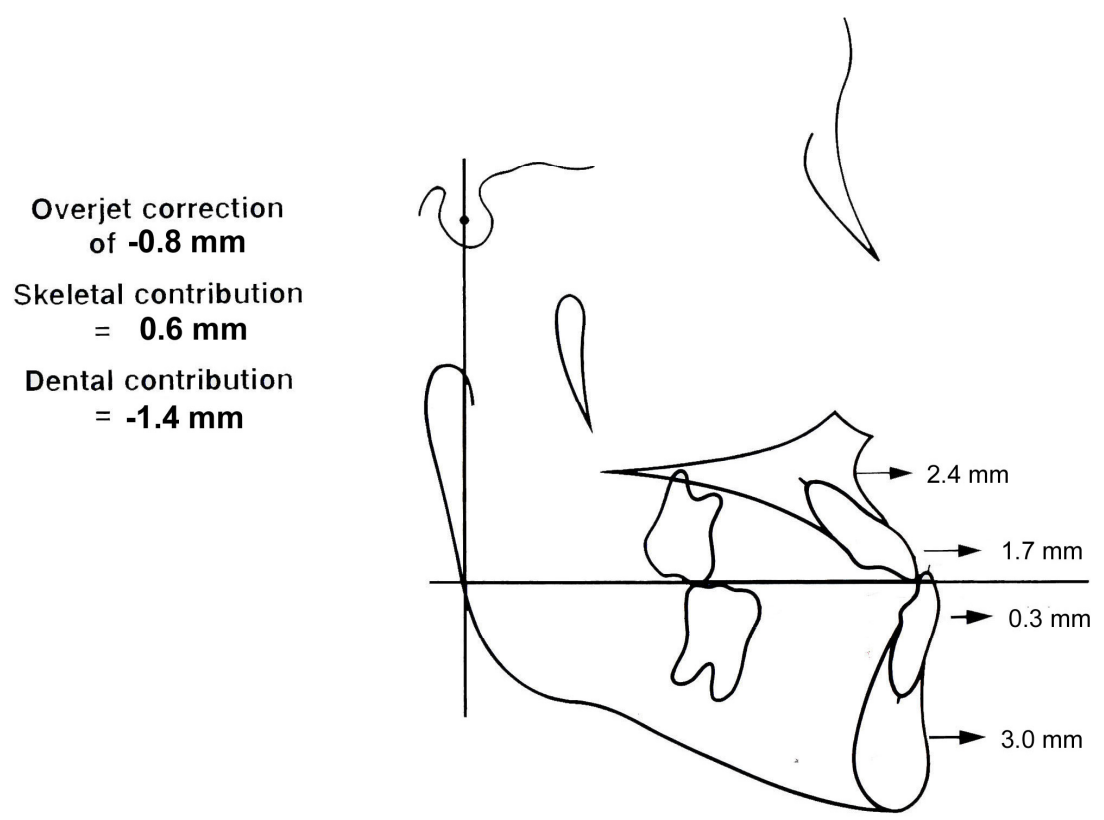

Figure 41. Components of overjet correction (T4-T3) 
Molar Relationship Change = Maxilla + Mx molar - Mandible - Md molar

Molar Relationship Change $=2.4+1.0-3.0-(0.4)=0.8 \mathrm{~mm}$

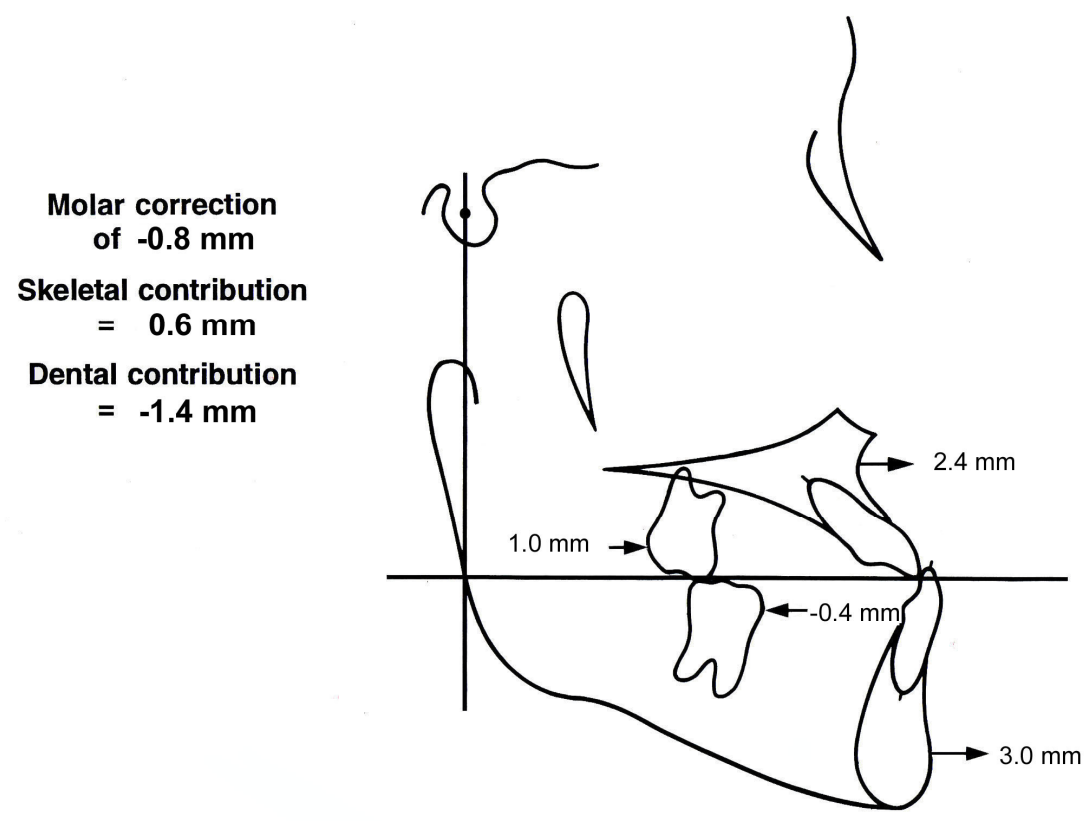

Figure 42. Components of molar relationship correction (T4-T3)

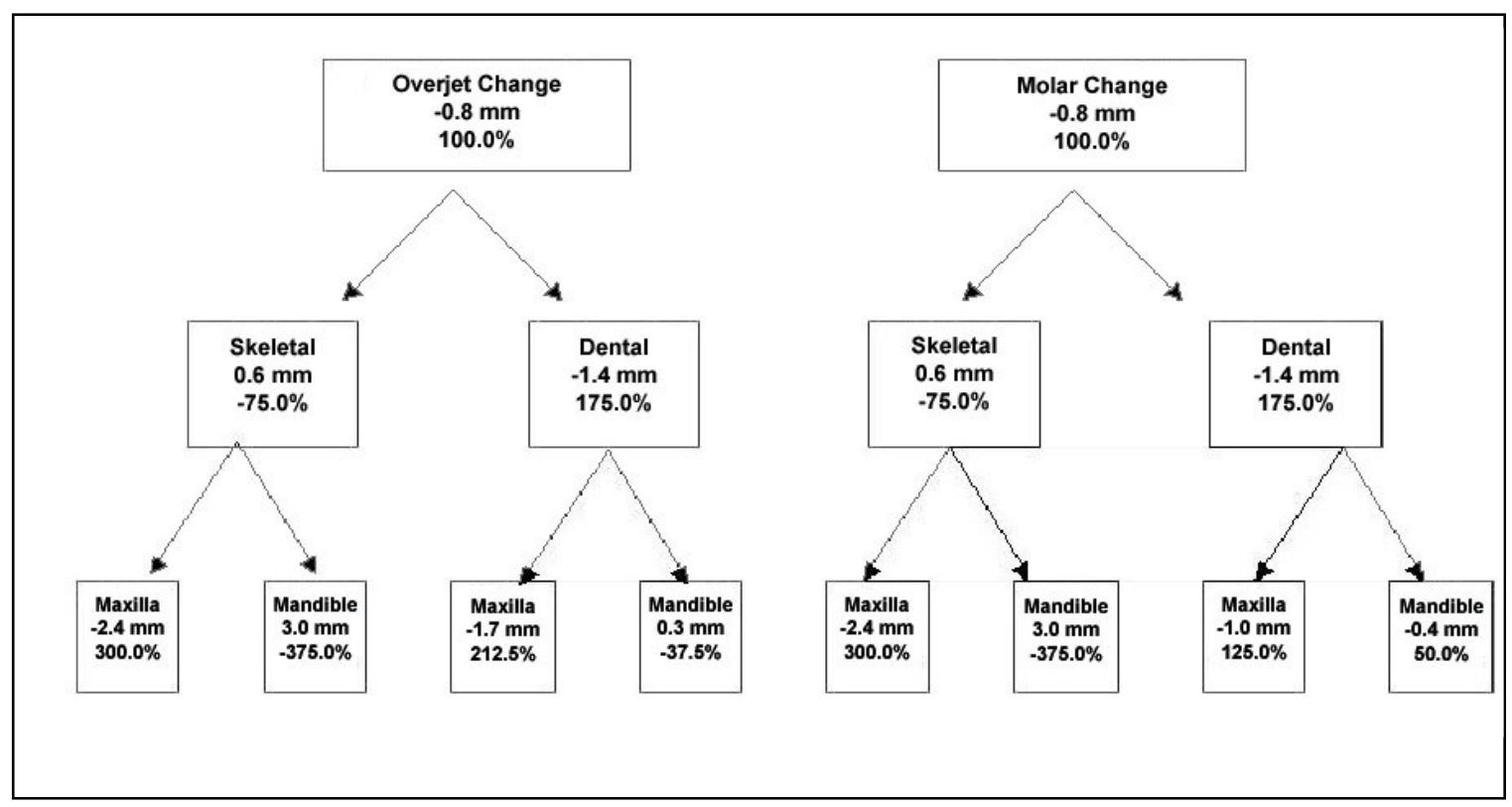

Figure 43. Pitchfork analysis of overjet and molar correction (T4-T3) 


\section{Net Overjet and Molar Relationship Change-Tx vs. Control Group (T4-T3)}

The amount of skeletal and dental contribution to the net overjet and net molar relationship change in the treatment group vs. the control group at T4-T3 was calculated using the formulas in Table 11. The amount of net overjet change in the treatment group relative to the control group was $-0.8 \mathrm{~mm}$. $-1.0 \mathrm{~mm}(125.0 \%)$ of the correction was due to skeletal movement. $0.2 \mathrm{~mm}(-25.0 \%)$ of the correction was due to dental movement. The amount of net molar relationship change was $-1.0 \mathrm{~mm} .-1.0 \mathrm{~mm}(100.0 \%)$ of the correction was skeletal in nature and $0.0 \mathrm{~mm}(0.0 \%)$ of the correction was dental in nature. Calculations are shown for the net overjet and net molar relationship change on the following pages. In addition, diagrams are provided to illustrate the net anterior or posterior movement of the maxillary base, mandibular base, maxillary incisors, mandibular incisors, maxillary molars, and mandibular molars (Figures 44 and 45). A pitchfork analysis describing the net skeletal and dental contributions to overjet and molar relationship change is shown in Figure 46. 


\begin{tabular}{|cccc|}
\hline Net Overiet Change: & & Net Molar change: & \\
\hline Skeletal Contribution: & -0.1 & Skeletal Contribution: & -0.1 \\
1) Maxilla & -1.1 & 1) Maxilla & -1.1 \\
2) Mandible & & 2) Mandible & \\
Dental Contribution: & 0.8 & 3) Mxtal Contribution: & -0.7 \\
3) Mx incisor & 1.0 & 4) Md molar & -0.7 \\
4) Md incisor & & & \\
\hline
\end{tabular}

\section{Net Overjet Change $=$ Maxilla + Mx incisor - Mandible - Md incisor}

\section{Net Overjet Change $=(-0.1)+0.8-(-1.1)-1.0=0.8 \mathrm{~mm}$}
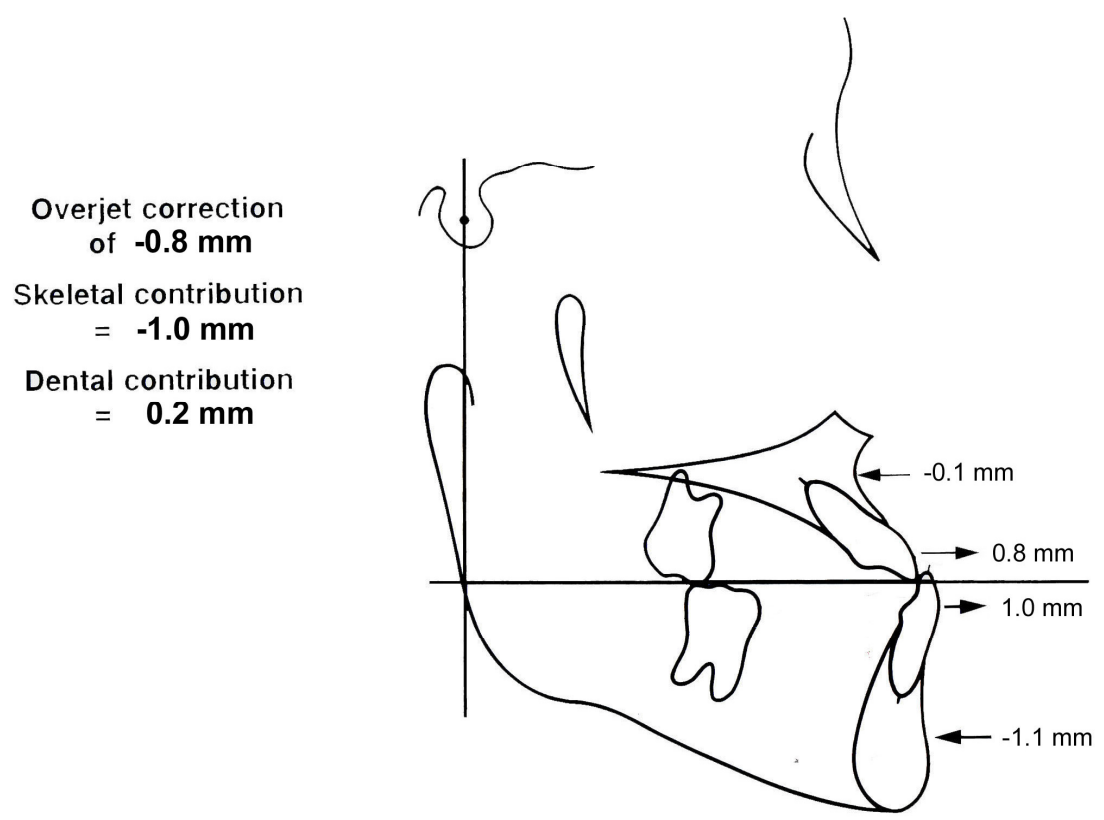

Figure 44. Components of net overjet correction (T4-T3) 
Net Molar Relationship Change = Maxilla + Mx molar - Mandible - Md molar

Net Molar Relationship Change $=(-0.1)+(-0.7)-(-1.1)-(-0.7)=1.0 \mathrm{~mm}$
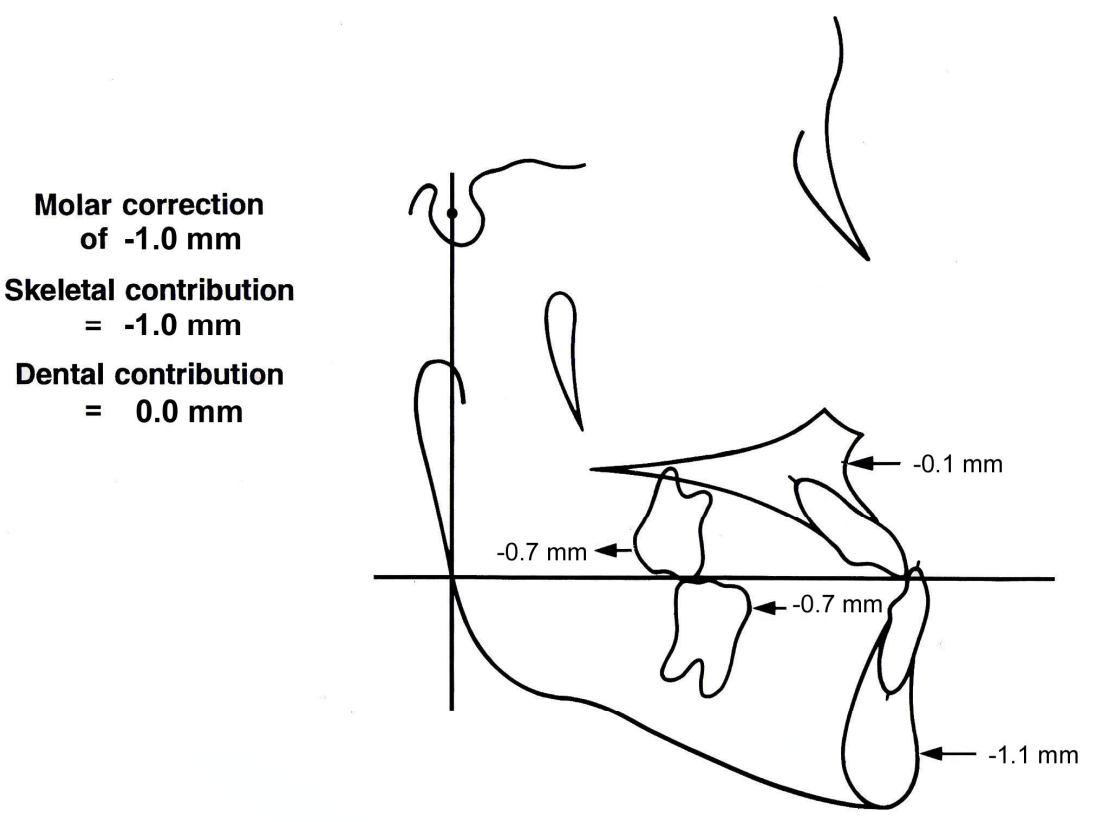

Figure 45. Components of net molar correction (T4-T3)

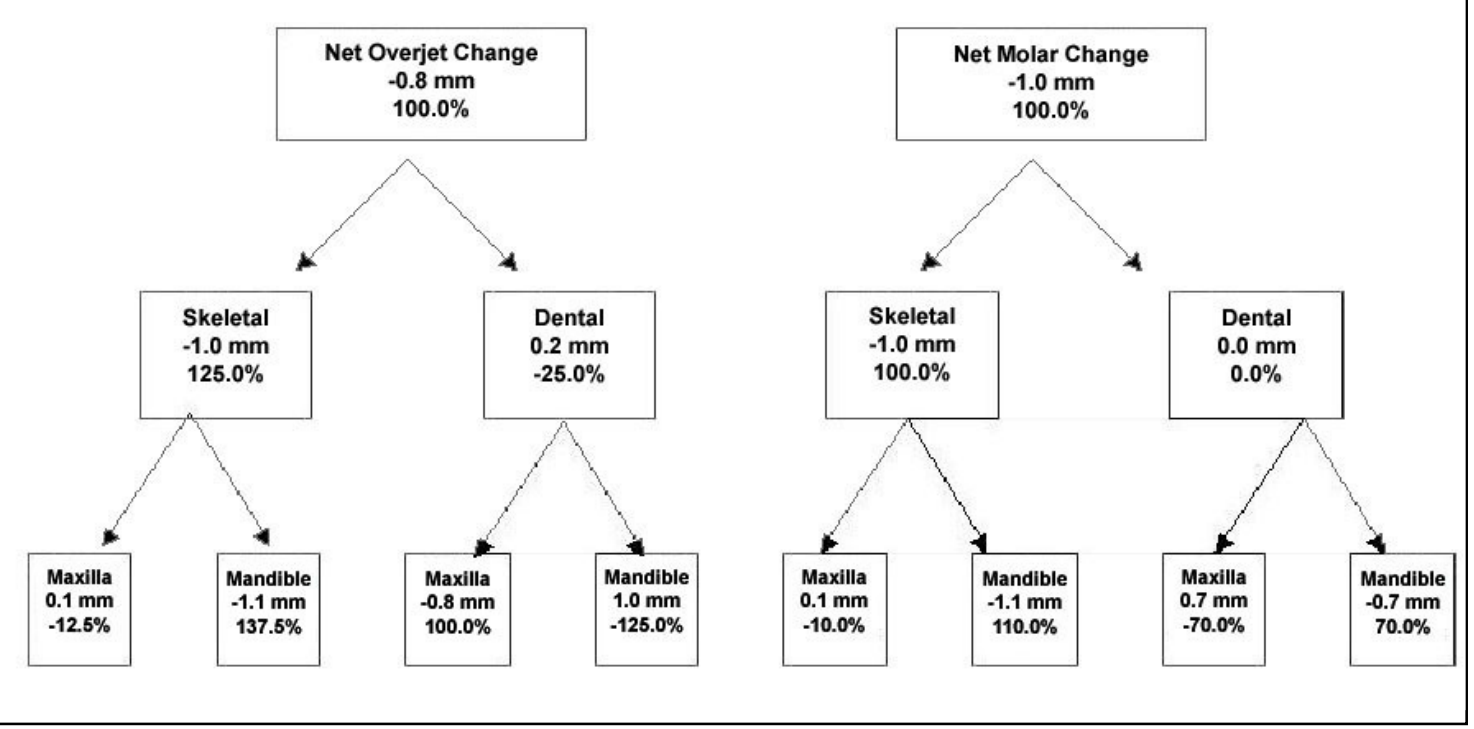

Figure 46. Pitchfork analysis of net overjet and molar correction (T4-T3) 


\section{DISCUSSION}

The purpose of this study was to determine the skeletal and dental changes of Class II patients treated with the crowned Herbst appliance in the early mixed dentition and followed through phase II orthodontic treatment for long-term changes. Twenty two patients were included in the study. Cephalometric analysis was performed on radiographs taken before phase I crowned Herbst treatment (T1), immediately after removal of Herbst appliance (T2), at the completion of phase I treatment (T3), prior to beginning of phase II orthodontic treatment (T4), and immediately after phase II treatment (T5). Results were compared to a control sample of 22 untreated Class II patients from the Bolton-Brush study that was matched in age, sex, and craniofacial morphology.

When investigating the correction of a Class II malocclusion, it is important to note that changes in the transverse and vertical dimensions can have positive or negative effects on the sagittal Class II correction. Although orthodontists have traditionally classified malocclusions using Angles classification system from a lateral view, it must be remembered that a complex arrangement of the teeth and jaws in the sagittal, vertical, and transverse planes is necessary to achieve optimal function, esthetics, stability, and periodontal health.

The impact of growth on Class II correction must also be considered. Although at one time it was believed that growth was entirely determined by the pre-existing genetic make-up of an individual, modern theories suggest the importance of the environment and form-function relationships in the development of the jaws. The timing of Class II 
treatment can become an important consideration if one is to maximize growth potential in Class II corrective treatment.

In interpreting the results of this study, it is best to evaluate the changes that occurred in both the sagittal direction and the vertical direction. Transverse dimensional changes were not investigated in this study. Describing the changes over time in the multiple anatomic components that determine the relationships of the teeth and jaws can identify where the effects of treatment occurred and if they were stable. 37 variables were used in this study to describe the changes in position of the maxillary skeletal base, the mandibular skeletal base, the maxillary molars and incisors, the mandibular molars and incisors, and the condyle/glenoid fossa region.

\section{Sagittal Changes (Skeletal)}

Treatment with the crowned Herbst for the time period T2-T1 resulted in significant skeletal differences between the treatment and control groups for all sagittal variables except OLp-A pt., OLp-Pg, and Co-Gn. The position of the maxillary base (OLp-A pt.) in the treatment group moved forward $1.0 \mathrm{~mm}$ from its original position and although it was not significant, the maxillary base was restrained $0.4 \mathrm{~mm}$ in the treatment group relative to the control group. This was consistent with previous studies in which the maxillary base moved forward 0.1-1.2 mm during treatment, ${ }^{7,12,18,59,80,105,109,111-116}$ which was found to be $0.2-1.2 \mathrm{~mm}$ less than the forward movement observed in the control group ${ }^{12,18,115}$. In some studies, A-point moved backwards 0.5-1.0 mm during treatment ${ }^{16,80,103,105,117}$. During treatment, the Herbst appliance exerts a posterior and upward force on the maxilla and the maxillary dentition similar to a high-pull headgear ${ }^{11,18,81,95,118}$. In the present study, the amount of forward movement of A pt. 
during the short and long-term post-treatment period was $1.2 \mathrm{~mm}$ and $3.6 \mathrm{~mm}$

respectively. The reduction of the forward movement of the maxillary base in the shortterm (T3-T1) and long-term (T4-T1) post-treatment periods appeared to be stable, exhibiting a net restriction of forward movement compared to the control group of 0.7 $\mathrm{mm}$ and $0.9 \mathrm{~mm}$ respectively. This was consistent with that shown in previous studies where the maxillary base moved forward 0.8-1.4 mm $\mathrm{mm}^{7,92,103,112}$ in the short-term and 1.3$5.1 \mathrm{~mm}^{12,95,99,112,114,119,120}$ in the long-term post-treatment period. During phase II treatment (T5-T1), A point experienced an additional net restriction of forward growth equal to $1.8 \mathrm{~mm}$ in the treatment group compared to the control group, giving a total net restriction of $2.8 \mathrm{~mm}$. These results suggest that treatment with the edgewise crowned Herbst appliance in the mixed dentition causes a restriction of forward movement of the maxillary base that is maintained after long term follow-up through phase II comprehensive orthodontic treatment.

Another indicator of the restraining effect on maxillary growth is the SNA angle. In the present study, initial treatment with the Herbst appliance (T2-T1) led to a $0.9^{\circ}$ decrease in the SNA angle relative to the control group. This change is supported by other studies that have reported similar decreases in the SNA angle during treatment of $0.4-1.2^{\circ 9,12,14,18,80-82,92,99,103,112-114,117,119,121-123}$. After phase I treatment (T3-T1), the SNA angle relapsed to only a net decrease of $0.5^{\circ}$, near pre-treatment levels, in the short-term post-treatment period which was consistent with most other studies ${ }^{92,112,121}$. In the longterm post-treatment period (T4-T1), the SNA angle had a net decrease of $0.7^{\circ}$, which was consistent with other investigations which reported a decrease of $0.6-0.8^{\circ}$ during the same period. Some investigators have reported an increase in the SNA angle of $0.2-4.0^{\circ}$ 
during this period ${ }^{12,98,119}$. Over the entire treatment period (T5-T1), this study showed a net significant difference of $-2.6^{\circ}$ in SNA angle in the treatment group relative to the control group which supports the concept that treatment with the edgewise crowned Herbst appliance in the mixed dentition causes a restriction of forward movement of the maxillary base that is maintained for the long term through phase II comprehensive orthodontic treatment.

The changes in Co-A pt. exhibited significant differences in the treatment group relative to the control group throughout all time periods in the study. During the initial phase of treatment, a net difference of $-2.6 \mathrm{~mm}$ was seen in the treatment group relative to the control group. Co-A pt. experienced a backwards movement of $0.5 \mathrm{~mm}$ in the treatment group from $\mathrm{T} 1$ to $\mathrm{T} 2$. In the short-term post-treatment period (T3-T1), a -2.0 $\mathrm{mm}$ net difference in treatment group relative to control group was observed. In the longterm post-treatment period (T4-T1), a $-3.0 \mathrm{~mm}$ net difference in treatment group relative to control group was apparent. From T1 to T5, an overall net restriction of $3.8 \mathrm{~mm}$ in Co-A pt. was seen. This data is further evidence that restriction in maxillary growth occurs with treatment with the Herbst appliance and is stable through the long term. In this study, the position of the mandibular base (OLp-Pg) moved forward 2.8 $\mathrm{mm}$ from its original position and although it was not significant, the mandibular base moved forward $2.0 \mathrm{~mm}$ relative to the control group in the initial time period T2-T1. This is consistent with previous studies that have shown forward movement of the mandibular jaw base (as measured by Pg-point) of 0.9-5.0 $\mathrm{mm}$ in response to treatment $^{12,14,59,80,82,92,103,105,109-119,122-125}$. In the short-term post-treatment period (T3-T1), a net increase in OLp-Pg of only $0.6 \mathrm{~mm}$ was shown in the treatment group relative to the 
control group, a relapse of $1.4 \mathrm{~mm}$. Although the lower jaw continued to move forward in the treatment group, net differences from the control group became smaller. This same trend occurred over the long-term post-treatment period (T4-T1), with the net difference of only $0.5 \mathrm{~mm}$ between the treatment and control groups. At T5, OLp-Pg became larger in the control group than in the treatment group with a net difference of $-1.6 \mathrm{~mm}$. These results suggest that the initial forward positioning of the mandibular base (OLp-Pg) in the treatment group as a response to Herbst treatment was not maintained during the followup period after Herbst treatment and was further reduced during phase II orthodontic treatment. Wieslander made similar conclusions when he found no significant long-term effect of Herbst treatment on the mandibular structures and in the mandibular position in comparison with changes in the control group ${ }^{120}$.

Another indicator of the change in position of the mandibular base is the SNB angle. In this study, a net increase of $1.0^{\circ}$ was observed in the treatment group compared to the control group at T2-T1. This is consistent with previous studies that have reported increases in the SNB angle of $0.2-2.6^{\circ}$ in response to Herbst treatment $^{7,9,12,14,18,80,81,92,96,98,112-114,117,118,121-124}$. During the short-term post-treatment period (T3-T1), the net difference in the treatment group compared to the control remained virtually unchanged at $0.9^{\circ}$, which was consistent with previous studies ${ }^{112,118}$. In the long-term post-treatment period (T4-T1), although the SNB angle in the treatment group increased by $1.7^{\circ}$, a net difference of only $0.3^{\circ}$ was found between the treatment and control groups. This was consistent with previous studies that showed an increase in the SNB angle of $0.3-2.6^{\mathbf{0}} 12,98,114,119$. At T5, the SNB angle became larger in the control group than in the treatment group with a net difference of $-0.5^{\circ}$. Again, this seems to 
demonstrate that the initial forward positioning of the mandibular base in the treatment group as a response to Herbst treatment was lost over the long term.

An initial increase in mandibular length as measured by Co-Gn was observed in the present study. The treatment group experienced an increase in mandibular length of $3.4 \mathrm{~mm}$ and the control group experienced an increase in mandibular length of $2.7 \mathrm{~mm}$, giving a net increase of $0.7 \mathrm{~mm}$ in the treatment group relative to the control group. This is consistent with other studies that report that the Co-Gn distance increased 3.4-6.4 $\mathrm{mm}^{14,16,93,117}$ in response to treatment, while subjects with no treatment only experienced an increase of $2.0 \mathrm{~mm}^{93}$. The increase in mandibular length was reduced in the shortterm post-treatment period (T3-T1) when a net difference of $-0.1 \mathrm{~mm}$ was seen in the treatment as compared to the control group. After the long-term post-treatment period (T4-T1), the length of the mandible in the control group was $2.6 \mathrm{~mm}$ longer than in the treatment group. After comprehensive phase II orthodontic treatment (T5-T1), the length of the mandible in the control group was still $1.9 \mathrm{~mm}$ longer than the treatment group. These results indicate that the increase in mandibular length with Herbst treatment is not maintained in the long term.

In this study, the sagittal intermaxillary jaw relationships were improved with Herbst appliance treatment. In the time period T2-T1, the Wits analysis showed a net decrease of $3.7 \mathrm{~mm}$ in the treatment group relative to the control group. This was slightly larger than the than the Wits decrease between 2.4 and $3.0 \mathrm{~mm}$ reported in other studies $^{14,92,113,118,121}$, however, it was consistent with the decrease in Wits of 3.0-5.1 mm seen in studies on Class II division 2 patients ${ }^{113,126}$. The net difference in Wits decreased to $-1.7 \mathrm{~mm}$ in the treatment compared to the control in the short-term post-treatment 
period (T3-T1). This change was different from other studies that reported the Wits appraisal remained substantially unchanged in the short-term post-treatment period $^{92,118,121,126}$. The net difference in Wits between the treatment group and control group continued to decline until T4 where the treatment and control group Wits appraisal was virtually the same. During the comprehensive phase II orthodontic treatment the Wits again experienced a net decline of $1.6 \mathrm{~mm}$ in the treatment group relative to the control group. These results indicate that the Herbst treatment had only a temporary impact on the existing skeletofacial growth pattern. After the treatment period, the intermaxillary relationship seemed to return to its pre-treatment pattern as previously described by Pancherz ${ }^{99}$.

Another indicator of sagittal intermaxillary jaw relationships is the ANB angle. In this study, the ANB angle decreased $2.0^{\circ}$ in the treatment group relative to the control group at T2-T1. This was consistent with other studies that reported decreases in the ANB angle from 1.1-3.9 9,12,14,16,18,80,81,92,93,96,99,112-114,117,118,121-124 in response to Herbst treatment. In the short-term post-treatment period (T3-T1), the ANB angle increased slightly to a $0.6 \mathrm{~mm}$ net difference in treatment compared to control, which was consistent with other studies that showed slight increases in this same period of $0.1-0.4^{\circ}$ 7,92,98,118,121. In the long-term post-treatment period (T4-T1), the net difference in ANB between the treatment group and control group increased to $1.1 \mathrm{~mm}$ although the treatment group still showed an overall decrease of $1.6^{\circ}$ from the pretreatment value. This is consistent with other studies that have shown a $0.4-4.0^{\circ}$ decrease in the long-term post-treatment period ${ }^{112,114,119,120}$. ANB experienced a net decrease of $1.0^{\circ}$ in the treatment group relative to the control group during phase II comprehensive orthodontic 
treatment. Overall, a net decrease in ANB of $2.1^{\circ}$ in the treatment group compared to the control group was experienced from $\mathrm{T} 1$ to $\mathrm{T} 5$.

\section{Sagittal Changes (Dental)}

The Herbst appliance exerts a posterior superior force on the maxillary dentition and an anterior inferior force on the mandibular dentition ${ }^{9,19,82,98,109,113,122}$, which generally results in distalization of the maxillary molars, retroclination of the maxillary incisors, mesial movement of the mandibular molars, and proclination of the mandibular incisors $^{19,82,93,122,124}$.

In this study, after subtracting maxillary movement, the maxillary molars were distalized in the treatment group as measured by Ms-OLp a distance of $2.9 \mathrm{~mm}$ during Herbst treatment at time period T2-T1. A net molar movement of $-3.1 \mathrm{~mm}$ was seen when the treatment group was compared to the control group. This is consistent with the amount of distal molar movement in response to Herbst treatment reported in other studies of 0.6-3.0 $\mathrm{mm}^{12,14,80-82,92,93,95,98,103,105,109,110,114,115,118,119,122,123}$. In contrast, some studies found mesial movement of the maxillary molars of $0.2-0.6 \mathrm{~mm}^{18,59,117}$. In the short-term post-treatment period, the maxillary molars in the treatment group moved forward $2.6 \mathrm{~mm}$, but still maintained a net posterior position of $1.5 \mathrm{~mm}$ compared to the control group. Previous studies have reported a mesial movement of the maxillary first molars of 0.7-1.4 mm after Herbst removal in the short-term post-treatment period $^{12,92,95,98,103}$. In the long-term post-treatment period, the maxillary molars in the treatment group had moved forward $0.8 \mathrm{~mm}$ from their original position, but a net molar movement of $2.1 \mathrm{~mm}$ in a backwards direction was still evident in the treatment group relative to the control group. Previous studies have reported forward movement of the 
maxillary molars of between 1.6 and $1.9 \mathrm{~mm}$ during this period ${ }^{12,98,115,119}$. At the completion of phase II comprehensive orthodontic treatment (T5-T1), the maxillary molars had moved forward $2.3 \mathrm{~mm}$ from their original position and maintained a net posterior position of only $-0.2 \mathrm{~mm}$ in the treatment group compared to the control group. Treatment mechanics during the phase II comprehensive orthodontic treatment may have led to the forward movement seen by the maxillary molars in the treatment group. The results of this study suggest that effective distalization of the maxillary molars occurs in response to Herbst treatment and the movement is stable in the long term, however, most of the posterior molar movement was eliminated during phase II comprehensive orthodontic treatment.

In the present study, the mandibular molars as measured by Ms-OLp moved forward a distance of $2.0 \mathrm{~mm}$ from their original position in the treatment group at time period T2-T1. A net mandibular molar movement of $1.1 \mathrm{~mm}$ in a forward direction was seen in the treatment group as a result of the anteriorly directed force of the Herbst appliance. This amount falls within the range of mandibular molar movement reported in previous studies of $0.9-5.5 \mathrm{~mm}^{7,14,18,19,59,80-82,92,93,103,105,109-111,113-115,117,119,121-124}$. In the short-term post-treatment period after Herbst removal (T3-T1), mandibular molars in the treatment group moved $1.0 \mathrm{~mm}$ forward from their original position, indicating a backwards movement of $1.0 \mathrm{~mm}$ in the treatment group from $\mathrm{T} 2$ to $\mathrm{T} 3$. This number is slightly more than the amount of distal relapse reported in the short-term post-treatment period in previous studies of $0.4-0.8 \mathrm{~mm}^{92,98,103,115,119,124}$. A net mandibular movement of $0.5 \mathrm{~mm}$ in a forward direction was seen at the time period T3-T1 when the treatment group was compared to the control group. In the long-term post-treatment period (T4- 
T1), the mandibular molars in the treatment group moved $0.7 \mathrm{~mm}$ forward from their original position, indicating a backwards movement of $1.3 \mathrm{~mm}$ in the treatment group from $\mathrm{T} 2$ to $\mathrm{T} 4$. This is consistent with previous studies that have reported a continued distal movement of 0.4-0.8 $\mathrm{mm}$ in the mandibular molars during the long-term posttreatment period ${ }^{12,98,119}$. A net mandibular movement of $0.1 \mathrm{~mm}$ in a backward direction was seen at the time period T4-T1 when the treatment group was compared to the control group. At the completion of phase II comprehensive orthodontic treatment (T5-T1), the mandibular molars had moved forward $1.6 \mathrm{~mm}$ from their original position and maintained a net anterior movement of only $0.8 \mathrm{~mm}$ in the treatment group when compared to the control group. Treatment mechanics during the phase II comprehensive orthodontic treatment may have led to the forward movement seen by the mandibular molars in the treatment group. The results of this study suggest that mesial movement of the mandibular molars occurs in response to Herbst treatment, however the forward movement is not stable in the long term. Treatment mechanics during the phase II comprehensive orthodontic treatment can lead to increased mandibular molar movement in an anterior direction.

In the present study, the maxillary incisors (Is-OLp) moved backwards $2.6 \mathrm{~mm}$ and were retroclined (Is/NL) $7.3^{\circ}$ from their original position in the treatment group at time period T2-T1. A net maxillary incisor movement of $3.7 \mathrm{~mm}$ in a backward direction and a net maxillary incisor retroclination of $7.0^{\circ}$ were seen in the treatment group in relation to the control group. This is consistent with the reported literature that shows maxillary incisor distal movement of 0.5-3.6 mm and maxillary incisor retroclination of 3.2-8. $2^{\circ}$ in response to Herbst treatment ${ }^{7,14,59,92,93,98,103,105,109-111,113,114,117-119,122,123}$. In 
contrast, other investigators found no significant differences in maxillary incisor position $^{9,80-82}$ or a mesial movement of $0.8 \mathrm{~mm}^{18}$. In the short-term post-treatment period at $\mathrm{T} 3$, the maxillary incisors rebounded forward $2.4 \mathrm{~mm}$ in the treatment group, leaving them $0.2 \mathrm{~mm}$ behind their original position. A net backward movement of $2.0 \mathrm{~mm}$ was still evident in the treatment group compared to the control group at time period T3-T1. This is inconsistent with the reported literature which shows that during the short-term post-treatment period, the maxillary incisor position remained unaffected ${ }^{92,98,103,115}$. In addition, the maxillary incisors were retroclined $1.3^{\circ}$ in the treatment group compared to the control group at time period T3-T1. During the long-term post-treatment period, the maxillary incisors continued to rebound in a forward direction a distance of $4.1 \mathrm{~mm}$ in the treatment group from the post-treatment position at T2. The maxillary incisors were moved forward a distance of $1.5 \mathrm{~mm}$ from their original position in the treatment group, however they showed a net posterior movement of $1.2 \mathrm{~mm}$ when compared to the control group at time period T4-T1. A net proclination of $1.7^{\circ}$ was seen in the maxillary incisors in the treatment group relative to the control group at time period T4-T1. Most reports in the literature show long-term post-treatment relapse of $0.4-2.1 \mathrm{~mm}$ in a mesial direction $^{12,98,114}$, however, other investigators did not observe a significant change in the incisor position during the same period ${ }^{119}$. At the completion of phase II comprehensive orthodontic treatment (T5-T1), the maxillary incisors had moved forward $0.8 \mathrm{~mm}$ from their original position and maintained a net posterior movement of $1.4 \mathrm{~mm}$ in the treatment group when compared to the control group. The net change in maxillary incisor proclination was $1.5^{\circ}$ compared to the control group at this same time period. The results of this study suggest that the maxillary incisors are moved posteriorly in response 
to Herbst treatment and although some relapse in a forward direction occurs after treatment, a net posterior movement is maintained over the long term in the treatment group relative to the control group. In addition, the maxillary incisors are initially retroclined in response to Herbst treatment, however over the long term, proclination of the maxillary incisors occurs as they relapse to their pre-treatment inclination.

In the present study, the mandibular incisors (Ii-OLp) moved forwards $2.0 \mathrm{~mm}$ and were proclined (Ii/ML) $7.1^{\circ}$ from their original position in the treatment group at time period T2-T1. A net mandibular incisor movement of $0.9 \mathrm{~mm}$ in a forward direction and a net mandibular incisor proclination of $7.6^{\circ}$ were seen in the treatment group in relation to the control group. This is consistent with the reported literature that shows mandibular incisor mesial movement of 0.2-4.0 $\mathrm{mm}$ and mandibular incisor proclination of 5.4-10.8 in response to Herbst treatment ${ }^{7,9,12,19,59,80-82,92,93,98,103,105,109,110,112-115,117-119,121-124,126-128 . ~ I n ~}$ contrast, other investigators found no significant differences in mandibular incisor position $^{119}$. It has been reported that the mandibular incisor proclination observed during Herbst treatment did not have an effect on the preexisting gingival recession or did not cause gingival recession $^{128}$. In the short-term post-treatment period at T3, the mandibular incisors rebounded backwards $0.8 \mathrm{~mm}$ in the treatment group, leaving them only $0.1 \mathrm{~mm}$ ahead of their original position. A net backward movement of $0.2 \mathrm{~mm}$ was evident in the treatment group compared to the control group at time period T3-T1. This is consistent with the reported literature which shows that during the short-term post-treatment period, the mandibular incisor position relapsed backwards a distance of 0.9-3.3

$\mathrm{mm}^{92,103,112,115,121}$, thus returning approximately to their initial position ${ }^{92,121}$. In addition, the mandibular incisors were proclined $0.8^{\circ}$ in the treatment group compared to the 
control group at time period T3-T1. The proclination of the mandibular incisors from T2 to $\mathrm{T} 3$ was reduced $5.8^{\circ}$ in the treatment group. This is close to the amounts reported in previous studies in which the mandibular incisor proclination was reduced between $6^{\circ}$ and $7.9^{\circ}$ during the first year of the post-treatment period ${ }^{98,103,112,121}$. During the longterm post-treatment period, the mandibular incisors continued to rebound in a backwards direction a distance of $1.5 \mathrm{~mm}$ in the treatment group from the post-treatment position at T2. The mandibular incisors were moved forward a distance of $0.5 \mathrm{~mm}$ from their original position in the treatment group and they showed a net anterior movement of 0.9 $\mathrm{mm}$ when compared to the control group at time period T4-T1. A net proclination of $3.3^{\circ}$ was seen in the mandibular incisors in the treatment group relative to the control group at time period T4-T1. Previous studies have found that during the long-term post-treatment period the mandibular incisors moved distally 1.6-3.8 $\mathrm{mm}^{12,98,112,114,119}$ and retroclined $1.9-2.5^{\circ}$ in relation to the sella-nasion line ${ }^{12,114}$. At the completion of phase II comprehensive orthodontic treatment (T5-T1), the mandibular incisors had moved backward -0.6 $\mathrm{mm}$ from their original position, however they maintained a net forward movement of $0.2 \mathrm{~mm}$ in the treatment group when compared to the control group. The net change in mandibular incisor proclination was $3.0^{\circ}$ compared to the control group at this same time period. The results of this study suggest that the mandibular incisors are initially moved forward and proclined in response to Herbst treatment but relapse to original pretreatment levels within the short-term post-treatment period.

\section{Overjet Changes}

In this study, the overjet correction was $6.4 \mathrm{~mm}$ in the treatment group in response to Herbst treatment. $1.8 \mathrm{~mm}(28.1 \%)$ of the correction was the result of skeletal changes 
and $4.6 \mathrm{~mm}(71.9 \%)$ of the correction was the result of dental changes. When the treatment group was compared to the control group, a net overjet correction of $7.0 \mathrm{~mm}$ was achieved. $2.4 \mathrm{~mm}(34.3 \%)$ of the correction was the result of skeletal changes and $4.6 \mathrm{~mm}(65.7 \%)$ was the result of dental changes. In previous studies, overjet reductions ranging from 3.3-9.8 $\mathrm{mm}$ after Herbst treatment have been reported $^{7,9,12,16,18,19,59,80,82,92,98,109-111,114-117,119,121-124,129}$. In the short-term post-treatment period, the overjet correction was reduced to $2.5 \mathrm{~mm}$, mostly as a result of dental relapse. $2.2 \mathrm{~mm}(85 \%)$ of the correction was the results of skeletal changes and only $0.3 \mathrm{~mm}$ $(12.0 \%)$ was the result of dental changes. When the treatment group was compared to the control group, a net overjet correction of $3.1 \mathrm{~mm}$ was observed. $1.3 \mathrm{~mm}$ (41.9\%) of the correction was the result of skeletal changes and $1.8 \mathrm{~mm}(58.1 \%)$ was the result of dental changes. Previous studies have reported that after Herbst removal the overjet relapsed 1.7-3.0 mm during the short-term post-treatment period ${ }^{92,98,103,121,129}$. In the long-term post-treatment period, the overjet correction in the treatment group was reduced to 1.8 mm. $2.8 \mathrm{~mm}(155.6 \%)$ of the correction was the result of skeletal changes and dental changes relapsed to have a $-1.0 \mathrm{~mm}(-55.6 \%)$ effect on the overjet correction. When the treatment group was compared to the control group, a net overjet correction of $2.5 \mathrm{~mm}$ was observed. Only $0.4 \mathrm{~mm}(16.0 \%)$ of the correction was the result of skeletal changes and $2.1 \mathrm{~mm}(84.0 \%)$ of the correction was the result of dental changes. Previous studies have found in the overjet of $0.3-2.4 \mathrm{~mm}$ in the long-term post-treatment period $^{12,98,114,119,120}$. In total, studies have found that the Herbst appliance caused an overjet correction between 3.3 and $5.7 \mathrm{~mm}$ from the pre-treatment to the long-term posttreatment period ${ }^{12,98,114,119,129}$. After the completion on phase II comprehensive 
orthodontic treatment, the overjet correction in the treatment group was $2.2 \mathrm{~mm} .3 .6 \mathrm{~mm}$ $(163.6 \%)$ of the correction was the result of skeletal changes and dental changes relapsed to have a $-1.4 \mathrm{~mm}(-63.6 \%)$ effect on the overjet correction. When the treatment group was compared to the control group, a net overjet correction of $2.8 \mathrm{~mm}$ was observed. 1.2 $\mathrm{mm}(42.9 .0 \%)$ of the correction was the result of skeletal changes and $1.6 \mathrm{~mm}(57.1 \%)$ of the correction was the result of dental changes.

In summary, the Herbst appliance initially produced a net overjet correction of 7.0 $\mathrm{mm}$ in the treatment group relative to the control group, then relapsed in the short-term post-treatment period until a relatively stable net overjet correction between $2.5-3.0 \mathrm{~mm}$ was maintained over the long-term. Figures 47 and 48 display graphs of the skeletal and dental contributions to net overjet correction. The skeletal contribution to net overjet correction was $2.4 \mathrm{~mm}$ initially but continuously dropped over the long-term posttreatment period to only $0.4 \mathrm{~mm}$. Relapse in the mandible was responsible for the reduction in skeletal contribution to overjet correction as the mandible continuously moved backwards in the treatment group relative to the control group at all time periods after the initial advancement of $2.0 \mathrm{~mm}$ after Herbst treatment. Restriction of the forward movement of the maxilla in the treatment group relative to the control group was found following Herbst treatment and was maintained for the long term and through phase II comprehensive orthodontic treatment. The dental contribution to net overjet correction was large $(4.6 \mathrm{~mm}-65.7 \%)$ immediately after Herbst treatment, but declined rapidly in the short-term post-treatment period when the maxillary and mandibular incisors relapsed significantly. The dental contribution to net overjet correction then increased during the long-term post-treatment period when the incisors appeared to compensate for the 
relapsing skeletal correction as the intermaxillary relationship seemed to return to its pretreatment pattern. The maxillary incisors are moved posteriorly in response to Herbst treatment and although some relapse in a forward direction occurs after treatment, a net posterior movement and sustained contribution to net overjet correction is maintained over the long term in the treatment group relative to the control group. The mandibular incisors are initially moved forward and proclined in response to Herbst treatment but relapse to original pretreatment levels within the short-term post-treatment period. In the long-term post-treatment period, the mandibular incisors were proclined to compensate for the relapsing intermaxillary relationship. 
Figure 47. Skeletal contribution to net overjet correction

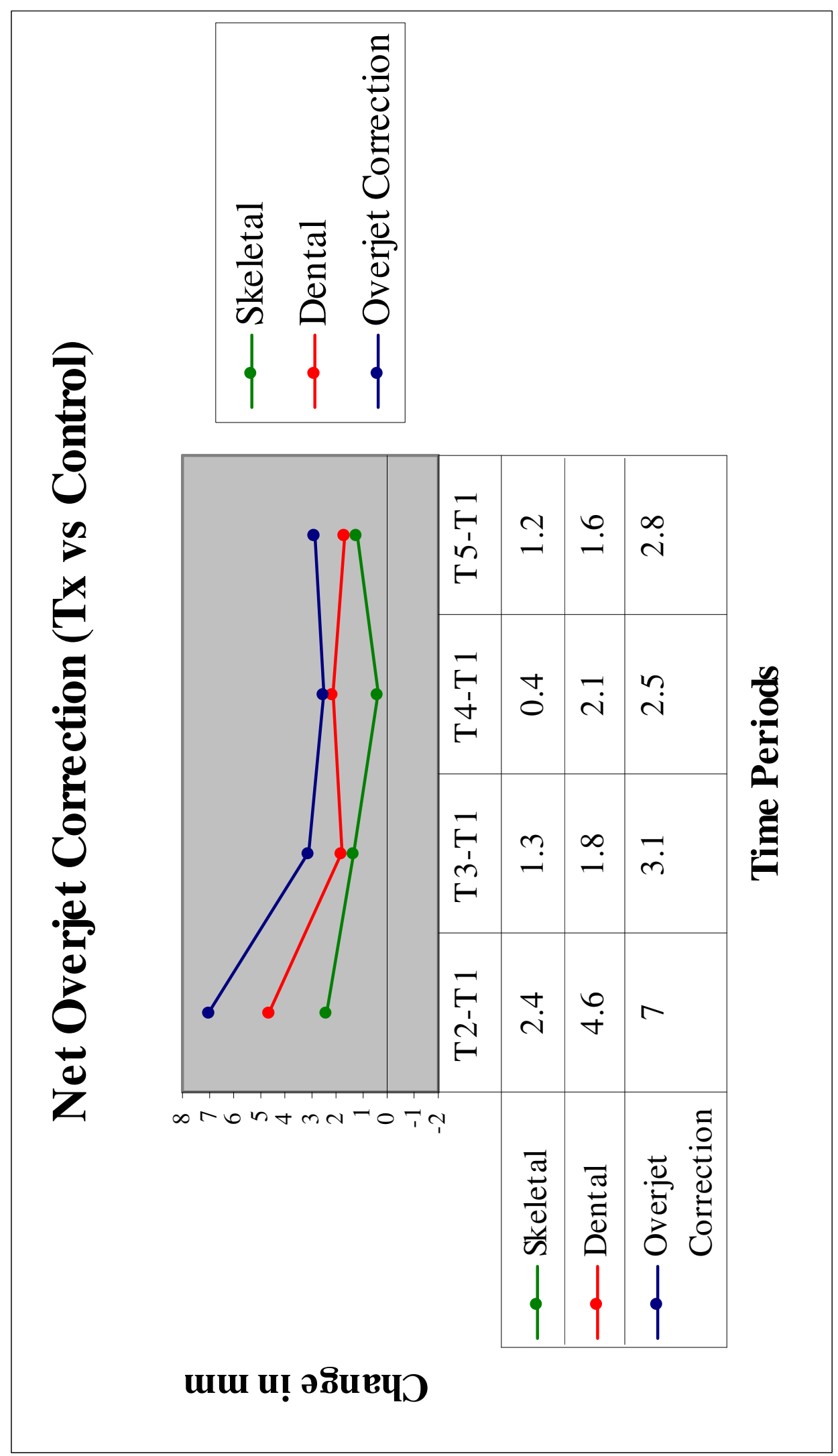


Figure 48. Contribution of the skeletal bases and incisors to net overjet correction

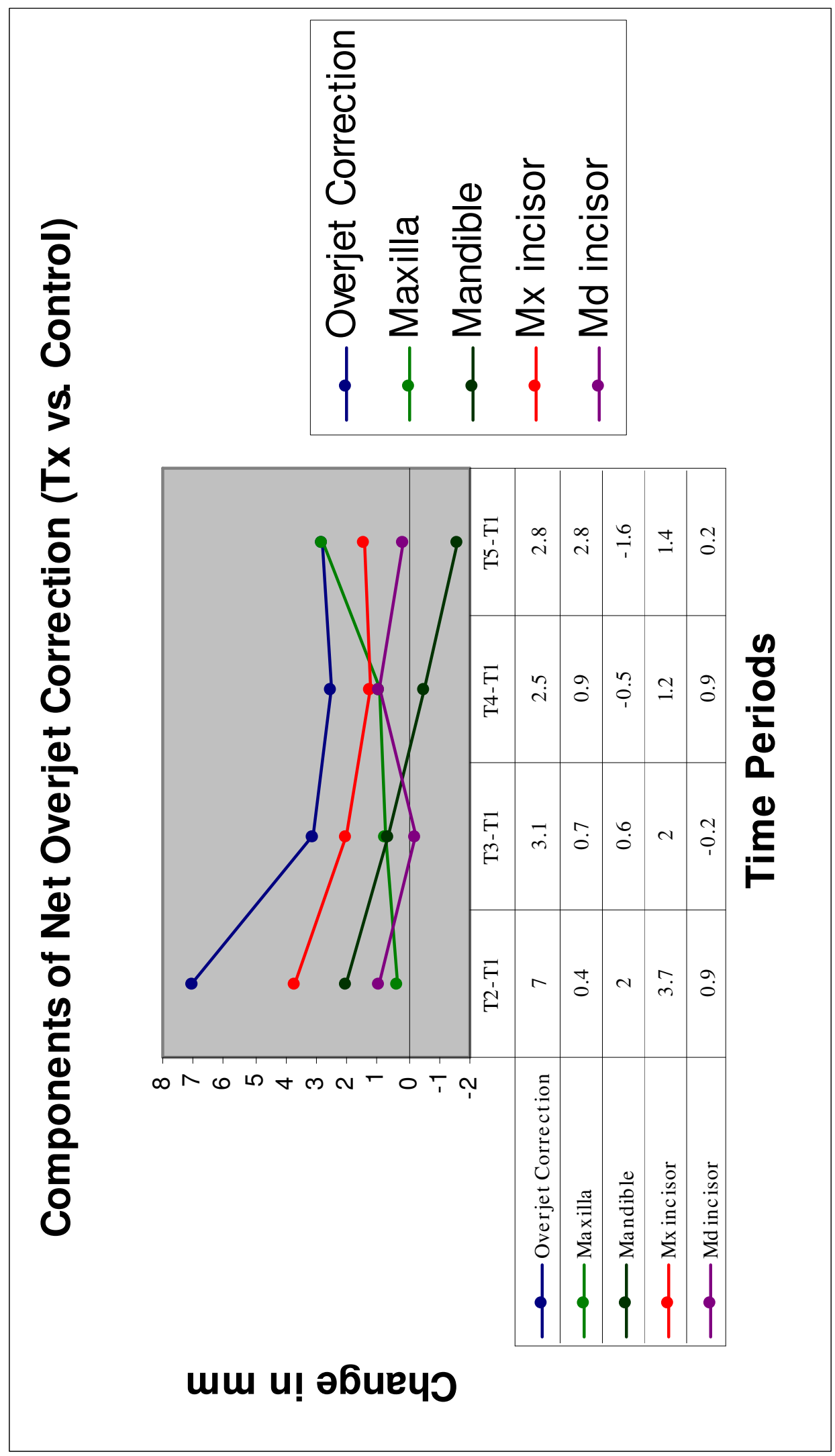




\section{Molar Relationship Changes}

In this study, the molar correction was $6.7 \mathrm{~mm}$ in the treatment group in response to Herbst treatment. $1.8 \mathrm{~mm}(26.9 \%)$ of the correction was the result of skeletal changes and $4.9 \mathrm{~mm}(73.1 \%)$ of the correction was the result of dental changes. When the treatment group was compared to the control group, a net molar correction of $6.6 \mathrm{~mm}$ was achieved. $2.4 \mathrm{~mm}$ (36.4\%) of the correction was the result of skeletal changes and $4.2 \mathrm{~mm}(63.6 \%)$ was the result of dental changes. In previous studies, molar relationship corrections ranging from 3.0-9.3 $\mathrm{mm}$ after Herbst treatment have been reported $^{12,18,19,59,80,82,92,109,113-117,122,123}$. In the short-term post-treatment period, the molar correction was reduced to $3.5 \mathrm{~mm}$. $2.2 \mathrm{~mm}(62.9 \%)$ of the correction was the result of skeletal changes and $1.3 \mathrm{~mm}(37.1 \%)$ was the result of dental changes. When the treatment group was compared to the control group, a net molar correction of $3.3 \mathrm{~mm}$ was observed. $1.3 \mathrm{~mm}(39.4 \%)$ of the correction was the result of skeletal changes and $2.0 \mathrm{~mm}(61.6 \%)$ was the result of dental changes. Previous studies have reported that after Herbst removal the molar relationship correction relapsed 1.1-1.7 $\mathrm{mm}$ during the short-term post-treatment period ${ }^{92,103,115}$. In the long-term post-treatment period, the overjet correction in the treatment group was reduced to $2.7 \mathrm{~mm}$. $2.8 \mathrm{~mm}(103.7 \%)$ of the correction was the result of skeletal changes and dental changes relapsed to have a $0.1 \mathrm{~mm}(-3.7 \%)$ effect on the molar correction. When the treatment group was compared to the control group, a net molar correction of $2.4 \mathrm{~mm}$ was observed. Only $0.4 \mathrm{~mm}$ (16.7\%) of the correction was the result of skeletal changes and $2.0 \mathrm{~mm}(83.3 \%)$ of the correction was the result of dental changes. Previous studies have found relapse in the molar relationship of 0.4-2.6 $\mathrm{mm}$ in the long-term post-treatment period ${ }^{12,114,119}$. After 
the completion on phase II comprehensive orthodontic treatment, the molar correction in the treatment group was $2.9 \mathrm{~mm} .3 .6 \mathrm{~mm}(124.1 \%)$ of the correction was the result of skeletal changes and dental changes relapsed to have a $-0.7 \mathrm{~mm}(-24.1 \%)$ effect on the molar correction. When the treatment group was compared to the control group, a net molar correction of $2.2 \mathrm{~mm}$ was observed. $1.2 \mathrm{~mm}(54.5 \%)$ of the correction was the result of skeletal changes and $1.0 \mathrm{~mm}(45.5 \%)$ of the correction was the result of dental changes.

The molar relationship correction followed the same general trends as the overjet correction. Figures 49 and 50 display graphs of the skeletal and dental contributions to net overjet correction. The Herbst appliance initially produced a net molar correction of $6.6 \mathrm{~mm}$ in the treatment group relative to the control group, then relapsed in the shortterm post-treatment period until a relatively stable net molar correction between 2.23.3mm was maintained over the long-term. The skeletal contribution to net molar correction was $2.4 \mathrm{~mm}$ initially but continuously dropped over the long-term posttreatment period to only $0.4 \mathrm{~mm}$. Relapse in the mandible was responsible for the reduction in skeletal contribution to molar correction as the mandible continuously moved backwards in the treatment group relative to the control group at all time periods after the initial advancement of $2.0 \mathrm{~mm}$ after Herbst treatment. Restriction of the forward movement of the maxilla in the treatment group relative to the control group was found following Herbst treatment and was maintained for the long term and through phase II comprehensive orthodontic treatment. The dental contribution to net molar correction was large $(4.2 \mathrm{~mm}-63.6 \%)$ immediately after Herbst treatment, but declined rapidly in the short-term post-treatment period when the maxillary and mandibular molars relapsed 
significantly. The dental contribution to net molar correction remained stable during the long-term post-treatment period when the molars appeared to compensate for the relapsing skeletal correction as the intermaxillary relationship seemed to return to its pretreatment pattern. The maxillary molars are moved posteriorly in response to Herbst treatment and although some relapse in a forward direction occurs after treatment, a net posterior movement and sustained contribution to net overjet correction is maintained over the long term in the treatment group relative to the control group. Most of the compensation for the relapsing intermaxillary relationship occurred in the maxillary molars. In phase II comprehensive orthodontic treatment, however, the maxillary molars were brought forward approximately to their pre-treatment position presumably due to treatment mechanics in an effort to achieve a Class I occlusion. The mandibular molars are initially moved forward in response to Herbst treatment but relapsed to original pretreatment levels over the long-term post-treatment period. They did not appear to compensate for the relapsing intermaxillary relationship. The mandibular molars were brought forward during phase II comprehensive orthodontic treatment in an effort to achieve a Class I occlusion. 
Figure 49. Skeletal contribution to net molar correction

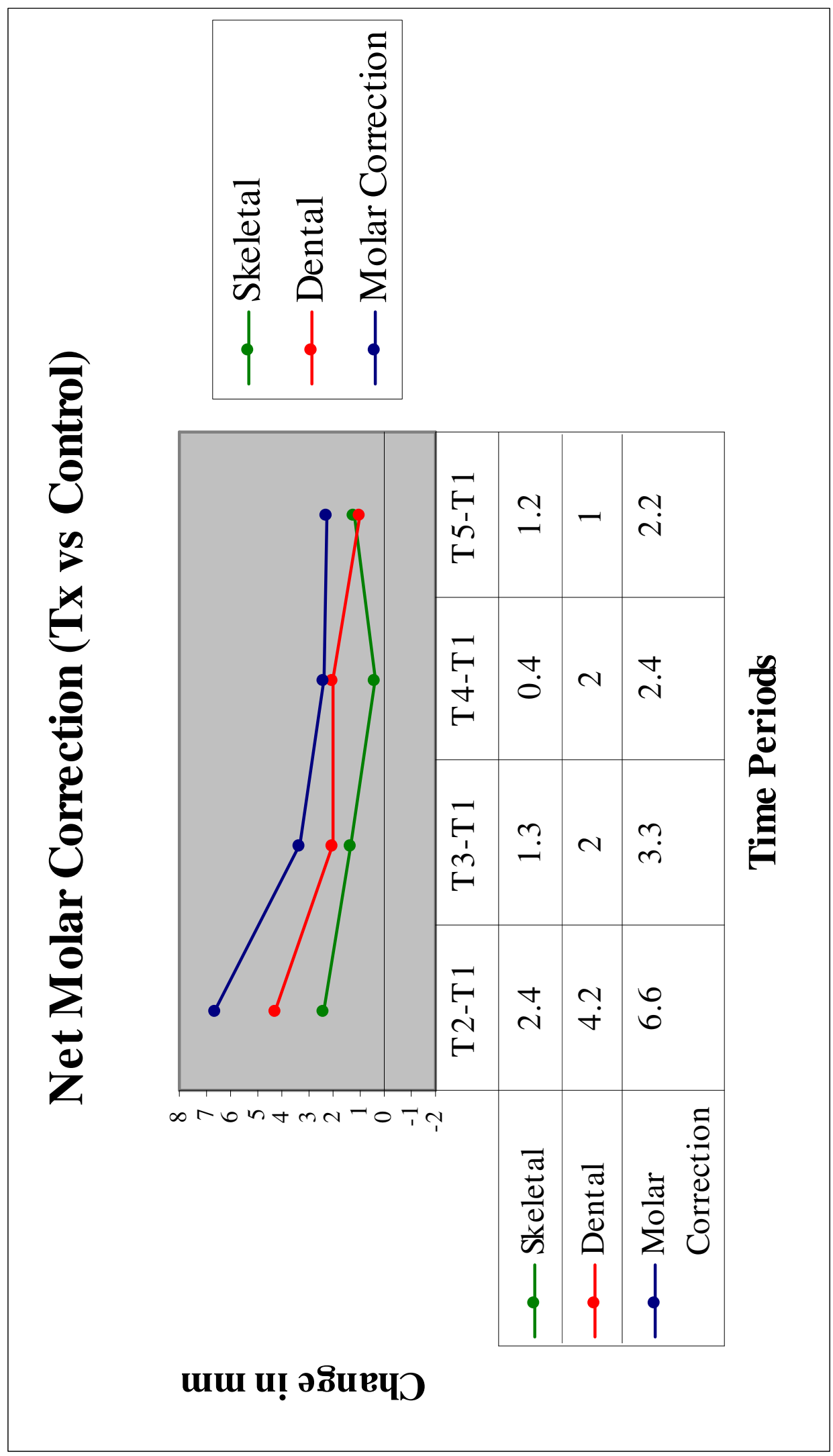


Figure 50. Contribution of skeletal bases and incisors to net molar correction

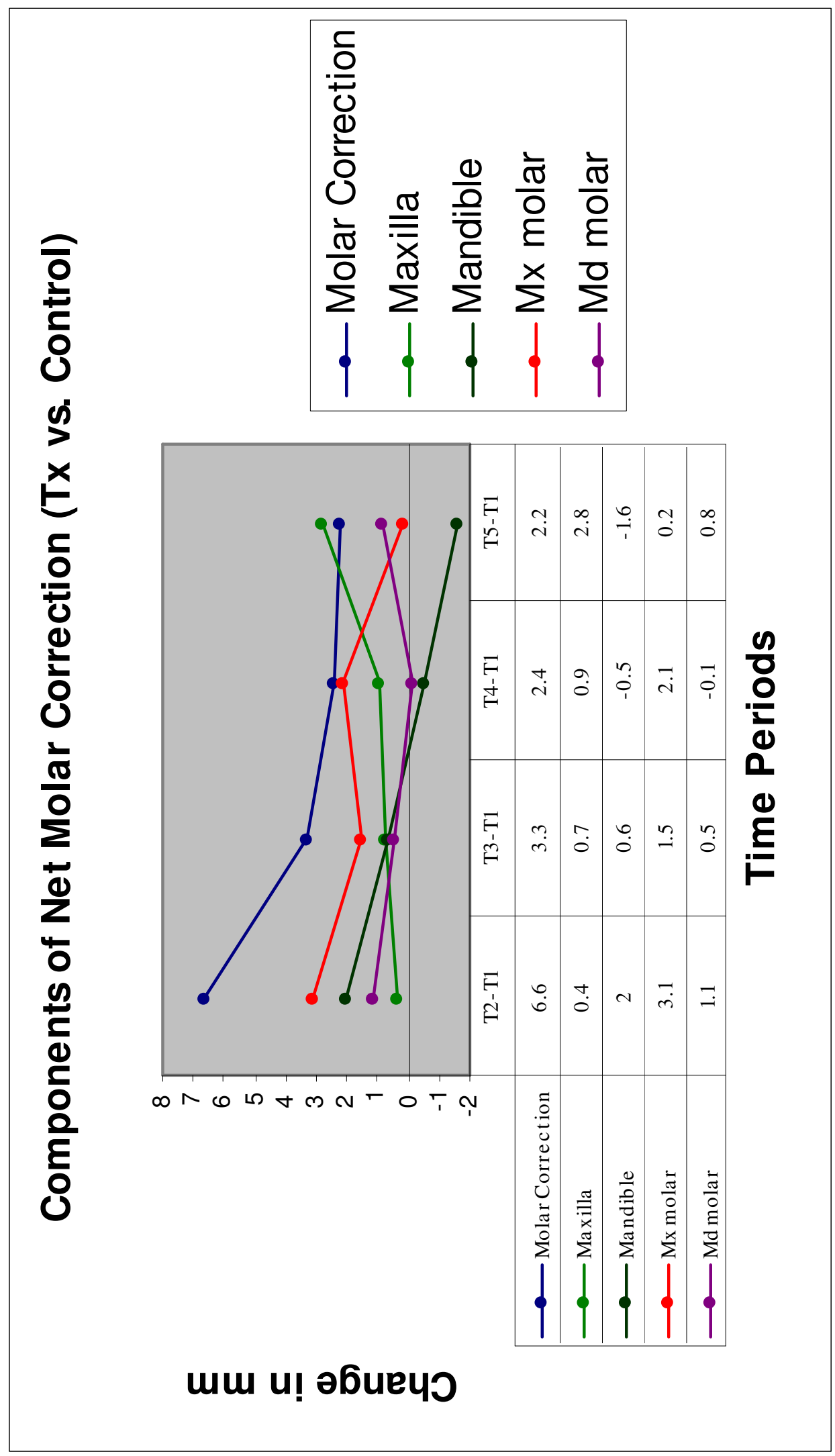




\section{Vertical Changes (Skeletal)}

None of the vertical skeletal variables showed significant differences between the treatment and control group in response to treatment with the Herbst appliance in this study except for the palatal plane angle (SNL-NL) and the occlusal plane angle (SNLOL). In this study, the palatal plane tipped downwards (counterclockwise) $1.7^{\circ}$ in the treatment group relative to the control group in response to Herbst treatment. In previous studies, it was reported that the palatal plane tipped downwards $0.2-1.0^{\circ}$ in response to Herbst treatment ${ }^{9,12,14,81,82,95,98,99,112,114,119,123}$. In the short-term post-treatment period, the palatal plane angle in the treatment group relapsed $1.4^{\circ}$ and showed no significant difference relative to the control group. This is consistent with previous studies that showed that the palatal plane angle did not present significant changes in the short-term post-treatment period ${ }^{95,98,99,112}$. In the long-term post-treatment period, no significant differences were found in the change in the palatal plane angle in the treatment group relative to the control group in response to Herbst treatment. In the long-term posttreatment period, some studies have reported a $1.0^{\circ}$ increase in the palatal plane angle ${ }^{95,114}$, others have reported a $0.5-0.6^{\circ}$ decrease $\mathrm{e}^{98,119}$, and others have reported nonsignificant changes ${ }^{112}$.

In this study, the occlusal plane angle (SNL-OL) tipped clockwise $3.4^{\circ}$ in response to treatment with the Herbst appliance. In the short-term post-treatment period, the occlusal plane angle in the treatment group relapsed in a counterclockwise direction $3.2^{\circ}$ to approximately its pre-treatment angulation, showing no significant difference in the changes relative to the control group. In the long-term post-treatment period, further counterclockwise tipping was noted, however no significant differences were found in the changes from $\mathrm{T} 1$ to $\mathrm{T} 4$ in the treatment group relative to the control group. This is 
consistent with previous studies that have shown an initial 1.1-5.1 ${ }^{\circ}$ clockwise tipping of the occlusal plane $e^{7,14,80,82,92,93,95,98,113,114,118,122,123}$, a counterclockwise tipping of $1.3-2.8^{\circ}$ in the short-term post-treatment period ${ }^{92,95,98}$, and a further counterclockwise tipping during the long-term post-treatment period ${ }^{7,98,114}$.

No significant differences were found in the changes in mandibular plane angle (SNL-ML) in the treatment group relative to the control group at any of the time periods in the study. The majority of investigators have found an increase in the mandibular plane angle during Herbst treatment ${ }^{7,9,80-82,92,98,99,105,112-114,118,121-123,130}$, others have found that the mandibular plane angle decreased $0.1-2.0^{\circ}$ during treatment ${ }^{93,103,105,117,119,130}$, and others have found that it remained unchanged ${ }^{9,12,116}$. In the short-term post-treatment period, some researchers have found that the mandibular plane angle decreased $0.5-0.7^{\circ}$, $98,103,121$, while others have reported that it remained unchanged ${ }^{92}$. In the long-term posttreatment period, Ruf and Pancherz concluded that the Herbst appliance does not have a significant effect on the mandibular plane angle ${ }^{130}$.

Although the anterior lower facial height (ANS-Me) initially increased $0.8 \mathrm{~mm}$ and continued to increase throughout all time periods, no significant difference was found between the treatment and control groups at any of the time periods in this study. Treatment with the Herbst appliance had no effect on the anterior lower facial height at any time period and increases in this measurement are attributable to normal growth. Previous studies have reported increases of 0.4-4.1 $\mathrm{mm}$ in response to Herbst treatment $^{9,14,80,93,105,117,124,131}$, however Pancherz found that no difference was evident between the treatment and control groups in the 12-month post-treatment period ${ }^{80}$. 


\section{Vertical Changes (Dental)}

Significant differences in the change in the vertical position of the maxillary molars (Msc-NL) and mandibular incisors (Ii-ML) were seen in the treatment group relative to the control group in this study. No other significant differences were found in the vertical dental changes in response to Herbst treatment in this study.

The maxillary molars were initially intruded $1.3 \mathrm{~mm}$ in the treatment group compared to an extrusion of $1.3 \mathrm{~mm}$ in the control group. A net intrusion of $2.6 \mathrm{~mm}$ was seen in the maxillary molars in response to Herbst treatment in this study in the time period T2-T1. This is consistent with the reports of maxillary first molar intrusion of 0.5$1.1 \mathrm{~mm}$ in response to Herbst treatment reported in previous studies ${ }^{80,93,95,103,126}$. Some studies reported an extrusion of the maxillary molars of 1.4-1.5 mm during the treatment period $^{117,126}$. In the short-term post-treatment period, $1.9 \mathrm{~mm}$ of extrusion in the maxillary molars was seen in the treatment group, producing an overall net intrusion of $1.1 \mathrm{~mm}$ in the treatment group relative to the control group in this study. This is slightly more than the 1.1-1.4 mm of extrusion noted in previous studies in the short-term posttreatment period $^{95,103}$. In the long-term post-treatment period, additional extrusion of 1.7 $\mathrm{mm}$ was seen in the treatment group totaling $3.6 \mathrm{~mm}$ of extrusive movement after treatment, however an overall net intrusion of $1.4 \mathrm{~mm}$ was found compared to the treatment group. This is consistent with the amount of extrusion reported in previous studies of $3.5 \mathrm{~mm}$ during the long-term post-treatment period ${ }^{95,103}$. During phase II comprehensive orthodontic treatment, the maxillary molars were extruded more in the treatment group than what was shown in the control group and the significant differences 
in the change in the vertical position of the maxillary molars between the treatment group and the control group disappeared.

The maxillary incisors (Is-NL) extruded $0.9 \mathrm{~mm}$ from their original position after Herbst treatment but experienced a relative intrusion of $0.9 \mathrm{~mm}$ in the treatment group compared to the control group. A relative intrusion of 0.9 remained through the longterm post-treatment period, however, there were no significant differences in the relative intrusion between the treatment and control groups in any of the time periods throughout this study. Previous studies have reported maxillary incisor extrusion of 0.2-2.2 $\mathrm{mm}$ after treatment $^{103,105,117}$, but no significant changes were found during the retention period ${ }^{103}$.

The mandibular molars (Mic-ML) extruded $1.2 \mathrm{~mm}$ from their original position after Herbst treatment, but no significant changes in the vertical position of the mandibular molars existed between the treatment and control groups. Although the mandibular molar extruded $2.2 \mathrm{~mm}$ from its original position during the time period T4T1, no long-term significant difference in the vertical position of the mandibular molars existed between the treatment and control groups. Previous studies have reported a molar extrusion of 1.3-2.8 mm after treatment ${ }^{80,93,103,105,124,126}$ followed by addition extrusion of $0.6 \mathrm{~mm}$ in the short-term post-treatment period $^{103}$.

The mandibular incisors were initially intruded $0.8 \mathrm{~mm}$ in the treatment group compared to an extrusion of $1.0 \mathrm{~mm}$ in the control group. A net intrusion of $1.8 \mathrm{~mm}$ was seen in the mandibular incisors in response to Herbst treatment in this study in the time period T2-T1. Although the differences became insignificant, a relative intrusion of 0.6 $\mathrm{mm}$ in the short-term post-retention period and a relative intrusion of $0.7 \mathrm{~mm}$ was seen in the long-term post-treatment. No significant changes in the vertical position of the 
mandibular incisors between the treatment and control groups occurred during phase II comprehensive orthodontic treatment. Previous studies report mandibular incisor intrusion of 0.4-2.4 $\mathrm{mm}$ in response to Herbst treatment $\mathrm{t}^{80,93,103,105,124,126}$, followed by an extrusion of $0.6 \mathrm{~mm}$ in the short-term post-treatment period ${ }^{103}$.

The overbite was initially reduced $1.1 \mathrm{~mm}$ in the treatment group compared to an increase of $1.3 \mathrm{~mm}$ in the control group. A net decrease in overbite of $2.4 \mathrm{~mm}$ was seen in response to Herbst treatment in this study in the time period T2-T1. The overbite reduction relapsed to approximate pre-treament levels in the short-term post-treatment period and remained relatively stable through the long-term post-treatment period and phase II comprehensive orthodontic phase. A relative decrease in overbite in the treatment group compared to the control group was maintained over the long-term. Previous studies have reported a reduction in overbite of 1.9-5.6 mm after Herbst treatment ${ }^{7,9,12,80,96,98,116,117,124,126,129}$. A relapse of 1.7-1.8 mm during the short-term posttreatment period ${ }^{80,119}$ followed by an increase of 0.5-1.1 mm during the long-term posttreatment period ${ }^{12,98,129}$ was reported in the previous literature.

\section{Condyle/Glenoid Fossa Changes}

Only two condyle/glenoid fossa variables showed significant differences between the treatment and control groups at T2-T1; OLp-CoC and OLp-GFA. Although not all significant, every sagittal condyle/glenoid fossa variable (OLp-CoC, OLp-GFS, OLpGFA, and OLp-GFP) showed a forward movement in the treatment group and a backward movement in the control group. Net anterior movements of $1.7 \mathrm{~mm}, 1.0 \mathrm{~mm}$, $2.1 \mathrm{~mm}$, and $1.6 \mathrm{~mm}$ were found in the treatment group relative to the control group for the condylar position (OLp-CoC), the superior aspect of the glenoid fossa (OLp-GFS), 
the anterior aspect of the glenoid fossa (OLp-GFA), and the posterior aspect of the glenoid fossa (OLp-GFP). No significant differences were found in the vertical condyle/glenoid fossa variables between the treatment and control groups.

Only one condyle/glenoid fossa variable, OLp-CoC, showed a significant difference between the treatment and control groups at T3-T1. Although not all significant, once again every sagittal condyle/glenoid fossa variable (OLp-CoC, OLpGFS, OLp-GFA, and OLp-GFP) showed a forward movement in the treatment group and a backward or only slightly forward movement in the control group. Net anterior movements of $1.2 \mathrm{~mm}, 1.0 \mathrm{~mm}, 0.9 \mathrm{~mm}$, and $1.3 \mathrm{~mm}$ were found in the treatment group relative to the control group for the condylar position (OLp-CoC), the superior aspect of the glenoid fossa (OLp-GFS), the anterior aspect of the glenoid fossa (OLp-GFA), and the posterior aspect of the glenoid fossa (OLp-GFP). No significant differences were found in the vertical condyle/glenoid fossa variables between the treatment and control groups at this time period.

Four condyle/glenoid fossa variables showed significant differences between the treatment and control groups at T4-T1; OLp-CoC, OLp-GFS, OLp-GFA, and OLp-GFP. Every sagittal condyle/glenoid fossa variable (OLp-CoC, OLp-GFS, OLp-GFA, and OLp-GFP) showed a forward movement in the treatment group and a backward movement in the control group. Net anterior movements of $1.8 \mathrm{~mm}, 1.8 \mathrm{~mm}, 1.3 \mathrm{~mm}$, and $1.9 \mathrm{~mm}$ were found in the treatment group relative to the control group for the condylar position (OLp-CoC), the superior aspect of the glenoid fossa (OLp-GFS), the anterior aspect of the glenoid fossa (OLp-GFA), and the posterior aspect of the glenoid 
fossa (OLp-GFP). No significant differences were found in the vertical condyle/glenoid fossa variables between the treatment and control groups.

Only one condyle/glenoid fossa variable, OLs-GFP, showed a significant difference between the treatment and control groups after phase II comprehensive orthodontic treatment (T5-T1). Although not significant, every sagittal glenoid fossa variable (OLp-GFS, OLp-GFA, and OLp-GFP) showed a forward movement in the treatment group and a backward movement in the control group. The sagittal condyle variable OLp-CoC showed only a slight backward movement of $0.3 \mathrm{~mm}$ in the treatment group compared to a greater backward movement of $1.1 \mathrm{~mm}$ in the control group. Net anterior movements of $0.8 \mathrm{~mm}, 0.9 \mathrm{~mm}, 0.6 \mathrm{~mm}$, and $1.7 \mathrm{~mm}$ were found in the treatment group relative to the control group for the condylar position (OLp-CoC), the superior aspect of the glenoid fossa (OLp-GFS), the anterior aspect of the glenoid fossa (OLp-GFA), and the posterior aspect of the glenoid fossa (OLp-GFP), respectively. The posterior aspect of the glenoid fossa (OLs-GFP) showed a significant upward movement in the treatment group relative to the control group. Although not significant, all other vertical condyle/glenoid fossa variables (OLs-CoC, OLs-GFS, and OLs-GFA) showed an overall upward net relative movement of the treatment group compared to the control group. Net superior movements of $1.3 \mathrm{~mm}, 0.7 \mathrm{~mm}, 0.7 \mathrm{~mm}$, and $1.1 \mathrm{~mm}$ were found in the treatment group relative to the control group for the condylar position (OLs-CoC), the superior aspect of the glenoid fossa (OLs-GFS), the anterior aspect of the glenoid fossa (OLs-GFA), and the posterior aspect of the glenoid fossa (OLs-GFP), respectively. None of the condyle/glenoid fossa variables showed significant differences between the treatment and control groups at T4-T3. Every sagittal condyle/glenoid fossa 
variable (OLp-CoC, OLp-GFS, OLp-GFA, and OLp-GFP) in the treatment group moved backward, although the distance was less than the backward movement of the sagittal condyle/glenoid fossa variables in the control group. No significant differences or trends were found in the vertical condyle/glenoid fossa variables between the treatment and control groups.

Only one condyle/glenoid fossa variable, OLs-CoC, showed a significant difference between the treatment and control groups during phase II comprehensive orthodontic treatment (T5-T4). Although not significant, every sagittal condyle/glenoid fossa variable (OLp-CoC, OLp-GFS, OLp-GFA, and OLp-GFP) showed a backward movement in the treatment group and a forward movement in the control group from T4 to T5. This suggests possible relapse in the anteriorly relocated condyle and glenoid fossa in the treatment group. Net posterior movements of $1.0 \mathrm{~mm}, 0.9 \mathrm{~mm}, 0.7 \mathrm{~mm}$, and $0.2 \mathrm{~mm}$ were found in the treatment group relative to the control group for the condylar position (OLp-CoC), the superior aspect of the glenoid fossa (OLp-GFS), the anterior aspect of the glenoid fossa (OLp-GFA), and the posterior aspect of the glenoid fossa (OLp-GFP). Although only OLs-CoC was significant, all vertical condyle/glenoid fossa variables (OLs-CoC, OLs-GFS, and OLs-GFA) showed an overall upward net relative movement of the treatment group compared to the control group from T4 to T5. Net upward movements of $1.0 \mathrm{~mm}, 0.6 \mathrm{~mm}, 0.6 \mathrm{~mm}$, and $0.6 \mathrm{~mm}$ were found in the treatment group relative to the control group for the condylar position (OLs-CoC), the superior aspect of the glenoid fossa (OLs-GFS), the anterior aspect of the glenoid fossa (OLsGFA), and the posterior aspect of the glenoid fossa (OLs-GFP), respectively. 
Previous studies have reported that the placement of the Herbst appliance caused an anterior and downward movement of the condyle which induced adaptive growth, modeling, and remodeling of the condyle, the glenoid fossa, and the articular tubercle ${ }^{7,9,132}$. It has been shown that adaptive growth in the condyle and remodeling of the glenoid fossa contribute to forward relocation of the mandible $e^{7,50,133}$. These changes have been reported to be stable after Herbst treatment ${ }^{132}$.

In summary, in response to Herbst treatment, the entire glenoid fossa appears to move in an anterior direction. The condyle appears to shift forward slightly within the anteriorly relocated glenoid fossa. Movement of the entire glenoid fossa in the control group appeared to occur in a posterior direction, compounding the net anterior movement of the glenoid fossa in the treatment group. Slight relapse in the anterior movement of the entire glenoid fossa occurs in the short-term post-treatment period, however the entire glenoid fossa maintained a net anterior position in the treatment group relative to the control group. The condyle appeared to return to a more centered position in the fossa during this time period. During the long-term post-treatment period, the entire glenoid fossa appeared to return to its normal pattern of backward and downward movement, however the net anterior relocation was maintained. During phase II comprehensive orthodontic treatment, the entire glenoid fossa showed a net backward movement in the treatment group relative to the control suggesting possible relapse in the anteriorly relocated condyle and glenoid fossa in the treatment group. After phase II comprehensive orthodontic treatment, the glenoid fossa appeared to have relocated in an anterior superior direction in the treatment group relative to the control group. Relocation of the glenoid fossa in the treatment group appears to occur in an anterior and 
superior direction relative to the control group in response to Herbst treatment and this relative change in position appears to be stable over the long term. From a study on nonhuman primates treated with the Herbst appliance, Voudouris et al. ${ }^{88}$ reported that the growth modification measured in the glenoid fossa was in an inferior and anterior direction. In addition, he noted that restriction of the downward and backward growth of the fossa observed in the control subjects might additionally contribute to the Class II correction. 


\section{CHAPTER V: SUMMARY, CONCLUSIONS, RECOMMENDATIONS}

\section{Summary}

The purpose of this study was to investigate the skeletal and dental changes of Class II patients treated with the crowned Herbst appliance in the early mixed dentition and examine the long term stability of these changes. Cephalometric analysis was performed on radiographs taken before phase I treatment (T1), immediately after Herbst removal during phase I treatment (T2), at the completion of phase I treatment (T3), prior to beginning of phase II orthodontic treatment (T4), and immediately following phase II orthodontic treatment (T5). Measurements were compared to a matched control sample of untreated Class II patients from the Bolton-Brush study. The results of this study should provide important information on the effectiveness of early treatment with the crowned Herbst appliance and offer new information on the long term stability of these treatment effects. This information could ultimately be used by clinicians to evaluate the best time and most effective technique for treating skeletal Class II deformities.

The difference in each variable between the treatment and control groups across the five time periods (T1 through T5) was analyzed for pooled subjects, and separately for male and female subjects. A repeated measures ANOVA was performed to determine if the differences between the treatment and control groups were the same across the five time periods.

The differences between certain time points were analyzed to investigate: T2-T1: treatment effects of the Herbst appliance (Tx (T2-T1)) minus (Control (t2-t1)), T3-T1: 
Phase I treatment effects (Tx (T3-T1)) minus (Control (t3-t1)), T4-T1: residual Phase I treatment effects (Tx (T4-T1)) minus (Control (t4-t1)), and T5-T1 combined Phase I and Phase II treatment effects (Tx (T5-T1)) minus (Control (t5-t1)). In addition, T5-T4: phase II treatment effects (Tx (T5-T4)) minus (Control (t5-t4)) were evaluated as well as T4-T3: the relapse that occurred from after Phase I treatment to before Phase II treatment (Tx (T4-T3)) minus (Control (t4-t3)).

For all time periods, the change in the values of the variables for pooled subjects, male subjects, and female subjects in the treatment group were compared to the change in the values of the variables for pooled subjects, male subjects, and female subjects in the control group, respectively. Matched pairs t-tests were performed for every variable at each time period to identify significant differences from the control group. In total, 37 variables were evaluated for each group including sagittal variables, vertical variables, angular variables, and condyle/glenoid fossa variables. In addition, an evaluation of the overjet correction and molar relationship correction for the treatment groups and an evaluation of the net overjet correction and net molar relationship correction for the treatment vs. control groups at each time period for pooled subjects were performed.

The results of this study were interpreted by evaluating changes that occurred in the sagittal and vertical directions. Transverse dimensional changes were not investigated in this study. Changes in the position of the maxillary skeletal base, the mandibular skeletal base, the maxillary molars and incisors, the mandibular molars and incisors, and the condyle/glenoid fossa region in response to treatment with the crowned Herbst appliance in the early mixed dentition were identified and followed over the long term through phase II orthodontic treatment. 


\section{Conclusions}

Treatment of Class II patients treated with the crowned Herbst appliance in the early mixed dentition resulted in the following changes relative to normal growth:

1) The forward movement of the maxillary base (OLp-A pt) was initially restrained after treatment (T2-T1) and gradually became more restrained in the short-term (T3-T1) and long-term (T4-T1) post-treatment periods. An even greater restraint was seen after phase II orthodontics (T5-T1).

2) The mandibular base (OLp-Pg) was initially moved forward after treatment (T2-T1), however, a gradual relapse was seen in the short-term (T3-T1) and long-term (T4-T1) post-treatment periods. Additional relapse in a posterior direction was seen after phase II orthodontics (T5-T1).

3) The maxillary molars (Ms-OLp) were initially distalized (T2-T1), relapsed slightly in the short-term post-retention period (T3-T1), and became distalized again in the long-term post-treatment period (T4-T1). The maxillary molars were mesialized during phase II orthodontic treatment (T5-T4) and most of the overall posterior molar movement was eliminated after this period (T5-T1).

4) The mandibular molars (Mi-OLp) were initially mesialized after treatment (T2-T1), however gradual relapse occurred during the short-term post-treatment period (T3-T1) until they returned to their pre-treatment position after the long-term posttreatment period (T4-T1). They were mesialized again after phase II orthodontic treatment (T5-T1).

5) The maxillary incisors (Is-OLp) moved backward and retroclined after treatment (T2-T1), then relapsed slightly during the short-term (T3-T1) and long-term 
(T4-T1) post-treatment period. A net posterior movement was maintained through the long-term post-treatment period (T4-T1). This posterior position of the maxillary incisor remained stable through phase II treatment (T5-T1).

6) The mandibular incisors (Ii-OLp) moved forward and proclined after treatment (T2-T1), then relapsed to their pre-treatment position after the short-term post-treatment period (T3-T1). Forward movement and proclination occurred during the long-term retention period (T4-T3), giving a net forward movement and proclination after this period (T4-T1). The mandibular incisors returned to their pre-treatment position after phase II orthodontic treatment (T5-T1).

7) A net overjet correction of $7.0 \mathrm{~mm}$ occurred after treatment (T2-T1), then relapsed in the short-term post-treatment period (T3-T1) until a relatively stable net overjet correction between 2.5-3.0mm was maintained over the long-term (T4-T1). The overjet correction remained stable through phase II treatment (T5-T1).

8) A molar relationship correction of $6.6 \mathrm{~mm}$ occurred after treatment (T2-T1), then relapsed in the short-term post-treatment period (T3-T1) until a relatively stable net molar correction between 2.2-3.3mm was maintained over the long-term (T4-T1). The molar correction remained stable through phase II treatment (T5-T1).

9) Relocation of the glenoid fossa occurred in an anterior and superior direction after treatment (T2-T1) and this relative change in position was stable over the long term (T4-T1). Restriction of the downward and backward movement of the fossa was observed and might additionally contribute to Class II correction. 


\section{Recommendations}

Upon completion of this study, the following recommendations were made:

1) Repeating the study with images from cone beam CT scans would allow more accurate identification of landmarks and more precise visualization of anatomic structures. Analysis of the changes, especially temporomandibular joint changes could be more accurately identified and observed. It is realized that it may be difficult to identify an adequate control sample due to the increased exposure to radiation with these scans.

2) A repeat study matching the treatment group to the control group based on skeletal maturation (determined by cervical vertebrae maturation) as opposed to age would provide more detailed information on the treatment responses of the Herbst appliance in relation to development and provide interesting insight into the importance of treatment timing.

3) Future studies directly comparing an early treatment group treated with the edgewise crowned Herbst appliance with a late treatment group of patients treated with the edgewise crowned Herbst appliance would be interesting. 


\section{REFERENCES}

1. Andresen, V., and Häupl, K.: Funktions-Kieferorthopädie. H. Meusser. Leipzig, 1936.

2. Balters, W.: Die Technik und Übung der allfemeinen und speziellen Bionatortherapie. Quintessenz, 1: 77, 1964.

3. Fränkel, R.: Funktionskeiferorthopädie und der Mundhof als apparative Basis. V.E.B. Verlag Volk \& Gesundheit. Berlin, 1967.

4. Pancherz, H. The Herbst Appliance Editorial Aquarium 1995; Barcelona Spain.

5. McNamara, J.A. Jr., Carlson, D.S. Quantitative analysis of temporomandibular joint adaptation to protrusive function. Am J Orthod. 1979; 76: 593-611.

6. Woodside, D.G., Metaxas, A, Altuna, G. The influence of functional appliance therapy on glenoid fossa remodeling. Am J Orthod Dentofacial Orthop. 1987; 92: 181-198.

7. Paulsen, H. U., Karle, A, Bakke, M., Heskind, A. CT scanning and radiographic analysis of temperomandibular joints and cephalometric analysis in a case of Herbst treatment in late puberty. Eur J Orthod. 1995; 17: 165-75.

8. Bakke, M., Paulsen, H. U., Herbst treatment in late adolescence: clinical, electromyographic, kenesiographic, and radiographic analysis of one case. Eur J Orthod. 1989; 11: 3997-407.

9. Pancherz, H.: Treatment of Class II malocclusions by jumping the bite with the Herbst appliance. A cephalometric investigation. Am J Orthod. 76: 423-442, 1979.

10. Hagg U, Pancherz H. Dentofacial orthopedics in relation to chronological age, growth period and skeletal development. An analysis of 72 male patients with Class II division 1 malocclusion treated with the Herbst appliance. Eur. J Orthod. 1988; 10:169-176.

11. Pancherz $\mathrm{H}$. The effects, limitations, and long-term dentofacial adaptations to treatment with the Herbst appliance. Sem Ortho. 1997; 3: 232-243.

12. Hansen, K., and Pancherz, H. Long-term effects of Herbst treatment in relation to normal growth development: a cephalometric study. Eur. J. Orthod., 14: 285-295, 1992. 
13. McNamara, JA Jr. Fabrication of the acrylic splint Herbst appliance. Am J Orthod Dentofacial Orthop. 1988; 94: 10-18.

14. Windmiller EC. The acrylic-splint Herbst appliance. Am J Orthod Dentofacial Orthop. 1993; 104: 73-84.

15. Jakobsson SO: Cephalometric evaluation of treatment effect on Class II, Division I malocclusions. Am J Orthod Dentofacial Orthop 53: 446-457, 1967.

16. Wieslander, L. Intensive treatment of severe Class II malocclusion with a Headgear-Herbst appliance in the early mixed dentition. Am J Orthod. 1984; 86: $1-13$.

17. Baumrind S, Korn EL, Isaacson RJ, et al.: Quantitative analysis of the orthodontic and orthopedic effects of maxillary traction. Am J Orthod Dentofacial Orthop 84: 384-398, 1983.

18. Croft, RS, Buschang, PH, English, JD, and Meyer R. A cephalometric and tomographic evaluation of Herbst treatment in the mixed dentition. Am J Orthod Dentofacial Orthop. 1999; 116: 435-443.

19. Pancherz H, Hagg U. Dentofacial orthopedics in relation to somatic maduration. An analysis of 70 cases treated with the Herbst appliance. Am J Orthod. 1985; 88: 273-287.

20. Tulloch JF, Profitt WR, Phillips C: Outcomes in a 2-phase randomized controlled clinical trial of early Class II treatment. Am J Orthod Dentofacial Orthop 125: 657-667, 2004.

21. Keeling SD, Wheeler TT, King GJ, et al: Anteroposterior skeletal and dental changes after early Class II treatment with bionators and headgear. Am J Orthod Dentofacial Orthop 113: 40-50, 1998.

22. Cozza P, Baccetti, T, Franchi L, Toffol LD, McNamara JA. Mandibular changes produced by functional appliances in Class II malocclusion: A systematic review. Am J Orthod Dentofacial Orthop. 2006; 129: 599.e1-599.e12.

23. Larsen, C.S.: Bioarchaeology: interpreting behavior from the human skeleton, 1997, Cambridge, Mass., Cambridge University Press.

24. Corrucini, R.S.: Anthropological aspects of orofacial and occlusal variations and anomalies. In Kelly MA, Larsen CS (editors), Advances in dental anthropology, New York, 1991, Wiley-Liss.

25. Corrucini, R.S., Pacciani, E.: "Orthodontistry" and dental occlusion in Etruscans, Angle Orthod. 59: 61-64, 1989. 
26. Kingsley, N.W.: Treatise on oral deformities as a branch of mechanical surgery, New York, 1880, Appleton.

27. Angle, E.H.: Treatment of malocclusion of teeth and fractures of the maxillae, Angle's system, ed. 6, Philadelphia, 1900, SS White Dental Mfg Co.

28. Profitt W.R., Fields, H.W. Contemporary Orthodontics. $3^{\text {rd }}$ ed. Moseby Inc. St. Louis, MO 2000.

29. McLain, J.B., Profitt, W.R. Oral Health Status in the United States: Prevalence of Malocclusion. J Dent Educ. 1985; 49: 386-396.

30. Kelly, J.E., Sanchez, M., Vankirk, L.E. An assessment of the occlusion of the teeth of children. DHEW Publication No. (HRA) 74-1612, Washington, DC: National Center for Health Statistics, 1973.

31. Kelly, J.E., Harvey, C. An assessment of the teeth of youths 12-17 years, DHEW Publication No. (HRA) 77-1644, Washington, DC: National Center for Health Statistics, 1977.

32. McLain, J.B., Steedle, J.R., Vig, P.S. Face height and dental relationships in 1600 children: A survey. J Dent Res. 1983; 62: 308.

33. Enlow, D.H. Facial Growth. $3^{\text {rd }}$ ed. WB Saunders Co. 1990.

34. McNamara, James Jr., Brudon, W. Orthodontic and Orthopedic treatment in the Mixed Dentition. Needham Press Inc. Ann Arbor, MI 1993.

35. McNamara, JA Jr. Components of Class II Malocclusion in children 8-10 years of age. Angle Orthod. 1981; 51: 177-202.

36. Ngan, P.W., Byczek, E., Scheik. Longitudinal Evaluation of Growth changes in Class II division subjects. Seminars in Orthod. 3: 4 Dec 1997 pp. 222-231.

37. Riedel, R.A. The relationship of maxillary structures to cranium in malocclusion and normal occlusion. Angle Orthod. 1952; 22: 142-145.

38. Steiner, CC. Cephalometrics for you and me. Am J Orthod. 1953; 39: 729-755.

39. McNamara, JA Jr. A method of cephalometric evaluation. Am J Orthod. 1984; 86: 449-469.

40. Ricketts, RM. The influence of orthodontic treatment on facial growth and development. Angle Orthod. 1960; 30: 103-133. 
41. Schudy, FF. Vertical growth versus antero-posterior growth as related to function and treatment. Angle Orthod. 1965; 35: 36-50.

42. Schudy, FF. The rotation of the mandible resulting from growth: Its implications in orthodontic treatment. Angle Orthod. 1965; 35: 36-50.

43. Tollaro I, Baccetti T, Franchi L, et al. Interarch transverse discrepancy in Class II malocclusion during the mixed dentition. Am J Orthod Dentofacial Orthop 1996.

44. Baccetti T, Franchi L, McNamara JA Jr, et al. Early Dentofacial features of Class II malocclusion: A longitudinal study from the deciduous through mixed dentition. Am J Orthod 1973; 63: 610-621.

45. Ayra BS, Savara BS, Thomas DR. Prediction of $1^{\text {st }}$ molar occlusion. Am J Orthod 1973; 63: 610-621.

46. Bishara SE, Hoppens BJ, Jakobsen JR, et al. Changes in the molar relationship between the deciduous and permanent dentitions: A longitudinal study. Am J Orthod Dentofacial Orthop 1988; 93: 19-28.

47. Spillane LM, McNamara JA Jr. Maxillary adaptations following expansion in the mixed dentition. Sem Orthod 1995; 1: 176-187.

48. McNamara JA Jr, Ellis E. Cephalometric analysis of untreated adults with ideal facial and occlusal relationships. Int J Ault Orthodont Oral Surgery 1988; 3: 221-231.

49. Ruf, S and Pancherz, H. Herbst/multibracket appliance treatment of Class II division I malocclusions in early and late adulthood. A prospective cephalometric study of consecutively treated subjects. Eur J Orthod. 2006; 28: 352-360.

50. Ruf, S, Pancherz, H. Temporomandibular joint remodeling in adolescents and young adults during Herbst treatment: a prospective longitudinal magnetic resonance imaging and cephalometric radiographic investigation. Am J Orthod Dentofacial Orthop 1999; 115: 607-618.

51. Moore, RN. Principles of Dentofacial Orthopedics. Sem Orthod. 1997; 3: 4 21221.

52. Weinberger, WW. Orthodontics. A historical review of its origin and evolution. Vol. II. The Mosby Company, 1926.

53. Breitner, C.: Experimentelle Veränderungen der mesiodistalen Beziehungen der oberen und untern Zahnreihen. Zschr. Stomatol., 28: 620-635, 1930. 
54. Nelson, C., Harkness, M., Herbison, P. Mandibular changes during functional appliance treatment. Am J Orthod Dentofac Orthop. 1993; 104 (2): 153-61.

55. Mills, JR. The effect of functional appliances on the skeletal pattern. Br J Orthod. 1991 Nov; 18 (4): 267-75.

56. Teuscher, U. A growth-related concept for skeletal Class II treatment. Am J Orthod. 1978. Sept; 74(3): 258-75.

57. Rudzki-Janson, I, Noachter, R. Functional appliance therapy with the Bionator. Sem Orthod. 1998; 4: 33-45.

58. Aelbers, CMF, Dermault, LR. Orthopedics in orthodontics: Part I, fiction or reality - a review of the literature. Am J Orthod Dentofac Orthop. 1996; 110: 513-19.

59. O'Brien et al. Effectiveness of treatment for Class II malocclusion with the Herbst or Twin-block appliances: A randomized, controlled trial. Am J Orthod Dentofacial Orthop. 2003; 124: 128-137.

60. Schwarz, M.: Erfahrungen mit dem Herbstschen Scharnier zur Behandlung des Distalbisses. Zahnärztl. Rundschau, 43: 47-54, 91-100, 1934.

61. Herbst, E.: Dreissigjährige Erfahrungen mit dem Retentionsscharnier. Zahnärztl. Rundschau, 43: 1515-1524, 1563-1568, 1611-1616, 1934.

62. Goodman, P, McKenna, P. Modified for the mixed dentition. J Clinc. Ortho. 1985; 19: 811-814.

63. Dischinger, TG. Edgewise bioprogressive Herbst appliance. J Clinc. Ortho. 1989; 23: 608-617.

64. Dischinger, TG. Edgewise Herbst Appliance. J Clinc. Ortho. 1995; 29: 738-742.

65. Held, A.J., Spirgi, M., and Cimasoni, G.: An orthopedically treated adult case of Class II malocclusion. Am. J. Orthod. 49: 761-765, 1963.

66. Egermark-Eriksson, I.; Carlsson, G.E., and Ingervall, B. Function and dysfunction of the masticatory system in individuals with dual bite. Eur J. Orthod. 1: 107-117: 1979.

67. Moss, ML. The primacy of functional matrices on orofacial growth. Dent Pract 19: 65-73, 1968.

68. Brodie, AG. On the growth pattern of the human head from third month to the eighth year of life. Am J Orthod 27: 633-647, 1941. 
69. Von Bremen, J, Pancherz, H. Efficiency of early and late Class II Division I treatment. Am J Orthod Dentofacial Orthop. 2002; 121: 31-37.

70. Tulloch, J.F., Phillips, C., and Profitt, W. Benefits of early Class II treatment: Progress report of a two-phase randomized clinical trial. Am J Orthod Dentofacial Orthop. 1998; 113: 62-72.

71. Viazis AD. Efficient orthodontic treatment timing. Am J Orthod Dentofacial Orthop. 1995; 108: 560-561.

72. Ghafari JG. Emerging paradigms in orthodontics. Am J Orthod Dentofacial Orthop. 1997; 111: 573-580.

73. Nelson G. Phase I treatment. Am J Orthod Dentofacial Orthop. 1997; 111: 239240.

74. Gianelly AA. Crowding: timing of treatment. Angle Orthod 1994; 64: 415-418.

75. Gianelly AA. One-phase versus two-phase treatment. Am J Orthod Dentofacial Orthop. 1995; 108: 556-559.

76. Tung AW, Kiyak HA. Pshychological influences on the timing of orthodontic treatment. Am J Orthod Dentofacial Orthop. 1998; 113: 29-39.

77. O'Brien et al. Effectiveness of early orthodontic treatment with the Twin-block appliance: A multicenter, randomized, controlled trial. Part 2: Pshchosocial effects. Am J Orthod Dentofacial Orthop. 2003; 124: 488-494.

78. Yang EY, Kiyak HA. Orthodontic treatment timing: A survey of orthodontists. Am J Orthod Dentofacial Orthop. 1998; 113: 96-102.

79. Lai M, McNamara JA Jr. An evaluation of two phase treatment with the Herbst appliance and pre-adjusted edgewise therapy. Sem Ortho 1998; 4: 46-58.

80. Pancherz H. The Herbst appliance_-it's biological effects and clinical use. Am J Orthod. 1985; 87: 1-20.

81. Valant JR, Sinclair PM. Treatment effects of the Herbst appliance. Am J Orthod Dentofacial Orthop. 1989; 95: 138-147.

82. Pancherz H. The mechanism of Class II correction in Herbst appliance treatment. A cephalometric investigation. Am J Orthod. 1982a; 82:104-113.

83. McNamara JA Jr. Neuromuscular and skeletal adaptations to altered function in the orofacial region. Am J Orthod 1973; 64: 578-606. 
84. Xiong H, Hagg U, Tang G-H, Rabie ABM, Robinson W. The effect of continuous bite-jumping in adult rats: a morphological study. Angle Orthod 2004; 74: 86-92.

85. Chen JY, Will LA, Niederman R. Analysis of the efficacy of functional appliances on mandibular growth. Am J Orthod Dentofacial Orthop 2002; 122 : 470-476.

86. Pancherz H, Littmann C. Somatische Reif undd morphologische Veranderungen des Unterkiefers bei der Herbst-Behandlung. Inf. Orthod. Kieferorthop. 1988; 20: $455-470$.

87. Pancherz, H. and Littmann, C. Morphologie und Lage des Unferkiefers bei der Herbst-Behandlung. Eine kephalometrische Analyse der Veränderungen bis zum Wachstumsabschluss. Inf. Orthod. Keiferorthop., 21: 493-513, 1989.

88. Voudouris et al. Condyle-fossa modifications and muscle interactions during Herbst treatment, Part 2. Results and conclusions. Am J Orthod Dentofacial Orthop. 2003; 124: 13-29.

89. Araujo AM, Buschang PH, Melo ACM. Adaptive condylar growth and mandibular remodeling changes with bionator therapy—an implant study. Eur. J Orthod. 2004; 26: 515-522.

90. Popowich K, Nebbe B, and Major P. Effect of Herbst treatment on temporomandibular joint morphology: A systematic literature review. Am J Orthod Dentofacial Orthop. 2003; 123: 388-394.

91. Rabie et al. Osteogenesis in the glenoid fossa in response to mandibular advancement. Am J Orthod Dentofacial Orthop. 2001; 119: 390-399.

92. Pancherz H, Hansen K. Occlusal changes during and after Herbst treatment: a cephalometric investigation. . Eur. J Orthod. 1986; 8: 215-228.

93. McNamara JA Jr, Howe RP, Dischinger TG. A comparison of the Herbst and Frankel appliance in the treatment of Class II malocclusions. Am J Orthod Dentofacial Orthop. 1990; 98: 134-144.

94. Pancherz $\mathrm{H}$. The effect of continuous bite jumping on the Dentofacial complex: A follow-up study after Herbst appliance treatment of Class II malocclusions. Eur J Orthod. 1981; 3: 49-60.

95. Pancherz H, Anehus Pancherz M. The head-gear effect of the Herbst appliance. Am J Orthod Dentofacial Orthop. 1993; 103: 510-520. 
96. Pancherz, H. Vertical dentofacial changes during Herbst appliance treatment. Swed. Dent. J. Suppl., 15: 189-196, $1982 b$.

97. Broadbent, B.H., Sr., Broadbent, B.H., Jr. and Golden, W. Bolton standards of dentofacial developmental growth. The C.V. Mosby Comp. St. Louis, 1975.

98. Pancherz, H. The nature of Class II relapse after Herbst appliance treatment: A cephalometric long-term investigation. Am. J. Orthod. Dentofacial Orthop., 100: 220-233, 1991.

99. Pancherz H, Fackel U. The skeletofacial growth pattern pre-and post-dentofacial orthopaedics: a long-term study of Class II malocclusions treated with the Herbst appliance. Eur J Orthod. 1990; 12: 209-218.

100. Voudouris JC, Kuftinec MM. Improved clinical use of Twin-block and Herbst as a result of radiating viscoelastic tissue forces on the condyle and fossa in treatment and long-term retention: Growth relativity. Am. J. Orthod. Dentofacial Orthop. 2000; 117: 247-266.

101. Berger et al. Long-term comparison of treatment outcome and stability of Class II patients treated with functional appliances versus bilateral sagittal split ramus osteotomy. Am. J. Orthod. Dentofacial Orthop. 2005; 127: 451-464.

102. VanLaecken R, Martin C, Dischinger T, Razmus T, and Ngan P. Treatment effects of the edgewise Herbst appliance: A cephalometric and tomographic investigation. Am. J. Orthod. Dentofacial Orthop. 2006; 130: 582-591.

103. Hagg U, Du X, Rabie ABM. Initial and late treatment effects of headgear-Herbst appliance with mandibular step-by-step advancement. Am. J. Orthod. Dentofacial Orthop. 2002; 122: 477-485.

104. Dischinger T. Dentofacial orthopedics without regard to patient cooperation. West Virginia Orthodontic Alumni Association Meeting; 2005 Sep 9; Morgantown, West Virginia 2005.

105. Du X, Hagg U, Rabie ABM. Effects of headgear Herbst and mandibular step-bystep advancement versus conventional Herbst appliance and maximal jumping of the mandible. . Eur J Orthod. 2002; 24: 167-174.

106. Rabie et al. The Correlation of Replicating Cells and Osteogenesis in the Condyle During Stepwise Advancement. Angle Orthodontist. 2003; 73: 457-465.

107. Baumrind S, Miller DM. Computer-aided head film analysis: the University of California San Francisco method. Am J Orthod. 1980; 78:41-65. 
108. Bjork, A. The face in profile: An anthropological x-ray investigation of Swedish children and Conscripts. Lund: Berlingska Boktrycheriet 1947: 40: 58.

109. Konik M, Pancherz H, Hansen K. The mechanism of Class II correction in late Herbst treatment. Am J Orthod Dentofacial Orthop 1997; 112:87-91.

110. Ruf S, Pancherz H. Dentoskeletal effects and facial profile changes in young adults treated with the Herbst appliance. Angle Orthod 199; 69: 239-246.

111. Ruf S, Pancherz H. The mechanism of Class II correction during Herbst therapy in relation to the vertical jaw base relationship: a cephalometric roentgenographic study. Angle Orthod 1997; 67: 271-276.

112. Hansen K, Koutsonas TG, Pancherz H. Long-term effects of Herbst treatment on the mandibular incisor segment: a cephalometric and biometric investigation. Am J Orthod Dentofacial Orthop 1997; 112:92-103.

113. Obijou C, Pancherz H. Herbst appliance treatment on Class II, division 2 malocclusions. Am J Orthod Dentofacial Orthop 1997; 112:287-291.

114. Omblus J, Malmgren O, Pancherz H, Hagg U, Hansen K. Long-term effects of Class II correction in Herbst and Bass therapy. Eur J Orthod 1997; 19: 185-193.

115. Franchi L, Baccetti T, McNamara JA Jr. Treatment and post-treatment effects of acrylic splint Herbst appliance therapy. Am J Orthod Dentofacial Orthop 1999; 115:429-438.

116. Nelson B, Hansen K, Hagg U. Class II correction in patients treated with class II elastics and with fixed functional appliances: a comparative study. Am J Orthod Dentofacial Orthop 2000; 118:142-149.

117. Burkhart DR, McNamara JA Jr, Baccetti T. Maxillary molar distalization or mandibular enhancement: a cephalometric comparison of comprehensive orthodontic treatment including the pendulum and Herbst appliances. Am J Orthod Dentofacial Orthop 2003; 123:108-116.

118. Eberhard H, Hirschfelder U. Treatment of Class II, Division 2 in the late growth period. J Orofac Orthop 1998; 59: 352-361.

119. Hansen K, Pancherz H, Hagg U. Long-term effects of the Herbst appliance in relation to the treatment growth period: a cephalometric study. Eur J Orthod 1991; 13: 471-481.

120. Wieslander L. Long-term effect of treatment with the headgear-Herbst appliance in the early mixed dentition. Stability or relapse? Am J Orthod Dentofacial Orthop 1993; 104:319-329. 
121. Pancherz H, Hansen K. Mandibular anchorage in Herbst treatment. Eur J Orthod 1988; 10: 149-164.

122. Pancherz H, Malmgren O, Hagg U, Omblus J, Hansen K. Class II correction in Herbst and Bass therapy. Eur J Orthod 1989; 11: 17-30.

123. Wong GW, So LL, Hagg U. A comparative study of sagittal correction with the Herbst appliance in two different ethnic groups. Eur J Orthod 1997;19: 195-204.

124. Sidhu MS, Kharbanda OP, Sidhu SS. Cephalometric analysis of changes produced by a modified Herbst appliance in the treatment of Class II division 1 malocclusion. Br J Orthod 1995; 22: 1-12.

125. Baltromejus S, Ruf S, Pancherz H. Effective termporomandibular joint growth and chin position changes: activator versus Herbst treatment. A cephalometric roentgenographic study. Eur J Orthod 2002; 24: 627-637.

126. Schweitzer M, Pancherz H. The incisor-lip relationship in Herbst/multibracket appliance treatment of Class II, Division 2 malocclusions. Angle Orthod 2001; 71: 358-363.

127. Ruf S, Pancherz H. Long-term TMJ effects of Herbst treatment: a clinical and MRI study. Am J Orthod Dentofacial Orthop 1998; 114:475-483.

128. Ruf S, Hansen K, Pancherz H. Does orthodontic proclination of lower incisors in children and adolescents cause gingival recession? Am J Orthod Dentofacial Orthop 1998; 114:100-106.

129. Hansen K, Iemamnueisuk P, Pancherz H. Long-term effects of the Herbst appliance on the dental arches and arch relationships: a biometric study. $\mathrm{Br} \mathrm{J}$ Orthod 1995; 22: 123-134.

130. Ruf S, Pancherz H. The effect of Herbst appliance treatment on the mandibular plane angle: a cephalometric roentgenographic study. Am J Orthod Dentofacial Orthop 1996; 110:225-229.

131. Schiavoni R, Grenga V, Macri V. Treatment of Class II high angle malocclusions with the Herbst appliance: a cephalometric investigation. Am J Orthod Dentofacial Orthop 1992; 102:393-409.

132. Paulsen HU. Morphologic changes of the TMJ condyles of 100 patients treated with the Herbst appliance in the period of puberty to adulthood: a long-term radiographic study. Eur J Orthod 1997; 19: 657-668. 
133. Ruf S, Pancherz H. Temporomandibular joint growth adaptation in Herbst treatment: a prospective magnetic resonance imaging and cephalometric roentgenographic study. Eur J Orthod 1998; 20: 375-388. 
APPENDICES 
APPENDIX A

IRB exemption 


\title{
WestVirginiaUniversity. \\ Office of Research Compliance
}

\section{Expedited - IRB Protocol - Exemption}

\author{
To: $\quad$ Ngan, Peter \\ From: $\quad$ WVU Office of Research Compliance \\ Date: $\quad$ Monday, September 17, 2007 \\ Subject: $\quad$ No action required
}

Tracking \#: $\mathrm{H}-20364$

Title: $\quad$ Long-Term Follow-Up of Patients Treated with the Edgewise Crowned Herbst Appliance in the Mixed Dentition.

The above-referenced study was reviewed by the Institutional Review Board and was granted exemption on [Review Date Not Found] in accordance with 45 CFR 46.101(4).

While no action is required on your part, the IRB made the following findings:

This research study was granted an exemption in accordance with Research on existing data, documents, records, pathological specimens, or diagnostic specimens [45 CFR 46.101(4)]. Please adhere to the requirements for disclosure of data as outlined in your Data Use Agreement. In accordance with the Health Insurance Portability and Accountability Act, a waiver of research authorization has been granted. Please fulfill the subject accounting requirements associated with the grating of this waiver. If you have questions please refer to the IRB website.

The following documents have been approved and validated for use in this study and are available in the BRAAN system:

HIPAA waiver has been acknowledged.

Thank you.

Board Designee: White, Barbara

Letter Sent By: White, Barbara, 9/17/2007 1:36 PM 


\section{APPENDIX B}

Approval for the use of orthodontic records from Dr. Terry Dischinger 


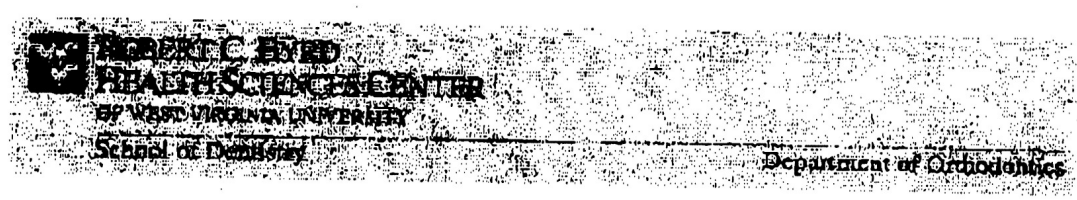

Permission is granted to Dr. Timothy Wigal, Dr. Peter Ngan, and co-workers to use the cephalometric radiographs provided by this office for research and educational purposes in the completion of the master's thesis "Long-Term Follow-Up of Patients Treated with the Edgewise Crowned Eerbst appliance in the Mixed Dentition".

Sincerelv.

Dr. Terry Dischinger

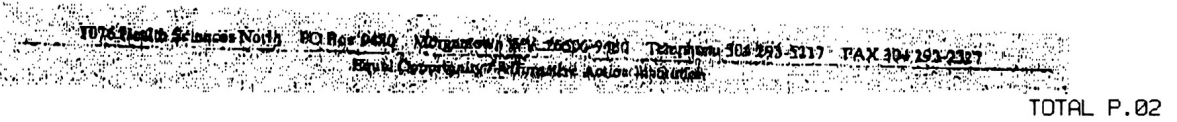


APPENDIX C

Approval for the use of orthodontic records from Dr. Mark Hans 


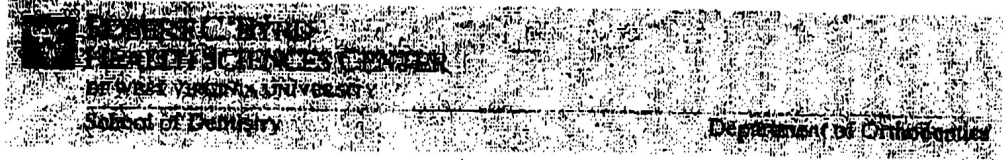

Permission is granted to Dr. Timothy Wigal, Dr. Peter Ngan, and co-workers to use the cephalometric radiographs provided by this office for research and educational purposes in the completion of the master's thesis "Long-Term Follow-Up of Patients Treated with the Edgeypise Crow hed Herbst appliance in the Mixed Dentition".

Maxk Hans, D.D.S., M.S.D.

Boltow-Brush Growth Study Center

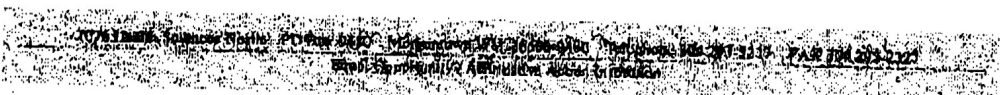

$2+1+2+$ of 


\section{APPENDIX D}

Control Group_-Pooled_Distribution of Sagittal Variable Measurements 

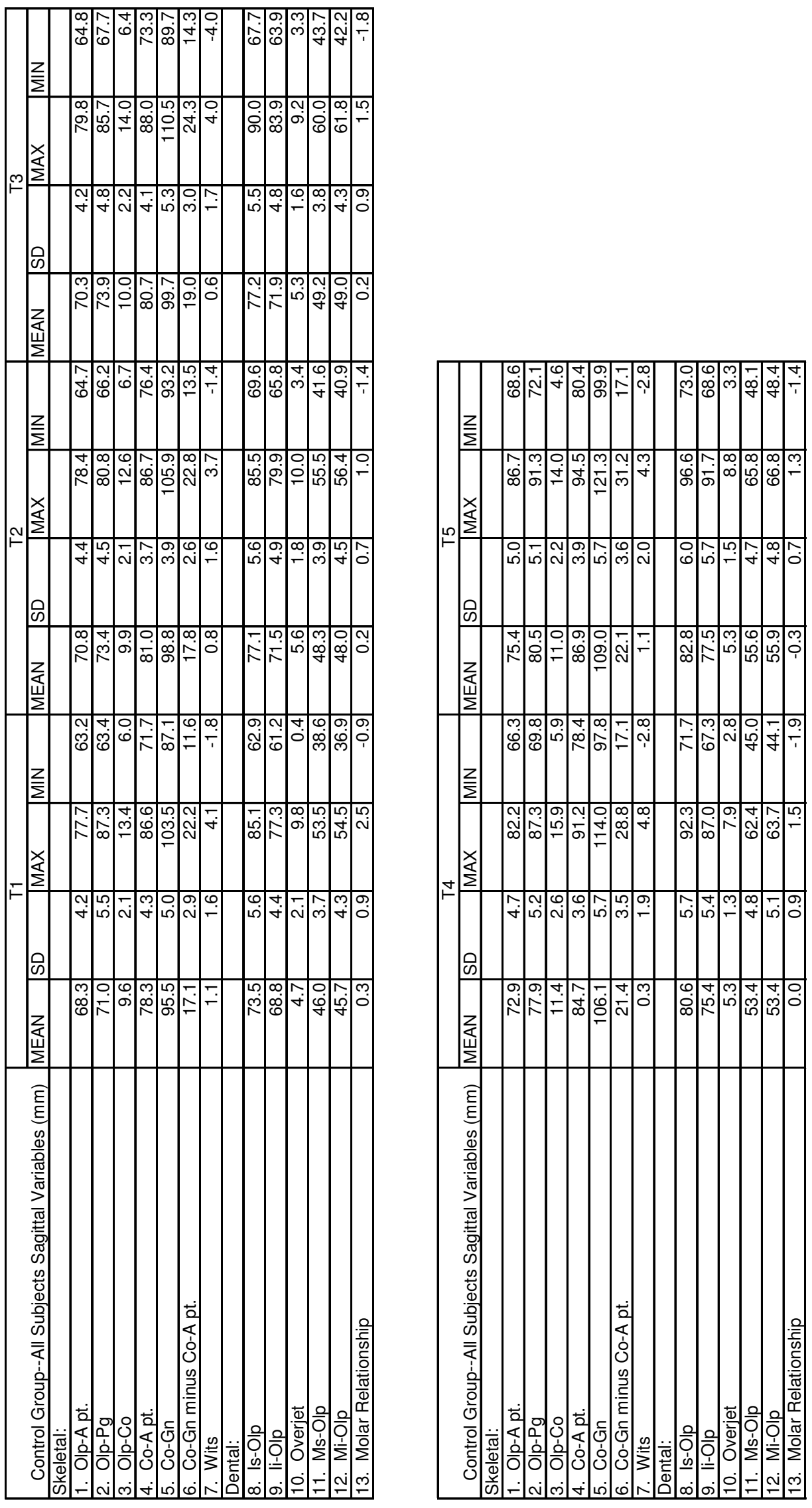


\section{APPENDIX E}

Control Group_-Pooled— Distribution of Vertical Variable Measurements 

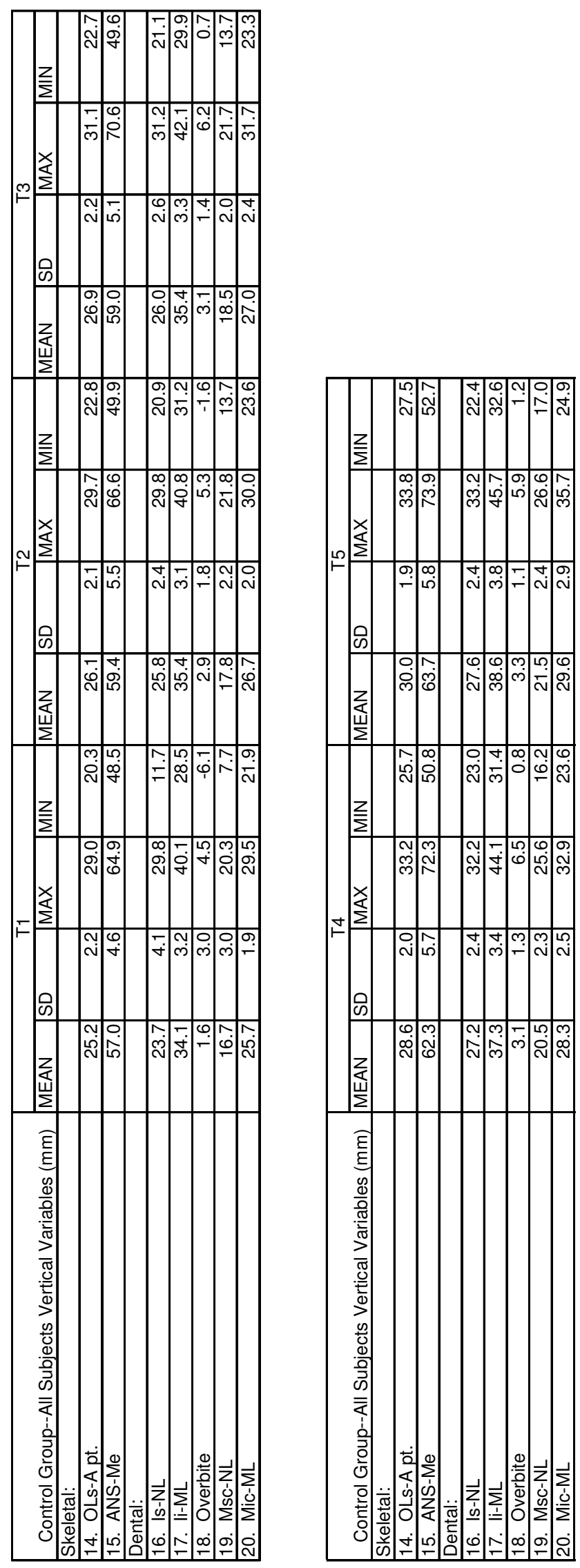
APPENDIX F 

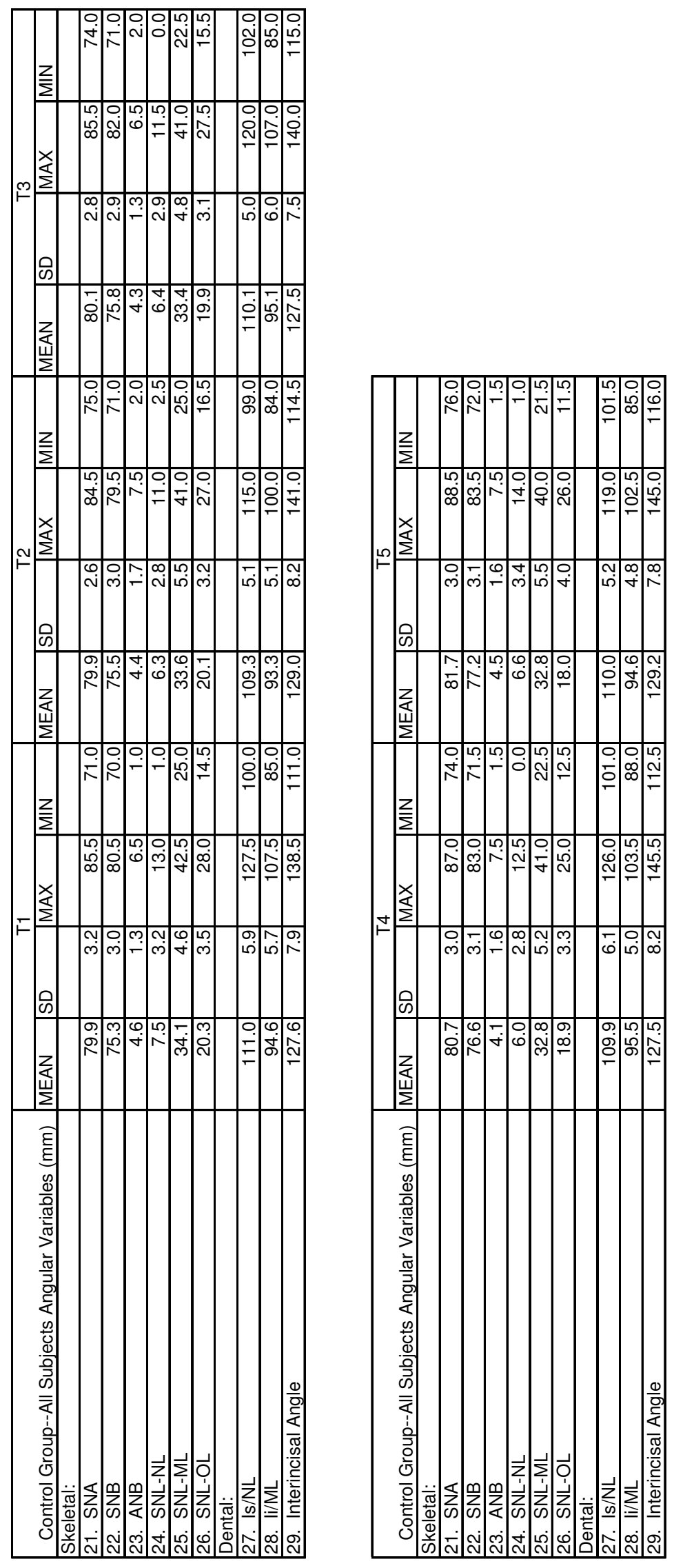
APPENDIX G 

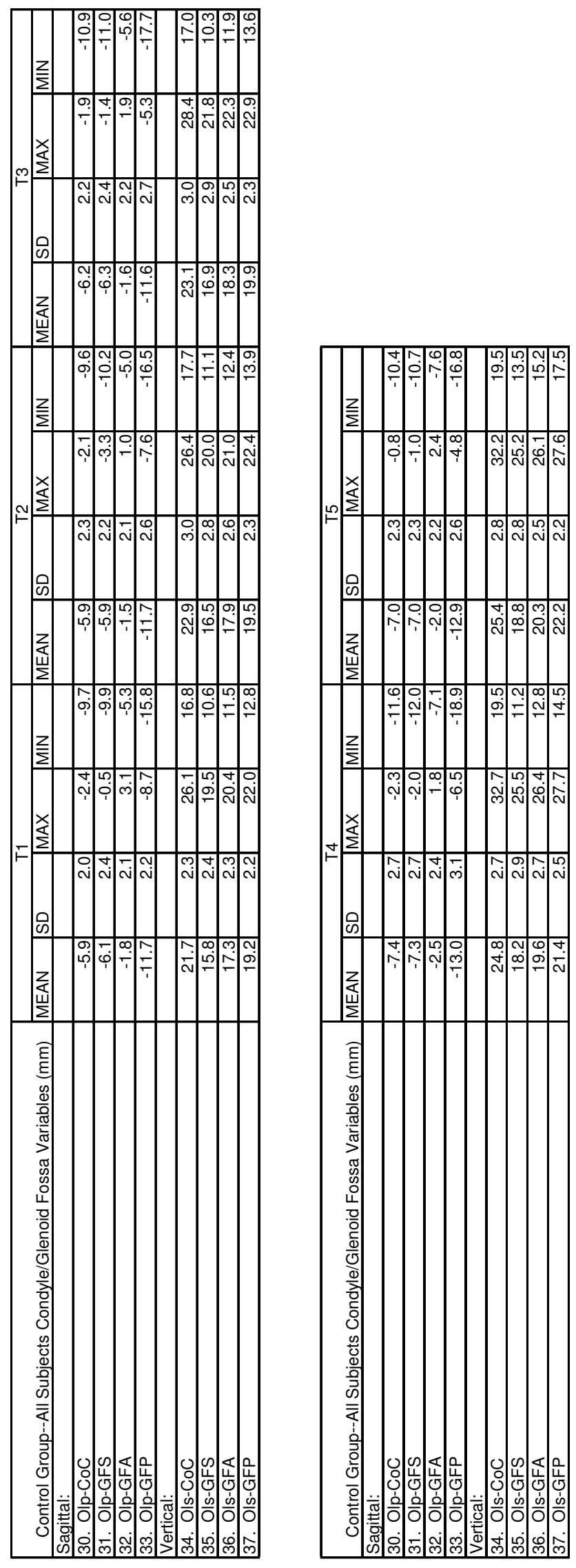
APPENDIX H 

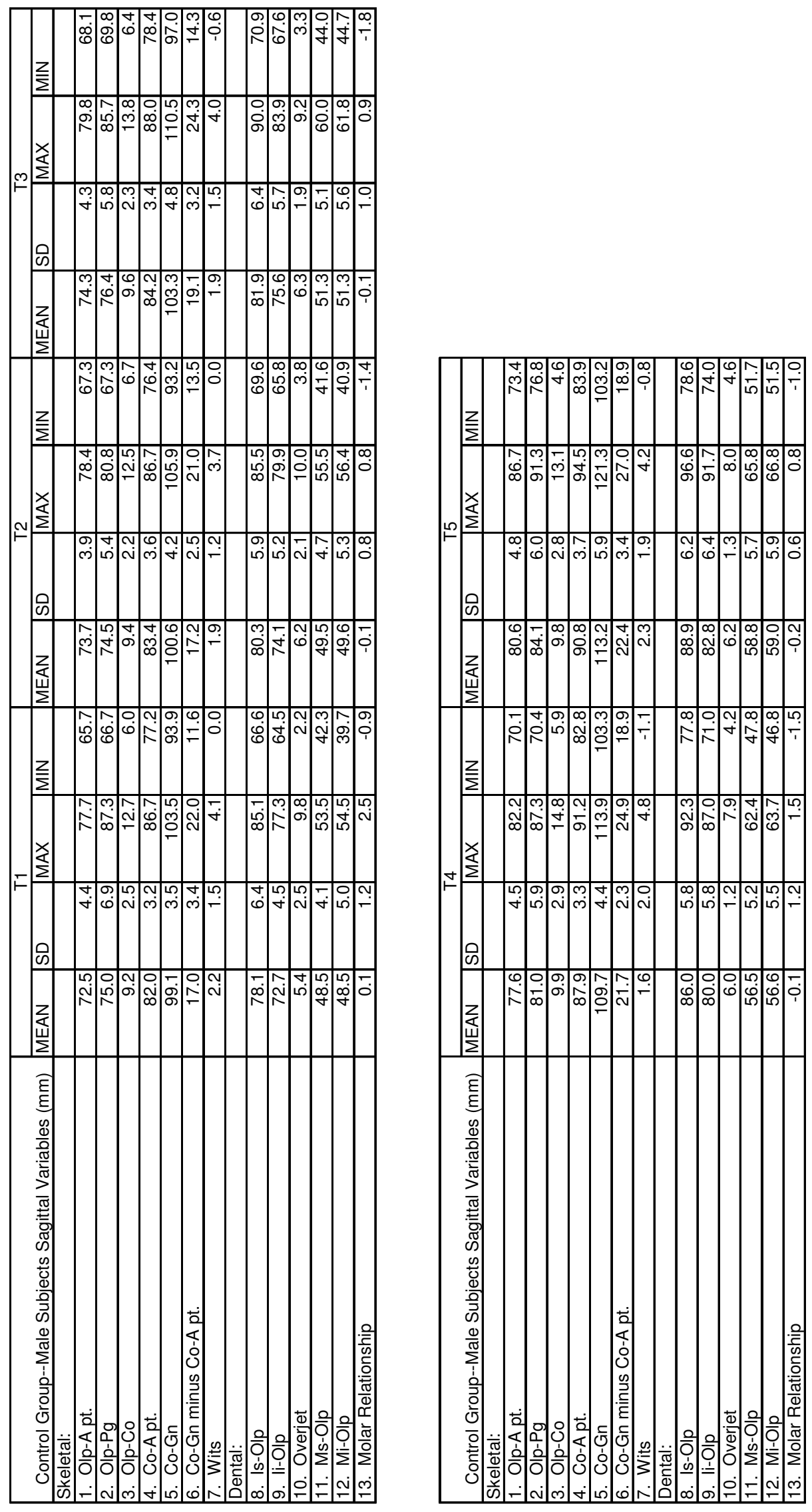
APPENDIX I 

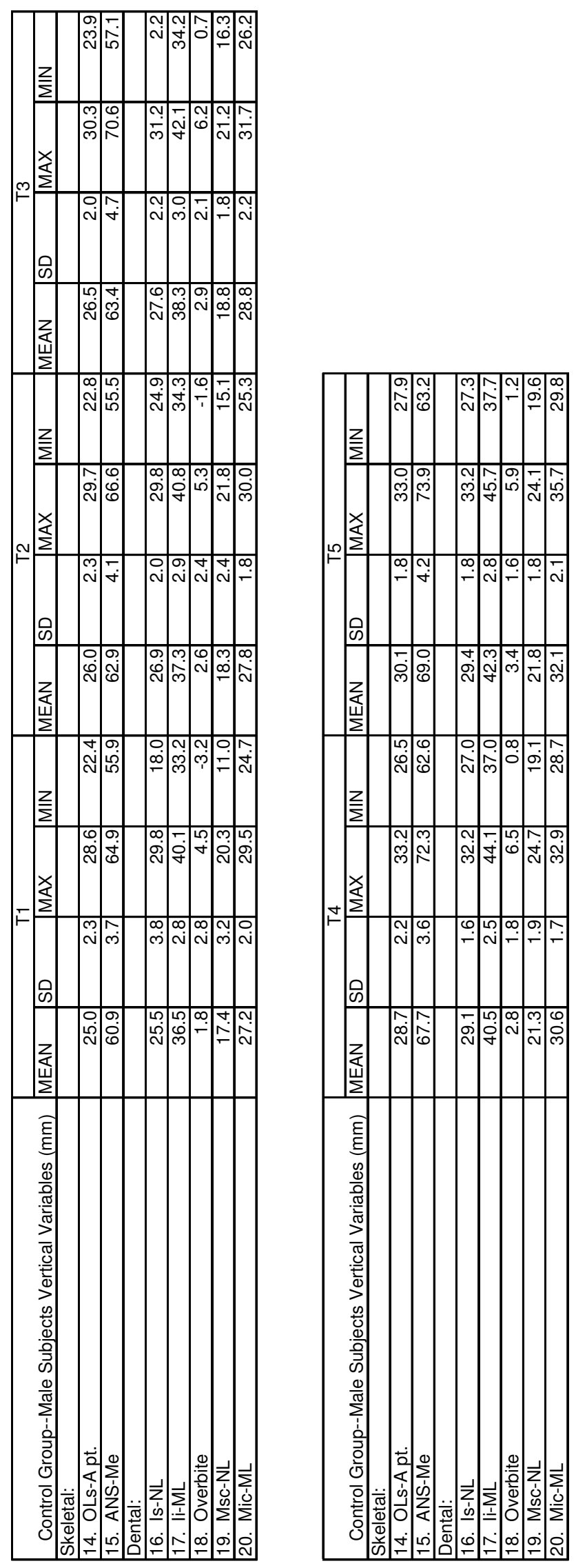
APPENDIX J 

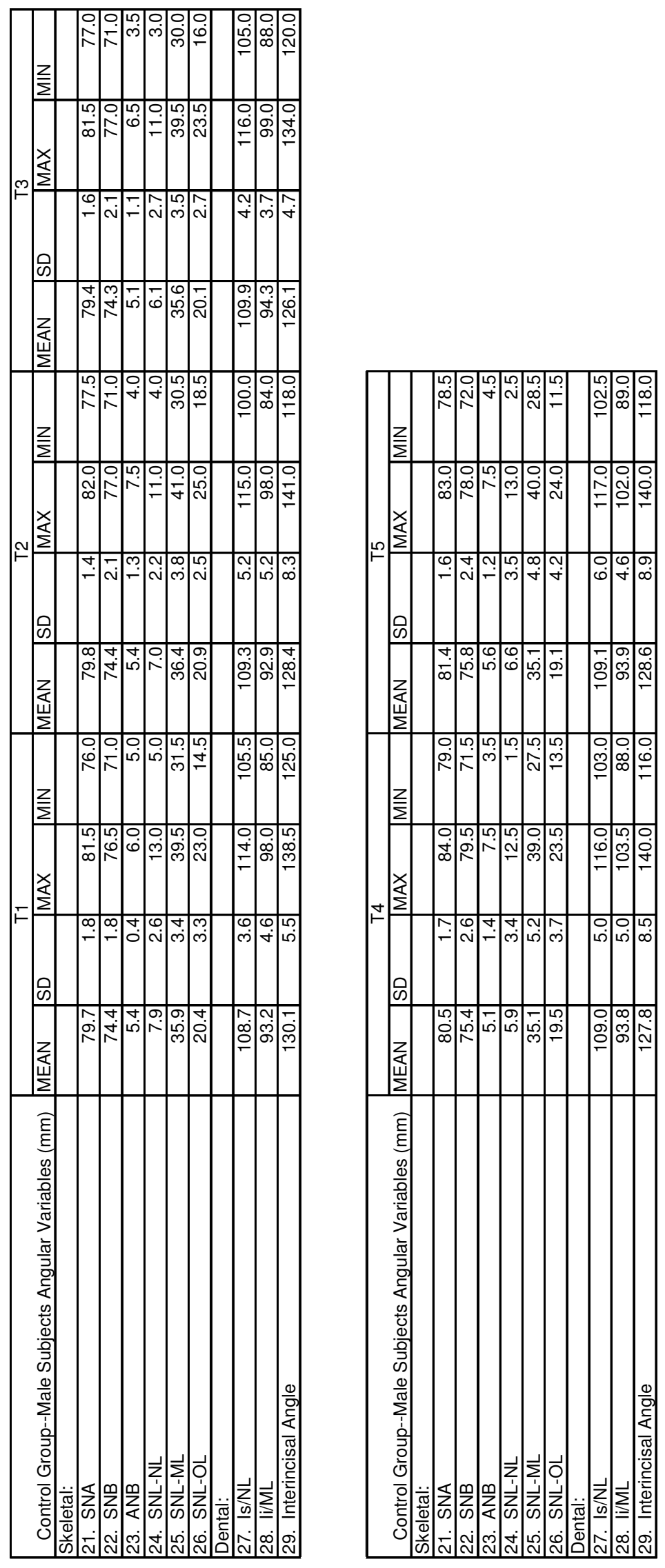
APPENDIX K 

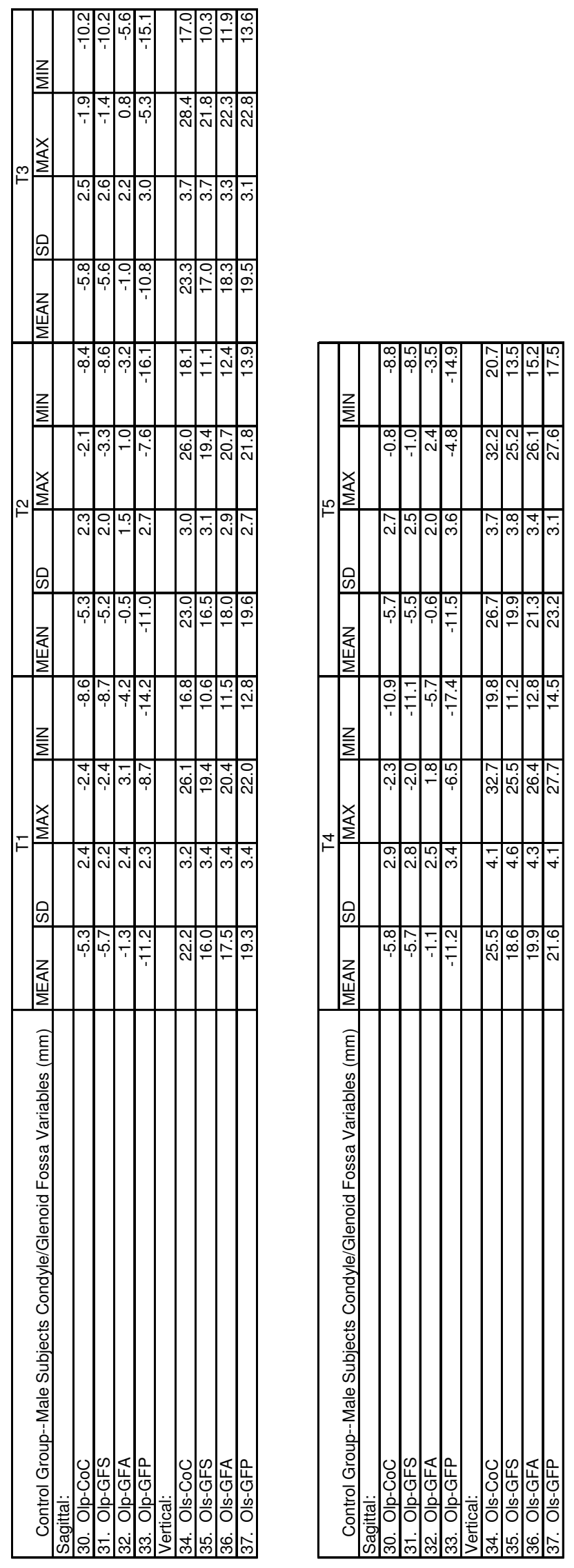
APPENDIX L 

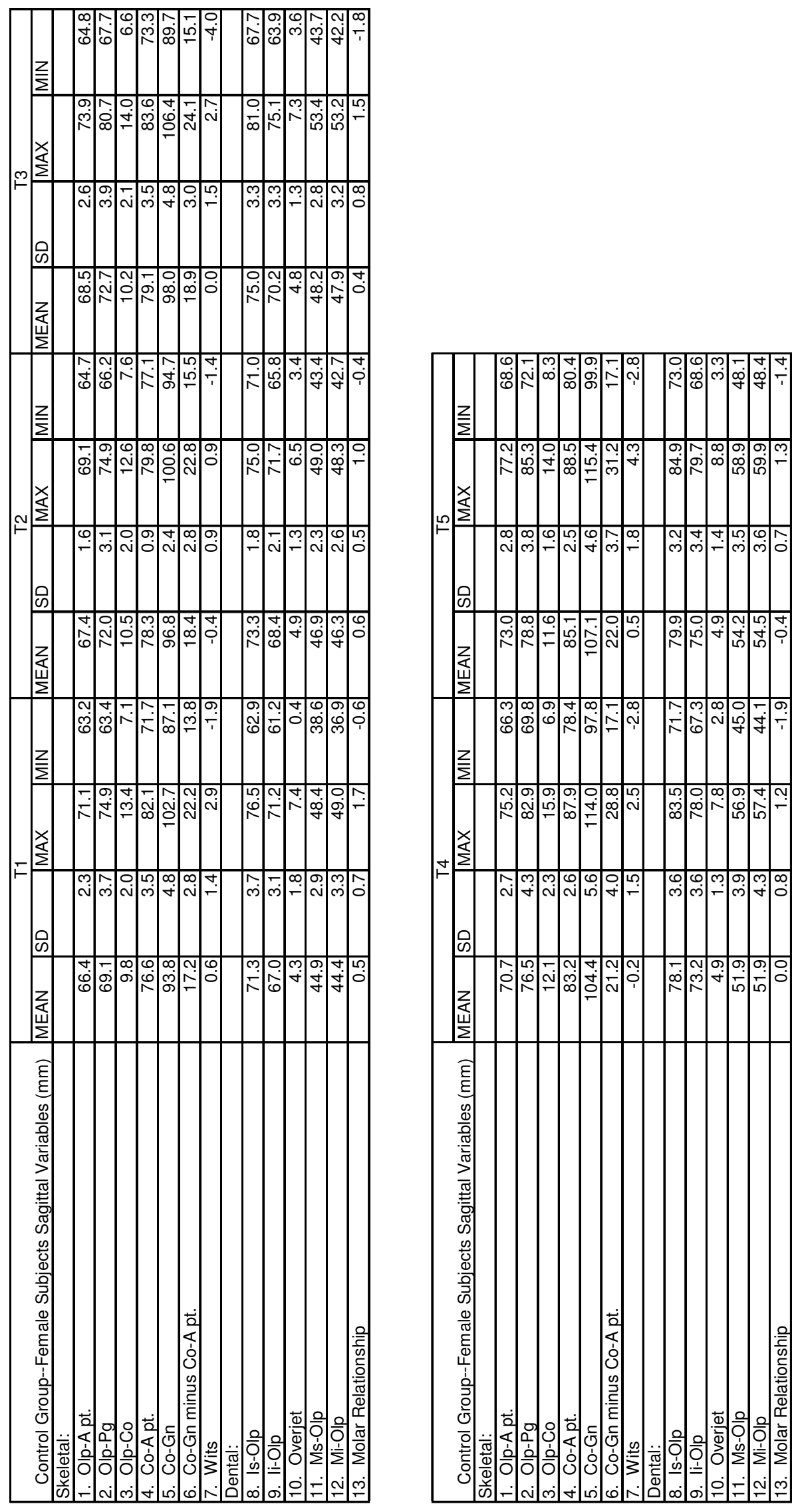
APPENDIX M 

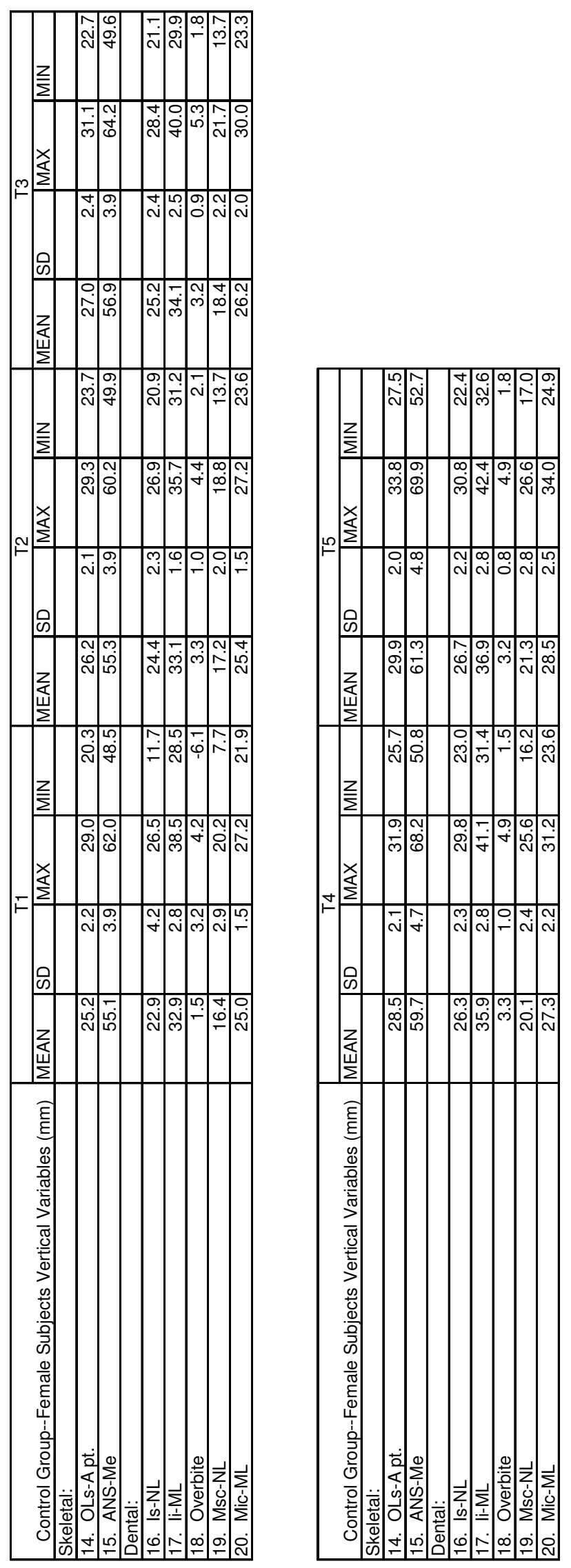
APPENDIX N 

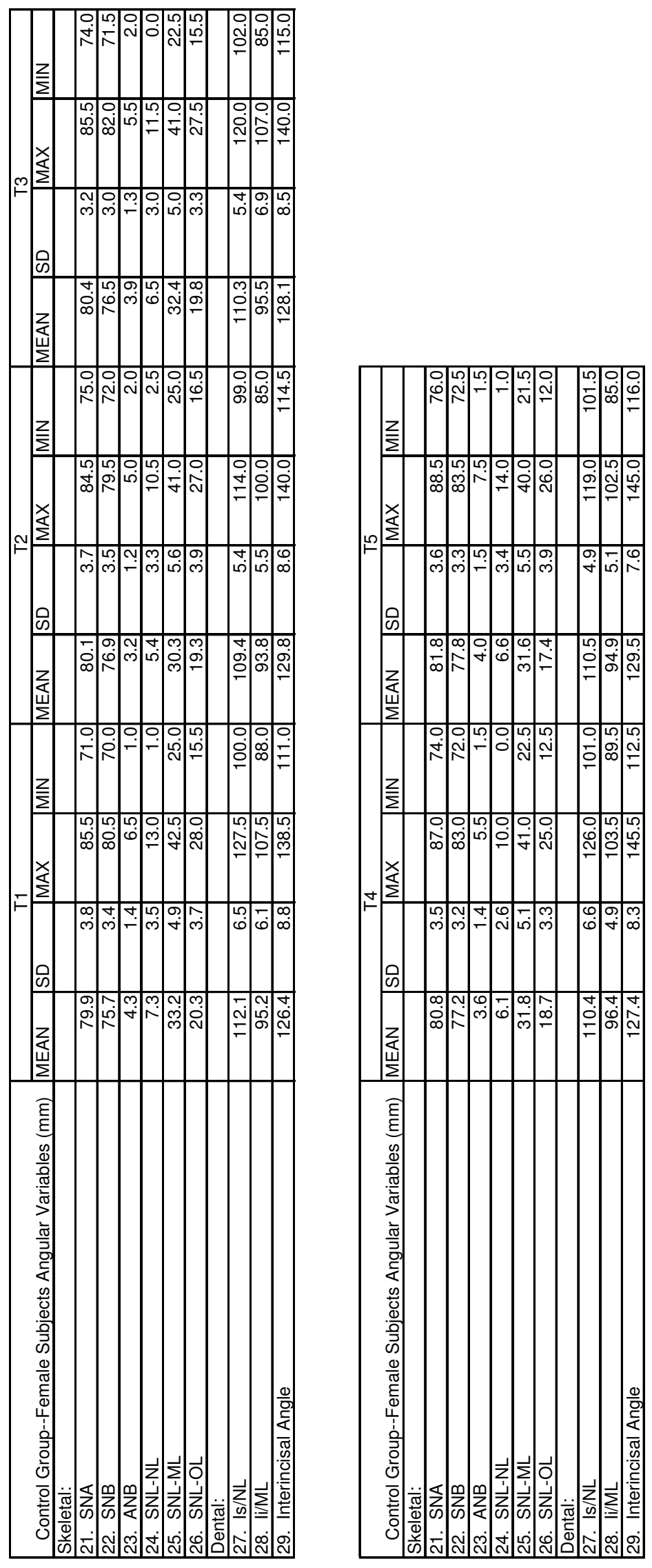
APPENDIX O 

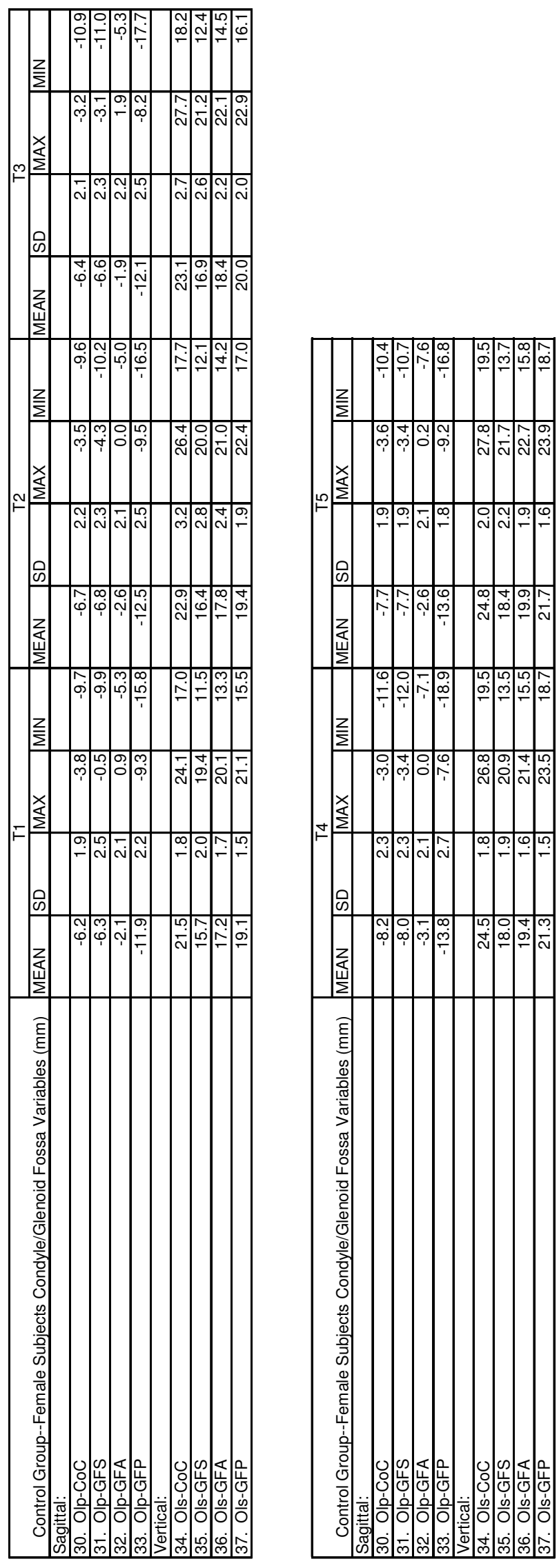
APPENDIX P 

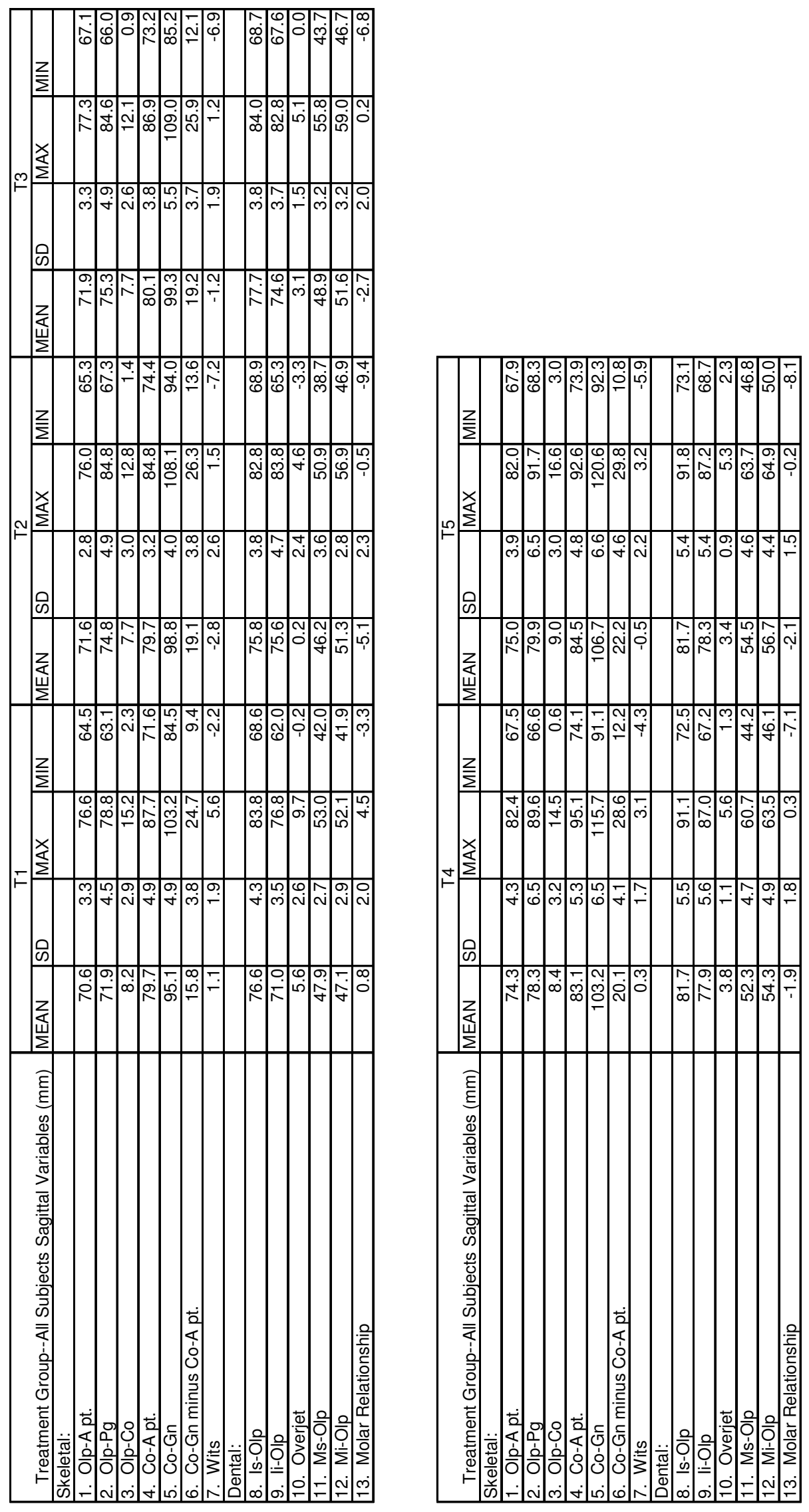
APPENDIX Q 

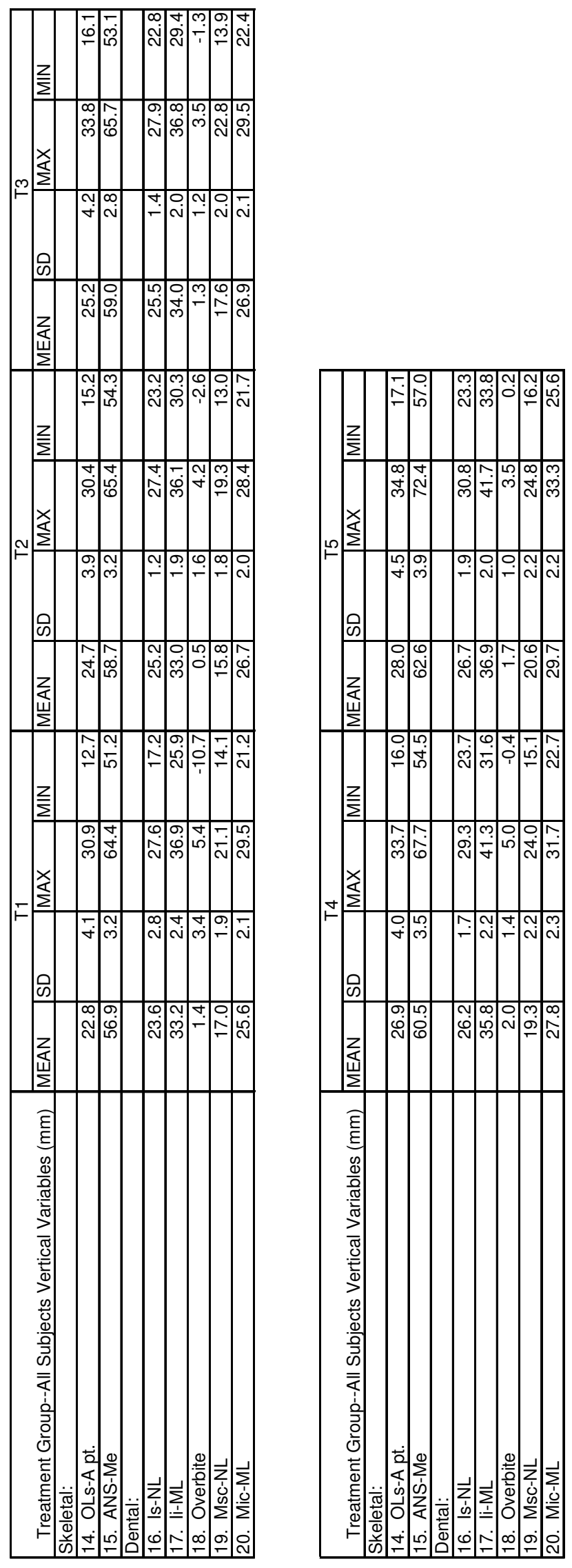
APPENDIX R 

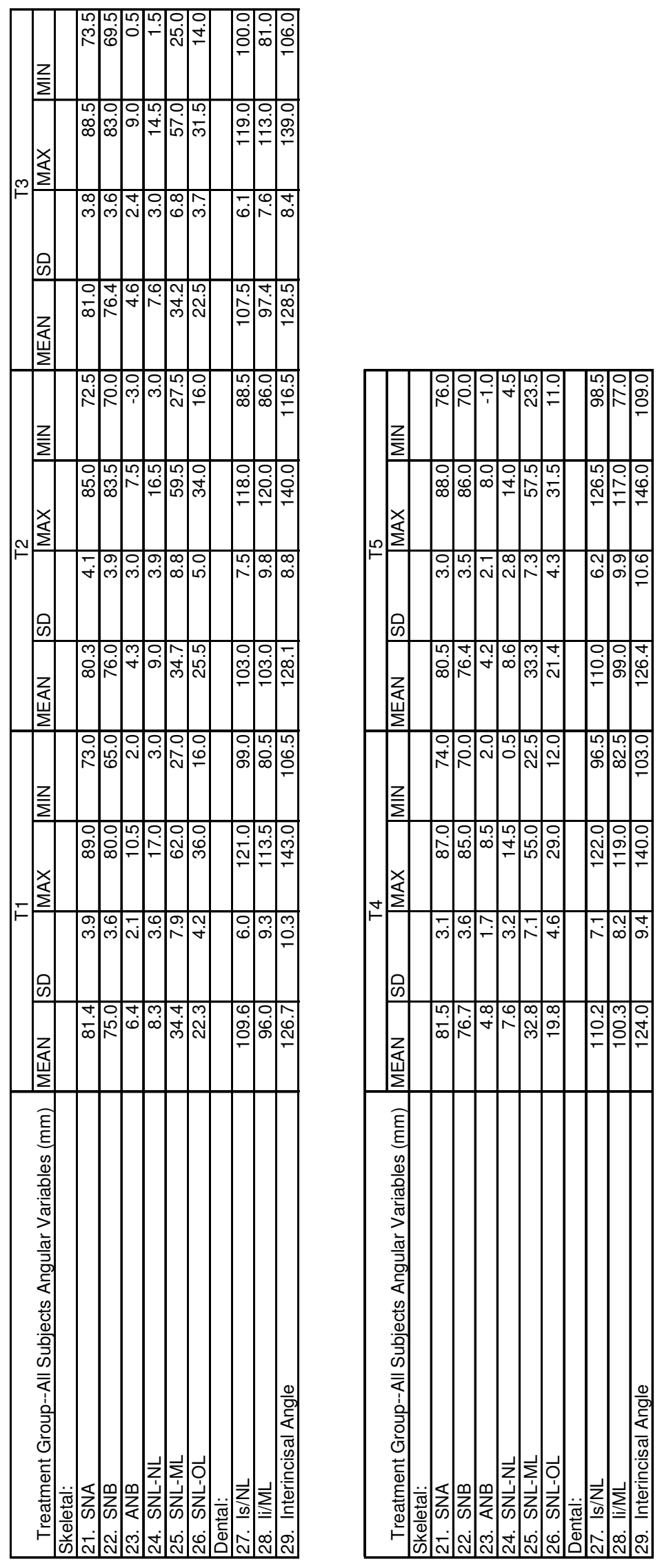
APPENDIX S 

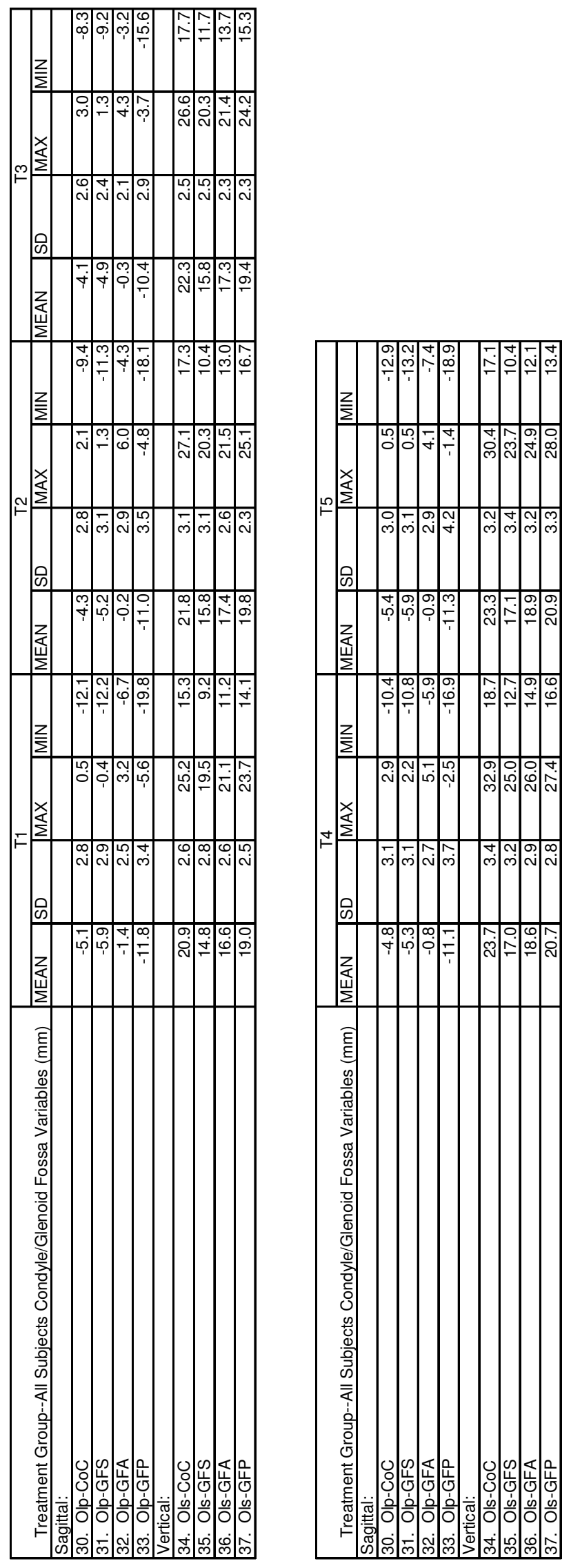
APPENDIX T 

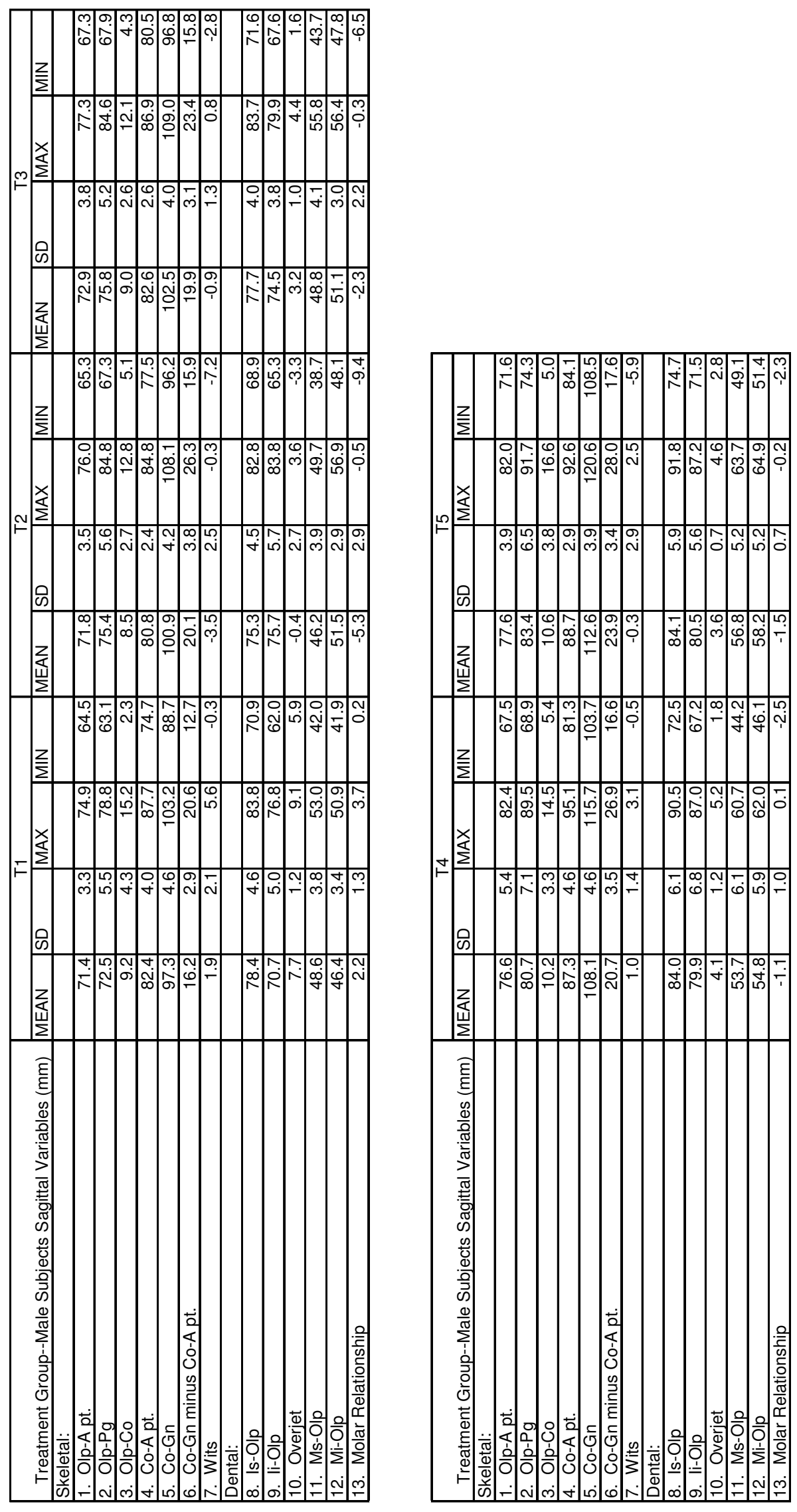
APPENDIX U 

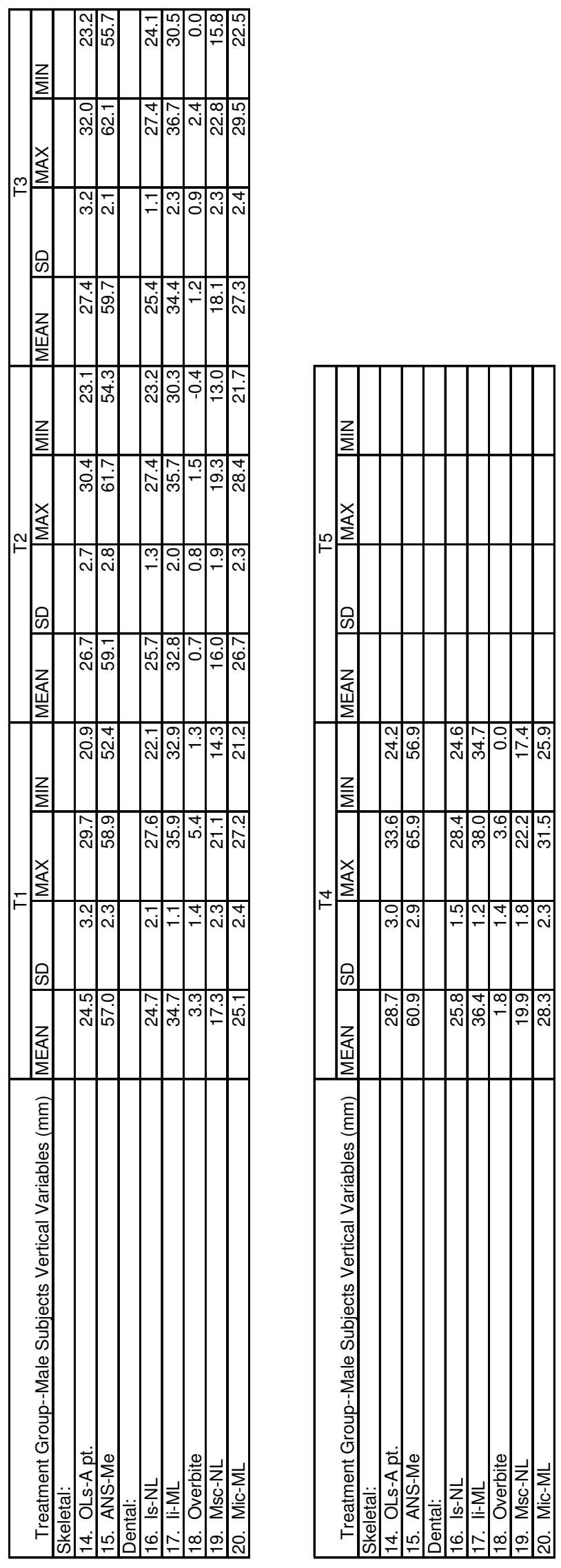
APPENDIX V 

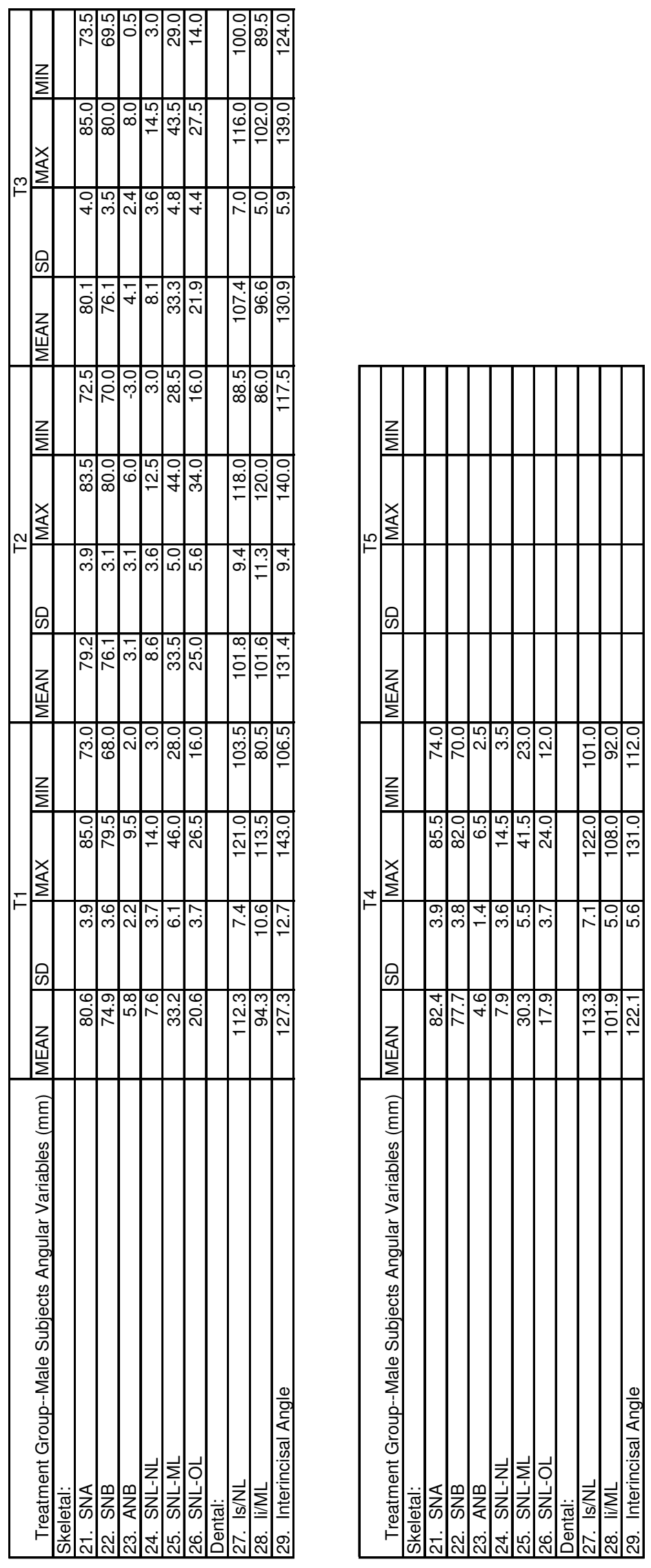
APPENDIX W 

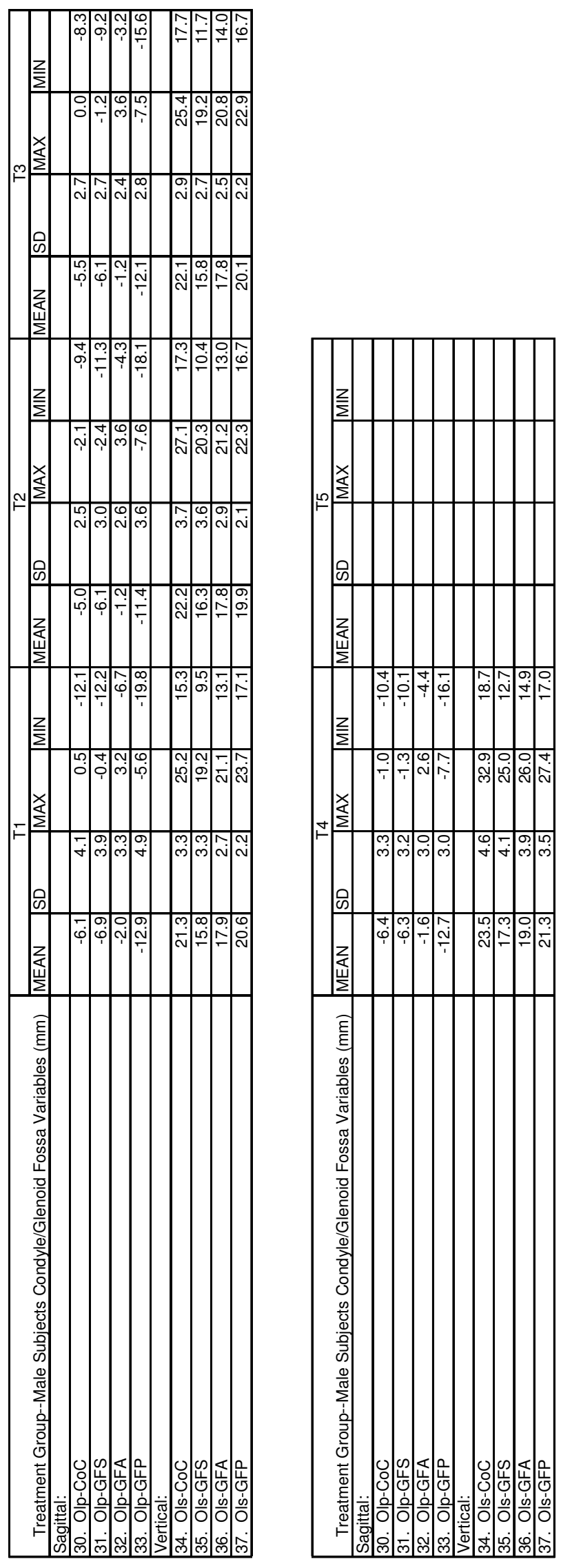
APPENDIX $\mathrm{X}$ 

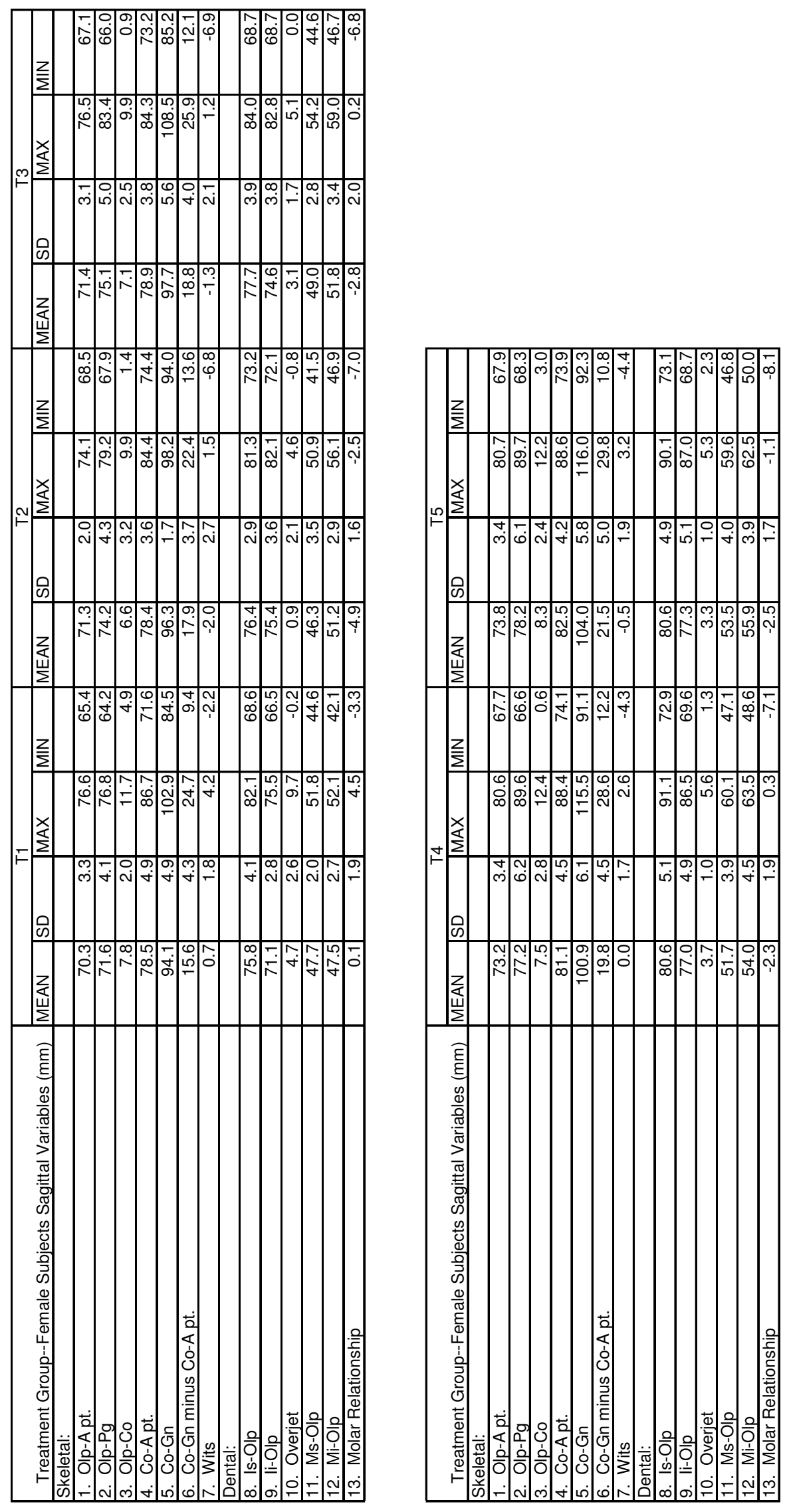
APPENDIX Y 

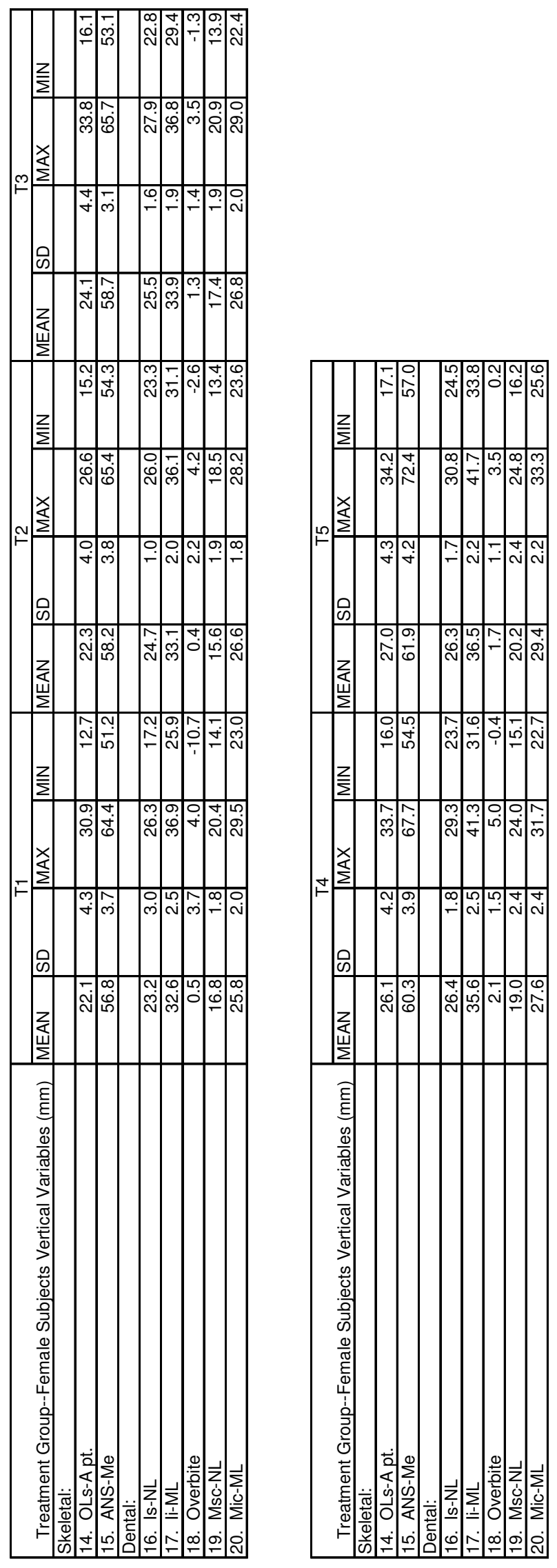
APPENDIX Z 

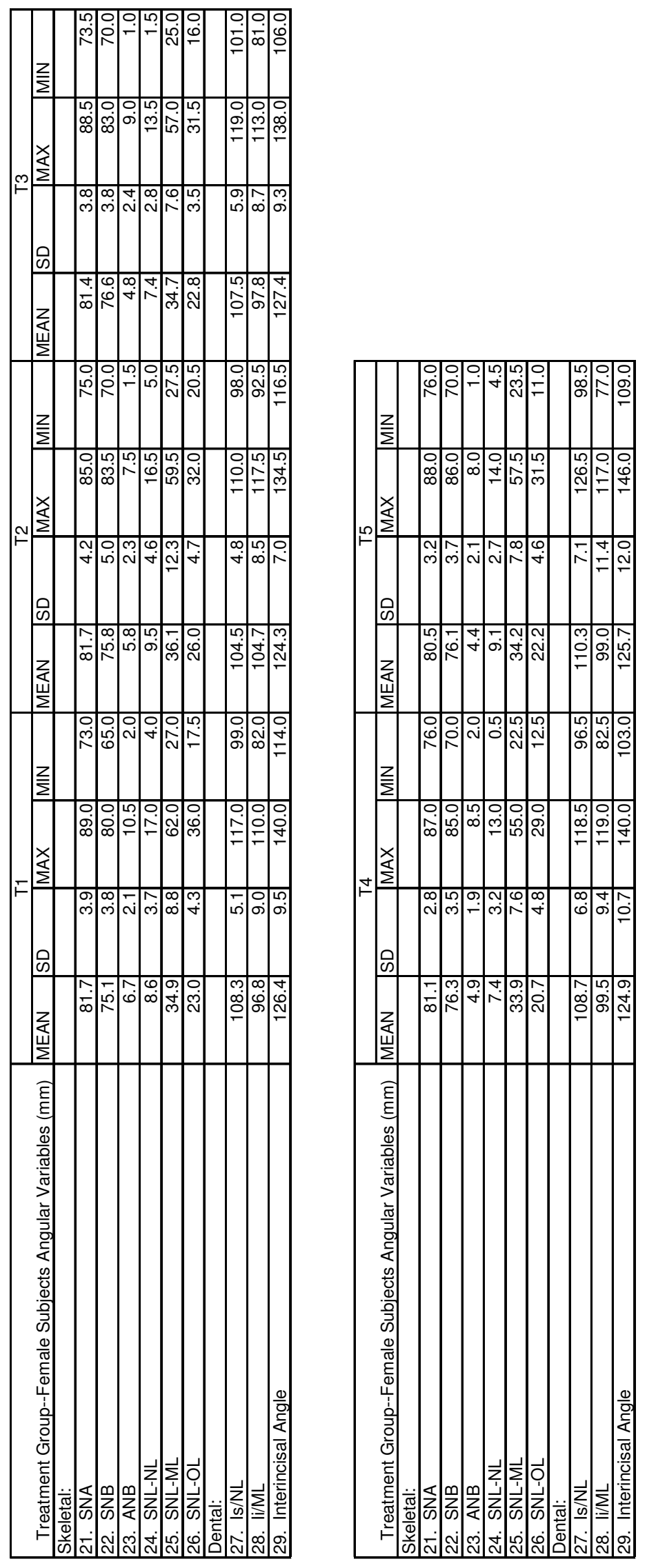
APPENDIX AA 

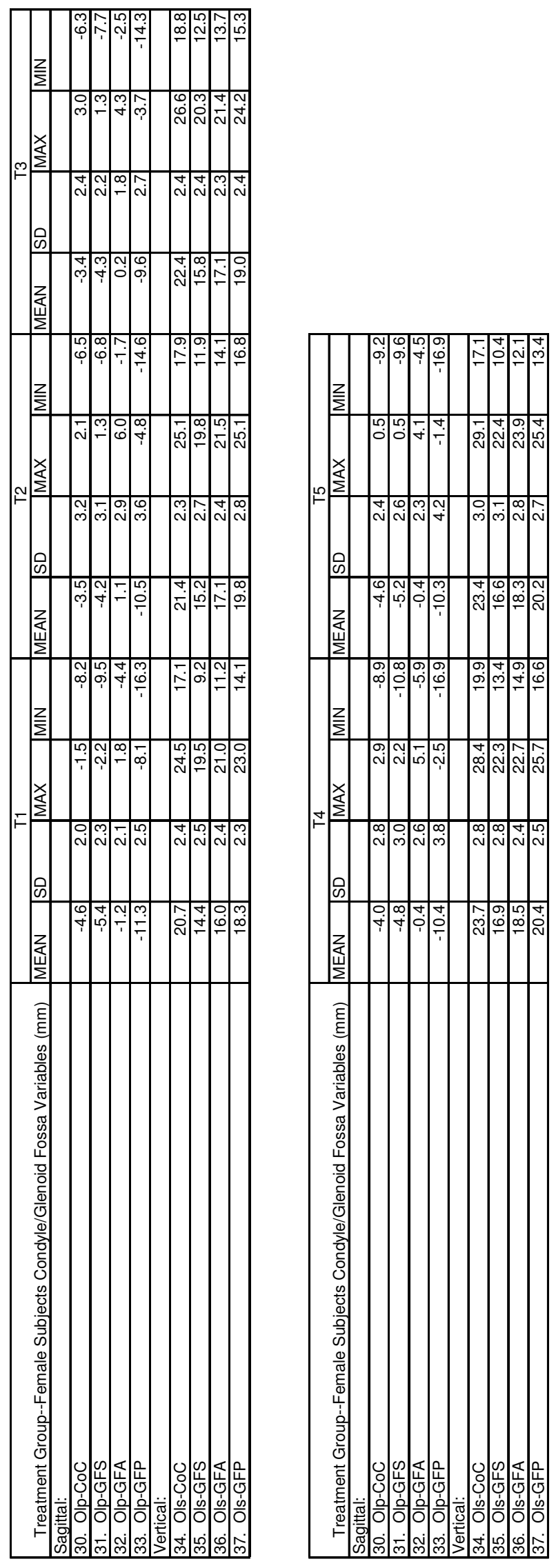
APPENDIX AB 

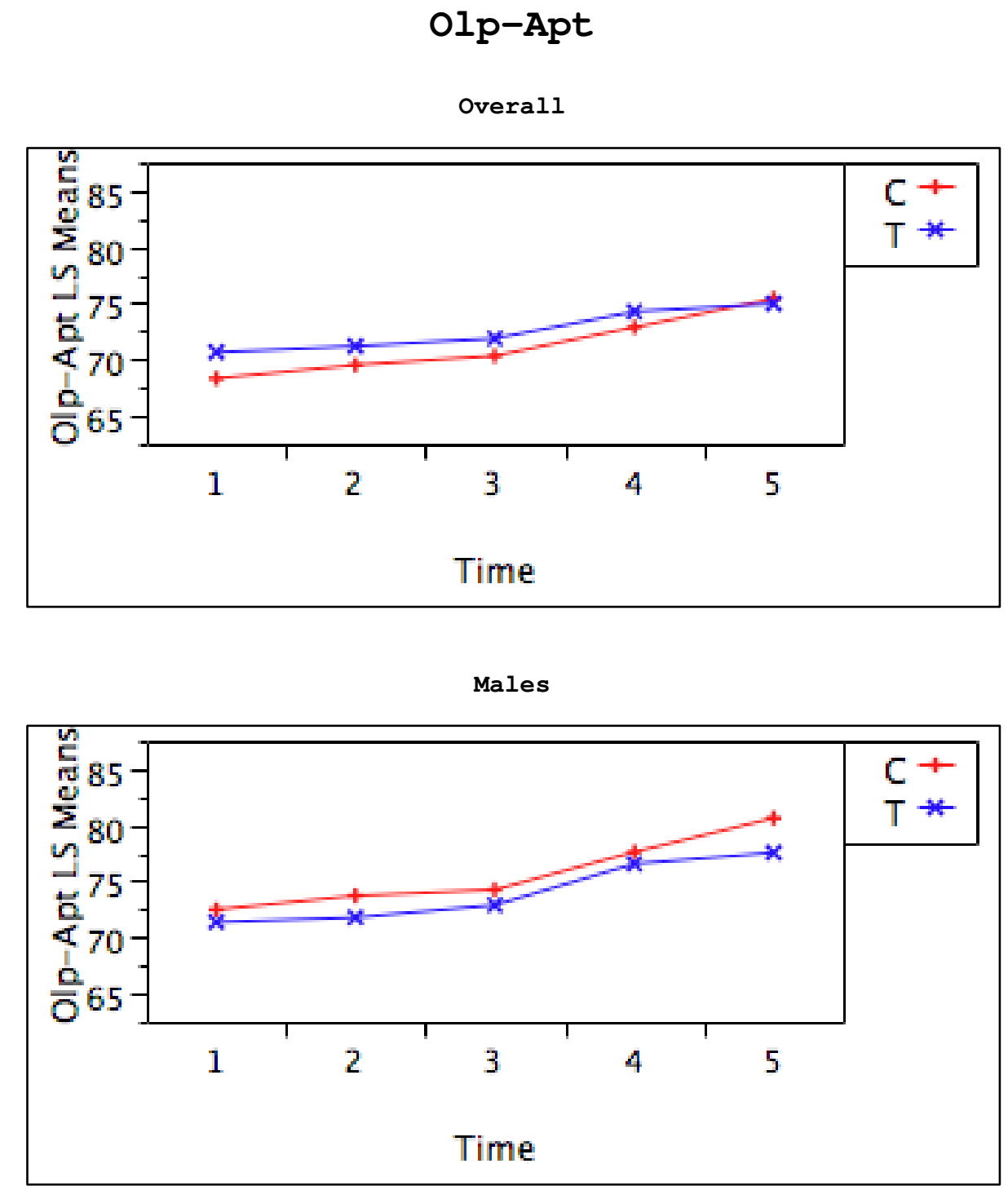

Females

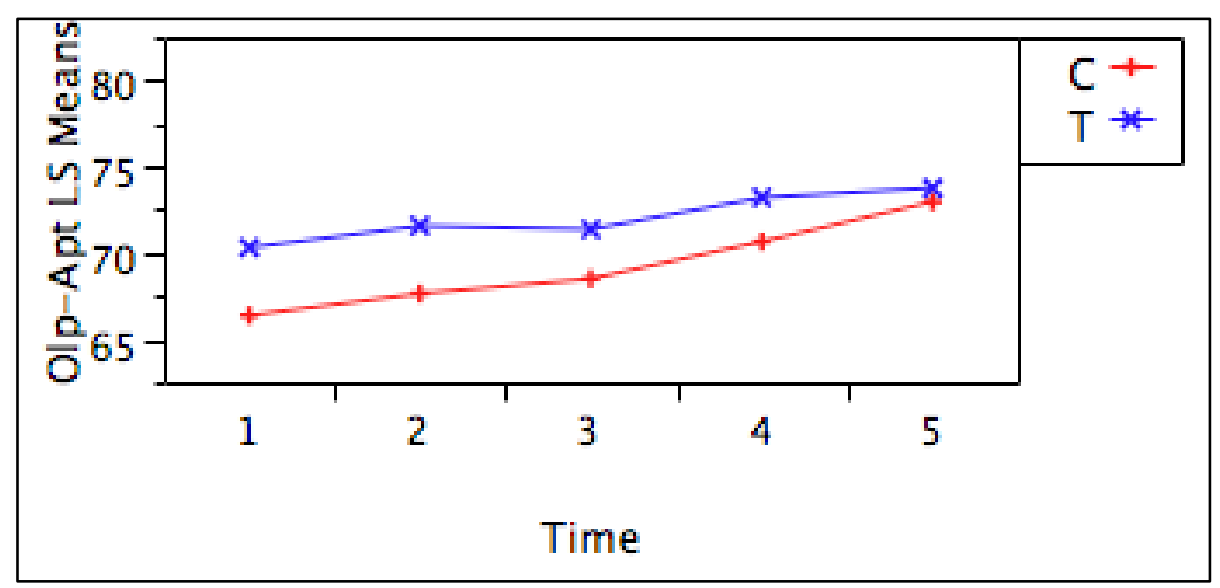




\section{Olp-Pg}

Overall

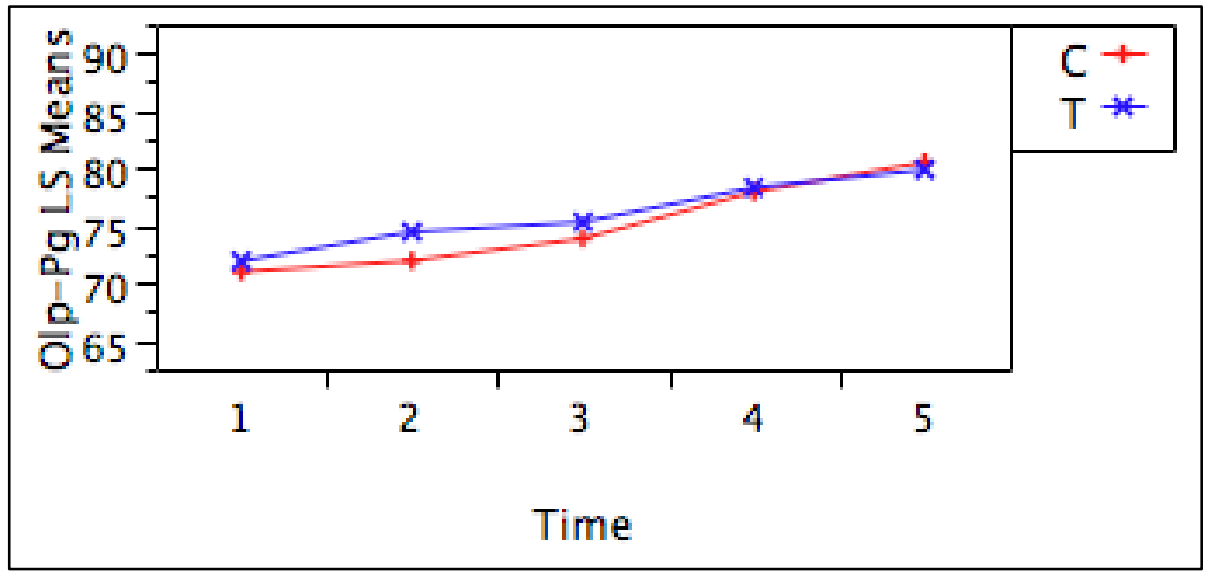

Males

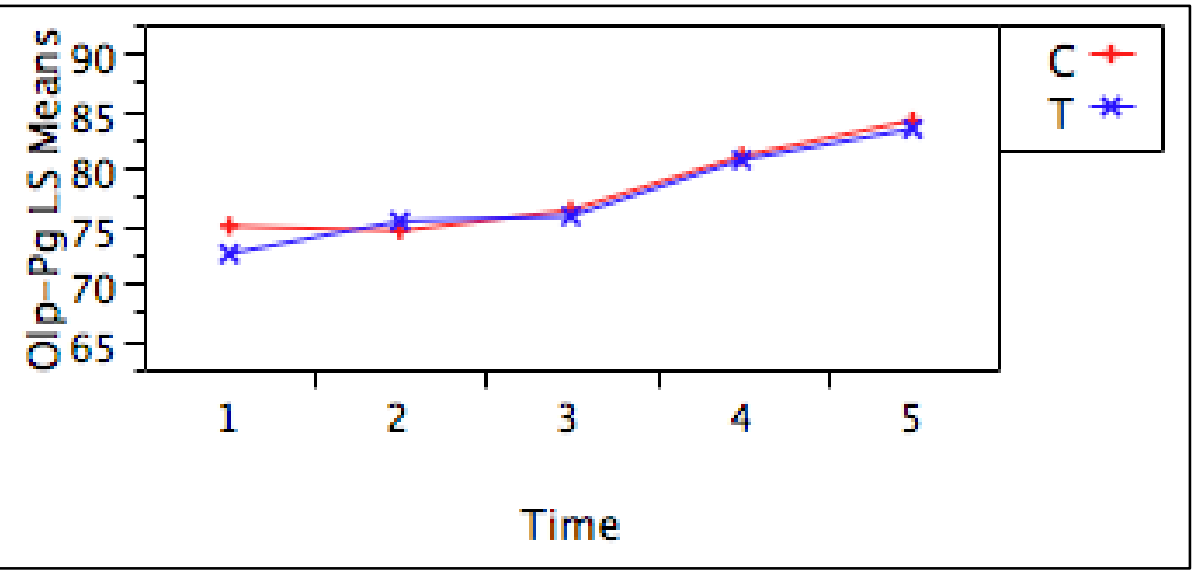

Females

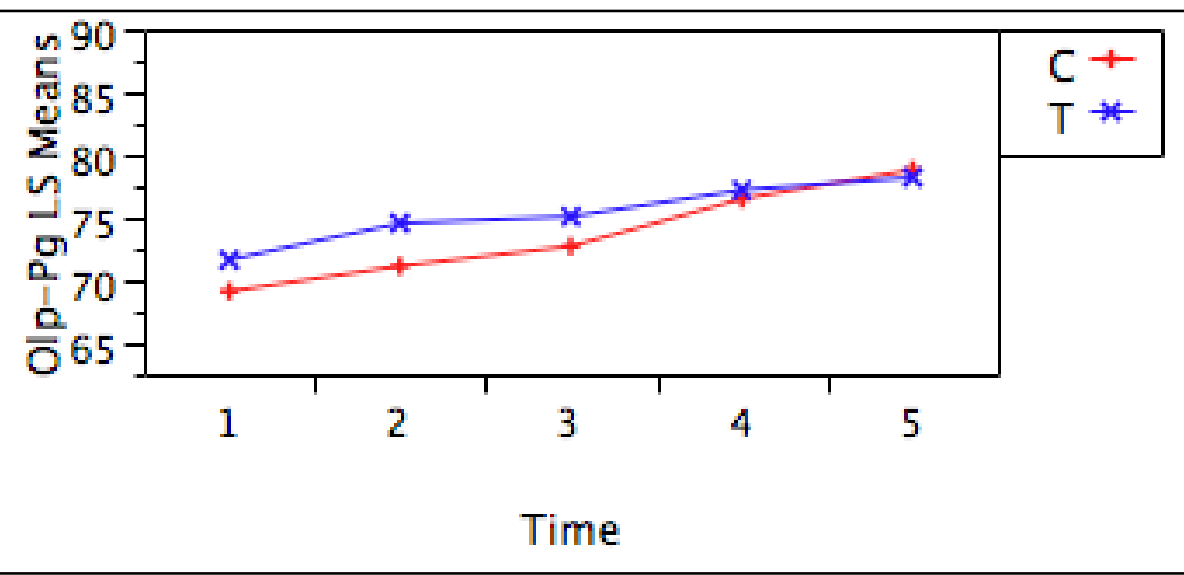




\section{Olp-Co}

Overall

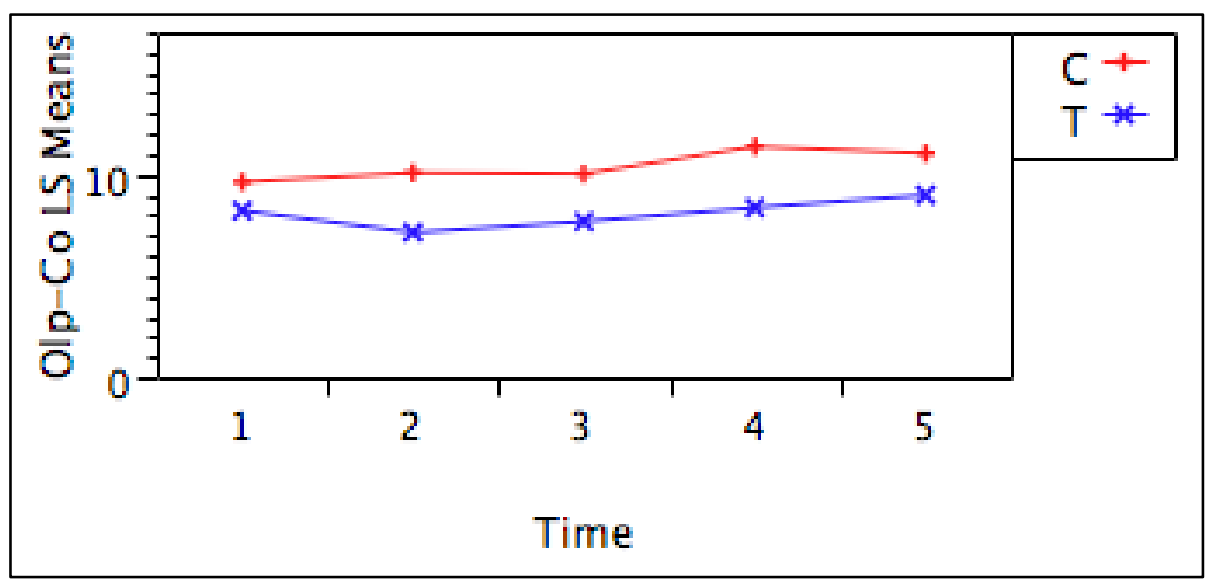

Males

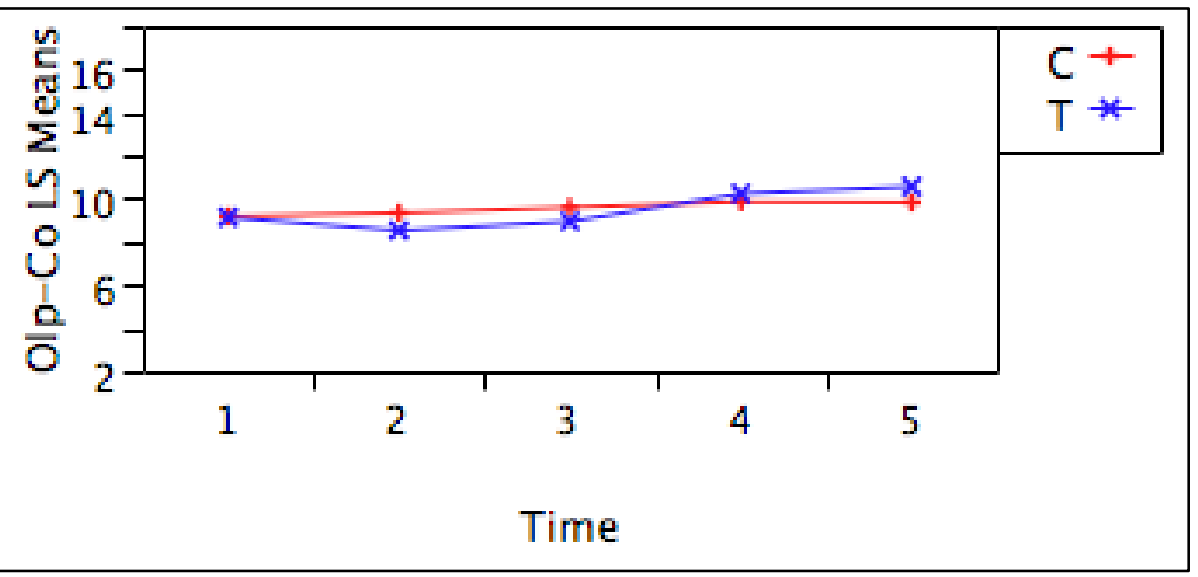

Females

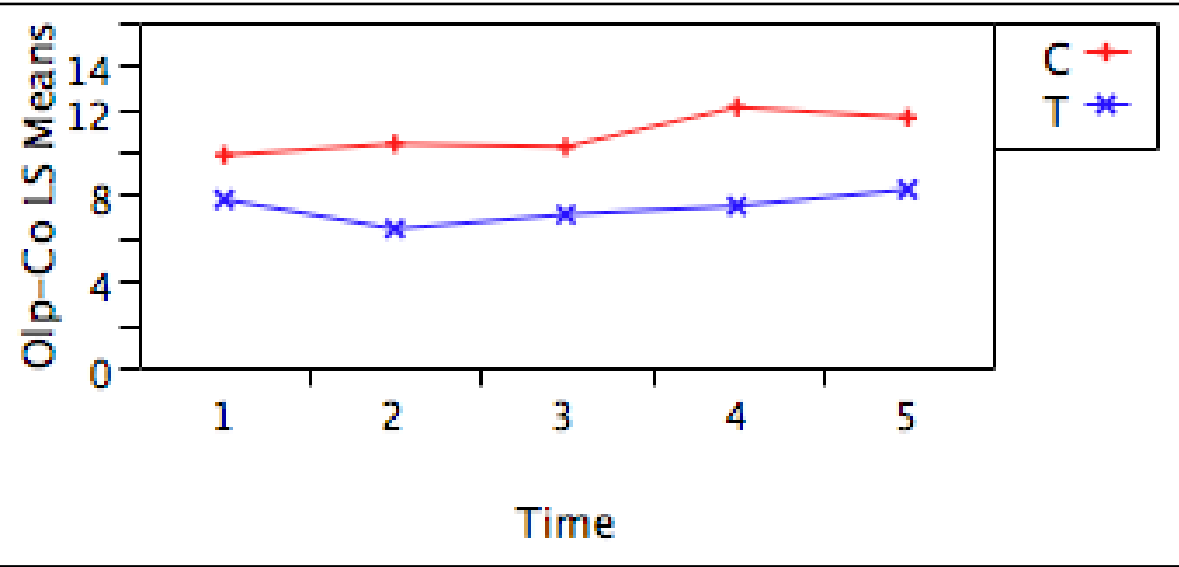


Co-Apt

Overall

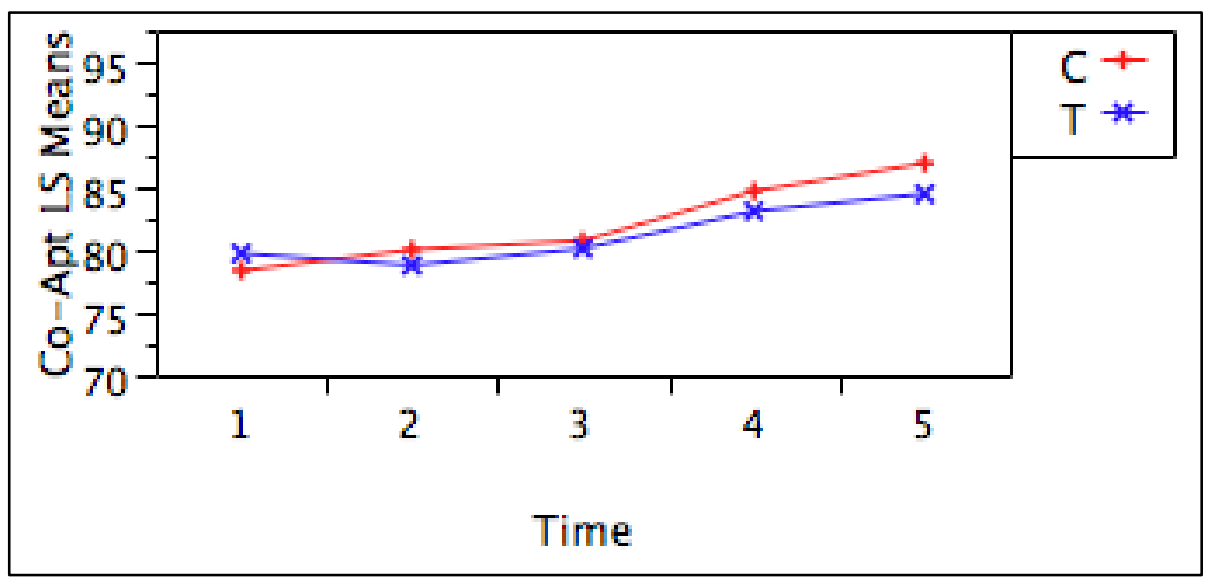

Males

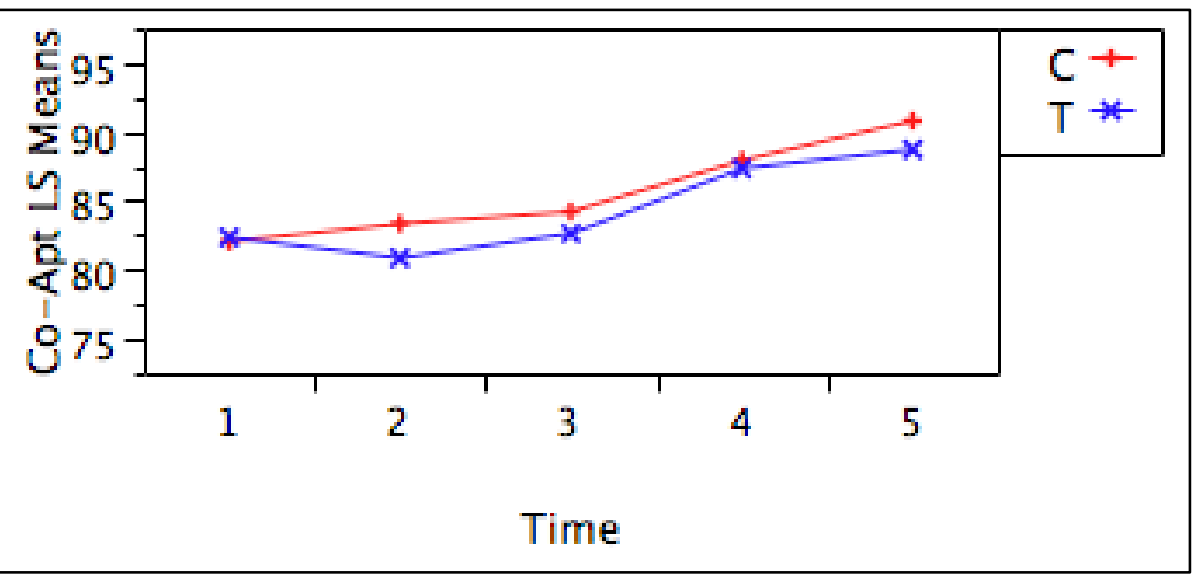

Females

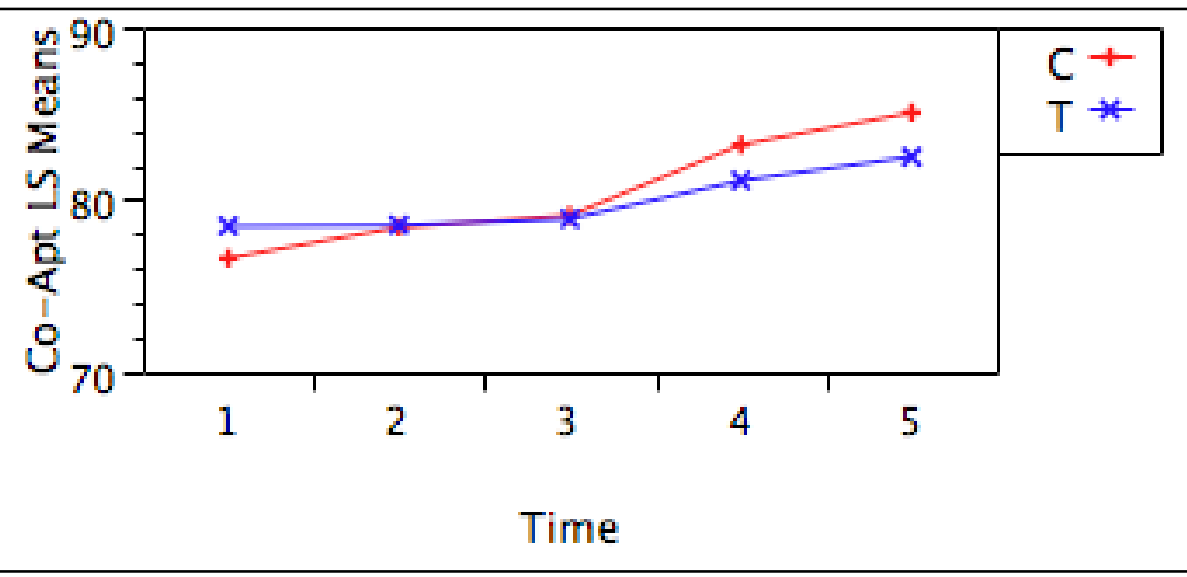




\section{C0-Gn}

Overall

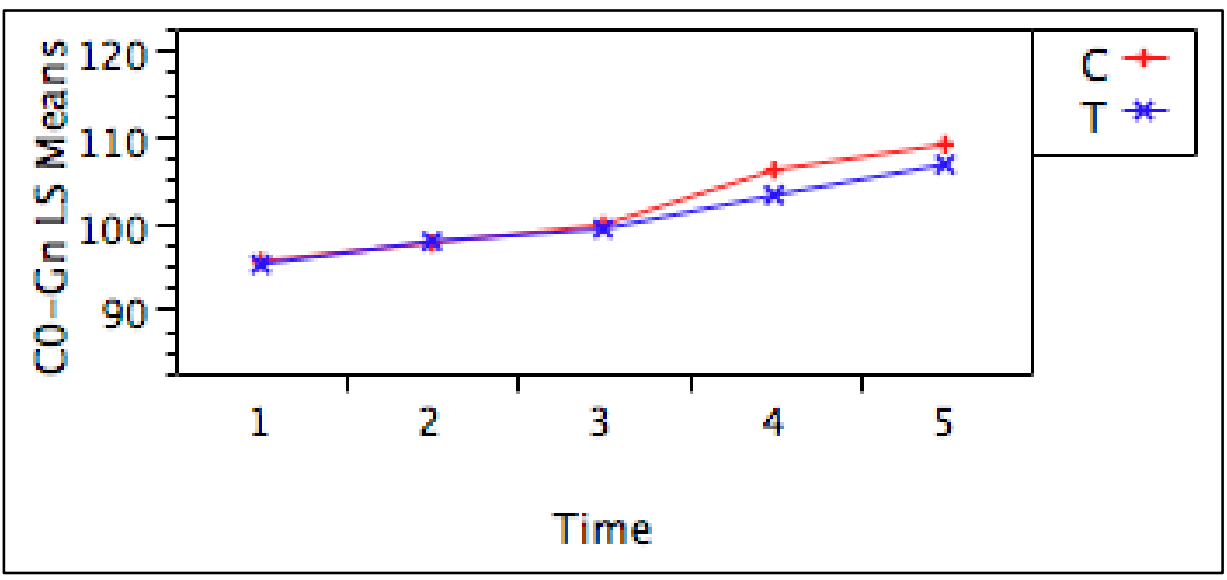

Males

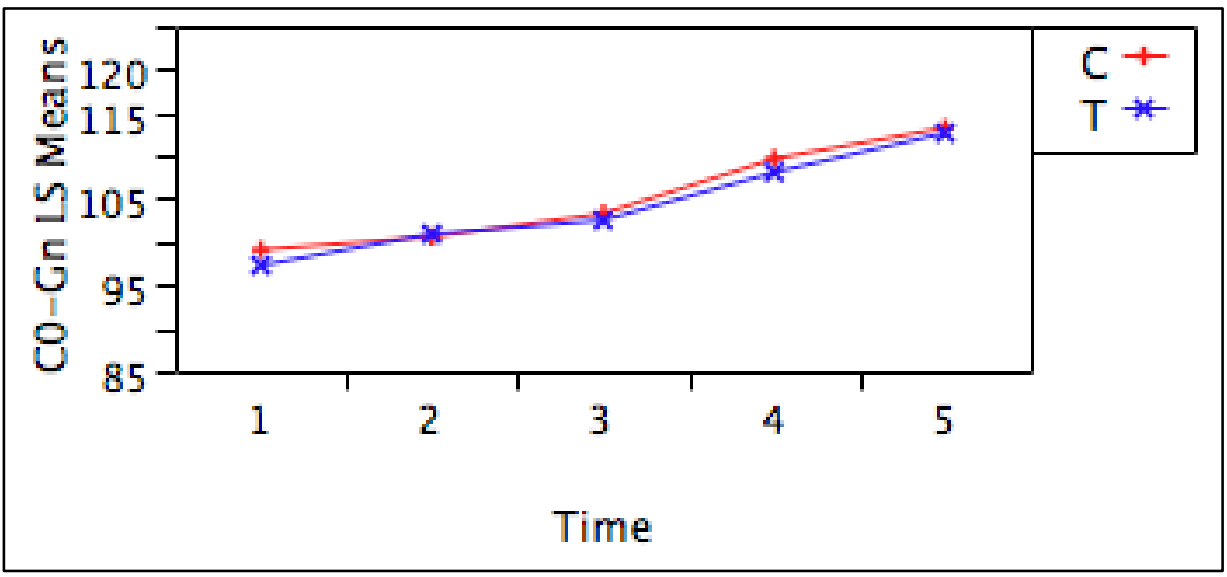

Females

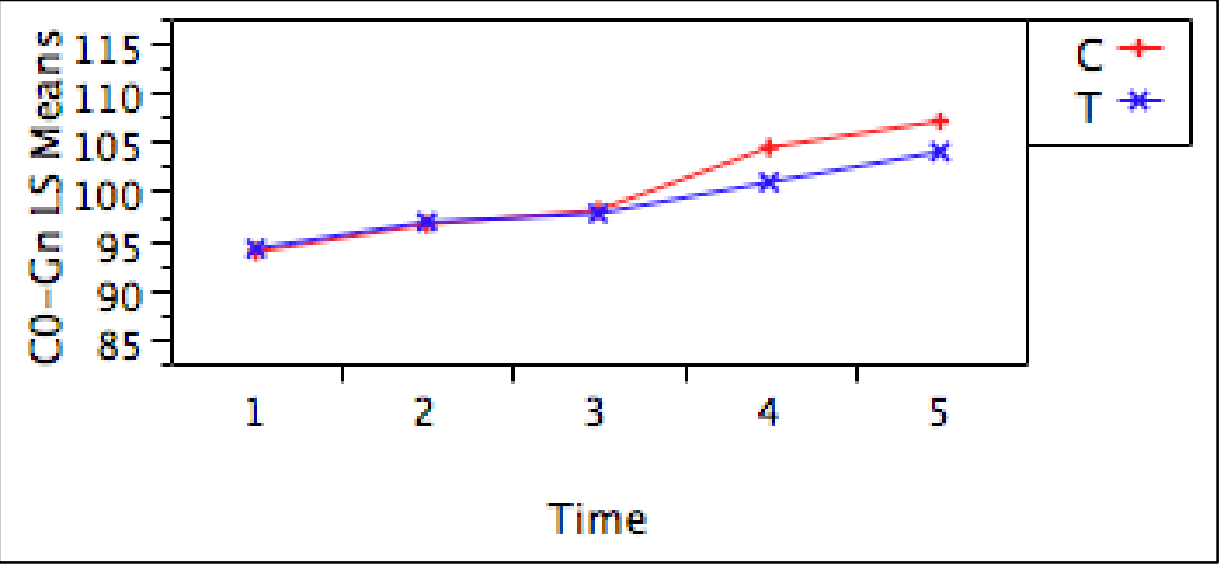


Co-Gn minus Co Apt

Overall

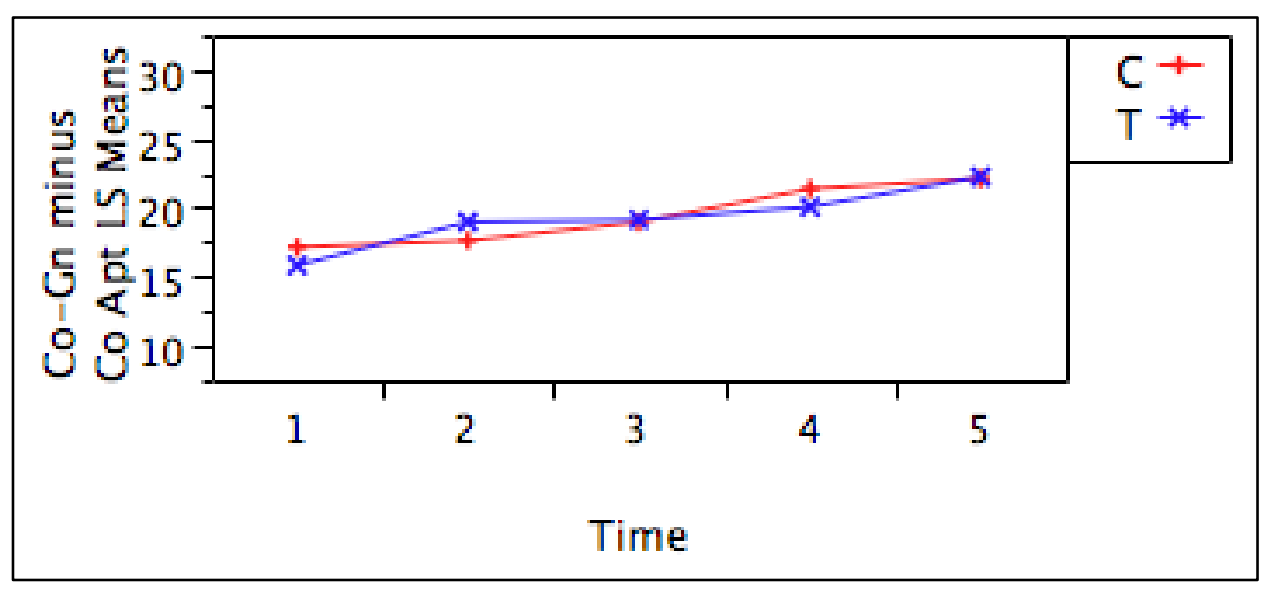

Males

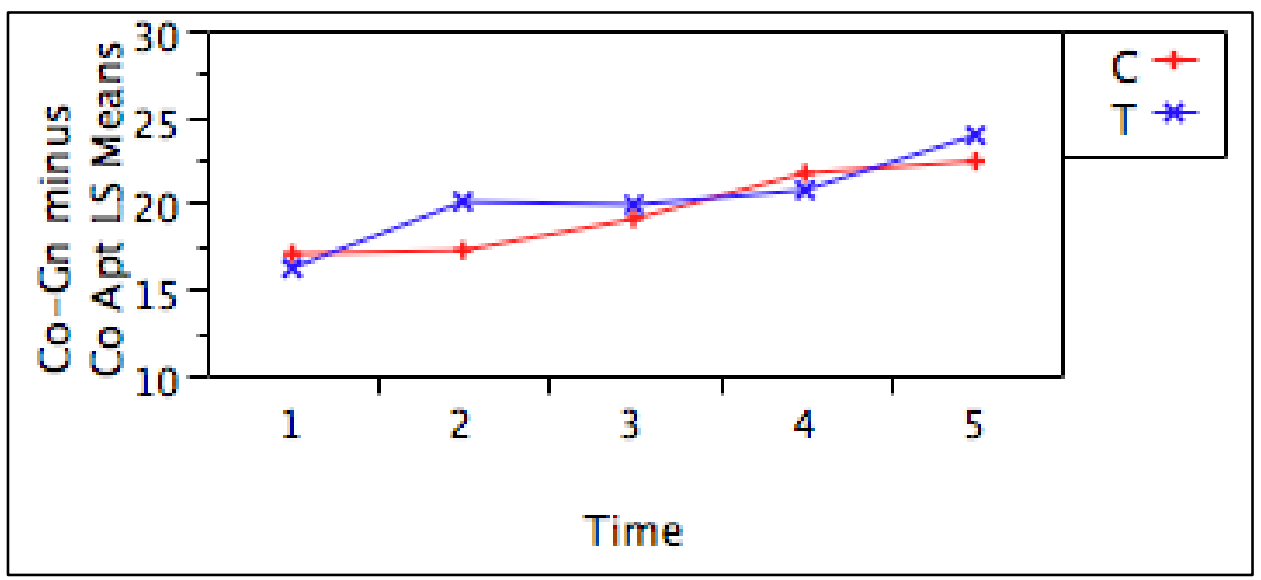

Females

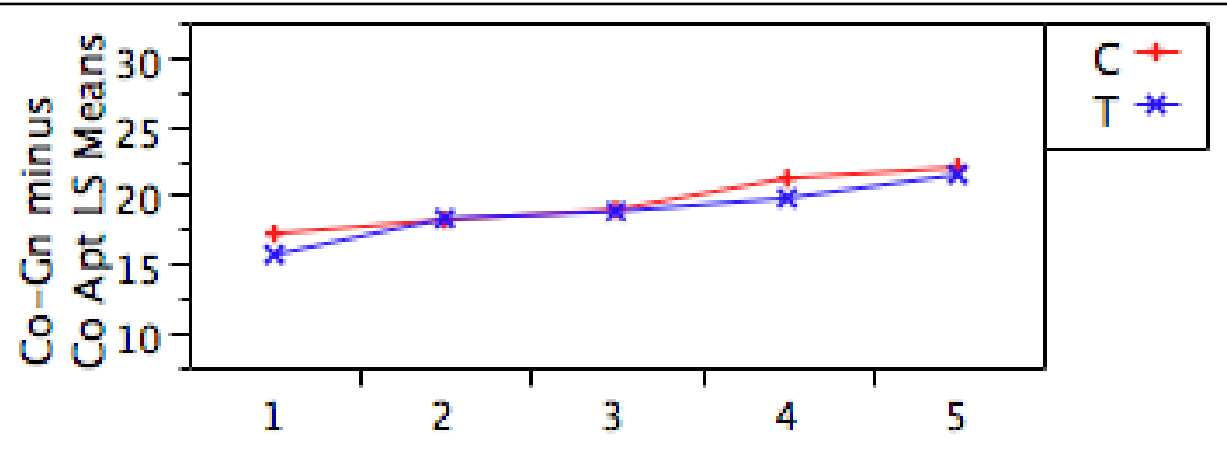

Time 
Wits Analysis

Overall

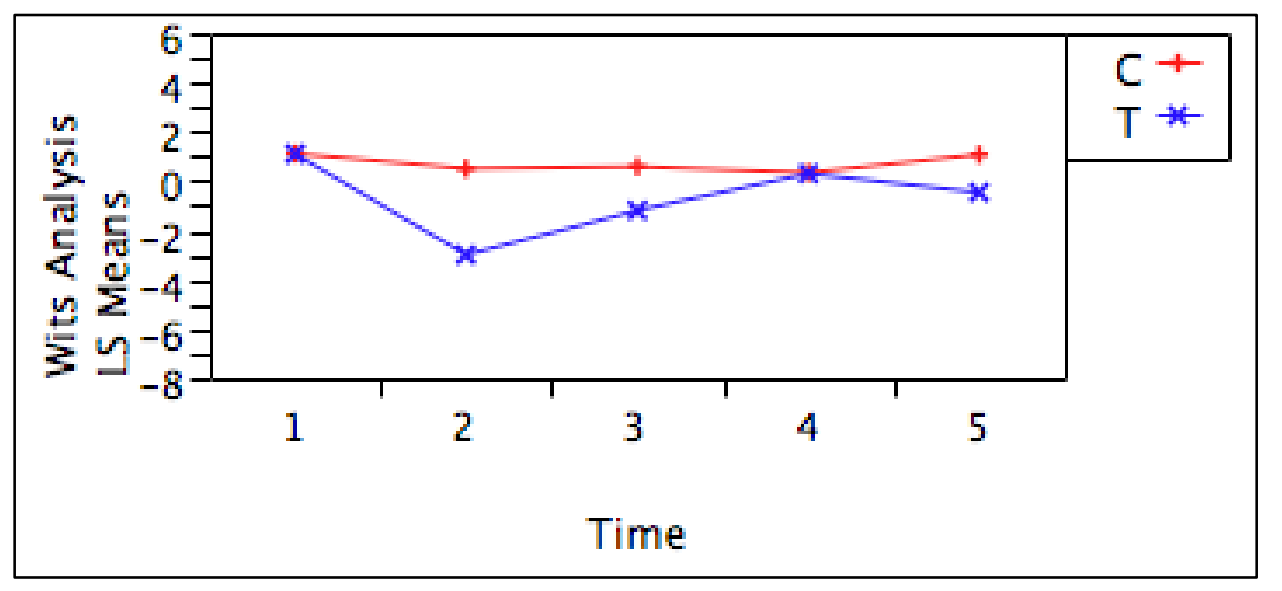

Males

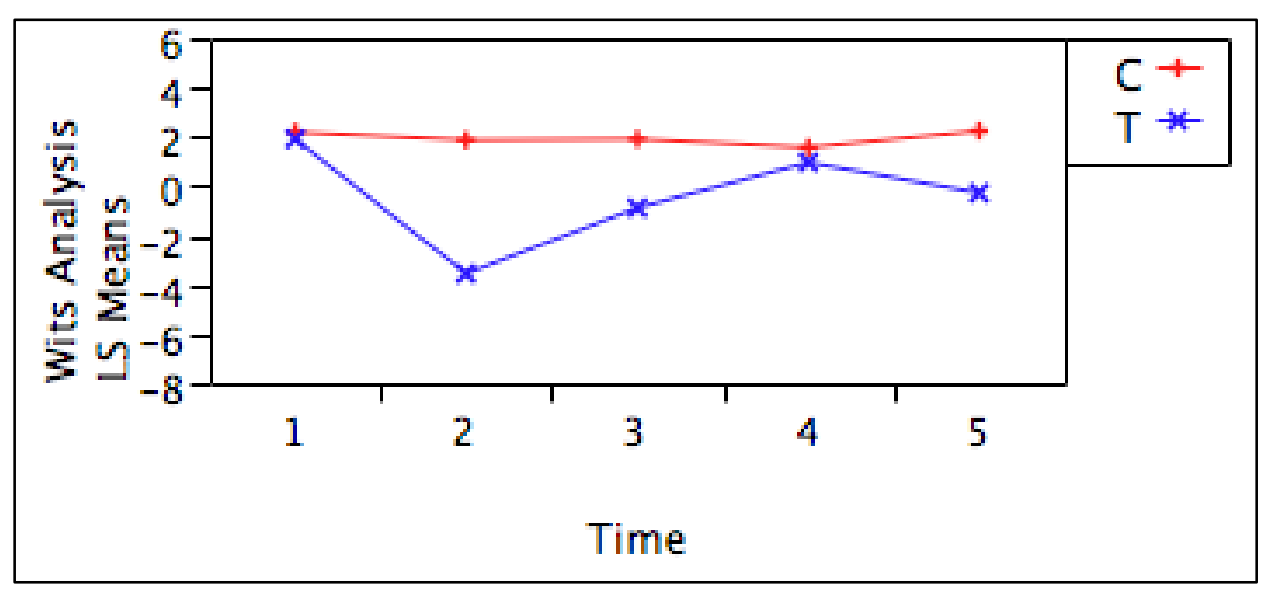

Females

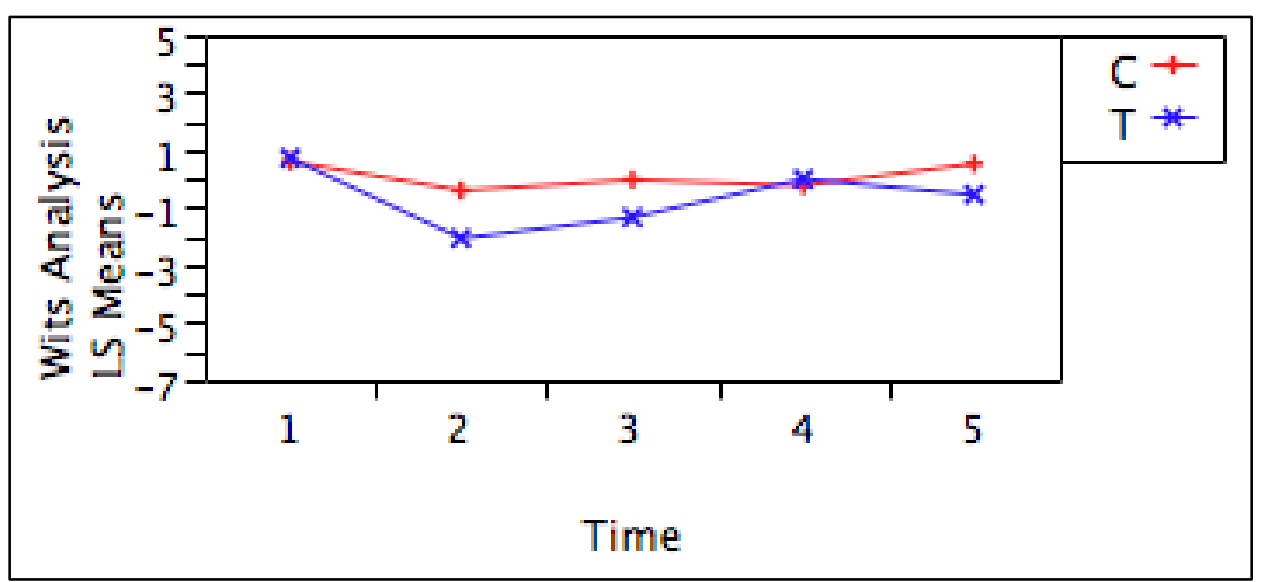




\section{Is-Olp}

Overall

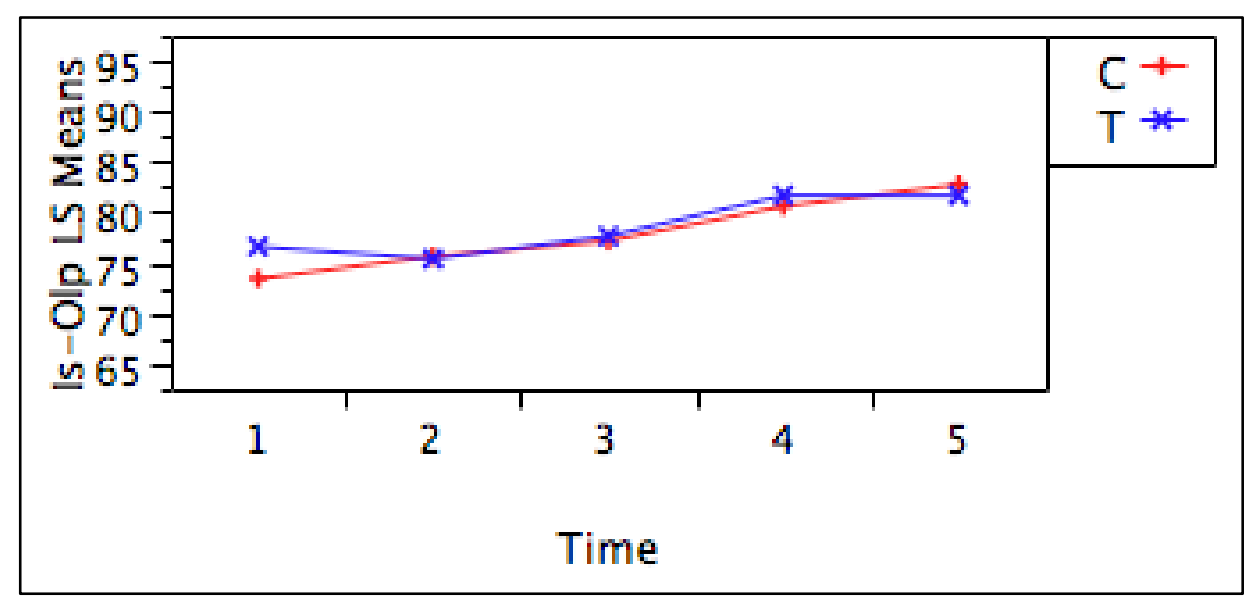

Males

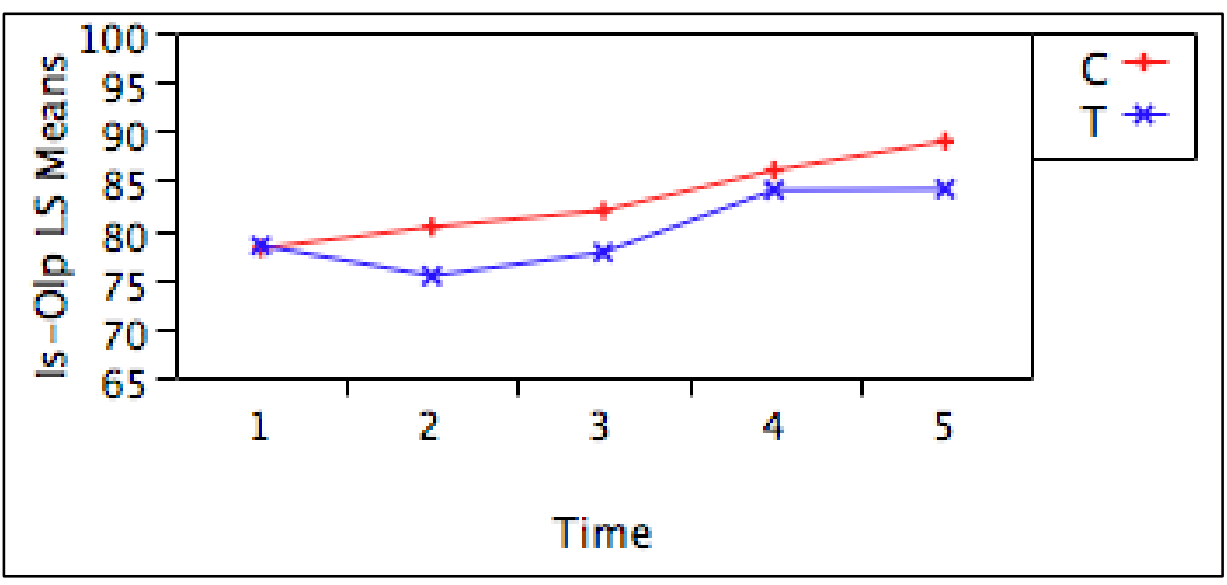

Females

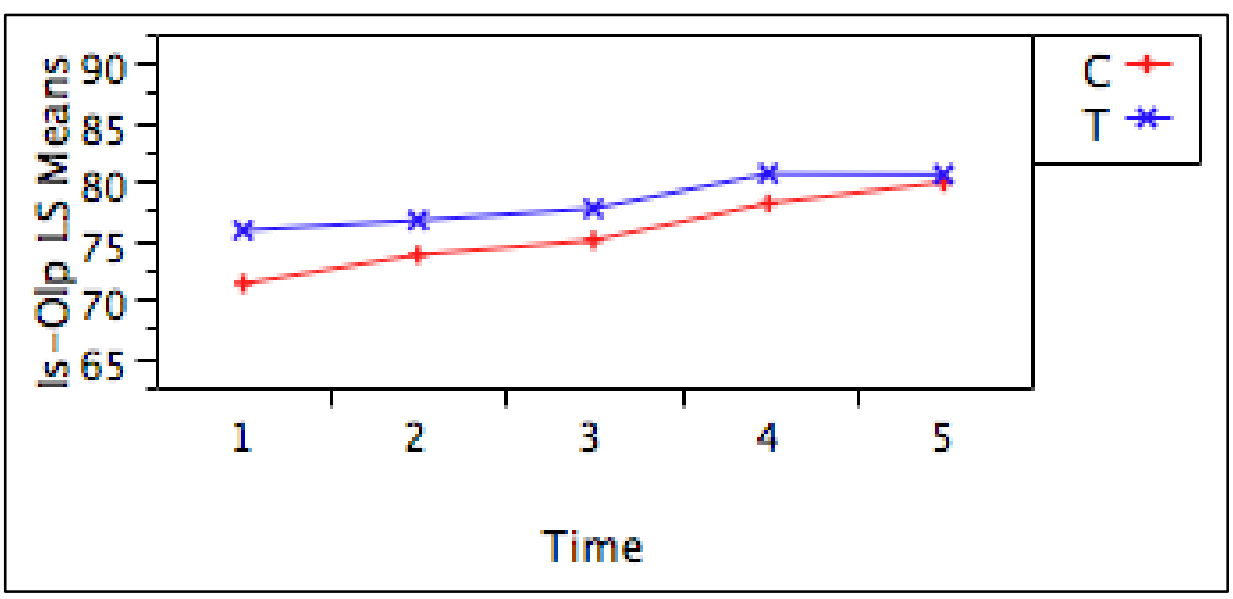




\section{Ii-Olp}

Overall
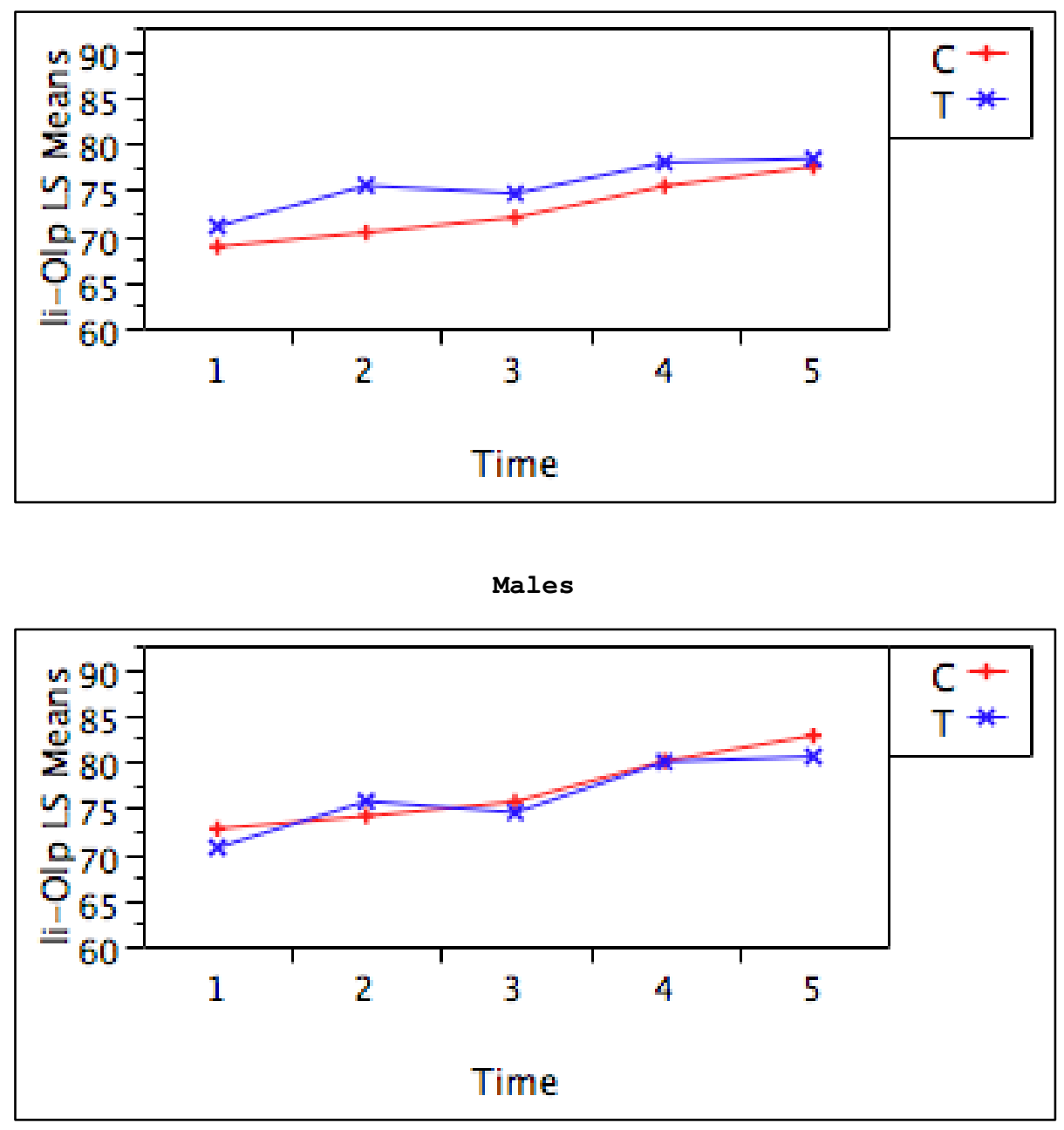

Females

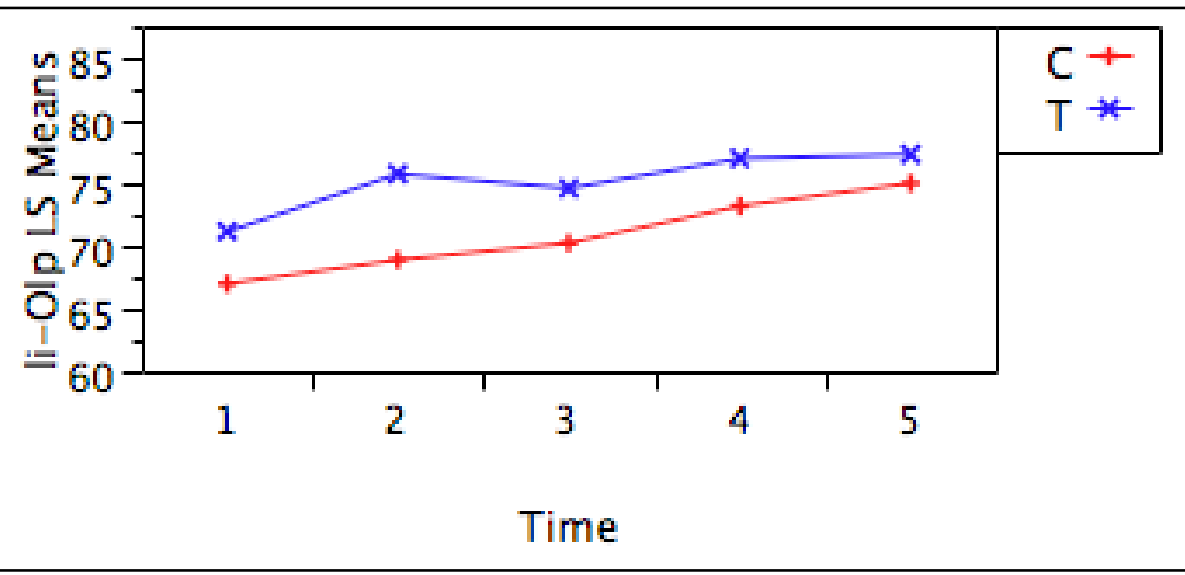


Overjet

Overall

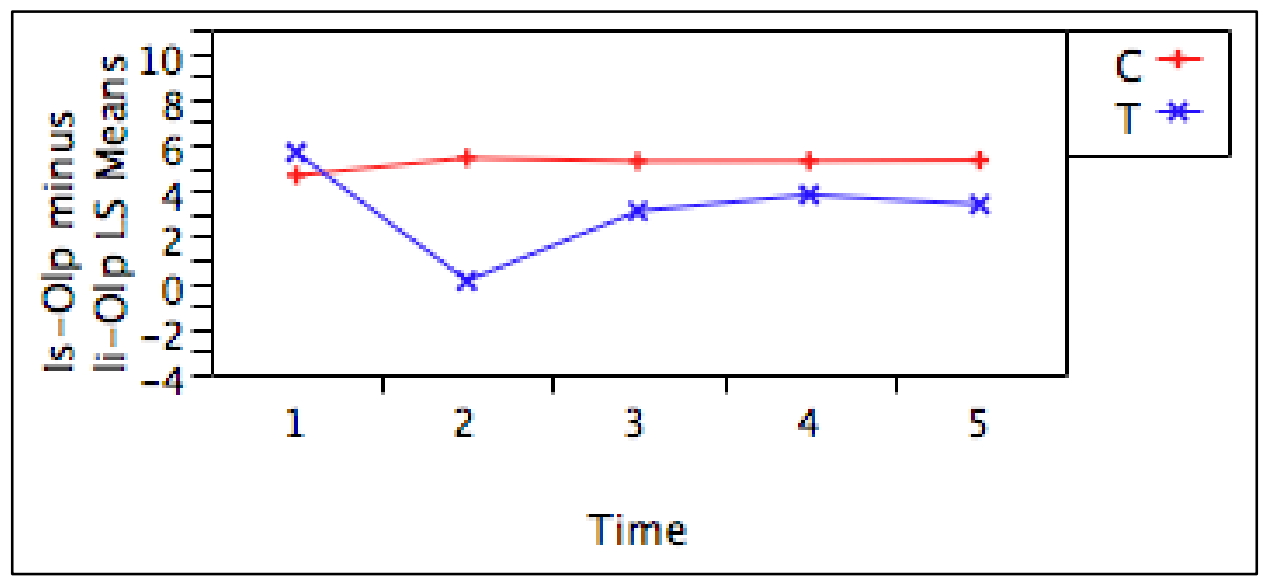

Males

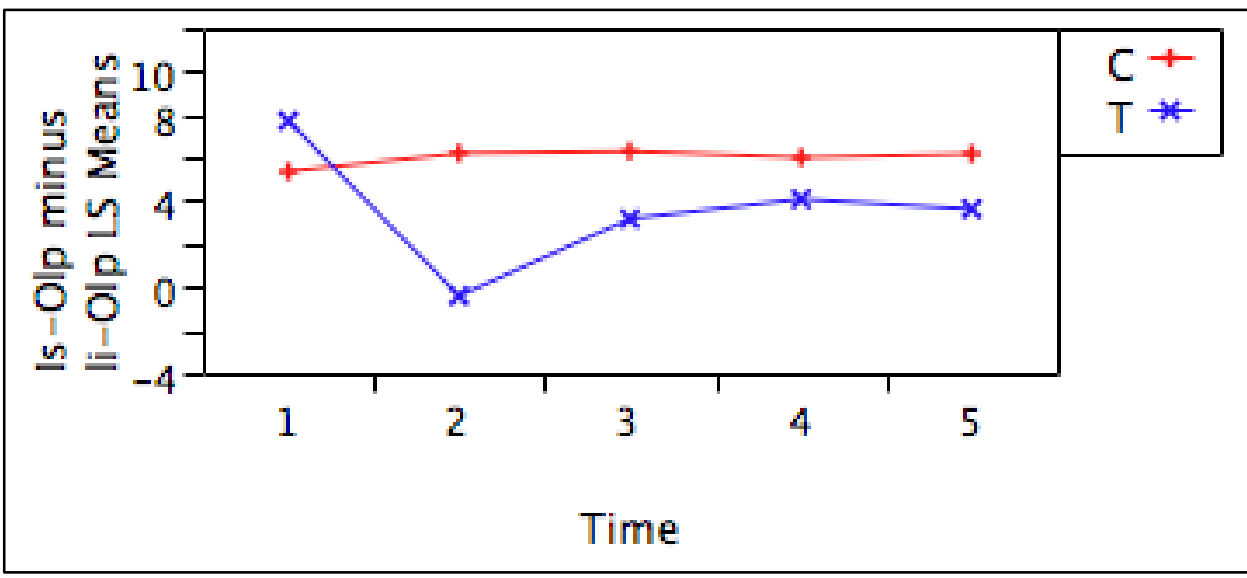

Females

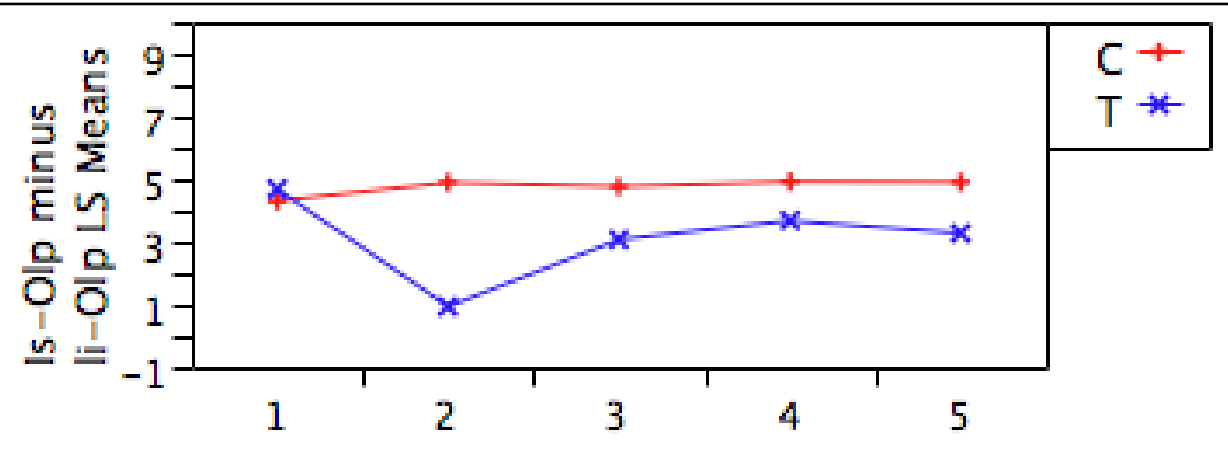

Time 
Ms-OLp

Overall

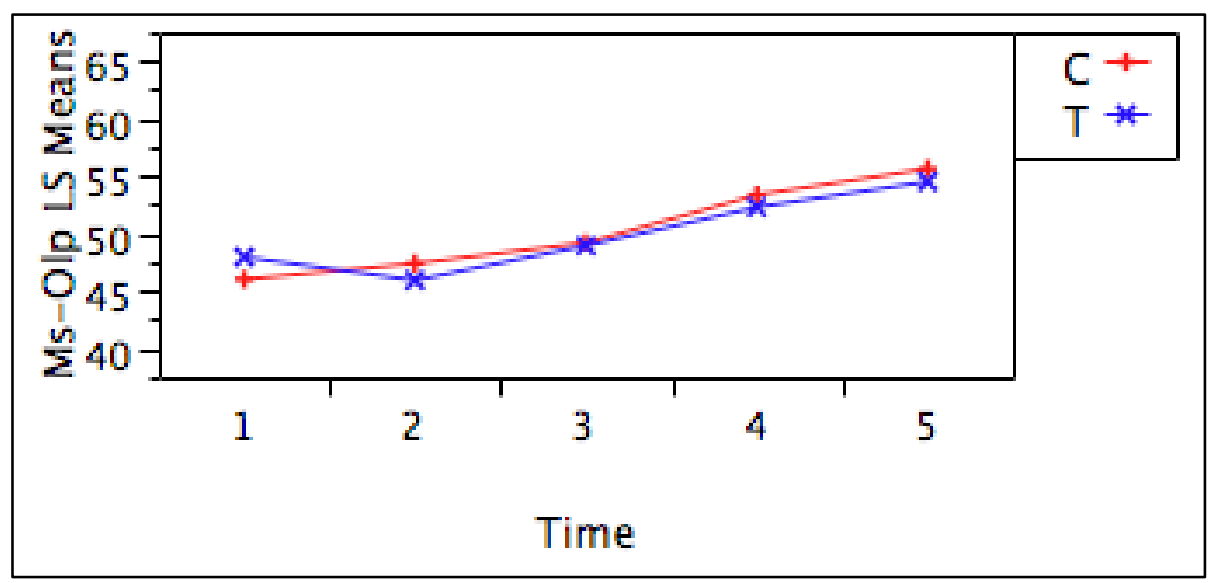

Males

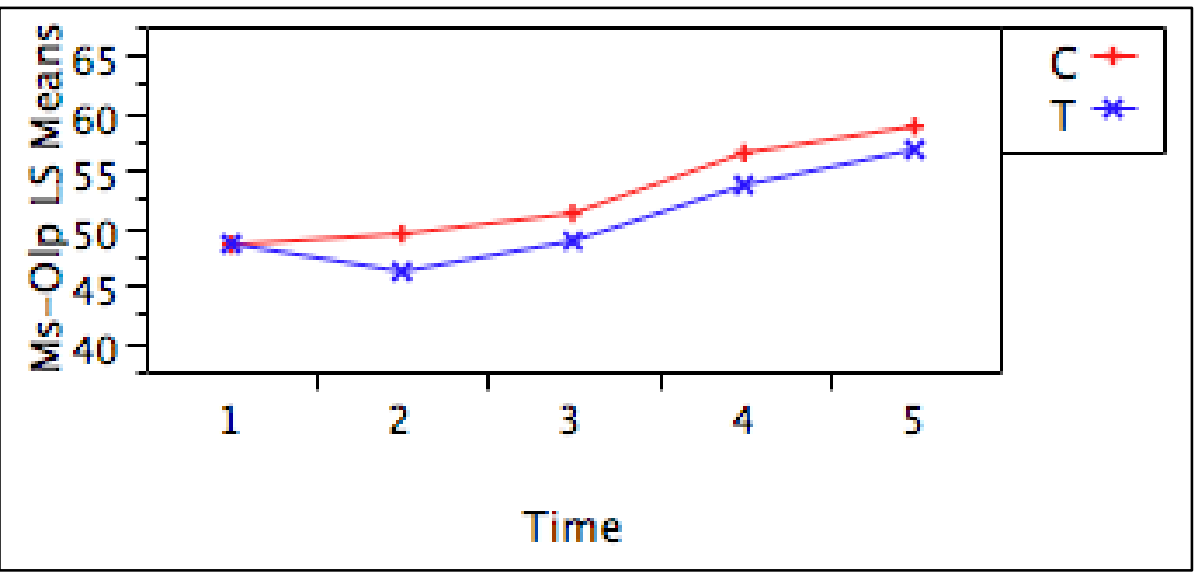

Females

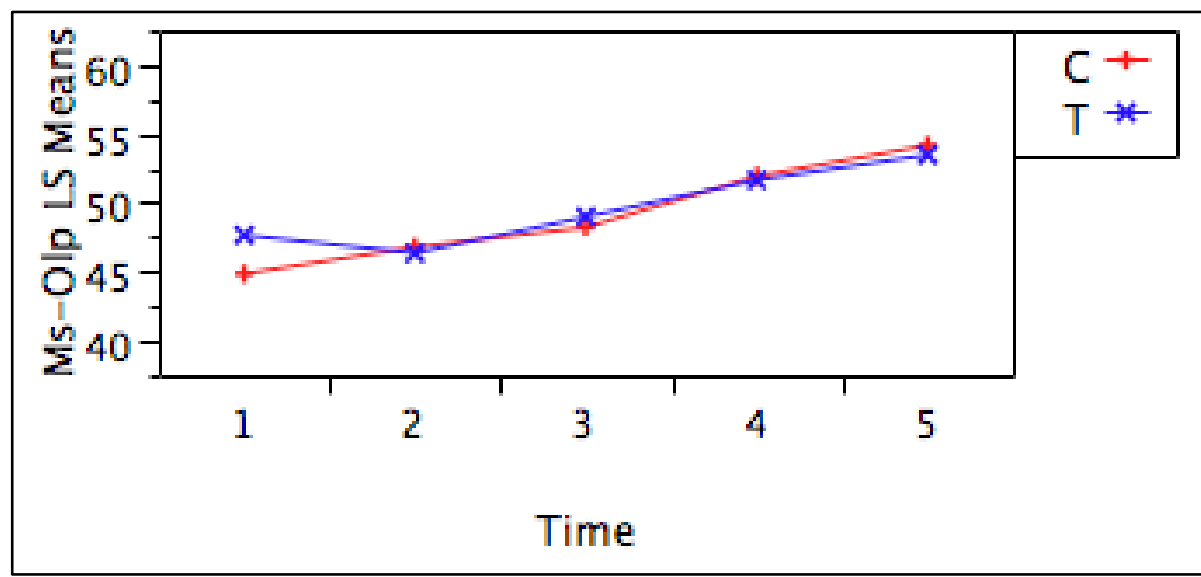


Mi-OLp

Overall

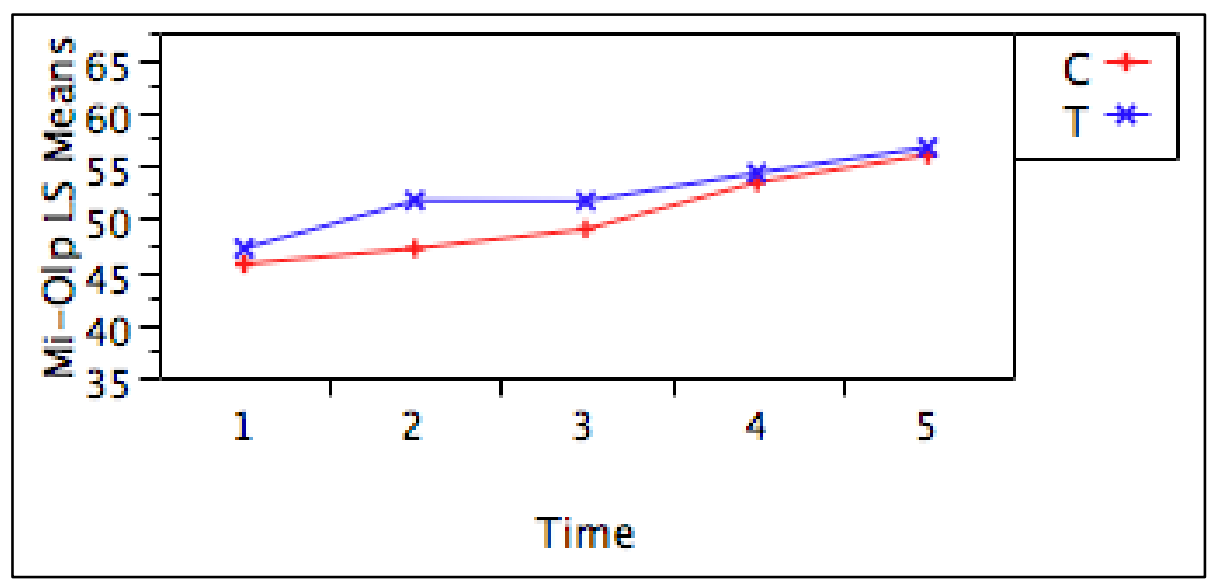

Males

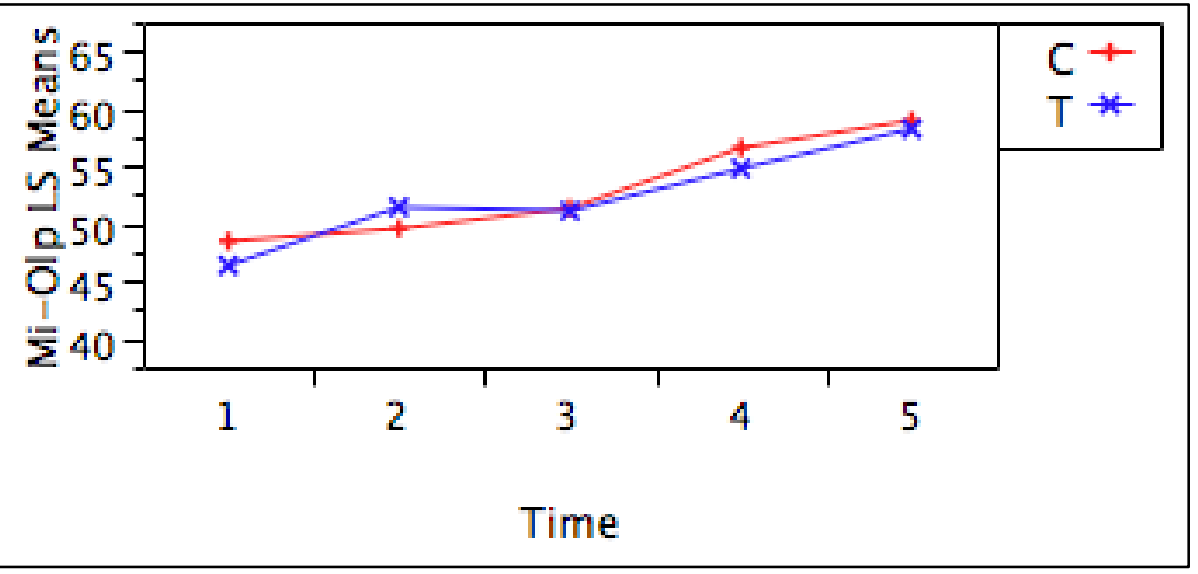

Females

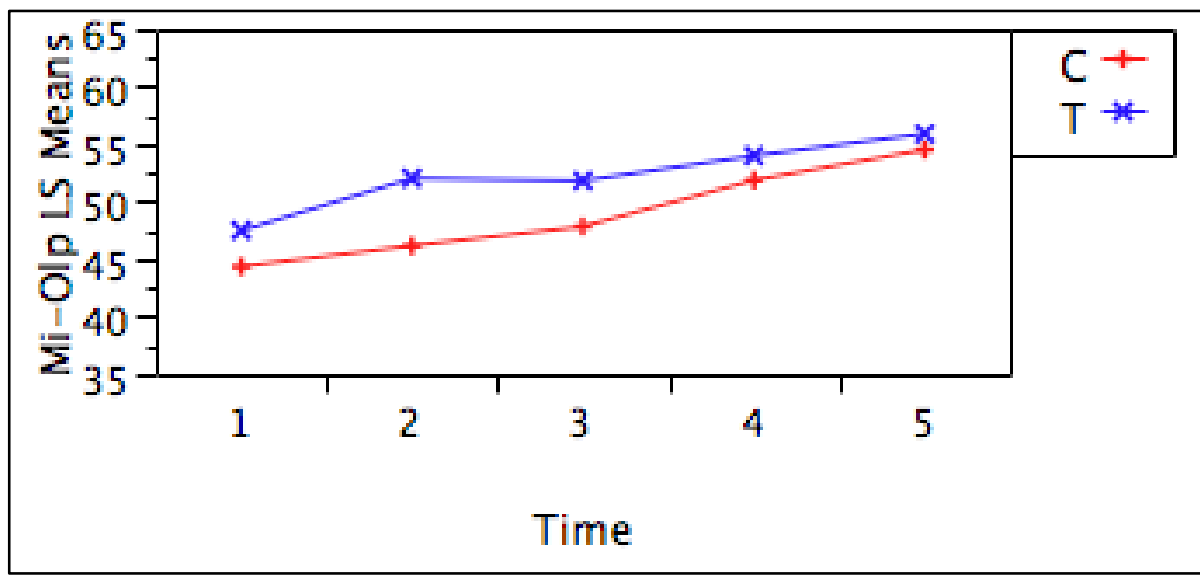




\section{Molar Relationship}

Overall

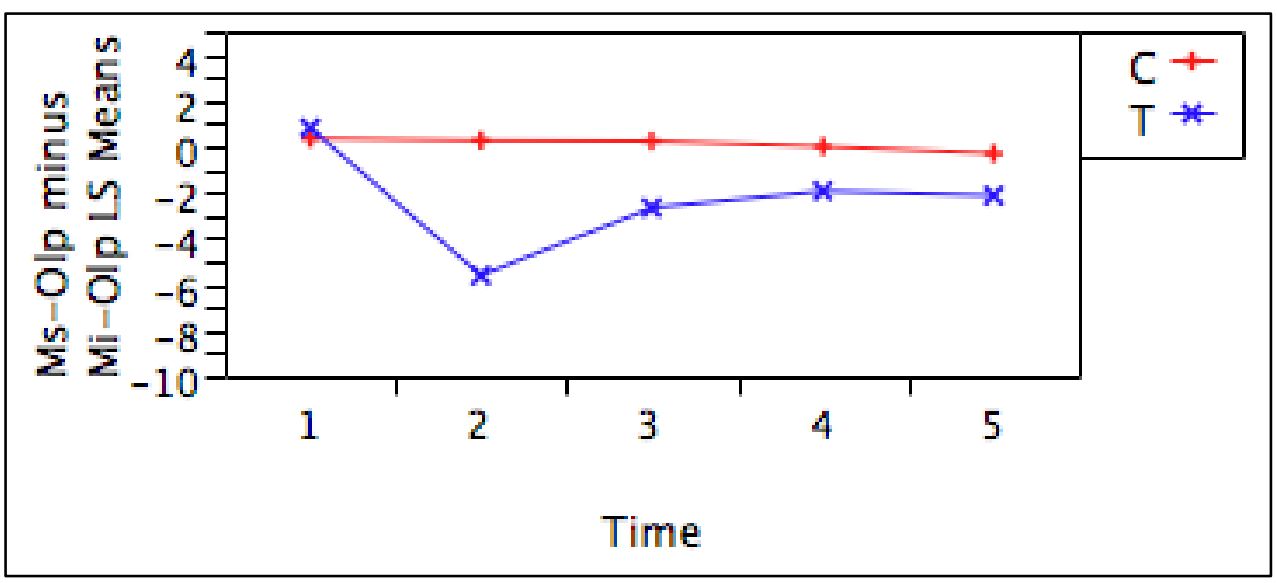

Males

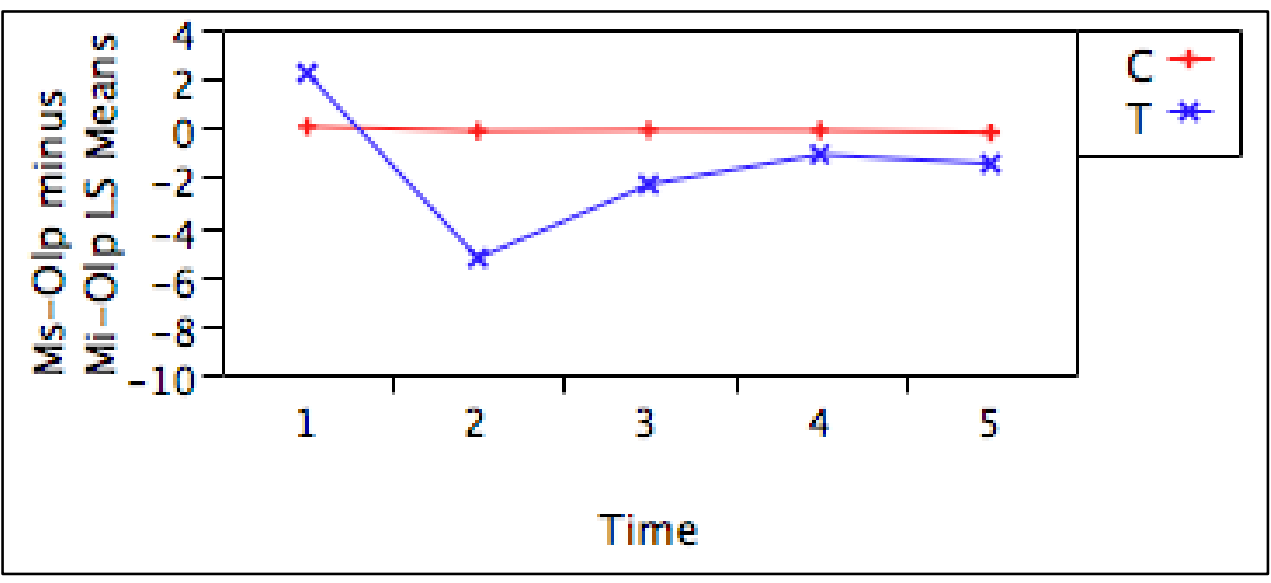

Females

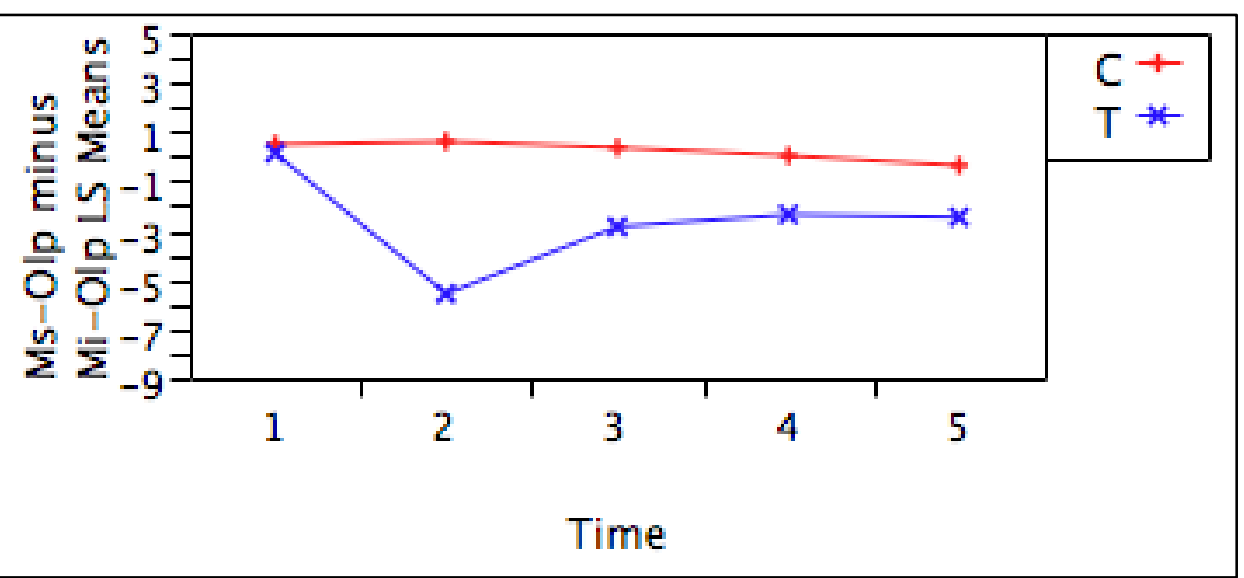



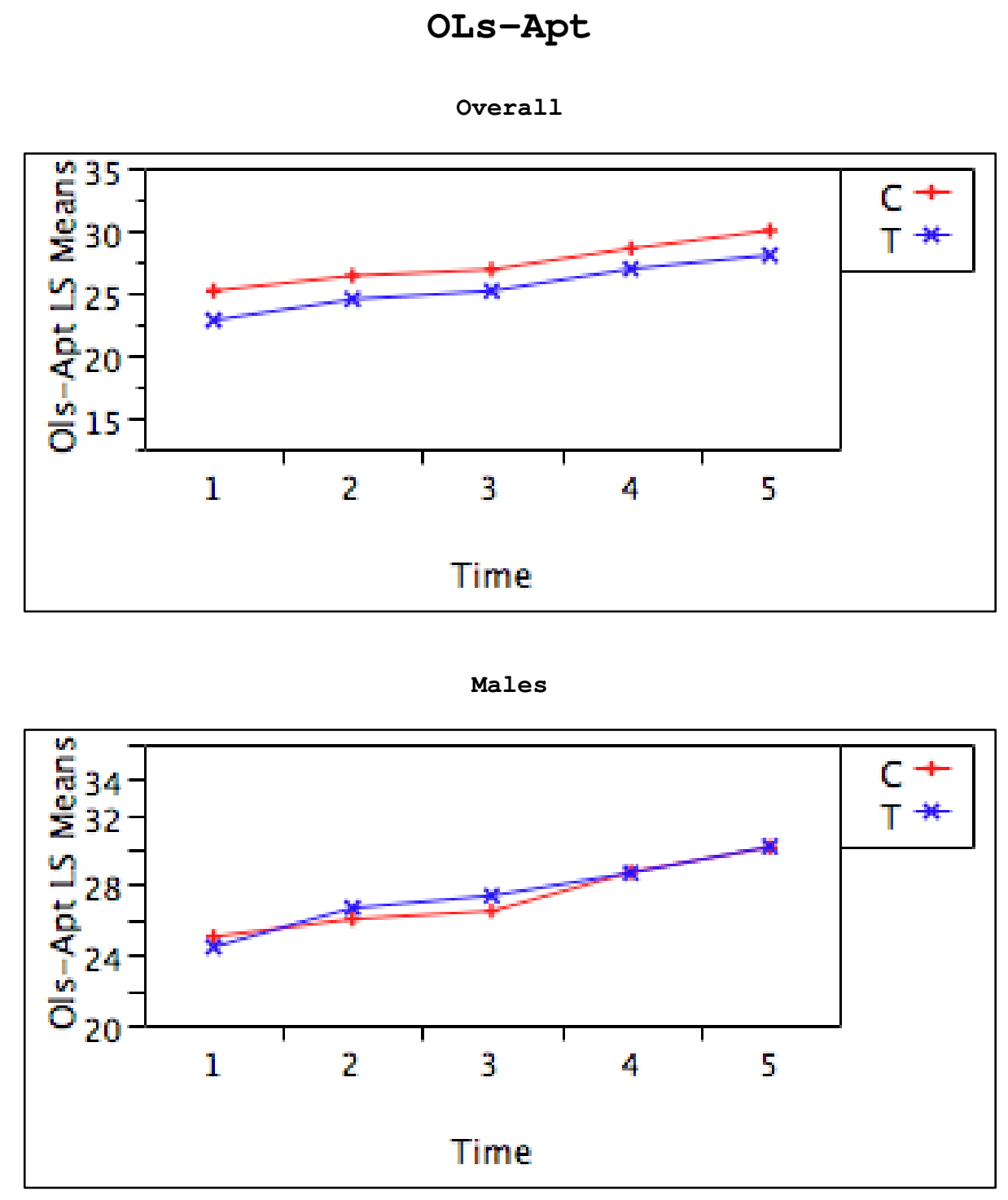

Females

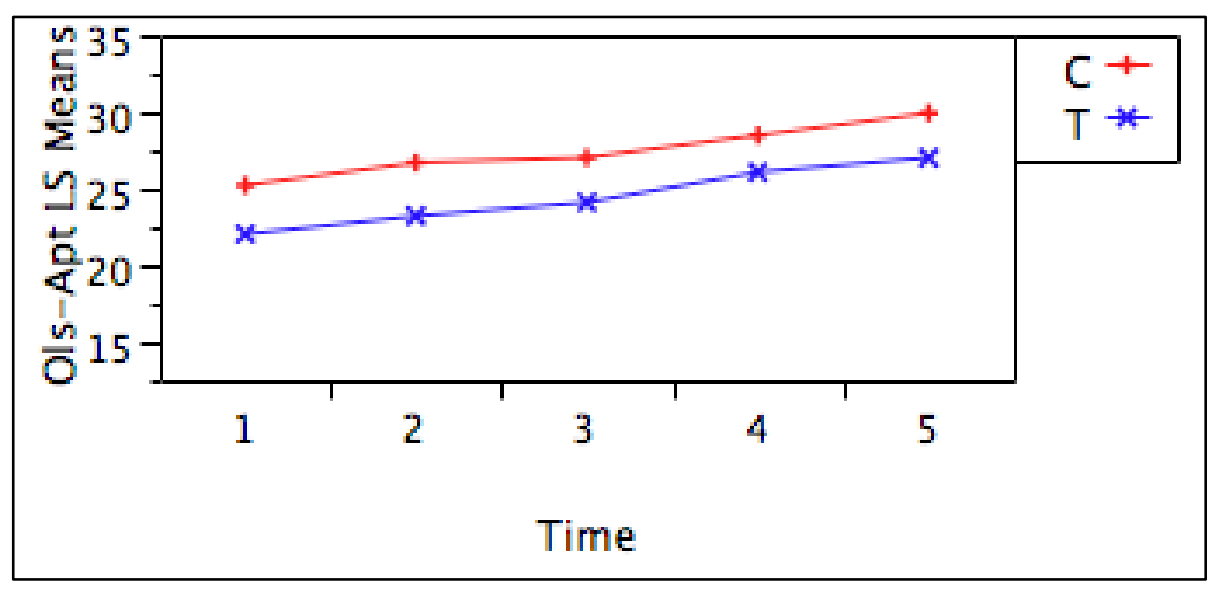




\section{ANS-Me}

Overall

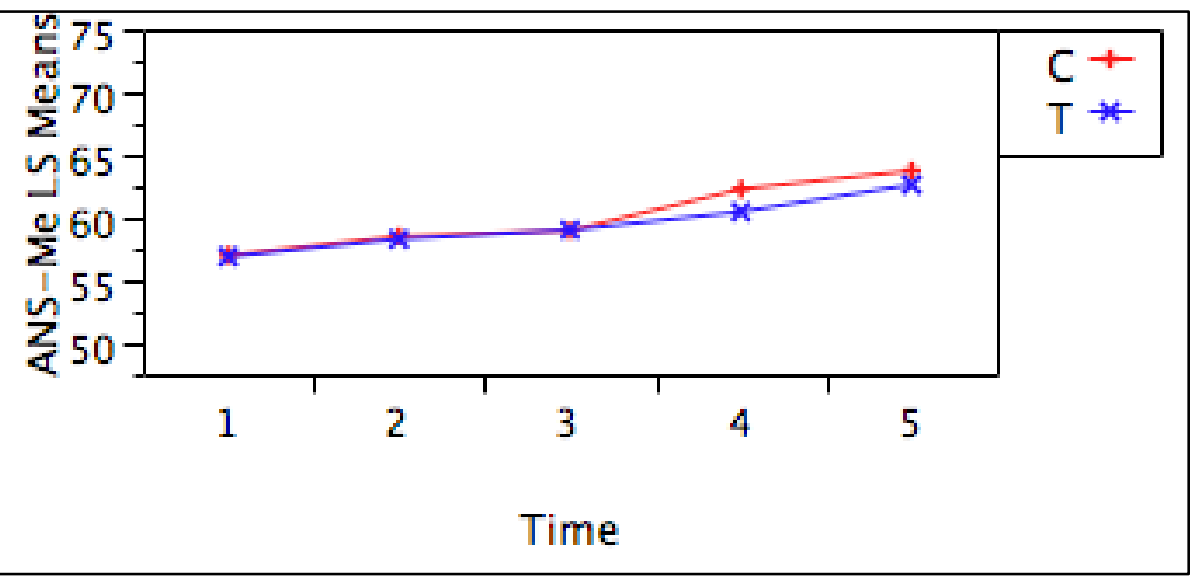

Males

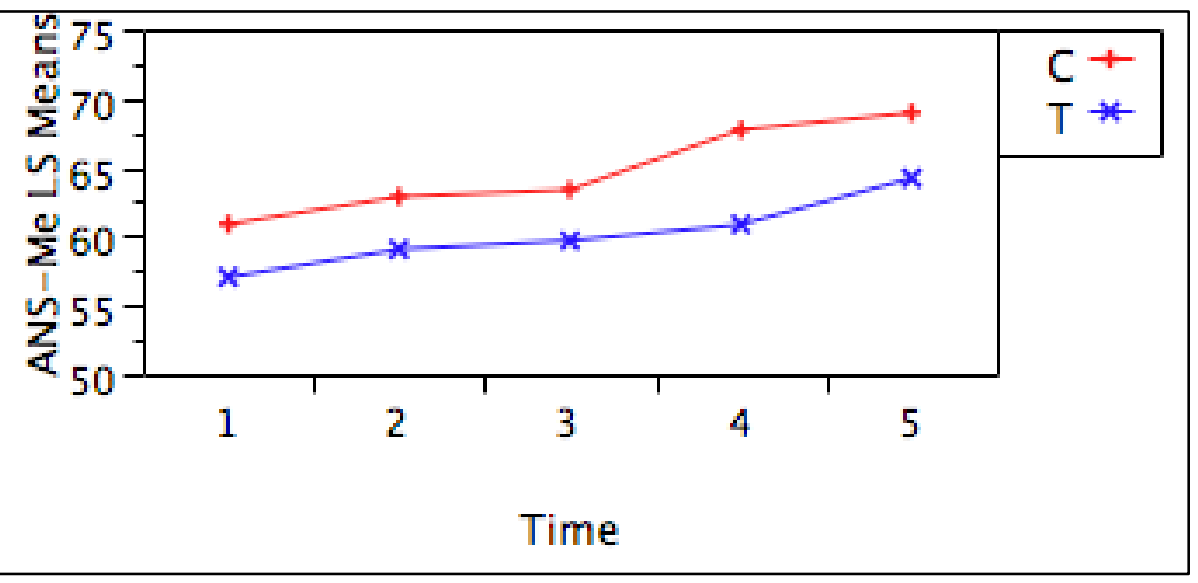

Females

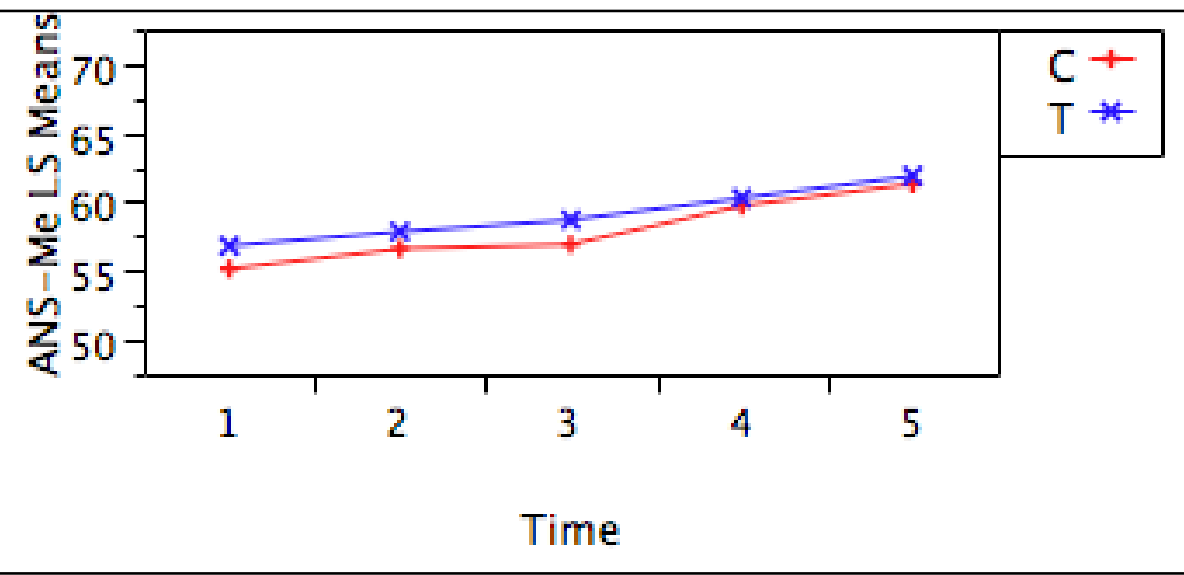


Is-NL

Overall

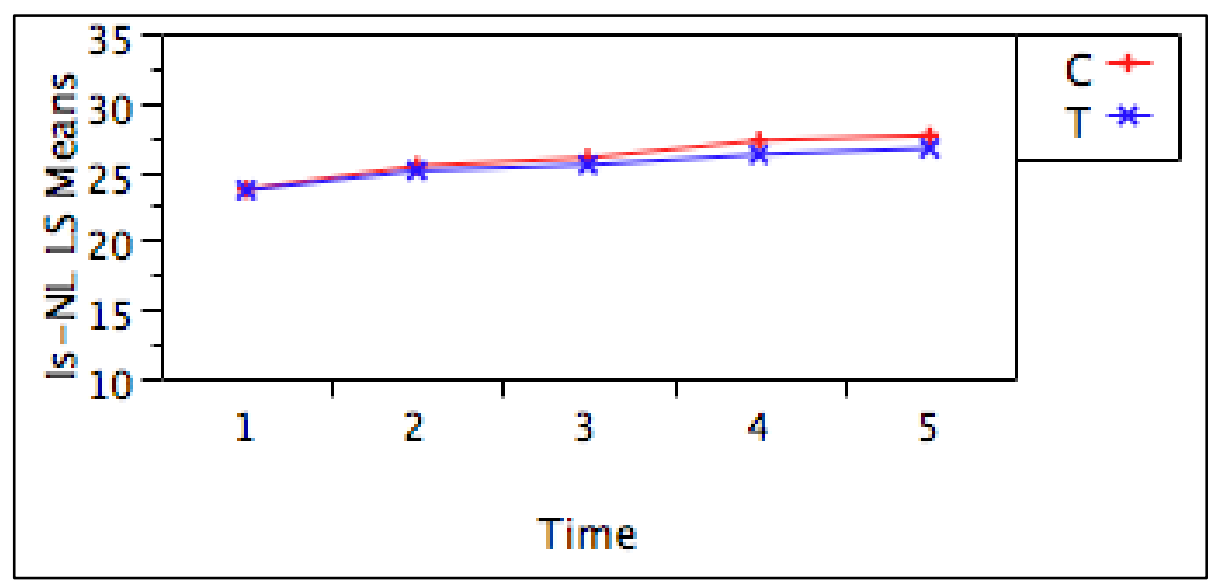

Males

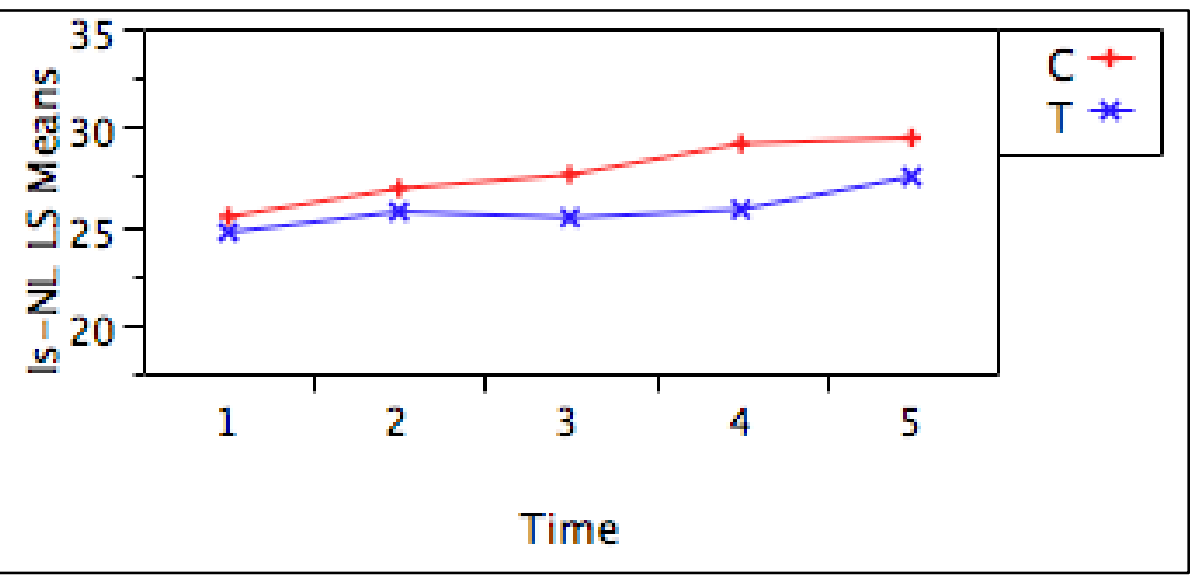

Females

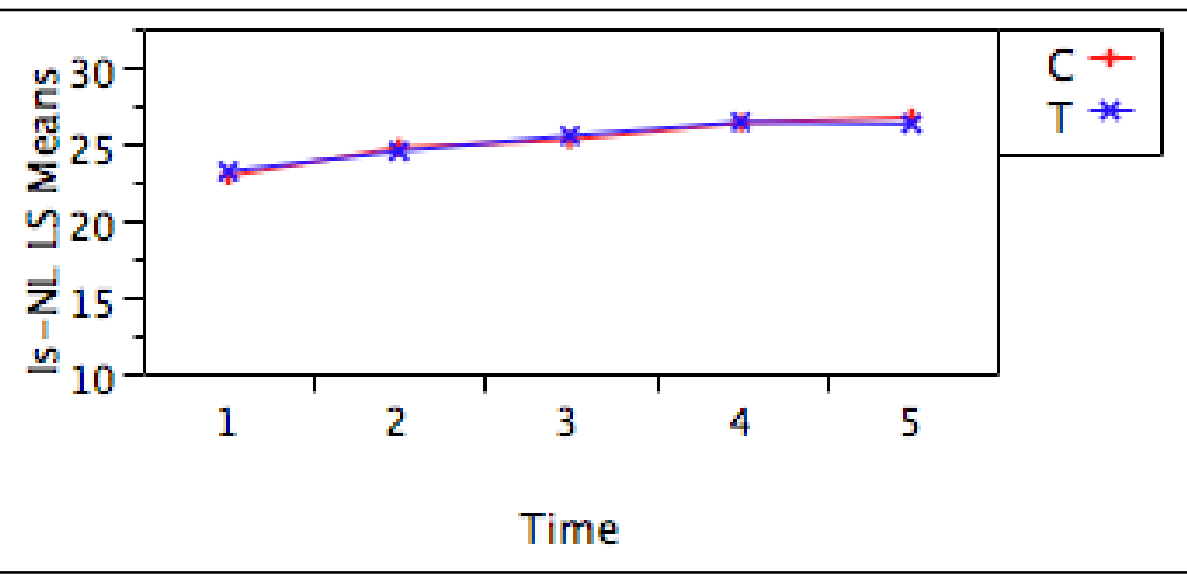




\section{Ii-ML}

Overall

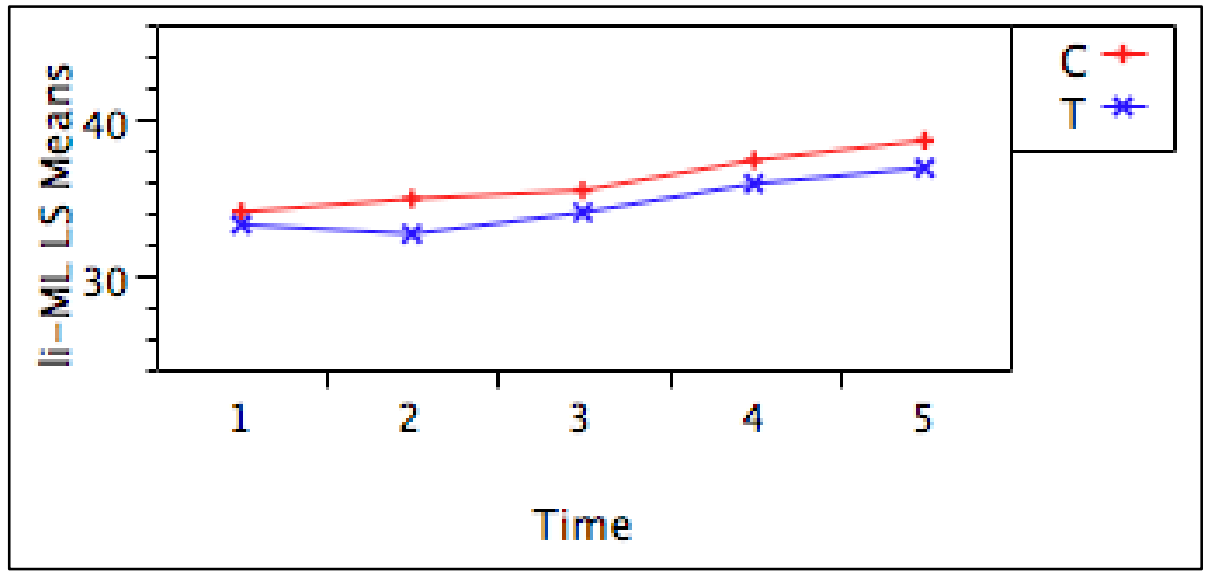

Males

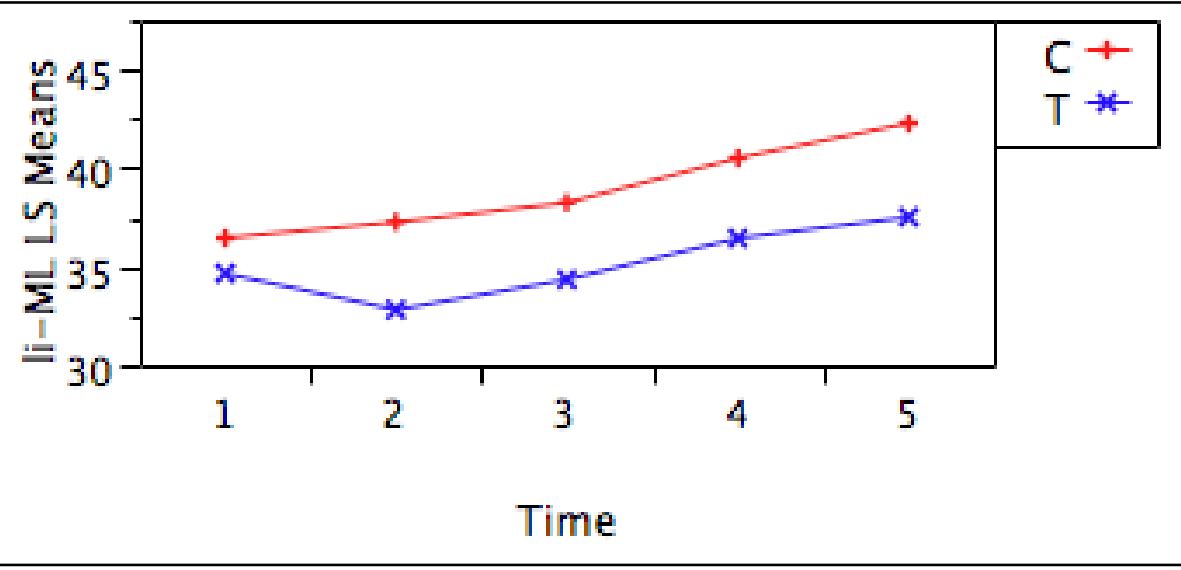

Females

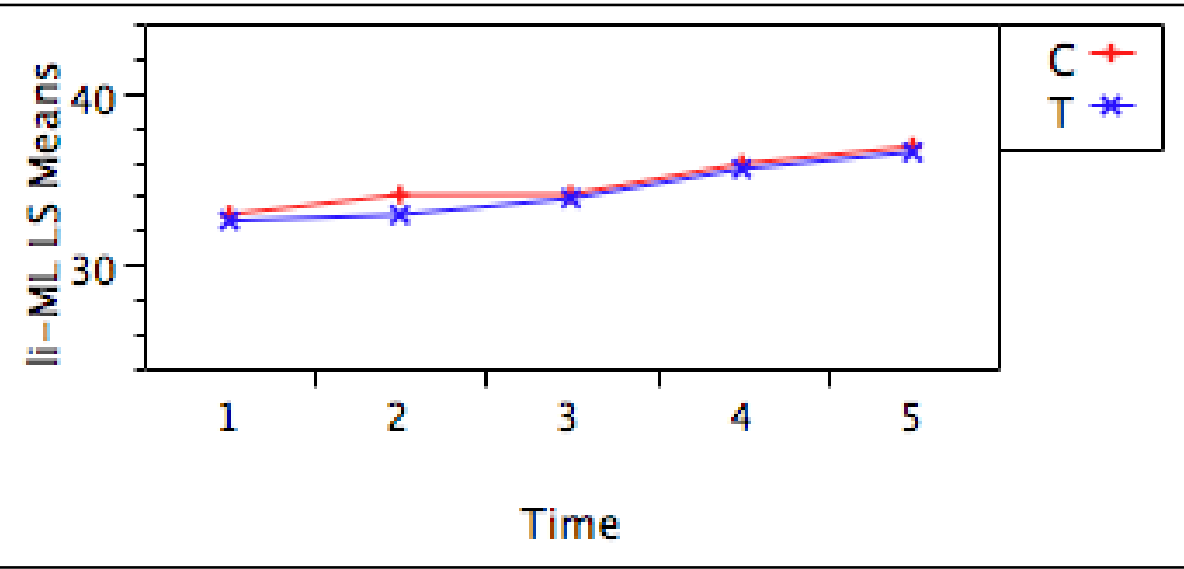




\section{Overbite}
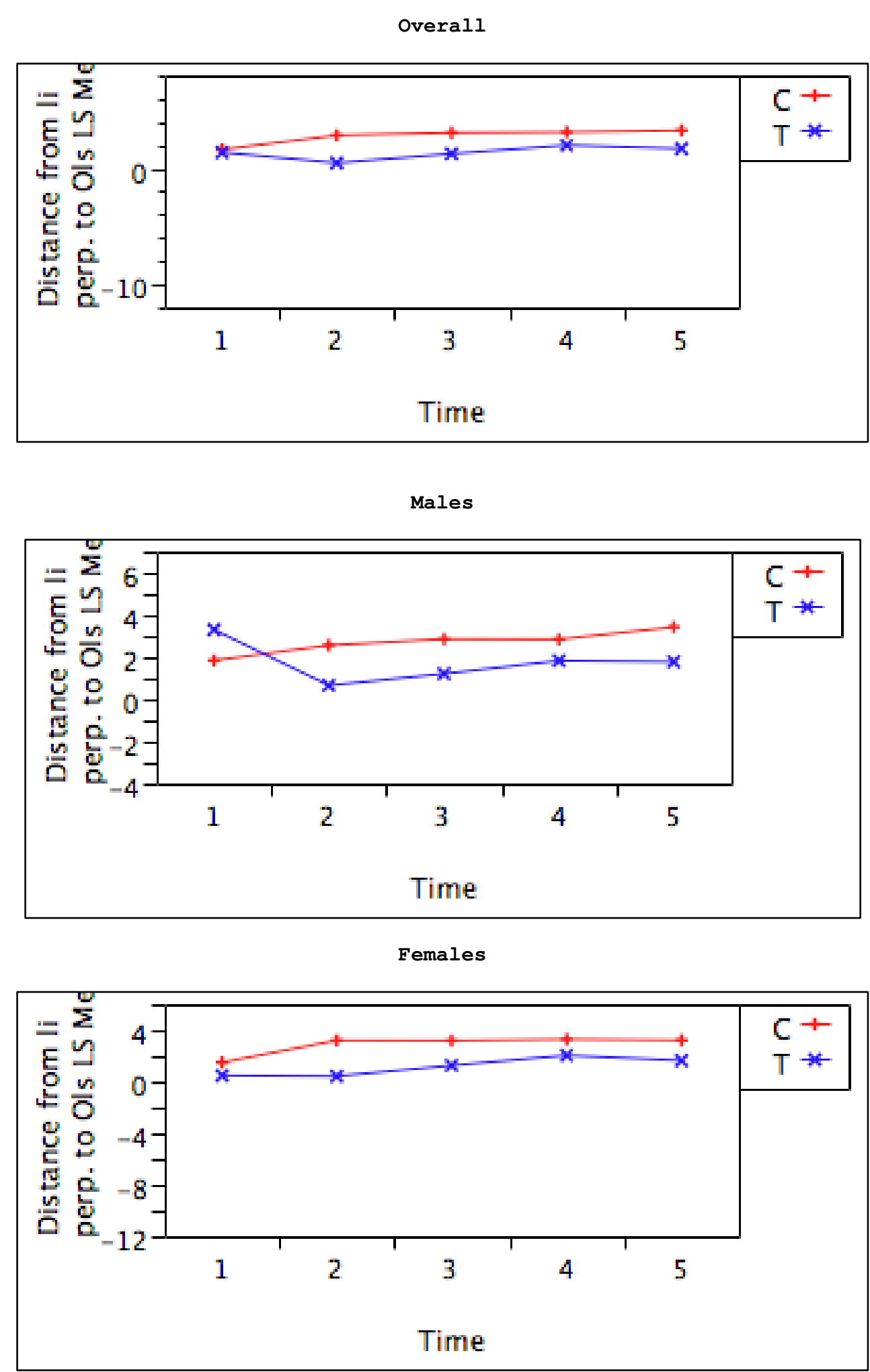


\section{Msc-NL}

Overall

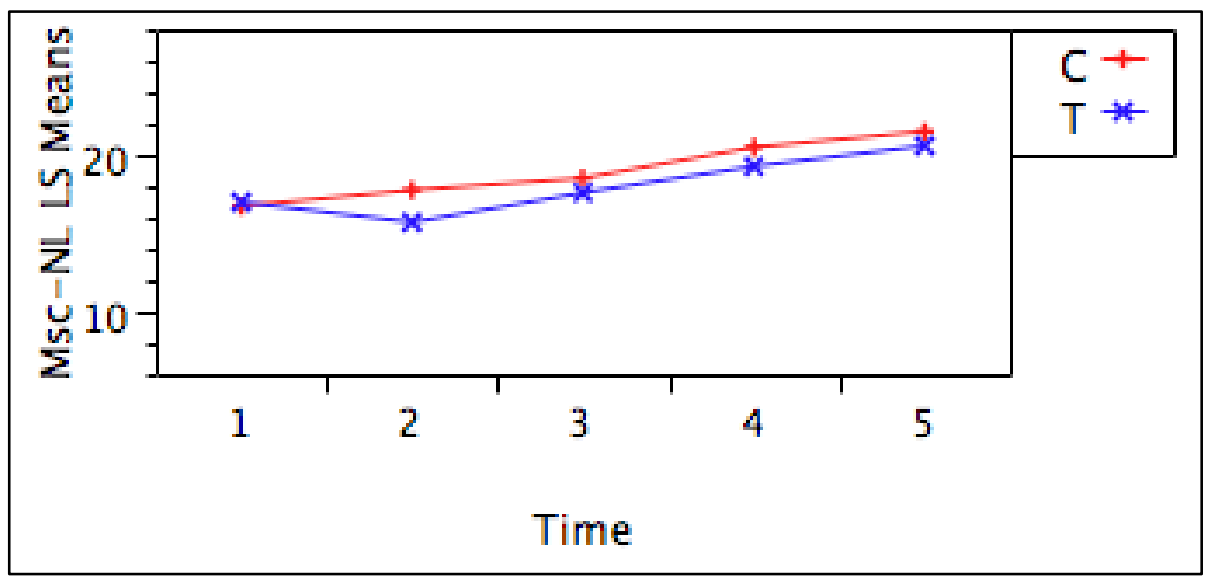

Males

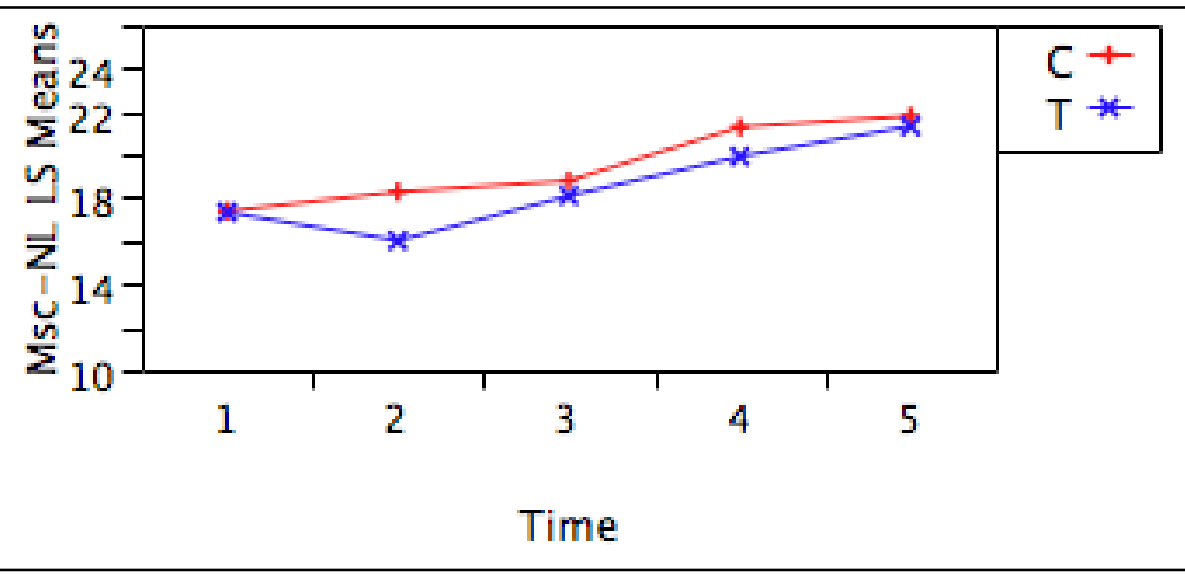

Females

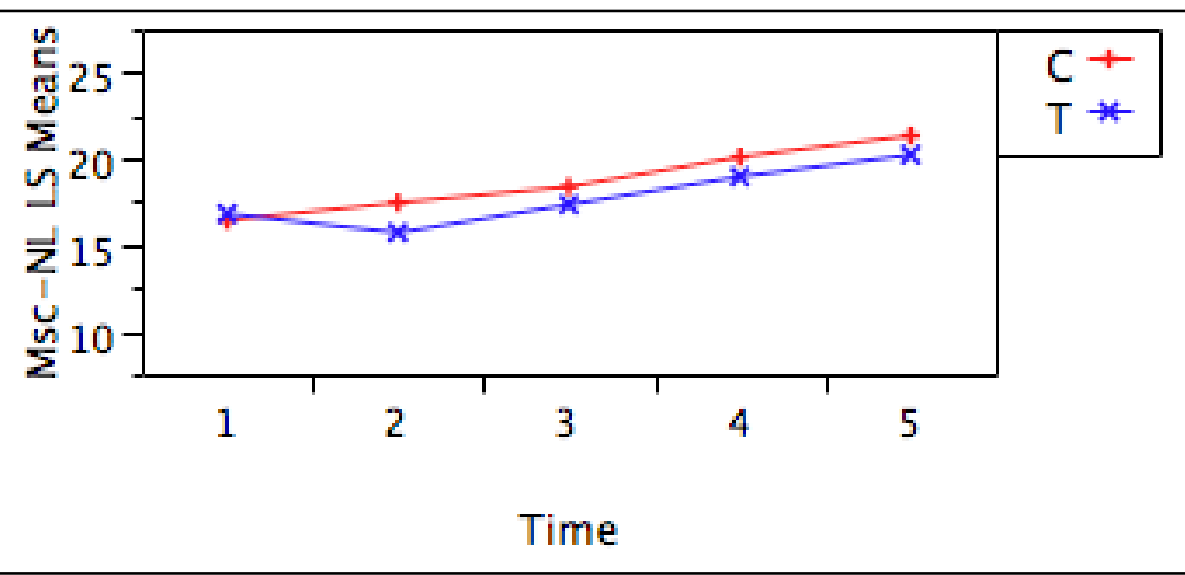




\section{Mic-ML}

Overall

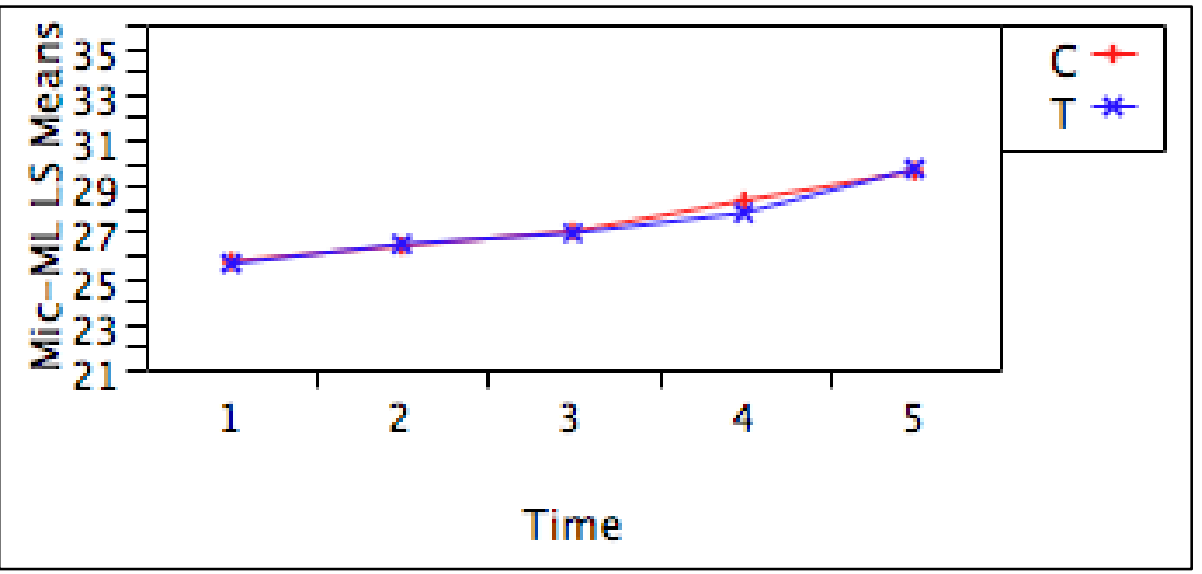

Males

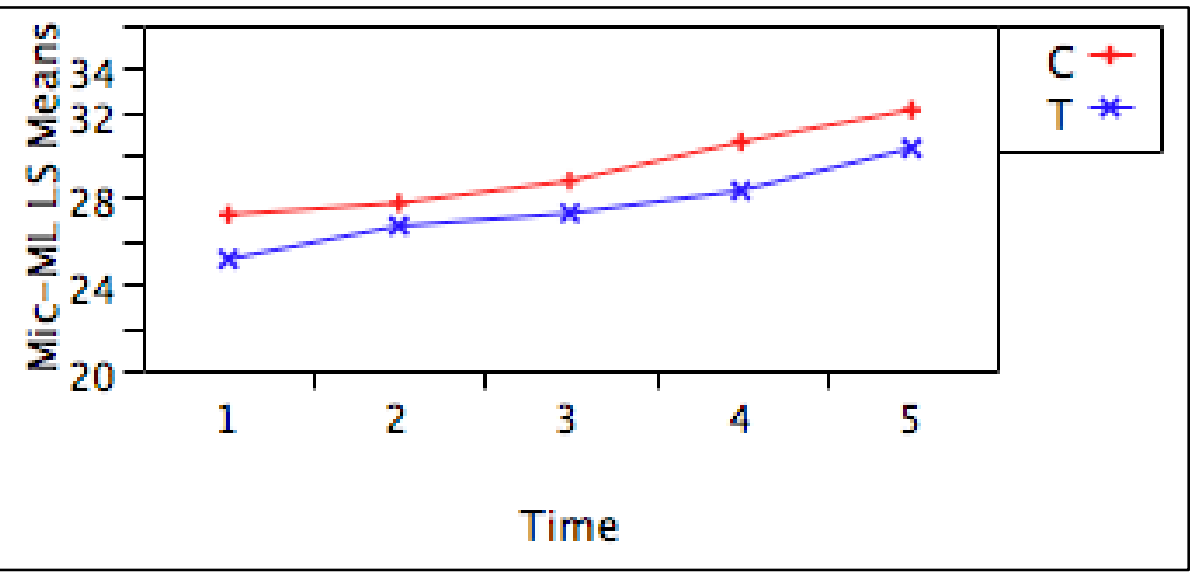

Females

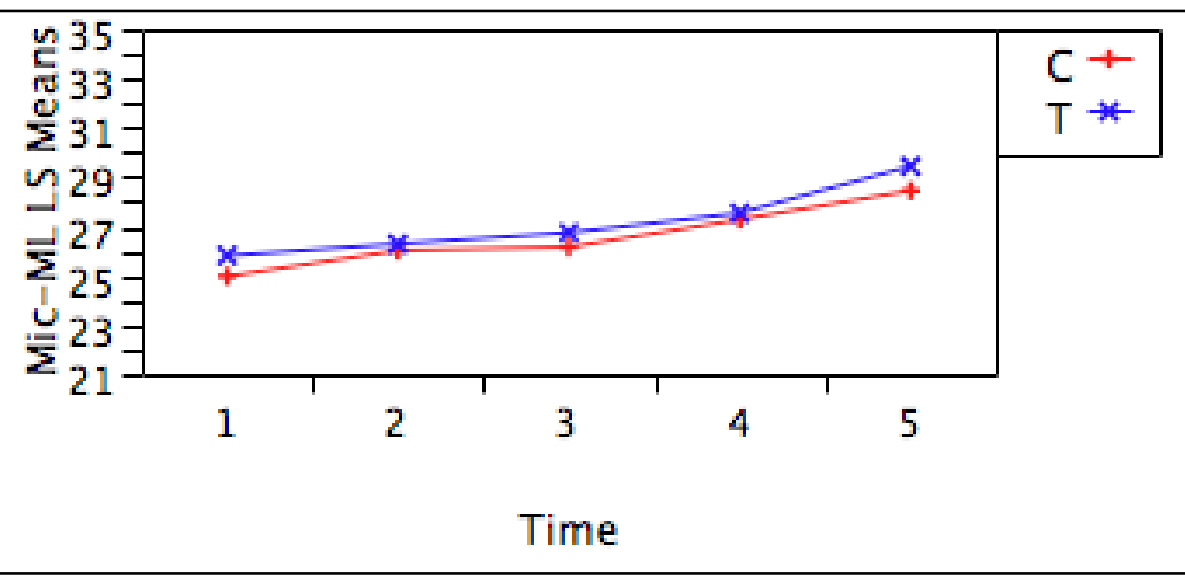




\section{SNA}

Overall

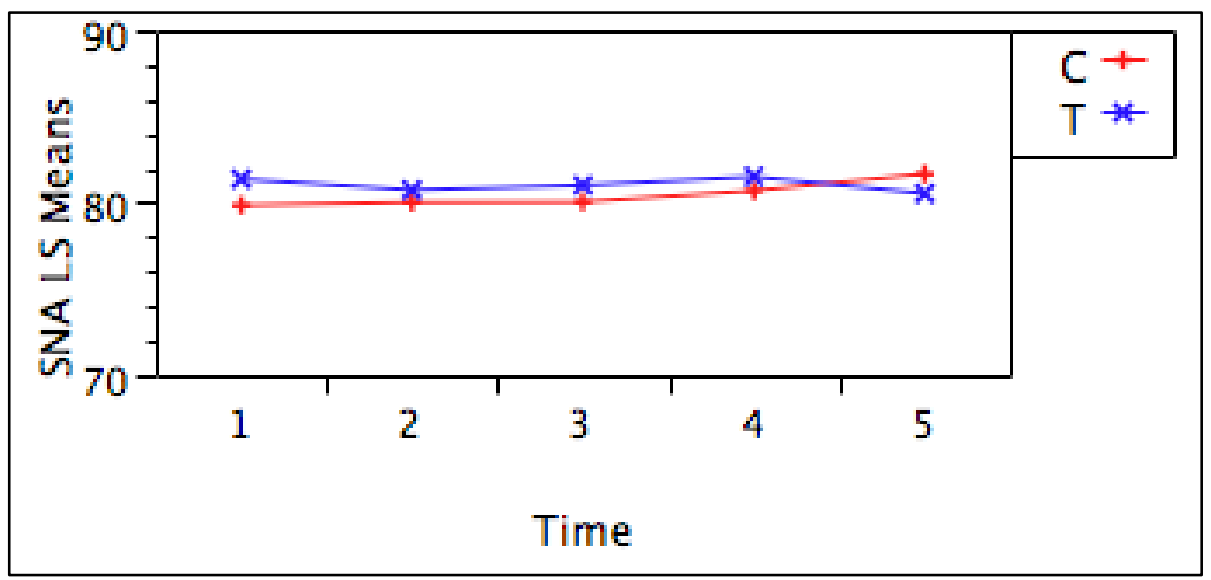

Males

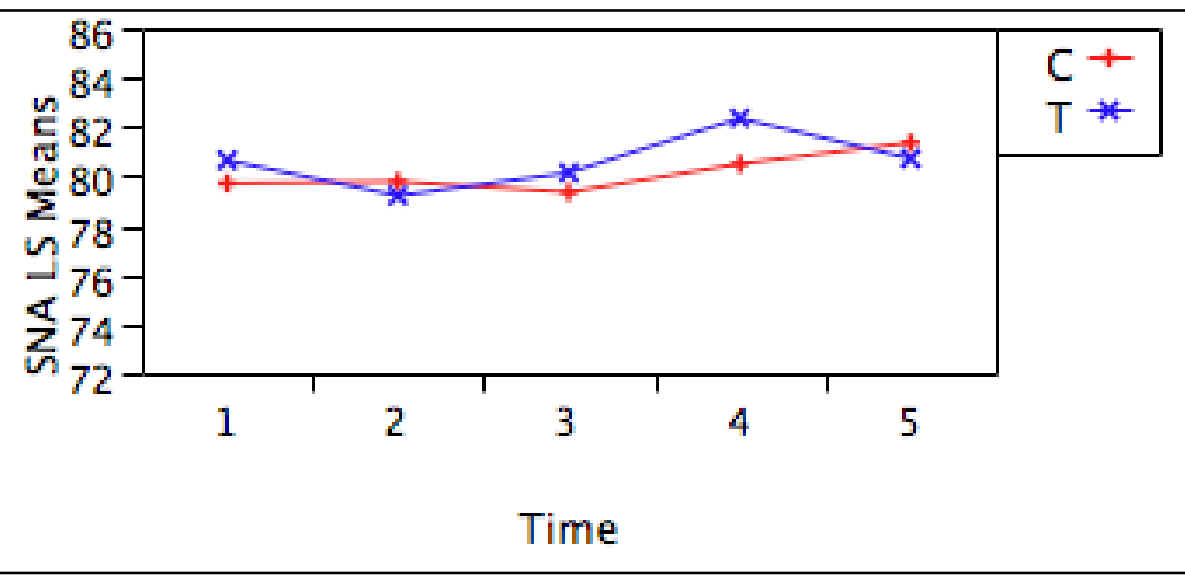

Females

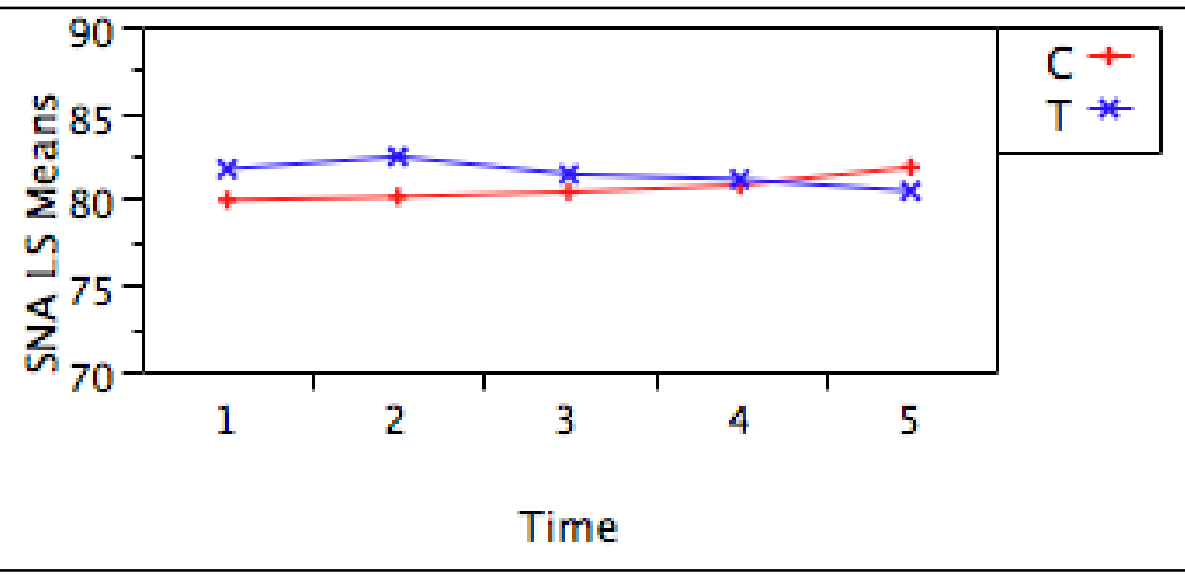




\section{SNB}

Overall

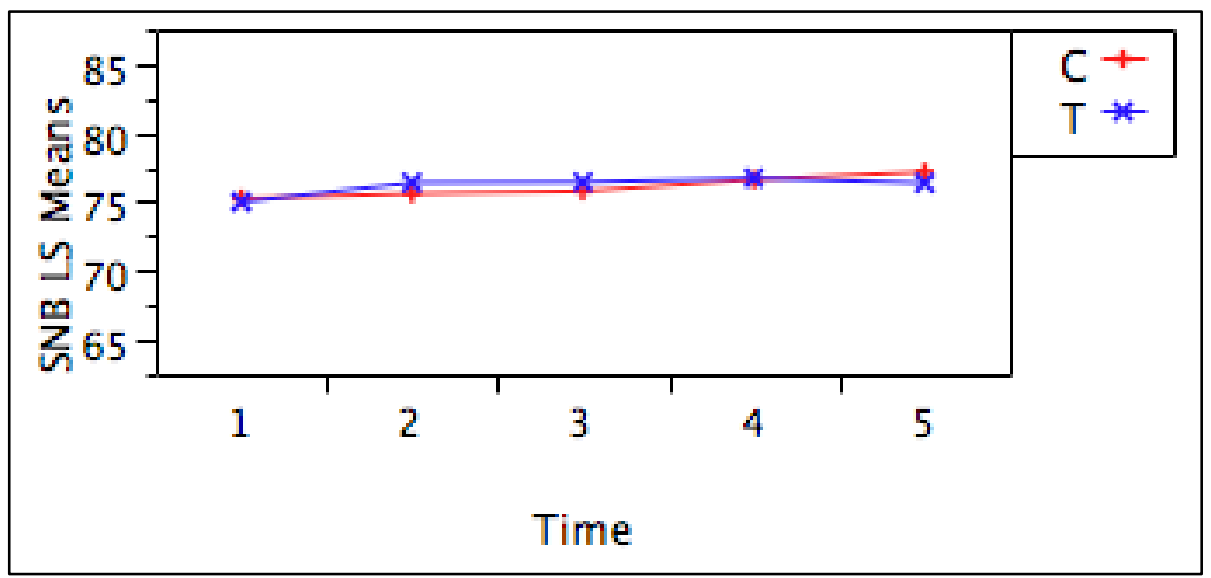

Males

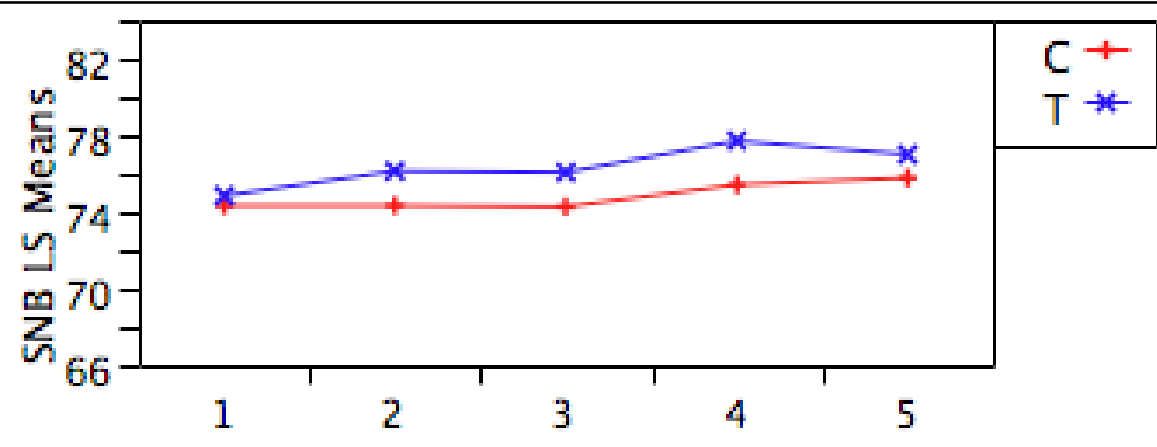

Time

Females

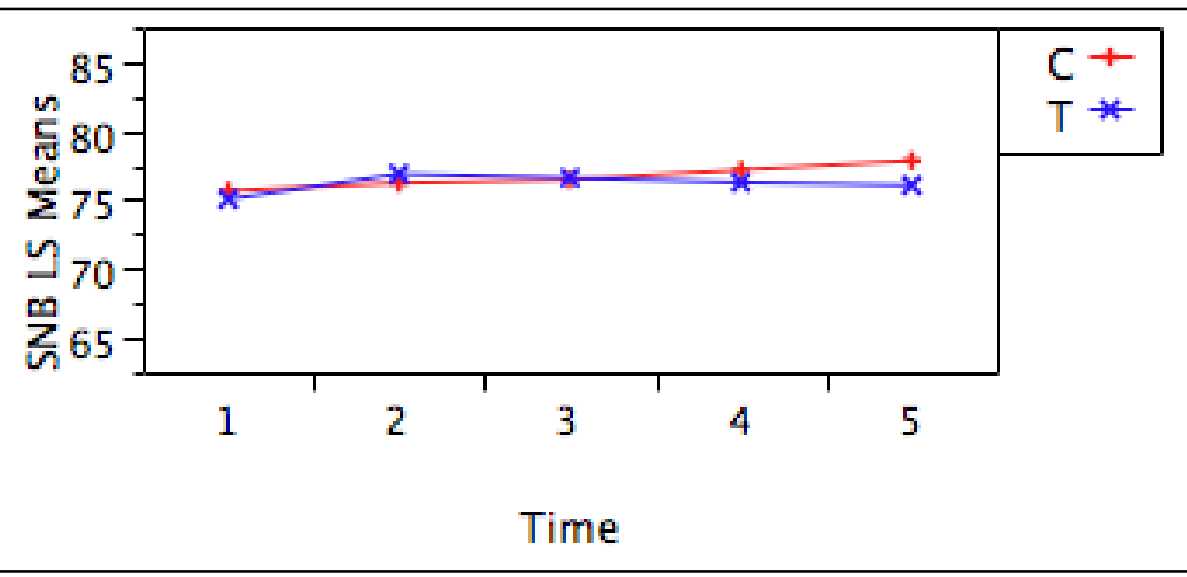



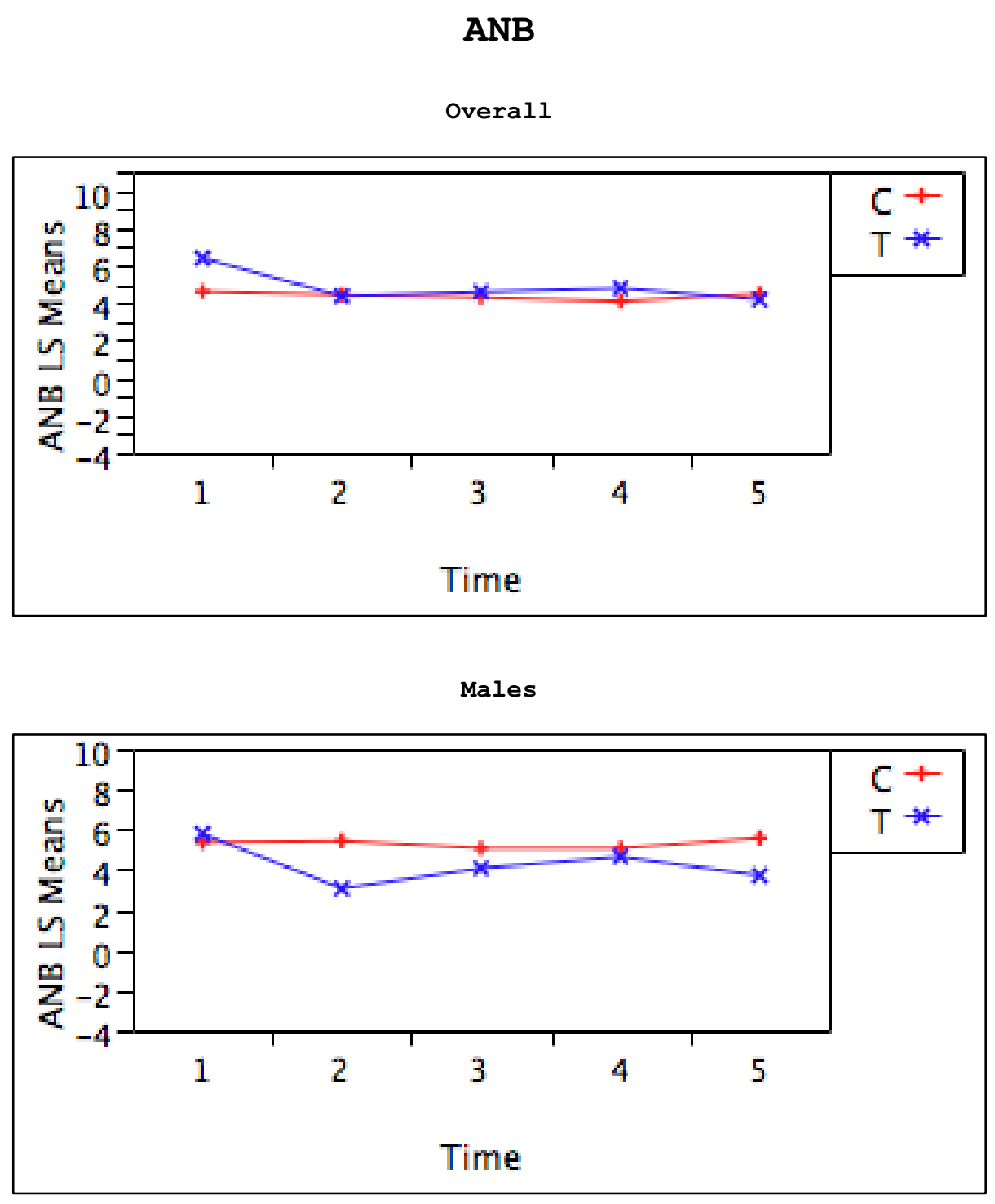

Females

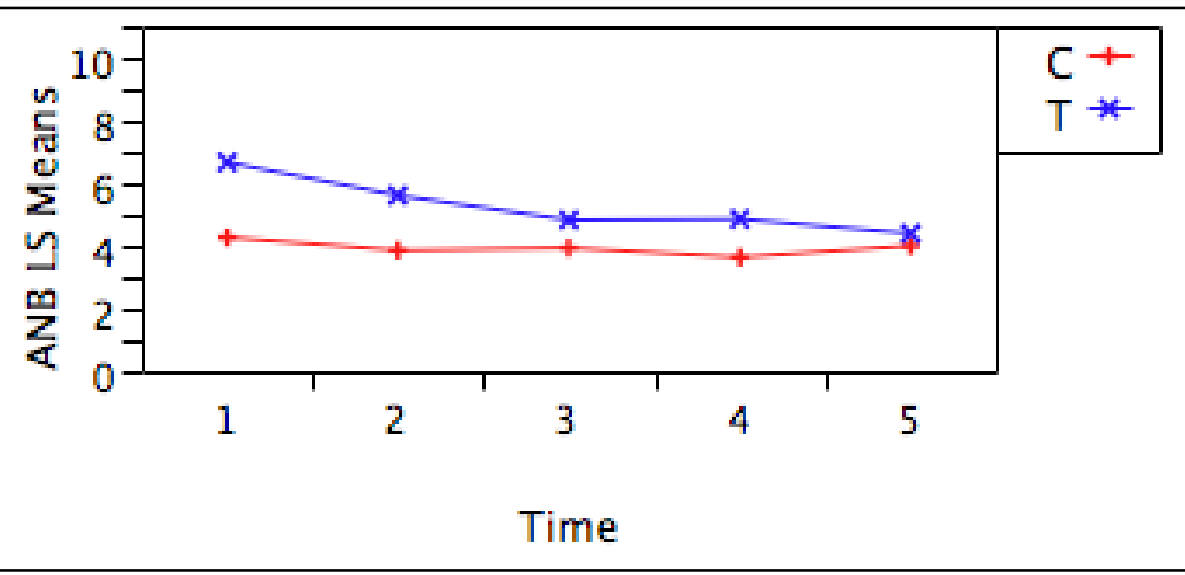


SNL-NL

Overall

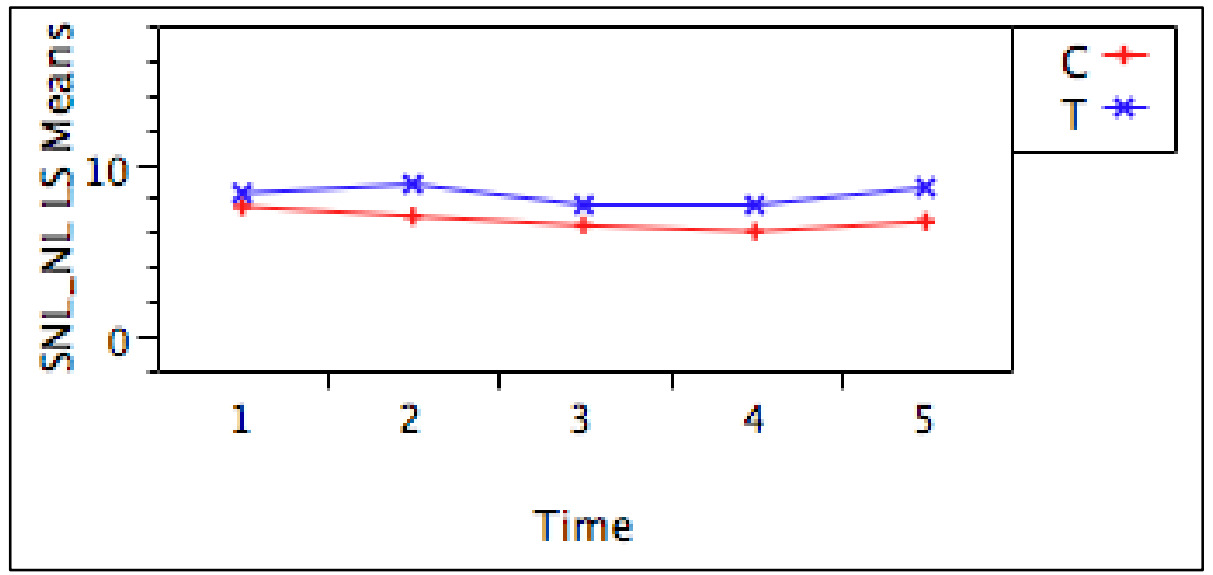

Males

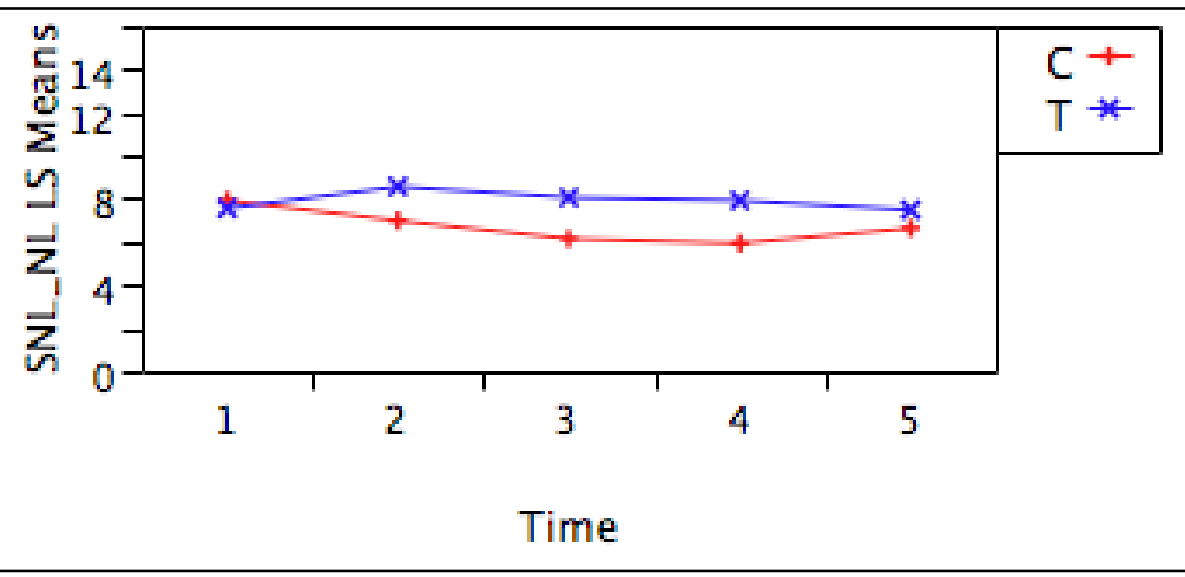

Females

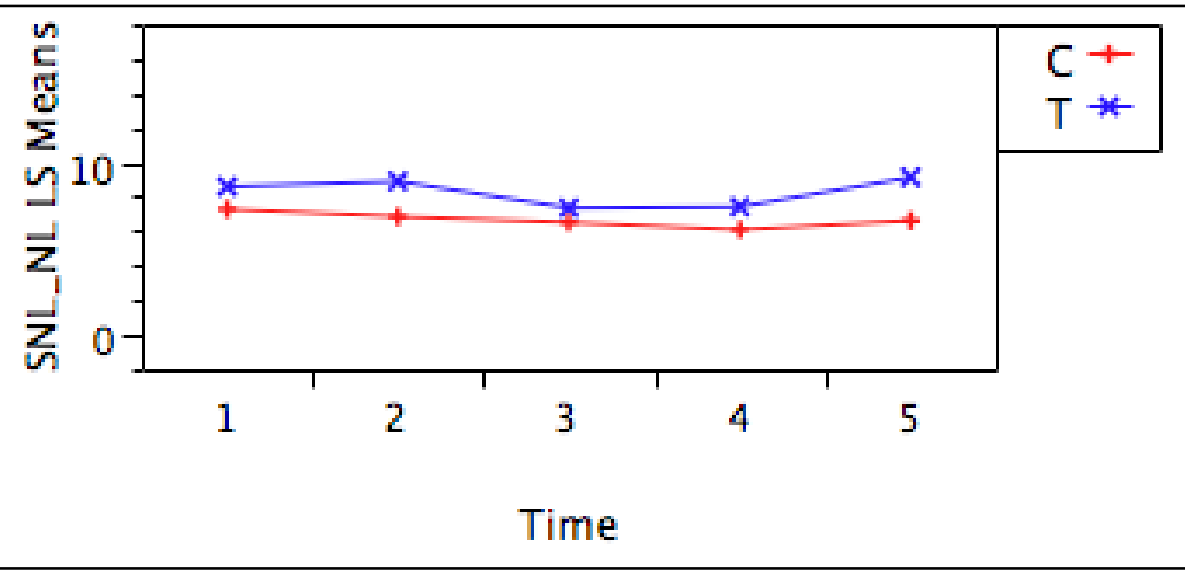


SNI-ML

Overall

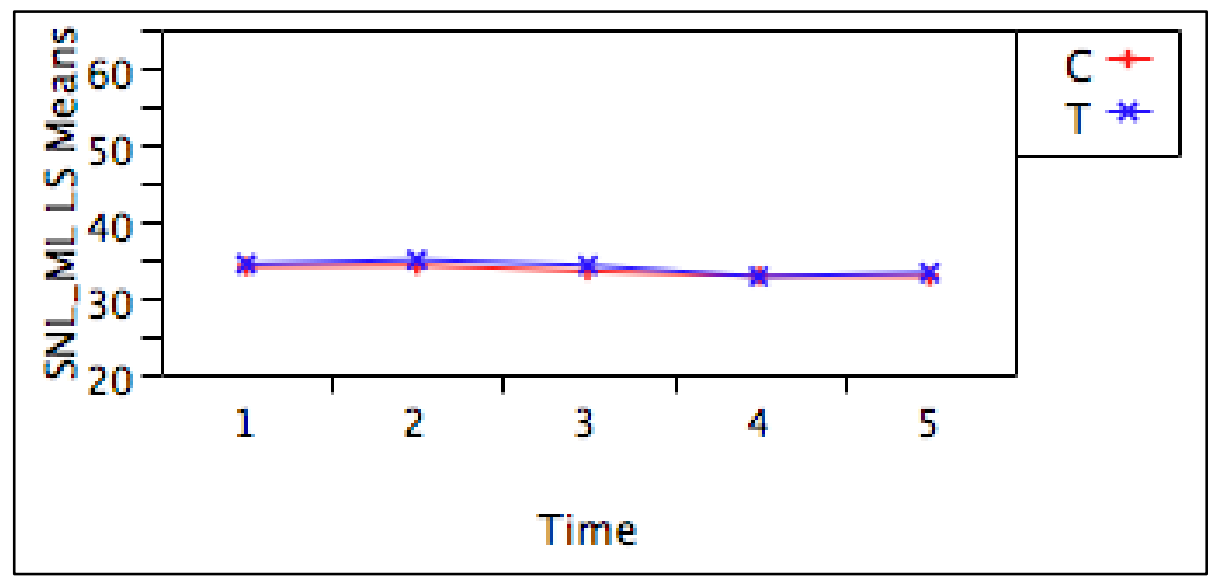

Males

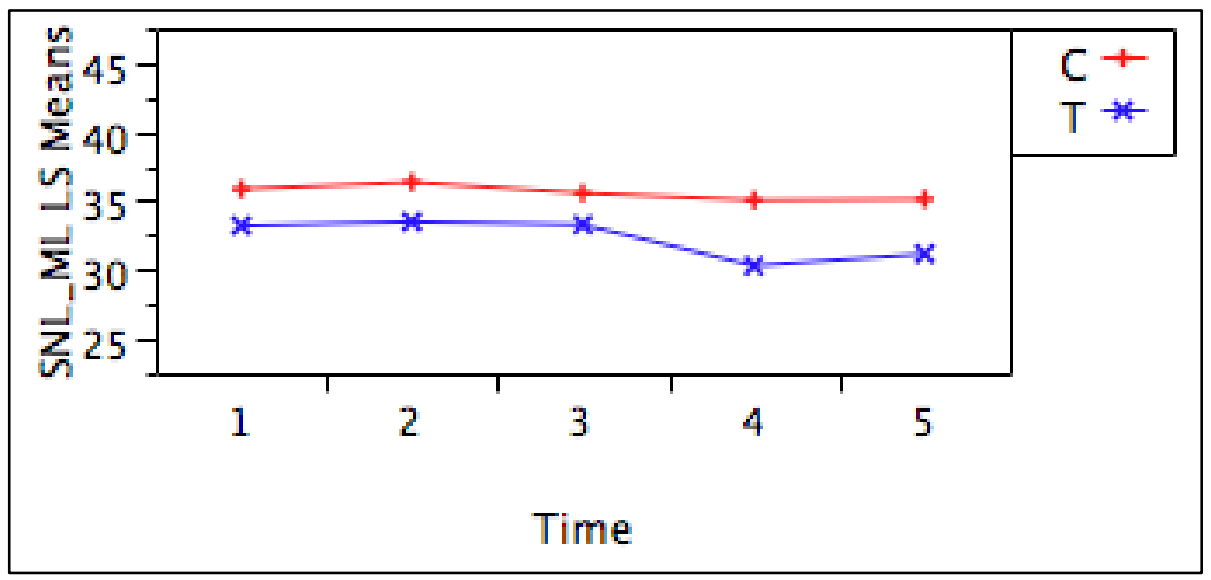

Females

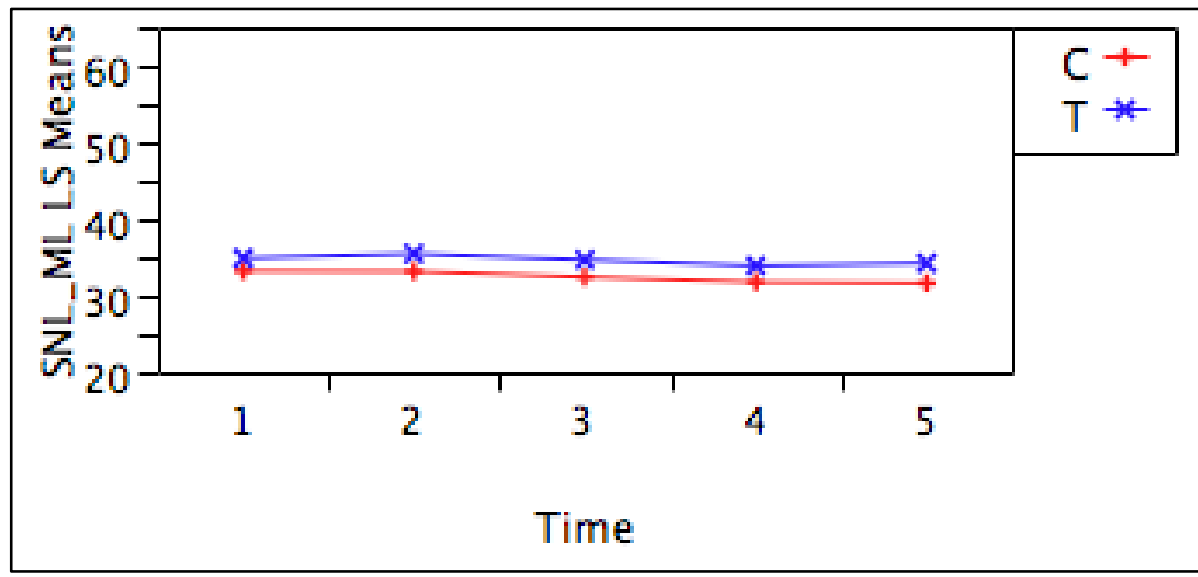


SNL-OL

Overall

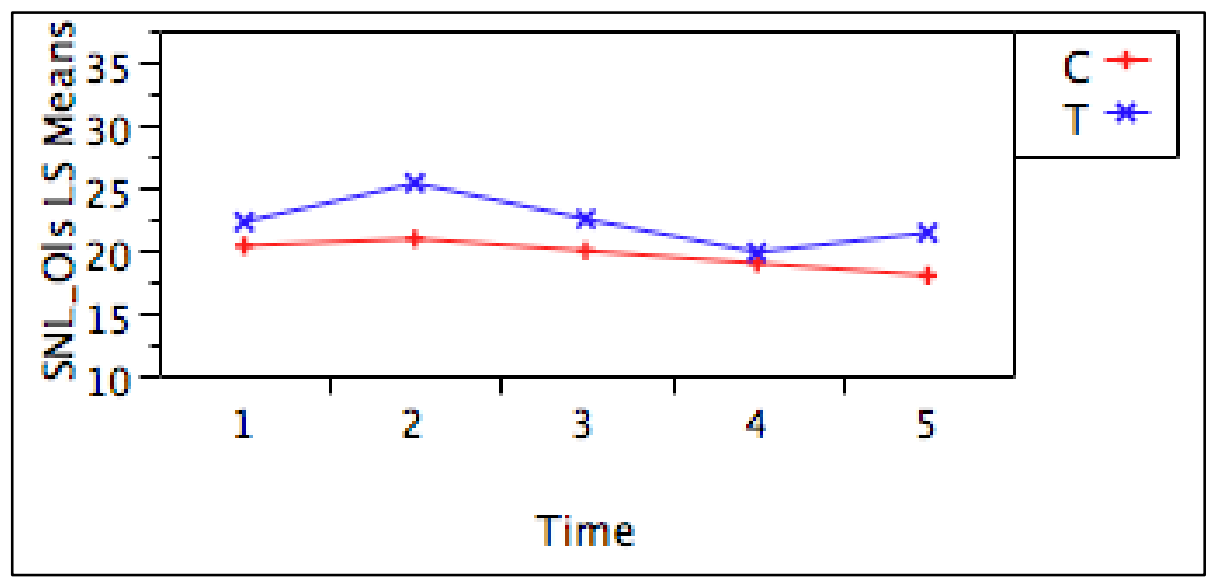

Males

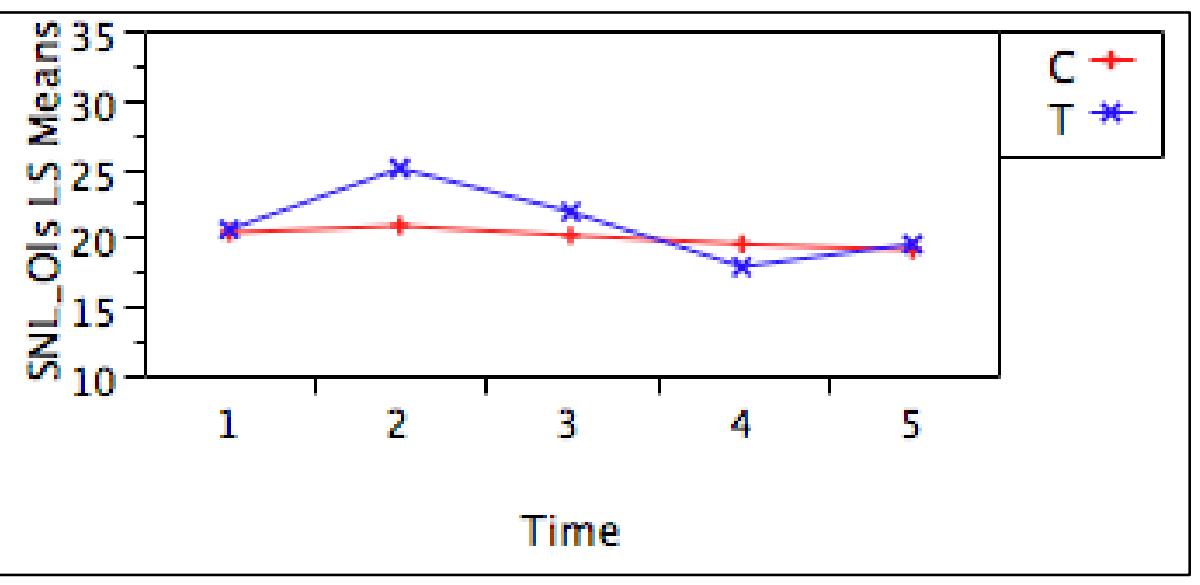

Females

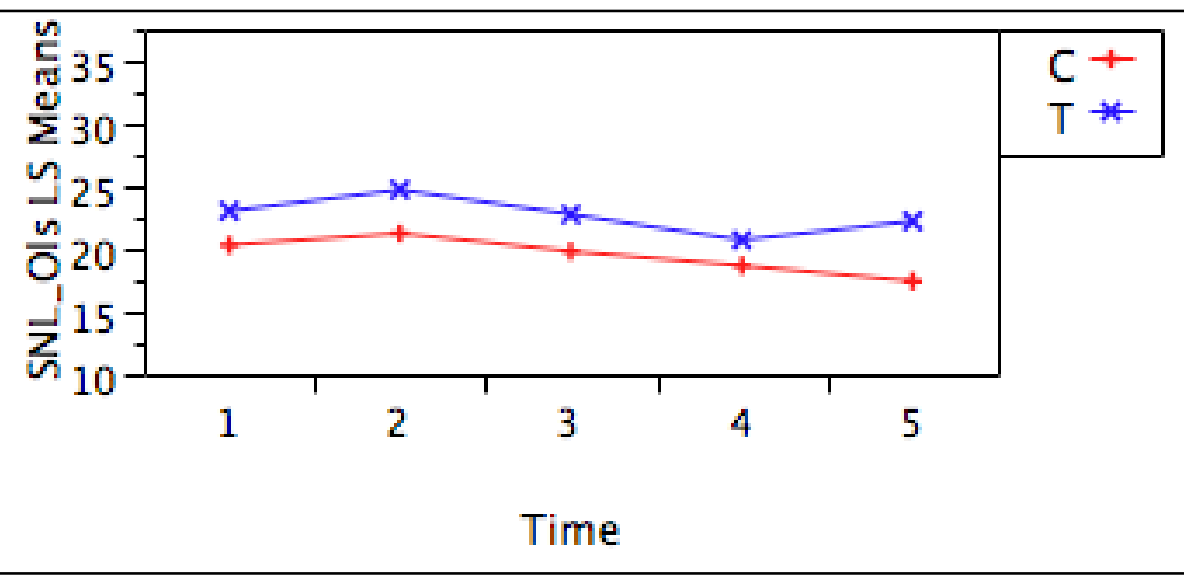




\section{Is/NL}

Overall

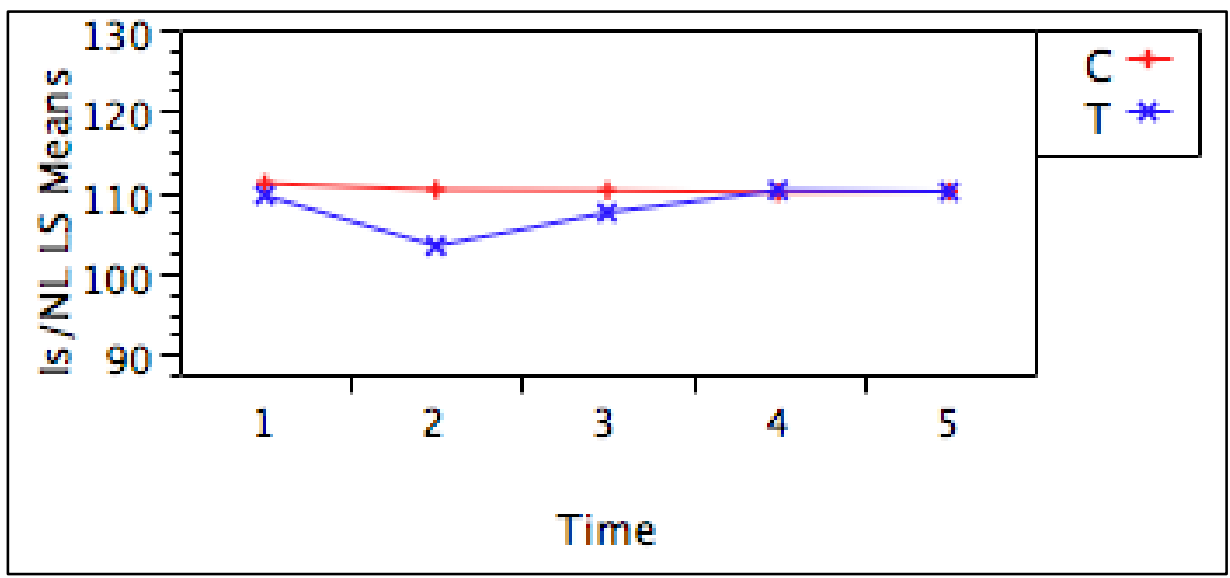

Males

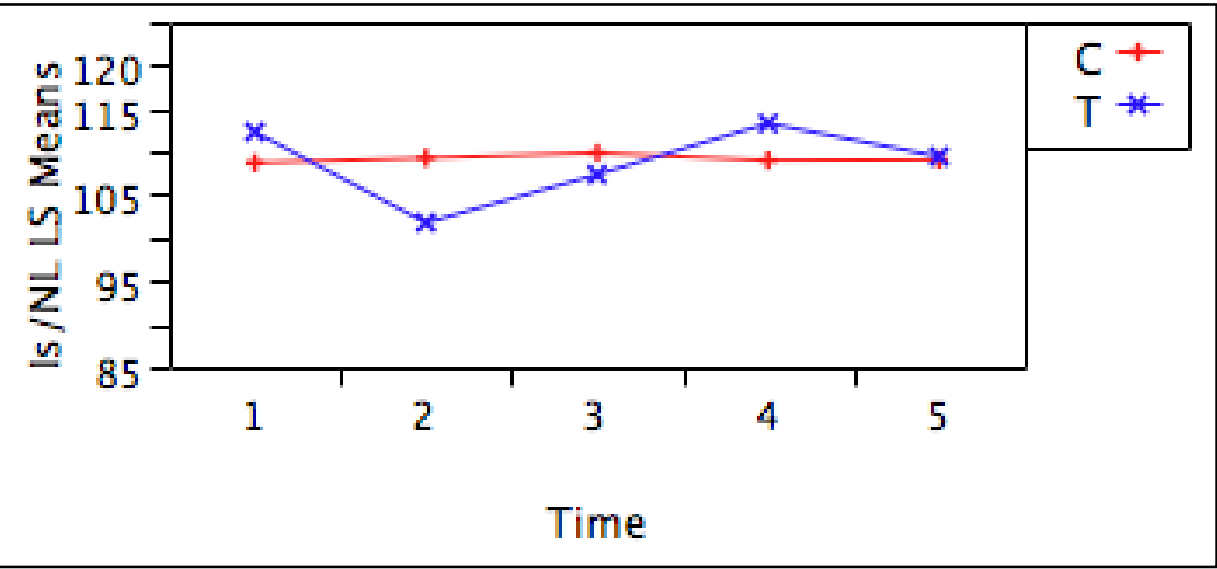

Females

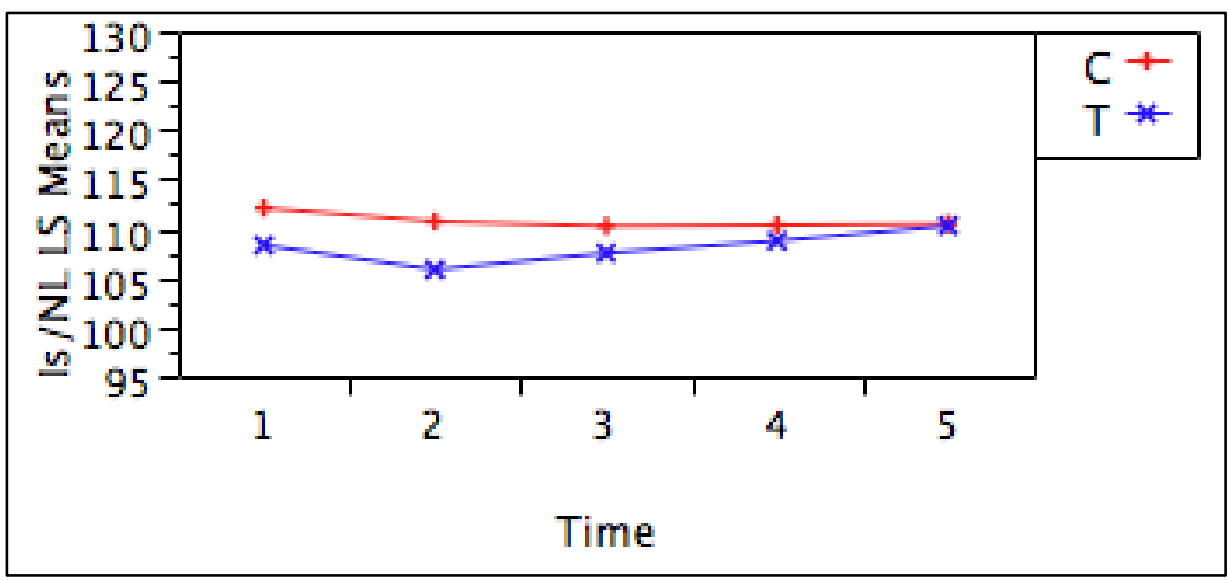




\section{I $i / M L$}

Overall

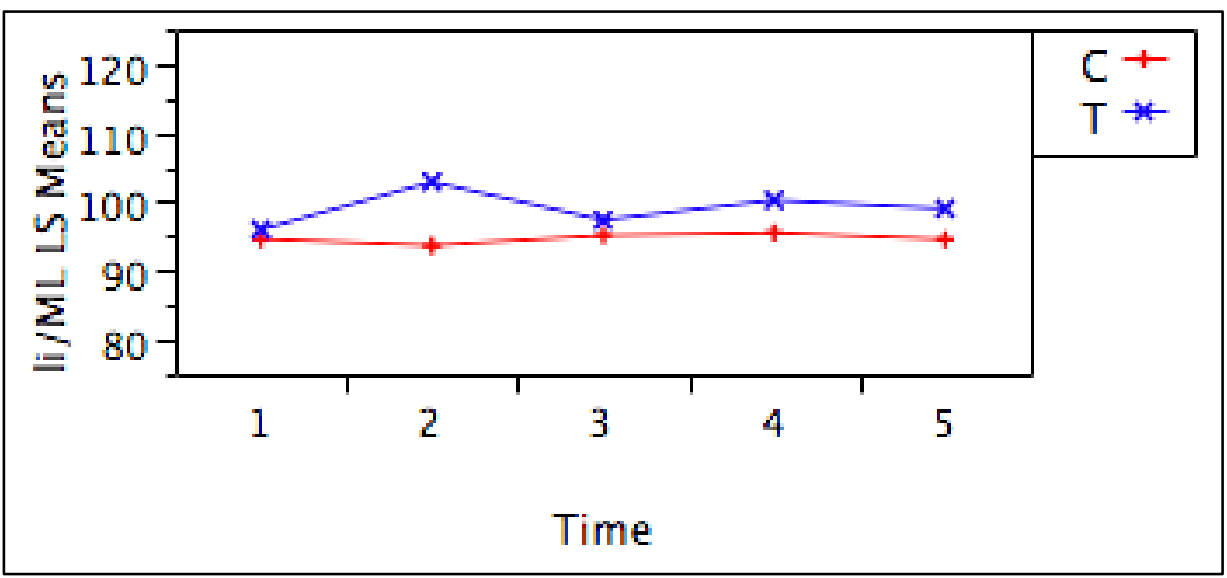

Males

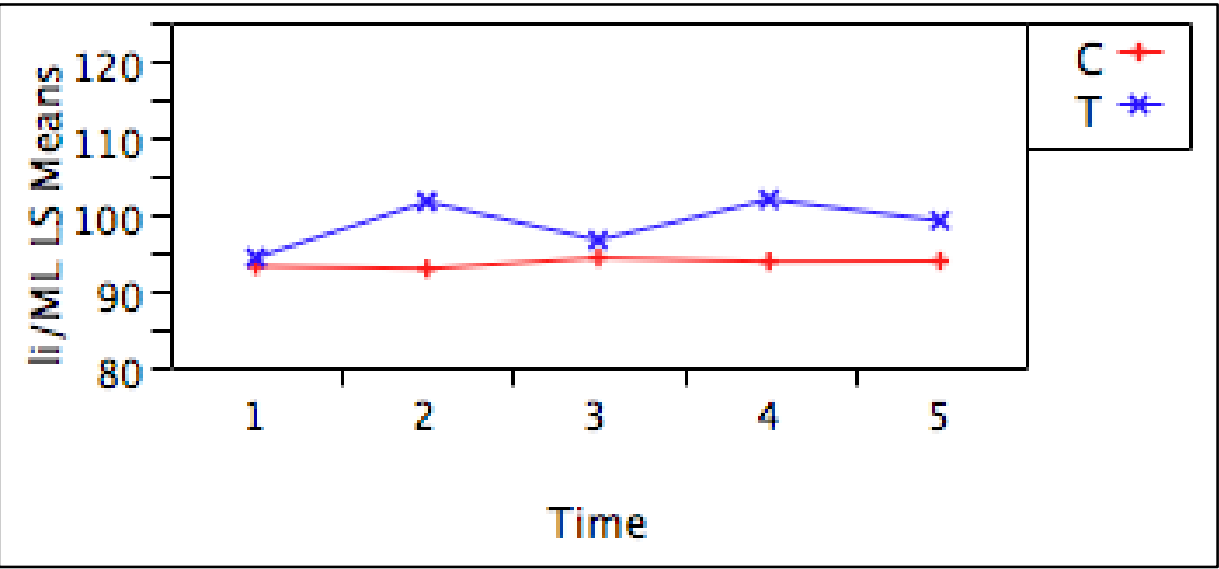

Females

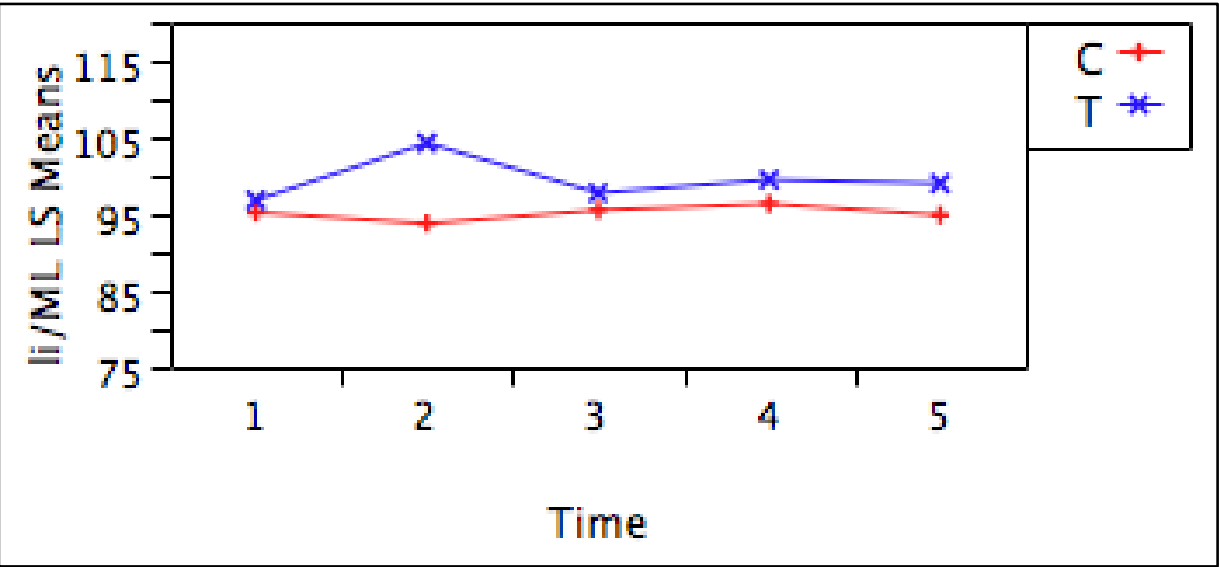




\section{Interincisal Angle}

Overall

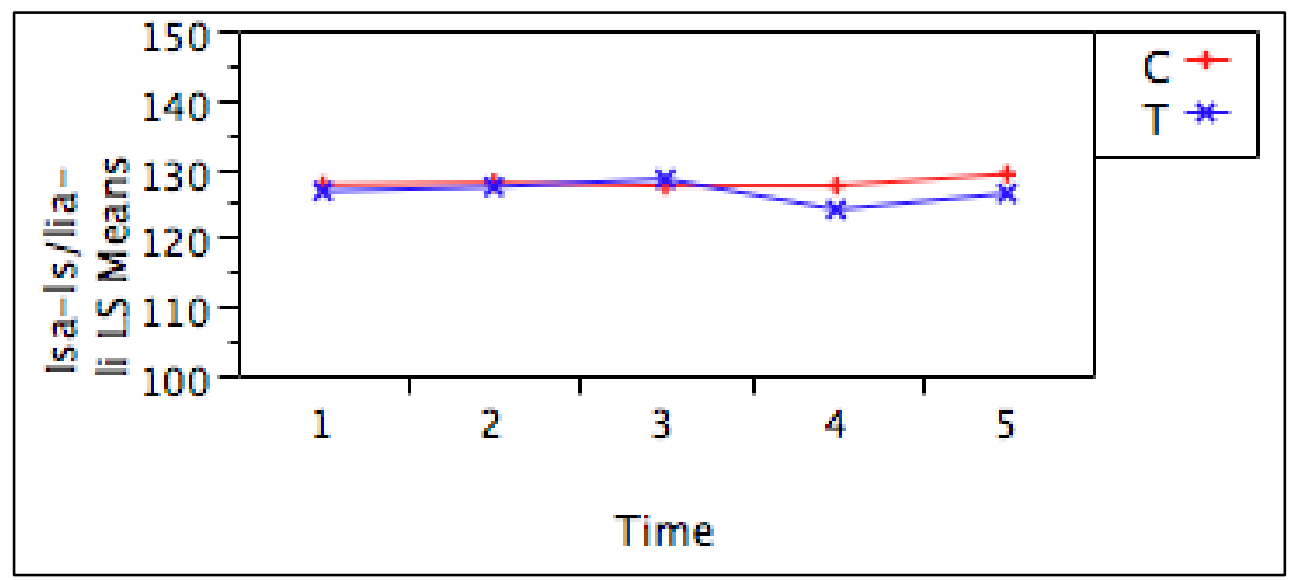

Males

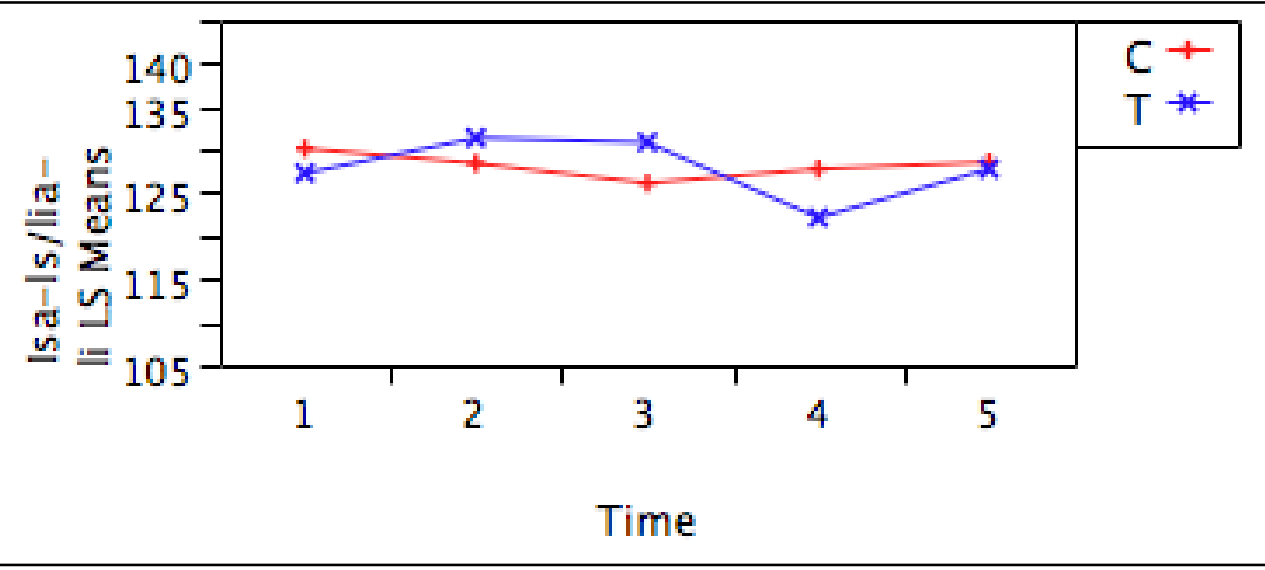

Females

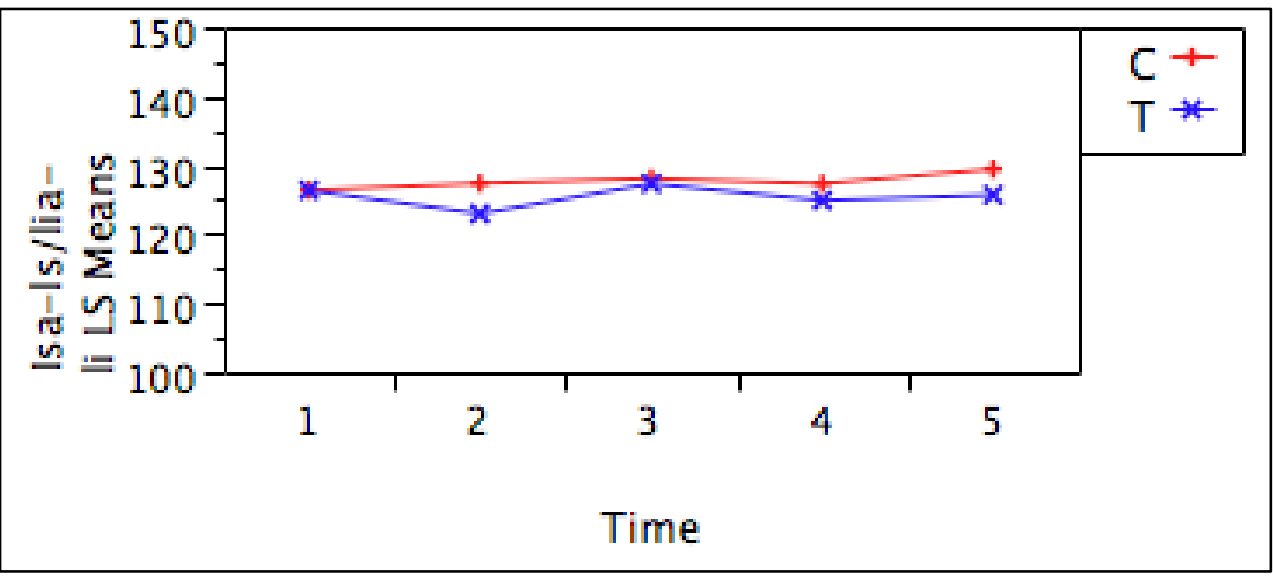




\section{OLp-COC}

Overall

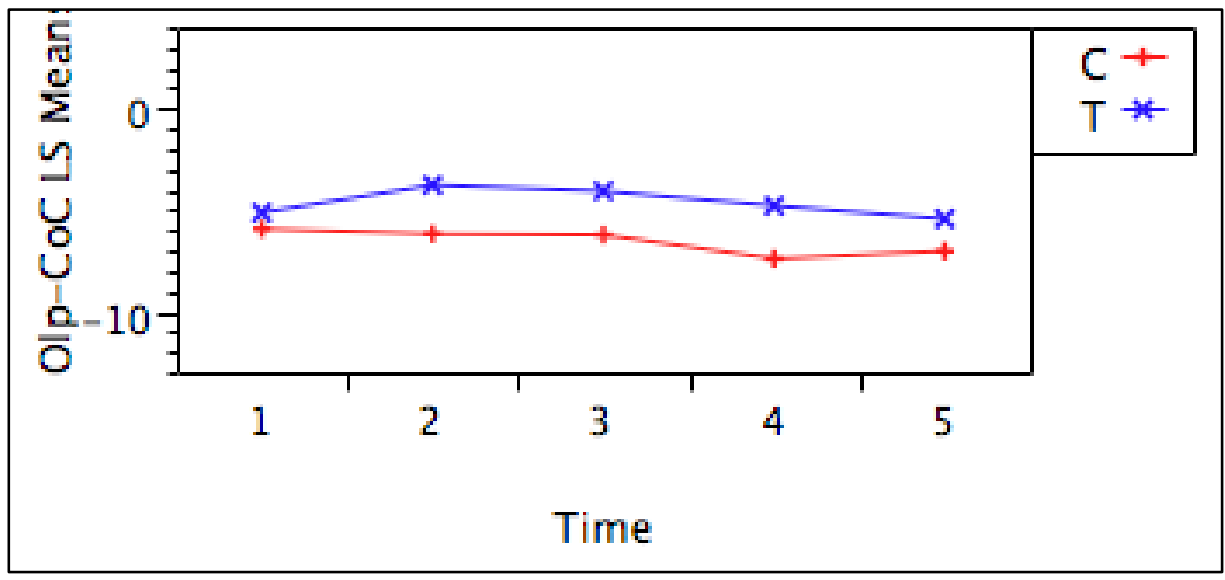

Males

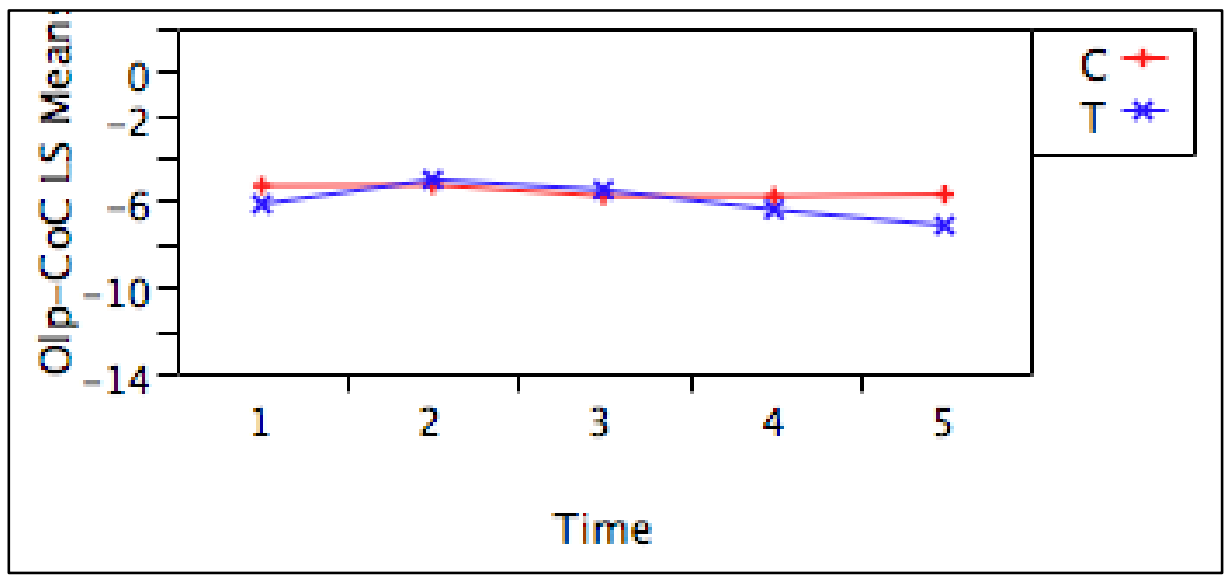

Females

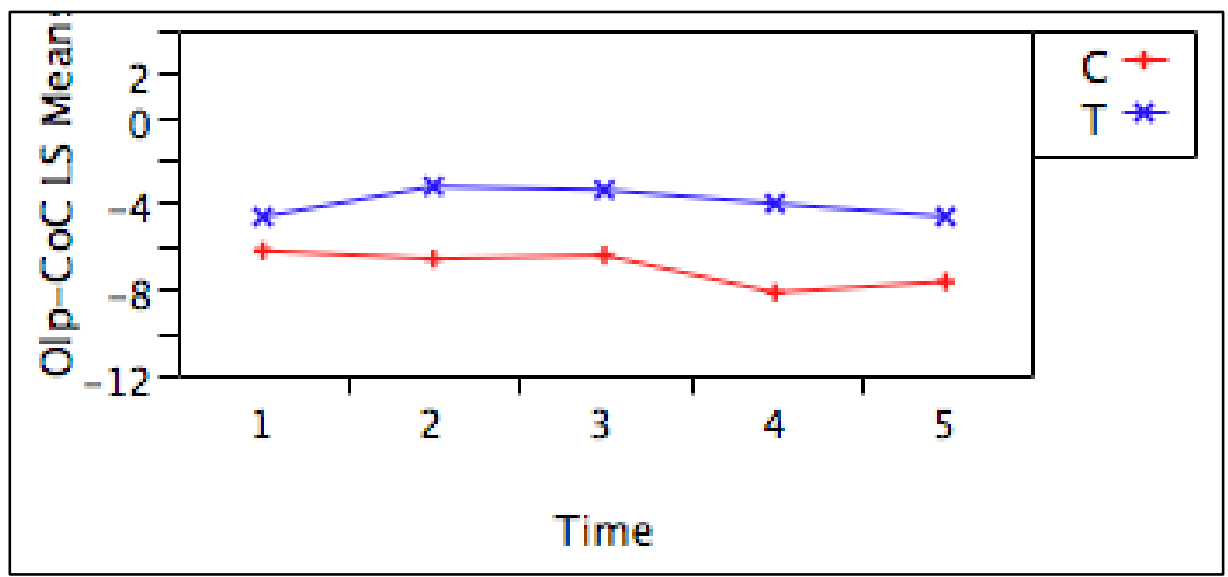




\section{OLP-GFS}

Overall

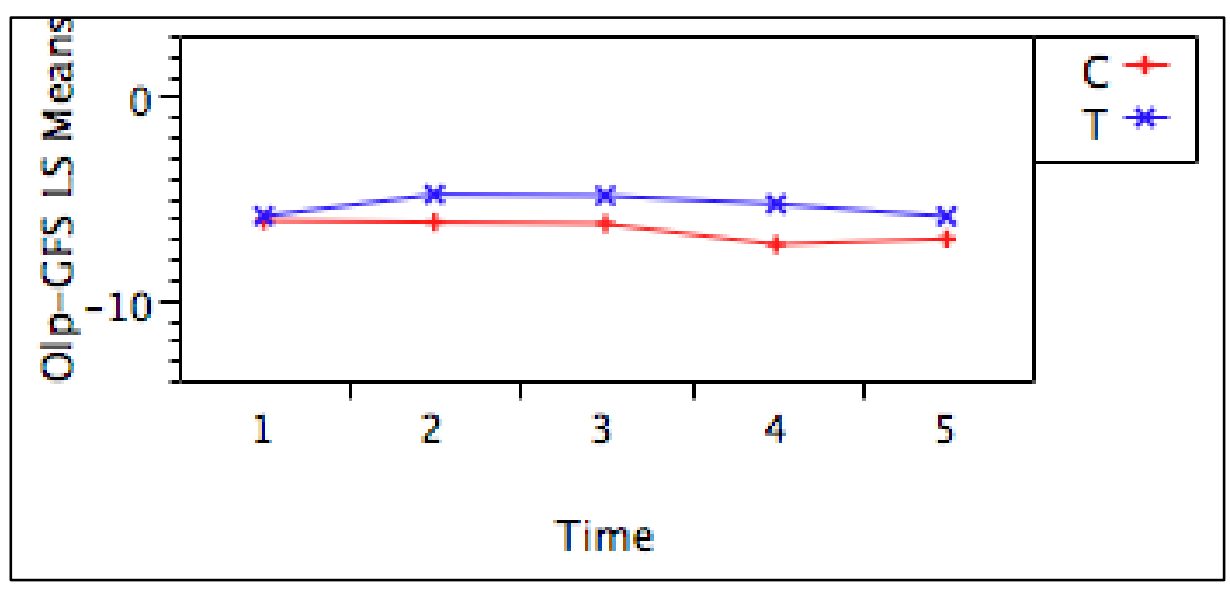

Males

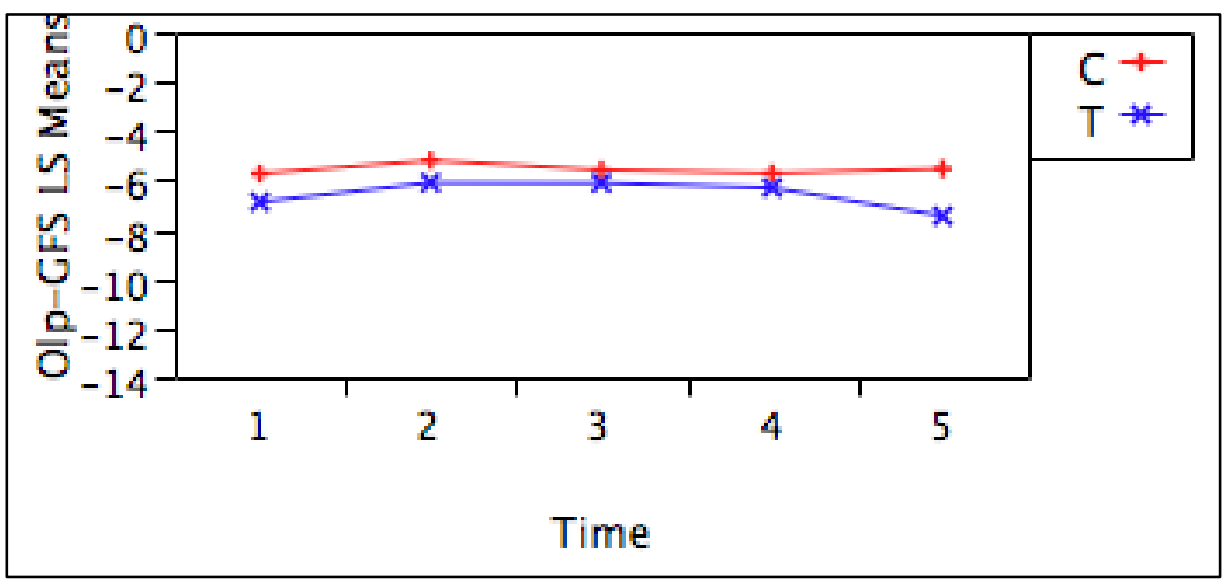

Females

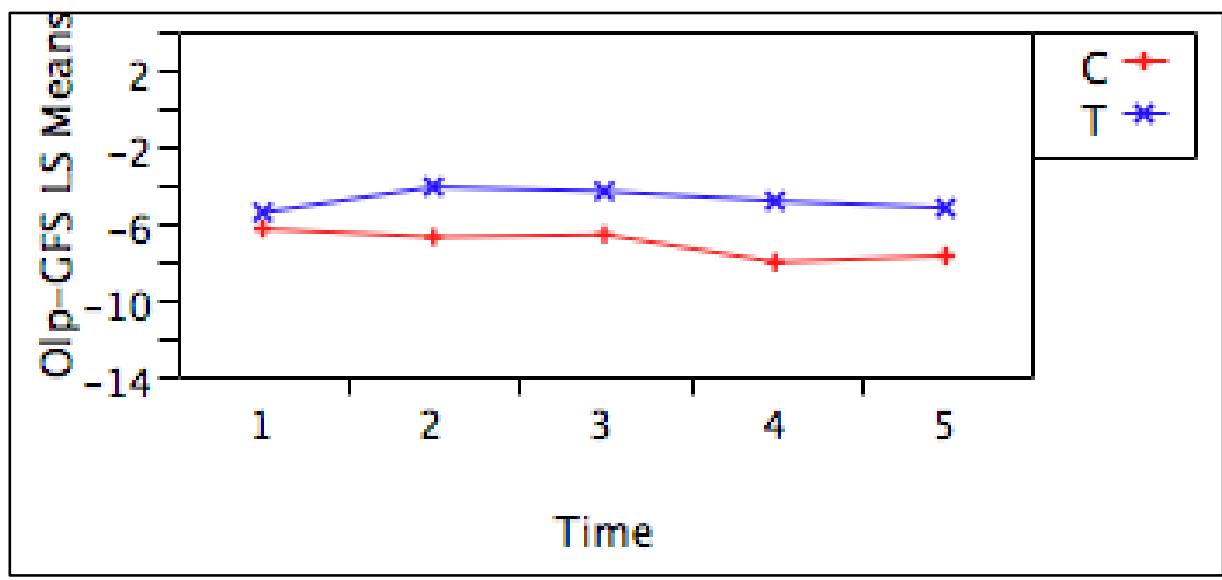




\section{OLp-GFA}

Overall

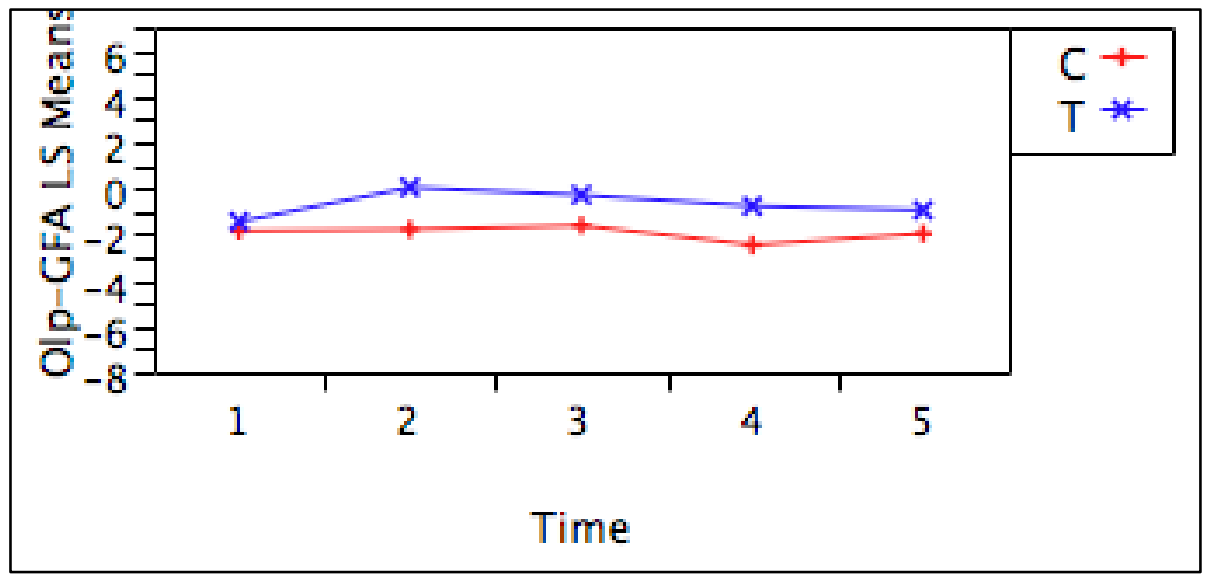

Males

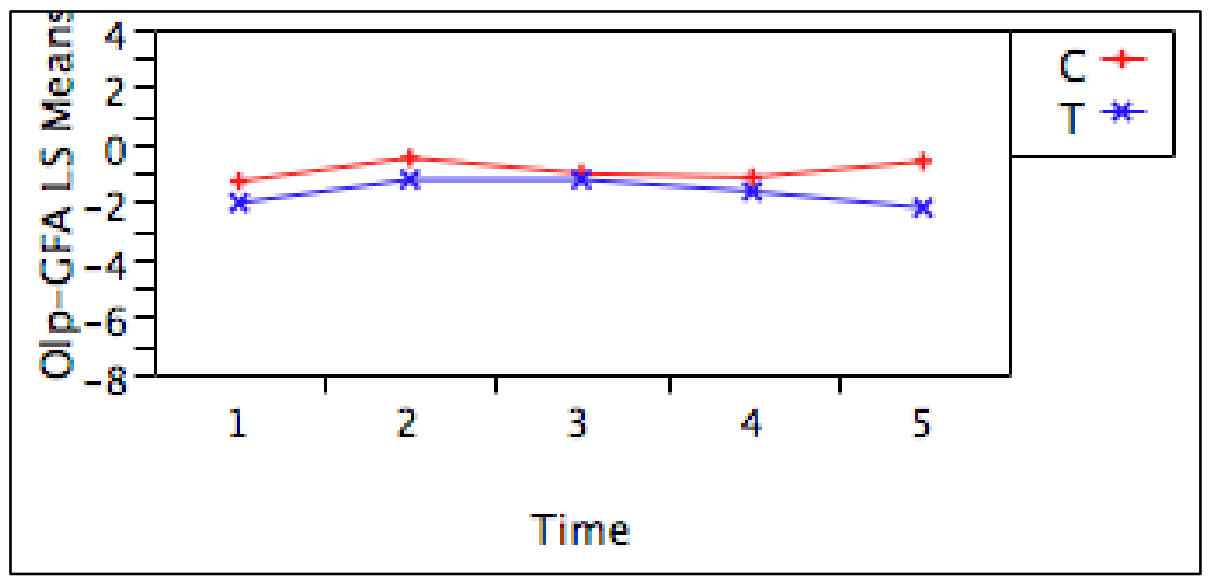

Females

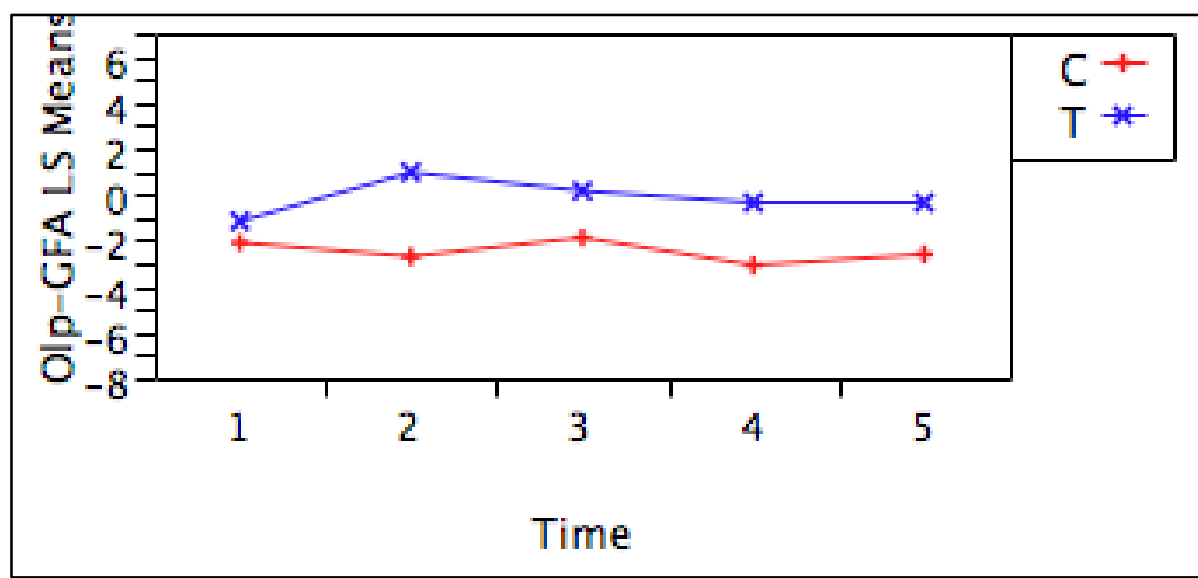




\section{OLP-GFP}

Overall

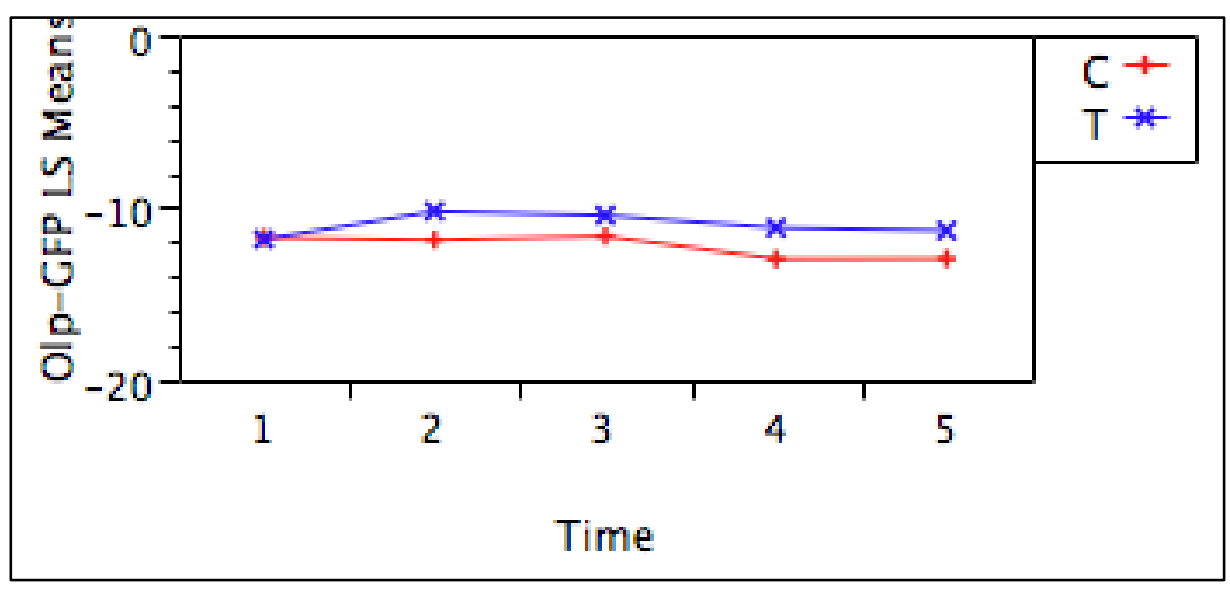

Males

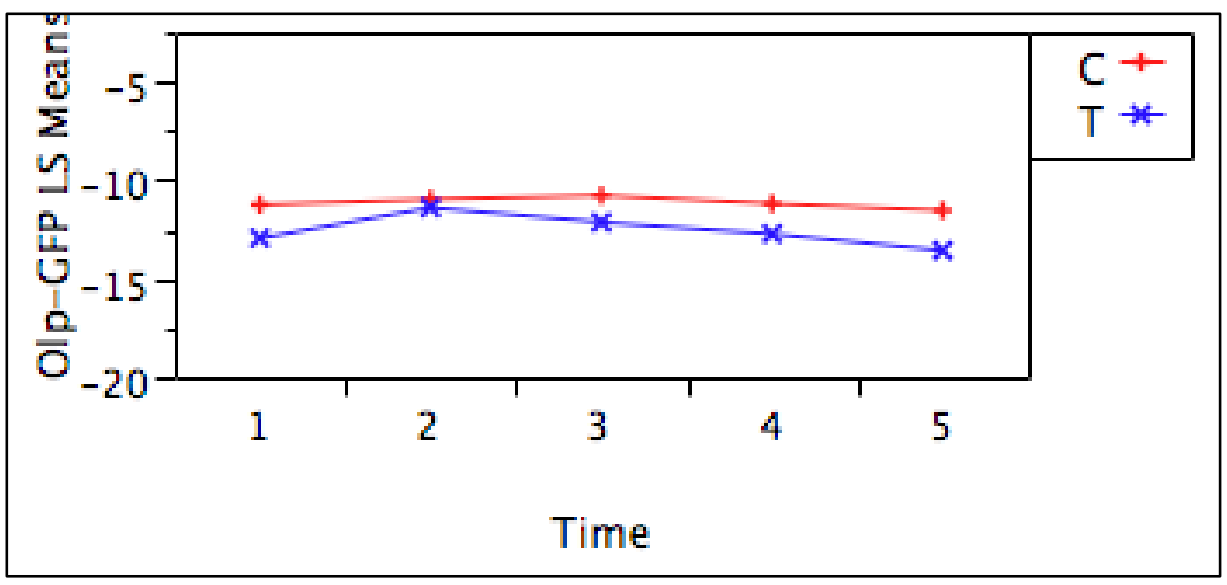

Females

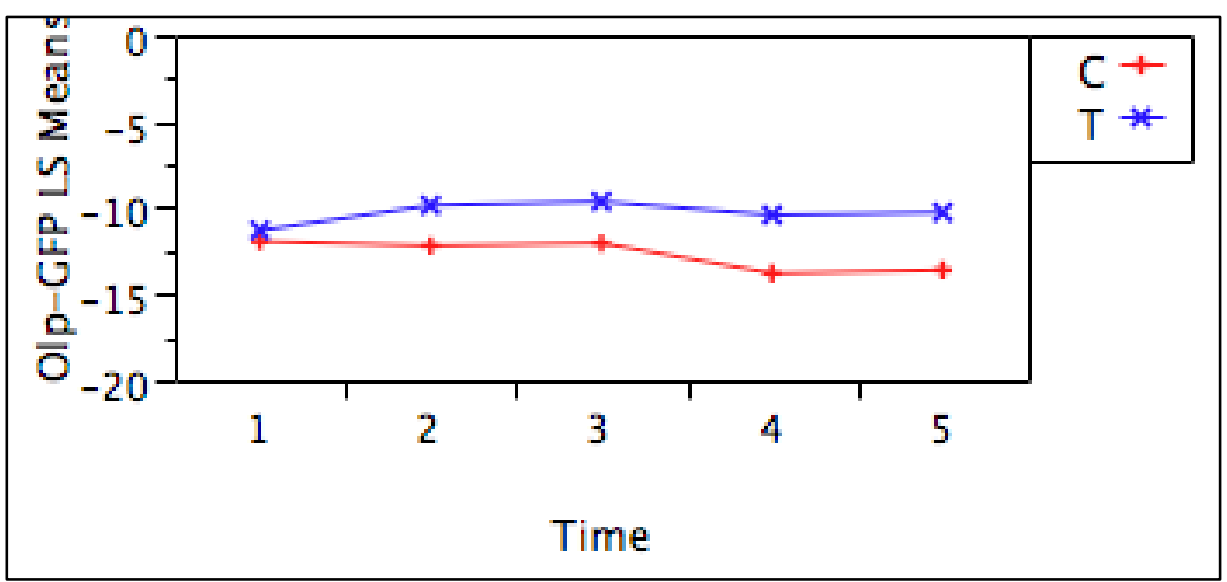



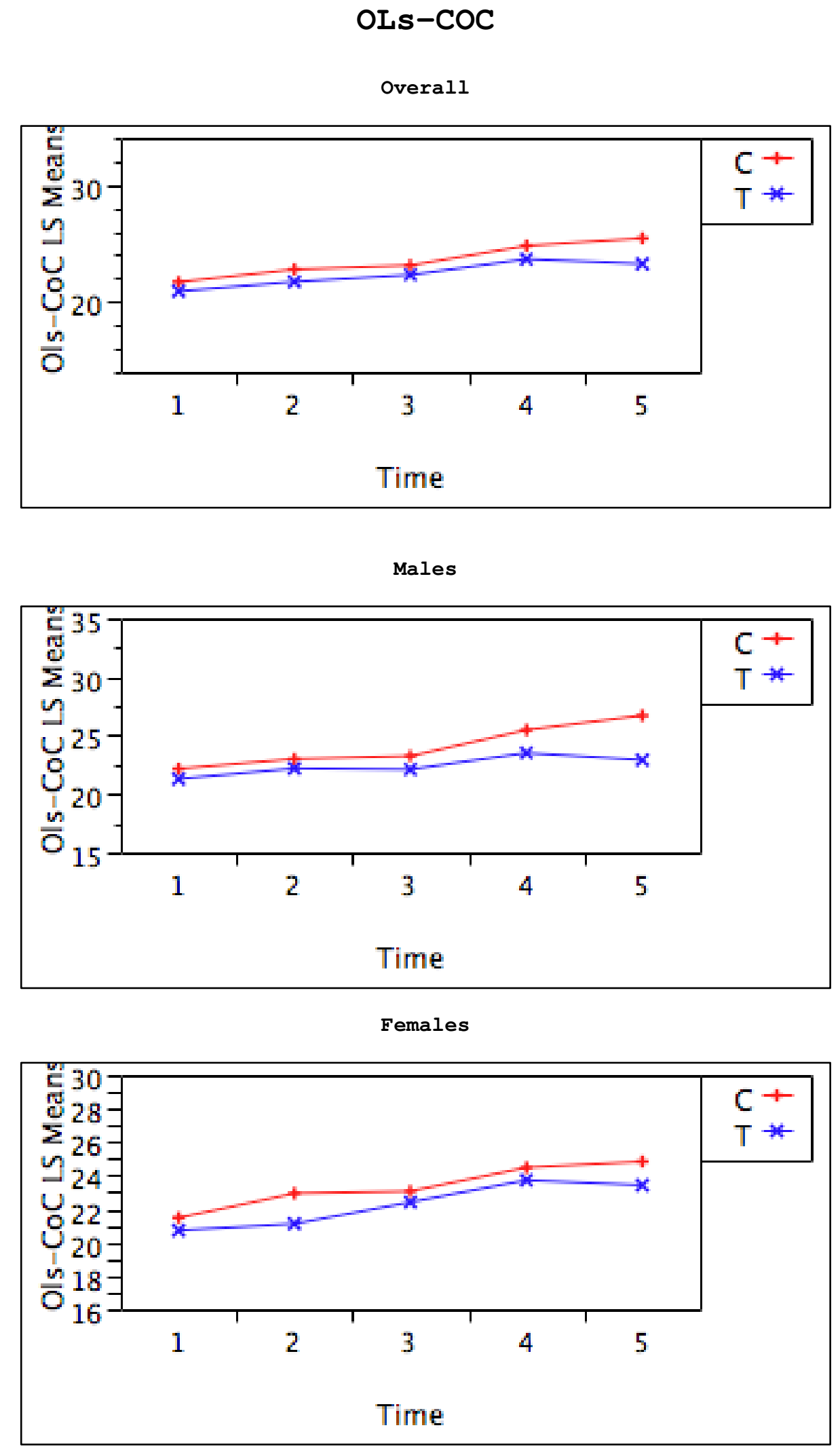


\section{OLs-GFS}

Overall

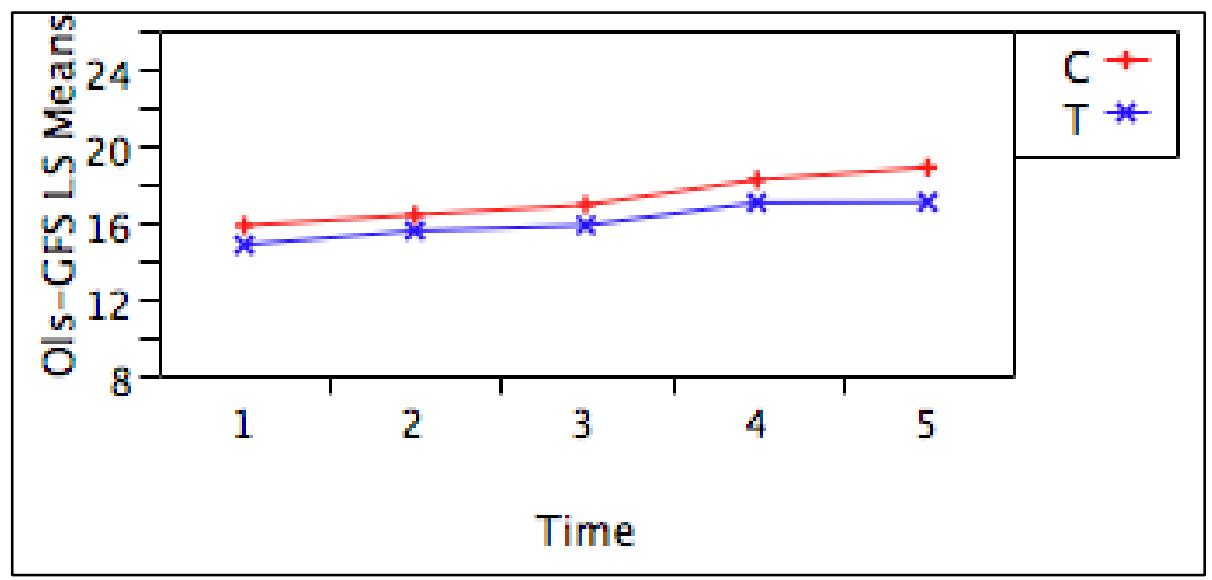

Males

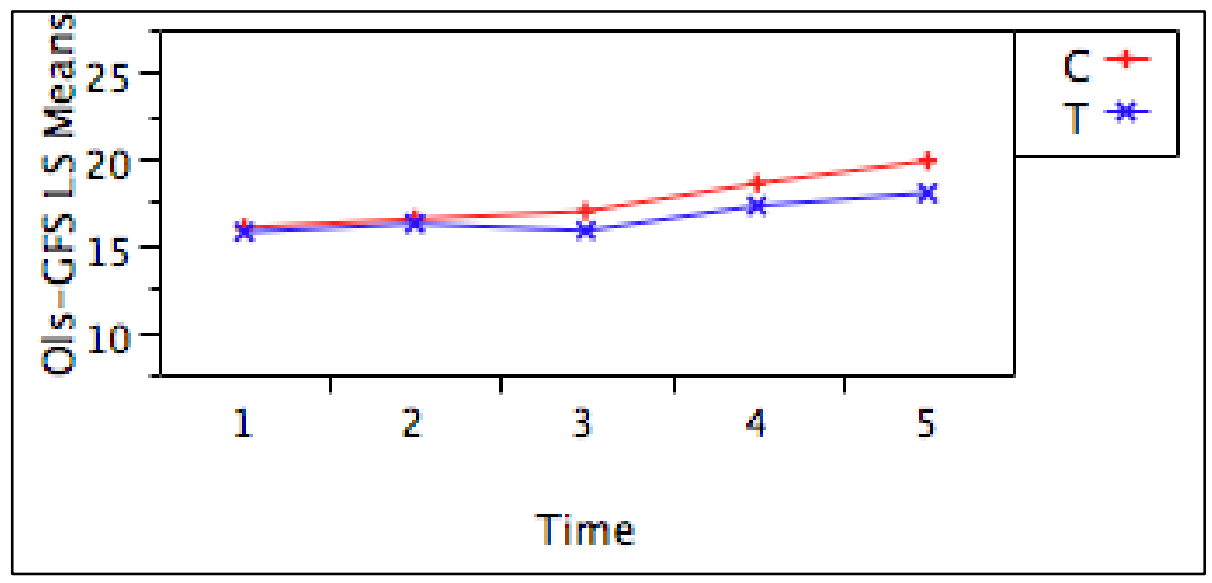

Females

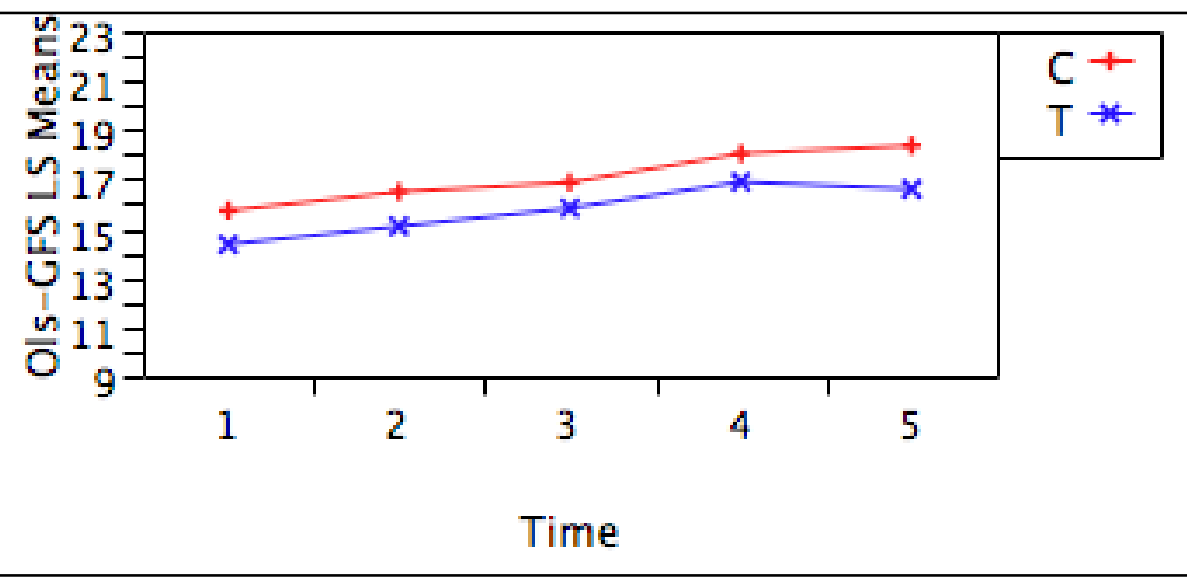



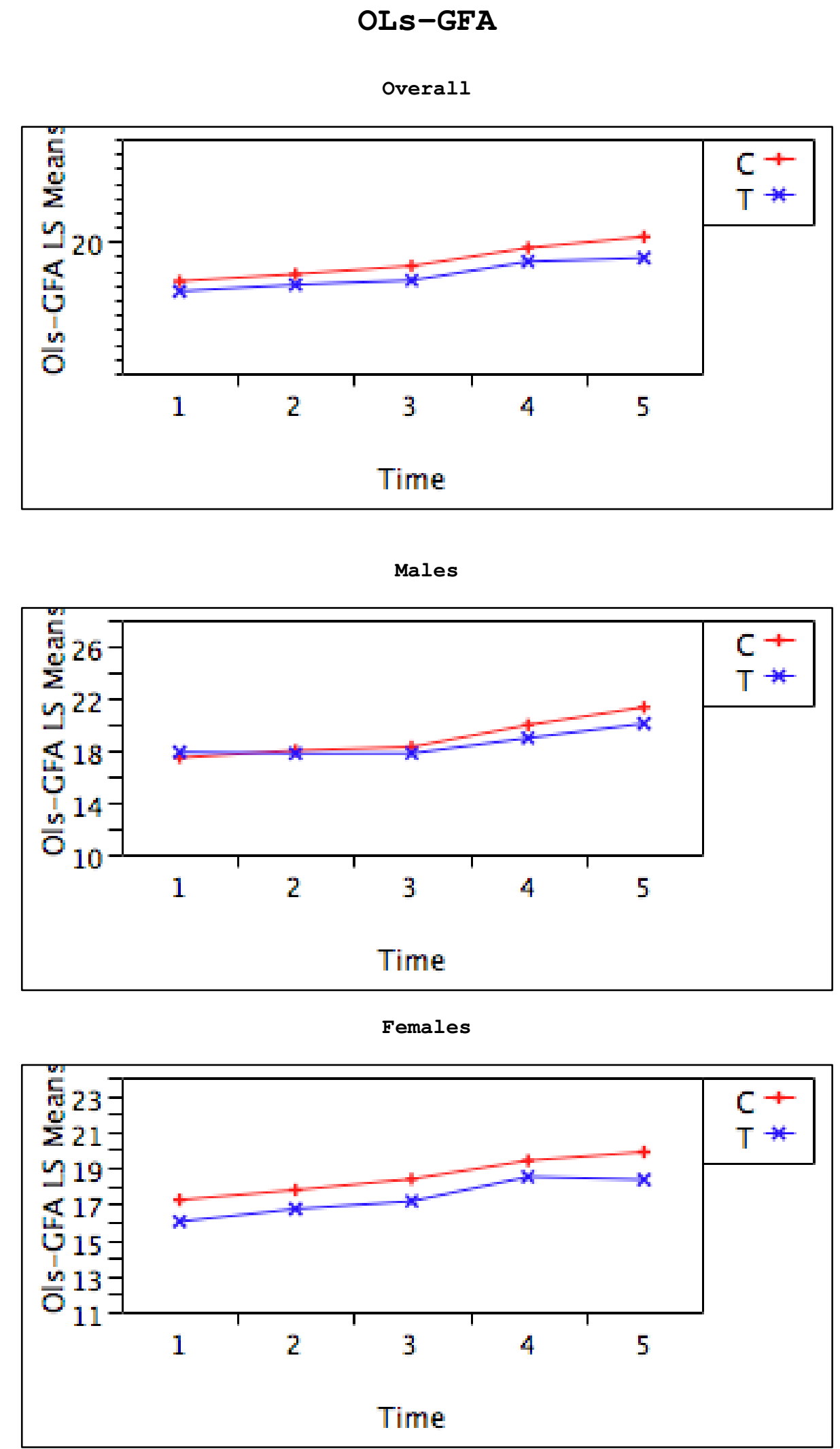

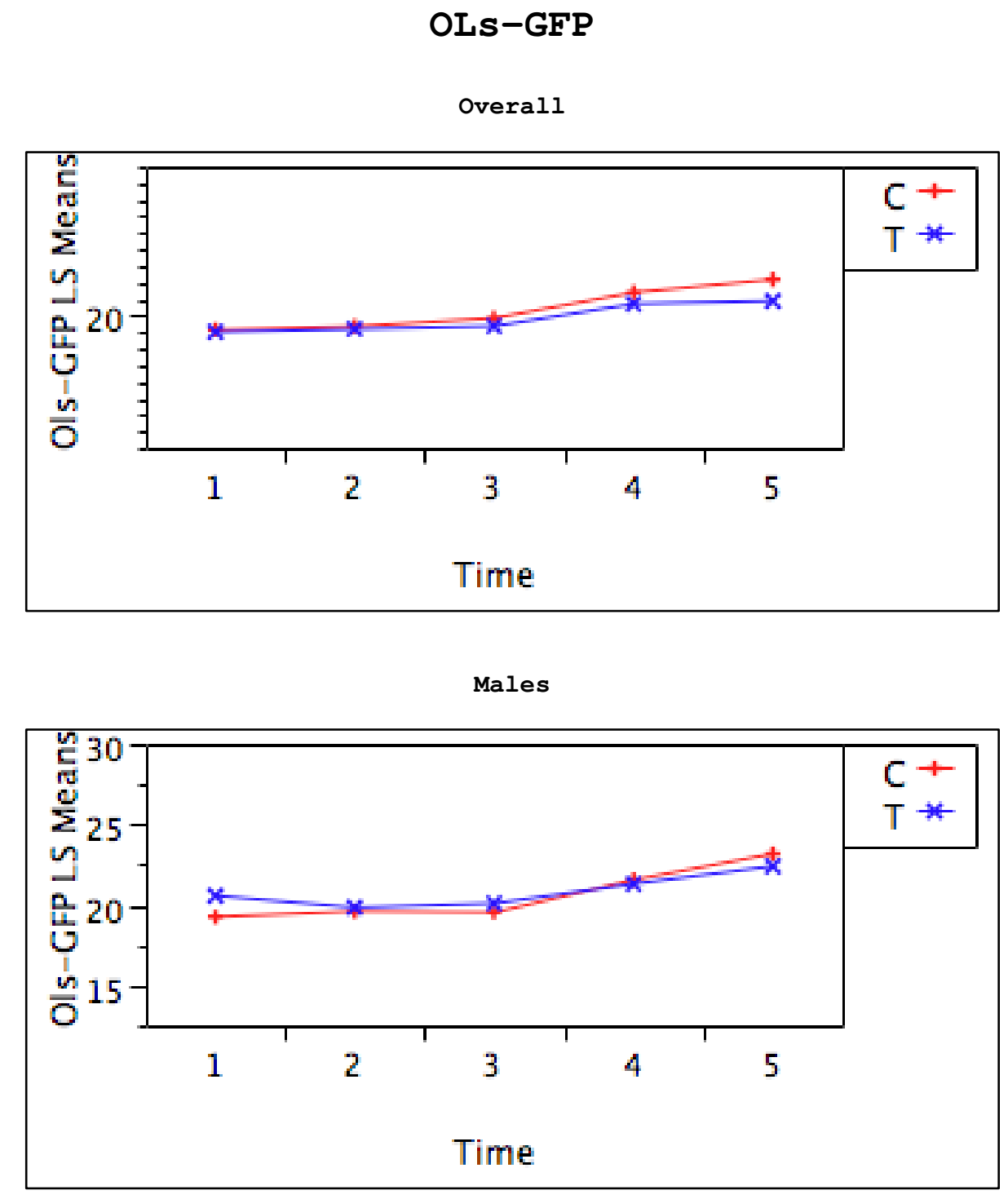

Females

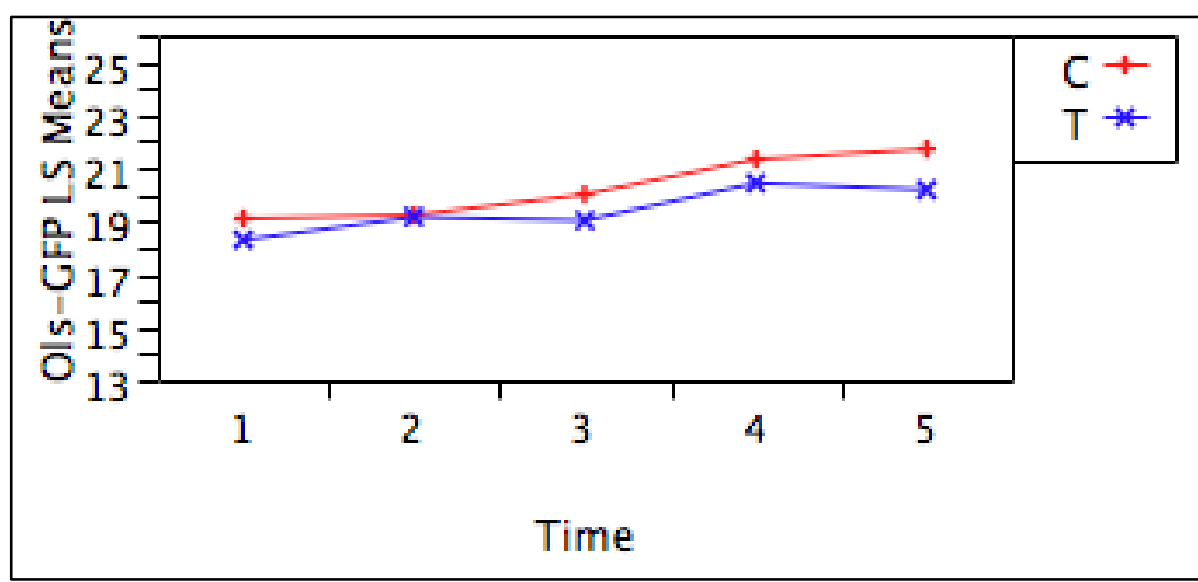




\section{CURRICULUM VITAE}

Name:

Date of Birth:

Place of Birth:

Education:

August 1997- May 2001:

est Virginia University

Morgantown, West Virginia

Bachelor of Arts, Biology

Minors in Business and Communications

Graduated with Honors

August 2001-May 2005: West Virginia University School of Dentistry Morgantown, West Virginia

Doctorate of Dental Surgery

July 2005-Present: $\quad$ West Virginia University School of Dentistry Department of Orthodontics Morgantown, West Virginia

Masters of Science (anticipated May 2008)

\section{Professional Memberships:}

August 2001-May 2005: American Student Dental Association

May 2005-Present:

May 2005-Present:

July 2005-Present:
American Dental Association

Omicron Kappa Upsilon-Honorary Dental Fraternity

American Association of Orthodontists 